\title{
Poster Session Abstracts
}

\section{2nd Annual International Conference of the American Society for Horticultural Science Las Vegas, Nevada}

Presenting authors are denoted by an astrisk $\left({ }^{*}\right)$

The number preceeding the poster title corresponds to the location of the poster in the Poster Hall

\section{Poster Session 1-Postharvest Quality: Fruit \\ 18 July 2005, 12:00-12:45 p.m. Poster Hall-Ballroom E/F}

(20) Effect of Fruit Dipping into Germanium Solution Just After Harvest on Fruit Quality of 'Niitaka' Asian Pear Wol-Soo Kim¹, Tae-Hyun Kim¹, Soon-Ju Chung ${ }^{1}$, Hyun Suk Choi*2 ${ }^{1}$ Chonnam National University, Department of Horticulture, 300 Yongbong-dong, Gwangju, 500-757, Korea; ${ }^{2}$ University of Arkansas, 316 Plant Science, Fayetteville, AR, 72701

Germanium has been reported as a mineral element affecting plant cell metabolism. Many trials to supply germanium to fruit have been carried out since tests have confirmed germanium's role as a medical substance. Supplying germanium to orchards by soil and foliar application was not effective because of loss from rainfall. Also, tree injection with germanium solution required the insertion of a tube to the tree xylem at each injection site. In order to increase germanium absorption by fruit, this study carried out the postharvest dipping of fruit into germanium solution. 'Niitaka' pear (Pyrus pyrifolia) fruit was treated with two types of germanium, $\mathrm{GeO}$ (inorganic type) and Ge-132 (organic type), in a concentration of $50 \mathrm{mg} \cdot \mathrm{L}^{-1}$ just after harvest in early Oct. 2004. Flesh browning after peeling the fruit was delayed by germanium treatment, and polyphenoloxidase (PPO) activities were lowered. Postharvest potentials were maintained at high levels for fruit firmness, physiological disorders, and decayed fruit during cold storage at 0 to $1{ }^{\circ} \mathrm{C}$ for 2 months. Antioxidant and some phenolic compounds were higher than those of control fruit.

(21) Quality Factors Important to Navel Orange Taste as Influenced by Maturation and Handling

David Obenland*1, Paul Neipp ${ }^{1}$, Jim Sievert, ${ }^{2}$ Sue Collin, ${ }^{2}$ Mary Lu Arpaia ${ }^{2}$

${ }^{1}$ USDA-ARS, San Joaquin Valley Agricultural Sciences Center, Parlier, CA, 93648; ${ }^{2}$ University of California, Kearney Agricultural Center, Parlier, CA, 93648

Maturity standards that determine when navel oranges can be harvested in California are currently based upon the ratio of soluble solids content (SSC) to titratable acidity (TA) and the rind color of the fruit. These standards may be inadequate to describe the quality of the fruit, which is important given the increased competition from other commodities in the marketplace and declining consumption of fresh citrus. To reevaluate the basis of the maturity standard, navel oranges were harvested at intervals throughout the season and evaluated for SSC, TA, juice ethanol concentration, percent juice, peel coloration, and sensory characteristics. Three varieties of navel oranges, representing early-, mid- and late-season maturities, were used. SSC : TA ratios averaged 6.3 at the beginning of the season and steadily increased to 23.4 at the end of the season. Changes in the hedonic rating, or likeability of the fruit taste as rated by the sensory panelists, were closely related to the SSC : TA ratio and ratings of sweetness and tartness. These relationships showed a similar pattern for all of the navel varieties. A hedonic rating of 6 (like slightly) was not reached until the SSC : TA ratio exceeded the current legal minimum of $8: 1$, suggesting that the standard should be raised. Juice ethanol levels and percent juice did not have any apparent influence on the sensory ratings. Fruit that were run over a packing line and waxed developed higher amounts of ethanol during storage than control fruit but did not differ substantially from them in hedonic rating.

\section{(22) Evaluation of Postharvest Texture and Weight} Loss in Apple Fruits by Destructive and Nondestructive Measurements

Sun Tay Choi*1, Judith Abbott ${ }^{2}$, Kyu Seob Chang ${ }^{3}$, Ji Gang Kim ${ }^{1}$, Chae Il Lim ${ }^{1}$

${ }^{1}$ National Horticultural Research Institute, Postharvest Technology Division, 475 ImokDong, Jangan-Gu, Suwon, Kyeonggi, 440-706, South Korea, ${ }^{2}$ USDA-ARS, Produce Quality and Safety Laboratory; ${ }^{3}$ Chungnam National University, Food Science and Technology

The relation between sensory and instrumental measurements of apple texture was investigated to find an effective postharvest texture measurement method of apple. Then nondestructive evaluation of texture and weight loss using NIR was conducted. 'Gala' and 'Fuji' apples were sampled during storage at $20{ }^{\circ} \mathrm{C}$ with $80 \%$ to $85 \%$ relative humidity. Instrumental measurements included penetration, compression, and bending tests with a texture analyzer, and sensory attributes were finger firmness, hardness, crispness, and mealiness. The penetration test was more effective for postharvest texture measurement than compression and bending tests in the correlation between sensory texture and instrumental measurement. As texture evaluation parameters, elastic modulus (slope before rupture point) and work (area to penetrate) of penetration test were more sensitive than maximum force. Maximum force, generally used as the parameter for texture evaluation, had a little problem under influence of weight loss in 'Fuji'; however, elastic modulus and work could detect the texture change of apple under influence of weight loss as well as softening. In the investigation of possibility of nondestructive evaluation using NIR of texture, the MLR analysis for elastic modulus determination of penetration test showed good correlation $(R=0.82, \mathrm{SEP}=2.66)$ in combination of two cultivars. Also, in the weight loss evaluation, MLR analysis showed the prediction correlation of 0.79 and SEP 1.08 in combination of two cultivars. These results showed the possibility of nondestructive evaluation using NIR of postharvest texture and weight loss.

(23) Sorbitol Transport, Sorbitol, and Watercore in Apple Cultivars Differ in Watercore Susceptibility

Wayne Loescher, Tad Johnson, Randolph Beaudry*, Sastry Jayanty

Michigan State University, Horticulture, East Lansing, MI, 48824

Sorbitol is the major carbohydrate translocated into apple fruit where it is normally metabolized to fructose. In watercored apple fruit tissues, however, the intercellular spaces become flooded and sorbitol content is consistently higher than in nonwatercored apples, suggesting a defect in sugar alcohol metabolism or transport. Our previous results have identified and characterized two sorbitol transporters, MsSOT1 and MsSOT2, in apple fruit tissues. Sorbitol transporter gene expression has been implicated in development of watercore with MsSOT expression diminished or absent in certain watercored fruit tissues. To 
explore this further, we have investigated the relationships between watercore, fruit maturation, fruit composition, and MsSOT expression in a number of apple cultivars that differ in watercore susceptibility. We also compared transporter expression between affected (watercored) and healthy parts of the same fruit and between watercored and nonwatercored fruits throughout the maturation and ripening processes. The MsSOT expression was often dramatically reduced in fruit tissues exhibiting watercore. Thus, in susceptible cultivars, maturing (ripening) fruit parenchyma cells lose the ability to transport sorbitol, and this in turn leads to sorbitol accumulation in the apoplastic free space and subsequent flooding of these spaces. These results are consistent with a relationship between watercore and sorbitol transport and also with a genetic susceptibility to the disorder.

\section{(24) Varietal Apple Wines from Great Plains-grown Cultivars}

Patricia Lattrell ${ }^{1}$, Durward A. Smith ${ }^{1}$, Paul Read*2, Susan S. Cuppett ${ }^{1}$

${ }^{1}$ University of Nebraska-Lincoln, Food Science and Technology, 253 Food Industry Complex, Lincoln, NE, 68583-0919; ${ }^{2}$ University of Nebraska-Lincoln, Agronomy and Horticulture, 377-J Plant Science, Lincoln, NE, 68583

There is little information regarding processing methods that result in quality and uniformity in varietal apple wines. The object of this research was to determine if apple cultivars grown in the Great Plains region could be used to produce premium quality single cultivar wines, and to establish efficient processing methods that optimize quality. The qualities of single cultivar apple (Malus $\times$ domestica) wines were investigated, including chemical characteristics of the apple juices, e.g. total soluble solids, acidities, and tannin contents. Analyses were performed on the fresh juices, fermenting juices, wines held for 6 months, and the aged wines. Fermentable sugar content was increased either by the addition of sucrose or by the addition of concentrated juice of the same apple cultivar. An optimized method of purge and cold trapping injection capillary gas chromatography was applied to the analysis of some volatile constituents. Profiles of the wine volatiles were analyzed to determine differences among cultivars. The harsh flavors and yeasty odors of the wines diminished after 6 months of storage. Acidity and volatile acidity increased slightly during storage. Tannin contents, fermentation efficiencies and volatile profiles differed among varieties. This research indicated that some apple cultivars grown in the Great Plains produce acceptable single cultivar wines.

\section{(25) Characterization of Volatile Biosynthesis in 'Jonagold' Apples (Malus $\times$ domestica Borkh.) during the Ripening Process}

\section{Nobuko Sugimoto*, Randy Beaudry}

Michigan State University, Horticulture, Plant and Soil Science Building, East Lansing, MI, 48824

The objective of the experiment was to determine developmental changes in major aroma profiles in 'Jonagold' apple (Malus $\times$ domestica Borkh.) and analyze climacteric fruit characteristics. Changes in internal ethylene production, respiration, skin color, texture, and aroma concentration were measured during maturation and ripening of 'Jonagold' apple fruit. Patterns for skin color, starch, and internal ethylene content were typical for the variety. Volatile compounds and $\mathrm{CO}_{2}$ increased after a rapid increase in ethylene production. Total ester emission peak coincided with fruit softening. Hexyl acetate, 2-methylbutyl acetate, butyl acetate, and hexyl 2-methylbutanoate were found to be the major volatile compounds detected by GC/MS. Long chain esters, such as hexyl acetate and butyl acetate, contributed during the early stages of ripening and short chain esters such as n-propyl acetate and butyl propanoate increased later. Esters are formed by combining alcohol moiety with CoA derivative of fatty acid moiety by the action of alcohol acyl transferase (AAT). The alcohols butanol, 2-methylbutanol, propanol, and hexanol increased at an earlier developmental stage than the esters for which they acted as substrates.

\section{(26) Commercial Film Coatings Reduce Weight Loss and Improve Appearance of 'Keitt' Mango Fruits (Mangifera indica L.)}

Manuel Baez-Sañudo*, Jorge Siller-Cepeda,

Rosalba Contreras-Martinez, Laura Contreras-Angulo, Rosabel Velez, Dolores Muy-Rangel

CIAD,A.C. Culiacan, Postharvest Physiology, Carretera a Eldorado Km. 5.5. Apdo. Postal 32-A., Culiacan, Sinaloa, 80129, Mexico

Mango 'Keitt' is characterized by a poor external color development and a slightly high transpiration rate during ripening, which affect external quality. When fruit is ripening, the peel turns from a green to yellowish or dull green color, and the peel has no shine. We evaluated the effectiveness of three film coatings to reduce weight loss, improve appearance, and maintain quality during ripening of 'Keitt' mango fruits. Four lots of fruits were obtained from a packinghouse in late September and transported to the laboratory. Each lot was sprayed at the commercial recommended rates with SemperFresh ${ }^{\mathrm{TM}}$, Natural Shine $^{\mathrm{TM}}$, TFC 210, and FreshSeal ${ }^{\mathrm{TM}}$ coatings. Water sprayed fruits were used as a control. After applications, fruits were stored for 15 days at $22{ }^{\circ} \mathrm{C}$ and $85 \% \mathrm{RH}$ to simulate marketing conditions. Quality parameters evaluated included weight loss (\%), firmness, external and internal colors (hue, chroma, 1$)$, respiration rate ( $\mathrm{CO}_{2}$ production), and chemical parameters such as $\mathrm{pH}$, titratable acidity and ${ }^{\circ}$ Brix. After 15 days, fruits coated with Natural Shine reduced $50 \%$ of the weight loss as compared to control fruits, while fruits coated with FreshSeal and SemperFresh reduced only $1.7 \%$ and $3.5 \%$, respectively. Firmness declined from $155 \mathrm{~N}$ to $10 \mathrm{~N}$ during storage, being more evident on day 10 , when fruits were table ripe. Fruits treated with SemperFresh were softer as compared with the other treatments. Titratable acidity decreased from $0.8 \%$ to $0.2 \%$ during storage and ${ }^{\circ}$ Brix increased from 13 to $17-18$ in all treatments. Fruit coated with Natural Shine had reduced weight and firmness loss. Additionally, fruits developed a better external color, with lower hue values, higher chromaticity and luminosity, which improve fruit appearance.

\section{(27) Peel Browning Development of Bananas Treated with SmartFresh $^{\mathrm{TM}}$ and Film Coatings Stored under Low Humidity Conditions}

Manuel Baez-Sañudo, Jorge Siller-Cepeda*,

Rosalba Contreras-Martinez, Laura Contreras-Angulo, Rosabel Velez, Dolores Muy-Rangel

CIAD,A.C. Culiacan, Postharvest Physiology, Carretera a Eldorado Km. 5.5. Apdo. Postal 32-A, Culiacan, Sinaloa, 80129, Mexico

Bananas are usually harvested at the "all green" maturity stage in the country of origin and exported to main markets. Upon arrival, fruits are forced to ripen with ethylene and moved to market conditions to accelerate color change and ripening. Fruits exposed to low relative humidity conditions at market frequently induce browning of the peel and diminish quality. To protect fruits marketed under those conditions and to reduce peel browning, SmartFresh ${ }^{\mathrm{TM}}$ (1-MCP) alone or combined with two film coatings was evaluated. Banana Cavendish type fruits obtained from a warehouse at all green color stage were applied with two film coatings: 1$) \operatorname{SemperFresh}^{\mathrm{TM}}(1.2 \%)$; or 2$)$ FreshSeal $^{\mathrm{TM}}\left(3^{\circ} \mathrm{Brix}\right)$. Additionally, a set of fruits were left as a control without coatings. Coated and control fruits were then exposed to $150 \mathrm{ppm}$ of ethylene for 24 hours at $20^{\circ} \mathrm{C}$. When fruits reached color stage 3 (more green than yellow), 0 and $300 \mathrm{ppb}$ of 1-MCP were applied for 12 hours at $22{ }^{\circ} \mathrm{C}$. Fruits from all six treatments were stored at $22{ }^{\circ} \mathrm{C}$ and $30 \%$ to $40 \%$ relative humidity for 5 days to follow quality changes and browning development. Weight loss, firmness, color, $\mathrm{pH}$, acidity, ${ }^{\circ} \mathrm{Brix}$ and appearance were evaluated daily. Control fruits, SmartFresh ${ }^{\mathrm{TM}}$ alone, FreshSeal ${ }^{\mathrm{TM}}+$ SmartFresh $^{\mathrm{TM}}$ and both film coatings alone lost more than $10 \%$ of weight after 5 days. Only fruits treated with SemperFresh $^{\text {TM }}+$ SmartFresh $^{\text {TM }}$ reduced weight loss below 10\%. Firmness tests indicated a higher force penetration due to dehydration of peel. Pronounced browning was observed on control fruits. SemperFresh ${ }^{\text {TM }}+$ SmartFresh ${ }^{\mathrm{TM}}$ delayed yellow color appearance, sugar spot incidence, and peel browning development, extending shelf-life. No significant changes were observed on chemical characteristics. 


\section{(28) Lenticel Development and Discoloration of Some Mango [Mangifera indica (L.)] Cultivars}

Jan-Louis Bezuidenhout*, Hannes Robbertse

University of Pretoria, Plant Production and Soil Science, South Africa

Discoloration of the lenticels of some mango cultivars is a serious problem, affecting the economic value of the fruit. Mango fruit lenticels develop from ruptured stomata on fruit from $20 \mathrm{~mm}$ in 'TA' and 'Keitt' and 30 to $40 \mathrm{~mm}$ in 'Kent'. Lenticels enlarge as the fruit grow due to stretching of the fruit surface. Adult lenticels of 'TA' and 'Keitt' are larger in size than those of 'Kent'. 'Kent' lenticels are also better insulated than 'TA' and 'Keitt', having a thick cuticle in the lenticel cavity and, in some instances, a phellogen is also present where 'TA' and 'Keitt' lack both of the above mentioned. Resin present in the skin of the fruit play an important role in the discoloration of 'TA' and 'Keitt' lenticels. Resin of both 'TA' and 'Keitt' fruit contain a considerable amount of an aggressive compound termed terpenes. These terpenes are volatile and able to move out of the resin ducts via the sublenticellular cells to the outside of the fruit. The integrity of tonoplasts situated in sublenticellular cells are lost due to the presence of terpenes, causing vacuolar bound phenols to come into contact with polyphenol oxidase, present in the cell walls. The product of the resultant reaction is a quinone, accumulating as a brownish deposit in the cell walls, the black markings visible from the outside. This is the spontaneous discoloration process. Lenticel discoloration may also occur due to maltreatment, i.e., rough handling, to high temperatures, extended period on brushes on the packline, breaking of the cold chain, and spilling of resin onto the surface of the fruit.

\section{Poster Session 2-Consumer Horticulture and Master Gardeners}

18 July 2005, 12:00-12:45 p.m. Poster Hall-Ballroom E/F

\section{(134) "Plant Propagation" CD-ROM}

Mary Welch-Keesey ${ }^{1}$, B. Rosie Lerner*1, Sharon Katz², Joan Crow ${ }^{2}$, Becky Goetz ${ }^{2}$, Janie Nordstrom Griffiths ${ }^{3}$

${ }^{1}$ Purdue University, Horticulture and Landscape Architecture, 625 Agriculture Mall Drive, West Lafayette, IN, 47907-2010; ${ }^{2}$ Purdue University, Agricultural Communications, 615 West State Street, West Lafayette, IN, 47907-2053; ${ }^{3}$ Purdue University, formerly Horticulture and Landscape Architecture, 625 Agriculture Mall Drive, West Lafayette, IN, 47907-2010

"Plant Propagation" is a CD-based course that covers seed propagation, divisions, layering, cuttings, and grafting. It is multimedia at its best-hundreds of photos, illustrations, and videos show close-up details of each propagation method and create a fresh and enjoyable way to test the viewer's knowledge. Although designed for the amateur gardener, it is detailed enough to be used as a supplemental text in college-level plant propagation courses. Additional features include: 1) an extensive Resources section that lists additional book and internet resources, scientific names of all the plants discussed in the course, and sources for tools; 2) an extensive Glossary, including audio of the correct pronunciation of 50 terms; 3) a Basics section that reviews the different types of plant propagation, plant biology, and horticultural concepts, such as potting media, lighting, and plant growth regulators; and 4) a short discussion of the use of tissue culture for plant propagation. "Plant Propagation" is available for $\$ 40$ from Purdue Extension's online education store at $h t t p: / / w w w . c e s . p u r d u e$. edu/new/. It's also available by calling (888) EXT-INFO or e-mailing media.order@purdue.edu. The product code is CD-HO-3.A free preview of the course is available online at http://www.hort.purdue. edu/plantprop/webversion/Intro.html. If you have questions about the course content, please contact the authors directly: Mary Welch Keesey(marywk@purdue.edu)or(317)630-3257 and B. Rosie Lerner (rosie@purdue.edu) or (765) 494-1311.
(135) Planttalk Colorado ${ }^{\mathrm{TM}}$ : 24-hour Answers for Gardeners

James Klett*

Colorado State University, Dept. of Horticulture and Landscape Architecture, Fort Collins, $\mathrm{CO}, 80523$

Planttalk Colorado ${ }^{\mathrm{TM}}$, established in Fall 1997, is a 24-hour toll-free automated phone service available in English and Spanish and website that provides gardening consumers with reliable and timely information on a variety of horticultural and related areas topics. Planttalk Colorado ${ }^{\mathrm{TM}}$ is unique in that it is sponsored by Colorado State University Cooperative Extension, Denver Botanic Gardens and the Green Industries of Colorado. Over 450 topics edited and approved by all entities ranging from general gardening to emerging issues, such as new disease and insect concerns. Recent efforts have included translation of a portion of the scripts into Spanish to reach a larger audience and the rising Hispanic population in the state and region. Marketing efforts have evolved to include a website with photos and illustrations along with linkages to other university research-based information. Other marketing tools have included: free incentives, mass media marketing, and tabletop and banner displays for use at educational functions. A review of phone usage vs. web hits will be discussed. Web hits averaged 92,528 monthly in 2004 vs. phone usage averaged 309 monthly in 2004. Consumers have the ability to post comments on both web and phone systems. They can rank the overall program on the web. Funding is a cooperative effort between all three partners. Planttalk Colorado $^{\mathrm{TM}}$ has increased visibility to Cooperative Extension and built partnerships with the Green Industry of Colorado and Denver Botanic Gardens for delivering reliable and accurate information to all citizens of Colorado and beyond.

\section{(136) Survey of Landscape Influence on Spider Migration into Homes}

\section{Carol O’Meara*}

Colorado State University, BioAgricultural Science and Pest Management, Longmont, $\mathrm{CO}, 80501$

Claims of disproportionate numbers of spiders in certain homes and public demand for non-pesticide means of pest control fostered a closer look at whether landscaping and the manipulation of yards can have an influence on spider migration into homes. Typically, spiders are unwanted houseguests, and homeowner concern over potential contacts with spiders poses challenges to acceptance of these beneficial animals. A2-year survey was conducted to determine if the complexity of landscaping surrounding a home influences the diversity and abundance of spiders entering houses. The survey consisted of simple and complex landscapes in a regional area. Complexly planted yards had significantly higher numbers of spiders and greater diversity of spider taxa in houses, suggesting a correlation between landscape density and spider invaders. Species data include those that are synanthropic throughout the United States as well as species that are seasonal home invaders. In all, 804 spiders were collected, with 26 species and 31 genera. Results of this 2-year survey will be presented.

\section{(137) Cultivar Comparison of Heliconias for Use in Guam} James McConnell*

${ }^{1}$ University of Guam, College of Natural and Applied Sciences, Mangilao, GU, 96923

Cultivars of heliconias were evaluated for use in Guam as a cut flower and in the landscape. Forty-five cultivars were planted at three locations in Guam. Due to insufficient plant material, the evaluation was preliminary. Noteworthy differences were observed among the cultivars. Differences were noted in time to establish, frequency of flowering, and resistance to wind damage. Establishment required large quantities of water. Once established, some cultivars appeared to be drought-tolerant; however, feral pigs and carabao became a problem due to massive mechanical damage. Typhoons also caused severe damage to the foliage. Rhizomes did not suffer obvious damage, resulting in recovery within 1 year. Heliconias as a cut flower does not appear feasible. As a landscape plant, heliconias should be given further consideration. 


\section{(138) Guam Native Trees and Shrubs for the Landscape}

James McConnell*

${ }^{1}$ University of Guam, College of Natural and Applied Sciences, Mangilao, GU, 96923

Plants native to Guam are being evaluated for use in the Guam landscape. The selected plants are being propagated by seed and/or cutting. The genera currently being evaluated and propagated include Scaevola, Eleaocarpus, Ochrosia, Guamia, Pemphis, and Bikkia. Variation in flower color and floral fragrance were observed in Scaevola and selections have been made. There has been some difficulty establishing some of the plants in the landscape environment. There have been some significant insect problems occurring on established plants.

\section{Poster Session 3-Nursery Crops 1}

18 July 2005, 12:00-12:45 p.m. Poster Hall-Ballroom E/F

\section{(54) Response of Betula nigra 'BNMTF' to Foliar and Drench Applications of Nickel}

John M. Ruter*

University of Georgia, Horticulture, Tifton, GA, 31794

Mouse ear disorder on container-grown river birch (Betula nigra L.) is a national problem caused by a deficiency of nickel. Symptomatic plants have leaves which are small, wrinkled, darker green, cupped, and have necrotic margins. Research showed that mouse ear could be cured by applications of nickel sulfate (Ruter, 2004). Further research was needed to determine optimal rates of application for sprays and drenches and to determine if phytotoxicity occurs at high rates. A study was initiated at a nursery in South Georgia on 25 June 2003, using river birch in their second growing season in \#15 containers. Plants were selected for uniformity of mouse ear disorder. Treatments included a control, urea $\left(0.24 \mathrm{~g} \cdot \mathrm{L}^{-1}\right)+$ surfactant $\left(1.0 \mathrm{~mL} \cdot \mathrm{L}^{-1}\right), 250,500,750$, and $1000 \mathrm{mg} \cdot \mathrm{L}^{-1}$ nickel sulfate sprays, and substrate drenches applied at 150 and $300 \mathrm{mg}$ of $\mathrm{Ni} /$ pot. After 30 days, all plants treated with nickel sulfate had $100 \%$ normal growth, except the $150 \mathrm{mg}$ of Ni/pot drench, which had $79 \%$ of the canopy showing normal growth. No phytotoxicity was noted. Plants receiving foliar sprays had a $66 \%$ to $72 \%$ increase in leaf area, a $64 \%$ to $68 \%$ increase in leaf dry mass, a $31 \%$ to $44 \%$ increase in stem length, and a $9 \%$ to $17 \%$ increase in specific leaf area compared to nontreated plants. Drench treatments increased leaf area up to $62 \%$, leaf dry mass to $55 \%$ and stem length up to $29 \%$ over control plants. Nickel in the foliage of nontreated plants was $2.3 \mathrm{mg} \cdot \mathrm{kg}^{-1}$. For the spray treatments, foliar Ni ranged from $5.5 \mathrm{mg} \cdot \mathrm{kg}^{-1}$ for the $250 \mathrm{mg} \cdot \mathrm{L}^{-1}$ treatment to $9.3 \mathrm{mg} \cdot \mathrm{kg}^{-1}$ for the $1000 \mathrm{mg} \cdot \mathrm{L}^{-1}$ treatment. Though plants at the high rate of drench treatment resumed normal growth, foliar $\mathrm{Ni}$ levels were not different from control plants. In general, if plants were treated with $\mathrm{Ni}$, then foliar $\mathrm{B}, \mathrm{Fe}$, and $\mathrm{Zn}$ decreased.

\section{(55) Root Pruning Techniques Do Not Help Pot-bound Plants}

Jeffrey H. Gillman*1, Chad P. Giblin ${ }^{1}$, Gary R. Johnson ${ }^{2}$

${ }^{1}$ University of Minnesota, Dept. of Horticultural Science, St. Paul, MN, 55108; ${ }^{2}$ University of Minnesota, Forest Resources, St. Paul, MN, 55108

Plants that have been grown in containers for a long period of time frequently develop roots that grow in circles, following the contour of the container in which they have been planted. This condition is commonly referred to as "pot-bound." It is considered common knowledge that if a pot-bound plant is transplanted without any treatment, its roots will continue to follow the contour of the now-removed container. There are, however, a number of transplanting techniques that are intended to reorient the roots in a direction that will be conducive to helping roots to grow out of this potentially harmful situation. These techniques include: butterflying, or slicing the rootball into two halves before planting; scoring, or making inch-deep slices around the rootball at $90^{\circ}$ increments and an X-shaped slice across the bottom; or teasing, where roots are manually pulled out of the shape of the container in a direction perpendicular to the stem. Severely pot bound Salix alba and Tilia cordata were treated with one of the three treatments previously listed or as a control and were transplanted into an experimental field and grown for two full seasons. After two seasons, the trees were harvested and the number and size of roots escaping from the pot-bound region were recorded. None of the treatments allowed roots of any size to escape the pot-bound mass more effectively than the control.

\section{(56) Transpiration and Photosynthesis of Grafted Watermelon Transplants as Affected by Environmental Factors during Graft Union Formation}

Sung Kyeom Kim*1, Duk Jun $\mathrm{Yu}^{1}$, Ro Na Bae ${ }^{2}$, Hee Jae Lee ${ }^{1}$, Changhoo Chun ${ }^{1}$

${ }^{1}$ Seoul National University, Dept. of Plant Sciences, Seoul, 151-921, Korea; ${ }^{2}$ Seoul National University, National Instrumentation Center for Environmental Management, Seoul, 151-921, Korea

Grafted transplants are widely used for watermelon culture in Korea mainly to reduce the yield and quality losses caused by soil-borne diseases. It is normal practice to cure the grafted transplants under high relative humidity $(\mathrm{RH})$ and low photosynthetic photon flux $(P P F)$ conditions for a few days after grafting to prevent the wilting of the transplants. Transpiration rate (TR) and net photosynthetic rate (NPR), however, could be suppressed under those environmental conditions. In the present study, TR and NPR of the grafted watermelon transplants were compared during graft union formation under 18 environmental conditions combining two air temperatures $\left(20\right.$ and $\left.28^{\circ} \mathrm{C}\right)$, three RHs $(60 \%, 80 \%$, and $100 \%)$, and three $P P F \mathrm{~s}\left(0,100\right.$, and $\left.200 \mu \mathrm{mol} \cdot \mathrm{m}^{-2} \cdot \mathrm{s}^{-1}\right)$. Percentages of graft union formation and survival were also evaluated. TR and NPR dramatically decreased just after grafting but slowly recovered 2 to 3 days after grafting at $28^{\circ} \mathrm{C}$. The recovery was clearer at higher $P P F$ and lower RH. On the other hand, the recovery of TR and NPR was not observed in 7 days after grafting at $20^{\circ} \mathrm{C}$. Differences in TR and NPR affected by RH were nonsignificant. Percentage of graft union formation was $98 \%$ when air temperature, $\mathrm{RH}$, and $P P F$ were $28^{\circ} \mathrm{C}, 100 \%$, and $100 \mu \mathrm{mol} \cdot \mathrm{m}^{-2} \cdot \mathrm{s}^{-1}$, respectively, which was the highest among all the treatments. Percentage of survival was over $90 \%$ when air temperature was $28{ }^{\circ} \mathrm{C}$ and $\mathrm{RH}$ was higher than $80 \%$ (when vapor pressure deficit was lower than $0.76 \mathrm{kPa}$ ). In addition, higher $P P F$ enhanced TR and NPR and promoted rooting and subsequent growth of grafted transplants. Results suggest that the acclimation process for grafted watermelon transplants can be omitted by properly manipulating environmental factors during graft union formation.

\section{(57) Bioassays and Small-scale Greenhouse Experiments Conducted to Evaluate the Suppression of Phytophthora cinnamomi Activity on Rhododendron $\times$ PJM 'Elite' by Different Composts Incorporated into Growing Media}

Jae H. Han ${ }^{1}$, George L. Good*1, Eric B. Nelson ${ }^{2}$, Harold M. Van Es ${ }^{2}$ ${ }^{1}$ Cornell University, Horticulture, Ithaca, NY, $14853 ;{ }^{2}$ Cornell University, Plant Pathology, Ithaca, NY, 14853; ${ }^{3}$ Cornell University, Crop and Soil Science, Ithaca, NY, 14853

Composts vary in their ability to suppress disease activity when incorporated into growing media. Bioassays that enable a reliable and quick assessment of compost's ability to suppress disease activity can save time, funds and space. A bioassay using Lupinus $\times$ 'Russell Hybrid' seedlings was evaluated as a short-term test for gauging the ability of three composts to suppress activity of $P$. cinnamomi. Colonized millet seeds were prepared via the V-8 agar method. The colonized millet seed were incorporated into the potting media at $0,50,100,200$, and 400 colonized millet seed/200 cc of the media used. Three composts, including composted sewage sludge, brewer's waste and cow manure, were incorporated into the media $(50 \%$ sand : $50 \%$ sphagnum peat, by volume) at rates of $0 \%, 10 \%, 25 \%$, and $50 \%$, by volume. The media, including the inoculated millet seed, were placed in small plastic pots (7.6-cm-diameter and $6.7 \mathrm{~cm}$ high), after which 10 Lupine seeds were sowed in each pot. Percentage of seedling loss was determined after 43 days of observation. The composted sewage sludge and the cow manure proved suppressive at the $50 \%$ incorporation rate and the $10 \%$ and $25 \%$ rate of the latter compost. The brewer's waste compost proved ineffective in this regard; thus, research with this product was discontinued. In a greenhouse study the same inoculation and compost incorporation rates were used, but rooted cuttings of Rhododendron $\times$ 
PJM 'Elite' were plotted into the various treatments. Suppression of disease activity by the composts was significant 2 and 4 months after initiation of treatments. Significance in disease suppression noted between these treatments decreased significantly during the fifth month of the experiment.

\section{(58) Suppression of Phytophthora cinnamomi Activity on Rhododendron $\times$ PJM 'Elite' by Two Compost-amended Container Media under Two Irrigation Regimes and Nursery Conditions}

Jae H. Han ${ }^{1}$, George L. Good*1, Eric B. Nelson², Harold M. Van Es ${ }^{3}$

${ }^{1}$ Cornell University, Horticulture, Ithaca, NY, $14853 ;{ }^{2}$ Cornell University, Plant Pathology, Ithaca, NY, 14853; ${ }^{3}$ Cornell University, Crop and Soil Science, Ithaca, NY, 14853

Composted municipal biosolids were incorporated into a potting mix containing sphagnum peat and sand (1:1 by volume) at rates of $0 \%$, $25 \%$, and $50 \%$, by volume. A second medium was prepared by mixing cow manure compost in the same basic mix at rates of $0 \%, 10 \%$, and $25 \%$ by volume. Each mix was inoculated with $P$. cinnamomi colonized millet seed at a rate of 200/200 cc of compost-amended media. The potted plants were placed outdoors under nursery conditions 14 July 2003. One half of the plants were irrigated every day, except when natural precipitation occurred; the other half was watered once each week. Soil water potential of all treatments was measured daily with tensiometers. Plants were harvested on 18 Aug. and 21 Oct. 2003, when the experiment was terminated. Frequent rainfall during the period prior to the first harvest masked any impact that the irrigation treatments may have had on disease suppression. Even so, three compost treatments proved successful in suppressing disease activity. Between the first and second harvest dates rainfall was significantly less frequent; thus, differences in P. cinnamomi activity between the wet and dry regimes was noted at the 21 Oct. harvest. Under the dry regime, all inoculated compost treatments, except the $25 \%$ municipal biosolid compost, exhibited disease suppression based on root symptom severity and percentage of root infection. Suppression based on shoot symptoms and percentage of shoot loss was evident only in the $50 \%$ and $25 \%$ biosolid and cow manure composts, respectively. Under the wet regime, only one treatment exhibited suppression of disease activity. All compost treatments held more water particularly at lower moisture tensions. The presence of more water would tend to favor more disease activity and not suppression.

\section{(59) An Examination of Irrigation Volumes and Controlled-release Fertilizer Application Methods and Rates to Reduce Nursery Container Leachate and Fertilizer Use}

Peter Purvis, Calvin Chong*, Glen Lumis

University of Guelph, Plant Agriculture, Guelph, Ontario, N1G 2W1, Canada

Plug-rooted liners of common ninebark [Physocarpus opulifolius (L.) Maxim.] were grown in 6-L nursery containers filled with $73 \%$ composted pine bark, $22 \%$ sphagnum peat moss, and 5\% pea gravel (by volume). Plants were fertilized with Polyon (Nutryon) 17-5-12 $(17 \mathrm{~N}-2 \mathrm{P}-5 \mathrm{~K}) 6$-month controlled-release fertilizer at various rates $\left(2.5,4.5,6.5\right.$, and $\left.8.5 \mathrm{~kg} \cdot \mathrm{m}^{-3}\right)$ pre-incorporated, topdressed, or dibbled (placed under the liner at potting). Plants were trickle-irrigated daily with low $(0.4-\mathrm{L})$, middle $(0.8-\mathrm{L})$, or high $(2.0-\mathrm{L})$ volumes of water to maintain leaching fractions of $<0.15,0.25-0.35$, or $>0.60$, respectively. Regression analysis indicated that growth of ninebark increased from 30 to $109 \mathrm{~g} /$ plant with increasing rates of incorporated fertilizer (mean over irrigation volumes), from 27 to $71 \mathrm{~g} /$ plant with topdress and from 59 to $103 \mathrm{~g} /$ plant with dibble. Electrical conductivity (EC, mean over five dates) of the leachate throughout the season was highest with dibble $\left(0.85 \mathrm{dS} \cdot \mathrm{m}^{-3}\right)$, intermediate with incorporated $\left(0.81 \mathrm{dS} \cdot \mathrm{m}^{-3}\right)$, and least with topdressed $\left(0.76 \mathrm{dS} \cdot \mathrm{m}^{-3}\right)$. With low irrigation volumes, growth of ninebark increased from 42 to $81 \mathrm{~g} /$ plant with increasing rates of fertilizer (mean over methods), and from 39 to $105 \mathrm{~g} / \mathrm{plant}$ with middle or high volumes (common regression curve). With low irrigation volumes, leachate EC increased from 0.74 to $0.94 \mathrm{dS} \cdot \mathrm{m}^{-3}$ with increasing rates of fertilizer, and from 0.75 to $0.81 \mathrm{dS} \cdot \mathrm{m}^{-3}$ with middle or high volumes.
(60) Rooting Stem Cuttings in Compost Tea and Anaerobic Digestion Wastewater

C. Chong*1, J. Yang ${ }^{1}$, B.E. Holbein ${ }^{2}$, R.P. Voroney ${ }^{3}$, H. Zhou ${ }^{4}$, H.-W. $\mathrm{Liu}^{2}$

${ }^{1}$ University of Guelph, Dept. of Plant Agriculture, Guelph, Ont., N1G 2W1, Canada; ${ }^{2}$ Super Blue Box Recycling Corporation, Etobicoke, Ont., M8V 3Y3, Canada; ${ }^{3}$ University of Guelph, Dept. of Land Resource Science, Guelph, Ont., N1G 2W1, Canada; ${ }^{4}$ University of Guelph, School of Engineering, Guelph, Ont., N1G 2W1, Canada

Cuttings of sage (Salvia officinalis 'Tricolor'), currant (Ribes aureum), euonymus (Euonymus fortunei var. vegetus), and weigela (Weigela florida 'Nana Variegata') were rooted under greenhouse conditions ( $40 \%$ shade) and mist in aerated hydroponic solutions consisting of deionized water, or mixtures of deionized water and nutrients with various levels of electrical conductivity (EC, $0.0625,0.125,0.25$, and $0.5 \mathrm{dS} \cdot \mathrm{m}^{-1}$ ) from each of three sources: compost tea from municipal solid waste; wastewater from anaerobic digestion of municipal solid waste; and Hoagland's (control) nutrient solution. Despite differences in species response, rooting tended to be similar with the three nutrient sources. Euonymus rooting percentage increased linearly with increasing $\mathrm{EC}$ and was similar with all three nutrient sources (common regression curve, $61 \%$ rooting at $\left.0.5 \mathrm{dS} \cdot \mathrm{m}^{-1}\right)$, as did root length $(1.4$ $\mathrm{cm}$ at $\left.0.5 \mathrm{dS} \cdot \mathrm{m}^{-1}\right)$, but root number was unresponsive. Currant rooting percent increased curvilinearly and similarly with nutrient sources ( $87 \%$ calculated maximum rooting at $\left.0.25 \mathrm{dS} \cdot \mathrm{m}^{-1}\right)$, but root number and length were unresponsive. Sage rooting percentage and root number also increased curvilinearly and similarly with nutrient sources (common regression curve, $100 \%$ rooting at $0.34 \mathrm{dS} \cdot \mathrm{m}^{-1}$, and 4.1 roots at $0.38 \mathrm{dS} \cdot \mathrm{m}^{-1}$, respectively), as did also root length with the compost tea and Hoagland's (common curve for these two nutrient sources, 11.0 $\mathrm{cm}$ at $0.30 \mathrm{dS} \cdot \mathrm{m}^{-1}$ ), but was unresponsive to wastewater. Weigela was unresponsive to EC or nutrient sources (mean percentage of rooting, 73 ; root number, 6.5 ; and root length, $1.9 \mathrm{~cm}$ ).

\section{(61) Pot-in-pot Production of Intermountain West Native Herbaceous Perennials}

Guillermo Cardoso ${ }^{1}$, Roger Kjelgren*1, Teresa Cerny-Koenig ${ }^{2}$, Rich Koenig

${ }^{1}$ Utah State University, Plants, Soils, and Biometeorology, Logan, UT, 84322; ${ }^{2}$ Washington State University, Horticulture; ${ }^{3}$ Washington State University, Agronomy

Low water landscapes are increasing popular and important in the urban areas of the Intermountain West (IMW). Perennial wildflowers are an essential part of low water landscapes, and are a dominant plant type in IMW native habitats. We compared pot-in-pot (PIP) vs. conventional above-ground (CAG) production of six IMW native wildflower species, Mirabilis multiflora, Aquilegia caerulea, Penstemon palmeri, Polemonium foliosissimum, Sphaeralcea grossularifolia, and Penstemon strictus in \#1 (4-L) containers. Media temperature, container-plant water loss, stomatal conductance, and growth were measured during two production cycles per year over 2 years. Growing medium temperatures in the PIP system averaged $10^{\circ} \mathrm{C}$ cooler than in the CAG system. Consistent with cooler growing media, overall water loss of PIP-grown plants averaged $10 \%$ lower than plants grown in the CAG production system. Lower growing media temperatures apparently affected transpiration, as stomatal conductance was about $60 \%$ higher in the PIP system as compared to the CAG-grown plants. The integrated effect of lower growing media temperatures on plant performance resulted in about one-third greater top and root growth for plants growing in the PIP system compared to those in the CAG system. Pot-in-pot production may be an economically suitable nursery system for producing IMW native perennial wildflowers by reducing water loss and enhancing growth.

\section{(62) Field Evaluation of Various Herbicide and Mulch Combinations for Ornamental Weed Control}

\section{Hannah M. Mathers*, Luke T. Case}

The Ohio State University, Horticulture and Crop Science, Columbus, OH, 43210-1096 Two experiments were conducted at the The Ohio State University Waterman Farm, Columbus, on efficacy and phytotoxicity with evalautions at $30,60,90$, and 120 DAT using dry weights and visual ratings $0-10$ with $>7$ being commercially acceptable for efficacy, and $1-10$ with $<3$ 
being commercially acceptable for phytotoxicity. The herbicide-treated mulches and herbicide-mulch application methods were compared to sprays of the five chemicals applied directly to the surfaces of the plots [oryzalin (oryzalin), (AS) Surflan (aqueous solution) $2 \mathrm{lb} / \mathrm{acre}$ (a.i.), flumioxazin (SureGuard WDG), $0.34 \mathrm{lb} /$ acre (a.i.), acetochlor $76 \%$ (Harness $2.5 \mathrm{lb} /$ acre (a.i.), dichlobenil(Casoron CS) $4 \mathrm{lb} / \mathrm{acre}$ (a.i.) and a combination of oryzalin and flumioxazin], two untreated mulches (pine and hardwood) and a weedy. Mulches were applied untreated, over the top of soil surfaces sprayed with the different herbicides. Mulches were also applied untreated to untreated soil surfaces and then sprayed with the different herbicides. Pretreated bark mulches were also evaluated and prepared by placing the mulches on a sheet of plastic, as a single layer thick and sprayed and allowed to dry for 48 hours. Twenty of 38 treatments gave efficacy rating of $>7$, pooled over all evaluation dates. One was a direct spray, Surflan + SureGuard (7.6). Three were pretreated mulches, Surflan + SureGuard (8.2), Harness (7.8) and Surflan (7.4) treated pine. None of the pretreated hardwood barks provided ratings of $>7$. Nine were treatments with the herbicides applied under the bark. Seven of the nine provided ratings of $>8$ and only one involved hardwood bark, Surflan + SureGuard under pine (9.1), Casoron under pine (8.9), Surflan under pine (8.7), Harness under pine (8.3), Harness under pine (8.0) and SureGuard under hardwood (8.0).

\section{Poster Session 4-Genetics and Germplasm 1}

\section{July 2005, 12:00-12:45 p.m. Poster Hall-Ballroom E/F}

\section{(1) Genetic Diversity of Cowpea [Vigna unguiculata (L.) Walp.] Breeding Lines from Different Countries Determined by AFLP Markers}

Jinggui Fang ${ }^{1}$, Panchanoor S. Devanand ${ }^{1}$, ChihCheng T. Chao*1, Philip A. Roberts ${ }^{2}$, Jeff D. Ehlers ${ }^{1}$

${ }^{1}$ University of California-Riverside, Botany and Plant Sciences, Dept. BPS, Riverside, CA, 92521-0124; ${ }^{2}$ University of California-Riverside, Nematology, Riverside, CA, 92521-0124

Cowpea $(2 n=2 x=22)$ is a high protein, short-cycle, and essential legume food crop of the tropics, especially in the low input agricultural areas of sub-Saharan Africa, Asia, and South America. Lack of genetic diversity within breeding programs can limit long-term gains from selection. The cowpea gene pool is thought to be narrow and the genetic diversity within breeding programs could be even less diverse. Genetic relationships among 87 cowpea accessions, including 60 advanced breeding lines from six breeding programs in Africa and the United States, and 27 accessions from Africa, Asia, and South America were examined using amplified fragment length polymorphism (AFLP) markers with six near-infrared fluorescence labeled EcoR I + 3/Mse I + 3 primer sets. A total of 382 bands were scored among the accessions with 207 polymorphic bands (54.2\%). Overall, the 87 cowpea accessions have narrow genetic basis and they shared minimum $86 \%$ genetic similarities. The data also show that the advanced breeding lines of different programs have higher genetic affinities with lines from the same program but not with lines from other programs. The results suggest that there is a need to incorporate additional germplasm of different genetic background into these breeding lines and to ensure the longterm genetic gains of the programs.

\section{(2) A Unique Late-blight Resistance Locus from Solanum pinnatisectum}

Monica J. Norby*, Michael J. Havey

University of Wisconsin-Madison, Department of Horticulture, Madison, WI, 53706

Phytophthora infestans is the casual agent of late blight and is a major threat to potato production worldwide. There are no curative control agents available and resistance genes offer promise in controlling late blight. To date, the primary source of late-blight resistance has been from hexaploid (6x) [4 Endosperm Balance Number (EBN)] Solanum demissum. Mexican diploid (2x) (1EBN) Solanum species possess a wealth of late-blight resistances, but have been neglected due to crossing barriers. Manipulation of EBN and ploidies should allow integration of $2 \mathrm{x}(1 \mathrm{EBN})$ germplasm into cultivated potato. Synteny between late-blight resistance loci from Solanum species of disparate ploidies and EBNs may facilitate the identification of unique resistance alleles and loci. Isolate MSU96 (US8/A2) of $P$. infestans revealed a late-blight resistance locus (Rpil) from 2x(1EBN) S. pinnatisectum (PI 253214) that mapped to chromosome seven (MGG 265:977-985). MSU96 was also avirulent on the late-blight differential R9-Hodgson 2573 (LB3), revealing the presence of the avirulence gene for R9 originating from $S$. demissum. To test the relationship between Rpil and R9, we evaluated a family segregating for $\mathrm{R} 9$ and revealed that it does not map to chromosome seven. The independent inheritance of R9 and Rpil indicates that Rpil is a unique resistance locus. We are conducting a variety of crossing schemes to introgress Rpil into cultivated potato.

\section{(3) Seed Regeneration of Short-day Onion Accessions in the U.S. Collection}

Christopher S. Cramer*1, Larry D. Robertson ${ }^{2}$

${ }^{1}$ New Mexico State University, Dept. of Agronomy and Horticulture, Las Cruces, NM, 88003; ${ }^{2}$ ARS, USDA, Plant Genetic Resources Unit, Geneva, NY, 14456-0462

Numerous short-day onion accessions maintained at the Plant Genetic Resources Unit (PGRU) of Geneva, N.Y., were in danger of being lost from the U.S. germplasm collection due to sub-standard viability and low seed supply of those accessions. Seed regeneration of short-day onions at Geneva, N.Y., has been difficult because of improper daylengths and environmental conditions. A project was initiated in Sept. 2001 between PGRU and the onion breeding program at New Mexico State University to regenerate 75 accessions that were in the most danger of being lost from the collection. Even though germination rates were low for most accessions, plants were recovered from 72 accessions. Two accessions did not produce bulbs as it was likely they were long-day accessions. Of the remaining accessions, two accessions produced bulbs but did not produce seed. Several accessions bolted during bulb production and plants were covered with crossing cages, crosses were made, and seed was collected. Seed of 54 accessions were sent to PGRU to be incorporated back into the collection and to become available for distribution. Seventeen accessions produced less than $35 \mathrm{~g}$ of seed and were retained in order to produce additional seed in a second regeneration step. Some of the short-day accessions that have become available include 'Amarela Globular Rio Grande', 'Babosa', 'Baia Performe Sintese No. 22', 'Beth Alpha', 'Burgundy', 'California Early Red', 'Dehydrator No. 5', 'Early Crystal', 'Eclipse L303', 'Imperial 48', 'New Mexico Yellow Grano', 'Pusa Red', 'Red Bermuda', 'Red Creole', 'Red Grano', 'Red Patna', and 'Rio Grande'.

\section{(4) Genotypic Variability of Iron and Zinc in Sweetpotato}

Don La Bonte, Michael Courtney*

Louisiana Stata University, Horticulture Department, Julian C. Miller Hall, Baton Rouge, LA, 70803

Sweetpotato [Ipomma batatas (L.) Lam.] is a major subsistence crop in southern Africa, where iron and zinc deficiency in humans is an important health problem. A cultivar of sweetpotato that is suited for subsistence farming in this region and that is high in iron and zinc could be an important means of combatting these deficiencies. As part of a program of the International Potato Center (CIP) to develop such a cultivar, we are working to identify the high and low range of iron and zinc in sweetpotato cultivars grown throughout the world by testing a number of cultivars for these nutrients. Subsidiary objectives include determining the heritability of iron and zinc levels and surveying the variability in the levels of these nutrients from root to root on the same plant, from plant to plant of the same cultivar, from the proximal to the distal end of a given root, and from cambium to cortex.

\section{(5) A Comparative Study of SRAP, AFLP, and SSR Markers for Detecting Genetic Differences among Elite Broccoli Inbreds}

Anna Hale*, Mark W. Farnham

USDA/ARS, U.S. Vegetable Laboratory, Charleston, SC, 29414

Private and public vegetable breeders are interested in using current 
and emerging PCR-based marker systems in their respective improvement programs. However, before new systems are employed to replace existing ones, the new systems must prove to be efficient and cost-effective alternatives. Sequence related amplified polymorphisms (SRAPs), amplified fragment length polymorphisms (AFLPs), and simple sequence repeats (SSRs) were compared for their ability to differentiate individuals of a diverse group of 24 elite broccoli (Brassica oleracea L. italica) inbreds. Genomic DNA was assayed using 24 AFLP, 24 SRAP, and 44 SSR primer pairs. In this assessment, SSRs produced an average of only two bands per primer, with $25 \%$ of these bands being monomorphic, and the remaining bands detecting very few differences among the inbreds. Although the AFLP method resulted in a lower rate $(63 \%)$ of polymorphism than the SSRs, it produced about 20 bands per primer. SRAPs produced an average of 14 bands per primer, with $82 \%$ of these bands being polymorphic. Since AFLP and SRAP markers had a higher multiplex ratio and SSRs were frequently monomorphic, AFLP and SRAPs were more effective in differentiating the elite broccoli inbreds examined in this study. Similarity matrices were generated from the AFLP and SRAP data, and resulting dendographs were compared.

\section{(6) Highly Polymorphic Genes in Cultivated Tomato}

\section{Angela Baldo*, Larry Robertson, Joanne Labate}

USDA ARS, Plant Genetic Resources Unit, Cornell University, Geneva, NY, 14456

Cultivated tomato varieties are genetically extremely similar. We identified 764 Unigenes with potential single nucleotide polymorphisms (SNPs) among more than 15 cultivars from public expressed tomato data. By sequencing regions from 53 of these Unigenes in two to three cultivars, we discovered an unexpected wealth of nucleotide polymorphism (62 SNPs and 12 indels in 21 Unigenes). This included a high proportion of predicted nonsynonymous nucleotide (17 of 33 SNPs in exons) and nonconservative amino acid (6 of 16 nonsynonymous SNPs) changes. We hypothesize that five of these regions are associated with introgressions from wild relatives. Identifying polymorphic, expressed genes in the tomato genome will be useful for both tomato improvement and germplasm conservation.

\section{Poster Session 5-Vegetable Crops Management- Cropping Systems 1}

\section{July 2005, 12:00-12:45 p.m. Poster Hall-Ballroom E/F}

\section{(179) An Overview of the Sonoran Vegetable Industry}

\section{Everardo Zamora*, Jose Cosme Guerrero, Santiago Ayala}

Universidad de Sonora, Agricultura y Ganadería, Luis Encinas, Hermosillo, Sonora, 83000, Mexico

Sonora, Mexico, is an outstanding area for growing good quality and high-yield vegetables, fruits, and nuts for year-round exportation. Each year, Sonora produces important, large quantities of fruits and nuts for exportation, including table grape, citrus, pecan, and olive fruit. Also, fresh vegetable production in Sonora is very important. Annually, large volumes of melon, pumpkin, summer squash, chili, husk tomato, tomato, and asparagus are produced for exportation to the United States, Europe, and Japan. Throughout the year, two important growing seasons for vegetable production have been established in Sonora. The most important growing season for vegetable exportation in Sonora is the autumn-winter season, when higher prices are reached for summer vegetables in the U.S. markets. The autumn-winter season begins in August and finishes in December. In Sonora, during the 2002-03 agricultural cycle, 39,666 ha (89,000 acres) of vegetables were established in the field. Many growers in Sonora are investing in imported high technologies for protected cropping from several developed countries, such as the United States, Canada, Israel, and some European countries. Currently in Sonora, high technology is applied by growers for vegetable production, i.e., plastic mulching, low and high tunnels, greenhouses, and shadow frames, which have been frequently used on fresh vegetable commercial production to improve both quality and yield. Because of a large labor force and the attractive income from fresh vegetable exportations to the United States, fresh vegetable production is a very important industry in Sonora. In fact, growing summer vegetables for exportation during the wintertime in Sonora, Mexico, is a good business.

\section{(180) Effects of Plant Density on Pickling Cucumber Fruit Quality}

\section{Mathieu Ngouajio*, Erin C. Hill, William Chase}

Michigan State University, Horticulture, East Lansing, MI, 48824

Cucumber is an important vegetable in Michigan, where it is grown for slicing (fresh) or processing. Michigan is the top producer of pickling cucumbers in the United States, with over $27 \%$ of the total national production. Studies were conducted in 2004 to test the effects of plant density on cucumber fruit quality. Cucumber var. 'Vlaspik' was seeded in $30.5,45.7,61.0$, and $76.2 \mathrm{~cm}$ rows with $12.7 \mathrm{~cm}$ spacing between plants inside the row, corresponding to final plant populations of 258 , 172,129 , and 103 thousand plants/ha, respectively. The experiment used a randomized complete-block design with 4 replications and four rows per plot. At harvest, 10 fruits of grade 2 were randomly selected from each plot for measurement of specific gravity, firmness, soluble solids, color, and seed size. Cucumber fruit specific gravity, soluble solids, and seed size were not affected by plant population size. However, fruit firmness and color varied with plant density. Low plant populations, when compared to high populations, produced darker green fruits, a desired trait in pickling cucumber production. On a scale of 0 (yellowish) to 5 (dark green), plants grown under a population of 258 thousand plants/ha scored an average of 2.8. The score was 4.6 for fruits produced in plots with 103 thousand plants/ha. Low plant populations increased fruit firmness as measured by a puncture test. Fruit firmness was 89 , 93,97 , and $95 \mathrm{~g} \cdot \mathrm{mm}^{-2}$ for $258,172,129$, and 103 thousand plants/ha, respectively. Results suggest that cultural practices may affect pickling cucumber fruit quality.

\section{(181) Effect of Mulch, Mycorrhizal Inoculation, and Surround on Late Fall Pepper Production}

Donald J. Makus*

${ }^{1}$ USDA, ARS, Integrated Farming and Natural Resources Unit, Weslaco, TX, 78596

Four week-old pepper (Capsicum annuum) cultivars Sonora Anaheim and Capistrano were transplanted on 7 Oct. 2004 into a sandy loam soil near Weslaco, Texas (lat. $26^{\circ} 08^{\prime} \mathrm{N}$ ). Plants were subject to eight treatments consisting of sweet sorghum mulch, mycorrhizal (Bio Organics) inoculation, kaolin (Surround) application and their factorial combinations. Mulch was applied at $2.4 \mathrm{~kg} \cdot \mathrm{m}^{-2}$ and kaolin weekly at $25 \mathrm{~kg} \cdot \mathrm{ha}^{-1}$. Mulch applications reduced soil temperatures at $5 \mathrm{~cm}$ typically $8{ }^{\circ} \mathrm{C}$ during the $1200-1800 \mathrm{HR}$ period of the day during the first 14 days after planting, but decreased soil temperatures to less than $2{ }^{\circ} \mathrm{C}$ by $22 \mathrm{Dec}$. Volumetric soil moisture content at $0-20 \mathrm{~cm}$ was initially $4 \%$ (absolute) higher in the mulch treatments during the first week after planting but deceased with time as the mulch deteriorated. Mulching increased root dry weight 70 days after transplanting. Mycorrhizal association was evaluated in four treatments, where incidence of mycorrhizal infection was "mulch + mycorrhizae" > "mycorrhizae only" = " "mulch only" $>>$ "control." Kaolin reduced plant height, plant top fresh weight, and improved yield in both cultivars by increasing earlier flowering and, in the case of 'Sonora Anaheim', reducing fruit drop caused by pepper weevil (Anthonomus eugenii). In both cultivars, mulch reduced yields and mycorrhizal inoculation gave no agronomic benefit.

\section{(182) Delayed Planting and Plug Cell Volume Effects on Growth, Development, and Yield of Transplanted Sweet Corn}

Sandra Menasha, Milton Tignor*, David Heleba

The University of Vermont, Plant and Soil Science, Burlington, VT, 05405-0082

Transplanting sweet corn is commonly practiced in the northeast U.S. to improve stand establishment and promote early harvest. However, early spring storms and labor constraints can delay transplanting when establishment is most desirable. 'Temptation' sugary enhanced (se) sweet corn transplants 0-, 2-, 4-, 6-, and 8-days-old beyond the "grower" 
2-week growth period were field planted to explore the effects delayed planting combined with plug cell volume differences would have on transplant ear quality and early yields. The transplant treatments were evaluated in a two-way factorial (five delayed planting dates $\times$ three plug volumes) arranged in a split-plot design with five replications. Field sites were the whole plot treatment and the factorial treatments were the split-plots. All transplants were planted on 24 May 2004 at the two field sites. The final density was $\approx 22,000$ plants/acre. Transplant cell volume $(15,19$, and $29 \mathrm{~mL})$ had no significant effect on ear quality and total marketable yield. Ear length was significantly affected by field site $(P \leq 0.0001)$ and ear diameter was significantly affected by planting delay $(P=0.0145)$. Field site $(P \leq 0.0001)$ and planting delay $(P=0.0090)$ both significantly affected the number of early marketable ears/acre. The results indicate that transplants can remain in the plug cells up to 20 days ( 2 weeks +6 day delay) before the delay negatively impacts ear diameter, tip fill, and early marketable yield.

\section{(183) Effects of Colored Plastic Mulches on Tomato Growth and Yield}

Maurice Ogutu*

University of Illinois at Urbana-Champaign, Extension, Countryside, IL, 60525

Different colored plastic mulches can influence tomato (Lycopersicon esculentum L.) growth and yield. A study was carried out to compare the effects of different colored plastic mulches and bare ground on growth and yield of tomato. Ten treatments, namely, control (bare ground), and plastic mulches (black smooth, red, black embossed, blue, olive, yellow, clear, white, and reflective) were replicated four times in a randomized complete-block design. Tomato variety 'Sunstart' seeds were planted in flats filled with Jiffy Mix in a greenhouse in late Apr. 2004 and seedlings transplanted in early June 2004. The seedlings planted in white and reflective plastic mulches were taller than seedlings planted in black smooth, black embossed, clear, blue, red, and olive mulches by 24 July 2004 . Weeds were growing underneath clear, yellow, and red plastic mulches, and squash bugs were observed in yellow plastic mulch treatment on 2 July. Cumulative marketable tomato yield was highest in plants grown in reflective and white plastic mulches, and lowest in plants grown in yellow plastic mulch. Marketable fruits from plants grown in reflective and white mulches were larger than fruits from other treatments. In comparison with black embossed plastic mulch, plants grown in reflective and white plastic mulches had 2 and 1.2 tons/acre higher marketable yields, respectively, than plants grown in black embossed plastic mulch.

\section{(184) Effects of Colored Plastic Mulches on Muskmelon Growth and Yield}

Maurice Ogutu*

University of Illinois at Urbana-Champaign, Extension, Countryside, IL, 60525

Colored plastic mulches can influence muskmelon (Cucumis melo L.) growth and yield. A study was carried out at the St. Charles Horticulture Research Center, St. Charles, Ill., to compare the effects of different colored plastic mulches on vine length and yield of muskmelons. An experiment was carried out with 10 treatments, namely, control (bare ground), and plastic mulches (black smooth, red, black embossed, blue, olive, yellow, clear, white, and reflective) in a complete randomized block and replicated four times. Muskmelon variety 'Athena' seeds were started in the greenhouse in late Apr. 2004 in flats filled with Jiffy Mix, and transplanted in mid-May 2004. Seedlings planted in black embossed, olive, red, blue, and white plastic mulches had longer vines than seedlings transplanted in black smooth, reflective, clear, and yellow mulches by 24 July. Seedlings planted on the control (bare ground) had much shorter vines compared to seedlings in other treatments. The cumulative fruit number and weight was higher in blue, olive, red, and black embossed plastic mulches than in plants grown in clear, yellow, and reflective plastic mulch treatments. Plants grown in white and reflective mulch treatments had larger fruits than plants in other treatments. In comparison with black embossed plastic mulch, plants grown in blue, olive, and red plastic mulches had higher fruit number and yields.

\section{(185) Response of Vegetable Crops to Mycorrhizal Inoculation in a Calcareous Soil in the Tropics}

Mari Marutani, Joseph Tuquero, Robert Schlub, James McConnell*

University of Guam, College of Natural and Applied Sciences, UOG Station, Mangilao, GU, 96923

The effects of a vesicular-arbuscular mycorrhizal fungus, Glomus aggregatum inoculation were examined on growth of vegetable crops in pot culture and field experiments with Guam cobbly clay loam soil (clayey, gibbsitic, nonacid, isohyperthermic Lithic Ustorthents). In pot experiments, the growth response of yard-long beans (Vigna unguiculata subs. sesquipendalis), sweet corn (Zea mays), watermelon (Citrullus lanatus), cucumber(Cucumis sativus), okra (Abelmoschus esculentus), green onion (Allium fistulosum), eggplant (Solanum melongena), and papaya (Carica papaya) were significantly improved with mycorrhizal inoculation. A pot experiment was also conducted to evaluate effects of G. aggregatum inoculation on the growth of corn seedlings at four different water regimes. Seedlings inoculated with G. aggregatum significantly improved the plant growth and the mineral uptake at all levels of water treatments. In the first field trial, prior to seed sowing the media in seedling trays were either inoculated or not inoculated with G. aggregatum. Treated watermelon and eggplant seedlings were transplanted in field. It was found that inoculating seedlings did not improve the harvest yield of two fruit-bearing crops. The second field experiment was conducted to study G. aggregatum inoculation and different levels of inorganic fertilizer application on growth of corn. Mycorrhizal colonization had positive effects on corn development and uptake of some minerals such as Fe. Experiments in the study suggested potential uses of a mycorrhizal fungus in an alkaline soil in the tropics.

\section{(186) Vegetable Yields under Sustainable Production Systems} Greg D. Hoyt*

${ }^{1}$ North Carolina State University, Dept. of Soil Science, Mtn. Hort. Crops Res.\& Ext. Center, Fletcher, NC, 28732

This experiment was designed to compare best management practices for conventional and conservation tillage systems, chemical IPM vs. organic vegetable production, and rotation effect on tomatoes. Four vegetables were grown under these management practices with peppers (first year), yellow squash and fall broccoli (second year) on half of the field plots and tomatoes on the other half. For the third year, both sections of the field plots were tomatoes. The treatments were: 1) conventional-tillage with chemical-based IPM; 2) conventional-tillage with organic-based IPM; 3) conservation-tillage with chemical-based IPM; 4) conservation-tillage with organic-based IPM; and 5) conventional-tillage with no fertilizer or pest management (control). This poster describes pepper, yellow squash, fall broccoli, and tomato yields from the various treatments over the 3 -year rotation. These results are for the third rotation sequence (years 79). Pepper yields were higher in treatments with chemical fertilizer and pest control. Fall broccoli yields were in the order: strip-tilled-chemical $\geq$ strip-till-organic $\geq$ conventional-tilled-chemical $\geq$ conventional-tilled-organic $\geq$ control. Yellow summer squash yields were in the order: conventional-tilled-chemical $\geq$ conventional-tilled-organic $\geq$ strip-till-chemical $\geq$ strip-tilled-organic $\geq$ control. Tomato yields were in the order: conventional-tilled chemical $\geq$ strip-till-chemical $\geq$ conventional-tilled-organic $\geq$ strip-tilled-organic $\geq$ control for each of the 3 years.

\section{Poster Session 6-Propagation 1}

18 July 2005, 12:00-12:45 p.m. Poster Hall-Ballroom E/F

\section{(168) Long-term Growth of Live Oak from Seed or Cutting}

\section{Yin-Tung Wang ${ }^{1}$, Genhua Niu*2}

${ }^{1}$ Texas A\&M University System, Horticultural Sciences, Texas Agricultural Experiment Station Weslaco, TX, 78596; ${ }^{2}$ Texas A\&M University System, Horticultural Sciences, Texas Agricultural Experiment Station, El Paso, TX, 79927

Live oak trees raised from acorns are highly non-uniform and many produce numerous undesirable rhizomic shoots. The objectives of this 
study were to 1) compare the growth rates between (Quercus virginiana Mill.) trees from seed and cutting in four production systems and 2) determine if trees from cuttings produce rhizomic shoots. Rhizomic shoot cuttings $25-30 \mathrm{~cm}$ long were taken from a single tree about 50 years old in late Aug. 1990, rooted, and planted in 2.6-L pots after 2 months. During the same week, acorns were collected from the same tree and germinated. All trees were planted into 13-L pots in July 1991 and then to a field in July 1992. Trees from both sources were planted either directly in the ground, in 36.6- or 45.7-cm-diameter polypropylene fabric bags buried in the ground, or in $13-\mathrm{L}$ pots on the ground. Trunk circumference $10 \mathrm{~cm}$ above the soil line was roughly measured yearly between 1992 and 1999. Initially, trees from cuttings grew slightly slower than seedlings, having a smaller trunk circumference, diameter, and cross-sectional area. These differences diminished and all trees had similar circumferences after 1996. In 1992, trees in 36.6$\mathrm{cm}$ bags and pots had more growth than trees in the ground. In 1993, trees in pots had better growth than those in the ground. After 1993, all trees had similar circumferences until the end of this study, probably due to roots extending beyond the bags and pots into the surrounding soil. About one-third of the seedling trees produced rhizomic shoots, whereas none of the trees from cuttings did. The rhizomic shoots of trees in pots were contained within the pot and none from the ground. Another significance of this research is that the cloned trees from cuttings were extremely uniform in growth habit and form.

\section{(169) Root Formation on Stem Cuttings of Yellow- flowered Cultivars of Magnolia Is Influenced by Time- after-budbreak and IBA}

\author{
Jyotsna Sharma*, Gary Knox, Maria Ishida \\ ${ }^{1}$ University of Florida, Environmental Horticulture, Quincy, FL, 32351
}

We propagated six yellow-flowered cultivars of Magnolia vegetatively by applying $0,8,16$, or $30 \mathrm{~g} \cdot \mathrm{kg}^{-1}$ indole-3-butyric acid (IBA) in talc to bases of terminal stem cuttings collected $5,7,9$, or 11 weeks after budbreak. Mean rooting percentage increased from $12 \%$ (in the absence of IBA) to $34 \%$ (after applying $30 \mathrm{~g} \cdot \mathrm{kg}^{-1} \mathrm{IBA}$ ). Rooting percentage also increased with increasing basal caliper $\left(r^{2}=0.25 ; P<0.0001\right)$ of a cutting. For each collection date, more cuttings of 'Ivory Chalice' and 'Yellow Lantern' developed roots than did other cultivars. When data were analyzed separately for selected cultivars, $63 \%$ rooting was observed among cuttings of 'Ivory Chalice' collected 7 weeks after budbreak. Rooting percentage was higher (22\%) among cuttings of 'Hot Flash' collected 5 or 7 weeks after budbreak in comparison to later collection dates, but harvest date did not influence rooting, which ranged from $44 \%$ to $59 \%$, among cuttings of 'Yellow Lantern'. Collection of stem cuttings early in the growing season (5 weeks after budbreak) was beneficial $(31 \%$ rooting) for inducing root formation among cuttings of 'Golden Sun'. We conclude that 'Ivory Chalice' and 'Yellow Lantern' are promising choices for growers interested in clonal propagation of yellow-flowered cultivars of Magnolia. To maximize rooting, terminal cuttings should be collected within 5 to 11 weeks after budbreak and should be treated with 16 or $30 \mathrm{~g} \cdot \mathrm{kg}^{-1}$ IBA in talc. Early collection dates improved rooting frequencies among cuttings of other cultivars but these, particularly 'Butterflies', remain variably recalcitrant and merit further study.

\section{(170) Scion Bud Removal Delays Leaf Development, But} Decreases Graft Success in Pecan Four-flap Graft

\section{Patrick Conner*}

${ }^{1}$ University of Georgia, Horticulture Department,Tifton, GA, 31793-0748

Pecan is a highly heterozygous outcrossing species that is normally propagated by grafting or budding onto seedling rootstocks. The four-flap or banana graft is commonly used by growers or researchers because of its high percentage of success, especially when employed by novice grafters. We removed scion buds before grafting in an attempt to delay budbreak, thus providing more time for vascular connections to form before leaf development and its associated demand for water takes place. Removal of buds from the scion wood was successful in delaying bud and leaf development, but did not increase graft success, and in one treatment actually lowered graft success.
(171) Auxin Affects Adventitious Rooting of Snowbells (Styrax L.)

Jason J. Griffin*1, F. Todd Lasseigne ${ }^{2}$

${ }^{1}$ Kansas State University, Dept. Horticulture, Forestry and Recreation Resources, John C. Pair Horticultural Center, Haysville, KS, 67060; ${ }^{2} 4325$ Pickwick Dr., Raleigh, NC, 27613

The snowbells (Styrax L.) are a group of flowering shrubs and trees distributed throughout the warm-temperate regions of the northern hemisphere. In all, there are about 120 species, of which only Styrax japonicus Sieb. \& Zucc. (Japanese snowbell) and its cultivars are currently of commercial significance. Other species may also posses desirable horticultural traits that could be valuable on their own merit, or used in plant improvement programs. Currently there is little information regarding asexual propagation of the lesser known species. The results herein show that propagation of a diverse collection of Styrax (15 taxa) is possible by stem cuttings. However, species and cultivars within a species do not respond to auxin treatment similarly. The percentage of rooting of many taxa was improved when cuttings were treated with 3000 or $8000 \mathrm{ppm}(0.3 \%$ or $0.8 \%)$ of the potassium salt of indolebutyric acid (K-IBA). However, rooting was unaffected by K-IBA treatment in some taxa, while rooting was negatively affected by K-IBA in others. Additionally, the number of roots produced per rooted cutting were affected by K-IBA treatment. In some instances, K-IBA increased the number of roots per rooted cutting. However, in most of the taxa, root number was unaffected.

\section{(172) The Influence of Environment, Media, and Zerotol on Forcing and In Vitro Establishment of Softwood Shoots from Large Stem Segments of Acer saccharinum and Fraxinus pennsylvanica}

Faheem Aftab ${ }^{1}$, Katayoun Mansouri², John E. Preece*2

${ }^{1}$ University of the Punjab, Department of Botany, Q.A. Campus, Lahore, 54590, Pakistan; ${ }^{2}$ Southern Illinois University, Plant, Soil and Agricultural Systems, Carbondale, IL, 62901

The objectives of this research were to study the effects of three environments (lab, mist, or fog), four media treatments [perlite, vermiculte, 1 perlite : 1 vermiculite (by volume), or a control (empty flats)] and zerotol treatments on shoot forcing and subsequent transfer of explants to in vitro conditions. Stem segments from field-grown trees were cut to $40-\mathrm{cm}$ lengths before being placed in flats with the media treatments. Half of the flats under mist and fog were drenched weekly with zerotol $\left(0.18 \% \mathrm{H}_{2} \mathrm{O}_{2}\right)$. In a separate study, silver maple was forced under mist and drenched weekly with zerotol at $0 \%, 0.09 \%, 0.108 \%, 0.135 \%$, $0.18 \%, 0.27 \%$, or $0.54 \% \mathrm{H}_{2} \mathrm{O}_{2}$. Shoots $(\geq 5 \mathrm{~cm})$ were harvested and nodal and shoot tip explants were surface disinfested and placed in vitro on DKW medium with 10-8 M thidiazuron plus $1.0 \mu \mathrm{M}$ indolebutyric acid. Species did not interact with environment, media, or zerotol treatment, and silver maple produced a mean of 6 shoots per stem segment, while green ash produced a mean of 1.2 shoots. There was a significant interaction among perlite, vermiculite and environment, with the most shoots (6.7/stem segment) produced under mist in the perlite: vermiculite mix. Silver maple explants from the lab had only $4 \%$ microbial contamination, whereas $68 \%$ of explants from fog and $92.2 \%$ of explants from mist were contaminated. When forcing was under fog, in perlite, and drenched with zerotol, explants had a $43 \%$ rate of contamination. In a separate study, when silver maple stems were placed under mist and drenched weekly with $0.18 \% \mathrm{H}_{2} \mathrm{O}_{2}, 46 \%$ (18 of 39 explants) established cleanly in vitro. Contamination was higher with misted explants that were drenched with higher or lower concentrations of zerotol.

\section{Poster Session 7-Ornamental Plant Breeding}

18 July 2005, 1:15-2:00 p.m. Poster Hall-Ballroom E/F

(234) Self-incompatibility in Pink Tickseed, Coreopsis rosea Nutt.

Marietta Loehrlein*1, Sandy Siqueira ${ }^{2}$

${ }^{1}$ Western Illinois University, Agriculture, Macomb, IL, 61455; ${ }^{2}$ Stellenbosch University, Botany, Matieland, 7602, South Africa

Coreopsis rosea is important as a landscape plant and is of some impor- 
tance for restoration of native species. In both situations it is important to understand the breeding system so that the pollination process may be controlled for optimal seed production. The study of the incompatibility system is important to seed production. In commercial crops, seeds may be products of open pollination or $\mathrm{F}_{1}$ hybrids. In the former, genetic variability exists. In conservation and recovery programs of local flora, seeds with genetic variability are desirable. In development of commercial crops, uniform seeds and plants are desirable. Regardless of whether seeds will ultimately be used for commercial crops or for species restoration, an understanding of self-incompatibility will allow the pollination process to be manipulated for optimal seed production. The purpose of this research was to investigate the sexual reproduction mode in Coreopsis rosea. The objectives were to determine whether Coreopsis rosea operates with a self-incompatibility system, and, if so, to discover whether it is a sporophytic or gametophytic mode. The sporophytic form of self-incompatibility has been found in other plants in the Asteraceae family, but no one has studied self-incompatibility in Coreopsis rosea. The purpose of this research was to identify the self-incompatibility system in Coreopsis rosea. A series of self- and cross-pollinations were made in situ, and in vivo pollinations were made and the pistils studied under the microscope. Results indicate that Coreopsis rosea is self-incompatible and operates under the sporophytic mode.

\section{(235) Genetic Diversity Analysis of Five Passiflora Genotypes}

Eric Stafne*, Jon Lindstrom, John Clark

University of Arkansas, Horticulture, 316 Plant Sciences, Fayetteville, AR, 72701

Passiflora is an important ornamental genus, mainly within tropical zones. However, two cold-hardy, North American Passiflora species exist. Previous work has been done to incorporate these species into breeding programs with some success. The intent of this study was to evaluate the extent of genetic diversity among five different Passiflora genotypes, including the two native North American species, $P$. incarnata $\mathrm{L}$. and $P$. lutea $\mathrm{L}$. Results indicate low genetic similarity among all genotypes with none at $50 \%$ or greater. $P$. incarnata and the ornamental cultivar 'Lady Margaret' displayed the highest relationship at 49\%. $P$. incarnata averaged $35.5 \%$ similarity with the other genotypes and $P$. lutea was $29.5 \%$. Average overall similarity among all genotypes was $31.1 \%$. These and other results show that the Passiflora genus has a high degree of genetic variation and breeding efforts could expand interest within North America.

\section{(236) Evaluation of Styrax japonicus for Time of Budbreak and Susceptibility to Spring Freeze Damage}

\section{Sandra Reed*}

USDA-ARS, Floral and Nursery Plants Research Unit, McMinnville, TN, 37110

Japanese snowbell (Styrax japonicus Sieb. \& Zucc.) is an outstanding small ornamental tree that is underutilized in the United States. Many of the cultivars of this Asian native frequently suffer spring freeze damage, especially when grown in the areas of the country that routinely experience dramatic fluctuations in late winter and early spring temperatures. The objectives of this study were to determine if there was variability within $S$. japonicus for time of budbreak and if this variability could be used for selecting plants with reduced susceptibility to spring freeze damage. In 1998, 224 open-pollinated seedlings were planted in the field. Percent budbreak was evaluated weekly during a 6 -week period in Spring 1999 and 2000. While weather conditions varied greatly between the 2 years, there was good consistency between mean budbreak ratings in 1999 and 2000. There was a 4-week difference between the earliest and latest plants to break dormancy. Based on the 1999 and 2000 data, 28 plants were selected and propagated. Areplicated trial involving these selections and three cultivars was carried out in 2002, 2003, and 2004. All of the selections broke bud later and suffered less freeze damage than 'Emerald Pagoda' and 'Carillon', but many performed similarly to 'Pink Chimes'. Variation in height, width, caliper, and canopy shape was observed among the selections. There is an opportunity to utilize the genetic variability in $S$. japonicus for developing cultivars with reduced susceptibility to spring freeze damage.

\section{(237) Hybridization of Hydrangea arborescens and H. involucrata}

Keri Jones*, Sandra Reed

USDA-ARS, Floral and Nursery Plants Research Unit, McMinnville, TN, 37110

Hydrangea arborescens L., or smooth hydrangea, is a shrub native to the eastern United States that produces large corymbs of pure white flowers in early summer. Rated as hardy to USDA cold hardiness zone 4 , it is one of the most cold-hardy members of the genus. Hydrangea involucrata Sieb. is an Asian species that produces lavender-blue flowers in midsummer. This species, which is not widely cultivated in the United States, is only rated as hardy to zone 6 to 7. The objective of this study was to hybridize $H$. arborescens and $H$. involucrata for the purpose of combining cold hardiness and flower color. Reciprocal crosses were made between $H$. involucrata and $H$. arborescens during Summer 2003. No seed were obtained when $H$. involucrata was used as the maternal parent. Approximately 500 seeds were collected from $H$. arborescens $\times H$. involucrata hybridizations, 36 of which germinated. Several of these seedlings were extremely weak and died at a young age. The remaining eight plants have not flowered and all possess reduced growth rates. Hybridity was verified using RAPD markers and morphological comparisons of hybrids and parents.

\section{(238) The Inheritance of Blue Flower Color in Phalaenopsis pulcherrima}

\section{Robert J. Griesbach*}

${ }^{1}$ U.S. National Arboretum, Floral \& Nursery Plants Research, USDA, ARS, BARC-W, Beltsville, MD, 20705-2350

Flower color results from the interaction of a pigment (anthocyanin) with a co-pigment (usually a flavonone or flavonol) at a specific $\mathrm{pH}$. At more alkaline $\mathrm{pHs}$ (pH 5 to 6), an anthocyanin/co-pigment complex is blue; while at more acidic pHs ( $\mathrm{pH} 3-4)$, the same anthocyanin/copigment complex is red. In Phalaenopsis pulcherrima, a mutation in $\mathrm{pH}$ resulted in a bluer flower color. The difference in $\mathrm{pH}$ between the normal-colored magenta flowers $(\mathrm{pH} 5.8)$ and mutant violet flowers ( $\mathrm{pH} 5.5)$ was due to a single co-dominantly inherited gene.

\section{(239) Genetics, Anatomy and Biochemistry of Flower Color in Anagallis monelli (L.) 'Pimpernel'}

Andrea Quintana*1, Jana Albrechtova ${ }^{2}$, Tom Davis ${ }^{3}$, Robert J. Griesbach $^{4}$, Rosanna Freyre ${ }^{1}$

${ }^{1}$ Univ. of New Hampshire, Plant Biology, Durham, NH, 03824; ${ }^{2}$ Charles University, Plant Physiology, Vinicna 5, Prague 2, 128 44, Prague, Czech Republic; ${ }^{3}$ Univ. of New Hampshire, Plant Biology, 46, Durham, NH, 03824; ${ }^{4}$ U.S. National Arboretum, U.S. Department of Agriculture, Agricultural Research Service, Floral and Nursery Plant Research, Beltsville, MD, 20705-2350

Wild Anagallis monelli has blue or orange flowers. Hybrids with red flowers were developed at the Univ. of New Hampshire. Orange is due to pelargonidin, but delphinidin and malvidin can also be present; red is due to delphinidin and malvidin; and blue is due to malvidin only. In this study, blue and orange wild diploid accessions were used to develop four $\mathrm{F}_{2}$ populations $(\mathrm{n}=46$ to 81$)$. In three populations, segregation ratios supported a previously proposed three-gene model for flower color in this species $(P>0.01)$. In the fourth population, white flower color was obtained in addition to blue, orange, and red. Molecular studies of genes in the anthocyanin pathway using a candidate gene approach are in progress. In a separate $\mathrm{F}_{2}$ population, blue, violet, lilac, and red flower colors were obtained. One hybrid per color was studied on three replicate plants. Cells with vacuoles containing anthocyanins in upper and lower petal epidermis peels were counted in five flowers per clone using light microscopy $(M=200 x)$. Blue and red hybrids had mostly blue and red cells, respectively, on both surfaces. Lilac and violet hybrids included cells that were blue and intermediate (containing both red and blue) on both surfaces, and also had red cells on the lower epidermis only. Violet hybrids had more blue cells on the upper epidermis than the lilac hybrids. Anthocyanins were determined by HPLC for each petal epidermis in the four flower colors. The blue hybrid had only malvidin in both upper and lower epidermis, and the red hybrid had mainly delphinidin in both surfaces. Lilac and violet hybrids had small amounts ( $2 \%$ and $2.5 \%$, respectively) of delphinidin on upper surfaces, 
while lower surfaces had $25 \%$ to $33 \%$ delphinidin.

\section{(240) Mode of Inheritance for Leaf Shape and Main Vein Color in Caladium}

Zhanao Deng*, Brent Harbaugh

University of Florida, Gulf Coast Research and Education Center, Wimauma, FL, 33598

Caladiums (Caladium $\times$ hortulanum) are ornamental aroids often forced in containers or grown in the landscape for their colorful leaves. The aesthetic value of caladium plants is largely determined by their leaf characteristics. Caladium breeding can be traced back to the mid-1800s when Gregor Mendel conducted his plant hybridization experiments, but information on the inheritance of caladium traits has been rather scant. To understand the mode of inheritance for three typical leaf shapes and three main vein colors in caladium, controlled crosses were made among commercial cultivars and breeding lines, and segregation of leaf shape and/or main vein color in the progeny was analyzed. The observed segregation ratios indicated that a single locus with three alleles seemed to determine the main vein color in caladium. The white vein allele was dominant over the green vein allele, but recessive to the red vein allele, which was dominant over both white and green vein alleles. The three leaf shapes (fancy, lance, and strap) in caladium seemed to be controlled by two co-dominant alleles at one locus. Leaf shape segregation was skewed in some crosses, which might imply the existence of other factors involved in caladium leaf shape development. Chi-square tests revealed that leaf shape and main vein color were inherited independently in caladium.

\section{(241) Genotyping of Ornamental Flowering Cherry Germplasm (Prunus species) using SSR Technology}

Hongmei Ma, Margaret Pooler*

USDA/ARS U.S. National Arboretum, Floral and Nursery Plants Research Unit, Washington, DC, 20002

Ornamental flowering cherry trees (Prunus species) are popular landscape plants that are used in residential and commercial landscapes throughout most temperate regions of the world. Most of the flowering cherry trees planted in the United States represent relatively few species. The U.S. National Arboretum has an ongoing breeding program aimed at broadening this base by developing new cultivars of ornamental cherry with disease and pest resistance, tolerance to environmental stresses, and superior ornamental characteristics. Knowledge of the genetic relationships among species would be useful in breeding and germplasm conservation efforts. However, the taxonomy of flowering cherry species and cultivars is complicated by differences in ploidy levels and intercrossing among species. We have used simple sequence repeat (SSR) markers developed for other Prunus species to screen a diverse collection of over 200 ornamental cherry genotypes representing 70 taxa in order to determine the genetic relationships among species, cultivars, and accessions. Data were generated from 9-12 primer pairs using an automated DNA genetic analyzer (ABI3770), and subjected to UPGMA cluster analysis. Extremely high levels of polymorphism were exhibited among the materials studied, thus indicating that ornamental flowering cherry germplasm has substantial inherent genetic diversity. This information, combined with traditional morphological characteristics, will be useful in determining genetic relationships among accessions in our collection and for predicting crossability of taxa.

\section{(242) 'Black Pearl': A New Ornamental Capsicum}

\section{John R. Stommel*1, Robert J. Griesbach ${ }^{2}$}

${ }^{1}$ USDA, ARS, Vegetable Laboratory, Beltsville, MD, 20705; ${ }^{2}$ USDA, ARS, National Arboretum, Floral and Nursery Plant Research Unit, Beltsville, MD, 20705

Considerable diversity exists in Capsicum L. germplasm for fruit and leaf shape, size and color, as well as plant habit. This morphological diversity, together with diverse ripe fruit color and varying hues of green to purple and variegated foliar pigmentation, affords myriad opportunities to develop unique cultivars for ornamental applications. The Agricultural Research Service of the United States Department of Agriculture announces the release of a new pepper [Capsicum annuum (L.)] cultivar named 'Black Pearl'. 'Black Pearl' is intended for ornamental applications and affords growers a new crop to add to their bedding and landscape plant assortment. 'Black Pearl' combines black foliage with erect clusters of small round red-pigmented fruit. The vibrant fruit and foliage colors of this new cultivar add interest to the summer and fall garden. Black Pearl' has been trialed extensively for use as a bedding plant where its compact growth habit, black foliage, and brightly colored fruit provide an attractive ornamental display. Limited evaluations suggest that this cultivar is equally well suited for pot culture under high light conditions. 'Black Pearl' was designated a 2006 All America Selection award winner after completion of national trials in 2004. 'Black Pearl' is a release made available from a cooperative research and development agreement with Pan American Seed Company. Seed of 'Black Pearl' is available from Pan American Seed Company, 622 Town Road, West Chicago, IL 60185. Plant Variety Protection for 'Black Pearl' is pending.

\section{(243) Ovule and Embryo Culture of $\times$ Chitalpa tashkentensis Hybrids}

\section{Richard T. Olsen*, Thomas G. Ranney, Zenaida Viloria}

N.C. State University, Horticultural Science, Mountain Horticultural Crops Research and Extension Center, Fletcher, NC, 28732-9244

A series of studies were conducted to determine medium components necessary for ovule and embryo culture of $\times$ Chitalpa tashkentensis Elias $\&$ Wisura hybrids in order to improve recovery of interploid crosses. Ovules were collected at 2, 3, 4, 5, and 6 weeks after pollination (WAP) from selfed tetraploid $\times$ Chitalpa $(\mathrm{S})$ and tetraploid $\times$ Chitalpa $\times$ diploid Catalpa bignonioides Walt. $(3 \times)$ hybrids. Excised ovules were placed in petri dishes with Schenk and Hildebrandt (SH) medium and $0.7 \%$ agar, with or without coconut-water $(2 \%)$ and three sucrose concentrations $\left(20,40\right.$, or $\left.80 \mathrm{~g} \cdot \mathrm{L}^{-1}\right)$. No ovules germinated for either cross in any treatment at 2, 3, and 4 WAP. Selfed ovules germinated at 5 WAP, in both 20 and $40 \mathrm{~g} \cdot \mathrm{L}^{-1}$ sucrose. At 6 WAP, $3 \times$ ovules germinated in 20 $\mathrm{g} \cdot \mathrm{L}^{-1}$ sucrose. Coconut water provided no apparent benefit. Embryos were apparent at 6 WAP, so a new study was initiated to compare ovule vs. embryo culture at this sample date. Excised embryos germinated in greater percentages than ovules, in all treatment combinations at 6 WAP. Germination in $80 \mathrm{~g} \cdot \mathrm{L}^{-1}$ sucrose was observed only for $\mathrm{S}$ embryos without coconut water. Greatest $3 \times$ germination $(16.7 \%)$ was observed for embryos in $20 \mathrm{~g} \cdot \mathrm{L}^{-1}$ sucrose without coconut water. A final study was conducted to investigate the effect of gibberellic acid $\left(\mathrm{GA}_{3}\right)$ on embryo germination. Embryos were harvested at 7 WAP for both crosses and grown in SH medium supplemented with $20 \mathrm{~g} \cdot \mathrm{L}^{-1}$ sucrose and 0 , 1,2 , or $4 \mu \mathrm{m} \mathrm{GA}_{3}$. The addition of $\mathrm{GA}_{3}$, regardless of concentration, increased germination from $30.6 \%$ to $99.1 \%$ for $\mathrm{S}$ embryos and from $11.1 \%$ to $99.1 \%$ for $3 \times$ embryos.

\section{(244) Interspecificic Hybridization of a White-flowered, Cold-hardy Alstroemeria}

Elizabeth L. Kollman*, Mark P. Bridgen

Cornell University, Horticulture, Ithaca, NY 14853.

Alstroemeria, the Inca Lily or Lily-of-the-Incas, is becoming a popular garden plant in the United States. In past years, the primary interest in Alstroemeria has been for its cut flowers. However, recent cold-hardy introductions (USDA hardiness zone 5) have expanded the interest of this colorful plant as a garden perennial throughout the United States. Previously, garden interests were restricted to warmer zones in the southern United States where Alstroemeria could overwinter. This research describes a breeding procedure that has been used with the objective to develop a cold-hardy, white-flowered Alstroemeria. The interspecific hybrids were bred with the use of in ovulo embryo rescue. Reciprocal crosses were made between several white-flowered cultivars and the cold-hardy Chilean species Alstroemeria aurea during Summer 2004. Ovaries were collected 10-23 days after hand pollination and their ovules were aseptically excised. Ovules were placed in vitro on $25 \%$ Murashige and Skoog (MS) medium under dark conditions until germination. Three weeks after germination, they were then placed on $100 \%$ MS medium, and subcultured every $3-4$ weeks thereafter until they were large enough for rooting. After rooting and acclimation, plants were transferred to the greenhouse. Successful hybrids that were produced 
in 2004 were evaluated under greenhouse and field trials during 2005, and the number of plants with white-colored flowers was noted. Although certain morphological characteristics indicate if plants are coldhardy, the hybrids will be overwintered outside in Ithaca, N.Y. (USDA zone 5), during the next several years to determine winter hardiness.

\section{Poster Session 8-Postharvest: MCP/Ethylene/Fresh Cut}

18 July 2005, 1:15-2:00 p.m. Poster Hall-Ballroom E/F

\section{(29) MCP Treatment Makes Delayed Application of Ethoxyquin Effective in Control of Superficial Scald of 'd'Anjou' Pears}

Jinhe Bai*

Oregon State University, Mid-Columbia Agricultural Research and Extension Center, Hood River, OR, 97031-9512

Superficial scald of 'd'Anjou' pears usually develops after storage of 2 months or longer. MCP application controls scald; however, fruit lose their ripening capacity if the dosage is $>30 \mathrm{ppb}$, but lower dosages cannot control scald substantially. In this study, fruit treated with or without $25 \mathrm{ppb} \mathrm{MCP}$ within $2 \mathrm{~d}$ after harvest were stored at $-1{ }^{\circ} \mathrm{C}$ for up to 5 months. After $1,7,30$, or $70 \mathrm{~d}$ of storage, part of the fruit were pulled from storage and treated with $1000 \mathrm{ppm}$ ethoxyquin line spray and immediately returned to the storage, left untreated as non-ethoxyquin control. Incidence of superficial scald along with the concentrations of $\alpha$-farnesene and conjugated trienes (CTs), and the ripening capacity of fruit were investigated after 3,4 , and 5 months storage. All fruit ripened properly within $7 \mathrm{~d}$ of conditioning at room temperature regardless of treatments. Both of MCP or ethoxyquin-1d (ethoxyquin was applied after 1 day storage at $-1^{\circ} \mathrm{C}$ ) alone controlled scald for only 3 months; however, MCP + ethoxyquin controlled scald for 5 months, whenever ethoxyquin was applied between 1 to $70 \mathrm{~d}$ after storage. Thus, with $25 \mathrm{ppb}$ MCP treatment, which is simple, with rapid and mass treatment available, a delayed application (up to $70 \mathrm{~d}$ ) of ethoxyquin becomes effective to control scald. Furthermore, the later application of ethoxyquin within $70 \mathrm{~d}$ after MCP treatment, the less incidence of scald was observed. Scald is caused by the CTs oxidation products of $\alpha$-farnesene. MCP and ethoxyquin inhibited accumulation of CTs of fruit peel by different mechanisms. MCP inhibited the production by influencing ethylene production through control of $\alpha$-farnesene synthesis; however, ethoxyquin worked by inhibiting the oxidation of $\alpha$-farnesene to the CTs.

\section{(30) Edaphic Factors on Crack Development of Cut and Peel Carrots}

Phillip Joy*1, Rajasekaran Lada ${ }^{1}$, Cameron Fullerton ${ }^{2}$, Brian Williams ${ }^{2}$, Angus Ells ${ }^{3}$

${ }^{1}$ Nova Scotia Agricultural College, Plant and Animal Sciences, Truro, Nova Scotia, B2N 5E3, Canada; ${ }^{2}$ Oxford Frozen Foods Ltd., Hillaton Foods; ${ }^{3}$ Oxford Frozen Foods Ltd, Bragg Lumber

The quick-frozen $(\mathrm{QF})$ cut and peel processing industry is growing and has significant economical importance. Crack development formation (CDF) and enhancement is a major obstacle in QF carrot processing since it lowers product quality, profitability and consumer preference. Studies were initiated to determine the role of edaphic factors on crack development. Carrot samples (var. Sugarsnax) were collected from nine different fields before processing, after processing, and after 8 weeks of $-8{ }^{\circ} \mathrm{C}$ freezer storage. Samples were tested for the percent cracked; the length, width, and depth of cracks; and membrane stability using electrical conductivity per gram (EC/g). Membrane injury index (MII) was also analyzed on freezer-stored samples. Very few cracks and low EC readings were observed in treatments prior to processing, with the exception of field VC38. Samples taken at the end of the processing line had a higher percentage of visual cracks and significant differences were found between fields in EC/g and length, but not in width or depth of cracks. Freezer-stored samples had significant differences in all parameters, including EC/g, MII, crack length, width, and depth, indicating that the length of freezer storage time can increase the potential for crack de- velopment. Samples from V49 cracked heavily during 8 weeks in freezer storage compared to the samples from other fields. Asignificant interaction between field and time was also observed in processed samples, indicating that CDF is dependent on both field parameters and freezer storage time. Significant differences were observed among different fields in terms of crack morphology, especially after 8 weeks in freezer storage.

\section{(31) Quality Changes in Oriental Melon as Affected by Washing after Fruit Harvest and 1-MCP Treatment}

Yu-Jin Park*, Duk-Hee Cha, Ki-yun Jung, Bong-Hwa Kang, Jung-Myung Lee

KyungHee Univ., Horticulture, KiHeung-up, YongIn-Si, Gyeonggi-Do, 449701, Korea

Washing oriental melon (Cucumis melo var. makuwa Makino) is a standard procedure because it facilitates the precise elimination of defective fruit, such as fruit having internal decay symptoms, and also facilitates easier handling of fruit by the elimination of gummy substances on the fruit surface. In most fresh fruits and vegetables, however, washing has never been recommended unless it is related to other practices, such as waxing or immediate processing. Harvested oriental melons were placed in a big water tank and washed with a brush machine immediately before grading, using an automatic grader. Fruit that had sunk down to the bottom of the tank were discarded, as they were premature-fermented fruit with no commercial value. Fruit, intact or washed, were treated with $1-\mathrm{MCP}$ at $0.5-2.0 \mathrm{ppm}$ for 12 hours and stored at room temperature for 3 weeks. Flesh firmness, soluble solids contents, fruit petiole color, and changes of surface suture color were measured to evaluate storability of the fruit. The washed fruit exhibited poor skin color and early suture-browning as compared to the non-washed fruit, regardless of 1-MCP pretreatment. 1-MCP treatment was also effective in maintaining fresh fruit quality as compared to the non-treated fruit. 1-MCP effects were, however, more pronounced in relatively smaller and less mature fruit as compared to the fully mature fruit. 1-MCP was also effective in maintaining white suture color, the most important visual factor currently used for quality evaluation in oriental melon.

\section{(32) Effects of 1-MCP Treatments on Several Major Apple Cultivars Grown in Korea}

Seok-Kyu Jung*, Jung-Myung Lee

Kyunghee University, Horticulture, Seocheon-ri Giheung-eup, Yongin-si, Gyeonggi-do, 449-701, Korea

Fruits of 'Tsugaru' (an early maturing cultivar), 'Hongro' (mid-season cultivar), and 'Fuji' (late cultivar), were harvested at different times of the year, depending upon their maturity, and treated with 1-MCP at $0.0,0.5,1.0$, and $2.0 \mathrm{ppm}$ for $8-24$ hours. Fruits were also treated with 1-MCP at different times after harvest. Portions of 1-MCP-treated apples were also treated with ethylene in order to study the interaction between 1-MCP and ethylene. In other experiments, fruits were treated with ethylene first and then treated again with 1-MCP. Major results are as follows. Treatment of 1-MCP greatly retarded the senescence of 'Tsugaru' apple stored at room temperatures as compared with the control. The sooner the time of 1-MCP treatment after harvest of fruit, the greater was the 1-MCP effect. In contrast to the time of 1-MCP treatment, the concentration of 1-MCP and duration of 1-MCP infiltration in a closed chamber exhibited only a minor effect. Ethylene treatment immediately before and/or after the 1-MCP treatment showed only the $1-\mathrm{MCP}$ effect, thus clearly showing that $1-\mathrm{MCP}$ treatment could completely reverse or counter the ethylene effect in 'Fuji' apples. Repeated treatments of 1-MCP after a certain period of low temperature storage of 'Fuji' apples were more effective than a single treatment. Parameters related with fruit quality will be discussed in detail.

\section{(33) Effect of Natural Products on Decay and Antioxidant Activities of Fresh-cut Papayas}

Chien Wang*1, Korakot Chanjirakul ${ }^{2}$, Shiow Wang ${ }^{3}$,

Jingtair Siriphanich ${ }^{2}$

${ }^{1}$ U.S. Department of Agriculture, Produce Quality and Safety Laboratory, BARCW, Beltsville, MD, 20705; ${ }^{2}$ Kasetsart University, Department of Horticulture; ${ }^{3}$ U.S. Department of Agriculture, Fruit Laboratory

The effect of naturally occurring volatile compounds on decay and 
antioxidant activities in fresh-cut papayas (Carica papaya L.) was studied. Exposure to methyl jasmonate (MJ), methyl salicylate (MS) or allyl isothiocyanate (AITC) substantially delayed the onset and reduced the severity of decay during and after storage at $5{ }^{\circ} \mathrm{C}$. Treatment with tea tree oil (TTO) or ethanol (ETOH) was also effective in retarding decay, but to a lesser extent. No beneficial effect was obtained with the use of vinegar vapor. MJ and MS increased oxygen radical absorbance capacity and elevated the activities of several antioxidant enzymes, including glutathione reductase, glutathione peroxidase, guaiacol peroxidase, ascorbate peroxidase, monodehydroascorbate reductase, dehydroascorbate reductase, and superoxide dismutase. The nonenzyme components in the ascorbate-glutathione cycle were also increased by MJ and MS treatments, including ascorbate and glutathione. It is possible that MJ and MS treatments enhanced the antioxidant system and increased the resistance of tissue to decay. However, while AITC also suppressed the development of decay in papaya slices, it had little effect on antioxidant levels and antioxidant enzyme activities. Apparently, AITC exerted its effect through different mechanisms. Studies are in progress to determine if AITC inhibits decay directly via its antimicrobial properties.

\section{(34) Maintaining the Analytical and Microbial Quality of Fresh-cut Apple Slices using Hot Water Pretreatment and a Low pH Dip Treatment}

Robert Saftner*, Judith Abbott, Arvind Bhagwat

USDA Agricultural Research Service, Produce Quality and Safety Laboratory, Beltsville, MD, 20705

A calcium ascorbate processing formulation is commercially used to prevent browning on fresh-cut apple slices but has little to no antimicrobial activity. Intact apples were surface-sanitized with chlorine water at $20^{\circ} \mathrm{C}$ or water at $60^{\circ} \mathrm{C}$, processed into fresh-cut slices, and the slices dipped in a calcium ascorbate formulation or a solution of isoascorbic acid, calcium, and $\mathrm{N}$-acetylcysteine at $\mathrm{pH}$ 2.0. The commercial and experimental dip treatments similarly maintained cut surface color, Kramer firmness, and aromatic volatile concentrations during 3 weeks of storage at $5{ }^{\circ} \mathrm{C}$ in air. Freshly prepared experimental dip treatment reduced the native bacterial population of the apple slices prepared from sanitized apples better than the calcium ascorbate treatment. With repeated use, the experimental dip solution became adulterated with apple tissue and juice and rapidly lost its antibacterial activity. Concomitantly the $\mathrm{pH}$ of the dip solution increased to 2.6 or higher. The lost antibacterial activity could be restored in highly contaminated experimental dip solutions by back titrating to $\mathrm{pH}$ 2.0. The experimental dip treatment also reduced the overall yeast and mold population, but specifically enhanced growth of Penicillium expansum on slices prepared from chlorine-sanitized apples. A hot water pretreatment of intact apples at $60^{\circ} \mathrm{C}$ for $3 \mathrm{~min}$ prior to fresh-cut processing essentially eliminated $P$. expansum contamination on the slices. The results indicate that the experimental dip treatment is a promising alternative to calcium ascorbate treatment for analytical and microbial quality retention of fresh-cut apple slices during storage, especially when the apple slices are processed from hot water-treated apples.

\section{(35) The Influence of 1-MCP on Firmness, Soluble Sugar Levels, Chlorogenic Acid, and Total Phenolic Compounds in Ripening Banana Fruit}

Daniel A. Stanley*, Donald J. Huber

University of Florida, Horticultural Sciences, Gainesville, FL, 32611-0690

In previous studies, 1-methylcyclopropene (1-MCP) was shown to significantly suppress peel degreening and appearance of senescent spotting of banana fruit (Stanley and Huber, 2004). In the present study, the effect of the ethylene antagonist on banana pulp soluble sugar levels and on peel soluble and total phenolics was measured. One hundred and sixty hands (10 boxes) of banana fruit (Musa acuminata cv. Cavendish) were treated with ethylene $\left(300 \mu \mathrm{L} \cdot \mathrm{L}^{-1}, 24 \mathrm{~h}, 15^{\circ} \mathrm{C}, 90 \% \mathrm{RH}\right)$ at a commercial ripening facility in Bradenton, Fla., and transported by truck $\left(15^{\circ} \mathrm{C}\right)$ to the University of Florida. Fruit were sorted and placed in 174-L ripening chambers, where 80 hands received 500 $\mathrm{nL} \cdot \mathrm{L}^{-1} 1$-MCP for two 12 -h periods at $18{ }^{\circ} \mathrm{C}$, while the other 80 hands (controls) were maintained in identical containers without 1-MCP for equal time periods at $18^{\circ} \mathrm{C}$. Mean whole fruit firmness in both treatment groups was $140 \mathrm{~N}$ and decreased to $15 \mathrm{~N}$ (controls) and $30 \mathrm{~N}$ (1-MCP) by day 12 . Soluble sugars in the pulp of control fruit achieved levels between $160-180 \mathrm{mg} \cdot \mathrm{g}^{-1}$ fresh weight by day 8 , while $1-\mathrm{MCP}$ treated fruit required about 12 days to achieve similar soluble sugar levels. Total phenolic compounds present in peel tissue of control and 1-MCP treated fruit required 10 and 14 days, respectively, to achieve levels of about $4000 \mu \mathrm{g}^{\mathrm{g}} \mathrm{g}^{-1}$ fresh weight. Chlorogenic acid levels, a subset of total peel phenolic compounds, peaked above $500 \mu \mathrm{g} \cdot \mathrm{g}^{-1}$ by day 10 in control fruit and by day 12 in 1-MCP treated fruit. Maintenance of fruit firmness along with the achievement of acceptable sugar levels of 1-MCP treated fruit demonstrate possible benefits of suppression of ethylene action for retail and processing markets for banana fruit.

\section{(36) The Influence of 1-Methylcyclopropene (1-MCP) on 'Athena' Cantaloupe Fruit Harvested at the Pre-ripe, Half-slip, and Full-slip Development Stages}

\section{Jiwon Jeong*, Donald Huber}

${ }^{1}$ Institute of Food and Agricultural Sciences, Horticultural Sciences Department, University of Florida, Gainesville, FL, 32611

The present study was performed to characterize the physiological responses of cantaloupe [Cucumis melo (L.) var. reticulates 'Athena'] fruit harvested at preripe (1/4 slip), half-slip, and full-slip stages of development and treated with 1-methylcyclopropene (1-MCP) prior to storage at 13 or $15^{\circ} \mathrm{C}$. Cantaloupe fruit (1/4 to full-slip stage) were treated with 1 -MCP $\left(0.01\right.$ and $\left.1 \mu \mathrm{L} \cdot \mathrm{L}^{-1}\right)$ for 18 hours at $20^{\circ} \mathrm{C}$ and then stored at $15^{\circ} \mathrm{C}$ (pre-ripe fruit) or $13{ }^{\circ} \mathrm{C}$ (half- and full-slip fruit). The firmness of pre-ripe 'Athena' fruit was significantly retained in response to $1 \mu \mathrm{L} \cdot \mathrm{L}^{-1} 1-\mathrm{MCP}$, but did not differ greatly from control fruit in response to $0.01 \mu \mathrm{L} \cdot \mathrm{L}^{-1} 1-\mathrm{MCP}$. Control fruit reached an edible condition $(\approx 70 \mathrm{~N})$ after 6 days of storage at $15^{\circ} \mathrm{C}$ and persisted until day $12(50 \mathrm{~N})$, whereas $1 \mu \mathrm{L} \cdot \mathrm{L}^{-1} 1-\mathrm{MCP}$-treated fruit reached an edible stage after 17 days and persisted through 21 days (over $60 \mathrm{~N}$ ). Fruit treated with 1 -MCP exhibited slightly $\left(0.01 \mu \mathrm{L} \cdot \mathrm{L}^{-1}\right)$ or dramatically $(1$ $\left.\mu \mathrm{L} \cdot \mathrm{L}^{-1}\right)$ lower electrolyte leakage throughout storage. 1-MCP $\left(1 \mu \mathrm{L}^{-\mathrm{L}^{-1}}\right)$ significantly suppressed ethylene production and respiratory rates of pre-ripe cantaloupe during storage at $15{ }^{\circ} \mathrm{C}$. Firmness retention was also highly significant for cantaloupe harvested and treated with 1-MCP $\left(1 \mu \mathrm{L} \cdot \mathrm{L}^{-1}\right)$ at the half-slip and full-slip stages of development. 1-MCP treatment had a significant effect at reducing decay incidence and the occurrence of depressed or sunken regions of the fruit surface.

\section{(37) Metabolism of Apple Peel Constituents during} Ripening is Differently Regulated by Ethylene

James Mattheis*, David Rudell

${ }^{1}$ USDA, ARS, TFRL, Wenatchee, WA, 98801

Metabolism of peel constituents was assessed during ripening of 'Delicious' and 'Golden Delicious' apples. The ethylene action inhibitor 1-methylcyclopropene (1-MCP) and/or controlled atmosphere storage (CA) were used to limit ethylene activity during and after storage at $1{ }^{\circ} \mathrm{C}$. 'Delicious' apples not exposed to 1-MCP developed a brownish discoloration (not superficial scald) during the initial 2 months of storage in air. LC/MS analyses of peel components indicated 1-MCP and/or CA inhibited the degradation of compounds responsible for red peel color (i.e., idaein) as well as other flavonoids. Ethylene regulation of metabolism of other phenolic and related constituents including (-)epicatechin and chlorogenic acid appears to be compound specific. The (-)epicatechin content is not impacted by 1-MCP or CA, while chlorogenic acid accumulation is reduced in fruit exposed to 1-MCP and/or stored in CA. $\beta$-carotene and lutein content in peel of 'Delicious' fruit stored in air was lower compared with untreated controls. Chlorophyll degradation was enhanced in air-stored fruit previously exposed to 1-MCP; however, this result was not observed in 1-MCP exposed fruit from CA. Results for 'Golden Delicious' apples also indicated that exposure to 1-MCP and CA, as well as storage duration, impacts metabolism of peel constituents. Chlorophyll degradation was delayed in fruit previously exposed to 1-MCP and then stored in CA. Impacts of 1-MCP and storage environment on concentrations of other 
'Golden Delicious' peel constituents increased with storage duration. The results indicate metabolism of apple fruit peel constituents during fruit ripening is differentially regulated by ethylene.

\section{Poster Session 9-Sustainable/Organic and Water Utilization in Horticulture}

18 July 2005, 1:15-2:00 p.m. Poster Hall-Ballroom E/F

\section{(160) Are All Vermicomposts Created Equal?}

\section{Gray R. Bachman*}

Illinois State University, Department of Agriculture, Normal, IL, 61790-5020

The horticulture industry continues to show interest in using stabilized organic wastes as a component of container media. Vermicompost, also known as worm-worked waste or worm castings, is one of these materials of interest and can be produced from a number of organic wastes, including manure wastes. One issue that has not been addressed is the uniformity of vermicomposts produced from wastes of different sources. Are all vermicomposts created equal? The uniformity of vermicompost is important for growers to consider when using as a medium amendment. This research project investigated the physical properties of vermicompost 1) from different sources of wastes and 2) from a single waste source sequentially sampled over time. The first stage determined the physical properties of vermicompost from beef manure, hog manure, and peat-based media used by two earthworm growers. There were significant differences between the four vermicomposts in bulk density, air volume, percent air volume, percent volumetric moisture, total porosity, and water holding capacity. The second stage involved determining the physical characteristics of vermicompost produced from beef manure collected at the Illinois State University Research Farm from cattle receiving a consistent diet through the year. Manure was collected bimonthly. There was no difference in vermicompost bulk density among the samples. There were significant differences in air volume, percent air volume, percent volumetric moisture, total porosity, and water holding capacity. These changes in vermicompost physical characteristics must be quantified for growers to accurately predict performance as a growth medium amendment.

\section{(161) Use of Food Waste Composts in Ornamental Plant Production in Florida}

\section{Olivia Riffo, Monica Ozores-Hampton*}

${ }^{1}$ Universidad de las Americas, Horticulture, Santiago, Chile; ${ }^{2}$ University of Florida/SWFREC, Horticulture, Immokalee, FL, 34143-9515

The nursery industry in Florida relies entirely on peat as a major component in potting soil. Escalating peat costs are a major concern, so alternative media are attractive in Florida. The objectives of the project were to study the feasibility of using food waste compost (FWC) to replace peat in different annual ornamental crops. The experiments were conducted in Spring 2004 at the University of Florida/SWFREC Immokalee, Fla. The crops basil (Ocimum basilicum L.), marigold (Calendula officinalis L.), and periwinkle (Vinca rosea L.) were grown in mixes of FWC. The treatments were: 1) $100 \% \mathrm{FWC}$; 2) $60 \% \mathrm{FWC}$, $25 \%$ vermiculite, $15 \%$ perlite; 3 ) $30 \%$ FWC, $30 \%$ peat, $25 \%$ vermiculite, $15 \%$ perlite; and 4 ) $0 \%$ FWC, $60 \%$ peat, $25 \%$ vermiculite, $15 \%$ perlite, by volume. Basil 'U.H' was direct seeded; marigold and periwinkle were transplanted $(5 \mathrm{~cm}$ tall) in pots ( 2 inches). All treatments received $4 \mathrm{~g}$ per pot of Osmocote (19-6-12) for 4 months. Percentage of basil germination and biomass were higher in mixes with $60 \%$ and $30 \%$ FWC as compared with $100 \%$ FWC and the control. Lower basil biomass in the control media was due to high weed biomass grown in the peat control media. There were no differences in biomass and number of flowers per plant among marigold treatments. But, periwinkle dry biomass and number of flowers per plant were higher in the control and $30 \% \mathrm{FWC}$ than in $60 \%$ and $100 \% \mathrm{FWC}$, indicating a negative effect of FWC in periwinkle. It can be concluded that FWC may become a viable alternative to replace peat in basil and marigold when included in potting mixes between $30 \%$ and $60 \%$ by volume, but a negative effect was reported in periwinkle production.

\section{(162) Edible Fungal Growth and Fruiting on Composted Containerized Inedible Crop Biomass}

Leopold M. Nyochembeng*, Caula A. Beyl, Rodulfo P. Pacumbaba Alabama A\&M University, Department of Plant and Soil Science, Normal, AL, 35762

Current goals for space exploration are predicated upon long-term manned space flights and colonization of planetary habitats. Long periods in space without payloads of necessary items from Earth require the development of a self-sustaining ecosystem that will allow astronauts to grow their own food and efficiently recycle the waste products. Crops suggested for growth in space include wheat, rice, carrots, soybean, mushrooms, etc. Optimal and rapid biodegradation of lignin and other cellulosic material of crop residues by candidate edible white rot fungal strains is paramount in the use of these organisms to achieve effective biomass recycling in an advanced life support system (ALS). The incorporation of organic $\mathrm{N}$ into the substrate and pairing crop residues may enhance growth and fruiting of the edible fungi, thus increasing the rate of biodegradation of the substrates and biomass recycling. We investigated the mycelial growth of two strains of Pleurotus ostreatus ('Grey Dover' and 'Blue Dolphin') on processed single vegetative residues of soybean, cowpea, tomato, sweetpotato, or their 1:1 combination with wheat or rice straw. Growth and fruiting of the two strains including another strain ('Pohu') on rice straw mixed with solid thermophilic aerobic reactor (STAR) effluent for degradation and recycling were also studied. Mycelial growth and fruiting in 'Grey Dover' and 'Blue Dolphin' were significantly repressed on sweetpotato and basil; however, growth of the two strains was improved when sweetpotato and basil substrates were paired with rice or wheat straw. Fruiting was prolific in paired combinations of soybean with wheat or rice straw. High concentration of STAR residue enhanced mycelial growth; however, a relatively lower concentration was required for abundant fruiting.

\section{(163) Influence of Single or Mixed Cover Crops on Biomass Production and Fruit Yields of Eggplant Grown with or without Synthetic Nitrogen}

Wayne F. Whitehead*, Bharat P. Singh

${ }^{1}$ Fort Valley State University, Agricultural Research Station, Fort Valley, GA, 31030-4313

The purpose of this study was to evaluate how leguminous and nonleguminous cover crops alone or in mixture with synthetic nitrogen rates affect aboveground biomass, fruit number, and yield of eggplant. The following fall-spring fertility treatments were applied using randomized complete-block design with three replications: 1) fall- $0 \mathrm{~N}$, fallow; spring- $0 \mathrm{~N} ; 2$ ) fall- $0 \mathrm{~N}$, abruzzi rye; spring- $0 \mathrm{~N} ; 3$ ) fall- $0 \mathrm{~N}$, hairy vetch; spring- $0 \mathrm{~N}$; 4) fall- $0 \mathrm{~N}$, abruzzi rye+hairy vetch; spring- $0 \mathrm{~N}$; 5) fall- $0 \mathrm{~N}$, fallow; spring-70 kg $\cdot \mathrm{ha}^{-1} \mathrm{~N}$; 6) fall-0 N, abruzzi rye; spring-70 $\mathrm{kg} \cdot \mathrm{ha}^{-1}$ $\mathrm{N}$; 7) fall-0 $\mathrm{N}$, hairy vetch; spring-70 $\mathrm{kg} \cdot \mathrm{ha}^{-1} \mathrm{~N}$; 8) fall-0 $\mathrm{N}$, abruzzi rye+hairy vetch; spring-70 $\mathrm{kg} \cdot \mathrm{ha}^{-1} \mathrm{Na}$; 9) fall- $0 \mathrm{~N}$, fallow; spring-140 $\mathrm{kg} \cdot \mathrm{ha}^{-1} \mathrm{~N}, 10$ ) fall- $0 \mathrm{~N}$, abruzzi rye; spring- $140 \mathrm{~kg} \cdot \mathrm{ha}^{-1} \mathrm{~N}$; 11) fall- $0 \mathrm{~N}$, hairy vetch; spring- $140 \mathrm{~kg} \cdot \mathrm{ha}^{-1} \mathrm{~N}$; and 12 ) fall- $0 \mathrm{~N}$, abruzzi rye+hairy vetch; spring-140 kg·ha ${ }^{-1}$ N. In Spring 2004, 'Megal' eggplant seedlings were transplanted. Total yield and fruit number were compiled over 7 weeks, while total vegetative dry matter was measured at final harvest. Maximum aboveground biomass (227.6 g/plant), total yield $\left(28.7 \mathrm{Mg} \cdot \mathrm{ha}^{-1}\right)$ and fruit number (13/plant) were produced by fall- 0 $\mathrm{N}$, hairy vetch; spring- $70 \mathrm{~kg} \cdot \mathrm{ha}^{-1} \mathrm{~N}$. Minimum aboveground biomass $(53.0 \mathrm{~g} /$ plant) was produced by fall- $0 \mathrm{~N}$, abruzzi rye; spring- $0 \mathrm{~N}$, while minimum total yield (7.8 Mg.ha $\left.{ }^{-1}\right)$ and fruit number (5/plant) were produced by fall- $0 \mathrm{~N}$, fallow; spring- $0 \mathrm{~N}$. Results imply that hairy vetch supplemented with $\mathrm{N}$ at $70 \mathrm{~kg} \cdot \mathrm{ha}^{-1}$ is most effective in supporting fruit number and yield of eggplant.

\section{(164) Effect of a Non-leguminous Cover Crop, Tillage Practices, and Inorganic Nitrogen on Aboveground Biomass Production and Yields of Southernpea}

Wayne F. Whitehead*, Bharat P. Singh

${ }^{1}$ Fort Valley State University, Agricultural Research Station, Fort Valley, GA, 31030-4313

The objective of this study was to examine how a non-leguminous 
cover crop, three tillage practices, and two synthetic nitrogen rates influence aboveground biomass, and yields of southernpea. The following fall-spring fertility treatments were applied using randomized complete-block design with four replications: 1) fall-0 N+abruzzi rye; spring-conventional till $+0 \mathrm{~N} ; 2$ ) fall- $0 \mathrm{~N}+$ abruzzi rye; spring-strip till +0 $\mathrm{N}$; 3) fall- $0 \mathrm{~N}+$ abruzzi rye; spring-No till $+0 \mathrm{~N}$; 4) fall- $0 \mathrm{~N}+$ abruzzi rye; spring-conventional till $+30 \mathrm{~kg} \cdot \mathrm{ha}^{-1} \mathrm{~N}$; 5) fall- $0 \mathrm{~N}+$ abruzzi rye; springstrip till $+30 \mathrm{~kg} \cdot \mathrm{ha}^{-1} \mathrm{~N} ; 6$ ) fall- $0 \mathrm{~N}+$ abruzzi rye; spring-No till $+30 \mathrm{~kg} \cdot \mathrm{ha}^{-1}$ N. In Spring 2004, 'Mississippi Purple' southernpea was drill planted in all plots. Pod yields were harvested at the fresh-market mature green stage and dry pod stage, while total vegetative dry matter was collected at the mature green stage. Optimal aboveground biomass ( $32.7 \mathrm{~g} / \mathrm{plant})$ was produced by fall- $0 \mathrm{~N}+$ abruzzi rye; spring-strip till $+30 \mathrm{~kg} \cdot \mathrm{ha}^{-1} \mathrm{~N}$ treatment, while maximum fresh-market pod yield $\left(4.9 \mathrm{Mg} \cdot \mathrm{ha}^{-1}\right)$ and dry pod yield (2.2 Mg.ha $\left.{ }^{-1}\right)$ were produced by fall- $0 \mathrm{~N}+$ abruzzi rye; spring-strip till $+0 \mathrm{~N}$. Minimum aboveground biomass (15.6 g/plant), fresh-market pod yield $\left(2.6 \mathrm{Mg} \cdot \mathrm{ha}^{-1}\right)$ and dry pod yield $\left(0.9 \mathrm{Mg} \cdot \mathrm{ha}^{-1}\right)$ were produced by fall- $0 \mathrm{~N}+$ abruzzi rye; spring-conventional till $+0 \mathrm{~N}$ treatment. Spring-strip till at $0 \mathrm{~N}$ produced fresh-market pod yield, dry pod yield, and plant biomass similar to spring-strip till at $30 \mathrm{~kg} \cdot \mathrm{ha}^{-1} \mathrm{~N}$. Results suggest strip-till provided adequate tilth and nitrogen fertilizer was not needed for producing southernpea in middle Georgia

\section{(165) Use of Chicken Manure as Source of Nutrients for Sweet Corn Production}

\author{
Muddappa Rangappa*1, Harbans Bhardwaj ${ }^{1}$, Harry Dalton ${ }^{2}$ \\ ${ }^{1}$ Virginia State University, Agricultural Research, Petersburg, VA, 23806; ${ }^{2}$ VA Dept. of \\ Cons. \& Rec., Water Conservation \& Recreation, Richmond, VA, 23219
}

An on-farm animal manure, such as chicken manure, can be a source of nutrients for the growth and production of agricultural crops. However, use of manures at rates that are considered adequate for crop production may cause excessive accumulation of phosphorus (P) and also result in leaching of nitrogen $(\mathrm{N})$, thus leading to potential pollution of ground and surface water. Composting of manures with a carbon (C) source can reduce $\mathrm{P}$ and $\mathrm{N}$ to manageable levels to support production of crops. In order to determine the potential of composted manure for crop production, we studied growth and production of sweet corn by using poultry manure composted with a carbon source of crimson clover hay or wheat straw. These experiments, conducted during 2002 and 2003, compared six treatments: 1) uncomposted chicken manure alone; 2) composted with wheat straw turned weekly; 3) composted with wheat straw turned bi-weekly; 4) composted with crimson clover hay turned weekly; 5) composted with crimson clover hay turned bi-weekly; and 6) a control with a commercial recommendation rate of $\mathrm{N}$ fertilizer. These treatments resulted in $9244 ; 13,866 ; 15,688 ; 16,734$; and 11,977 marketable ears/acre, respectively, indicating significant superiority of treatments 4 and 5 over all others. Similar results were obtained for ear length, ear fresh weight, and plant height. Results indicated that composting of poultry litter with wheat straw or crimson clover hay is a viable way to utilize poultry manure for production of sweet corn and other agricultural crops. This study implies that composting of on-farm animal manure with organic material, such as hay and straw, could play an important role in development of an environmentally friendly, economically feasible, and sustainable organic production of agricultural crops.

\section{(166) Economic Return in Production of Lettuce and Cantaloupe Is Affected by Cropping System and Value of Hand Weeding}

Edmund J. Ogbuchiekwe' ${ }^{1}$, Mathieu Ngouajio², Milton E. McGiffen*1

${ }^{1}$ University of California, Botany and Plant Sciences, Riverside, CA, 92521; ${ }^{2}$ Michigan State University, Horticulture, East Lansing, MI, 48824

Field experiments were established at the University of California Desert Station in Coachella Valley from 1998 to 2000. The main plot treatments included: 1) summer cowpea used as mulch in the fall; 2) summer cowpea incorporated into soil in the fall; 3) summer sudangrass incorporated into the soil in the fall; and 4) summer fallow (bare-ground). An economic comparison of cover crop treatments and crop management programs vs. the effect on yield, crop value, value of hand weeding, costs of production and net return, and dollar investment from each treatment was determined. Among the cropping systems tested in 1999, lettuce following the incorporation of a cowpea cover crop produced the highest yield (1082.43 boxes/ha), with a net return of $\$ 883.04 /$ ha. The return for each dollar invested in the cowpea-incorporated system was an additional $\$ 0.65$ if cowpeaincorporated was chosen over cowpea mulch. In 2000, the net return from lettuce following cowpea-incorporated was much higher with 1294.23 boxes/ha and a net return of $\$ 1698.46 /$ ha. In 1999, cantaloupe grown in the cowpea-incorporated system had the highest net return of $\$ 973.34 /$ ha, with 874.58 boxes. An additional $\$ 0.93$ was made for choosing cowpea-incorporated over sudangrass. In 2000, cantaloupe grown in the cowpea-incorporated system had even higher yields than in 1999 , producing 1522.89 boxes/ha and returning over $\$ 3000.00$. And an additional $\$ 0.93$ was made for choosing cowpea-incorporated over sudangrass cover crop. Overall, the rate of return on investment favored cowpea-incorporated over all cover crops.

\section{(167) The Effect of Cover Crops and Alternative Management Practices for the Management of Soil-borne Diseases in Sweet Onions}

Hector Valenzuela*, Robin Shimabuku, John Cho

University of Hawaii at Manoa, CTAHR, Honolulu, HI, 96822

Pink root (Phoma terrestris) is among the major limiting factors for the production of sweet onions on Maui, Hawaii. Few management options exist for the control of pink root in onions. Two split-plot experiments were conducted in the area of Kula, Maui, over 2 years to evaluate several alternative management practices. In Expt. 1, the main plots were a rotation with cabbage, solarization with a clear plastic mulch, and a fallow period. Subplots were plus or minus Vapam fumigation. Sub-subplots were biomass application of Sudex or rape, inoculation with an EM biostimulant, and control. Each treatment had four replications for a total of 96 plots. In the follow-up experiment, the main plots were Vapam fumigation, rotation with either a Sudex or rape cover crop, and controls. The subplots were plus or minus EM biostimulant application. In Expt. 1, three separate treatments: solarization, cabbage rotation, and Sudex incorporation had a synergistic effect with Vapam fumigation. Fumigation and solarization also decreased pink root incidence. Rape contributed to a decreased disease incidence while EM contributed to increased bulb size. In Expt. 2, EM and rape contributed to increased yields. Rape and sorghum rotations contributed to decreased pink root incidence. EM inoculation had differential effects on several diseases, contributing to reduced bacterial bulb rot levels. The data indicate that growers may have several alternative management tools at their disposal, in addition to proper varietal selection, to improve yields and reduce disease incidence in sweet onions.

\section{Poster Session 10-Fruit and Nut Breeding}

18 July 2005, 1:15-2:00 p.m. Poster Hall-Ballroom E/F

\section{(228) 'Golden Hills' Pistachio-A Replacement for 'Kerman'}

Dan E. Parfitt ${ }^{1}$, Craig E. Kallsen*2, Joe Maranto ${ }^{2}$

${ }^{1}$ Univ. of California, Davis, Dept. of Plant Sciences, Davis, CA, 95616; ${ }^{2}$ Univ. of California, Kern Co. Farm Advisors Office, Bakersfield, CA, 93307

'Golden Hills' is a new female pistachio cultivar with improved performance characteristics compared to the standard female cultivar Kerman. 'Golden Hills' produces a greater yield and higher percentage of split, edible nuts than 'Kerman' while maintaining a similar low percentage of loose shells and kernels. Harvest date is $2-4$ weeks earlier than 'Kerman', which will permit growers to extend their harvest period and better utilize their harvesting equipment and personnel. Earlier harvest may reduce disease in the northern production areas of California by permitting an earlier harvest before fall rains, as well as reducing navel orangeworm infestations. The cultivar requires less chilling than 'Kerman', which improves uniformity of foliation, bloom, 
nut set, nut fill, and uniformity of nut maturity at harvest in years with insufficient chilling for 'Kerman'. Based on all of our evaluations, this cultivar appears to be an exceptional producer and has the potential to increase grower profits by more than $40 \%$.

\section{(229) 'Lost Hills' Pistachio-A New and Improved Cultivar}

Dan E. Parfitt*1, Craig E. Kallsen², Joe Maranto²

${ }^{1}$ Univ. of California, Davis, Dept. of Plant Sciences, Davis, CA, 95616; ${ }^{2}$ Univ. of California, Kern Co. Farm Advisors Office, Bakersfield, CA, 93307

'Lost Hills' is a new female pistachio cultivar that is being released as a potential replacement for 'Kerman', the industry standard female cultivar. 'Lost Hills' produced substantially higher percentages of split, edible nuts than 'Kerman' in 2003 when split percentages for 'Kerman' were very poor due to reduced winter chilling, a condition that is likely to be more frequent in the future. Nut size for 'Lost Hills' is larger than for 'Kerman'. Harvest date is 2-4 weeks earlier than 'Kerman', which will permit growers to extend their harvest period and better utilize their harvesting equipment and personnel. Earlier harvest may reduce disease in the northern production areas of California by permitting an earlier harvest before fall rains, as well as reducing navel orangeworm infestations. The cultivar requires less chilling than 'Kerman', which improves uniformity of foliation, bloom, nut set, nut fill, and uniformity of nut maturity at harvest in years with insufficient chilling for 'Kerman'. This cultivar could increase grower profits by more than $20 \%$ above that received for 'Kerman'.

\section{(230) Genetic Differences in Sweet Cherry Fruit Size Are Determined by Cell Number and Not Cell Size}

\section{James W. Olmstead*1, Amy F. Iezzoni ${ }^{1}$, Matthew D. Whiting ${ }^{2}$}

${ }^{1}$ Michigan State University, Department of Horticulture, East Lansing, MI, 48824 ${ }^{2}$ Washington State University, Irrigated Agriculture Research and Extension Center, Prosser, WA, 99350

Although maximizing fruit size is critical for profitable sweet cherry (Prunus avium L.) production, little is known about the cellular differences among and between cultivars that contribute to fruit size differences. A wide range of fruit size exists among sweet cherries, and, due to cultural and environmental differences, significant variation exists among genetically identical fruit from the same cultivar. To determine the relative contributions of flesh cell number and cell size to final fruit size in sweet cherry, equatorial sections of three cultivars with a wide range in final average fruit size ['New York 54' (NY54; $1.4 \mathrm{~g}$ fresh weight, $11.8 \mathrm{~mm}$ diameter), 'Emperor Francis' (EF; $6.1 \mathrm{~g}, 21.0 \mathrm{~mm}$ ), and 'Selah' (12.8 g, $25.5 \mathrm{~mm})$ ] were created from mature fruit. Cells intersecting a transverse line were counted and average cell length was calculated. The average cell numbers were significantly different $(P \leq 0.05)$ between 'NY54', 'EF', and 'Selah' (26.7, 47.4, and 83.2, respectively), indicating that flesh cell number is the major contributor to differences in fruit size between cultivars. Flesh cell numbers of 'NY54', 'EF', and 'Selah' were similar at bloom and increased rapidly for a short duration after fertilization, suggesting a key developmental period for fruit size differences. To determine the contribution of cell number differences to variation in fruit size within a cultivar, fruit from 'Bing' and 'Regina' trees exhibiting a range of size due to cultural and environmental differences were measured. In both cases, average cell number was not significantly different $(P=0.9, P=0.3$, respectively), while average cell size was $(P \leq 0.05)$, further indicating fruit flesh cell number is a genetically controlled trait.

\section{(231) Correlation of Cluster Number and Tendril Density in Grapevines}

Peter Cousins*

${ }^{1}$ USDA-ARS, Plant Genetic Resources Unit, New York State Agricultural Experiment Station, Cornell University, Geneva, NY, 14456

The grapevine shoot has a zone in which leaf-opposed clusters are found at the nodes. Beyond the cluster zone, leaf-opposed tendrils are borne at the nodes in a patterned distribution. Cluster number is a primary yield component and selection programs for increasing yield in grapevine frequently consider cluster number. However, selection for increased cluster number requires direct observation, which is only possible once the vine matures. Clusters and tendrils are developmentally related, so it may be that tendril density (tendrils per node) reflects cluster number. In contrast to cluster number, tendril density can be observed on plants of all ages. The hypothesis that tendril density is related to cluster number was tested here. Cluster numbers and tendril density were assessed on 10 primary shoots each of 180 grapevine (Vitis) accessions. The accessions analyzed are cultivars and wild species collections held in the United States National Plant Germplasm System. The correlation coefficient of the number of clusters and tendril density was calculated using the means of 10 observations per accession. Tendril density was determined by calculating the mean number of tendrils per node in the nodes beyond the cluster zone. Cluster number and tendril density were positively correlated; the correlation coefficient was 0.35 . This implies that vines with more tendrils per node also tend to have more clusters. The positive correlation of cluster number and tendril density has implications for grapevine improvement, pointing to the possibility of indirect selection for higher cluster number through selection for higher tendril density. Correlation between juvenile tendril density and mature cluster number is yet to be tested.

\section{(232) 'Randy' Pistachio_-A New Early Flowering Male Cultivar}

Dan E. Parfitt ${ }^{1}$, Craig E. Kallsen*2, Joe Maranto ${ }^{2}$

${ }^{1}$ Univ. of California, Davis, Dept. of Plant Sciences, Davis, CA, 95616; ${ }^{2}$ Univ. of California, Kern Co. Farm Advisors Office, Bakersfield, CA, 93307

'Randy' is an early flowering male pistachio that will be used as a pollenizer for 'West Hills' and 'Lost Hills'. It has excellent flowering synchrony with 'West Hills' and 'Lost Hills' and can be used to cover the earlier part of the 'Kerman'flowering period during seasons in which 'Kerman' flowering is extended. This generally occurs during seasons of low chill, which are expected to become more frequent in the future due to continued global warming. 'Peters', the standard male used to pollenize 'Kerman', often flowers too late to cover the earlier part of the 'Kerman' bloom period under these conditions or to serve as an effective pollenizer for the new female cultivars. 'Randy' was selected for high pollen viability, pollen durability, and a high level of pollen production (based on visual evaluation). 'Randy' flowers 1-3 weeks earlier than 'Peters', the standard pollenizer for 'Kerman'.

\section{(233) Relationship of European Persimmon Cultivars to Asian Cultivars Is Characterized using AFLPs}

Keizo Yonemori ${ }^{1}$, Chitose Honshu ${ }^{2}$, Malli Aradhya ${ }^{3}$, Edgardo Giordani ${ }^{4}$, Elvio Bellini ${ }^{4}$, Dan E. Parfitt*5

${ }^{1}$ Kyoto University, Graduate School of Agriculture, Sakyo-ku, 606-8502, Kyoto, 6068502 , Japan; ${ }^{2}$ University of Miyazaki, Facuty of Agriculture, Miyazaki, 889-2192, Japan; ${ }^{3}$ USDA-ARS, National Clonal Germplasm Repository, Univ. of California, Davis, CA, 95616; ${ }^{4}$ University of Florence, Department of Horticulture, Polo Scientifico, Viale delle Idee, 30, 50019, Sesto Fiorentino (FI), 30, 50019, Italy; ${ }^{5}$ Univ. of California, Davis, Dept. of Plant Sciences, Davis, CA, 95616

Sixty-two persimmon selections, including 16 Italian, 9 Spanish, 16 Japanese, 6 Korean, and 5 Chinese cultivars, were evaluated for genetic differences by AFLP analysis. Four-hundred-seventy characters were scored. Similarities were calculated by the method of Nei and Li. Relationships among cultivars were evaluated by UPGMA clustering and neighbor joining. Most cultivars were quite diverse ( 0.60 to 0.80 similarity between cultivars), while similarities among groups were generally less than 0.60 . Both UPGMA and neighbor joining produced clusters for the European and Asian cultivars. Spanish and Italian cultivars did not cluster, while Chinese and Korean cultivars formed distinct groups. The diversity within groups was greater than the diversity between groups. In addition, the presence of several Japanese cultivars in the European group and Spanish cultivars in the Asian group suggest that similar, but diverse progenitors were used in the development of the current cultivars. Duplicate accessions of 'Kaki Tipo' from different sources were clearly different by AFLP pattern (similarity less than 0.85 ). 


\section{Poster Session 11-Controlled Environments}

18 July 2005, 1:15-2:00 p.m. Poster Hall-Ballroom E/F

\section{(294) Radiation Cycle Affects Biomass Production and Carotenoid Accumulation in Kale}

Mark G. Lefsrud*, Dean A. Kopsell

University of Tennessee, 252 Plant Sciences Building, Knoxville, TN, 37996-4561

Plant growing systems have consistently utilized the standard Earth day as the radiation cycle for plant growth. However, the radiation cycle can easily be controlled by using automated systems to regulate the exact amount of time plants are exposed to irradiation (and darkness). This experiment investigated the influence of different radiation cycles on plant growth, chlorophyll and carotenoid pigment accumulation in kale (Brassica oleracea L. var. acephala D.C). Kale plants were grown in growth chambers in nutrient solution culture under radiation cycle treatments of $2,12,24$, and $48 \mathrm{~h}$, with $50 \%$ irradiance and $50 \%$ darkness during each time period. Total irradiation throughout the experiment was the same for each treatment. Radiation cycle treatments significantly affected kale fresh mass, dry mass, chlorophyll $a$ and $b$, lutein, and beta-carotene. Maximum fresh mass occurred under the 2-h radiation cycle treatment. The maximum dry mass occurred under the 12-h radiation cycle treatment, which coincided with the maximum accumulation of lutein, beta-carotene, and chlorophyll $a$, expressed on a fresh mass basis. The minimum fresh mass occurred during the $24 \mathrm{~h}$ radiation cycle treatment, which coincided with the largest chlorophyll $b$ accumulation. Increased levels of chlorophyll, lutein and beta-carotene were not required to achieve maximum fresh mass production. Environmental manipulation of carotenoid production in kale is possible. Increases in carotenoid concentrations would be expected to increase their nutritional contribution to the diet.

\section{(295) Measuring and Reporting Growing Conditions in Controlled Environments}

Marc W. van Iersel*

University of Georgia, Department of Horticulture, Athens, GA, 30602

Do you accurately measure and report the growing conditions of your controlled environment experiments? Conditions in controlled environment plant growth rooms and chambers should be reported in detail. This is important to allow replication of experiments on plants, to compare results among facilities, and to avoid artefacts due to uncontrolled variables. The International Committee for Controlled Environment Guidelines, with representatives from the U.K. Controlled Environment Users' Group, the North American Committee on Controlled Environment Technology and Use (NCR-101), and Australasian Controlled Environment Working Group (ACEWG), has developed guidlines to report environmental conditions in controlled environment experiments. These guidelines include measurements of light, temperature, humidity, $\mathrm{CO}_{2}$, air speed, and fertility. A brochure with these guidelines and a sample paragraph on how to include this information in a manuscript will be available.

\section{(296) Effects of Lighting Intensity on the Yield of Tomato and Pepper Crops Grown under Space Station (ISS) Environmental Conditions}

Matthew Sisko*1, Jeffrey Richards ${ }^{1}$, Sharon Edney ${ }^{1}$, Neil Yorio ${ }^{1}$, Gary Stutte ${ }^{1}$, Raymond Wheeler ${ }^{2}$

${ }^{1}$ Dynamac Corporation, Food and Crop Systems, Kennedy Space Center, FL, 32899; ${ }^{2}$ NASA Biological Sciences, Kennedy Space Center, FL, 32899

Of the many environmental variables, light intensity $(P P F)$ has primary effect on photosynthesis and significantly influences crop yield. With the eventual use of a crop production system on the International Space Station (ISS), Mars transit vehicle, or in a lunar/Martian habitat, there exists certain engineering constraints that will likely affect the lighting intensity available to plants. Tomato and pepper are candidate crops being considered by NASA that were selected based on their applicability to such mission scenarios. To study the effects of lighting intensity, tomato
(Lycopersicon esculentum L. cv. Red Robin) and pepper (Capsicum annuum L. cv. Hanging Basket) plants were grown under cool-white fluorescent (CWF) lamps with light intensities of 8.6, 17.2, or $26 \mathrm{~mol} \cdot \mathrm{m}^{-}$ ${ }^{2} \cdot \mathrm{d}^{-1}$, with a constant air temperature of $25{ }^{\circ} \mathrm{C}, 65 \%$ relative humidity, and $\mathrm{CO}_{2}$ supplementation of $1200 \mu \mathrm{mol} \cdot \mathrm{mol}^{-1}$ in order to duplicate conditions plants might be subjected to in an open environment of a space cabin. Following 105 days of growth, edible and total mass for both tomato and pepper increased with increasing light levels. Fruit development and time to ripening was also affected by light treatments. The effects of lighting when combined with other environmental factors typical of spaceflight systems will help define crop production for future missions that incorporate plant-based life support technologies.

(297) Continuous Fogging using a Nozzle with an Upward Air Stream Contributes to Steady Air Temperature during Greenhouse Cooling

Hiromi Toida*1, Toyoki Kozai ${ }^{1}$, Handarto ${ }^{1}$, Katsumi Ohyama ${ }^{2}$

${ }^{1}$ Chiba University, Faculty of Horticulture, Matsudo, Chiba, 271-8510, Japan; ${ }^{2}$ Tottori University, Arid Land Reserch Center, Tottori, 680-0001, Japan

Fogging systems are still not widely used for greenhouse cooling, primarily due to their low fog : evaporation ratio, resulting in a low cooling efficiency and a high risk of pathogen expansion caused by excess wetness of plant foliage. The fogging is operated intermittently because of these problems. Consequently, the air temperature and relative humidity fluctuates inside the greenhouse. If nozzles with a high fog : evaporation ratio are employed, the fogging can be operated continuously. By continuous fogging, steady air temperature and relative humidity can be achieved inside the greenhouse. In our previous study under indoor conditions, a high fog : evaporation ratio was achieved by installing two small fans close to a conventional upright nozzle in order to obtain an upward air stream. The objective of this study was to draw a comparison between the environmental conditions inside a greenhouse with the continuous fogging with small fans and that with the conventional intermittent fogging without fans. Reduced fluctuation of the air temperature and relative humidity inside the greenhouse were observed in the case of continuous fogging as compared with that observed in the case of intermittent fogging. The air temperature inside the greenhouse during cooling was lower than that before cooling in both methods. In the case of continuous fogging, the adjustment of the amount of fogged water will provide the desired environmental conditions inside the greenhouse.

\section{(298) Lighting Intensity and Temperature: How They} Affect the Yield of Salad Crops Grown under ISS Baseline Environmental Conditions

Jeffrey Richards ${ }^{1}$, Sharon Edney ${ }^{1}$, Neil Yorio*1, Gary Stutte ${ }^{1}$, Matthew Sisko, ${ }^{1}$ Raymond Wheeler ${ }^{2}$

${ }^{1}$ Dynamac Corporation, Food and Crop Systems, Kennedy Space Center, FL, 32899; ${ }^{2}$ NASA Biological Sciences, Kennedy Space Center, FL, 32899

Environmental factors such as light intensity $(P P F)$ and/or air temperature may be limiting engineering constraints in near or long-term space missions. This will potentially affect NASA's ability to provide either dietary augmentation to the crew or maintain a large-scale bioregenerative life support system. Crops being considered by NASA to provide supplemental food for crew consumption during such missions consist primarily of minimally processed "salad" species. Lettuce (Lactuca sativa L. cv. Flandria), radish (Raphanus sativus L. cv. Cherry Bomb II), and green onion (Allium fistulosum L. cv. Kinka) are being evaluated under a range of $P P F$ and temperature environments likely to be encountered in space systems. Plants were grown for 35 days under cool-white fluorescent (CWF) lamps with light intensities of $8.6,17.2$, or $26 \mu \mathrm{mol} \cdot \mathrm{m}^{-2} \cdot \mathrm{d}^{-1}$, at air temperatures of 25 and $28{ }^{\circ} \mathrm{C}$, and $50 \%$ relative humidity, and 1200 $\mu \mathrm{mol} \cdot \mathrm{mol}^{-1} \mathrm{CO}_{2}$. Regardless of temperature, all three species showed an increase in edible mass with increasing light levels. When grown at $28^{\circ} \mathrm{C}$, edible mass of radish was significantly reduced at all lighting intensities compared to $25^{\circ} \mathrm{C}$, indicating a lower optimal temperature for radish. Understanding the interactions of these environmental factors on crop performance is a critical element to defining future missions that incorporate plant-based life support technologies. 


\section{(299) Comparison of Growth of Salad Crops under ISS Baseline Environmental Conditions in Mixed Crop versus Monoculture Hydroponic Systems}

Sharon Edney*, Jeffrey Richards ${ }^{1}$, Matthew Sisko ${ }^{1}$, Neil Yorio ${ }^{1}$, Gary Stutte ${ }^{1}$, Raymond Wheeler ${ }^{2}$

${ }^{1}$ Dynamac Corporation, Food and Crop Systems, Kennedy Space Center, FL32899; ${ }^{2}$ NASA Biological Sciences, Kennedy Space Center, FL 32899

Development of a crop production system that can be used on the International Space Station, long duration transit missions, and a lunar/Mars habitat, is a part of NASA's Advanced Life Support (ALS) research efforts. Selected crops require the capability to be grown under environmental conditions that might be encountered in the open cabin of a space vehicle. It is also likely that the crops will be grown in a mixed-cropping system to increase the production efficiency and variety for the crew's dietary supplementation. Three candidate ALS salad crops, radish (Raphanus sativus L. cv. Cherry Bomb II), lettuce (Lactuca sativa L. cv. Flandria) and bunching onion (Allium fistulosum L. cv. Kinka) were grown hydroponically as either monoculture (control) or mixed-crop within a walk-in growth chamber with baseline environments maintained at $50 \%$ relative humidity, $300 \mu \mathrm{mol} \cdot \mathrm{m}^{-2} \cdot \mathrm{s}^{-1}$ $P P F$ and a 16-hour light/8-hour dark photoperiod under cool-white fluorescent lamps. Environmental treatments in separate tests were performed with either 400,1200 , or $4000 \mu \mathrm{mol} \cdot \mathrm{mol}^{-1} \mathrm{CO}_{2}$ combined with temperature treatments of $25^{\circ} \mathrm{C}$ or $28{ }^{\circ} \mathrm{C}$. Weekly time-course harvests were taken over 28 days of growth. Results showed that none of the species experienced negative effects when grown together under mixed-crop conditions compared to monoculture growth conditions.

\section{(300) Effect of Planting Density, $\mathrm{CO}_{2}$, and Harvest Intervals on Biomass of Three Allium Species}

\section{Amanda L. Broome*, Ellen B. Peffley}

Texas Tech Univeristy, Plant \& Soil Science, Lubbock, TX, 79409

This research evaluated, for the NASA ALS program, the effect of spacing and harvest intervals on edible biomass of green salad onions grown at two $\mathrm{CO}_{2}$ levels. Shoot biomass of Japanese bunching onion (Allium fistulosum), bulbing onion (A. cepa), and chives $(A$. schoenoprasum) grown at 10-, 15-, and 20-mm spacings harvested at 7- and 14-day intervals, seven and four harvests, respectively, over 70 days were compared. Onions were grown hydroponically in growth chambers, 16-hour light/8-hour dark, $24 / 20{ }^{\circ} \mathrm{C}, 75 / 99 \%$ at $\sim 450$ and $1200 \mathrm{ppm} \mathrm{CO}_{2}$. The design was a completely randomized block with repeated measures; subsamples were plants completely surrounded by neighboring plants. Weekly shoot removal began 28 days after planting (dap); destructive harvest was 70 dap. Length and diameter of longest leaf, weight, and number of leaves/tillers were taken at each harvest; bulb caliper and weight were taken 70 dap. Bunching and bulbing onion leaves were longest at 28 dap and decreased over time; chives were slow to establish but 70 dap had longest leaves. Leaf diameter of all species increased as spacing increased. At 56 through 70 dap chives at all three spacings produced more leaves. Mean weight of shoots differed significantly at 20 -mm spacing: chives the least, bulbing onion the most. Bulb weight for bulbing onion and chives increased with increased spacing; bulbing onion weighed significantly more at 15- and 20-mm spacings compared to the other species and spacings. Chives grown at $20-\mathrm{mm}$ spacing had tillering clumps of rhizomes. Total edible biomass weight (bulb, pseudostem, and shoots) of bulbing onion grown at $10-\mathrm{mm}$ spacing exhibited similar ontogeny to chives grown at 10 - and 15-mm spacings; bulbing onion grown at 20-mm spacing had the most edible biomass. On average, biomass was greatest in plants grown at $1200 \mathrm{ppm} \mathrm{CO}_{2}$.

\section{(301) Screening Carrot Cultivars for Adaptability to Growth in a Nutrient Film Hydroponics System}

Desmond Mortley*1, Jill Hill², Conrad Bonsi² ${ }^{2}$ Walter Hill ${ }^{2}$, Carlton Morris ${ }^{2}$

${ }^{1}$ Tuskegee University, Agricultural Sciences, Tuskegee, Alabama, 36088; ${ }^{2}$ Tuskegee University, Agricultural Experiment Station, Tuskegee, AL, 36088

Tuskegee University is conducting research on salad crops as part of the National Aeronautics and Space Administration's (NASA) goal of supporting humans on near-term space missions, such as on the International Space Station. Small areas of salad crops are ideal candidates for growing in limited volumes, and would provide a source of fresh food to enhance the crew's nutrition. Baseline controlled environment studies were initiated to evaluate the response of eight carrot cultivars ('Baby Mini', 'Nantes Touchan', 'Danvers 126', 'Kundulus', 'Nanco Hybrid', 'Thumbelina', 'Early Nantes', and 'Juwarot') to growth and yield in hydroponics. Seeds were sown in moist arcillite and transplanted into growth troughs $(0.15 \times 0.15 \times 1.2 \mathrm{~m})$ after 18 days in reach-in growth chambers, and nutrients continuously supplied by a half-Hoagland solution. Growth chambers conditions included 300 $\mu \mathrm{mol} \cdot \mathrm{m}^{-2} \cdot \mathrm{s}^{-1}$ photosynthetic photon flux, $16 / 8$ photoperiod, a constant $25{ }^{\circ} \mathrm{C}$ and relative humidity of $50 \%$. Plants were harvested at about 80 days. All eight cultivars grew well in the hydroponic system. Seven cultivars produced greater shoot fresh than root mass except 'Baby Mini', which showed the reverse. 'Danvers 126', followed by 'Nanco Hybrid' and 'Nantes Touchan', produced highest root yields. The $\beta$-carotene content varied by cultivars. The highest level of 10,400 IU/100 g was obtained for 'Thumbelina', followed by 'Baby Mini' (8040 IU/100 g), 'Juwarot' (6160 IU/100g), and 'Early Nantes' (5210 IU/100 g), and the lowest by 'Nantes Touchan' (3510 IU/100 g). These results show that while carrots adapted well to growth in hydroponics, carotene, a major nutrient, was at relatively low levels.

\section{(302) Photoautotrophic Micropropagation Systems Demonstrate Rooting Stage Improvement of Laelia purpurata var. alba}

Hope Jones*, Chieri Kubota

The University of Arizona, Department of Plant Sciences, Tucson, AZ, 85721

In vitro culture of orchid plantlets within conventional photomixotrophic micropropagation (PMM) systems (sucrose containing media in a non-enriched $\mathrm{CO}_{2}$ environment) often induces vigorous growth and multiplication. However, transition to ex vitro conditions frequently results in significant plantlet loss during the acclimatization process. Recent studies investigating micropropagation within photoautotrophic (PAM) systems (sucrose-free media in enriched $\mathrm{CO}_{2}$ conditions) have demonstrated improved plantlet survival during the acclimatization period due to greater root growth and stomata adaptation. Laelia purpurata var. alba, an orchid with many endangered relatives, was chosen as a model orchid species to investigate if plantlet culture within PAM in vitro systems has the potential to improve propagation success and ex vitro survival of endangered Laelia species. Protocorm-like bodies with developed two fully extended leaves were transferred into PMM (photosynthetic photon flux $50 \mu \mathrm{mol} \cdot \mathrm{m}^{-2} \cdot \mathrm{s}^{-1}$ under nonenriched $\mathrm{CO}_{2}$ conditions) and PAM (photosynthetic photon flux 150 $\mu \mathrm{mol} \cdot \mathrm{m}^{-2} \cdot \mathrm{s}^{-1}, \mathrm{CO}_{2}$ level enriched to $\left.1500 \mu \mathrm{mol} \cdot \mathrm{mol}^{-1}\right)$ systems. After 6 weeks, plantlet rooting within the PMM system was variable and inconsistent, while all PAM plantlets produced healthy robust root systems. Average fresh weights and percent shoot development were not significantly different between treatments. Induction of improved root growth by PAM systems may improve orchid plantlet survival rates during acclimatization and advance our ability to increase endangered orchid populations.

\section{(303) Challenges of Organic Hydroponic Production of Strawberries (Fragaria $\times$ ananassa)}

Brandon Jewell*, Chieri Kubota

The University of Arizona, Department of Plant Sciences, Tucson, AZ, 85721

Feasible protocols for organic hydroponic production of strawberry are necessary and this study compares the yield and fruit quality of organic and conventional inorganic hydroponic production. Some issues identified with organic hydroponic strawberry production are: 1) dominant ammonium nitrogen form; 2) solution alkalinity; and 3) dissolved oxygen level of nutrient solution. Eighty bare-rooted 'Diamante' plantlets were planted in coconut fiber pots with a mixture of coconut coir $(30 \%)$ and perlite $(70 \%)$ and grown in a modified nutrient film technique system inside a polycarbonate greenhouse. The organic nutrient solution contains mostly ammonium nitrogen 
and little nitrate nitrogen. To enhance colonization and activities of nitrifying bacteria, coconut fiber mats were placed in the organic nutrient solution reservoir. A similar system was also introduced for stock solution pre-conditioning where nitrification and $\mathrm{pH}$ stabilization were achieved before application to the strawberry plantlets. The organic nutrient solution prior to pre-conditioning had only $1.53 \mathrm{mg} \cdot \mathrm{L}^{-1}$ nitrate nitrogen, although the nitrate nitrogen level increased to $63.2 \mathrm{mg} \cdot \mathrm{L}^{-1}$ after pre-conditioning. The organic nutrient solution $\mathrm{pH}$ was 4.5 initially, 8.5 after 24 hours of pre-conditioning, and finally, shifted to and stabilized at 5.7-5.9 after 3 days. Dissolved oxygen level is critical for both nitrifying bacteria activities and plantlet root growth; therefore, oxygen enrichment was achieved by constantly aerating the nutrient solution in the reservoir, which raised the oxygen level from 2.5 to 7.4 $\mathrm{mg} \cdot \mathrm{L}^{-1}$. Comparisons of yield and quality of strawberry fruits between organic and inorganic nutrient solutions will be presented and further improvements of hydroponic systems will be discussed.

\section{(304) Effects of Supporting Material and Nutrient Supply Cycle on the Growth of Potato Plantlets in a Nutrient- circulated Micropropagation System}

Jung Eek Son*, Yil Jang, Jung Hyuk Seo

Seoul National University, Plant Science, Silim 9-dong, Seoul, 151-921, Republic of Korea

Supporting materials for rooting have a considerable influence on the growth and quality of in vitro plantlets. Various supporting materials (rockwool, perlite, vermiculite, and polyurethane) and nutrient supply cycles $(12,24,36$, and 48 hours) were examined to find the optimum conditions for photoautotrophic micropropagation of potato plantlets in the nutrient-circulated micropropagation (NCM) system. In the NCM system, nutrient solution was circulated between the culture vessel and the nutrient reservoir. A plug cell tray with 70 plantlets was placed inside. The number of air exchanges was 10 hours under forced ventilation. Nodal leafy cuttings of plantlets were cultured at $\mathrm{CO}_{2}$ concentrations $\left(\mathrm{mol} \cdot \mathrm{mol}^{-1}\right) / P P F \mathrm{~s}\left(\mathrm{~mol} \cdot \mathrm{m}^{-2} \cdot \mathrm{s}^{-1}\right)$ of $350 / 80,700 / 120$, and $1500 / 250$ on day 5-11, 12-18, and 19-28, respectively, for all treatments. All growth factors of in vitro plantlets grown for 28 days using rockwool, perlite and vermiculite were greater than those grown using polyurethane. Dry weight of plantlets grown using rockwool was eight times greater than those grown using polyurethane. The same results were obtained in the growth and survival percentages 14 days after transplanting to ex vitro conditions. Optimum nutrient supply cycles were 12,24 , and 48 hours when perlite, rockwool, and vermiculite were used as supporting materials, respectively. It was considered that the range of optimum nutrient supply cycle was affected by water retention characteristics of supporting materials. This study proved that the supporting material and the nutrient supply cycle were very important environmental factors in photoautotrophic mass propagation.

\section{(305) Influence of Hypobaria on Gas Exchange and Growth of Lettuce for Advanced Life Support Systems (ALS)}

\section{Chuanjiu He' ${ }^{1}$, Fred T. Davies*1, Ronald Lacey²}

${ }^{1}$ Texas A\&M University, Dept. of Horticultural Sciences, College Station, TX, 77843$2133 ;{ }^{2}$ Texas A\&M University, Biological and Agricultural Engineering, College Station, TX, 77843-2133

There are advantages in growing plants under hypobaric (reduced atmospheric pressure) conditions in biomass production for extraterrestrial base or space-flight environments. Elevated levels of the plant hormone ethylene occur in enclosed crop production systems and in space-flight environments - leading to adverse plant growth and sterility. Objectives of this research were to characterize the influence of hypobaria on growth and ethylene evolution of lettuce (Lactuca sativa L. cv. Buttercrunch). Growth was comparable in lettuce grown under low $(25 \mathrm{kPa})$ and ambient $(101 \mathrm{kPa})$ total gas pressures. However, tip burn occurred under ambient, but not low pressure - in part because of adverse ethylene levels. Under ambient pressure, there were higher $\mathrm{CO}_{2}$ assimilation rates and dark respiration rates (higher night consumption of metabolites) compared to low pressure. This could lead to greater growth (biomass production) of low pressure plants during longer crop production cycles.

(306) NFT versus Subirrigation: I. Yield and Water Use Efficiency of Tomato Grown in Closed Soilless Systems under Salinity or Water Stress

Francesco Montesano*1, Gianfranco Favuzzi ${ }^{1}$, Angelo Parente ${ }^{2}$, Francesco Serio ${ }^{2}$, Pietro Santamaria

${ }^{1}$ University of Bari, Department of Crop Science, via Amendola 165/A, Bari, 70126, Italy; ${ }^{2} \mathrm{CNR}$, Institute of Science of Food Production, via Amendola 122/o, Bari, 70126, Italy

Sustainability of the soilless greenhouse system is under discussion in open cycle systems, where excess nutrient solution (NS) draining from the substrate is released into the environment. Closed growing systems (CGS) lead to the saving of water and fertilizers. The aim of this research was to compare two CGS: nutrient film technique (NFT) and trough-bench technique [Subirrigation (SUB)]. We report the results of yield and water use efficiency (WUE) of tomato ( $\mathrm{Lyco}-$ persicon esculentum Mill. cv. Kabiria) plants. NFT plants were grown with two electrical conductivity (EC) levels $\left(2-4\right.$ and $\left.6-8 \mathrm{dS} \cdot \mathrm{m}^{-1}\right)$ of NS (its highest EC was obtained by increasing all the ions therein). In the SUB system, two water tensions ( -4 and $-8 \mathrm{kPa})$ of susbtrate were compared; a NS with an electrical conductivity level of $2 \mathrm{dS} \cdot \mathrm{m}^{-1}$ was used. The tensions were measured through tensiometers. Tomato plants were transplanted at the fourth to fifth true-leaf stage into pots containing $8 \mathrm{~L}$ of perlite for SUB. In both CGS, the plants were placed on steel gullies (slope of 2\%). Six clusters per plant were harvested. Total and commercial yield were not influenced by the CGS (on average, 1959 and $1853 \mathrm{~g} /$ plant, respectively). The average weight of the fruit was lower in the SUB system's plants (40 vs. $43 \mathrm{~g} /$ fruit, respectively, for SUB and NFT). Salinity and water stresses resulted in a reduction of $26 \%$ of the yield and $16 \%$ of the average weight of fruits. The WUE was higher in SUB than NFT (30.7 vs. $26.0 \mathrm{~g} \cdot \mathrm{L}^{-1}$, respectively). Salinity stress reduced WUE (29.4 v.s $22.6 \mathrm{~g} \cdot \mathrm{L}^{-1}$ with 2-4 and 6-8 dS' $\mathrm{m}^{-1}$, respectively), whereas water stress did not.

\section{(307) NFT versus Subirrigation: II. Tomato Fruit Quality} Grown in Closed Soilless Systems under Salinity or Water Stress

Francesco Montesano*1, Cristina Ferulli, ${ }^{1}$ Angelo Parente ${ }^{2}$, Francesco Serio ${ }^{2}$, Pietro Santamaria

${ }^{1}$ University of Bari, Department of Crop Science, via Amendola 165/A, Bari, 70126, Italy; ${ }^{2} \mathrm{CNR}$, Institute of Science of Food Production, via Amendola 122/O, Bari, 70126, Italy

Nutrient solutions (NS) containing moderate to high concentrations of salts are frequently supplied to improve the taste of tomato fruits grown in soilless systems. The aim of this study was to determine whether salinity and water stress affect the tomato fruit quality similarly. The research was conducted in Mola di Bari, Italy, during Autumn 2004, and compared the nutrient film technique (NFT) with the trough-bench technique [Subirrigation (SUB)] in terms of tomato (Lycopersicon esculentum Mill. cv. Kabiria) fruit quality. In the NFT, the plants were grown with two electrical conductivity (EC) levels (2-4 and $\left.6-8 \mathrm{dS} \cdot \mathrm{m}^{-1}\right)$ of NS. The highest EC was obtained by increasing all the ions in the NS. In the SUB system, two water tensions ( -4 and -8 $\mathrm{kPa}$ ) of substrate (perlite) were examinated. At harvest, in each cluster (six/plant), fruit dry matter (DM) and total soluble solids (TSS) were determinated. In the fourth and sixth cluster, vitamin $\mathrm{C}$ content and titratable acidity were determined. Total yield was not influenced by either soilless system, while the average weight of the fruit was lower in the SUB. The DM and TTS were influenced by soilless system (on average, 6.6 vs $7.3 \mathrm{~g} / 100 \mathrm{~g}$ of fresh matter and 5.3 vs. $5.9^{\circ}$ Brix, with NFT and SUB, respectively). Both of the stresses resulted in the increase of DM and TSS, principally in SUB (water stress) in respect to NFT (salinity stress), while vitamin $\mathrm{C}$ and titratable acidity were not influenced by soilless system or water/salinity stress $(25.2 \mathrm{mg} / 100$ $\mathrm{g}$ fresh matter and $0.45 \mathrm{~g} / 100 \mathrm{~mL}$ of citric acid juice, respectively). Results of NFT with the highest EC of NS exceeded $9 \mathrm{dS} \cdot \mathrm{m}^{-1}$, without any stress symptoms in the plants, while EC in the SUB system remained unchanged (about $2.5 \mathrm{dS} \cdot \mathrm{m}^{-1}$ ). 


\section{(308) Irrigation Strategies for Rockwool-grown Greenhouse Tomatoes}

Athanasios Papadopoulos ${ }^{1}$, Uttam Saha*1, Xuiming Hao ${ }^{1}$, Shalin Khosla ${ }^{2}$

${ }^{1}$ Agriculture and Agri-Food Canada, Greenhouse and Processing Crops Research Centre, Harrow, Ontario, NOR 1G0, Canada; ${ }^{4} 2$ Ontario Ministry of Agriculture and Food, Harrow, Ontario, N0R 1G0, Canada

In rockwool-grown greenhouse vegetables, unsatisfactory spatial root development, rapid root collapse, and increased incidence of root diseases are very common. Improved water management could alleviate these problems to some extent, because this could favorably modify water-air distribution in the slab, thereby improving greenhouse vegetable yield and quality. The present study tested six irrigation strategies on the productivity of rockwool-grown tomatoes (cv. Rapsodie) during Jan. ${ }^{\circ}-$ Aug. 2004. The four treatments, based on electronic Grodan? water content meters (WCMs), received irrigations when the slab water content (SWC) was $\approx 60 \%, 70 \%, 80 \%$, and $90 \%$ while the other two treatments, based on balances, applied irrigations after a 700- or 500-g loss in the daily-adjusted slab weight (LDASW). Initially, we noticed a heterogeneous EC build-up in the slabs across various treatments, which probably distorted the expression of treatment effects (if any) on plant growth, yield, and water use. To minimize this problem, an EC control strategy of applying extra irrigation was devised and adopted in two sequential phases: 1) application of a 30-minute-long extra irrigation twice a week (for 7 weeks); and 2) extra irrigation(s) using the irrigation control routine of an Argus computer when the slab EC was $\approx 3.5 \mathrm{mS} / \mathrm{cm}$ (for 5 weeks). Slab EC was well controlled in both these phases and we observed significant treatment effects on root growth and marketable yield. Analyzing the results, we concluded that irrigating at $70 \%$ to $80 \% \mathrm{SWC}$ was best for maximum root growth as well as marketable yield. The two irrigation treatments based on the 700- and 500-g LDASW were well maintained and performed equally well, producing marketable yields comparable to those produced by irrigating at $70 \%$ and $80 \%$ SWC.

\section{Poster Session 12-Floriculture Production}

18 July 2005, 1:15-02:00 p.m. Poster Hall-Ballroom E/F

\section{(63) Production Systems for Celosia in a Tobacco Transplant Greenhouse}

\section{Carl E. Niedziela, Jr.*, Guochen Yang}

North Carolina A\&T State University, Natural Resources and Environmental Design, Greensboro, NC, 27411

Plug seedlings of Celosia cristata L. 'Persimmon Chief' were planted in four production systems (harvest lugs, lay-flat bags, pots, and polystyrene trays) on 7 May 2004. Production systems were randomized in a Latin-square design with four replications of each system. Each treatment plot was $0.7 \mathrm{~m} \times 1.1 \mathrm{~m}$. Planting density was 31 plants $/ \mathrm{m}^{2}$. The harvest lugs were $55 \mathrm{~cm} \times 37 \mathrm{~cm} \times 16 \mathrm{~cm}$. The lay-flat bags were $114 \mathrm{~cm} \times 30 \mathrm{~cm} \times 3 \mathrm{~cm}$. The pots were $25 \mathrm{~cm}$ bulb pans. The polystyrene trays were $67 \mathrm{~cm} \times 34 \mathrm{~cm} \times 5 \mathrm{~cm}$ and contained 32 square cells. All of the containers were filled with the same tobacco germination media. The plants in the harvest lugs, lay-flat bags and pots were irrigated daily with $150 \mathrm{mg} \cdot \mathrm{g}^{-1} \mathrm{~N}$ from $20 \mathrm{~N}-4.4 \mathrm{P}-16.6 \mathrm{~K}$. The plants in the polystyrene trays were floated on a solution of $150 \mathrm{mg} \cdot \mathrm{g}^{-1} \mathrm{~N}$ from $20 \mathrm{~N}-4.4 \mathrm{P}-16.6 \mathrm{~K}$. Float solutions were monitored and adjusted weekly for volume and fertilizer concentration. Individual stems were harvested at the appropriate stage of development for market. The fresh weight, stem length and flower diameter of individual stems were recorded. Stems produced in float trays had the lowest fresh weight $(162.2 \mathrm{~g})$. Stems grown in harvest lugs ( $363.5 \mathrm{~g}$ ) weighed more than those in pots $(298.4 \mathrm{~g})$ but not lay-flat bags $\left(338.4 \mathrm{~g}, \mathrm{LSD}_{0.05}=42.7\right)$. Stems grown in float trays ( $88.8 \mathrm{~g})$ were shorter than lay-flat bags (121.5 g), harvest lugs $(120.5 \mathrm{~g})$, and pots $\left(113.5 \mathrm{~cm}, \mathrm{LSD}_{0.05}=10.5\right)$. Flower diameter did not differ between production systems (mean diameter $=7.2 \mathrm{~cm}$ ).

\section{(64) Effect of Plug Flats on Posttransplant Growth and Prevention of Stunting}

Aliya Donnell*, John Dole

North Carolina State University, Horticultural Science, Raleigh, NC, 27695

Plug production is an integral part of today's floriculture industry. However, if seedlings are held in plug flats for too long, they may not return to a normal growth rate after transplanting. Stunting may render plants unsuitable for sale. Common bedding plant and cut flower species were grown in 288-plug flats to determine how long plugs could be held in the flats and still regain a normal growth rate and desirable growth form after transplanting. Species surveyed included: Antirrhinum, Begonia, Brassica, Callistephus, Celosia, Consolida, Dianthus, Eustoma, Gazania, Helianthus, Impatiens, Lycopersicon, Matthiola, Tagetes, and Viola. Ten randomly selected plugs were transplanted to 15 - or $17-\mathrm{cm}$ pots every 1 or 2 weeks for 10 weeks, when root balls were sufficiently developed to hold together after removal from the flat. Overall plant height was recorded for all species every 1 or 2 weeks. Plant diameter was recorded every 2 weeks for Begonia, Celosia, Eustoma, Helianthus, Impatiens, Lycopersicon, and Tagetes. A plug was considered to be stunted if it died after transplanting or did not resume a normal growth rate. Species that exhibited stunting included Brassica, Callistephus, Celosia, Consolida, Dianthus, and Tagetes. For example, Consolida seedlings held in the plug flat for 7 weeks after optimal transplanting time were six times smaller than those that were transplanted at the optimal time. Several factors were investigated to determine how they affected the degree of stunting, including: light quality, root obstruction, nitrogen enrichment prior to transplanting, gibberellic acid addition prior to transplanting, teasing of the root ball prior to transplanting, and length of drainage column.

\section{(69) Effects of Photoselective Shadecloths on Growth and Flowering of Potted Chrysanthemum}

\section{Kent D. Kobayashi*}

University of Hawaii at Manoa, Tropical Plant \& Soil Sciences, Honolulu, HI, 96822

Controlling plant height is an important practice in the ornamental plant industry. Though commonly used, growth regulators are expensive, and there are concerns about environmental consequences and safety of workers. Alternative ways of controlling growth may be advantageous. The objective of this study was to determine the effects of photoselective shadecloths on the growth and flowering of 'Arezzo' chrysanthemum. One-month-old potted 'Arezzo' chrysanthemum plants were grown in a saranhouse in chambers built with PVC (polyvinyl chloride) pipe covered with $30 \%$ shadecloths - red, blue, gray, and black (control). The blue shadecloth was more effective in reducing plant height, with no differences among the other shadecloths. Plant canopy dimensions - greatest canopy width and average canopy width - did not show any differences among the shadecloths. The red shadecloth was more effective in hastening flowering, followed by the blue shadecloth. This was evident by flowering first occurring with the red shadecloth and initially the greatest number of buds showing color. Additionally, the red shadecloth had the highest proportion of the number of flowers to the combined number of flowers and buds showing color. Specifically, the total number of flowers was similar to the total number of buds showing color. In contrast with the other shadecloths, there was a greater number of buds showing color than the number of flowers. The most buds showing color occurred with the gray shadecloth. The three shadecloths resulted in a greater number of the combined buds showing color and flowers than the black shadecloth. In conclusion, photoselective shadecloths may provide an alternative to controlling plant height and altering the flowering pattern of potted chrysanthemums.

\section{(65) Evaluation of Curcuma as Potted Plant and Cut Flower}

Mark Roh*1, Roger Lawson ${ }^{2}$, Jong Suk Lee ${ }^{3}$, Jeung Keun Suh, ${ }^{4}$ Richard A. Criley ${ }^{5}$, Pimchai Apavatjrut ${ }^{6}$

${ }^{1}$ Floral and Nursery Plants Research Unit, USDA, ARS, National Arboretum, B-010A, Beltsville, MD, 20705; ${ }^{2}$ Retired; ${ }^{3}$ Dept. of Horticulture, Chungnam National University, 
College of Agriculture and Life Sciences, Daejeon, 305-764, Korea; ${ }^{4}$ College of BioResources Science, Laboratory of Floriculture, Dankook University, Cheonan, 330-714, Korea; ${ }^{5}$ Department of Horticulture, University of Hawaii, Honolulu, HI, 96822; 6 Department of Horticulture, H.M. the King's Initiative Center, Chiang Mai University, Chiang Mai, 50200, Thailand

Sixteen accessions of Curcuma germplasm and several selected accessions of Curcuma were evaluated for use as potted plants or as cut flowers. Curcuma alismatifolia Gagnep. and C. thorelii Gagnep. 'Chiang Mai Snow' met standards for cut flower and pot plant use, respectively. Furthermore, C. parviflora Will. 'White Angel' proved to be a good selection for potted plant production. Optimum storage temperatures of rhizomes were studied in relation to greenhouse forcing and carbohydrate changes. It is recommended to store rhizomes at 25 to $30{ }^{\circ} \mathrm{C}$ after harvest for 2 to 3 months to break dormancy. Plants of C. parviflora 'White Angel' flowered in 50 to 89 days and $C$. 'CMU Pride' flowered in 104 days after potting, and were acceptable as potted plants. Plants of C. alismatifolia flowered 96 to 133 days after potting with floral stem length suitable for use as a cut flower. A high level of boron or manganese may cause the burn at the margin of the leaves (marginal leaf burn) observed on old leaves of 'CMU Pride' at flowering. The level of ethanol-soluble fructose, glucose, and sucrose in elongated rhizomes with emerged short shoots of Curcuma was higher than the level in rhizomes and increased as storage temperatures increased. Accelerated leaf emergence may be associated with the increase in the glucose and fructose content. Based on the similar morphological characters between $C$. thorelli 'Chiang Mai Snow' and C. parviflora 'White Angel', identification of Curcuma accessions is required in future studies.

\section{(66) Modeling Flower Bud Development of Impatiens hawkeri and I. walleriana}

James E. Faust*, Kelly P. Lewis

Clemson University, Horticulture, Clemson, SC, 29634

Three cultivars of New Guinea impatiens (Impatiens hawkeri) and two cultivars of double impatiens (I. walleriana) were grown in greenhouses maintained at 15,20 , and $25^{\circ} \mathrm{C}$. Bud diameter was measured twice weekly on five plants per cultivar from the time of visible bud to open flower. The experiment was repeated twice. For New Guinea impatiens, the time from visible bud (1-mm diameter) to open flower was 31,43 , and 72 days at 25,20 and $15{ }^{\circ} \mathrm{C}$, respectively. Flower bud diameter increased linearly as the bud expanded from 1 to $9 \mathrm{~mm}$. For double impatiens, the time from visible bud (1-mm diameter) to open flower was 25,30 , and 58 days at 25,20 and $15^{\circ} \mathrm{C}$, respectively. Flower bud diameter increased at an increasing rate (curvilinear response) as the bud expanded from 1 to $8 \mathrm{~mm}$. These models are currently in commercial use to aid greenhouse growers in accurately timing crops for specific market dates.

\section{(67) Survey at Poinsettia Open House Reveals Preferred Cultivars}

\section{Catanzaro, S. Bhatti*, S. Muhammad, S. Abdullah}

Tennessee State University, Institute of Agricultural and Environmental Research, Nashville, TN, 37209

A high quality finished plant from each of 22 cultivars was displayed at a poinsettia [Euphorbia pulcherrima Willd. ex Klotzsch] open house at Tennessee State University in Dec. 2004. The cultivars represented the range of flower colors, flower traits, and plant vigor available through the major suppliers Dummen USA, Ecke, Fischer, and Oglevee. Attendees of the open house completed a written survey $(n=101)$ in which they were asked to rate their cultivar preferences. Cultivars (identified only by an alphabetic letter) were rated by respondents on a Likert-type scale $(1=$ strongly dislike to $5=$ strongly like $)$. Highly rated cultivars (mean $\geq 4$ ) included 'Freedom Red', 'Premium Red', 'Nutcracker White', 'Early Orion', 'Cortez Electric Fire', and the new cultivars 'Visions of Grandeur' and 'Kris Krinkle'. Cultivars were also rated on the price range potential consumers were willing to pay. Respondents were willing to pay the most to purchase 'Visions of Grandeur', which is a vigorous cultivar with large, pillowy, peach-colored bracts. Overall, traditional red cultivars and large, non-red cultivars were preferred. Most of the respondents indicated that they purchased red plants, and color was the most important selection criterion. Results suggest that although most consumers prefer traditional red cultivars, women prefer some alternative inflorescence colors and unique bract shapes more than men.

\section{(68) Ceratostigma plumbaginoides Is an Intermediate-day} Plant

Ki Sun Kim*1, Arthur C. Cameron², Erik S. Runkle ${ }^{2}$

${ }^{1}$ Seoul National University, Horticulture, Seoul, 151-921, Korea; ${ }^{2}$ Michigan State University, Horticulture, East Lansing, MI, 48824

We performed experiments to determine the photoperiodic response of Ceratostigma plumbaginoides Bunge., or leadwort, which is a low-growing hardy herbaceous perennial native to China with deep gentian-blue flowers. Tip cuttings were rooted in 72-cell trays and grown under a 24-hour photoperiod for 2 weeks and then transplanted into $11.4-\mathrm{cm}$ pots and grown for one more week. Plants were then placed under different primary photoperiods $(10,16$, or 24 hours $)$ for 4,6 , or 8 weeks, then transferred to secondary photoperiods $(10,14,16$, or 24 hours $)$ at a constant $20^{\circ} \mathrm{C}$. Pots were also placed under continuous $10,14,16$, or 24 hours. Nearly all plants flowered under all treatments except under continuous 10- or 24-hour photoperiods, in which no plants flowered. Plants grown under 14 hours flowered earliest (50 days), followed by plants under the 16 -hour primary treatment. The 10-hour primary treatment delayed flowering for as long as its duration, whereas the 16-hour primary photoperiod initiated rapid flowering, regardless of duration and subsequent secondary photoperiod. Flowering was also delayed when the primary photoperiod was 24 hours. Collectively, these responses indicate that Ceratostigma is an intermediate-day plant.

\section{(70) Hydroponic Sunflower Production as Influenced by Cultivar, Nitrogen Fertilization, and Root-knot Nematode Infestation}

Yan Chen*1, Donald Merhaut ${ }^{2}$, J. Ole Becker ${ }^{3}$

${ }^{1}$ LSU AgCenter, Hammond Research Station, Hammond, LA, 70403; ${ }^{2}$ UC Riverside, Botany and Plant Sciences; ${ }^{3}$ UC Riverside, College of Natural and Agricultural Sciences Nematology

Nitrogen $(\mathrm{N})$ fertilization is critical for successful production of cut flowers in a hydroponic system. In this study, two sunflower cultivars: single-stand 'Mezzulah' and multi-stand 'Golden Cheer' were grown under two $\mathrm{N}$ fertilization rates: $50 \mathrm{mg} \cdot \mathrm{L}^{-1}$ and $100 \mathrm{mg} \cdot \mathrm{L}^{-1}$ in a recirculating hydroponic system. At the same time, 'Mezzulah' sunflowers were biologically stressed by exposing each plant to 2000 second-stage juveniles of the plant parasitic nematode Meloidogyne incognita, race 1. The experiment was conducted in May and repeated in Sept. 2004, and plant growth and flower quality between control and nematode-infested plants were compared at the two $\mathrm{N}$ rates. The two cultivars responded differently to fertilization treatments. With increasing $\mathrm{N}$ rate, the dry weight of 'Mezzulah' increased, while that of 'Golden Cheer' decreased. Flower size and harvest time were significantly different between the two cultivars. However, $\mathrm{N}$ had no effect on flower quality and harvest time. Flower quality rating suggests that quality cut stems can be obtained with $50 \mathrm{mg} \cdot \mathrm{L}^{-1} \mathrm{~N}$ nutrient solution. Nematode egg count suggests that plants in the nematode treatment were successfully infested with Meloidogyne incognita, however, no significant root galling was observed, and plant growth and flower quality were not affected by nematode infestation.

\section{(71) Day Length Controls Flowering and Height of Sunflower}

\section{Meriam Karlsson*, Jeffrey Werner}

University of Alaska Fairbanks, Department of Plant, Animal and Soil Sciences, Fairbanks, AK, 99775-7200

Flowering in response to day length was identified for sunflower $\mathrm{He}$ lianthus annuus L. 'Pacino Gold'). Germination and seedling development occurred at $20^{\circ} \mathrm{C}$ and long days (LD, 16 hours) following direct seeding into $10-\mathrm{cm}$ pots. Sixteen days after seeding, plants were placed at LD or short days (SD, 8 hours), $20{ }^{\circ} \mathrm{C}$ and $8 \mathrm{~mol} \cdot \mathrm{d}^{-1} \cdot \mathrm{m}^{-2}$. Flowering 
was recorded at the stage of reflexed petals after $48 \mathrm{SD}$. At the time of flowering in SD, flower buds were of minute size under LD. Plants started at LD, and moved to SD after 1, 2, or 3 weeks, flowered at similar times as those grown under uninterrupted SD conditions. Four initial weeks of LD delayed flower development with 7 days, compared to a continuous SD environment. On the other hand, 2 to 3 weeks of initial SD followed by LD hastened flowering with 5 to 10 days. With increasing number of early LD from 1 to 4 weeks, plant height at flowering doubled from 20 to $40 \mathrm{~cm}$. Average plant height in continuous SD was $18 \mathrm{~cm}$. Plants grown exclusively or moved to LD after 1 to 4 weeks of SD were similar in height to plants finished at SD with 4 initial weeks of LD. Combinations of SD and LD may be used to manage height and rate of development in the sunflower 'Pacino Gold'.

\section{(72) Effects of Photoselective Shadecloths on Growth of Potted Orchids}

Kent D. Kobayashi*1, Edwin F. Mersino²

${ }^{1}$ University of Hawaii at Manoa, Tropical Plant \& Soil Sciences, Honolulu, HI, 96822 ${ }^{2}$ University of Hawaii at Manoa, Plant \& Environmental Protection Sciences, Honolulu, HI, 96822

The objective of this study was to determine the effects of photoselective shadecloths on the growth of potted orchids. At an orchid nursery in Waianae (Oahu), 10 kinds of orchids were grown under four $30 \%$ shadecloths - red, blue, gray, and black (control). At the University of Hawaii Magoon Facilities (Oahu), two kinds of orchids were grown in a saranhouse in chambers built with PVC pipe and covered with the four $30 \%$ shadecloths. At the orchid nursery, for the two orchids that plant height measurements were taken, 11055 (Epi. Joseph Glow-Star Valley) $\times$ Epc. Pele's Flame 'Orange Star' had the greatest percentage of increase in height under the gray shadecloth. For M-11347 Epidendrum Pompon 'Pink Ruby', the three shadecloths resulted in greater height increases than the control, with the blue shadecloth having the greatest increase. At the Magoon Facilities, for M-10973 Rhv. Herbert Kurihara 'Flori', the red shadecloth resulted in the largest increase in plant height compared to the black shadecloth. The gray shadecloth and blue shadecloth resulted in a smaller increase in plant height. The black shadecloth had the largest increase in leaf number compared to the other treatments. Slight leaf loss occurred with the red shadecloth. For M-10878 Colmanara Sphacetante 'Evelyn'AM/AOS, the smallest increase in plant height was under the blue shadecloth compared to the black shadecloth, which was similar to the other two shadecloths. Leaf loss occurred for all treatments, with the three shadecloths having less leaf loss than the black shadecloth. All treatments had similar numbers of new shoots. Thus, photoselective shadecloths influenced vegetative growth, but their effects varied with the orchid.

\section{(73) Is the Shorter Time to Flower for Late-planted Curcuma alismatifolia Real?}

Richard A. Criley*1, Jeff S. Kuehny ${ }^{2}$

${ }^{1}$ University of Hawaii, Tropical Plant and Soil Sciences, Honolulu, HI, $96822 ;{ }^{2}$ Louisiana State University, Dept. of Horticulture, Baton Rouge, LA, 70803-2120

Several reports suggest that late-planted rhizomes of Curcuma alismatifolia produce their inflorescences in less time than those that have been planted earlier in the forcing season. Two cultivars of this ginger species were removed from the ground in late February following a lengthy dormancy period in the field. About 6 weeks later, after air drying, weekly plantings were initiated through the end of June. Five rhizomes per cultivar were planted singly in $15-\mathrm{cm}$ pots in ProMix BX medium. All plants were forced outdoors under full sun conditions and an overhead spray stake irrigation system that delivered $200 \mathrm{ppm}$ each of nitrogen and potassium with each watering. Cultivar differences were apparent. Plant-to-sprout days for the DP and LP cultivars ranged from 20-51 and 21-57 days, respectively, with means of $38 \pm$ 9.2 and $44 \pm 11.9$ days, respectively, over the 10 -week planting cycle. Sprout-to-flower days showed much less difference with ranges of 61-75 and 58-72 days for DP and LP and means of $69 \pm 4.3$ and $66 \pm$ 4.0 days, respectively. Plant to flower times differed largely because of the length of time required for the rhizomes to sprout rather than for the amount of time spent in inflorescence initiation and development. Plant heights at flowering and inflorescence counts were not different within cultivars over the 10 -week planting period. Degree days and solar integrals will be presented for the 10 growing periods.

\section{(74) Effect of Temperature on Axillary Bud Formation and Polyamine Contents of Nonbranching Chrysanthemum}

Yeun Joo Huh*1, Seoung Youl Choi ${ }^{1}$, Hak Ki Shin, ${ }^{1}$ Chun Ho Pak ${ }^{2}$

${ }^{1}$ National Horticultural Research Institute, Dept. of Floriculture, Top Dong 540-41, Suwon, Kyungkido, 441-440, Korea; ${ }^{2}$ Korea Univ, Division of Bioindustrial Science

Nonbranching chrysanthemums [Dendranthema $\times$ grandiflorum (Ramat.) Kitamura] are preferred because they require less labor in disbudding. High temperature is responsible for this phenotype of not having axillary buds or poor lateral shoot development. This study attempted to find out the effect of temperature and identify the involvement of endogenous polyamine contents in axillary bud formation of nonbranching chrysanthemum cv. Iwanohakusen. Plants were treated at $22,26,30,34$, and $38^{\circ} \mathrm{C}$ for 9 hours midday for 2 months. Polyamine content [putrescine (Put), spermidine (Spd), spermine $(\mathrm{Spm})]$ was analyzed 1 month after treatment and axillary buds were counted when the flowers opened. Results revealed that viable axillary buds decreased remarkably at 30 and $34^{\circ} \mathrm{C}$. It was also found out that not only low temperature, but also the excessively high temperature of $38^{\circ} \mathrm{C}$ induced axillary bud formation. Exposure to 38 ${ }^{\circ} \mathrm{C}$ increased the Put contents and resulted in high Put/(Spd $\left.+\mathrm{Spm}\right)$ ratio as $22{ }^{\circ} \mathrm{C}, 26{ }^{\circ} \mathrm{C}$. Temperature of $30,34{ }^{\circ} \mathrm{C}$ lowered Put/(Spd + $\mathrm{Spm})$ ratio. Results further showed that not polyamine contents, but polyamine ratio (Put/Spd $+\mathrm{Spm})$ or transformation of Put to Spd and Spm may be involved in the axillary bud formation in nonbranching chrysanthemum.

\section{(75) Quantifying the Vernalization Response of Dianthus gratianopolitanus 'Bath's Pink'}

Sonali Padhye*, Erik S. Runkle, Arthur C. Cameron

Michigan State University, Horticulture, East Lansing, MI, 48824

Two experiments were conducted to quantify the effect of vernalization temperature and duration on flowering of Dianthus gratianopolitanus 'Bath's Pink'. In Expt. 1, plants were vernalized at $5{ }^{\circ} \mathrm{C}$ for $0,3,6$, 9, 12, or 15 weeks and in Expt. 2, plants were vernalized at 0,5 or $10{ }^{\circ} \mathrm{C}$ for $0,2,4,6$ or 8 weeks. After treatments, plants were forced in a greenhouse at $20{ }^{\circ} \mathrm{C}$. Node development, days to first visible bud (DVB), days to first open flower (DFLW), number of buds and height at FLW were recorded. In Expt. 1, 10\% of nonvernalized plants flowered and $100 \%$ of vernalized plants flowered. As vernalization duration increased from 3 to 15 weeks, DTVB decreased from 24 to 13. Average DFLW were 114, 41, 34, 33, 33, and 28 for 0-, 3-, 6-, 9-, $12-$, and 15-week treatments, respectively. In Expt. 2, 40\% of plants flowered without vernalization. Following 2 weeks of vernalization at $0{ }^{\circ} \mathrm{C}, 80 \%$ of plants flowered and as the duration of vernalization increased to $\geq 4$ weeks, all plants flowered. Average DFLW decreased from 38 to 28 following 2 or 4 weeks of vernalization at $0{ }^{\circ} \mathrm{C}$. Longer vernalization did not further reduce DFLW. All plants cooled at $5{ }^{\circ} \mathrm{C}$ flowered and vernalization duration did not affect DFLW. Percent flowering after vernalization at $10{ }^{\circ} \mathrm{C}$ for $2,4,6$, and 8 weeks was $20 \%, 60 \%, 90 \%$, and $100 \%$, respectively, and average DFLW were 46 , 45,35 , and 33, respectively. In conclusion, vernalization is required to force $D$. 'Bath's Pink'. To achieve complete flowering, plants should be vernalized at $5^{\circ} \mathrm{C}$ for $\geq 2$ weeks or at $0{ }^{\circ} \mathrm{C}$ for 4 weeks or at $10^{\circ} \mathrm{C}$ for 8 weeks. Qualitative effects of vernalization such as node development and number of buds and height at FLW will be discussed.

\section{(76) Thermal Effects on Vegetative Growth and Reproductive Behavior of Phalaenopsis Orchids}

\section{Yin-Tung Wang*}

Texas A\&M University System, Horticultural Sciences, Texas Agricultural Experiment Station, Weslaco, TX, 78596

Since Phalaenopsis orchids are CAM plants, learning how they respond to night temperature warmer than the day would help regulate their production. On 1 Apr. 2003, P. amabilis plants were subjected to 
day/night temperatures at 30/25, 25/30, 25/20, 20/25, 20/15, or $15 / 20$ ${ }^{\circ} \mathrm{C}$ under $140 \mu \mathrm{mol} \cdot \mathrm{m}^{-2} \cdot \mathrm{s}^{-1} P P F$. After 4 months, the total length of new leaves was shorter as a result of fewer and shorter new leaves when nights were cooler than the days and as the average daily temperature declined. More spikes were produced at $25 / 20$ and $20 / 25^{\circ} \mathrm{C}$ than at $20 / 15$ or $15 / 20{ }^{\circ} \mathrm{C}$. In another experiment, P. amabilis plants were moved to the above conditions on 12 Aug. Plants exposed to 30/25 or $25 / 30{ }^{\circ} \mathrm{C}$ had more leaf growth than at lower temperatures, but no flowering. Plants that were exposed to $25 / 20$ or $20 / 25^{\circ} \mathrm{C}$ spiked in 2 weeks; but plants took 20 and 18 d to spike under $20 / 15$ or $15 / 20^{\circ} \mathrm{C}$, respectively. Again, as average daily temperature decreased, there was less leaf growth. Cooler day than the night reduced vegetative growth, regardless of temperature. Plants at $25 / 20$ or $20 / 25^{\circ} \mathrm{C}$ had higher flower count (12) than those at $20 / 15$ or $15 / 20^{\circ} \mathrm{C}(8)$. In a third experiment, plants of a large-flowered Doritaenopsis hybrid spiked at 22-24 d when exposed to $25 / 20$ or $20 / 25^{\circ} \mathrm{C}$, whereas $30-33$ d were needed to spike under $20 / 15$ or $15 / 20^{\circ} \mathrm{C}$. In a fourth experiment, a Doritaenopsis hybrid spiked after 22,21 , or 25 d under $25 / 25,25 / 20$, or $20 / 20{ }^{\circ} \mathrm{C}$. However, $37 \mathrm{~d}$ was required to spike under $20 / 15{ }^{\circ} \mathrm{C}$. These results suggest that the best temperature range for spiking these orchids is 25 to $20^{\circ} \mathrm{C}$ and a day/night temperature differential is not needed for spiking when temperature is at or below $25^{\circ} \mathrm{C}$.

\section{(77) Tolerance to Rhizoctonia solani and Garden Performance of Wax Begonia Cultivars}

Carlos E. Bogran ${ }^{1}$, H. Brent Pemberton*2, Thomas Isakeit ${ }^{3}$, William R. Roberson ${ }^{2}$

${ }^{1}$ Texas A\&M University, Entomology, College Station, TX, 77843; ${ }^{2}$ Texas A\&M University, Texas Agricultural Experiment Station, Overton, TX, 75684; ${ }^{3}$ Texas A\&M University, Plant Pathology and Microbiology, College Station, TX, 77843

A strain of Rhizoctonia solani was isolated from wax begonia (Begonia Semperflorens-Cultorum hybrids) plants in garden evaluation trial plots. This strain was then used to test for disease tolerance in a controlled environment experiment. Inoculated plants of 12 cultivars were evaluated for disease development and the area under the disease progress curve was calculated. No plants were disease free, but 'Stara White', 'Stara Pink', and three colors from the Party series exhibited greater disease tolerance than 'Ambassador Coral', 'Ambassador Deep Rose', and two experimental varieties. 'Stara White', 'Party Pink Bronze Leaf', and 'Party White Bronze Leaf' were more tolerant than 'Cocktail Vodka', an industry standard. When the same cultivars were grown in field garden evaluation plots, 'Cocktail Vodka', four colors from the Stara series, and three colors from the Party series exhibited superior garden performance and flowering ratings to 'Ambassador Coral' and an experimental 'Rose' cultivar. For most cultivars, garden performance was correlated to disease tolerance. However, 'Cocktail Vodka' exhibited good garden performance despite having a high level of disease in the inoculation experiment, indicating that other factors may be involved in determining garden performance.

\section{(78) Establishment and Growth of Begonias in the Landscape as Affected by Root Ball Condition at Transplant}

\section{Sloane M. Scheiber*, Richard C. Beeson, Jr., Sudeep Vyapari}

University of Florida, Environmental Horticulture, Mid Florida Research and Education Center, Apopka, FL, 32703

Root ball slicing is often recommended for root-bound woody ornamentals to promote new root development during establishment in the landscape. It is a common practice among gardeners, but not necessarily landscapers, to disrupt root-bound annuals during transplant. However, little if any evidence exists for such practices. Therefore, this study evaluated the effect of root ball condition of annual bedding plants on landscape establishment and growth. Begonia semperflorens were transplanted from 0.72 -L (\#1) containers into field plots in an open-sided clear polyethylene covered shelter and managed with Best Management Practices. Three root ball conditions were evaluated: non root-bound (6-week-old plants), root-bound (10-week-old plants), and root-bound with the bottom $1 \mathrm{~cm}$ of the root ball removed. Shoot and root dry masses and growth indices were collected weekly for 12 weeks and evaluated relative to root ball condition by linear regression analysis. Nonroot-bound plants had significantly greater biomass, growth indices, height, and root dry weights than the other treatments tested. No significant differences were found between root-bound and manipulated root-bound plants for any parameter examined. The data indicate that the practice of disrupting root-bound plants has no benefit on establishment or growth of annual bedding plants in the landscape.

\section{Poster Session 13-Plant Biotechnology 1}

18 July 2005, 1:15-2:00 p.m.

Poster Hall-Ballroom E/F

\section{(262) Transgenic Tomato Lines Expressing Plant Defense} Genes Show Resistance to Early Blight Disease

Scott C. Schaefer, Ksenija Gasic, Schuyler S. Korban*

University of Illinois, Department of Natural Resources \& Environmental Sciences, Urbana, IL, 61801

Several plant defense genes, including an iris ribosomal-inactivating protein (I-RIP) and a maize $\beta$-glucanase (M-GLU) as well as a small antimicrobial peptide ( $5 \mathrm{kd}$ ) from Mirabilis jalapa (Mj-AMP) were separately introduced into tomato (Lycopersicon esculentum) cv. Sweet Chelsea using Agrobacterium tumefaciens-mediated transformation. Transgenic lines carrying each of the transgenes were confirmed for integration into the tomato genome using Southern blot hybridization. Transcription of $I-R I P, M-G L U$, and $M j-A M P$ genes in various transgenic lines was determined using Northern blot analysis. Plants of some transgenic lines were inoculated with a $2 \times 10^{4}$ to $3 \times 10^{4}$ conidial spores $/ \mathrm{mL}$ suspension of the fungal pathogen Alternaria solani, the causal agent of tomato early blight disease. Several transgenic lines carrying either a $M-G L U$ or $M j-A M P$ transgene showed a higher level of resistance to early blight than control (nontransgenic) plants. The implications of this approach on developing disease resistance in tomato will be discussed.

\section{(263) Temperature Effects on Meristem Identity Genes Controlling the Reproductive Development of Cauliflower (Brassica oleracea var. botrytis) and Broccoli (Brassica oleracea var. italica)}

Denise V. Duclos*, Thomas N. Björkman

Cornell University, Department of Horticultural Sciences, NYSAES, Geneva, NY, 14456

Brassica oleracea species differ in the developmental stage of their reproductive meristems at harvest. The stage that characterizes each variety depends on its genetic makeup, environment and the interaction between them. We tested a model of arrest in $B$. oleracea to determine functional redundancy among the paralogous genes CAL, AP1a, AP1c, FULa, FULb, FULc, and FULd; and to resolve the immediate effect of temperature on gene expression in meristems whose developmental fate is temperature regulated. By varying temperature during reproductive development, three stages of arrest were obtained: inflorescence meristem (cauliflower), floral meristem (intermediate) and floral bud (broccoli), the latter initiated by low temperature. Gene expression was measured by quantitative real time PCR (qRT-PCR). The LFY/TFL1 ratio increased as the reproductive development advanced, mainly due to decreased TFL1 expression; influenced by a dramatic increase in AP1c toward floral bud formation. The expression patterns of the FUL paralogs indicate different roles in reproductive development. FULa was more abundant in the floral primordia, while FULb, FULc, and FULd were associated with earlier arrest at the inflorescence meristem stage. The high expression of FULc and FULd at all stages of arrest differs from their homolog in Arabidopsis. High temperature reduced AP1 and LFY expression but the meristem did not revert from reproductive to vegetative. Floral bud formation in plants recessive for AP1a and CAL reaffirm that functional redundancy among some of these genes can complement the mutations. Varying temperature alone, at a fixed developmental stage, caused little variation in the expression of genes studied, causing small significant differences in TFL1 and AP1c. 


\section{(264) In Vitro Pollen Germination of Wild Type and Transgenic 'Galia' Male Parental Line Melon [Cucumis melo (L.) var. reticulatus Ser.]}

Hector G. Nunez-Palenius*, Daniel J. Cantliffe, Harry J. Klee, Don J. Huber

University of Florida, Horticultural Sciences Department, Gainesville, FL, 32611-0690

Pollen germination timing has a paramount role in fertilization of a flower. Rapid germination and outgrowth of a pollen tube that penetrates the stigma is required. Physical and biological factors can affect pollen germination timing. The objective of this study was to determine if ACC oxidase antisense gene expression could influence in vitro pollen germination and in vitro pollen tube length growth. A transgenic (ACC oxidase antisense) 'Galia' male parental line had a reduced fruit set compared to its wild type. Likewise, embryo abortion and empty seeds after self-pollination in a 'Galia' male parental line were observed. Wild type and transgenic 'Galia' male parental line melon plants were grown in a greenhouse according to the practices of Rodriguez (2003). Male flowers were collected from these plants between 10 to $12 \mathrm{am}$; pollen was obtained by dipping the anther in germination medium $(10.25 \%$ sucrose, $0.031 \%$ calcium nitrate, $0.015 \%$ boric acid, $0.0075 \% \mathrm{KNO}_{3}$, and $0.016 \% \mathrm{MgSO}_{4}$ ) at $25{ }^{\circ} \mathrm{C}$ and analyzed immediately, either for total percentage of germination after 5 minutes of incubation or to measure pollen tube growth rate every 5 minutes during 1 hour. Each flower provided an average of 250 pollen grains. Assays were conducted by using the "Hanging Drop Method" (Okay and Ayfer, 1994). Percentage of pollen germination in WT 'Galia' male parental line was greater than the transgenic line. Likewise, in vitro pollen tube growth in wild type 'Galia' melon was greater than pollen from the transgenic line. Possibly the ACC oxidase antisense gene expression in 'Galia' male parental line may have had an influence on the reduced fruit set observed.

\section{(265) HSP101 in the Model Strawberry Fragaria vesca}

\section{Janet Slovin*}

USDA/ARS, Fruit Laboratory, BARC-W Bldg 010A, Beltsville, MD, 20705

Our lab has initiated a project to determine if specific proteins expressed by strawberry function as part of the thermotolerance system. We have developed tools for investigating the role of heat shock proteins (HSPs) and other gene products in strawberry thermotolerance. These tools include an inbred diploid testing system, EST sequence data, and molecular markers for heat tolerance. We developed an inbred line, 5AF7, of the diploid strawberry Fragaria vesca for testing gene function because the diploid genome is small (164Mbp), the life cycle of the plant is short (about 4 months), the plant size is small (a plant will produce fruit in a 4-inch pot), some genetic work is already done, F. vesca is transformable with Agrobacterium tumefaciens, and results should be transferable to the commercial octoploid varieties. A cDNA library was constructed in the pCMVsport 6.1 vector using combined RNA from batches of aseptically grown $F$. vesca seedlings treated to various elevated temperature regimes. Over 1500 EST sequences from the library have been deposited in GenBank and are available annotated at the ESTAP Fragaria database (http://staff.vbi.vt.edu/estap/index. shtml). HSP101 affects thermotolerance in Arabidopsis (Queitsch et al., 2000, Plant Cell 12:479). A PCR fragment for HSP101 was generated from $F$. vesca with degenerate primers, and used to obtain a full-length cDNA clone from the library. Primers spanning an intron were designed for RTPCR from the sequence of the cDNA. Semi-quantitative RTPCR indicates that HSP101 is expressed constitutively in young leaves at $25^{\circ} \mathrm{C}$ and is not induced at moderately higher temperatures $\left(32{ }^{\circ} \mathrm{C}\right)$ even after 5 hours. Induction occurs within 1 hour at $37^{\circ} \mathrm{C}$.

\section{(266) Gene Discovery in Octoploid Strawberry}

Philip J. Stewart*, Dawn H. Bies, Kevin M. Folta

University of Florida, Horticultural Sciences, Gainesville, FL, 32611

Fragaria $\times$ ananassa, the cultivated octoploid strawberry, is an intensively cultivated fruit crop in which relatively small variations in disease susceptibility and flowering habit can have significant economic impacts. In order to facilitate future studies of the molecular mechansisms governing these characters, we have initiated studies to identify and sequence the strawberry homologs of a number of important genes known to be critical to pathogenesis response and photoperiodism in model systems such as arabidopsis, rice, and tomato. Using the primary Florida cultivar Strawberry Festival, we have employed a variety of techniques to identify such genes, including EST sequencing of a salicylate-induced cDNA library, PCR with degenerate primers, and colony hybridization. Possible homologs of the targeted genes and their relationships to similar genes in other species are presented. These results will form the basis of future studies of gene expression and evolutionary relationships among the Rosaceae and other species.

\section{(267) A Rapid Transformation System for Octoploid Strawberry}

Leighan Howard, Philip Stewart*, Amit Dhingra, Craig Chandler, Kevin Folta*

University of Florida, Horticultural Sciences Department, Gainesville, FL, 32611

Cultivated strawberry (Fragaria $\times$ ananassa) is a valuable crop, yet has benefitted little from recent advances in biotechnology and genomics. A high-throughput system for transformation and regeneration would hasten elucidation of gene function for strawberry and possibly the Rosaceae in general. In this report, a protocol for high-frequency octoploid strawberry transformation and regeneration is presented. The protocol uses leaf, petiole, and stolon as explants from a newly selected genotype, 'Laboratory Festival \#9'. This genotype was selected from progeny of a 'Strawberry Festival' self-cross exclusively for its rapid regeneration and robust growth in culture. Direct organogenesis has been achieved from the leaf or from prolific callus with multiple shoots being visible in as few as 14 days. Over 100 viable regenerants may be obtained from a single leaf explant of about $3-\mathrm{cm}^{2}$ size. This laboratory-friendly genotype allows high-throughput, statistically relevant, studies of gene function in the octoploid strawberry genetic background as well as generation of large transgenic populations.

\section{(268) Nonspecific Fusarium Wilt Resistance in Watermelon Using Copper Inducible IPT Gene}

Fahrettin Goktepe*, Harrison Hughes

Colorado State University, Dept. of Horticulture \& Landscape Architecture, Fort Collins, CO 80525

'Crimson Sweet' watermelon was transformed with a copper inducible ipt gene. Clonally propagated transformed and non-transformed plants were sprayed with three different concentrations $(0,50,100$ $\mathrm{mm}$ ) of $\mathrm{CuSO}_{4}$ at the 2-3 leaf stage twice in a 24-hour period prior to their inoculation with fusarium wilt organisms. Plants were inoculated via root dip with two different isolates of Fusarium oxysporum sp. niveum Race 2. The pathogenic strains of Fusarium oxysporum sp. niveum Race 2, F1 99-1, and Calg 15-19, were cultured on PDA solid medium and then transferred to a sterile flask filled with $50 \mathrm{~mL}$ of potato dextrose broth (PDB) liquid medium. These flasks were placed on a shaker at $100 \mathrm{rpm}$ for $4-5$ days before the inoculation date and the final concentration of 106 spores $/ \mathrm{mL}$ was adjusted for inoculation. Roots of the experimental units were gently washed and were then infected by dipping them in to the beaker containing the isolates for $1 \mathrm{~min}$. Inoculated plants were transferred to planting trays and maintained under growth chamber conditions. Plants then were watered as needed. Fusarium wilt symptoms initially appeared approximately $7-10$ days after the infection. The $\mathrm{Cu}$-ipt transformants exhibited a clear and significant resistance over non-transformed plants. The severity of disease development was relatively higher in the control $\mathrm{Cu}$-ipt and non-transformed plants when compared to the plants treated with $\mathrm{CuSO}_{4}$. The control Cu-ipt plants were comparatively healthier than the control non-transformed plants. Infected plants were removed from soil 2 weeks after inoculation, washed and the stems were cut vertically for rating of browning of the vascular system. 
(269) Taxonomic Relationship of Korean Native Aster, Based on Internal Transcribed Spacer (ITS) Sequences of Nuclear Ribosomal DNA

Su-Young Hong*1, Kwang-Soo Cho ${ }^{1}$, Ki-Oug Yoo $^{2}$, Jong-Taek Suh ${ }^{1}$, Dong-Lim Yoo $^{1}$

${ }^{1}$ National Institute of Highland Agriculture, Horticulture, Heonggae, Doam, Pyeongchang, Gangwon Province, 232-955, Rep. South Korea; ${ }^{2}$ Gangwon National University, Department of Biology, Chuncheon, Gangwon Province, 200-701, Rep. South Korea

There are 25 species of aster in Korea. There is a controversy about the taxonomical classification of Aster. The genus Aster was classified into four genera, Aster, Gymnaster, Kalimeris, and Heteropappus, by morphological characters. In order to clarify the phylogenetic position of aster, the nucleotide sequence of the nuclear ribosomal DNA internal transcribed spacer(ITS) region was compared among 11 taxa in Korean native aster. The size of ITS1 and ITS2 ranged from 283 to $286 \mathrm{bp}$ and from 251 to $257 \mathrm{bp}$, respectively. The size of $5.8 \mathrm{~S}$ region was $164 \mathrm{bp}$ in 11 taxa. The total length of ITS1, 5.8S and ITS2, A. tripolium was shown to be the shortest length, $701 \mathrm{bp}$; and $A$. scaber was shown to be the longest length, $706 \mathrm{bp}$. The $\mathrm{G}+\mathrm{C}$ content of ITS1 ranged from $47.9 \%$ to $51.2 \%$ and ITS2 ranged from $52.2 \%$ to $55.1 \%$. The range of each taxon was narrow. The total length of the character matrix was 708 characters. Among them, total indel showed 9; in the ITS1 region indel showed 6 it was $67 \%$; and in the ITS2 region, indel showed 3. Most of the indels showed deletion or insertion of only one base pair, but in A. spathulifolius deleted two base pairs and in A. tripolium deleted five base pairs. But in A. yomena, A. hayatae, A. koraiensis, and A. hispidus, the indel was not detected. Phylogenetic trees did not even make a difference inter-genus, but $A$. yomena and $A$. koraiensis called genus Kalimeris and genus Gymnaster, respectively; these constituted a clade. A. hispidus called genus Heteropappus was placed as a sister group to the clade of $A$. ageratoides and A. glehni.

\section{Poster Session 14-Water Utilization in Horticulture}

19 July 2005, 12:00-12:45 p.m. Poster Hall-Ballroom E/F

\section{(352) Genetic and Environmental Effects Related to Water Use Efficiency in Peach}

D. Michael Glenn*1, Ralph Scorza ${ }^{1}$, William R. Okie ${ }^{2}$

${ }^{1}$ Appalachian Fruit Research Station, USDA, Kearneysville, WV, 25430; ${ }^{2}$ Fruit and Tree Nut Research Laboratory, USDA-ARS, Byron, GA, 31008-1008

Two unpruned willow leaf and two unpruned standard leaf peach [Prunus persica (L.) Batsch.] selections were evaluated for physiological components related to water use efficiency (WUE). The purpose of the study was to assess the value of willow leaf phenotypes to improve water use efficiency in peach and separate the environmental from the genetic components. The willow leaf characteristic itself did not confer improved water use efficiency. Light interception was a key determinant of WUE in these genotypes and the relationship of WUE with intercepted photosynthetically active radiation $(P A R)$ by the entire canopy indicated a significant negative correlation. Internal shading of the tree by excessive leaf area reduced WUE and canopies that intercept more than $60 \%$ of the $P A R$ have reduced WUE. While WUE is improved by reducing the amount of PAR interception of the canopy, productivity is reduced. Neither of the willow leaf genotypes had a significant correlation of WUE with yield (leaf and fruit weight); however, the standard leaf type cultivars, 'Bounty' and 'Redhaven', had significantly different regressions that indicate greater productivity in 'Bounty' for a given level of WUE. 'Redhaven' was the least productive cultivar; 'Bounty' was the most productive, and the two willow leaf genotypes were intermediate in the relationship of intercepted PAR with yield. Therefore, genetic differences in peach growth types can be selected for both increased WUE as well as increased productivity. Future work in peach breeding to improve WUE and productivity must take into consideration light interception, productivity, and WUE in an integrated manner to make progress in the efficient use of water and light.
(353) University of California Water Quality Program for Floriculture and Nursery Growers in Ventura and Los Angeles Counties

Julie Newman*1, Kristine Gilbert ${ }^{1}$, Ben Faber ${ }^{1}$, Donald Merhaut ${ }^{2}$, Laosheng $\mathrm{Wu}^{3}$, Jay $\mathrm{Gan}^{3}$, Richard Evans ${ }^{4}$

${ }^{1}$ University of California, UC Cooperative Extension, Ventura Co., Ventura, CA, 930035401; ${ }^{2}$ University of California, Riverside, Botany and Plant Sciences, Riverside, CA;

${ }^{3}$ University of California, Riverside, Soils \& Environmental Sciences; ${ }^{4}$ University of California, Davis, Environmental Horticulture, Davis, CA, 95616

Nursery growers must implement "Best Management Practices"(BMPs) to mitigate runoff and leaching of pollutants. However, there is little data on the effectiveness of BMPs, and further research is needed. Growers require training to minimize runoff and capital to comply with evolving regulations. We collected irrigation efficiency data at 26 nursery sites using catch cans. Uniformity value was calculated as: $D U=100 \times$ (Average of the "Low Quarter"/Average of All Measurements). Results showed that one-third of the nurseries had irrigation uniformities below $67 \%$, and only one nursery exceeded $82 \%$. Continuous flow monitoring at 10-minute intervals was conducted at three nursery sites to determine daily and monthly variation. One hundred samples of the runoff were taken four times at each nursery and analyzed for nitrate, chloride, and sulfate. We developed a 29-page checklist of BMPs to reduce runoff, which we used to survey 53 growers in Ventura County. After completing the survey, 20 growers applied for funds from a 1.2 million dollar cost-share program that we initiated. This program provides funds to implement improved technologies to reduce runoff and/or conserve water; funds were awarded to 18 nurseries. We are collecting monitoring data from each cooperating nursery implementing improvements. These data measure the number of BMPs used by growers, provide a current "snapshot" of the industry, and document the effectiveness of future BMP implementation. We offer on-farm consulting, and conducted eight water quality/irrigation educational programs - four in Spanish. We elevated grower awareness concerning regulations and options for reducing runoff, and the data will be useful in evaluating future improvements.

\section{(354) A Novel Automated System for Irrigation and Simulating Drought Stress in Potted Plants}

Krishna S. Nemali*, Marc W. van Iersel

University of Georgia, Horticulture Department, 1111 Miller Plant Sciences Building, Athens, GA, 30602

We have developed a completely automated irrigation system that measures and maintains substrate volumetric water content $(\theta)$ at a target level for any length of time. Advantages of this system include complete automation of irrigation and simulation of precise levels of drought stress for potted plants. This system uses $\mathrm{ECH}_{2} \mathrm{O}$ moisture sensors interfaced with a CR10X datalogger and solenoid valves connected to the datalogger by a SDM CD16 AC/DC controller. The datalogger measures the $\theta$ of the substrate hourly. When the $\theta$ of the substrate drops below the set point, the datalogger opens the solenoid valves, which results in irrigation. Substrate $\theta$ is maintained at a constant level as the datalogger is programmed to increase $\theta$ by $2 \%$ to $3 \%$ during each irrigation. When the system was validated for its accuracy, we determined that the $\theta$ measured in the substrate within the range of 0.15 to $0.35 \mathrm{~m}^{3} \cdot \mathrm{m}^{-3}$ was close $(2 \%$ to $3 \%)$ to the $\theta$ determined by the conventional volumetric analysis. The daily average $\theta$ maintained in the substrate was slightly higher (within 3\%) than the target level. Using this system, we were able to maintain four distinct levels of substrate $\theta$ for a prolonged period ( 40 days), regardless of differences in plant size and environmental conditions. Significant increases in number of irrigations, total water-use, and transpiration rate of impatiens, salvia, vinca, and petunia were noticed with increasing target $\theta$ of the substrate. For all species, highest and lowest water-use efficiency (WUE) were seen at 0.09 and $0.32 \mathrm{~m}^{3} \cdot \mathrm{m}^{-3}$, respectively, while WUE was not different between 0.15 and $0.22 \mathrm{~m}^{3} \cdot \mathrm{m}^{-3}$.

\section{(355) Evaluation of Three Models for Estimated Potential Evapotranspiration under Sonoran Desert Conditions}

Fabián Robles-Contreras, Raul Leonel Grijalva-Contreras*, Manuel de Jesus Valenzuela-Ruiz, Rubén Macias-Duarte

${ }^{1}$ INIFAP-Caborca, Agroclimatology, Caborca, Sonora, 83600, México; ${ }^{2}$ INIFAP-Caborca, 
Protected Horticulture; ${ }^{3}$ INIFAP-Caborca, Viticulture; ${ }^{4}$ INIFAP-Caborca, Soli \& Horticultural

The main crops in Caborca, Sonora, Mexico, in the Sonoran Desert, are grapes, asparagus, olive, and vegetables, such as melons and green beans. The growers in this area normally do not use methods to calculate water requirements of the crops, although in a desert region water use management needs to be as efficient as possible. A reason for using some of the models is the need to fit water requirements to regional conditions, or some stress could be caused in the crops. Recently, studies have been made in northwestern Mexico that indicate it is feasible to adapt the use of the Makkink model. Three models for estimated potential evapotranspiration (Eto) were evaluated: Penman-Monteith, Hargreaves, and Makkink, and were compared with the Class A pan method (control). Measured variables were the correlation coefficient $\left(R^{2}\right)$ between the models and the control; and the daily average difference between the models and the control. The results indicate that a low $R^{2}$ exists between the three evaluated models and the control $(0.55,0.67$, and 0.54 for Hargreaves, Penman-Monteith, and Makkink, respectively). The average difference of the daily Eto in the course of 75 days of evaluation was of $0.62,0.5$, and $0.81 \mathrm{~mm} /$ day for Hargreaves, Penman-Monteith, and Makkink, respectively. This represents almost 6-10 cm less of potential evapotranspiration with the models, for a cycle crop of 120-130 days.

\section{(356) Adaptation of Makkink Model to Obtain Potential Evapotranspiration under Sonoran Desert Conditions}

Fabián Robles-Contreras ${ }^{1}$, Raul Leonel Grijalva-Contreras*1, Manuel de Jesus Valenzuela-Ruiz ${ }^{2}$, Rubén Macias-Duarte ${ }^{3}$

${ }^{1}$ INIFAP-Caborca, Agroclimatology, Caborca, Sonora, 83600, México; ${ }^{2}$ IINIFAP-Caborca, Viticulture; ${ }^{3}$ INIFAP-Caborca, Soli \& Horticultural

Water is a very limited resource in the Sonoran Desert region of Caborca, Sonora, Mexico. For an efficient use of irrigation water, a method of calculating water requirements of the crops is needed. Potential evapotranspiration (Eto) value obtained with the Penman-Monteith model from a regional weather station was not dependable, since some parameters, such as sensible heat flux in the soil, are estimated from a fixed rate with net radiation ( $\mathrm{Rn})$, also an estimated value. The weather station did not have a sensor for heat flux in its network. Studies in northwestern Mexico have indicated that it is feasible to adapt the use of the Makkink model, because a single measurement of solar radiation and temperature would be required. We compared the daily Makkink Eto against the Class A pan method (control) Eto during 75 days and found a value of $0.81 \mathrm{~mm} /$ day less with the Makkink model. To fit the Makkink model to regional conditions, we ran the Makkink model varying the value of $\mathrm{C}$ constant (from 0.5 to 0.95 ), and found that a value of $\mathrm{C}=0.87$ substituted for $\mathrm{C}=0.65$ (original value) has an daily average difference of $0.09 \mathrm{~mm} /$ day less with respect to the control. This could be because there are few clouds in the region, and a greater proportion of global radiation arrives at the surface from the earth or the crops in form of net radiation.

\section{Poster Session 15-Vegetable Breeding 1}

\section{July 2005, 12:00-12:45 p.m. Poster Hall-Ballroom E/F}

\section{(245) 'WhipperSnapper', a Dual-purpose Southernpea for the Production of Both Snaps and Fresh-shell Peas}

\section{Richard L. Fery*1, Blair Buckley ${ }^{2}$, Dyremple B. Marsh ${ }^{3}$}

${ }^{1}$ USDA-ARS, U.S. Vegetable Laboratory, Charleston, SC, 29414-5334; ${ }^{2}$ LSU AgCenter, Red River Research Station, Bossier City, LA, 71113; ${ }^{3}$ Delaware State University, 127 Washington Extension Center, Dover, DE, 19901

Home gardeners and farmers in the southern United States have traditionally grown southernpeas to produce both fresh-shell peas and immature, fresh pods, or snaps. American growers do not presently have access to a single variety that is ideally suited for both uses. In 1988 , a plant breeding effort was initiated to incorporate genes conditioning superior yield and seed characteristics of Asian "vegetable cowpeas" into American snap-type southernpeas. This effort resulted in the development of 'WhipperSnapper', which is suited for use as a dual-purpose variety that can be used to produce both snaps and fresh-shell peas. Typical ready-to-harvest 'WhipperSnapper' snaps are green colored, $6.4 \mathrm{~mm}$ in diameter, $7.6 \mathrm{~mm}$ in height, and $24 \mathrm{~cm}$ long. Typical mature-green pods suitable for fresh-shell harvest exhibit an attractive yellow color, are $25 \mathrm{~cm}$ long, and contain 14 peas. Fresh peas are cream-colored, kidney-shaped, and weigh $24.5 \mathrm{~g}$ per 100 peas. Dry pods exhibit a light straw color, and the dry peas have a smooth seedcoat. The total 'WhipperSnapper' yield of snaps can be as much as $62 \%$ greater than the total snap yield of the snap-type variety 'Bettersnap'; pea yield can be as much as $69 \%$ greater. The quality of 'WhipperSnapper' seed is excellent and much superior to that of 'Bettersnap'. 'WhipperSnapper' can be used by home gardeners and market gardeners to produce abundant quantities of snaps and fresh-shell peas during seasons too hot for successful culture of such table legumes as snap beans. 'WhipperSnapper' also has the potential for use as a mechanically harvested source of snaps for use by food processors in mixed packs of peas and snaps.

\section{(246) Crude Lipid Content and Its Relationship to Carotenoid and Tocopherol Concentration in Carrot (Daucus carota)}

Jennifer L. Baeten*, Thomas C. Koch, Irwin L. Goldman

University of Wisconsin-Madison, Horticulture, Madison, WI, 53706

Carrot has been bred for increased levels of pro-vitamin $\mathrm{E} \alpha$-tocopherol. This vitamin is lipid soluble. Carrot root has been shown to have measurable levels of lipid, but it is not certain if the lipid level is correlated to $\alpha$-tocopherol levels. The HPLC method is needed to quantify levels of $\alpha$-tocopherol. Measuring lipids may be less time consuming in a breeding program. We developed a method for extracting lipids from carrot tissue based on the Soxhlet extraction method. The Soxhlet extraction uses a non-polar ether solvent to pull lipids out of freeze-dried tissue. A collection of carrot accessions ranging in $\alpha$-tocopherol concentration $0.04-0.18 \mathrm{ppm}$ and carotenoid concentration $10.63-1673.76 \mathrm{ppm}$ were used in this investigation. Root tissue was freeze-dried and lipid levels were measured in an experiment with two replications. The mean lipid level of root tissue was $0.05 \mathrm{~g}$ fat $/ \mathrm{g}$ tissue. The range was $0-1.1 \mathrm{~g}$ fat $/ g$ tissue. Phenotypic correlations were performed among lipid, $\alpha-$ tocopherol, and $\beta$-carotene concentrations in these samples. Twenty-four samples were tested for lipid levels (12 high and 12 low). From these results, percent lipid of the root was determined. Correlations were made between the lipid data and $\alpha$-tocopherol data of the given samples.

\section{(247) Genetic and Environmental Effects on Glucosinolate Content in Chinese Cabbage}

Ji Yeon Kang ${ }^{1}$, Khalid E. Ibrahim*1, Doo Hwan Kim², Wha-Jeung Kang ${ }^{3}$, John A. Juvik ${ }^{1}$

${ }^{1}$ University of Illinois, Natural Resources and Environmental Sciences, Urbana, IL, 61801; ${ }^{2}$ Konkuk University, Horticultural Science, Seoul, 143-701, Korea $;{ }^{3}$ National Horticultural Research Institute, Vegetable Research Division, Suwon, 440-706, Korea

Gluconasturtiin is a glucosinolate (GS) present in Chinese cabbage and its breakdown product, phenelethyl isothiocyanate (PEITC), inhibits phase I enzyme activation of endogenous carcinogenic compounds and enhances phase II enzyme detoxication, reducing cancer risk and promoting health in humans. This study was conducted to evaluate the interaction between the genotype and the environment to influence GSs in Chinese cabbage. Twenty-five accessions were grown in three environments and tissue quantified for GS levels by HPLC. While gluconasturtiin was observed to be the most abundant GS form, 3-indolylmethyl GS (glucobrassicin) and 1-methoxy-3-indolylmethylGS (neoglucobrassicin) were also found. Significant differences were observed among tissues, genotypes and environments in GS concentration and composition. Gluconasturtiin ranged from $0.56 \mu \mathrm{mol} \cdot \mathrm{g}^{-1}$ DW in leaf tissue of Hau No. 2 to $11.89 \mu \mathrm{mol} \cdot \mathrm{g}^{-1} \mathrm{DW}$ in Chilsung. There were dramatic differences among different tissues of the same genotype with young leaf and root tissues having significantly higher concentrations of gluconasturtiin than other tissues. Gluconasturtiin in Sandong No. 5 ranged from $1.69 \mu \mathrm{mol} \cdot \mathrm{g}^{-1} \mathrm{DW}$ in mature leaves to $18.69 \mu \mathrm{mol} \cdot \mathrm{g}^{-1} \mathrm{DW}$ in root tissue. GS content of the same genotypes 
in three different environments indicated that plants grown in the greenhouse had higher GS content compared to field grown plants. Results of this study indicate that genotypic variation and the growing environment have substantial effects on GS content in Chinese cabbage. This investigation provides important information for future genetic and molecular studies and has identified Chinese cabbage genotypes that offer superior health benefits to consumers.

\section{(248) New Four Genes Related to Seed Characteristics, Flower Appearance, and Red Color}

Zhoo-Hyeon Kim*

Gyeongsang National University, Dept. of Horticulture, 900 Gazwa-dong, Jinju, Gyeongsangnam-Do, 660-701, South Korea

New four traits not yet reported were founded. One mutant plant was from a population of 81-1251-D-20M treated with EMS (ethylmethane sulfonate), which had tubular petals. This tubular petal plant had normal pollens in anthers, but could almost not produce its seeds without artificial pollination. It was controlled by one single recessive gene. One new spontaneous dwarf mutant line, R3-10, which bore seedcoatless-like seeds with short pappus, was crossed with normal breeding lines GL5 and $87-25 \mathrm{M}-2 \mathrm{M}$. From $\mathrm{F}_{2}$ and $\mathrm{F}_{3}$ results, it was found that the two traits (seedcoatless-like and short pappus) were governed by each one single recessive gene. A stem lettuce type cultivar, 'Baimach', seemed to be almost green, but was really tinged red, which was extremely suppressed in red color expression. Its tinged red color could not be seen, except on only very limited base parts of the stem and dorsal petal. In two $\mathrm{F}_{2}$ population experiments of the crosses of 'Baimach' with 'Oakleaf' and 98-43-3, it was found that the suppression of red color expression in 'Baimach' was caused by a single recessive gene. It looked different from that of gene " $v$ " ( vanishing) by Lindqvist, because the red color of plants with "v" gene of Lindqvist were typically tinged and could be identified easily at a young plant stage, but not that of 'Baimach'. I designated these new four genes as Tu-tu (Tu $=$ normal, $\mathrm{tu}=$ tubular petal $), \mathrm{Pp}-\mathrm{pp}(\mathrm{Pp}=$ normal, $\mathrm{pp}=$ short pappus $)$, Scl-scl $(\mathrm{Scl}=$ normal, $\mathrm{scl}=$ seedcoatless-like $)$, and $\mathrm{In}$-in $(\mathrm{In}=$ normal, in $=$ inhibiting red color expression extremely).

\section{(249) Evaluation of Five Genotypes of Tomato (Lycopersicon esculentum Mill.) in Greenhouse}

Marcelino Bazan Tene*, Juan Manuel González Gonzalez, Francisco Radillo Juarez, Pablo Enrique Ramírez Castillo

Universidad de Colima, Facultad de Ciencias Biológicas y Agropecuarias, Km 40 Autopista Colima-Manzanillo, Tecomán, Colima, 28100, México

The tomato (Lycopersicon esculentum Mill.), is native to South America. It occupies the second place in worldwide vegetable consumption. Because of this, the evaluation of tomato varieties for the fresh consumption is important. The Mexican production is 1,908,607 tons of fresh product (SAGARPA, 2004). In the state of Colima, production has a mean efficiency of $18.13 \mathrm{t} \cdot \mathrm{ha}^{-1}$ (INEGI, 2000). The following genotypes were evaluated 'Peralta', 'Montijo', Pavia', 'Grande River', and 'Yaqui' (control). A randomized experimental block was used, with five treatments and four repetitions. The obtained results indicate that 'Yaqui' (control) had the better yield of fresh fruit, with $37.5 \mathrm{t} \cdot \mathrm{ha}^{-1}$, followed by 'Peralta' $\left(27.2 \mathrm{t} \cdot \mathrm{ha}^{-1}\right)$, and 'Montijo' $\left(12.6 \mathrm{t} \cdot \mathrm{ha}^{-1}\right)$, respectively. The height of plant in 'Yaqui' was $68.8 \mathrm{~cm}$ and $60.26 \mathrm{~cm}$ in 'Pavia'. In the days to flowering, after showing a homogenous behavior, pronouncing itself up to 27 days after the transplant; whereas the variety 'Grande River' was pronounced up to 40 days. With respect to the number of total fruits by plant, a highly significant difference was observed. 'Yaqui' produced 91 fruits, with 'Pavia' and 'Peralta' producing 50 and 37 fruits per plant, respectively. In conclusion, 'Yaqui' was the genotype with greater yield and vigor.

\section{(250) 'Elegance' and Ark 98-348: Two New Southernpea Varieties for the Mid-South}

Teddy E. Morelock*1, D.R. Motes², L.W. Martin², S.E. Eaton ${ }^{2}$

${ }^{1}$ University of Arkansas, Horticulture, Fayetteville, AR, 72701; ${ }^{2}$ University of Arkansas, Vegetable Substation, Kibler, AR, 7295

Southernpeas, Vigna unguiculata, are a popular vegetable in the south- eastern United States. Southernpeas (cowpeas) are widely known by the many different horticultural types, i.e., blackeye, pinkeye, purple hull, cream, cowder, etc. 'Elegance' was widely tested under the designation Ark 96-918. It was entered in the Regional Southernpea Cooperative Trials from 1997-2002, where it performed well. It is a root-knot nematode resistant cream that exhibits an upright bush habit with concentrated pod set and good yield potential. The seed are medium size and produce a high quality canned product. 'Elegance' is unique in the fact that it is a purple hull cream with the pods turning from dark green to purple when the seed reach the green mature stage. The second release, Ark 98-348, is a selection out of 'Chinese Red' that is less viney and has a more concentrated pod set and maturity than the 'Chinese Red' types that are commercially grown. It was tested in the observational Regional Southernpea Cooperative Trials from 2000-02. In trials at the University of Arkansas Vegetable Substation, it outyielded industry standard 'Chinese Red' types Ark 93-640 and 93-641, by $30 \%$.

\section{(251) 'Evergreen' and F415: Two New Spinach Varieties for the Mid-South}

Teddy E. Morelock*1, J.C. Correll ${ }^{2}$, Frank J. Dainello ${ }^{3}$, D.R. Motes ${ }^{4}$ ${ }^{1}$ University of Arkansas, Horticulture, Fayetteville, AR, 72701; ${ }^{2}$ University of Arkansas, Plant Pathology, Fayetteville, AR, 72701; ${ }^{3}$ Texas A\&M University, Horticulture, College Station, TX, 77843; ${ }^{4}$ University of Arkansas, Vegetable Substation, Kibler, AR, 72956

Spinach, Spinacia oleracea, is a highly nutritious vegetable that is increasing in popularity more rapidly than any other salad crop. In the eastern United States spinach production is severely impacted by white rust, Albugo occidentalis. For many years, the University of Arkansas has bred spinach to cope with this endemic problem. While fungicides can provide a degree of control, the combination of genetic resistance and fungicides is the most effective method to insure production stability. 'Evergreen' and F415 are the latest developments of this breeding program. 'Evergreen', widely tested as Ark 88-212, is a slow growing, dark green, semi-savoy spinach that exhibits a good level of white rust resistance. It is not long-standing and should not be used for spring production in Arkansas and Oklahoma. It has been widely tested in Arkansas and Texas. F415, widely tested as Ark 91415 , is an upright, dark green, flat leaf spinach that has a good level of white rust resistance. It is is well suited to the Arkansas, Oklahoma and Texas production area and, because of its better color and more upright growth habit, it should replace Ark F380.

\section{(252) Correlation of Pungency, Thiosulfinates, Antiplatelet Activity, and Total Soluble Solids in Two Garlic Families}

Pablo Cavagnaro ${ }^{1}$, Douglas Senalik ${ }^{2}$, Claudio Galmarini ${ }^{1}$, Philipp Simon*3

${ }^{1}$ Universidad Nacional de Cuyo and EEA INTA La Consulta-Mendoza, Facultad de Ciencias Agrarias, Mendoza, 5519, Argentina; ${ }^{2}$ USDA-ARS Vegetable Crops Research Unit and Department of Horticulture, University of Wisconsin-Madison, Madison, WI, 53706

Allium plants possess organosulfur compounds and carbohydrates that provide unique flavor and health-enhancing properties. In previous studies of onion $\mathrm{F}_{3}$ families, significant phenotypic and genetic correlations have been reported between pungency, in vitro antiplatelet activity (IVAA), and soluble solids content (SSC); although in other studies SSC and pungency have not always been correlated. In this study we analyzed SSC, pungency, garlic-induced in vitro antiplatelet activity and the content of three predominant thiosulfinates in bulbs from two garlic families obtained from unrelated self-pollinated plants. A strong positive correlation was observed between pungency and IVAA for both sample sets, indicating that it will be difficult to develop garlic populations with low pungency and high IVAA. Allicin was the most abundant thiosulfinate and its content was positively correlated with pungency and IVAA $(r=0.70$ and 0.74 , respectively). The thiosulfinates AllS $(\mathrm{O})$ SPropenyl and AllS $(\mathrm{O}) \mathrm{SMe}$ were also positively correlated with pungency and IVAA. When compared with IVAA, AllS(O)SMe had higher $r$ values than AllS(O)SPropenyl (0.88 and 0.50, respectively). These differences could reflect differential platelet anti-aggregatory properties of different thiosulfinates. SSC was not correlated with IVAA, pungency, or thiosulfinates content, suggesting that soluble solids in garlic can be independently selected. 
(253) TAM 'Dulcito' and 'Tropic Bell'-Two New Sweet Peppers with Enhanced Beneficial Phytochemical Levels

Kevin M. Crosby ${ }^{1}$, Daniel I. Leskovar*2, Kil Sun Yoo $^{3}$

${ }^{1}$ Texas A\&M University, Horticultural Sciences, Texas Agricultural Experiment Station, Weslaco, TX, 78596; ${ }^{2}$ Texas A\&M University, Horticultural Sciences, Texas Agricultura Experiment Station, Uvalde, TX, 78801; ${ }^{3}$ Texas A\&M University, Horticultural Sciences, Vegetable and Fruit Improvement Center, College Station, TX, 77845

At the Vegetable and Fruit Improvement Center, plant breeding has produced pepper lines with enhanced beneficial phytochemical levels. TAM 'Dulcito' is a new jalapeño cultivar with no detectable levels of capsaicin, but increased levels of lutein. In greenhouse cultivation, it contained 122 ppm of this important human health-related compound, which aids in prevention of macular degeneration. This is a significant improvement over popular cultivars, such as 'Grande', which contained 25 ppm or less. In addition to improved lutein levels, 'Dulcito' also possesses resistance to three important potyviruses: TEV, PepMoV, and PVY. In field trials at Weslaco, Texas, 'Dulcito' outyielded both TAM 'Mild Jalapeño 2', and 'Mitla'. This new cultivar produces a concentrated set of large, thick-fleshed fruit with few cuticular cracks. Because of its lack of pungency, it should be useful for the processing industry. TAM 'Tropic Bell' is a medium-sized, blocky bell with enhanced levels of both ascorbic acid and lutein compared to other cultivars. Grown under greenhouse conditions, it contained $100 \mathrm{ppm}$ lutein compared to $6 \mathrm{ppm}$ in 'Jupiter'. It also contained $660 \mathrm{ppm}$ ascorbic acid at the green stage, compared to less than $100 \mathrm{ppm}$ for three commercial bell cultivars tested. 'Tropic Bell' produced yields equal to both 'Valiant' and 'Summer Sweet' commercial hybrids at Weslaco. Fruit of 'Tropic Bell' were slightly smaller than the hybrid cultivars. TAM 'Tropic Bell' possesses resistance to the same three potyviruses as 'Dulcito' and demonstrated excellent tolerance to Phytophthora capsici in a controlled inoculation. These two new cultivars will be useful for production in locations with high potyvirus pressure or as specialty market items for health-conscious consumers.

\section{Poster Session 16-Plant Biotechnology 2}

\section{July 2005, 12:00-12:45 p.m. Poster Hall-Ballroom E/F}

\section{(270) Single-nucleotide-polymorphism Isolation in Fruiting-} mei (Prunus mume Sieb. et Zucc.) from AFLP Fragments

Jinggui Fang, Pachanoor S. Devanand, ChihCheng T. Chao*

${ }^{1}$ University of California-Riverside, Department of Botany and Plant Sciences, Riverside, CA, 92521-0124

Single-nucleotide-polymorphism (SNP) is the most abundant genetic variation among individuals within a species. SNPs can be used as markers for gene discovery and for assessment of biodiversity. We established a practical strategy for discovering candidate SNPs in fruiting-mei (Prunus mume Sieb. et Zucc.), a non-model tree fruit, from amplifiedfragment-length-polymorphism (AFLP) fragments. Eighty-one of the 150 chosen bands from 10 cultivars of fruiting-mei were successfully re-amplified and 67 of these re-amplified PCR products yielded 13 groups of reliable sequences. The sequencing results from both directions of 23 randomly selected PCR products using the corresponding selective primers showed that all the purified fragments from the gels were EcoR I-EcoR I fragments. The sequence alignment of 13 groups of sequence yielded 95 SNPs from a total of $5252 \mathrm{bp}$, averaging one SNP every $55 \mathrm{bp}$. Among these SNPs, 73 were heterozygous in the loci of some individual cultivars. The SNPs distribution were: $58 \%$ transition, $40 \%$ transversion, and $2 \%$ InDels. There were also one di-nucleotide polymorphism and one tetra-nucleotide deletion. The procedure of SNP isolation from AFLP fragments can be useful for transferring AFLP markers into sequence-tagged-site markers.

\section{(271) Expression of the NRT1 Gene in Cornus and Rhododendron}

David R. Sandrock*1, Anita N. Azarenko², Ruth M. Martin², Nahla V. Bassil ${ }^{3}$

${ }^{1}$ University of Florida, Environmental Horticulture, Gainesville, FL, 32611; ${ }^{2}$ Oregon State
University, Horticulture, Corvallis, OR, 97331; ${ }^{3}$ Agricultural Research Service, National Clonal Germplasm Repository, Corvallis, OR, 97333

The NRT1 gene family encodes transport proteins with dual or low affinity for nitrate. The objectives of this experiment were to develop a system that could be used to compare the expression of the NRT1 genes between species. This was accomplished by comparing sequences of $N R T 1$ homologues from various species and designing degenerate primers in regions of high homology. These primers were used to amplify a region of the NRT1 gene from species of interest. A $635 \mathrm{bp} \mathrm{PCR} \mathrm{product} \mathrm{was}$ amplified from each species using the MD2-1 (5'ATGTTACCAAYWTGGGCMAC-3') and MD2-2 (5'-GCCAMWARCCARTAGAAAT-3') primers. The PCR products were cloned and sequenced. At the nucleotide level, Cornus sericea L. 'Kelseyi' and Rhododendron L. 'Unique' were $79.52 \%$ identical. Species-specific primers were designed and used for RT-PCR to compare NRT1 expression in roots of hydroponically grown C. sericea, C. sericea 'Kelseyi', and Rhododendron 'Unique'. The relative levels of $N R T 1$ expression, normalized using $18 \mathrm{~S}$ rRNA as a standard, were $\approx 3.2$ to 1.7 to 1.0 for $C$. sericea, C. sericea 'Kelseyi', and Rhododendron 'Unique', respectively. This approach may eventually be used to examine nitrate uptake potential in different taxa of plants at different times during the growing season.

\section{(272) DNA Markers Linked to the Resistance Gene of Scab in Oriental Pear (Pyrus sp.)}

Kang-Hee Cho*1, Il-Sheob Shin ${ }^{2}$, Seong-Sig Hong ${ }^{2}$, Ki-Taek Kim ${ }^{1}$, Hwa-Suk Song ${ }^{1}$, Sang-Jo Kang ${ }^{2}$, Il Gin Mok ${ }^{3}$

${ }^{1}$ National Horticultural Research Institute, Horticultural Biotechnology, Tap Dong 540-41, Suwon, Gyeonggi Province, 441-440, Republic of Korea; ${ }^{2}$ National Horticultural Research Institute, Fruit Research, I-mok Dong 475, Suwon, Gyeonggi Province, 440-706, Republic of Korea ${ }^{3}$ National Horticultural Research Institute, I-mok Dong 475, Suwon, 440-706, Republic of Korea

Pear scab caused by Venturia nashicola is one of the most important diseases of oriental pear. Breeding a variety resistant to scab can be improved through marker-assisted selection (MAS). Bulked segregant analysis (BSA) and amplified fragment length polymorphic (AFLP) analysis were performed to identify DNA markers linked to the scab-resistant gene $(V n)$ using a population from a cross between PS2-93-3-98 (resistant parent) and Yali (susceptible parent). A total of 480 EcoR I/Mse I primer combinations were used to identify markers specific to PS2-93-3-98 and resistant pool. Three AFLP markers linked to $V n, \mathrm{E}-\mathrm{AGT} / \mathrm{M}-\mathrm{CCA}_{245}$, E-ATT/M-CCG ${ }_{300}$, and E-GGT/M-TCT 225 , were selected. Linkage analysis between the selected markers and $V n$ locus was conducted with 51 individual plants. The selected markers, E-AGT/M-CCA 245 , E-ATT/M-CCG ${ }_{300}$, and E-GGT/M-TCT 225 , were located at $3.9,3.8$, and $1.2 \mathrm{~cm}$ away from $V n$, respectively. For practical application, we are currently converting selected markers to simple PCR-based markers. The markers could be used to increase selection efficiency in pear-breeding programs for scab resistance.

\section{(273) Engineering Female Sterility for Horticultural Crops}

\section{Alan Smith*, Nicole Gardner, Elizabeth S. Zimmermann}

University of Minnesota, Department of Horticultural Science, Saint Paul, MN, 55108

Female sterility is desirable in horticultural crops for many reasons, including decreasing invasiveness and weediness, reducing nuisance fruit production, promoting vegetative growth, and increasing flower longevity and number. This study tested a method of creating female sterility through genetic transformation of plants with a gene that ablates tissue necessary for female fertility and reproduction. A gene construct was created containing barnase, a cytotoxic RNAse, expressed with a transmitting tract specific promoter from the tobacco gene $s P 41$. The $s P 41$ gene encodes a $(1,3)-\beta$-glucanase in the transmitting tract of the pistil of mature tobacco flowers. The construct also expressed barstar, a barnase inhibitor, driven by the CaMV $35 \mathrm{~S}$ promoter to protect other plant tissues from unexpected barnase expression. Seed set data taken after controlled pollinations showed tobacco plants transformed with this construct had greatly reduced fertility in young flowers and female sterility in mature flowers relative to nontransformed controls. Light microscopy showed ablation of the transmitting tract tissue in transformed plants. The expression of barnase with a transmitting tract specific promoter is an effective way to reduce or eliminate female 
fertility. Due to the conservation of $(1,3)-\beta$-glucanase activity in the styles of other plant species, this construct has potential for producing female-sterile cultivars of other horticultural crops.

\section{(274) Inter-and Intra-specific Variation in Yield and Quality Traits of Chile Pepper Breeding Lines}

Reddy R. Chinthakuntla*1, Frank Matta ${ }^{2}$, Rao S. Mentreddy ${ }^{3}$, Umesh Reddy ${ }^{4}$, Padmavathi Nimmakayala ${ }^{4}$, Daniel Peterson ${ }^{5}$, Om Prakash Vadhwa ${ }^{1}$

${ }^{1}$ Alcorn State University, Department of Agriculture, Alcorn State, MS, 39096; ${ }^{2}$ Mississippi State University, Plant and Soil Sciences, Dorman, Mississippi State, MS, 39762; ${ }^{3}$ Alabama A\&M University, Plant and Soil Science, Huntsville, AL, 35802; ${ }^{4}$ West Virginia State University, Plant Biotechnology, Dunbar, WV, $25064{ }^{5}$ Mississippi State University, Biotechnology, Mississippi State, MS, 39762

Chile pepper (Capsicum spp.) is the third most important vegetable crop in the United States. The market value of chile peppers for spices and condiments exceeds $\$ 650$ million per year. With a growing Hispanic population across the United States, the demand for high yielding, good quality cayenne pepper continues to increase. In order to fulfill this niche market, a study has been initiated to develop pepper varieties that combine high yield potential with superior agronomic traits, including insect and disease resistance, and fruit characteristics, using molecular marker assisted breeding/selection. In preliminary trials, several $F_{1}$ generations were created through inter- and intra-specific crosses among 220 germplasm lines belonging to six Capsicum sp. in the greenhouse. Selected $\mathrm{F}_{1}$ progeny, parent lines, and selected accessions were planted in single-row field plots the following summer. The crossing success was higher within species than between. The genotypic variation was significant for all parameters examined. The average percent germination (81.1) of $F_{1}$ progeny was $32 \%$ and $45 \%$ higher than that of the parent lines and selected accessions, respectively. The $\mathrm{F}_{1}$ progeny were shorter in height; more vigorous in growth, flowered early, and with fewer, but heavier, fruits per plant out-yielded the parent lines and accessions by $50 \%$ and $120 \%$, respectively. The study showed a marked heterosis in $\mathrm{F}_{1}$ progeny compared to the parent lines and accessions. Microsatellite genotyping to estimate genetic diversity and validation of markers that are linked to various traits is in progress and will be discussed in the presentation.

\section{(275) Cloning of a Myrosinase cDNA from Horseradish (Armoracia rusticana) Root and Its Heterologous Expression in Spodoptera frugiperda Insect Cells}

\section{Xian $\mathrm{Li}^{1}$, Hans Bohnert ${ }^{2}$, Mary Schuler ${ }^{3}$, Mosbah Kushad*1}

${ }^{1}$ University of Illinois, Natural Resources and Environmental Sciences, Urbana, IL, 61801; ${ }^{2}$ Department of Plant Biology; ${ }^{3}$ Department of Cell and Structural Biology

A full-length cDNA (ArMY1) encoding myrosinase ( $\beta$-thioglucoside glucohydrolase, EC 3.2.3.1) was cloned from horseradish (Armoracia rusticana) root. ArMY1 has an open reading frame of 1614 nucleotides with a deduced protein of 538 amino acids and molecular mass of $61.6 \mathrm{kD}$. ArMY1 shows highest overall amino acid identity $(72 \%)$ with Arabidopsis thaliana myrosinase TGG2. ArMY1 mRNA signal of about $1.95 \mathrm{~kb}$ was detected in the leaves and roots of horseradish, but not in the leaves of broccoli. Heterologous expression of ArMY1 in baculovirus-infected $\mathrm{Sf} 9$ cells resulted in an immunologically active recombinant ArMY1 protein when probed with myrosinase-specific monoclonal antibody 3D7 with apparent mass $65 \mathrm{kD}$. Phylogenetic analysis showed that ArMY1 does not cluster with any of the current myrosinase subfamilies, i.e., the MA, MB, and MC subfamilies, and may represent a novel myrosinase subfamily in root tissue. This is the first report of cloning of myrosinase cDNA from horseradish root. It provides important sequence information that will enable further studies of myrosinase expression patterns and their interaction with myrosinase-binding proteins and other myrosinase-associated proteins.

\section{(277) Behavior of Glomus intraradices in Agave Roots Transformed with Agrobacterium rhizogenes}

Guillermo Rodríguez, Sergio Aguilar-Espinosa,

Eugenio Perez-Molphe Balch, María del Rocío Flores-Bello, Javier Farias-Larios*, José Gerardo López-Aguirre
Universidad de Colima, Facultad de Ciencias Biológicas y Agropecuarias, Autopista ColimaManzanillo, Km. 40, Tecomán, Colima, 28100, México

The present work is the first report in vitro on root induction of Agave salmiana Otto, using Agrobacterium rhizogenes. Several concentrations of bacteria and acetosyringone were used, and different inoculation sites were tested, such as leaves, shaft, and root. Incubation time in darkness was 6 days. The transformed adventitious roots appeared 25 days after inoculation. The best treatment was when the shaft was inoculated with: $1 \times 108$ bacteria/mL and $100 \mu \mathrm{m}$ acetosyringone; in this treatment, induction of transformed roots was $57.5 \%$ in the inoculated sites. The activity and presence of the foreign genes in the transformed roots of $A$. salmiana were verified as follows: 1) histochemical staining for GUS activity was determined in $80 \%$ of the tested root; and 2) molecular analysis via PCR was made to verify the presence of nptII gene and rol B gene (both were present in $60 \%$ of the tested root). This is the first report of the arbuscular mycorrhizal colonization on wild roots and transformed roots of Agave with Glomus intraradices Schenck and Smith. The result of the monoxenic culture was as follows: mother spore germinated 5 days; the colonization of the transformed roots was $70 \%$. Then we proceeded to the recovery of daughter spores, in which we obtained an average 300 daughter spores per petri dish, 6 months after inoculation.

Poster Session 17-Seed and Stand Establishment

19 July 2005, 12:00-12:45 p.m., Poster Hall-Ballroom E/F

(420) Germination and Radicle Elongation Responses of Seven Vegetable Crops to Aqueous Extracts of Hairy Vetch (Vicia villosa) and Cowpea (Vigna unguiculata)

Erin C. Hill*, Mathieu Ngouajio

Michigan State University, Horticulture, East Lansing, MI, 48824

Hairy vetch (Vicia villosa Roth) (HV) and cowpea [Vigna unguiculata (L.) Walp.] (CP) are two leguminous cover crops used in vegetable production systems. The residues of both species have been shown to suppress weeds via allelopathic interactions; however, they may also carry a risk of crop injury. A laboratory experiment was designed to study the dose response of carrot, sweet corn, cucumber, lettuce, onion, pepper, and tomato germination and radicle elongation to the aqueous extracts of both HV and CP. Aqueous extracts of fresh, whole plants were lyophilized to obtain a dry powder. Treatments of $0.00,0.25,0.50$, $1.00,2.00,4.00$, and $8.00 \mathrm{~g}$ dry extract/L of distilled water were applied to 10 seeds on filter paper in petri dishes. The petri dishes were then sealed and placed in the dark at $21{ }^{\circ} \mathrm{C}$ for 4 to 7 days, depending on the species germination. After the incubation period, germination rates and radicle lengths were recorded. Each treatment had 4 replications and the full experiment was executed twice. Pepper germination was reduced by increasing concentrations of $\mathrm{HV}$ extract; however, all other crops were not affected by HV or CP extracts. The HV extract had a significant effect on radicle elongation in carrot, corn, cucumber, lettuce, onion, and tomato. Inhibition of radical growth at $8 \mathrm{~g} \cdot \mathrm{L}^{-1}$ ranged from $42 \%$ in cucumber to as high as $81 \%$ in carrot. The CP extract had a negative effect on the radicle elongation of carrot, corn, lettuce, and tomato. Inhibition at $8 \mathrm{~g} \cdot \mathrm{L}^{-1}$ ranged from $42 \%$ in carrot to $67 \%$ in tomato. This study shows that both HV and CP extracts hold the potential to negatively affect the listed crops. Therefore, studies need to be done on the persistence of these effects in the field to maximize weed control while avoiding crop injury.

\section{(421) Light and Temperature Interactions in Promoting Lettuce Seed Germination}

\section{Samuel Contreras*1, David Tay ${ }^{2}$, Mark Bennett ${ }^{1}$}

${ }^{1}$ The Ohio State University, Horticulture and Crop Science, Columbus, OH, 43210; ${ }^{2}$ The Ohio State University, Ornamental Plant Germplasm Center, Columbus, OH, 43210

Lettuce seeds (Lactuca sativa var. acephala cv. Tango) were used with the objective of determining the effect of temperature, light, and their interactions in promoting germination. Under standard op- 
timal conditions $\left(20^{\circ} \mathrm{C}\right.$, light), the seed presented $100 \%$ germination (radicle emergence $5 \mathrm{~d}$ after sowing). Different treatments evaluated germination under dark conditions, with or without a red light break $\left(\mathrm{LB}, 28.8 \mathrm{mmol} \cdot \mathrm{m}^{-2}\right) 48 \mathrm{~h}$ after sowing, and with different combination of temperatures pre- (soaking temperature, ST) and post- (germination temperature, GT) the LB. Germination at constant $20{ }^{\circ} \mathrm{C}$ without LB was less than $5 \%$, and with LB, it was around $30 \%$. However, germination was close to $100 \%$ at GT of $20{ }^{\circ} \mathrm{C}$ when LB was applied after a ST of $10{ }^{\circ} \mathrm{C}$, and around $50 \%$ under the same conditions, but without LB. When GT was $30^{\circ} \mathrm{C}$ and LB was applied, germination was less than $3 \%$ with $\mathrm{ST}=30^{\circ} \mathrm{C}$, less than $10 \%$ with ST $=20^{\circ} \mathrm{C}$, and around $100 \%$ when ST $=10^{\circ} \mathrm{C}$. With ST and GT of $10^{\circ} \mathrm{C}$ and $30^{\circ} \mathrm{C}$, respectively, and no LB, germination was less than 5\%. Germination at $10{ }^{\circ} \mathrm{C}$ constant, with and without LB, was around $90 \%$ and $0 \%$, respectively. When ST was $40{ }^{\circ} \mathrm{C}$ and LB was applied, germination was around $40 \%$ at $\mathrm{GT}=20^{\circ} \mathrm{C}$, but less that $3 \%$ with $\mathrm{GT}=30^{\circ} \mathrm{C}$. In summary, a severe inhibition of germination was observed when seeds were germinated in dark, which was partially reversed by either a light treatment or soaking at $10^{\circ} \mathrm{C}$, and fully reversed when both treatments were applied together. Inhibition of lettuce germination at $30^{\circ} \mathrm{C}$ was observed when this temperature was applied after a light treatment, but not when applied before. Possible implications of these results for the phytochrome mechanism of action are discussed.

\section{(422) Application of X-Ray in Flower Seed Technology}

\section{David Tay*, Joseph Tychonievich, Stephanie Burns}

The Ohio State University, Ornamental Plant Germplasm Center, Columbus, OH, 43210

The Association of Official Seed Analysts adopted X-ray technology for testing agricultural and forest tree seeds in 1979. It has not been applied on flower seeds. To date, its use is still lacking, despite the relatively simple and nondestructive nature of the test. One of the reasons for the slow adoption is the lack of a simple X-ray unit that gives instant high resolution digital images. The Faxitron MX-20, a cabinet X-ray unit designed for high detail radiographic imaging of medical specimens, fulfills this need. The high magnification capacity of $1 \times, 1.5 \times, 2 \times, 3 \times$, $4 \times$, and $5 \times$, and the low kilovoltage $(\mathrm{kV})$ provide enhanced image performance with good quality contrast. The exposure time and X-ray tube $\mathrm{kV}$ can be selected to produce the best images. Its laser locator eases the positioning of a sample under examination accurately and the 2- $\times 4$-inch field of view digital camera with $10 \mathrm{lp} / \mathrm{mm}$ resolution provides the instant high quality on-screen viewing of seed sample images. The most useful application at the Ornamental Plant Germplasm Center is not in seed testing as recommended for agricultural and tree seeds, but as a tool during seed cleaning to see in a matter of seconds whether empty, immature, insect-damaged, and broken seed have been removed. It has proven useful in Achillea, Alstroemeria, Aquilegia, Aruncus, Aster, Baptisia, Begonia, Campanula, Chrysanthemum, Coreopsis, Dianthus, Euphorbia, Geranium, Hemerocallis, Impatiens, Iris, Lilium, Lupin, Lysimachia, Narcissus, Pelargonium, Penstemon, Petunia, Phlox, Platycodon, Ranunculus, Rudbeckia, Salvia, Silene, Stokesia, Tagetes, Talinum, Verbena, Veronica, and Viola.

\section{(423) Effect of Seed Radiography on Seed Quality}

\section{David Tay*, Xiaolei Hu}

${ }^{1}$ The Ohio State University, Ornamental Plant Germplasm Center, Columbus, OH, 43210

Radiography is a simple and nondestructive technique to detect empty, immature, and insect- and mechanically damaged seed during seed processing and testing. However, there is a lack of information on the effect of X-ray on seed quality despite recommendations by the Association of Official Seed Analysts for testing agricultural and forest tree seeds since 1979. Two experiments were carried out using lettuce seed of Seed Dynamics, Inc. (No. 52694) and Faxitron MX-20 cabinet $\mathrm{X}$-ray unit set at 20 kilovoltage $(\mathrm{kV})$ for 20 seconds, a standard setting to observe many species of flower seeds. In both experiments, the focus-object distance was $34 \mathrm{~cm}$ with no image magnification. The treatments in Experiment 1 were 0 (control), 4, 8, and 12 times of Xray exposures and Experiment 2 were 0 (control), 15, 30, and 60 times of X-ray exposures on non- and 5-hour imbibed seed. In Experiment 1 , germination was done in 288-cell seedling trays in soilless potting mix under greenhouse conditions with four replications of 50 seeds per replicate to observe germination rate, and cotyledon and young leaf discoloration and deformation. Experiment 2 was analyzed using computerized seedling imaging system on germination paper to examine seed vigor and germination rate. There were no significant differences in germination rate in both the non- and imbibed seed in the two experiments. The mean germination rates were $77.75 \%$ in Experiment 1 and 94.81\% in Experiment 2. No cotyledon and young leaf discoloration and deformation were observed in Experiment 1 and no significant differences in vigor index were found in Experiment 2. The conclusion is that there was no observable effect of repeated Xray exposures up to 60 times at $20 \mathrm{kV}$ and 20 seconds on a seed lot for both non- and imbibed lettuce seed.

\section{(424) Vigor Tests on Lettuce Seeds and Their Correlation with Emergence}

Samuel Contreras*, Margarita Barros

Pontificia Universidad Católica de Chile, Departamento de Ciencias Vegetales, Casilla 306-22, Santiago, Chile

The main objective of this study was to evaluate some of the available seed vigor tests to predict lettuce (Lactuca sativa L.) seedling emergence. Eight lettuce seed lots were evaluated by the following laboratory vigor tests: germination (GT); accelerated aging (AA); saturated salt accelerated aging (SSAA); conductivity (EC); and seed vigor imaging system (SVIS). Also evaluated were the percentage (EP) and speed (ES) of the seed lots' emergence under three conditions: seedling trays (ST) filled with a mixture of peat $(80 \%)$ and perlite $(20 \%)$; boxes with a clay loam soil (BS); and boxes with a mixture of clay loam soil $(66 \%)$ and sand $[34 \%(\mathrm{BSS})]$. Correlation coefficients among the laboratory and emergence test results were calculated and significant differences were found. The correlation coefficients between EC results and each emergence parameter were nonsignificant, while AA results were only significantly correlated with the emergence percentage for BSS. GT values and emergence results were significantly correlated in all cases. SSAA results were equally or more positively correlated than GT results with the EP and, for the three sowing conditions, they were more correlated with the ES than GT values. Vigor index results from the SVIS were significantly correlated with both emergence parameters, and its correlation with emergence on ST (EP and ES) was greater than GT values. The results of this study showed that SSAA and SVIS were the best laboratory tests for lettuce seed vigor evaluation, especially for seed lots to be used for plug seedling production.

\section{(425) Effect of Shading on the Germination and Vegetative Development of 'Serrano' Hot Pepper (Capsicum annuum L.)}

Marcelino Bazán-Tene*, Jaime Molina-Ochoa, Enrique Alejandro Bracamontes-Ursúa

Universidad de Colima, Facultad de Ciencias Biológicas y Agropecuarias, Tecomán, Colima, 28140, Mexico

Hot pepper (HP), Capsicum annuum (L.), is a solanum plant domesticated in Mesoamerica. It is currently widespread worldwide, and its uses are varied, such as an excellent flavoring, pigment base, and as a food resource with source of vitamins. The seven top world producers of HP are China, Mexico, Turkey, Spain, United States, Nigeria, and Indonesia. Mexico is producing about 623,238 t/year of fresh fruits in 136,398 ha; Colima produced $17,181 \mathrm{t}$ in $676 \mathrm{ha}$, with a mean of

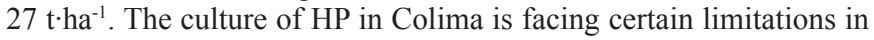
showing its productive potential, such as maintaining fertile and welldrained soils, and constant soil moisture; being weed-free during the first weeks after transplanting; and sustaining plant uniformity into transplantation. Transplantation is made in seed beds, but there is a lack of scientific evidence on shade requirements in the seed nursery to accelerate and improve plant quality for transplanting, and to impact on fruit yield. The aim was to evaluate the effect of levels of shading on the germination and vegetative development of 'Serrano' HP under greenhouse conditions. Four levels of shading were evaluated using mesh fabrics to produce $90 \%, 75 \%$, and $50 \%$ shade, and a control without shading on the seed beds. A completely randomized design 
with four treatments and four replications was used. The shading treatments reduced the germination period in about 1 day, increased the percentage of germination with a range between $1.75 \%$ and $3.25 \%$; increased the plant height $0.83,2.85$, and $4.38 \mathrm{~cm}$ at 3,6 , and 10 days post-emergence; increased the root biomass about $0.01 \mathrm{~g} / \mathrm{plant}$, and $0.24 \mathrm{~g}$ of fresh foliage with the $90 \%$ shade compared with the control. Overall, a better agronomic performance of 'Serrano' HP was obtained with $90 \%$ shading.

\section{(426) Evaluation of Pregerminative Treatments in Soursop (Annona muricata L.) Seeds}

Juan Manuel González Gonzalez*, Salvador Guzman Gonzalez, Arnoldo Michel Rosales, Francisco Radillo Juarez, Marcelino Bazan Tene, Fernando Cervantes T.

Universidad de Colima, Facultad de Ciencias Biológicas y Agropecuarias, Tecomán, Colima, 28100, México

The most common spread of this species is sexual or by seed. In normal conditions, the germination of the seeds of Anonaceae can increase with pregerminative treatments prior to sowing. The objective was to determine the best pregerminative treatment to increase germination of soursop seeds. This study was carried out under the the dry, tropic conditions of Tecomán, Colima, Mexico. The experimental design was completely random with 12 treatments: 1) dip in water for 24 hours; 2) dip in water for 24 hours + gibberellic acid $\left(\mathrm{GA}_{3}\right)$ at $\left.350 \mathrm{ppm} ; 3\right)$ dip in water for 24 hours $+\mathrm{GA}_{3}$ at $500 \mathrm{ppm}$; 4 ) dip in water for 24 hours + $\mathrm{GA}_{3}$ at $1000 \mathrm{ppm}$; 5) mechanical scarification; 6) dip in water for 24 hours + mechanical scarification; 7) mechanical scarification $+\mathrm{GA}_{3}$ at $350 \mathrm{ppm}$; 8) mechanical scarification $+\mathrm{GA}_{3}$ at $500 \mathrm{ppm}$; 9) mechanical scarification $+\mathrm{GA}_{3}$ at $\left.1000 \mathrm{ppm} ; 10\right) \mathrm{GA}_{3}$ at $\left.350 \mathrm{ppm} ; 11\right) \mathrm{GA}_{3}$ at 500 $\mathrm{ppm}$; and 12$) \mathrm{GA}_{3}$ at $1000 \mathrm{ppm}$; and control. There were four repetitions with 10 seeds in each experimental unit. The evaluated variables were the percentage of germination and the number of days from planting to emergence. To record results, analysis of variance and Tukey's test averages were used. The major percentage of germination resulted from the seeds treated with soaking in water for 24 hours plus $\mathrm{GA}_{3}$ to $350 \mathrm{ppm}$, dip in water for 24 hours plus scarification and $\mathrm{GA}_{3}$ at 1000 $\mathrm{ppm}$, and equalized statistically to the control. For the number of days from planting to emergence, the treatment with mechanical scarification $+\mathrm{GA}_{3}$ at 500 ppm was statistically better. The use of gibberellic acid with mechanical scarification diminishes the dormancy of soursop seeds, producing plants in a relatively short period.

\section{(427) Seed Germination after Steeping in Saturated Lime Solutions}

Augusto Trejo-Gonzalez*1, Marita Cantwell ${ }^{2}$

${ }^{1}$ UPIBI-IPN, Bioprocesos, Av. Acueducto de Guadalupe, Col. La Laguna-Ticoman, Mexico; ${ }^{2}$ University of California, Plant Sciences, Davis, CA, 95616

A lime solution is an efficient starch gelatinization agent during the traditional process of nixtamalization of corn for tortilla production. Although the saturated $\mathrm{Ca}(\mathrm{OH})_{2}$, solution is usually heated to speed the process, similar physical-chemical changes occur to corn steeped at room temperature. In addition, the steeped grains are capable of rapid germination. In this study we explored whether, in barley grains subjected to the same steeping conditions, there would be an acceleration of biochemical changes for the production of malt. Barley grains cv. Esmeralda six-row were steeped in saturated solutions of lime from $0 \%$ to $2 \%(\mathrm{w} / \mathrm{w})$ at 18 to $23{ }^{\circ} \mathrm{C}$ for up to 72 hours. After treatment, the grains were washed with water and placed in a germination cabinet at $20 \pm 2{ }^{\circ} \mathrm{C}$ and $90 \% \mathrm{RH}$ for up to 96 hours to germinate. Activity of $\alpha$-amylase (U/mg protein), sprout length ( $\mathrm{cm})$, seed viability (tetrazolium test), and respiration rates were determined. Scanning electron micrographs were prepared. There was a very rapid uptake of lime solution by the barley grains during the first 30 hours of treatment. The barley grains were $98 \%$ viable after all periods of steeping. Grains steeped 24 hours and germinated 70 hours had the highest activity of $\alpha$-amylase, longest sprout length and highest percentage of germination. Under SEM, chemical gelatinization of starch grains was observed in barley sections after different steeping treatments, and starch breakdown was observed in grains during germination. No fungal growth was observed during germination after the steeping treatments. These results demonstrate that steeping in lime solutions could shorten the period required for barley germination and similar conditions may be useful for germination of other cereal and vegetable seeds.

\section{(428) Seed Threshing and Cleaning in Flowers}

\section{David Tay*}

The Ohio State University, Ornamental Plant Germplasm Center, Columbus, OH, 43210

Flower seed threshing and cleaning are challenging because many flowers have tiny seed, e.g., the 1000-seed weight of Begonia is 0.01 $\mathrm{g}$, and others have odd-shaped seed, e.g., Tagetes has pappus-bearing seed and Fibigia has winged seed. There is a lack of information on the threshing and cleaning of flower seeds. At the Ornamental Plant Germplasm Center, a small-plot grain belt thresher was modified by disengaging its winnower and a special chute installed to collect the threshed seed and chaff together for cleaning. A custom-made threshing board is used for small samples. The seed with chaff is passed through screen with mesh size that allows all the seed to pass through so that the big pieces of chaff are retained and separated, i.e., scalping. Accurate selection of the next scalping screen (SS) is critical so that the mesh size is just right for at least $95 \%$ of the seed to pass through to remove all the chaff larger than the seed. The seed is then sieved on a grading screen (GS) of mesh size that retains at least $95 \%$ of the seed to remove all the chaff smaller than the seed. A seed blower is used to further separate the remaining chaff and empty seed based on weight and surface area by adjusting the blowing velocity (BV). A vibratory separator (VS) is used for species with round seed, e.g., Antirrhinum. An X-ray machine is used to monitor the cleaning process. The SC, GS, BV, and VT are given for Agastache, Anisodontea, Antirrhinum, Aquilegia, Aster, Astilboides, Begonia, Belamcanda, Bergenia, Cleome, Coreopsis, Dianthus, Eupatorium, Gaillardia, Geranium, Gypsophila, Iris, Lilium, Lysimachia, Myosotis, Nothoscordom, Oenothera, Passiflora, Penstemon, Petunia, Platycodon, Ranunculus, Rudbeckia, Silene, Stokesia, Synnotia, Tagetes, Talinum, Thalictrum, Verbena, Veronica, and Zinnia.

\section{(429) "Artificial Exosperm" Development Using Antistress, Antioxidant Compounds for Promoting and Synchronizing Seedling Emergence at Limiting Low Temperature and Moisture Conditions in Carrot}

Rowan Briscoe*1, Rajasekaran Lada ${ }^{1}$, Claude Caldwell ${ }^{1}$, Kevin Sibley ${ }^{2}$, Christine Pettipas ${ }^{1}$, Azure Stiles

${ }^{1}$ Nova Scotia Agricultural College, Plant and Animal Sciences, Truro, Nova Scotia, B2N 5E3, Canada; ${ }^{2}$ Nova Scotia Agricultural College, Engineering

Producing carrots with optimal root grades is the most critical aspect of carrot production for maximizing profits. Desired root grades can be optimized by maintaining optimal plant population. While precision seeding helps to seed required seeding rate, obtaining optimum seed germination and uniform emergence, especially in mineral soils and under cold and dry climates, have been great challenges to carrot producers around the world. Therefore, stand establishment is critical for optimizing yield and quality in carrots. Experiments were conducted to identify suitable germination and emergence promoters (GEPs) that will promote early and uniform emergence under temperatures of $5{ }^{\circ} \mathrm{C}$ and $20^{\circ} \mathrm{C}$ and under $20 \% \mathrm{FC}$ and $40 \% \mathrm{FC}$ combinations. GEPs, belonging to both natural and synthetic antistress, antioxidant groups of compounds, and mineral salts were used. Carrot seeds of cv. Oranza were used in this study. Seeds were preconditioned with various GEPs, then submerged into laponite RD gel that was used as a potential "artificial exosperm" for carrot seeds. Data on emergence was collected and emergence and vigor value was calculated. Under ideal conditions, that is, at the $20^{\circ} \mathrm{C}$ and $40 \% \mathrm{FC}$ combination, there was no significant difference between treated seeds and untreated control. Germination was delayed at the $5{ }^{\circ} \mathrm{C}$ and $20 \%$ FC combination. However, seeds preconditioned with GEP-PN1.5\%, GEP-LU at $1 \mathrm{mg} \cdot \mathrm{L}^{-1}$, GEP-CA at $10 \mathrm{mg} \cdot \mathrm{L}^{-1}$, GEP-AA at $100 \mathrm{mg} \cdot \mathrm{L}^{-1}$ and GEP-SD at $10 \mathrm{mg} \cdot \mathrm{L}^{-1}$ all promoted emergence resulting in the highest number of seedlings emerged at $5{ }^{\circ} \mathrm{C}$ and at $20 \%$ FC. Enhanced emergence under low temperature and low moisture may perhaps be due to synthesis of specific proteins. 


\section{Poster Session 18-Weed Management}

19 July 2005, 12:00-12:45 p.m., Poster Hall-Ballroom E/F

\section{(339) Preemergence Weed Control in Container-grown} Herbaceous Perennials

James E. Klett*1, David Staats ${ }^{1}$, Matt Rogoyski ${ }^{2}$

${ }^{1}$ Colorado State University, Department of Horticulture and Landscape Architecture, Fort Collins, CO, 80523; ${ }^{2}$ Colorado State University, Department of Horticulture and Landscape Architecture, Grand Junction, CO, 81503-9621

During the 2004 season, preemergence herbicide was applied to 12 container-grown herbaceous perennials and woody plants and evaluated for weed control, phytotoxicity, and effect on plant growth. The herbicide and rates were: pendimethalin (Pendulum 2G) $908 \mathrm{~g}$ (label rate), $1816 \mathrm{~g}$, and $3632 \mathrm{~g} / \mathrm{acre}$ a.i. Herbicides were applied to lady's mantle (Alchemilla mollis), purple rock cress (Aubretia species), blue wild indigo (Baptisia australis), pink pussytoes (Antennaria dioica var. rosea), common sneezeweed (Helenium autumnale), redhot poker (Kniphofia uvaria), showy goldenrod (Solidago speciosa), heartleaf foamflower (Tiarella cordifolia), lavender (Lavendula angustifolia), blue flax (Linum perenne), catmint (Nepeta $\times$ faassenii), and hen and chicks (Sempervivum tectorum). At 32 and 117 days after application, plants were evaluated for phytotoxicity. No phytotoxicity symptoms were apparent on any of the plants tested. Weed control was good in most cases with this herbicide but it did not control all weeds. Increasing the rates from $1 \times$ (label rate) did not significantly improve weed control.

\section{(340) Root Hardiness and the Influence of DNA Herbicides in Overwintered Containers}

Michele Bigger*, Hannah M. Mathers

The Ohio State University, Hort. and Crop Science, Columbus, OH, 43210

A limiting factor in container production is cold temperature. Young roots have been found to be less hardy than mature roots (Steponkus, 1976; Studer et al., 1978). Proper overwintering procedures are essential to assure a viable crop in the spring. A common overwintering practice is the application of a preemergent dinitroanaline (DNA) herbicide prior to covering. The objectives of this research were to: 1) determine young and mature root hardiness values for containerized plants that did and did receive DNA herbicides prior to overwintering; 2) investigate differences in regrowth potential between untreated and DNA herbicide treated containers 30,60, and 180 days after freezing (DAF). Research began in June 2003 and concluded Mar. 2004. In Aug. and Oct. 2003, herbicide treatments of $1 \times$ oryzalin $(2.0 \mathrm{lb} /$ acre a.i.), prodiamine $(2.0 \mathrm{lb} /$ acre a.i. $)$, pendimethalin $(3.0 \mathrm{lb} /$ acre a.i. $)$, trifluralin $(2.0 \mathrm{lb} /$ acre a.i.), or no treatment (control) was applied to the plants. In Jan. or Mar. 2004, plants were frozen to temperature treatments of, $0,-5,-10,-15$, or $-20{ }^{\circ} \mathrm{C}$. After freezing, they were placed in a heated greenhouse and evaluated for regrowth. Regrowth and hardiness were evaluated two ways: by a visual rating score $(0-10)$, where $0=$ dead and $10=$ healthy; and plant live height. Results pooled over all species, temperatures, sampling dates at $30 \mathrm{DAF}$ show prodiamine significantly increased hardiness $(23.7 \%)$ compared to the control. Results pooled over all species, temperatures, sampling dates, and all DAF show prodiamine significantly increased regrowth potential $(24.5 \%)$ compared to the control. Both sampling date and DAF were significant when pooling over all species, temperatures, and herbicide treatments, indicating root injury had occurred.

\section{(341) Weed Resistant Cowpeas: Experiments and Models}

Guangyao Wang ${ }^{1}$, Jeff D. Ehlers ${ }^{1}$, Philip A. Roberts ${ }^{2}$, Eddie J. Ogbuchiekwe ${ }^{1}$, Milton E. McGiffen, Jr.*1

${ }^{1}$ University of California, Botany and Plant Sciences, Riverside, CA, 92521-0124; ${ }^{2}$ University of California, Nematology, Riverside, CA, 92521

Competitive cover crop varieties are needed to reduce weed problems and herbicide use. Identifying specific crop traits related to competitive ability would provide breeders with useful information that could be used to develop an ideotype for highly competitive cover crop varieties. Cowpea varieties with different growth habits were grown with sunflower or purslane to determinate which growth habit (erect, semi-erect, and prostrate) is more likely to be most competitive with tall or short growing weeds. Regression models were used to analyze additive and replacement series experiments. The results showed that erect varieties were more competitive with weeds than semi-erect varieties and prostrate varieties. However, the simple regression models did not provide much information about competitive mechanisms helpful to breeders. An ecophysiological model, INTERCOM, was used to understand competitive mechanisms. Validated INTERCOM model provided us with more information about competitive cover crop traits, including competitive growth habit.

\section{(342) Cool-season Living Mulches for Florida}

\section{Carlene A. Chase*, Odemari S. Mbuya}

${ }^{1}$ University of Florida, Horticultural Sciences, Gainesville, FL, 32611-0690; ${ }^{2}$ Florida A\&M University, Agronomy Program \& Center for Water Quality, Tallahassee, FL, $32307-4100$

Living mulches between beds of polyethylene-mulched vegetable crops may suppress weeds and decrease surface and ground water contamination by pesticides. They should be either low growing or amenable to mowing and should withstand traffic. Twelve winter cover crops were planted in north (N.) and north central (N.C.) Florida in Fall 2004: black oats (Avena strigosa cv. Soilsaver), annual ryegrass (Lolium multiflorum cv. Gulf), rye (Secale cereale cv. Wrens Abruzzi), hard fescue (Festuca longifolia cv. Oxford), white clover (Trifolium repens cvs. Dutch white and New Zealand white), berseem clover ( $T$. alexandrinum cv. Bigbee), crimson clover (T. incarnatum cv. Dixie), subterranean clover (T. subterraneum cv. Mt. Barker), arrowleaf clover (T. vesiculosum cv. Yuchi), a barrel medic (Medicago trunculata $\mathrm{cv}$. Parabinga), and a disc $\times$ strand medic (M. tornata $\times$ M. littoralis $\mathrm{cv}$. Toreador). Black oats, rye, and annual ryegrass established quickly and suppressed winter annual weeds. Canopy development of the other species was poor. Shoot biomass was greater in N. Florida than in N.C. Florida. The highest shoot biomass occurred with black oats. By 8 weeks after planting (WAP) rye and annual ryegrass had similar amounts of biomass, but by 16 WAP the yield of rye was greater. At some harvests, biomass with wheel traffic or mowing was lower than without, but black oats, rye, and ryegrass did not succumb to these treatments. Of the legumes, only crimson clover and 'Toreador' medic in N. Florida produced sufficient biomass by 16 WAP to permit a harvest. Black oats, rye, and annual ryegrass appear to be the best living mulch candidates; however, black oats would require more frequent mowing.

\section{(343) Weed Control in Vineyard Following Fall and Spring Application of Selected Herbicide Combinations}

\section{Sorkel Kadir*1, Kassim Al-Khatib ${ }^{2}$}

${ }^{1}$ Kansas State University, Horticulture, Manhattan, KS, 66506; ${ }^{2}$ Kansas State University, Agronomy, Manhattan, KS, 66506

Soil residual herbicides registered for use on grapes can be applied from fall to spring, before weed emergence. However, ample early-spring moisture and warm weather may enhance weed emergence before herbicide application in the spring and prevent timely application. Therefore, fall application of herbicides can be beneficial if herbicides would provide adequate weed control in the following spring. Warm and wet winters may enhance herbicide degradation and shorten herbicide residual activity that result in poor weed control the following spring. Fall and spring application of oryzalin or norflurazon applied alone or in combination with diuron, simazine, or oxyfluorfen were evaluated for weed control in commercial vineyards at Oskaloosa and Eudora in northeast Kansas in 2003 and 2004. Weeds were not controlled adequately with oryzalin or norflurazon applied alone. At the end of the growing season, however, weed control was greater with spring than fall application. In addition, weed control with norflurazon was slightly greater than oryzalin. Norflurazon or oryzalin applied in combination with simazine, diuron, or oxyfluorfen controlled more weeds than norflurazon or oryzalin applied alone. The greatest control was with norflurazon or oryzalin applied with oxyfluorfen. In general, all herbicide combinations applied in the spring and fall provided similar weed control 4 months after spring application. However, at the end 
of the growing season, weed control was $10 \%$ to $20 \%$ greater when herbicides applied in the spring than fall. This study showed that acceptable weed control can be achieved when norflurazon or oryzalin is applied with oxyfluorfen and diuron in the fall.

\section{Poster Session 19-Pest Management}

19 July 2005, 12:00-12:45 p.m. Poster Hall-Ballroom E/F

(362) Assessment of Woody Ornamental Plants for Resistance to Three Meloidogyne Species

Jyotsna Sharma*1, Jim Rich ${ }^{2}$

${ }^{1}$ University of Florida, Environmental Horticulture, Quincy, FL, 32351; ${ }^{2}$ University of Florida, Entomology and Nematology, Quincy, FL, 32351

Plants infected with Meloidogyne spp. (root-knot nematodes) often are stunted and lose aesthetic value due to chlorosis, wilting, and leaf margin necrosis. We assessed reproduction of three root-knot nematode species, Meloidogyne arenaria, $M$. incognita, and $M$. javanica, on five plant taxa native to the southeastern U.S. The plant taxa included were: Hydrangea quercifolia 'Oakleaf', Viburnum obovatum 'Densa', Itea virginica 'Little Henry', Illicium parviflorum, and Clethra alnifolia 'Ruby Spice'. Three commonly grown non-native shrubs, Ligustrum japonicum 'Texanum', Ilex crenata 'Compacta', and Buxus microphylla 'Wintergem', also were included in the study to serve as susceptible, positive controls. Highest gall rating (10) was observed on roots of $I$. crenata 'Compacta' infected with $M$. incognita, but highest number of eggs (6397 eggs/g of roots) was observed in plants of this cultivar inoculated with M. javanica. Few or no galls were observed on roots of the five native plant taxa, and nematode eggs were recovered only from roots of I. virginica 'Little Henry' inoculated with $M$. arenaria and M. javanica (13 and 20 eggs/g of roots, respectively). Fresh weights of shoots or roots were not affected by nematode inoculation. Due to lack of root gall development and little or no reproduction on the native taxa, we conclude that these are resistant or immune to the three species of Meloidogyne and might be suitable for planting in infested soil.

\section{(363) Effect of Visible Light Wavelengths on the Population Growth Rate of the Two-spotted Spider Mite (Tetranychus urticae Koch.)}

Takeshi Suzuki*, Hiroshi Amano, Toyoki Kozai

Chiba University, Faculty of Horticulture, Chiba, 271-8510, Japan

The two-spotted spider mite (Tetranychus urticae Koch.) has a worldwide distribution and is one of the most harmful agricultural pests for a variety of plant species. To reveal a visible light wavelength that reduces the population growth rate (as $r_{\mathrm{m}}$, unit: $\mathrm{d}^{-1}$ ) of the mite, we investigated the $r_{\mathrm{m}}$ under wavelength peaks of 468,515 , and 658 $\mathrm{nm}$ with half bandwidths of 23,44 , and $22 \mathrm{~nm}$ using blue, green, and red light-emitting diodes, respectively. In all treatments, light intensity was set at $2.3 \mathrm{~W} \cdot \mathrm{m}^{-2}$ with a light period of $16 \mathrm{~h} \cdot \mathrm{d}^{-1}$, and air temperature was set at $25{ }^{\circ} \mathrm{C}$. The survival percentage $\left(l_{\mathrm{x}}\right)$ and the number of eggs deposited per female $\left(m_{\mathrm{x}}\right)$ on each age $(x$, unit: $\mathrm{d})$ were determined to calculate the $r_{\mathrm{m}}$ by the following equation: $\operatorname{\Sigma exp}\left(-r_{\mathrm{m}} \cdot x\right) \cdot l_{\mathrm{x}} / 100 \cdot m_{\mathrm{x}}=1$. The $r_{\mathrm{m}}$ and the total $m_{\mathrm{x}}$ decreased with increasing wavelength. This result shows that the population growth rate can be reduced under red light $(658 \mathrm{~nm})$.

(364) Evaluation of Beneficial Microorganisms for Controlling the Wilt Caused by Fusarium oxysporum f. sp. melonis on Cantaloupe Plants under Greenhouse Conditions

Mario Orozco-Santos ${ }^{1}$, Javier Farías-Larios*2, Jaime Molina-Ochoa ${ }^{2}$, José Gerardo López-Aguirre ${ }^{2}$

${ }^{1}$ INIFAP, Campo Experimental Tecomán, Colima, 28100, México; ${ }^{2}$ Universidad de Colima, Facultad de Ciencias Biológicas y Agropecuarias, Tecomán, Colima, 28100, México

Development of resistance to chemical pesticides has been reported in about 150 plant pathogenic species, mostly fungi. Biocontrol of plant pathogens is an alternative to chemical pesticides. Actually, there are products formulated with beneficial microorganisms, such as mycorrhizal fungi, rhizobacteria, antagonistic fungi, and others. The objec- tive was to evaluate the development of Fusarium oxysporum f. sp. melonis (FOM) on melon plants inoculated with commercial biological formulations based on beneficial microorganisms. Twelve treatments were evaluated: T1) VAM media nursery + FOM; T2) Hortic Plus + FOM; T3) BioPak F + FOM; T4) Glomus intraradices + FOM; T5) FOM; T6) control; T7) VAM media nursery; T8) Hortic Plus; T9) BioPak F; T10) Glomus intraradices; T11) FOM + Mancozeb wp80; and T12) FOM + BioPak F. The melon cultivar used was 'Colima' (Peto Seed Co.). Seeds were planted in Styrofoam growing containers containing coconut fiber powder as substrate. One seed was planted per cell and maintained until transplanting. Plants were transplanted to pots containing sterile soils 13 days postemergence. Inoculation of treatments with Fusarium was made with a concentrated suspension at $1 \times 106$ conidia $/ \mathrm{mL}$. For inoculation with beneficial microorganisms, manufacturer specifications were followed. A completely randomized design with 12 treatments and 12 replications was used to estimate the incidence of Fusarium, number of leaves, leaf area, root biomass, and percentage of roots colonized by mycorrhizal fungi. Overall, T10 showed the best behavior in all variables. Inoculation of cantaloupe plants with Fusarium affected their performance, but those treatments including mycorrhizal fungi enhanced their performance withstanding the damage by Fusarium.

(365) Susceptibility of Scyphophorus acupunctatus Gyllenhal (Coleoptera: Curculionidae) Larvae to Entomopathogenic Nematodes Steinernema (Rhabditida: Steinernematidae)

Eva Judith Hueso*1, Jaime Molina-Ochoa ${ }^{1}$, Jalil Fallad-Chávez ${ }^{2}$, Roberto Roberto Lezama-Gutiérrez $z^{3}$, Marilú López-Edwards ${ }^{3}$, Javier Farías-Larios ${ }^{3}$

${ }^{1}$ Universidad de Colima, Mexico, Nematology, Crucero de Tecomán., Colima, 28100, Mexico; ${ }^{2}$ Universidad de Guadalajara, Engineering, Autlan de Navarro, Jalisco, 48900, Mexico; ${ }^{3}$ Universidad de Colima, Mexico, Control Biologico, Crucero de Tecomán., Colima, 28100, Mexico

Scyphophorus acupunctatus is the main pest of Agave tequilana. Its adults are vectors of Erwinia carotovora, which causes plant destruction. The susceptibility of $S$. acupunctatus larvae to various strains of entomopathogenic nematodes has been demonstrated previously (Molina et al., 2004). In the current paper, the use of seven different concentrations: $0,10,20,50,100,200$, and 500, of infected juveniles per larva in petri dishes containing a filter paper against Steinernema carpocapsae strains $\mathrm{All}, \mathrm{Ca}$, and $\mathrm{Fl}$, and also against native insolated N1, N2, N4, belonging to the genera Steinernema sp. The studies were conducted under laboratory conditions to determine the susceptibility of S. acupunctatus larvae to entomopathogenic nematodes. One hundred percent mortality of $S$. acupunctatus larvae was achieved by $S$. carpocapsae strains All, $\mathrm{Ca}$, and Fl with exposure to 100 infected juveniles. In the case of native isolates, $\mathrm{N} 2$ registered $95 \%$ mortality, and for $\mathrm{N} 4$ and $\mathrm{N} 1$, mortality registered was $75 \%$. An analysis of variance was conducted in order to determine whether strain or isolate had the highest virulence against $S$. acupunctatus larvae. Means for $S$. acupunctatus larvae by entomopathogenic nematodes presented significant differences $(\mathrm{F}=57.01$; $\mathrm{df}=55,223 ; P<0.0001)$, resulting in two levels. At the first level, $S$. carpocapsae All, Fl, and Ca are statistically the same as isolate N4. At the second level, the isolates N4 and N1 are statistically the same. The results indicate the high susceptibility of $S$. acupunctatus larvae. The infectivity of native isolates as well as $S$. carpocapsae strains All, Fl, and $\mathrm{Ca}$ are associated with the symbiotic bacterium Xenorharbdus sp., suggesting they have potential for use against $S$. acupunctatus larvae.

\section{Poster Session 20-Pomology-Culture/Production/ Management}

19 July 2005, 12:00-12:45 p.m. Poster Hall-Ballroom E/F

(309) Effect of Chitin-incubated Solution (CIS) Spray on Tree Growth and Fruit Quality of 'Niitaka' Asian Pear

Wol-Soo Kim ${ }^{1}$, Jung-An Jo ${ }^{1}$, Soon-Ju Chung ${ }^{1}$, Kil-Yong Kim ${ }^{1}$, Hyun Sug Choi*

${ }^{1}$ Chonnam National University, Department of Horticulture, 300 Yongbong-dong, Gwangju, 
500-757, Korea; ${ }^{2}$ Chonnam National University, Department of Agrochemical; ${ }^{3}$ University of Arkansas, Fayetteville, Arkansas, 72701

The shells of crab, shrimp, beetles, etc., could be decomposed by chitinase to chitin, calcium, and protein, respectively. We incubated the mixture solution of $1.5 \mathrm{~kg}$ crab shell, $1.5 \mathrm{~kg}$ multinutrient, $2 \mathrm{~kg}$ compost with microorganisms to decompose the chitin substance, $3 \mathrm{~kg}$ sugar, and $700 \mathrm{~L}$ water at room temperature for 7 days. During the incubation, aeration with an air pump was essential. We sprayed the chitin-incubated solution (CIS) after filtering to 'Niitaka' pear (Pyrus pyrifolia) trees at 15-day intervals from May to Sept. 2004. Leaf area, leaf thickness, leaf specific weight, and chlorophyll contents were increased by the treatment with CIS. In fruit characteristics, fruit weight, soluble solids, fruit firmness, and Hunter values "a" and "b"were increased by the CIS treatment. Flesh browning after peeling the fruit was delayed by the CIS treatment, and polyphenoloxidase (PPO) activities were lowered.

\section{(310) Peach Orchard Systems Management Trial: The First Six Years}

\section{Desmond R. Layne*, Eric J. Hitzler}

Clemson University, Horticulture, 177 PooleAgriculture Building, Clemson, SC, 29634-0319

In 1999, a trial was established at the Clemson University Musser Fruit Research Farm to investigate the effects of training system/tree density, rootstock, and irrigation/fertilization on tree growth, productivity and profitability. The replicated trial comprised three training systems/tree densities (open center-332 trees/ha; quad V-664 trees/ha; and perpendicular V-996 trees/ha). The two rootstocks used were Lovell and Guardian. Three irrigation/fertilization treatments included: natural rainfall only plus granular program; supplemental irrigation plus granular; and supplemental irrigation plus fertigation at a reduced nitrogen rate from the granular program. The scion was the popular midseason cultivar Redglobe. There were a total of 18 treatment combinations replicated 4 times with 5 trees per treatment plot. Soil moisture was determined by TDR and pan evaporation monitored by weather station. Seventy-two minirhizotron tubes were installed in 2002 to monitor fine root growth. During 1999-2001, drought conditions limited rainfall to $35 \%$ below the annual average. Spring freeze events in 2001 and 2004 reduced crop load disproportionately in shorter, open-center trees. As tree density within the tree row increased, trunk cross sectional area (TCA) decreased. Trees on Guardian rootstock had significantly greater TCA than Lovell each year. Trees that received supplemental irrigation had greater TCA than nonirrigated trees each year. By reducing N rate through fertigation, TCA was reduced. Cumulative yield was not affected by training system/tree density. Cumulative yield was not affected by rootstock. Cumulative yield was $7 \%$ greater by supplemental irrigation. Pruning, thinning and harvesting was easier in V-systems than for open center trees.

\section{(311) Armillaria Root Rot of Peach: A Multipronged Approach}

Desmond R. Layne*1, Guido Schnabel ${ }^{2}$, Kerik $\mathrm{Cox}^{2}$, Ralph Scorza ${ }^{3}$, Karen Bussey ${ }^{1}$

${ }^{1}$ Clemson University, Horticulture, 177 Poole Agriculture Building, Clemson, SC, 29634 ${ }^{2}$ Clemson University, Entomology, Soils and Plant Sciences; ${ }^{3}$ Appalachian Fruit Research Station, USDA-ARS, Kearneysville, WV, 25430

Armillaria root rot (ARR) of peach caused by the soil-borne basidiomycete fungus Armillaria tabescens is causing premature decline and mortality of peach trees on most southeastern U.S. peach farms. Soil inoculum may be present both in former peach orchard sites and on sites that were once in hardwood forest. The fungus is protected under the bark of dead root pieces and may survive up to 100 years at various depths in the soil profile. No commercially available rootstocks are resistant to ARR. Since 2002, we have embarked on a multipronged strategy to develop control options to combat ARR. First, we have two replicated trials on commercial grower replant sites with a history of ARR. Trial 1 compares four preplant fumigation treatments (none, Telone II, methyl bromide, and Enzone), three rootstocks (Lovell, Halford, and Guardian) and preplant root dips with endomycorrhizal fungi. Trial 2 compares the use of raised beds, root collar excavation and preplant root dips. Both trials examine long-term productivity and tree survival. Second, we are examining the use of systemic fungicide injection into infected trees to protect trees around infection foci. Third, we are trying to develop a genetically modified ARR-resistant rootstock. We have inserted the gene encoding the gastrodia antifungal protein (GAFP - a low molecular weight lectin that binds mannose and chitin) from a Chinese orchid into tobacco (model herbaceous system) and plum (model Prunus system). GAFP has antifungal activity against several basidiomycete root rot pathogens. Pathogenicity tests with transformed tobacco plants show enhanced tolerance to several root rot pathogens when compared to nontransformed plants. Transformed plums are being multiplied for pathogenicity tests.

\section{(312) Replant Apple Tree Performance, and Rhizotron Observations of Root Development, Distribution, and Survival for Three Rootstock Clones in a New York Orchard}

\section{Shengrui Yao*, Ian A. Merwin, Michael G. Brown}

Cornell University, Department of Horticulture, Ithaca, NY, 14853

Rhizotron observations enabled us to compare the performance of three apple (Malus $\times$ domestica) rootstock clones following different pre-plant soil treatments in an apple replant study at Ithaca, NY. Trees were planted in Nov. 2001, with one minirhizotron tube per tree in three replicate plots of three rootstocks (M7, CG30, and CG6210), three pre-plant soil treatments (fumigation, compost amendment, and untreated controls), and two planting positions (within the old tree rows, or in the old grass lanes). Monthly root observations were conducted during the 2003 and 2004 growing seasons. There were substantially fewer new roots observed in the first bearing year (2004) than the previous nonbearing year (2003), for all three rootstocks. A root-growth peak in early July accounted for more than $50 \%$ of all new roots in 2003, but there was no midsummer root growth peak in 2004 . Neither pre-plant soil treatments nor old row or grass-lane planting positions had much influence on root growth. The median lifespan for roots of CG6210 was twice as long as that of CG30 and M7 in 2004. Also, CG6210 had more roots below $30-\mathrm{cm}$ depth, while M7 had more roots from $11-20 \mathrm{~cm}$. Trees grafted on CG6210 were bigger and yielded more fruit in the third year after planting, compared with trees on CG30 and M7 rootstocks. Crop load severely inhibited new root development and changed root-growth dynamics during the first cropping year, with a surge in root growth after fruit harvest in Oct. 2004. Rootstock genotype was the dominant influence on root lifespan and distribution, compared with pre-plant soil fumigation, compost amendments, or replanting positions within the previous orchard rows or grass lanes.

\section{(313) Climatic Effects on Four Low-chill Peach Cultivars in North Central and Central Florida}

Todd Wert, Jeffrey G. Williamson*, RobertE. Rouse, E. Paul Miller

University of Florida, Horticultural Sciences Department, Gainesville, FL, 32611

Four low-chill peach cultivars were evaluated for vegetative and reproductive growth, fruit quality, and yield in north central and central Florida. Twenty-trees (five of each cultivar) were planted at each site in Feb. 2002. Prior to budbreak in the spring of 2004 and 2005, three shoots of average length and diameter were selected at a height of $1.5-2.0 \mathrm{~m}$ and the number of vegetative and flower buds was recorded for each shoot. Percentage of bloom was estimated, and the number of open flowers on selected shoots was measured weekly. Trees were harvested twice per week starting in mid-April in central Florida, and in late April in north central Florida. Total number and weight of marketable fruit was measured for each tree. Ten representative fruits were selected from each tree at each harvest. Fruit were measured for blush, weight, and size. Soluble solids, TAA, and pressure were determined for five fruit from each 10 -fruit sample. Preliminary results indicate a higher mean number of blind nodes in central Florida and a higher mean number of flower buds in north central Florida. In central Florida, $90 \%$ bloom was about 4 days earlier than north central Florida. Fruit number and individual fruit size, weight, and marketable yield were higher in north central Florida than in central Florida. Fruit blush 
was higher in central Florida than in north central Florida and tended to increase as the season progressed. In north central Florida, blush decreased slightly throughout the season.

\section{(314) Geneva ${ }^{\circledR}$ 41: A New Fire Blight Resistant, Dwarf Apple Rootstock}

Gennaro Fazio*1, Herb S. Aldwinckle ${ }^{2}$, Terence L. Robinson ${ }^{3}$, James Cummins ${ }^{3}$

${ }^{1}$ Cornell University, USDA ARS, Plant Genetic Resources Unit Geneva, Geneva, NY, 14456; ${ }^{2}$ Cornell University NYSAES, Plant Pathology, Barton Labs; ${ }^{3}$ Cornell University NYSAES, Horticultural Sciences, Hedrick Hall

The Geneva ${ }^{\circledR}$ Apple Rootstock Breeding program initiated in 1968 by Cummins and Aldwinckle of Cornell University and continued as a joint breeding program with the USDA-ARS since 1998, has released a new dwarf apple rootstock named Geneva ${ }^{\circledR} 41$ or G.41. G.41 (a progeny from a 1975 cross of 'Malling 27' $\times$ 'Robusta 5') is a selection that has been tested at the N.Y. State Agricultural Experiment Station, in commercial orchards in the United States, and at research stations across the United States, Canada, and France. G.41 is a fully dwarfing rootstock with vigor similar to M.9 T337, but with less vigor than M.9 Pajam2. It is highly resistant to fire blight and Phytophthora with no tree death from these diseases in field trials or inoculated experiments. G.41 has also shown tolerance to replant disease. Its precocity and productivity have been exceptional, equaling M.9 in all trials and surpassing M.9 in some trials. It also confers excellent fruit size and induces wide crotch angles in the scion. It appears to be very winter hardy and showed no damage following the test winter of 1994 in New York. Propagation by layering in the stool bed G.41 is not consistent and may require higher layering planting densities or tissue culture mother plants to improve its rooting. G.41 also produces some side shoots in the stool bed. The nursery liners of G.41 produce a smaller tree than G.16 liners, but similar to M.9, which is very acceptable. Unlike G.16, G.41 is not sensitive to latent viruses. G.41 has similar graft union strength to M.9 and requires a trellis or individual tree stake when planted in the orchard. Suggested orchards planting densities with this rootstock are 2,000-4,000 trees/ha. This rootstock has been released for propagation and commercial sale by licensed nurseries.

\section{(315) Geneva ${ }^{\circledR 35}$ : A New Fire Blight Resistant, Semi- dwarfing Apple rootstock}

Gennaro Fazio*1, Herb S. Aldwinckle², Terence L. Robinson ${ }^{3}$, James Cummins ${ }^{3}$

${ }^{1}$ USDAARS, Plant Genetic Resources Unit Geneva, Cornell University, Geneva, NY, 14456; ${ }^{2}$ Cornell University NYSAES, Plant Pathology, Barton Labs, Geneva, NY, 14456; ${ }^{3}$ Cornell University NYSAES, Horticultural Sciences, Hedrick Hall, Geneva, NY, 14456

The Geneva ${ }^{\circledR}$ Apple Rootstock Breeding program, which was initiated in 1968 by Dr. James Cummins and Dr. Herb Aldwinckle of Cornell University and which has been continued as a joint breeding program with the U.S. Dept. of Agriculture Agricultural Research Service (USDA-ARS) since 1998, has released a new semi-dwarfing apple rootstock which is named Geneva ${ }^{\circledR} 935$ or G.935. G.935 (a progeny from a 1976 cross of 'Ottawa 3' $\times$ 'Robusta 5') is a selection that has been widely tested at the New York State Agricultural Experiment Station in Geneva, N.Y., in commercial orchards in the United States and at research stations across the United States and Canada. G.935 is a semi-dwarfing rootstock that produces a tree slightly larger than M.26. G.935 is the most precocious and productive semi-dwarf rootstock we have released. It has had similar yield efficiency to M.9 along with excellent fruit size and wide crotch angles. It showed no symptoms of winter damage during the 1994 test winter in N.Y. G.935 is resistant to fire blight and Phytophthora; however. it is susceptible to infestations by woolly apple aphids. G.935 has shown tolerance to replant disease complex in several trials. It has good propagation characteristics in the stool bed and produces a large tree in the nursery. G.935 has better graft union strength than M.9, but will require a trellis or individual tree stake in the orchard to support the large crops when the tree is young. G.935 will be a possible replacement for M.26. Suggested orchards planting densities with this rootstock are 1,500-2,500 trees/ha. It has been released for propagation and sale by licensed nurseries. Liners will be available in the near future.

\section{(316) Development of Rootstocks to Promote Early Bearing in Pawpaw}

Kirk W. Pomper*, Sheri B. Crabtree

Kentucky State University, Land Grant Program, Frankfort, KY, 40601

The propagation of clonal rootstocks for the pawpaw [Asimina triloba (L.) Dunal] has been unsuccessful; therefore, nurseries currently graft cultivars onto rootstock derived from locally available seed of diverse genetic origin. Great variation in pawpaw scion growth and suckering is observed with this seedling rootstock and grafted trees are also slow to come into production, often producing fruit 5 to 6 years after planting. In an effort to develop superior seedling rootstocks for pawpaw cultivars, seedstock was evaluated from the cultivars PA-Golden (\#1), Sunflower, Susquehanna, NC-1, K8-2, and commercially available seed (RVT). The objectives of the experiment were to determine if: 1) genotype and seed size influenced vigor of greenhouse-grown container seedlings; 2) graft compatibility and growth rate of scions would vary by rootstock; and 3) scion precocity was influenced by various seedling rootstocks in the field. Greenhouse experiments were conducted in 2002, 2003, and 2004, and each year all seedstocks had a high germination percentage (95\%) and uniform size within each seedstock. Seed size was an important factor in determining vigor in container production. Seed of 'Sunflower' was large (1.65 g/seed) and consistently produced vigorous seedlings that were able to be chipbudded within 6 months. Seed of the selection K8-2 was smallest $(0.94 \mathrm{~g} / \mathrm{seed})$ and showed the least vigor. Bud take was similar for the scions 'Sunflower' and 'Susquehanna' on all rootstocks. Twenty-one weeks after budding, scions of 'Sunflower' were about 30\% larger than scions of 'Susquehanna'; however, source of seedling rootstock did not affect growth of either cultivar. Field evaluations have begun with the two cultivars budded onto the six rootstocks.

\section{(317) Effects of Different Organic Mulch on Soil Physical Characteristics and Leaf Nutrition in Apple Orchards}

Hyun-Sug Choi*, Curt Rom, Jason McAfee

University of Arkansas, Horiculture, Fayetteville, AR, 72701

Mulch may affect soil chemistry, soil microclimate, biological communities, and tree performance. The trial was conducted to evaluate the effects of different orchard mulches on leaf nutrition, soil moisture, bulk density, root density, and water infiltration for understanding potential use in organic orchards for weed control and as a nutrient resource. Black plastic, hardwood chips, and shredded white paper were applied to three apple cultivars, 'Gala', 'Jonagold', and 'Braeburn' on M.9 rootstocks. A control was sprayed with contact herbicide. Trees grown in hardwood mulch had the highest foliar $\mathrm{P}$ and $\mathrm{K}$ in year 3. Trees in other mulches showed no difference of leaf nutrition in year 5. All treatments had consistently higher soil moisture than control in year 1,2, and 4. Mulch did not affect soil bulk density in year 2 . The root density was lowest under black plastic mulch in year 2 , but was similar in all treatments in year 3 . In year 2 , water infiltration was fastest in hardwood mulch and control treatments.

\section{(318) Influence of Orchard Site Parameters and Fruit Distribution within Canopy on Fruit Quality of 'Fuji' Apple} Zlatko Cmelik*1, Stanislav Tojnko²

${ }^{1}$ University of Zagreb, Department of Pomology, Svetosimunska 25, Zagreb, 10000, Croatia; ${ }^{2}$ University of Maribor, Fruit Growing, Vrbanska 30, Maribor, 2000, Slovenia

Canopies of 'Fuji' apple trees, grafted on M.9 rootstock, planted in 1998 on two orchard sites at $2.8 \times 0.7 \mathrm{~m}$ and trained as super spindles, were subdivided in Spring 2003 into upper and lower parts. In each part, the number of fruits, yield per tree, external (fruit size classes, and fruit coloring), and internal (total sugar content, titratable acid content, and flesh firmness) fruit quality attributes were determined. The orchard site parameters affected growth, yield, and fruit quality in different ways. The less suitable orchard site had less growth, lower yield per tree, and a lower percentage of first class fruits, but most fruits had good color ( $86 \%$ in top and $75 \%$ in lower part of canopy). The favorable orchard site produced higher growth and yield, and a higher percentage of first 
class fruits, but fruits had poorer color. In the lower part of the canopy, fruits were of a good size, but had poor color. Fruits of the best quality were obtained from the top part of the tree.

\section{Poster Session 21-Computer Applications in Horticultural Science}

19 July 2005, 12:00-12:45 p.m. Poster Hall-Ballroom E/F

\section{(357) GIS Tools for Documentation and Analysis of Germplasm Collections from a Secondary Center of Diversity: A Case Study for East African Sweetpotatoes}

Arthur Villordon*1, Wambui Njuguna ${ }^{2}$, Simon Gichuki ${ }^{3}$, Heneriko Kulembeka ${ }^{4}$, Jeremiah Simon ${ }^{4}$, Bernard Yada ${ }^{5}$, Phinehas Tukamuhabwa ${ }^{5}$, Don LaBonte ${ }^{6}$

${ }^{1}$ LSU AgCenter, Sweetpotato Research Station, Chase, LA, 71324; ${ }^{2}$ Kenyatta University, School of Graduate Studies, Nairobi, Kenya: ${ }^{3}$ KARI, Biotechnology Centre, Nairobi, Kenya;

${ }^{4}$ ARI-Ukiriguru, MAF Department of Research and Development, Mwanza, Tanzania;

${ }^{5}$ Makerere University, Department of Crop Science, Kampala, Uganda; ${ }^{6}$ Louisiana State University, Department of Horticulture, Baton Rouge, LA, 70803

The East African region in sub-Saharan Africa (SSA) is widely considered as one of the secondary centers of diversity for sweetpotatoes [Ipomoea batatas (L.) Lam.]. Farmers in the region typically grow landraces, but hybridizations occasionally result in new genotypes. Factors such as regional conflicts, natural disasters, disease, and land pressure continually threaten the SSA sweetpotato gene pool. Despite this threat, very little updated information is easily accessible about SSA germplasm collections. Such information is valuable for purposes of management, exploration, and conservation. Using germplasm collection data from Kenya, Tanzania, and Uganda, we demonstrate how publicly available GIS-based tools, e.g., DIVA-GIS, can be used to document current collections as well as make this information easily accessible, searchable, and portable. First, collection data from each country were compiled and known collection sites were georeferenced using available gazetteers. Following data cleaning and verification, georeferenced data were then converted into a GIS-compliant format, primarily as shapefiles. All files were then copied into storage media for exchange among stakeholders. To further demonstrate the portability of the GIS database files, available World Wide Web GIS web viewers enabled real-time access to GIS files uploaded to an experimental web site. This work demonstrates that with very little expense, access to extant SSA germplasm information for sweetpotatoes can be improved using publicly available GIS tools.

\section{(358) A GIS Approach to Managing the Invasive Species \\ of Texas}

\section{William Spencer*1, Justin Williams ${ }^{2}$}

${ }^{1}$ Sam Houston State University, Agricultural Sciences, Huntsville, TX, 77340-2088; ${ }^{2}$ Sam Houston State University, Biological Sciences, Huntsville, TX, 77340-2116

The state of Texas consists of roughly 4800 species of vascular plants. In 1970, it was estimated that 200 of these were introduced species. By 2003, the number of introduced species almost doubled to 350. Using the Atlas of the Vascular Plants of Texas, a database was compiled listing the invasive species in Texas and which of the 254 counties they inhabited. This database was then converted into a GIS platform that allowed us to analyze those data spatially. With these data, we were able to calculate the actual number of invasive species per county. In addition, these data were used to predict possible points of invasive species introduction, the rate of spread for certain problematic species, routes of migration, and to isolate counties under threat of possible infestation.

\section{(359) Production of the Print-on-demand Publication Weeds of Guam}

James McConnell*, Mari Marutani, Robert Schlub, Lynn Rauler- son, Lauren Gutierrez, Gregoiro Perez

University of Guam, College of Natural and Applied Sciences, Mangilao, GU, 96923

This publication was produced with the goal of printing the booklet on demand. The photographs were from multiple sources: scanned film, digital photographs (camera), and digital photographs (flatbed scanner). Fifty-six plants were included. Each plant was allocated four half-letter-size pages (one double-sided letter). These four pages include text descriptions of the plants and about nine images to give the user information on habit, seed, fruit, inflorescence, flower, stem characteristics, leaf pattern, pest damage, and other unique characteristics. Magnified images were used as necessary. The original digital images were in either TIFF or RAW format. The final images were in either TIFF or PSD format. Images were edited in Adobe Photoshop and various plug-ins used to enhance the images to optimize color and information that could be obtained from the printed image.

\section{(360) Development of a Viticulture Website at Kentucky State University for Growers}

Sanjun $\mathrm{Gu}^{*}$, Kirk W. Pomper

Kentucky State University, Community Research Service, Frankfort, KY, 40601

Kentucky has a rich history in viticulture. The Kentucky Vineyard Society was founded in 1798 and Kentucky was the third largest grape and wine producer by 1860 . During Prohibition, however, vines were either uprooted or left unattended, and the grape industry essentially disappeared in Kentucky. Since 1990, the grape and wine industry has shown a resurgence; however, there are limited educational opportunities in viticulture in Kentucky. Kentucky State University (KSU) emphasizes the development of alternative high-value crops for sustainable agriculture production. In 2000, a viticulture program was initiated at KSU to develop cultivar, vine management, and pest and disease control recommendations. Aware of the fact that grape growers in Kentucky are mostly new to grape culture, KSU has developed a viticulture website (http://www.pawpaw.kysu.edu/viticulture/index. $\mathrm{htm})$ to disseminate viticulture information. The website provides information that includes setting up a new vineyard, managing a "mature" vineyard (Vitis, Kentucky weather and climate, site selection, cultivars, rootstocks, trellising, care of young vines, canopy management, irrigation and nutrition, pest, and disease management), grape growers' corner (questions and answers, buy and sale, resources), and selected links. A monthly viticulture calendar is also available. In the future, the site will be updated with research results in viticulture from KSU and other southeastern institutions, growers' feedback, and information on wine making. The viticulture website will aid in the promotion of the grape and wine industry in Kentucky and states with a similar climate, and benefit grape growers from this profitable and expanding market.

\section{(361) Public Domain Computer Programs for Quantifying Size and Shape in Horticultural Research}

Arthur Villordon*, Jason Franklin

LSU AgCenter, Sweetpotato Research Station, Chase, LA, 71324

Shape measurements in horticultural research have generally been expressed as ratios or indexes. Computer-based image analysis enables the objective quantification and statistical analysis of two-dimensional sample shape variability. In addition, the availability of public domain software facilitates the inexpensive but accurate quantification of object shape in horticultural research. We describe the procedures for measuring sample shape using the following publicly available software: Image J, ImageTool, and SHAPE. Using U.S. \#1 sweetpotato storage root samples from plots subjected to various weed control treatments, we detected significant differences in elongation, compactness, as well as shape attributes. We also measured size and shape variability from representative fruit, leaf, and floral organ samples. The results demonstrate that, where possible, measurement of two-dimensional samples can be undertaken inexpensively and accurately using public domain software applications. 


\section{Poster Session 22-Postharvest Quality: \\ Cross-commodity}

19 July 2005, 12:00-12:45 p.m. Poster Hall-Ballroom E/F

(38) Carbohydrate Content in Leaves of Three Poinsettia Cultivars (Euphorbia pulcherrima) Grown at Two Locations

Maria-Teresa Colinas-Leon*1, Iran Alia-Tejacal ${ }^{2}$

${ }^{1}$ Universidad Autonoma Chapingo, Department of Fitotecnia, Mexico-Texcoco, Chapingo, Edo, 56230, Mexico; ${ }^{2}$ Universidad Autonoma del Estado de Morelos, Facultad de Ciencias Agropecuarias, Domicilio Conocido, Cuernavaca, Morelos, 62210, Mexico

In Mexico, poinsettia plants are grown under very different and changing environments, thus influencing their metabolism and changing the sugar content that is important in leaf and bract longevity. In the present study, the content of total soluble and reducing sugars and starch was evaluated in leaves of three cultivars, 'Marmol', 'Supjibi', and V-17 'Angelika', in two contrasting environments: Cuautla, Morelos [24.6 ${ }^{\circ} \mathrm{C}, 74 \%$ relative humidity $(\mathrm{RH})$, lat. $\left.18^{\circ} 49^{\prime} \mathrm{N} ; 1300 \mathrm{msl}\right]$, and Texcoco, Mexico $\left(14.6{ }^{\circ} \mathrm{C}, 61.6 \% \mathrm{RH}\right.$, lat. $\left.19^{\circ} 31^{\prime} \mathrm{N} ; 2310 \mathrm{msl}\right)$. Plants were grown under greenhouse conditions in 6-inch pots; the substrate and cultural practices were similar in both locations. In Texcoco, plants were covered with black plastic for 12 hours at night to control growth and flowering initiation (15 Sept. to 12 Nov.). In Cuautla, this was not necessary. Leaf samples were taken 8 days after initial covering of plants in Texcoco ( 84 days after transplant) and 155 days after transplant, when plants were ready for sale. Total soluble sugars were reduced between 84 and 110 days after transplant in leaves of 'Supjibi' and ' $\mathrm{V}-17$ ' cultivars independently of the location, while changes in 'Marmol'were minimal between days 84 and 155. Significant statistical differences were found for leaf total soluble sugars between locations, being higher in Cuautla, Morelos. For reducing sugars, no differences were detected among cultivars and for the two locations.

\section{(39) Chlorine Dioxide Treatment Extends Longevity of Cut Gerbera Flowers}

Andrew J. Macnish*, Ria T. Leonard, Terril A. Nell

University of Florida, Environmental Horticulture, Gainesville, FL, 32611

The vase life of many cut flowers is often limited by bacterial occlusion of stem bases. In this study, we tested the efficacy of a novel antimicrobial agent, aqueous chlorine dioxide $\left(\mathrm{ClO}_{2}\right)$, to extend the longevity of cut Gerbera flowers by reducing the number of bacteria in vase water. Commercially mature and freshly cut Gerbera jamesonii 'Monarck' flowers were placed into clean vases containing deionized water and $0,2,5,10,20$, and $50 \mu \mathrm{L} \cdot \mathrm{L}^{-1} \mathrm{ClO}_{2}$. Stems were then maintained in solutions at $21 \pm 0.5^{\circ} \mathrm{C}$ and $42 \pm 11 \%$ relative humidity until the end of vase life. Inclusion of 2, 5, and $10 \mu \mathrm{L} \cdot \mathrm{L}^{-1} \mathrm{ClO}_{2}$ in vase water had beneficial effects on flower longevity. For instance, treatment with 5 and $10 \mu \mathrm{L} \cdot \mathrm{L}^{-1} \mathrm{ClO}_{2}$ extended flower longevity by 1.4 -fold or 3.7 days, as compared to control flowers $\left(0 \mu \mathrm{L} \cdot \mathrm{L}^{-1} \mathrm{ClO}_{2}\right)$. In contrast, exposure to the higher concentrations of 20 and $50 \mu \mathrm{L}^{-\mathrm{L}^{-1}} \mathrm{ClO}$, did not extend flower vase life. Relative to control flowers, treatment with $10 \mu \mathrm{L} \cdot \mathrm{L}^{-1}$ $\mathrm{ClO}_{2}$ delayed the onset of detectable bacterial colonization of vase solutions from day 3 to day 6 of vase life. However, this $\mathrm{ClO}_{2}$ treatment did not reduce the number of bacteria that subsequently accumulated in vase water as compared to control flowers. Treatment with $10 \mu \mathrm{L} \cdot \mathrm{L}^{-1}$ $\mathrm{ClO}_{2}$ also increased rates of solution uptake by stems and reduced the loss of flower fresh weight over time. These results highlight the potential use of $\mathrm{ClO}_{2}$ treatments to extend the postharvest longevity of Gerbera flowers.

\section{(40) A Procedure for Quantitation of Fatty Acid Precursors in Relation to Capsaicinoid Accumulation in Pepper Fruits}

Janakiraman Maruthavanan*, Niels Maness, Donna Chrz Oklahoma State University, Horticulture \& LA, Stillwater, OK, 74078

The pungency in hot peppers [Capsicum annuum (L.) var. annuum] is mostly due to two capsaicinoids, capsaicin (CAP) and dihydrocapsaicin
(DC), which are amide derivatives of vanillylamine and 8-methyl6-nonenoic acid (E) or 8-methyl-nonanoic acid (A), respectively. During our investigation of the mechanism of capsaicinoid-specific metabolism in pepper fruit, we have developed a method to extract, purify, and quantitate these fatty acids from the free fatty acid pool in placental tissue. Fresh placenta was ground using a mortar and pestle and extracted with diethyl ether. Fatty acids were methanolysed and fatty acid methyl esters were quantitated using GC with capric acid as internal standard. Capsaicinoids accumulated in the same placenta were extracted with $N, N$-dimethylformamide (DMF) and quantitated using HPLC. The lipid fraction had to be separated from capsaicinoids, since capsaicinoids yielded about $10 \%$ of their respective fatty acids during methanolysis. An aminopropyl column was used to separate capsaicinoids from free fatty acids. Extraction recovery for both fatty acids was greater than $70 \%$. This procedure is being used to quantitate fatty acid precursors for capsaicinoid biosynthesis in pepper placenta. We will demonstrate use of this procedure with pepper selections varying in $\mathrm{CAP} / \mathrm{DC}$ ratio to evaluate the effect of metabolic precursors on capsaicinoid metabolism.

\section{(41) Value-added Products from Agriculture: Sprouts from Canola and Lupin Seeds \\ Harbans Bhardwaj*, Anwar Hamama \\ ${ }^{1}$ Virginia State University, Agricultural Research Station, Petersburg, VA, 23806}

Sprouts from various seeds are considered healthy for human consumption. However, no information is available about sprouts made from canola (Brassica napus L.) and white lupin (Lupinus albus L.), two new potential alternate crops in the mid-Atlantic region of the United States. Canola sprouts, on an average, contained (g/100 g, dry weight basis) 38.9 oil, and $61.5,18.6,9.2,7.4,92.6,64.8$, and 27.8 percent of 18:1, 18:2, 18:3, total unsaturated, total saturated, MUFA, and PUFA fatty acids, respectively, in the oil. Corresponding values for white lupin sprouts were: $6.5,43.0,24.9,9.3,17.9,82.1,47.9$, and 34.2. Canola sprouts contained $26.9 \%$ protein, whereas white lupin sprouts contained $26.3 \%$ protein. Details of these experiments and further results would be presented.

\section{(42) Sun Exposures Impact the Postharvest Quality and Firmness of Harvested Bell Peppers}

Maria Dolores Muy-Rangel ${ }^{1}$, Marita Cantwell*2

${ }^{1}$ Centro de Investigaciones en Alimentacion y Desarrollo, A.C., Dept. Postharvest Technology, Carretera Culiacan-El Dorado, Sinaloa, 80129, Mexico; ${ }^{2}$ University of California, Dept. Plant Sciences, Davis, CA, 95616

Temperature management of fresh products begins with proper handling at harvest. Inadvertent abuses, such as lengthy delays to cool or exposure of harvested product to the sun, can detrimentally impact postharvest quality. We used mature-green bell peppers to determine the periods of sun exposure (midday during August in Davis, Calif.) necessary to affect quality attributes (visual appearance, gloss, weight loss, and firmness). Peppers were evaluated after cooling, storage at $7.5^{\circ} \mathrm{C}$ for 3 or 7 days, and storage plus 2 days at $20^{\circ} \mathrm{C}$. The impacts of sun exposure, although sometimes barely detectable after cooling, became more noticeable once the peppers were stored. The additional transfer period to $20{ }^{\circ} \mathrm{C}$ after storage further accentuated the impact of the exposure. Depending on the experiment, sun-exposed areas reached 45 to $55{ }^{\circ} \mathrm{C}$ within 1 hour. Peppers typically lost $0.4 \%$ to $0.5 \%$ and $1.0 \%$ to $1.3 \%$ weight during 1 - and 2 -hour exposures, respectively. Changes in gloss and firmness (whole fruit compression and pulp penetration) were preceded by changes in visual appearance. Exposure to the sun for 0.5 hour did not impact postharvest quality of peppers. Exposures from 1 to 1.5 hours usually resulted in changes apparent only after the storage period. Such exposures are problematic in commercial situations because these peppers are unlikely to be eliminated during sorting on the packingline. Exposures of 1.5 to 2 hours usually resulted in an immediate change in appearance (pitting, blistering, color change). 


\section{(43) Maturity Influences Lycopene Segregation during Filtration Processing of Red-fleshed Watermelons}

Ioannis P. Oikonomakos*1, Niels O. Maness ${ }^{1}$, Donna Chrz ${ }^{1}$, William McGlynn ${ }^{1}$, Penelope Perkins-Veazie ${ }^{2}$

${ }^{1}$ Oklahoma State University, Horticulture and Landscape Architecture, Stillwater, OK, 74075; ${ }^{2}$ USDA-ARS SCARL, South Central Agriculture Research Laboratory, Lane, OK, 74555-0159

Lycopene from ground watermelon flesh can be segregated between filtrate and filter cake by coarse filtration. Low speed centrifugation of the filtrate can further segregate filtrate lycopene between an easily recoverable precipitated high lycopene pellet and a serum. Lycopene in watermelon flesh increases steadily during maturation and remains constant, or slightly decreases in overripe melons. This study was conducted to document the effect of melon maturity on lycopene segregation during filtration/centrifugal processing. Flesh of three seedless watermelon cultivars was ground and filtered through two layers of Miracloth. Filter cakes were rinsed with water and filtrates were centrifuged at $3500 \mathrm{~g}$ to precipitate lycopene. Centrifugal recovery of lycopene from filtrates was about the same for undermature and mature melons ( $50 \%$ to $70 \%$ ), but was much lower for overripe melons (35\% to $45 \%)$. This decline in recoverable lycopene from overripe melons could be negated if ground flesh was heated to 60 or $85^{\circ} \mathrm{C}$ prior to filtration. Lycopene from preheated flesh segregated predominately into the filter cake for all three maturity groupings. The interaction between melon maturity and pre-filtration heating will be evaluated and integrated into a potential watermelon lycopene production system.

\section{(44) Postharvest Physiology and Quality of Pigeon Pea [Cajanus cajan (L.) Millsp.]}

\section{Annette Wszelaki*1, Karla Deza-Duran ${ }^{2}$, Carol Harper}

${ }^{1}$ University of Puerto Rico, Horticulture, Mayaguez, PR, 00681; ${ }^{2}$ University of Puerto Rico, Food Science and Technology; ${ }^{3}$ University of Puerto Rico, Agricultural Engineering

Pigeon pea is an important food crop for the Puerto Rican diet, as well as the economy. Pigeon pea ranks fourth in production among edible legumes in production worldwide. It can be consumed dried or as a vegetable (fresh, frozen, or canned). Canned, frozen, and dried peas are commonly used when fresh peas are no longer available. Due to the preferred flavor of fresh pigeon pea, it commands a higher market premium, selling for more than twice the price of the dried product. Although there is a great demand for this vegetable in Puerto Rico, virtually no research has been done on fresh pigeon pea postharvest physiology and its overall keeping quality. Baseline data on pigeon pea physiology, including respiration and ethylene production rates, soluble solids, titratable acidity, color reflectance, chlorophyll content, and responses to ethylene are presented here in order to establish the optimum storage temperature. Using this information, fresh pigeon pea consumption could increase locally, and exporting opportunities for shipping pigeon pea to alternative markets could be expanded.

\section{(45) Effect of the Sugar : Acid Background on Perception of Tomato Aroma}

\section{Elizabeth Baldwin*, Kevin Goodner, Karen Pritchett}

USDA/ARS, Citrus \& Subtropical Products Laboratory, Winter Haven, FL, 33881

Sugars (sucrose, glucose, fructose, or glucose/fructose in combination) were added to coarsely chopped, deodorized tomato puree, increasing the sugar level of the puree by $2 \%$ to $3 \%$. Sugars (equal amounts of glucose and fructose) along with citric acid were also added to another puree, at two different levels, to create a range of sugar : acid ratios (4.88-19.07). This second puree was then spiked with two different levels of aroma volatiles, reported to affect tomato flavor, in order to understand the influence of the sugar : acid background on tomato aroma and taste perception. The tomato puree was presented to a trained panel and was rated for intensity of aroma and taste descriptors on a $15-\mathrm{cm}$ unstructured line scale. For the puree spiked with sugars only, panelists detected differences for overall aroma, ripe aroma, overall taste, sweetness and sourness intensities $(P<0.15)$. Adding sweet sugars, like fructose and sucrose, resulted in decreased ratings for aroma descriptors, apparently detracting from panelists' perception of aroma. The sugar : acid ratio of the second tomato puree was found to correlate with perception of taste descriptors sweet $(+)$, sour $(-)$, bitter $(-)(P<0.05)$, and citrus $(-)(P<0.15)$ for most volatiles tested. Correlations were also found for the sugar : acid ratio with overall aftertaste (-) when the puree was spiked with furanol, trans-2-hexenal, geranylacetone, or acetaldehyde; fruity $(+)$ with $\beta$-ionone and linalool; and tropical $(+)$ with cis-3-hexenal and geranylacetone $(P<0.15)$. The study suggests that increasing taste factors, like sweetness, result in decreased perception of tomato aroma in general, and affect how aroma compounds influence sensory descriptors.

\section{(46) Foliar-applied Potassium: Effects on Muskmelon Quality, Sugar, Ascorbic Acid, and Beta-carotene}

Gene E. Lester*1, John L. Jifon ${ }^{2}$, Gordon Rogers ${ }^{3}$

${ }^{1}$ Agricultural Research Service, U.S. Department of Agriculture, Weslaco, TX, 78596; ${ }^{2}$ Texas A\&M University, Horticulture, Weslaco, TX, 78596; ${ }^{3}$ University of Sydney, Food and Natural Resources, John Woolly Building, Sydney, Australia

Muskmelon fruit [Cucumis melo L. (Retiulatus Goup)] sugar content is related to potassium $(\mathrm{K})$-mediated phloem loading and unloading of sucrose into the fruit. During fruit growth and maturation, soil fertility is often inadequate (due to poor root uptake) to satisfy the demand for $\mathrm{K}$. Potassium uptake also competes with the uptake of $\mathrm{Ca}$ and $\mathrm{Mg}$, two essential minerals needed for melon fruit membrane structure, function and postharvest shelf-life. Supplemental foliar-applied K could alleviate this problem especially during the critical fruit growth/maturation period. We conducted experiments to determine the effects of timing of supplemental foliar K applications on fruit quality and health attributes of orange-flesh muskmelon 'Cruiser'. Plants were grown in a greenhouse and fertilized with a regular soil-applied N-P-K fertilizer throughout the study. Entire plants, including the fruit were sprayed with a solution of a novel glycine amino acid-complexed potassium (Potassium Metalosate, $24 \% \mathrm{~K}$ ), diluted to $4.0 \mathrm{~mL} \cdot \mathrm{L}^{-1}, 3$ to $5 \mathrm{~d}$ after anthesis (fruit set) and up to 3 to $5 \mathrm{~d}$ prior to abscission (full-slip). Three sets of plants were either sprayed weekly, or bi-weekly or not sprayed (control). Fruit from plants receiving supplemental foliar K matured on average 2 days earlier, and had significantly higher fruit $K$ concentrations, soluble solids, total sugars, ascorbic acid (vitamin C), beta-carotene, and were firmer than fruit from control plants. In general, there were few differences in fruit quality aspects between bi-weekly or weekly treatments. The data demonstrate that fruit quality and marketability as well as some of the developmentally induced $\mathrm{K}$ deficiency effects can be alleviated through foliar nutrition.

Poster Session 23-Vegetable Crops: Cultivar Evaluation

\section{July 2005, 1:15-2:00 p.m. Poster Hall-Ballroom E/F}

\section{(187) Zucchini and Yellow Squash Variety Evaluation Results}

Michelle L. Infante-Casella*1, Mel Henninger ${ }^{2}$

${ }^{1}$ Rutgers Cooperative Extension, Agriculture and Resource Management Agents, Clayton, NJ, 08312; ${ }^{2}$ Rutgers The State University, Plant Biology and Plant Pathology, New Brunswick, NJ, 08901-8520

Zucchini and straightneck yellow squash are important crops for vegetable farmers. Variety choices change from year to year, based on breeding programs that try to find disease tolerance or resistance by developing new lines. Astudy was conducted at the Rutgers Agricultural Research and Extension Center in Bridgeton, N.J., to determine yield and quality of 14 zucchini, 6 yellow squash, and 5 specialty squash varieties. Squash were seeded on 17 May 2004, at 30 inches between holes into black plastic mulch on high raised beds. Rows were spaced 60 inches apart. Drip irrigation was used for supplying water and fertigation. Prefar4E at a rate of $5 \mathrm{qt} /$ acre applied on the soil surface just before laying plastic was used for preemergent weed control. Five days after planting, Sandea $75 \mathrm{WF}$ at a rate of $1 \mathrm{oz} /$ acre and Gramoxone Max $3 \mathrm{SC}$ at a rate of $1.5 \mathrm{pt} /$ acre were applied with a backpack sprayer between the rows for added weed control. Admire was applied in the seed hole at a rate of $24 \mathrm{oz} /$ acre after planting using a backpack sprayer 
for control of aphids and cucumber beetle. Harvests began on 22 June 2004, and were continued 3 times weekly for 5 weeks for a total of 15 harvests. Zucchini varieties 'Revenue', 'Cashflow', 'Justice III', 'Spineless Beauty', 'Senator', 'HMX-2724', and 'EXT 04629728' had statistically higher yields than did 'Radiant', 'Wildcat', 'Payroll', 'HMX-2723', 'Lynx', 'Tigress', and 'Independence II'. Varieties are listed in values from highest yielding to lowest yielding, respectively. All yellow squash varieties had statistically similar yield values. These included 'General Patton', 'Cougar', 'Sunray', 'XPT1832', 'Goldbar', 'Sunbar'. Specialty varieties evaluated included 'Zephyr', 'Starship', 'Magda', 'Flying Saucer', and 'Costata Romanesco'

\section{(188) Evaluation of Edamame Cultivars in Central Pennsylvania}

Elsa Sánchez*, Kathleen Kelley, Lynn Butler

${ }^{1}$ The Pennsylvania State University, Department of Horticulture, University Park, PA, 16802

Eight edamame [Glycine max (L.) Merrill] cultivars were evaluated in the field in 2002, 2003, and 2004 to determine their suitability for growing in central Pennsylvania. Each cultivar was direct seeded and data collected included plant populations (percentage of stand) and marketable yields. Plant populations ranged from less than $1 \%$ to $81 \%$ and, with one exception in 2002, were below $80 \%$. Eighty percent plant populations or higher are considered optimal. Based on sub-optimal plant populations, none of the edamame cultivars evaluated in the field were determined to be suitable for direct seeding in central Pennsylvania. The effect of temperature on seedling emergence, and therefore, plant populations was then studied. Four of the edamame cultivars used in the field trial were evaluated in growth chambers programmed with varying day/night temperature regimes. Seedling emergence varied by cultivar and was generally below $80 \%$ with two exceptions. When grown in a $21.1^{\circ} \mathrm{C}$ day $/ 15.6{ }^{\circ} \mathrm{C}$ night temperature regime, 'Butterbeans' and 'Early Hakucho' exceeded $80 \%$ seedling emergence. These methods could be used to produce transplants; however, the economic feasibility of doing so should first be evaluated. In the field trial, conclusions on marketable yields were unattainable because soybean plants are known to compensate in yield for plants missing in sub-optimal plant populations. Plant compensation and sub-optimal plant populations rendered yield comparisons between cultivars questionable. The issue of sub-optimal seedling emergence and plant population needs to be studied further before suitability of growing these edamame cultivars in central Pennsylvania can be determined.

\section{(189) Heirloom Tomato Cultivar Evaluations for the New Jersey Market}

Wesley Kline*1, Peter Nitzsche ${ }^{2}$

${ }^{1}$ Rutgers University, Agricultural and Resource Management Agents, Rutgers Coop. Research and Extension, Millville, NJ, 08332; ${ }^{2}$ Rutgers University, Agricultural and Resource Management Agents, Rutgers Coop. Research and Extension, Morristown, NJ, 07963

A 3-year study was established to evaluate a large number of heirloom tomato cultivars for horticultural characteristics and yield. The initial 2001 screening included 110 cultivars with fruit types from currant to beefsteak. The 110 cultivars were reduced to 12 ('Arkansas Traveler', 'Box Car Willie', 'Brandywine Red', 'Carmello', 'Cherokee Purple', 'Costoluto Genovese', 'Eva Purple Ball', 'Hawaiian Pineapple', 'Mortgage Lifter', 'Prudens Purple', 'Ramapo', and 'Santa Clara Canner') based on yield, consumer preference and fruit characteristics and evaluated in 2004. The cultivars were arranged in a complete-block design with plots of eight plants replicated four times. Fruits were harvested 10 times from 15 July to 16 Sept., graded into marketable and cull, counted, and weighed. Internal and external fruit characteristics were evaluated at the seventh harvest from 10 randomly selected marketable fruit from three replications. Days to harvest from transplanting ranged from 61 to 82 days. For the early harvest (1-4), 'Mortgage Lifter' (20.18 t·ha $\left.{ }^{-1}\right)$ and 'Cherokee Purple' (19.23 th $\left.\mathrm{ha}^{-1}\right)$ had significantly more marketable fruit than the other cultivars. By mid-season harvests (5-7), the cultivar Carmello (43.38 $\left.\mathrm{t} \cdot \mathrm{ha}^{-1}\right)$ yielded statistically more marketable fruit than all other cultivars. There were few differences among the cultivars for the late harvest (8-10) period. When all harvests were combined,
'Carmello' (76.59 t'ha' $\left.{ }^{-1}\right)$ had significantly higher yields than the other cultivars except 'Mortgage Lifter' (74.72 $\left.\mathrm{t} \cdot \mathrm{ha}^{-1}\right)$. External and internal fruit characteristics varied among the various cultivars. All 12 cultivars would be acceptable in different market segments.

\section{(190) Productive Behavior of Varieties with Different Planting Densities in Okra [Hibiscus esculentus (L.)] Cultivation with Controlled Irrigation}

Francisco Radillo Juarez*, Juan Manuel González Gonzalez, Marcelino Bazan Tene, J. Hyvan Castañeda Alvarez

Universidad de Colima, Facultad de Ciencias Biológicas y Agropecuarias, Tecomán, Colima, 28100, México

Vegetables are important in Mexican agriculture because of the exportation opportunities made available by the opening of the Free Trade Agreement. Okra represents a potentially profitable crop, and it is important to understand its behavior in a predetermined environment, and determine its optimal sowing density. The present work was realized to evaluate three genotypes and three densities of okra plants in the production and quality of fresh fruit. The work was realized in the winter-spring cycle in the dry tropic region, using a randomized block design with a bifactorial of nine treatments. During the cultivation cycle, the vegetative and productive variables did not present changes in phenology, and only registered differences in plant height (58.4 and $57.6 \mathrm{~cm}$., respectively) of PX 416543 and 'Green Best', with a distance between plants of $18 \mathrm{~cm}$. These results indicate that with increased densities of $41,600,50,000$, and 69,444 plants/ha, there were no differences in the number and weight of fresh fruit/plant. Nevertheless, with the production and support the quality of fresh fruit increased. We conclude that high densities of plants increase the total crop of fresh fruit per hectare without affecting quality. The variety PX 416543 presented the best vegetative and productive behavior.

\section{(191) Vegetative and Productive Components of Genotypes of Red Tomato (Lycopersicon esculentum Mill.) under Greenhouse Conditions}

Francisco Radillo Juarez*, Juan Manuel González Gonzalez, Marcelino Bazan Tene, Luis Fernando Velasco Garcia

${ }^{1}$ Universidad de Colima, Facultad de Ciencias Biológicas y Agropecuarias, Tecomán, Colima, 28100, México

In world production of vegetables, the red tomato contributes $47 \%$ of the total production and occupies second place in world consumption. The objective of this research was to evaluate 13 genotypes of red tomato with high technology for horticultural production in the greenhouse. This study was realized in "Zamora" greenhouses in Quesería-Montitlán, Colima, Mexico. The evaluated materials were: 'Sun', D-0289, D-2465, D-2467, D-2475, D-2503, D-2505, D-2512, D-2515, D-2534, D-2541, D-2552, D-7705, and, as control, the 'Roman' variety. The tallest height was that of 'Roman' plants, $2.46 \mathrm{~m}$, vs. the height of the first cluster of fruits in D-2575 with $51 \mathrm{~cm}$. With respect to largest number of fruits per cluster and total harvested, D-0289 stood out with four and 18 fruits per plant, respectively. In regard to fruit size, the genotypes D-0289 and D-2534 presented the largest equatorial and polar diameter, with 19.2 and $14.2 \mathrm{~cm}$, respectively. For fruit weight, the genotypes 'Sun' and D-0289 presented the largest weight with 160 and $151 \mathrm{~g}$, respectively. We conclude that agronomic management influences production under technical systems. For vegetative and productive desirable characteristics, the genotypes 'Roman', D-0289, and D-77055 were the more adaptable for production in the greenhouse.

\section{(192) Commercial Evaluation of Green Snap Bean Varieties in Northwest Mexico}

Raul Leonel Grijalva-Contreras*1, Rubén Macias-Duarte², Fabián Robles-Contreras ${ }^{3}$, Manuel de Jesus Valenzuela-Ruiz ${ }^{4}$

${ }^{1}$ INIFAP-Caborca, Protected Horticulture, Caborca, Sonora, 83600, México; ${ }^{2}$ INIFAPCaborca, Soli \& Horticultural; ${ }^{3}$ INIFAP-Caborca, Agroclimatology; ${ }^{4}$ INIFAP-Caborca, Viticulture

Production of green snap beans is a good alternative for Caborca, Sonora, Mexico. This vegetable can be harvested during the last week 
of November when market prices are good, and has good adaptation, and high yield and pod quality. The objective of this experiment was to evaluate 11 green snap bean varieties. This experiment was carried out on a commercial field, where seed was sown on 25 Aug. 2003. Density was $20 \mathrm{seeds} / \mathrm{m}\left(60 \mathrm{~kg} \cdot \mathrm{ha}^{-1}\right)$. In this trial, we used a drip-irrigation system on beds $2 \mathrm{~m}$ apart and two rows with $36 \mathrm{~cm}$ of separation per bed. The first harvest was 68 days after the sowing date and lasted for 20 days, with four cuttings during that time. The varieties with greater yield were 'Castaño', 'Festina', and 'Landmark' with 541, 494, and 463 boxes/ha ( $>30$ pounds/box), respectively. The varieties with low yield were 'Espada' and 'Leader' with only 52 and 75 boxes/ha, respectively. The control 'Savannah' yielded 235 boxes/ha. The pod quality distribution was $20 \%, 35 \%$, and $45 \%$ for first, second, and third classification, respectively. 'Savannah' and 'Festina' had the best pod color (dark green). None of the varieties evaluated had pest or disease problems.

\section{(193) Yield and Quality of Six Bell Pepper Varieties in Sonora, Mexico}

Rubén Macias-Duarte ${ }^{1}$, Raul Leonel Grijalva-Contreras*2, Fabián Robles-Contreras ${ }^{3}$, Manuel de Jesus Valenzuela-Ruiz ${ }^{1}$

${ }^{1}$ INIFAP-Caborca, Soli \& Horticultural, Caborca, Sonora, 83600, México; ${ }^{2}$ INIFAP-Caborca, Protected Horticulture; ${ }^{3}$ INIFAP-Caborca, Agroclimatology

Bbell pepper (Capsicum annum L.) production is an appropriate alternative for the northeastern Sonora, México (Magdalena River). Because of the fresh temperature conditions of this region, production is possible in spring and summer. However, it is necessary to have appropriate varieties with a high potential for quality and yield under these conditions. The objective of this research was to evaluate the yield and quality of six varieties of bell pepper. The evaluation was carried out at the INIFAP-CIRNO Experimental Station (Magdalena of Kino, Sonora) in Spring 2002 under field conditions. The evaluated varieties were: 'Baron', X3R Wisar, PS 236894, 'Bamoa', 'Admiral', and 'Navolato'. The date of seedling transplant was 29 Mar. in furrows with $1 \mathrm{~m}$ of separation and $0.33 \mathrm{~m}$ between plants under a drip-irrigation system. In the trials, we used a completely randomized design with four replications. The measured variables were yield and fruit weight. The harvest period was 26 June to 23 Aug. The results indicated that the highest yields were obtained from: 'Baron', X3R Wisard, and PS 236894 with $43.2,42.3$, and $38.8 \mathrm{t} \cdot \mathrm{ha}^{-1}$, respectively, and the lowest yields obtained were from 'Admiral' and 'Navolato', with 33.3 and $30.0 \mathrm{t} \cdot \mathrm{ha}^{-1}$, respectively. The highest fruit weights corresponded to PS 236894 and X3R Wisard with 145 and 140 g, respectively.

\section{(194) Productivity and Quality of 14 "Saladette"-type Tomato Varieties under Field Conditions}

Rubén Macias-Duarte ${ }^{1}$, Raul Leonel Grijalva-Contreras*1, Fabián Robles-Contreras ${ }^{1}$, Manuel de Jesus Valenzuela-Ruiz ${ }^{1}$

${ }^{1}$ INIFAP-Caborca, Soli \& Horticultural, Caborca, Sonora, 83600, México; ${ }^{2}$ INIFAP Caborca, Protected Horticulture; ${ }^{3}$ INIFAP-Caborca, Agroclimatology; ${ }^{4}$ INIFAP-Caborca, Viticulture

In the north of Sonora, Mexico, it is possible to obtain high yields and quality in "saladette"-type tomato production in two cycles, spring and summer. However, seed varieties adapted to the temperature conditions of these seasons that have a high potential for quality and yield are needed. The objective of this experiment was to evaluate 14 varieties of "saladette"-type tomato (indeterminate). The evaluation was carried out in the INIFAP-CIRNO Experimental Station (Magdalena of Kino, Sonora) in Spring-Summer 2002 under field conditions, in furrows 2 $\mathrm{m}$ apart and three plants per linear meter (15,150 plants/ha). The date of seedling transplant was 29 May under a drip-irritation system. In the trials, we used a completely randomized design with two replications. We measured the yield, fruit weight, and shape. The harvest period was from 20 Aug. to 30 Nov. The results indicated that the highest yields were obtained from SSC-1020, 'Brigade', 'Azteca', 'Purepecha', and 'Yaqui' with 77.7, 74.8, 73.3, 71.8, and 69.7 t ha $^{-1}$, respectively. The lowest yields corresponded to 'Rio Grande', 'Silvestre', and 'Fierce Rio' with 51.5, 50.4, and $36.9 \mathrm{t} \cdot \mathrm{ha}^{-1}$, respectively. The highest fruit weights were from 'Purepecha', SSC-1020, and 'Yaqui' with 109, 108, and 102 $\mathrm{g}$, respectively. The fruit shape was oval-square in all varieties.

\section{Poster Session 24-Herbs, Spices, and Medicinals 1}

\section{July 2005, 1:15-2:00 p.m. Poster Hall-Ballroom E/F}

(388) Media Type and Moisture Influence Growth and Development of Ginger (Zingiber officinalis) Propagules

Lurline Marsh*1, Corrie Cotton ${ }^{1}$, Elizabeth Philip ${ }^{1}$, Isoken Aighewi ${ }^{2}$

${ }^{1}$ University of Maryland Eastern Shore, Agriculture, Princess Anne, MD, $21853 ;{ }^{2}$ University of Maryland Eastern Shore, Natural Sciences

Ginger (Zingiber officinalis) is a spice crop with a variety of medicinal uses. Potentially, it may be suitable for ethnic production following necessary studies to determine optimum cultural conditions. The propagation of ginger from rhizomes was investigated using three growth media, three media moisture levels, and two types of propagules. The media were poultry compost amended with peat and perlite in a volume ratio of $2: 1: 1$, municipal yard waste compost, and the commercial mix Promix. The moisture levels of each medium were: no applied water, moderately watered (between wilting point and field capacity), and field capacity, which represented moisture tension levels of $>-1.5,-0.08$, and $-0.03 \mathrm{MPa}$, respectively. Growth from single-node rhizome propagules and large pieces of 5.6 to $7.6 \mathrm{~cm}$ long with one or more nodes was determined over 90 days. The large propagules and the field capacity moisture regime produced the tallest shoots, and largest number of shoots and leaves per propagule, as well as the highest percentages of secondary rhizomes, root, and shoots per propagule. The yard waste and Promix were superior to poultry compost in the development of the propagules for all the traits measured. The large propagules produced earlier shoot emergence at field capacity than at the moderate moisture levels. Single-node propagules generally failed to emerge without applied moisture or when in poultry compost.

\section{(389) Enhanced Growth in Acclimatization of In Vitro Plantlets of Wasabi japonica using Hydroponics}

Joo Hyun Lee, Yong-Beom Lee*, Kyu Sook Lee

University of Seoul, Environmental Horticulture, University of Seoul, Korea

Wasabi japonica plantlets were acclimatized in a hydroponic system to determine effective procedures. The plantlets were cultured on solid Murashige-Skoog medium with 3\% sucrose. Shoots that formed roots were transplanted into hydroponic systems: 1) acclimatization in ebb-and-flow (EBB) for subirrigation (medium: granulated rockwool and coir); and 2) acclimatization in deep flow technique (DFT). The plantlets were acclimatized for 5 weeks under two irradiance treatments, 50 and $300 \mathrm{mmol} \cdot \mathrm{m}^{-2} \cdot \mathrm{s}^{-1}$. Photosynthetic capacity in high $P P F$ was higher than that in low $P P F$ during acclimatization. Electron transport rate from PS II (ETR) and biomass production increased significantly with increased light availability. The fresh weight, dry weight, and leaf area of plantlets in high $P P F$ were higher than those in low $P P F$. In particular, the dry weight and ETR of the plantlets grown in high $P P F$ increased more than twice as much as those in low $P P F$. At $50 \mathrm{mmol} \cdot \mathrm{m}^{-2} \cdot \mathrm{s}^{-1} P P F$, growth indexes, such as number of leaves, leaf length, leaf width, leaf area, fresh weight, and dry weight, were higher in EBB (granulated rockwool) $>$ EBB (coir culture) $>$ DFT. At $300 \mathrm{mmol} \cdot \mathrm{m}^{-2} \cdot \mathrm{s}^{-1} P P F$, those indexes were higher in DFT $>$ EBB (granulated rockwool) $>$ EBB (coir). The Wasabi japonica plantlets acclimatized in a hydroponic system also had a superior performance when they were transferred to the field.

\section{(390) Chemotype Variation among Black Cohosh Populations}

Hussein Al-Amier, Khaled A. Nasr, Lorna Lück, Lyle E. Craker*

${ }^{1}$ University of Massachusetts, Medicinal Plant Program, Amherst, MA, 01003

Black cohosh [Actaea racemosa L.; syn. Cimicifuga racemosa (L.) Nutt.] is a medicinal plant native to America and the woodlands of eastern North America. The roots and rhizomes of black cohosh, used by Native Americans to ease childbirth and treat menstrual cramps, rheumatism, headaches, coughs, asthma, and snakebites, are currently popular as an herbal remedy in the United States and Europe for the 
relief of discomfort associated with menopause. To determine chemical variation among populations of this perennial plant, root samples from 33 locations within the natural range of the species, ranging from Massachusetts to South Carolina and west to Missouri and Tennessee, were collected and chemically analyzed by HPLC-PDA using a C-18 reversed phase column (Phenomenex) for separation of the chemical constituents. The constituents were identified by comparison with commercial standards, including actein, methyl-beta-arabinopyranoside, caffeic acid, cimicifugoside, cimicifugoside $\mathrm{H} 1$, cimiracemoside A, 26 deoxyactein, ferulic acid, isoferulic acid, kaempferol, formononetin, and others. Chemically, an extract of the root and rhizome is known to contain at least three major natural product groups: cycloartenal-type triterpenes, phenolics, and flavonoids. Chemical constituents, especially formononetin, varied among the populations.

\section{(391) Black Cohosh (Actaea racemosa L.) Propagation and Growth in Perlite Hydroponic Systems}

Hyung Jun Kim ${ }^{1}$, Chris Harlow², Mary Peet*2

${ }^{1}$ National Horticultural Research Institute, Div. Protected Cultivation, Imok-Dong 475, Gangan-Gu, Suwon, 440-706, Korea; ${ }^{2}$ North Carolina State University, Horticultural Science, Raleigh, NC, 27695-7609

Rhizomes of black cohosh (Actaea racemosa L.) grown in the deep woodland shade of eastern North America have been used historically as medicinals, but wild populations have declined because of collection pressure. The purpose of this study is to determine the potential for black cohosh production in perlite. Currently, cultivated plants represent just $3 \%$ of the total harvest. Perlite production should also result in clean, uniform plant material. Rhizomes were grown at 18 ${ }^{\circ} \mathrm{C}$ in controlled environment chambers in the North Carolina State University (NCSU) Phytotron in perlite for 42 days with fertigation 3 , 6 , or 12 times daily and $18.5,21.5$, or $24.5^{\circ} \mathrm{C}$ root zone temperatures adjusted using heating cables. Leaf areas of the 21.5 and $24.5^{\circ} \mathrm{C}$ root temperature treatments were greater than the $18.5^{\circ} \mathrm{C}$ treatment. Stem number and new root number was highest in the $21.5^{\circ} \mathrm{C}$ treatment. No effects of the fertigation treatments were significant. The second experiment was conducted 7 June-31 Oct. 2004 in a naturally lit temperature-controlled $\left(22 / 18^{\circ} \mathrm{C}\right)$ glass greenhouse in the NCSU Phytotron at nutrient solution EC levels of $0.7,1.1$, or $1.5 \mathrm{dS} \cdot \mathrm{m}^{-1}$ and shading levels of $0 \%, 50 \%$, and $75 \%$. Highest leaf area and increase in fresh weight of the rhizomes over the experimental period was in the $50 \%$ shading treatment, but no significant effects of EC treatments were observed. Rhizome fresh weight increased $310 \%$ in the $50 \%$ shade, compared to $193 \%$ and $196 \%$ in the $0 \%$ and $75 \%$ shading treatments, respectively. In conclusion, black cohosh appears to prefer some shading during summer and $21.5^{\circ} \mathrm{C}$ root temperatures. Low EC $\left(0.7 \mathrm{dS} \cdot \mathrm{m}^{-1}\right)$ and infrequent watering ( 3 times daily) did not appear to limit growth in this system, but these results should be confirmed in larger studies in commercial greenhouses.

\section{(392) Effect of Bovine Manure Application to Soil on the Development of Sabila Crops (Aloe vera barbadensis) in the Sonoran Desert}

Fabián Robles-Contreras ${ }^{1}$, Rubén Macias-Duarte ${ }^{2}$,

Raul Leonel Grijalva-Contreras*3,

Manuel de Jesus Valenzuela-Ruiz

${ }^{1}$ INIFAP-Caborca, Agroclimatology, Caborca, Sonora, 83600, México; ${ }^{2}$ INIFAP-Caborca, Soli \& Horticultural; ${ }^{3}$ INIFAP-Caborca, Protected Horticulture; ${ }^{4}$ INIFAP-Caborca, Viticulture

The sabila plant is considered a strategic crop for the arid and semi-arid lands of Mexico, because it can be a high water-efficient crop due to its low water requirements, and is currently developing satisfactorily on an experimental scale in the agricultural area of Caborca, Sonora, Mexico, in the Sonoran Desert. This agricultural zone is characterized by a sandy soil with little or no organic matter and limited water supplies. Research consisted of evaluating the effect of bovine manure (BM) application to soil on the yield and size of sabila leaves. A sabila planting was established in Summer 2002, with a density of 15,000 plants/ha. Two applications of BM $\left(9 \mathrm{t} \cdot \mathrm{ha}^{-1}\right)$ were made, one at planting time in Aug. 2002, and another one in Feb. 2003. BM was not applied to the control treatment. Although the harvest of leaves initiated in Dec. 2003 (plant formation), the first commercial harvest was made in Jan. 2005. We measured the yield and the average weight of leaves. The results indicated statistical differences $(0.05)$ and an increase in the yield of $12.2 \mathrm{t} \cdot \mathrm{ha}^{-1}$, which represents $26 \%$ more with the BM application with respect to the control, which produced $47.1 \mathrm{t} \cdot \mathrm{ha}^{-1}$. As far as the average weight of leaves, there were no statistical differences between the BM application (597 g) and the control (532 g), although in both cases, they met the standards demanded by companies that manufacture products with sabila.

\section{(393) Diversifying Into a New Market-Medicinal Herbs}

\section{Jeanine M. Davis*, Jacqulyn T. Greenfield}

${ }^{1}$ North Carolina State University, Horticultural Science, Mountain Horticultural Crops Research and Extension Center, Fletcher, NC, 28732; ${ }^{2}$ Gaia Herbs, Inc., Botanicals Division, Brevard, NC, 28712

Seventeen North Carolina farmers received $\$ 5000$ grants to grow medicinal herbs as part of a research study to determine the economic feasibility of producing herbs in different regions of the state, including producing the quality and quantity of medicinal herbs required by the industry at a price that is competitive in a global market. With the help of five buyers in the natural products industry, four medicinal herbs were selected to be grown: California poppy, dandelion, Echinacea purpurea, and valerian. The growers experimented with new crops, learned new production methods, and adapted existing methods and equipment to these crops. These growers were also introduced to new markets and made connections with buyers, statewide and nationally, in an industry that can be difficult to enter. Growers were responsible for keeping detailed records of production, harvest, and postharvest handling. To produce a marketable crop in 1 year, some of the growers started seedlings in their greenhouses, while others direct seeded into the field. With the natural products industry moving toward a nonchemically grown product, growers in this project had to produce their crop without pesticides. Weed pressures were the biggest challenge to most of the growers. Prior to harvest, bioactive constituents were tested on the dried raw material to see if levels met buyers' requirements. Other testing methods determined percentage of ash, moisture content, microbial limits, and heavy metal accumulation. For postharvest handling, tobacco farmers who had drying facilities experimented with different temperature regimes to produce a uniformed dried material. Buyers and growers were then introduced to each other to complete the sale of goods.

\section{(394) Antimutagenicity, Antioxidant Activity, and Polyphenolic Contents of Bitter Melon Varieties (Momordica charantia L.)}

\section{Shahidul Islam*1, M. Jalaluddin ${ }^{1}$, Navam Hettiarachchy ${ }^{2}$}

${ }^{1}$ University of Arkansas, Agriculture(Plant Physiology \& Nutrition), Pine Bluff,AR, 71601; ${ }^{2}$ University of Arkansas, Food Science, Fayetteville, AR 72701

Bitter melon (Momordica charantia L.), an annual vegetable of Cucurbitaceae family, is a vegetable with important nutritional and medicinal qualities. Four adaptable lines/varieties were tested in replicated field trials for productivity, and biochemical and medicinal characteristics at the University of Arkansas at Pine Bluff. The total phenolic contents of the oven-dried and freeze-dried tissues, and seeds, ranged from $5.39-7.75,6.72-8.02,6.40-8.90$, and $4.67-6.69 \mathrm{mg} \cdot \mathrm{g}^{-1}$ on a dry weight basis, respectively. The total phenolic content of bitter melon from India green (IG), India white (IW), China green (CG) and China white $(\mathrm{CW})$ varieties were 4.67-6.72, 6.03-8.02, 5.39-7.81, and $6.69-8.90 \mathrm{mg} \cdot \mathrm{g}^{-1}$ dry material, respectively. The main phenolic acids in bitter melon flesh were gallic acid, gentisic acid, catechin, chlorogenic acid, and epicatechin. Bitter melon seeds had the phenolic acids, gallic acid, catechin, and epicatechin. The antioxidant activities of methanolic extracts from the bitter melons varieties IG, IW, CG, and CW ranged from $79 \%$ to $85 \%, 79 \%$ to $83,80 \%$ to 85 , and $79 \%$ to $86 \%$ inhibition, respectively. The antioxidant activities of the seed ranged from $79 \%$ to $84 \%$ inhibition. Methanolic extracts of freeze-dried flesh and seed from var. IW and CG showed very high antimutagenic effects against benzo(a)pyrene with Salmonella TA98(92\% to 100\% inhibition) TA100 
(79\% to $86 \%$ inhibition), but lower antimutagenicity activities against sodium azide that ranged from $46 \%$ to $54 \%$ and $17 \%$ to $32 \%$ inhibition, respectively. The popular belief that bitter melon improves glucose tolerance in Type II diabetes and lowers blood cholesterol is being investigated. It has not been determined which alkaloids, polypeptides, or combination of chemicals found in bitter melon are responsible for the beneficial medicinal effect.

\section{(395) Greater Inoculation Rate Enhances Biological Efficiency and Returns of Shiitake Mushrooms}

Cathy M. Sabota*, Caula A. Beyl

Alabama A\&M University, Plant and Soil Science, Normal, AL, 35762

To determine if biological efficiency of shiitake mushrooms was affected by the density of spawn inoculation, white oak logs about 31 inches $(0.79 \mathrm{~m})$ long were cut from trees harvested 14 Apr. and inoculated 6 May 2003 with strain WR46 of Lentinula edodes using four rates of inoculation. The number of holes drilled and inoculated with spawn was determined by multiplying the weight of each $\log$ by $0.5,1,2$, or 3 . A 15 -pound $\log (6.8 \mathrm{~kg})$ inoculated at " 3 " times the weight would have 45 holes drilled and inoculated. Each rate of inoculation treatment was replicated three times with three subsamples per replication. After six harvests over a 21 -month period, the biological efficiency (BE) of the logs increased by $1.94 \%$ per additional hole per pound $(0.45 \mathrm{~kg})$. This increase in BE would result in $\$ 1.15$ in additional returns per log with a cost of only $\$ 0.15$ more per log due to increased spawn use, resulting in a net profit, excluding increased labor and wax costs, of $\$ 1.00$ per log.

\section{(396) Growth of American Mayapple Rhizome Segments Affected by Time of Transplant}

Kent Cushman*, Muhammad Maqbool

University of Florida, SWFREC, Immokalee, FL, 34142-9515

American mayapple (Podophyllum peltatum) is being investigated as a domestic, renewable, and alternative source of podophyllotoxin, a precursor compound used in the manufacture of several drugs. Indian mayapple ( $P$. emodi) is the current source of the compound. The objective of this study was to examine growth of transplanted rhizome segments of American mayapple at four transplant times during the year. Two-node rhizome segments were carefully dug with roots intact from naturally occurring wild populations near Holly Springs, Miss. Segments were dug in Oct. 2002, Dec. 2002, Feb. 2003, or June 2003. Within 1 day of each harvest, segments were transplanted into 1-gal pots containing a mixture of sandy soil and a finely ground pine bark mulch. Pots were then set in a raised bed, such that the soil surface within the pots was even with that of the plant bed. Pots and plant bed then received a 3-inch layer of pine bark mulch. Rhizome segments were harvested from pots four times during the year following the date of transplant. Rhizome and roots were separated according to new or old growth and then dried. Rhizome segments transplanted during October and December increased about $36 \%$ in dry mass during the 1 -year period after transplant. This was significantly greater than an increase of $12 \%$ for segments transplanted during June. Segments transplanted during February performed intermediately, increasing by $22 \%$. Our results show that rhizome segments of American mayapple performed better when transplanted during fall and winter compared to those transplanted during summer. Segments transplanted during spring performed intermediately.

\section{(397) Atypical Disease Response to Hop Powdery Mildew} Jodi M. Smith*1, Kim E. Hummer ${ }^{2}$, Walt Mahaffee ${ }^{3}$

${ }^{1}$ Oregon State University, Horticulture, Agricultural Life Science Building, Corvallis, OR, 97331; ${ }^{2}$ USDAARS, National Clonal Germplasm Repository, Corvallis, OR, 97333-2521; ${ }^{3}$ USDA ARS, HCRL, Corvallis, OR, 97330

Open-pollinated hop seeds (Humulus lupulus var. lupuloides E. Small, H.l. var. pubescens E. Small, H.l. var. neomexicanus Nelson and Cockerell, and H.l. var. lupulus L.) were collected from the United States, Canada, and Kazakhstan and screened for resistance to hop powdery mildew (Podosphaera macularis Braun \& Takamatus). A total of 2108 seedlings were repeatedly inoculated with high levels of $P$. macularis. Under greenhouse conditions, most seedlings exhibited a compatible disease response typical of susceptible hosts with sporulating colonies covering both leaf surfaces. Three genotypes from hop seed native to Emba, Kazakhstan, remained uninfected in greenhouse assays. Further experimentation of those genotypes in growth chambers at $18^{\circ} \mathrm{C}$ revealed that they demonstrated an atypical disease response. Six days after inoculation, necrotic lesions on the adaxial leaf surfaces were visually apparent. Microscopic examination showed areas of collapsed epidermal cells, collapsed hyphae, and golden-brown discolorations extending out from the center of the infection. These symptoms contrasted those of a hypersensitive response in which fungal growth is restricted by the collapse of epidermal cells in advance of the fungus. The infection frequency of Kazakhstani genotypes was intermediate compared to H.l. cultivars Symphony (susceptible) and Nugget (resistant) after exposure to three preinoculation temperature regimes. These genotypes could represent a new source of polygenic resistance to hop powdery mildew, and could broaden hop germplasm available to global breeding programs.

\section{Poster Session 25-Stress Physiology}

19 July 2005, 1:15-2:00 p.m. Poster Hall-Ballroom E/F

\section{(445) Responses of Several Herbaceous Perennials and Groundcovers to Salinity}

Genhua Niu*, Denise S. Rodriguez

Texas A\&M University, El Paso, TX, 799277

In order to use reclaimed water to irrigate landscape plants and minimize damage and loss, salinity tolerance of commonly used landscape plants needs to be identified and characterized. Eight herbaceous perennials and groundcovers were obtained from a nursery, transplanted to $2.6-\mathrm{L}$ plastic containers, and grown in the greenhouse for 2 weeks before salinity treatments $\left(1.0,3.2,6.4\right.$, and $\left.12 \mathrm{dS} \cdot \mathrm{m}^{-1}\right)$ were initiated. Plants were irrigated with measured amounts of saline solutions to obtain a $30 \%$ leaching when $\approx 50 \%$ water was depleted. After 12 weeks, half of the plants in each treatment were destructively harvested and dry weights of shoots and roots were taken. Three Penstemon species (pseudospectabilis, eatoni, and strictus) and Lavandula angustifolia at 6.4 and $12 \mathrm{dS} \cdot \mathrm{m}^{-1}$ and most of them at $3.2 \mathrm{dS} / \mathrm{m}$ did not survive. Shoot dry weight of Delosperma cooperi decreased by $25 \%$ at $12 \mathrm{dS} \cdot \mathrm{m}^{-1}$, but there were no significant differences among the rest of the treatments. All plants of Teucrium chamaedrys survived, but growth was reduced significantly with lower visual scores as salinity of irrigation water increased. Although growth was reduced in Gazania rigens as salinity increased, no other signs of stress were observed. Ceratostigma plumbaginoides had less growth at $3.2 \mathrm{dS} \cdot \mathrm{m}^{-1}$, and older leaves showed reddish pigmentation at $6.4 \mathrm{dS} \cdot \mathrm{m}^{-1}$, whereas those at $12 \mathrm{dS} \cdot \mathrm{m}^{-1} \mathrm{did}$ not survive. Among the tested species, D. cooperi and G. rigens indicated a high tolerance to salinity; T. chamaedrys and C. plumbaginoides were moderately tolerant; and the rest were salt sensitive.

\section{(446) Salinity Tolerance of Eight Ornamental Herbaceous Perennials}

Nickolee Zollinger*1, Teresa Cerny-Koenig ${ }^{2}$, Roger Kjelgren ${ }^{1}$, Rich Koenig $^{3}$, Kelly Kopp ${ }^{1}$

${ }^{1}$ Utah State University, Plants, Soils, \& Biometeorology, Logan, UT; ${ }^{2}$ Washington State University, Plants, Soils, \& Biometeorology; ${ }^{3}$ Washington State University, Agronomy, Pullman

Although salinity is becoming an increasing concern for landscape plants in many areas of the West, few studies have been carried out to evaluate salinity responses of ornamental plants, especially herbaceous perennials. We investigated salinity tolerance of four traditionally grown and four Intermountain West native ornamental herbaceous perennials. Penstemon $\times$ mexicali 'Red Rocks', Leucanthemum $\times$ superbum 'Alaska', Echinacea purpurea, Lavandula angustifolia, Geranium viscosissimum, Eriogonum jamesii, Penstemon palmeri, and Mirabilis multiflora were irrigated with water containing a mixture of $2 \mathrm{CaCl}_{2}: 1 \mathrm{NaCl}$ at salinity levels of 0.33 (tap water control), 2.2, 5.4, and $8.3 \mathrm{dS} \cdot \mathrm{m}^{-1}$ for 8 weeks. Growth, visual quality, and gas exchange were assessed. Mirabilis multiflora and L. xsuperbum 'Alaska' showed high salt tolerance based 
on visual quality. No noticeable leaf necrosis was observed for either species at any salinity level. However, over the 8 -week period, growth rates for $L$. superbum were reduced by $35 \%, 58 \%$, and $72 \%$ compared to the control for the $2.2,5.4$, and $8.3 \mathrm{dS} \cdot \mathrm{m}^{-1}$ salinity levels, respectively. The decrease in growth did not reduce visual quality. Growth rates for M. multiflora were slightly higher than the control for the 2.2 and 5.4 $\mathrm{dS} \cdot \mathrm{m}^{-1}$ salinity levels and dropped about $20 \%$ at the highest salinity level. Echinacea purpurea showed the lowest tolerance to salinity, as evidenced by substantial margin burn at all salinity levels as well as high mortality; all plants in the highest salinity treatment died.

(447) Response of Two Salt-stressed Cultivars of Sweetpotato to Changes in Calcium Levels under In Vitro Conditions

Devi Prasad V. Potluri*, Nkechiyere Nwami

Chicago State University, Biological Sciences, Chicago, IL, 60628

Two cultivars of sweetpotato, 'Commensal' and 'Salyboro', were subjected to salt stress using axillary bud cultures. The salt levels ranged from 0 to $10 \mathrm{~g} \cdot \mathrm{L}^{-1}$. After the initial experiments, levels of calcium in the medium were changed from $3 \mathrm{~mm}$ in the MS medium to $1.5,6$, and $12 \mathrm{~mm}$. After 10 weeks of growth, plantlet shoot height, dry weight, number of nodes, levels of proline, soluble carbohydrate, and protein were measured. 'Commensal' was tolerant to salt levels up to $4 \mathrm{~g} \cdot \mathrm{L}^{-1}$, but 'Salyboro' was sensitive to concentrations of salt even at lower concentrations as evidenced by the growth and dry weight. Proline accumulation was higher in the shoot than in the root. The protein : carbohydrate ratios did not change much in 'Commensal', but levels of carbohydrates increased in 'Salyboro'. Reduction in calcium levels had a synergistic affect on salt-stressed cultivars. Enhanced levels of calcium reduced the inhibitory affects of salt stress. This was more pronounced in 'Salyboro', which was susceptible. Proline levels were higher in plants subjected to salt stress and higher levels of calcium than controls, but lower than the plants subjected to salt stress. These and other metabolic changes suggest that calcium can reduce the adverse affects of salt stress in these two sweetpotato cultivars.

(448) Arbuscular Mycorrhizal Fungi Enhance Tolerance of Rosa multiflora cv. Burr to Bicarbonate in Irrigation Water

Andrew D. Cartmill*, Fred T. Davies, Jr., Alejandro Alarcon, Luis A. Valdez-Aguilar

Texas A\&M University, Horticultural Sciences, Dept. Horticultural Sciences, College Station, TX, 77843-2133

Sustainable horticultural production will increasingly have to rely on economically feasible and environmentally sound solutions to problems associated with high levels of bicarbonate $\left(\mathrm{HCO}_{3}^{-}\right)$and associated high $\mathrm{pH}$ in irrigation water. The ability of arbuscular mycorrhizal fungi(AMF; Glomus ZAC-19) to enhance plant tolerance to $\mathrm{HCO}_{3}{ }^{-}$was tested on the growth, physiology and nutrient uptake of Rosa multiflora Thunb. ex J. Murr. cv. Burr (rose). Arbuscular mycorrhizal colonized and noninoculated (non-AMF) plants were treated with $0,2.5,5$, and $10 \mathrm{~mm}$ $\mathrm{HCO}_{3}^{-}$. Increasing $\mathrm{HCO}_{3}^{-}$concentration and associated high $\mathrm{pH}$ and electrical conductivity (EC) reduced plant growth, leaf elemental uptake and acid phosphatase activity (ACP), while increasing alkaline phosphatase activity (ALP). Inoculation with AMF enhanced plant tolerance to $\mathrm{HCO}_{3}{ }^{-}$as indicated by greater plant growth, leaf elemental uptake (N, P, K, Ca, Fe, Zn, Al, Bo), leaf chlorophyll content, higher mycorrhizal inoculation effect (MIE), lower root iron reductase activity, and generally lower wall-bound $\mathrm{ACP}$ (at $2.5 \mathrm{mM} \mathrm{HCO}_{3}^{-}$), and higher soluble $\mathrm{ALP}$ (at $10 \mathrm{~mm} \mathrm{HCO}_{3}^{-}$). While AMF colonization (arbuscules, vesicles, and hyphae formation) was reduced by increasing $\mathrm{HCO}_{3}{ }^{-}$concentration, colonization still occurred at high $\mathrm{HCO}_{3}^{-}$. At $2.5 \mathrm{~mm} \mathrm{HCO}_{3}^{-}$, AMF plant growth was comparable to plants at $0 \mathrm{mM}^{-} \mathrm{HCO}_{3}$, further indicating the beneficial effect of AMF for alleviation of $\mathrm{HCO}_{3}{ }^{-}$stress.

\section{(449) Influence of Irrigation Frequency on Establishment and Growth of Ilex cornuta 'Burfordii Nana' and Viburnum odoratissimum in Landscapes}

Sloane M. Scheiber ${ }^{1}$, Maria Paz*2, Edward F. Gilman², Kimberly A. Moore ${ }^{3}$, Sudeep Vyapari ${ }^{4}$, Richard C. Beeson, Jr. ${ }^{1}$

${ }^{1}$ University of Florida, Environmental Horticulture, Apopka, FL, 32703; ${ }^{2}$ University of
Florida, Environmental Horticulture, Gainesville, FL, 32611; ${ }^{3}$ University of Florida, Environmental Horticulture, Ft. Lauderdale, FL, 33314; ${ }^{4}$ University of Florida, Environmental Horticulture, Plant City, FL, 33566

Landscape water consumption has become a prime target for water conservation and regulation. Imposing water restrictions during landscape establishment is detrimental to plants that have not developed sufficient root systems to compensate for transpirational water losses. Generally, municipalities regulate irrigation frequency but not application rate. Application frequency affects establishment rates of shade trees, but the effects on shrub establishment are not well documented. This study evaluated three irrigation frequencies during establishment of Ilex cornuta 'Burfordii Nana' and Viburnum odoratissimum in a landscape. To simulate maximum stress, both species were transplanted into field plots in an open-sided, clear polyethylene covered shelter. Each species was irrigated either every 2, 4, or 7 days, and received $9 \mathrm{~L}$ of water per plant per event. Predawn, midday, and dusk water potentials were recorded at 28-day intervals and cumulative stress intervals calculated. Water potentials were taken the day prior to irrigation (maximum stress day) and the day of irrigation (minimum stress). Growth indices were also recorded. As days after transplant (DAT) increased, significant declines in cumulative water stress of Ilex were found among treatments on the day of maximum stress. The 7-day treatment declined at a faster rate than the other treatments tested. No differences were found for Viburnum. No significant differences were found on the day of irrigation as DAT increased. Differences in canopy size were not significant among treatments for either species.

\section{(450) Drought Responses of Ornamental Herbaceous Perennials}

Nickolee Z ${ }^{* 1}$, Roger Kjelgren ${ }^{1}$, Teresa Cerny-Koenig ${ }^{2}$,

Rich Koenig $^{3}$, Kelly Kopp ${ }^{1}$

${ }^{1}$ Utah State University, Plants, Soils, and Biometeorology, Logan, UT, $84322 ;{ }^{2}$ Washington State University, Horticulture; ${ }^{3}$ Washington State University, Agronomy

We investigated drought responses of Echinacea purpurea, Gaillardia aristata, Lavandula angustifolia, Leucanthemum $\times$ superbum 'Alaska', Penstemon barbatus 'Rondo', and Penstemon $\times$ mexicali 'Red Rocks' established in a 10-gal pot-in-pot system in northern Utah. Plants were irrigated at frequencies of 1, 2, or 4 weeks between June and Sept. 2004. Osmotic potential, gas exchange, visual quality, leaf area, and dry biomass were assessed. In a confined root zone, $P$. barbatus showed the greatest tolerance to drought, avoiding desiccation by increasing root : shoot ratio and decreasing transpiration as water became more limiting. Plants maintained high visual quality throughout the study and experienced little wilt, burn, or dieback. However, P. barbatus above-ground biomass was reduced by $15 \%$ for the 2 -week treatment and by $40 \%$ for the 4 -week treatment. Alternatively, G. aristata and $L$. superbum displayed drought avoidance mechanisms, dying back when water was limiting and resprouting after they were watered. Aboveground biomass declined by $50 \%$ and $84 \%$ for G. aristata and $47 \%$ and $99 \%$ for L. superbum, respectively, for the 2- and 4-week treatments. Root mass was affected similarly for both species. However, transpiration remained high for all treatment levels. Leaf burn and reduction in above- and below-ground biomass were also evident for E. purpurea at the 2- and 4-week treatments, but results were not as pronounced as for G. aristata and L. superbum. Overall, P. barbatus exhibited the greatest drought tolerance while maintaining an acceptable appearance. G. aristata, contrary to expectations, did not exhibit drought tolerance with a confined rooting volume, suggesting that it avoids drought in landscapes by means of deep rooting.

(451) Acclimation to Long-term Water Deficit Stress in Four Birch Taxa (Betula L.): Water Relations and Gas Exchange Mengmeng Gu*1, Curt R. Rom ${ }^{1}$, James A. Robbins ${ }^{2}$

${ }^{1}$ University of Arkansas, Dept. of Horticulture, Fayetteville, AR, 72701; ${ }^{2}$ University of Arkansas, Cooperative Extension Service, Department of Horticulture, Little Rock, AR, 72203

Four birch taxa, Betula alleghaniensis, B. davurica, B. nigra 'Heritage', and $B$. papyrifera, were grown in a greenhouse and exposed to water deficit stress for 35 days. Daily water was withheld from the plants until the combined weight of each container and the plant was reduced to $40 \%$ of the control. Supplemental water was supplied to each container to 
maintain $40 \%$ of the initial combined weight. Predawn water potential, gas exchange, and abscised leaf area were measured daily during the first week and at 3-day intervals after the first week. Predawn water potential dropped to lowest value before the containers were rehydrated and remained low throughout the treatment period. $\mathrm{Net}_{\mathrm{CO}}$ assimilation (A), stomatal conductance $\left(g_{5}\right)$ and evapotranspiration ( $\mathrm{Et}$ ) of all taxa decreased significantly during the first week of water deficits. Changes in A and Et varied among taxa after the first week of water deficits. Water use efficiency (WUE $=\mathrm{A} / \mathrm{Et}$ ) of four birch taxa decreased to significant lower values than control in the first week that water was withheld, and then increased to significantly higher values than control. Gas exchange data were fit into 2- or 3-segmented linear model. The type and shape of the models, and the joint of each segment gave an indication of how the gas exchange responded to the long-term water deficit stress. At the end of the water deficit treatment, B. papyrifera had abscised most of its leaves and maintained a high A, while $B$. alleghaniensis maintained more leaves on the tree, but had a relatively low A.

\section{(452) Growth Responses of Salvia greggii and Dalea frutescens to Drought Stress}

\section{Genhua Niu*, Denise S. Rodriguez}

Texas A\&M University, E1 Paso, TX, 79927

Salvia greggii (salvia) and Dalea frutescens (dalea) are two popular shrubs. However, little information is available on their drought tolerance. The objectives of this study were to investigate the effect of various degrees of water stress on growth and to characterize the dynamics of water relations to root substrate water content for developing best irrigation management. Salvia and dalea plants in 12-L plastic containers were grown in a greenhouse and pruned to one node at the base of the soft shoots for salvia or at the same height for dalea prior to the start of the experiment. There were three irrigation regimens: plants were irrigated daily (control), or irrigation was withheld until moderate or severe water stress signs exhibited. After several weeks of intermittent cyclic dry-down irrigation regimens, total shoot number per container was reduced by $40 \%$ to $50 \%$ for salvia and $35 \%$ to $40 \%$ for dalea. Average shoot length was reduced by $35 \%$ to $45 \%$ for salvia and $50 \%$ to $65 \%$ for dalea in moderate and severe stressed treatments compared to the control. Drought stress resulted in less shoot elongation and fewer new shoots in both species. To examine the relationship between plant water status and substrate water content, a dry down test was performed on five well-watered plants by withholding irrigation until midday water potential dropped to below $-4 \mathrm{MPa}$. As substrate water contents in both species reached $8 \%$, the predawn water potentials did not recover from the midday water potential of the previous day, indicating there was no available water in the substrate for roots to take up. The drought tolerance of these two species needs further study using various growing media.

\section{(453) Effect of Drought Stress on Growth and Secondary Compound Production in Greenhouse-grown Guayule}

Maren E. Veatch-Blohm*, Dennis T. Ray

${ }^{1}$ University of Arizona, Plant Sciences, Tucson, AZ, 85721

As a native of the Chihuahuan desert, guayule (Parthenium argentatum Gray) has a history of dealing with low water availability. Agronomic studies have shown that increasing irrigation increases overall rubber yields, but decreases rubber concentration per plant. As water availability is an important factor in agricultural production, this study was conducted to examine how drought affects plant growth and secondary compound distribution throughout the plant. One-year-old guayule plants were subjected to water stress from June through August, in 2003 and 2004. The well-watered treatment was irrigated daily, and the drought-stressed plants were irrigated when the soil water potential reached $6(0.6)$ or 3 (0.3) bars (megapascals) in 2003 and 2004, respectively. Plant growth was monitored by measuring height, width, and stem diameter. Fresh weight of shoots and roots was recorded at harvest, and a subset of plants were defoliated and used to determine leaf weight and area. Resin and rubber were extracted from dried and ground plant samples. Growth, leaf weight, and leaf to stem ratio were decreased in the drought-stressed plants compared to the well-watered plants. Rubber concentration, but not resin concentration, was higher in the drought-stressed plants. There were no significant differences in resin and rubber concentration in the leaves and roots of the different treatments; however, they were both higher in the stems of the drought-stressed plants. In guayule, rubber is deposited mainly in the bark parenchyma of the stems. The drought-stressed plants had a greater contribution of stem biomass to overall biomass and a reduced stem diameter with higher bark to wood ratio, which could account for the higher rubber concentration in the drought-stressed plants.

\section{(454) Detecting Plant Stress by Chlorophyll Fluorescence}

Hussein Al-Amier ${ }^{1}$, Robert Lussier ${ }^{2}$, Ming Coler ${ }^{1}$, Margaret Stoltzman ${ }^{1}$, Lyle Craker*1

${ }^{1}$ University of Massachusetts, Plant and Soil Sciences, Amherst, MA, 01003; ${ }^{2}$ GrowTech, Inc., Waltham, MA, 02452

The stress level in a plant may be directly associated with the intensity of the Kautsky effect (the sudden increase in fluorescence emission by chlorophyll following a dark adaptation). The decrease in photosynthetic efficiency, linked with the rate of photochemistry of plants under stress, provides a definitive signature (graphical pattern) that can be quantified and monitored, even for plants that have no visible stress symptoms. Using a prototype GrowScanner ${ }^{\circledR}$, signature differences in plants under nitrogen and water stress, as compared with plants not under stress, could be detected and measured. Returning stressed plants to a nonstressed condition returned the stress signatures to that of control plants not under stress. Development of the technology may provide a relatively quick, presymptomatic methodology for detecting plant stress without sacrificing plant tissue.

\section{(455) Differential Patterns of Expression and Regulation of Two Dehydrin Genes from Peach (Prunus persica) Bark Tissues}

Michael Wisniewski*1, Carole Bassett ${ }^{1}$, Timothy Artlip ${ }^{1}$, Jenny Renaut ${ }^{2}$, Robert Farrell ${ }^{3}$

${ }^{1}$ AFRS, USDA-ARS, Kearneysville, WV, 25430; ${ }^{2}$ Gabriel Lippmann (Cellule de Recherche en Environnement et BiotechnologieS - CREBS), Centre de Recherche Public, av. de la Faiencerie, 162a, Luxembourg, L-1511, Luxembourg; ${ }^{3}$ Pennsylvania State University, Biology, York, PA, 17403

We have characterized the seasonal accumulation of transcripts and proteins in peach (Prunus persica), particularly a $60 \mathrm{kDa}$ dehydrin (PCA60; PpDhn1). Recently, we have isolated another dehydrin gene (PpDhn2). The present report compares the structural organization of the two dehydrin genes, their promoters, and the response of the genes to temperature, photoperiod, and water deficit. Trees were exposed for 3 or 5 weeks to either short day (SD) or long day (LD) photoperiods at either 25 or $5{ }^{\circ} \mathrm{C}$. Additional experiments exposed trees to a period of water deficit followed by recovery. Transcript abundance of both genes, as assessed by RT-PCR, was determined, in response to the different photoperiods and temperatures as well as a prolonged $\mathrm{SD} / 5^{\circ} \mathrm{C}$ regime, from monthly-collected field samples, and trees subjected to water deficit. Results indicated that water deficit increased transcript abundance of both genes, but their abundance differed dramatically in response to low temperature and seasonal cues. Surprisingly, neither gene exhibited a significant elevation in transcript abundance in response to SD conditions. The lack of response of $P p D h n 1$ to SD is problematical given the observation that transcript levels in field-collected samples begin to increase substantially in September, prior to the onset of cold temperatures. Analysis of the promoter regions and cis-acting elements suggest that ABAmay play an important role in seasonal expression, interacting with photoperiod in field conditions. Two CRT/DRE elements are present in the promoter region of $P p D h n 1$, but absent in the promoter of PpDhn2.

(456) Abiotic Stress Responses in Cucumber (Cucumis sativus L.) Plants Expressing the Arabidopsis thaliana Transcriptional Activators- $C B F 1$ and $C B F 3$

Mohamed Tawfik, Alejandra Ferenczi, Daniel Enter, Rebecca Grumet*

Michigan State University, Horticulture, Plant and Soil Sci. Bldg., East Lansing, MI, 48824 Abiotic stresses (e.g., salinity, drought, cold, oxidative stress) can be major factors limiting plant productivity worldwide. We sought to 
increase abiotic stress resistance in cucumber by expressing the $A$. thaliana transcription factors $C B F 1$ and $C B F 3$, which regulate genes responsible for enhanced dehydration-stress resistance in Arabidopsis. Our previous studies in the greenhouse and field demonstrated increased salinity tolerance in $C B F$-expressing cucumber lines. In the current studies, we tested response of $C B F$-cucumber plants to drought, chilling, and oxidative stresses. Transgenic cucumber plants subjected to drought stress in the greenhouse showed elevated levels of the stress-inducible compatible solute, proline, compared to the nontransgenic controls. Preliminary results also indicate greater photochemical efficiency in $C B F$-expressing plants under drought stress conditions compared to the nontransgenic controls. Under nonstressed conditions, there were no significant differences in growth between the transgenic and the nontransgenic cucumber plants; however, after a cycle of drought stress, $C B F$-cucumber lines had less growth reduction compared to the nontransgenic counterparts. The advantage in growth was less pronounced after a second cycle of drought. We also evaluated the transgenic cucumber plants under chilling conditions (i.e., low, nonfreezing temperatures within the 0 to $12^{\circ} \mathrm{C}$ range). Based on plant height and cotyledon and leaf damage measurements, transgenic cucumber seedlings did not show chilling tolerance compared to the wild-type control. The response of transgenic $C B F$-cucumber plants to oxidative stress using methyl viologen is also being evaluated.

\section{(457) An Approach-grafted, Split-rooted Apple System to Evaluate the Effects of Partial Rootzone Drying and Deficit Irrigation on Tree Water Relations}

\section{Todd C. Einhorn*1, Horst W. Caspari ${ }^{1}$, Steve Green², Greg Litus}

${ }^{1}$ Colorado State University, Department of Horticulture and Landscape Architecture, Fort Collins, CO, 80523; ${ }^{2}$ HortResearch, Environmental and Risk Management, Palmerston North, New Zealand

One-year-old 'Gala'/M7 apple trees were potted into 30-L containers and approach-grafted about $45 \mathrm{~cm}$ above the graft union in late Spring 2003. Trees were grown with both tops for the remainder of the 2003 season in a greenhouse. In Apr. 2004, one of the tops was removed. Trees were fully watered by an overhead irrigation system until July 2004, when trees were subjected to one of four irrigation regimes: control received $>100 \%$ of ETc applied evenly to the two pots; PRD 100 received $>100 \%$ ETc applied to one pot only; and two regimes received $50 \%$ ETc applied to either one (PRD50) or both pots (DI50). Both gravimetric (tripod) and volumetric (time-domain reflectometry) soil moisture measurements were taken daily prior to and after irrigations. In addition, heavy isotope $\mathrm{H}_{2} \mathrm{O}\left({ }^{18} \mathrm{O}\right)$ was applied to one of the two root compartments and analyzed in the leaves to further determine the validity of the model. Sap flow was monitored in six split-rooted trees using miniaturized heat-pulse probes inserted into the stem above the graft union and into each of the two root systems below the graft union. Under fully irrigated conditions, root sap flow was proportional to root trunk cross-sectional area, and was not a function of root system origin (i.e., roots of mother plant with original top remaining or roots of daughter plant with original top detached). Water uptake from a previously dried root zone was rapid when the irrigated side was switched, but much more gradual when the other side was maintained wet. Interactions between soil moisture and sap flow in relation to factors governing canopy demand will be presented.

\section{(458) pH Optima for Myrosinase Activity in Crude Extracts from Cruciferous Crops}

\section{Craig S. Charron, Carl E. Sams*}

The University of Tennessee, Department of Plant Sciences, Knoxville, TN, 37996-4561

There has been significant interest in the glucosinolate-myrosinase system in plants of the Brassicaceae due to accumulating evidence that some glucosinolate degradation products are anticarcinogenic and/or suppressive to plant pathogens. Because glucosinolate hydrolysis is catalyzed by endogenous myrosinase, characterization of myrosinase activity is important for elucidating the potential bioactivity of crop glucosinolates. We measured the specific activity in citrate-phosphate buffer extracts across the $\mathrm{pH}$ range 4.5-6.5 of two cultivars each of five Brassica groups grown during two fall and two spring seasons.
Specific activity in two kale cultivars was highly variable, but tended to have highest activity from $\mathrm{pH}$ 5.0-6.0. In both cauliflower cultivars from Fall 2000, Fall 2001, and Spring 2002, optimal $\mathrm{pH}$ was around $\mathrm{pH}$ 6.0. In Spring 2000, however, specific activity was highest at pH 5.0. Maximum specific activity in both cabbage cultivars occurred in the pH range 5.5-6.0 in Fall 2000, Fall 2001, and Spring 2002. In Spring 2000, specific activity in 'Red Acre' cabbage was uniform across the range $\mathrm{pH} 4.5-5.5$ and maximum specific activity was at $\mathrm{pH} 5.0$ for 'Early Round Dutch' cabbage. Both brussels sprouts cultivars had $\mathrm{pH}$ maxima around $\mathrm{pH}$ 5.5-6.0 and significantly lower activity at $\mathrm{pH} 4.5$. Specific activity in broccoli was much like that of cauliflower in that highest activity occurred around pH 5.5-6.0 in Fall 2000, Fall 2001, and Spring 2002, but in Spring 2000, maximum activity was at pH 5.0. These results indicate that in most cases, $\mathrm{pH}$ optima were in the range 5.5-6.0, but varied somewhat with season and genotype.

\section{Poster Session 26-Fruit Crop Physiology}

\section{July 2005, 1:15-2:00 p.m. Poster Hall-Ballroom E/F}

\section{(319) Mycorrhizal Symbiosis and Response of Sorghum} Plants to Combined Drought and Salt Stresses

\section{Robert Augé*1, Keunho Cho ${ }^{2}$, Jean Stutz ${ }^{3}$, Heather Toler ${ }^{1}$}

${ }^{1}$ University of Tennessee, Department of Plant Sciences, Knoxville, TN, 37996-4561; ${ }^{2}$ University of Florida, Plant Medicine Program, Gainesville, FL, 32611-0680; ${ }^{3}$ Arizona State University, Department of Plant Biology, Tempe, AZ, 85287-1601

Colonization of roots by arbuscular mycorrhizal (AM) fungi can increase host resistance to drought stress, although the effect is unpredictable. Since AM symbiosis also frequently increases host resistance to salt stress, and since drought and salt stress are often linked in drying soils, we speculated that the AM influence on plant drought response may be linked to AM influence on salt stress. We tested the hypothesis that AM-induced effects on drought responses would be more pronounced when plants of comparable size are exposed to drought in salinized soils. In two greenhouse experiments, several water relations characteristics were measured in sorghum plants colonized by Glomus intraradices, Gigaspora margarita, or a mixture of AM species during a sustained drought following exposure to salt treatments $(\mathrm{NaCl}$ stress, osmotic stress, or soil leaching). The presence of excess salt in soils widened the difference in drought responses between AM and non-AM plants in just two instances: days needed for plants to reach stomatal closure, and promotion of stomatal conductance. In other instances, the addition of salt tended to nullify an AM-induced change in drought response; e.g., an AM effect on the decline in leaf or soil water potential required to cause stomatal closure disappeared when soils were salinized. Our findings confirm that AM fungi can alter host response to drought but do not lend much support to the idea that AM-induced salt resistance might help explain why AM plants can be more resilient to drought stress than their non-AM counterparts.

\section{(320) Influence of Light Microclimate on the Growth, Yield, and Fruit Quality of Apple}

\section{Zimian Niu*1, Dapeng Zhang ${ }^{2}$, Jicheng Zhan ${ }^{2}$, Curt Rom}

${ }^{1}$ Horticulture, P.R. China; ${ }^{2}$ Pomology, Horticulture, P.R. China; ${ }^{3}$ University of Arkansas, Horticulture, Fayetteville, AR, 72701

Influence of photosynthetically active radiation $(P A R)$ microclimate in the canopy of four training systems [open-center with high trunk $(\mathrm{OH})$; open-center with middle trunk (OM); open-center with low trunk (OL); and a traditional round canopy (RC)] on the growth, yield and fruit quality of apple were studied in the Beijing area. The results showed that: 1) the growth and yield potential were affected by canopy light microclimate. The average leaf chlorophyll content from $\mathrm{OH}, \mathrm{OM}$ and OL systems was $12.3 \%$ to $18.1 \%$ greater than that from the RC system. Trees from OH, OM, and OL systems produced $84.2 \%$ to $89.7 \%$ of shoot forming flower clusters compared to only $47.3 \%$ to $50.9 \%$ of the $\mathrm{RC}$ shoots. Training system did not affect total yield of 8-year-old trees, but in 10-year-old trees the RC system had lower yields compared with open-center systems. 2) Fruit quality was also affected by canopy light microclimate. The average anthocyanin content in the skin of fruit from 
$\mathrm{OH}, \mathrm{OM}$, and $\mathrm{OL}$ systems was $35.9 \%$ to $46.1 \%$ higher than that from the RC system, but chlorophyll content from the OL system was higher than in the open-center systems. Meanwhile, the contents of TSS and esters in apple flesh from the open-center systems were significantly higher than that from the RC system. 3) When the relative value of PAR in canopy exceeded $33.8 \%$, the growth index of trees (chlorophyll : return-bloom ratio) exceeded $66.6 \%$ and the fruit quality index (TSS $\times$ anthocyanin) exceeded $94.7 \%$. When $P A R$ was less than $20.6 \%$, the growth index was under $37.2 \%$ and the fruit quality index was under $67.5 \%$. PAR value was significantly correlated with the growth and fruit quality index in the four training systems, and the total canopy volume of higher PAR (exceeding 33.8\%, relative value) from $\mathrm{OH}, \mathrm{OM}$, and OL systems was $37.1 \%$ to $45.0 \%$ greater than that from the RC system.

\section{(321) Rapid and Differential Rates of Root Browning in Apple Trees under Different Irrigation Treatments}

Katie Palanjian*1, Luis Valenzuela ${ }^{1}$, Denise Neilsen ${ }^{2}$, Gerry Neilsen², David Eissenstat

${ }^{1}$ Pennsylvania State University, Department of Horticulture, University Park, PA, 16802-4200; ${ }^{2}$ Agriculture Canada, PARC,Summerland, BC, V0H 1Z0, Canada

As roots change color from white to brown, their absorptivity for water and nutrients typically diminishes. The effects of irrigation on root pigmentation were studied during 2003 and 2004 in Summerland, British Columbia, using an experimental orchard of 'Golden Delicious' apple trees on M9 rootstocks. Root pigmentation was monitored weekly over the growing season using a minirhizotron camera inserted into clear plastic tubes in the root zone. Each tree had two emitters, one on either side of the bole and $\approx 30 \mathrm{~cm}$ from the trunk. Four irrigation treatments were tested: full irrigation with replenishing $100 \%$ of daily evapotranspiration (ET) on both sides of the tree (100\% both), $50 \%$ ET irrigation on both sides ( $50 \%$ both), irrigating alternating sides of the tree with $50 \%$ ET (50\% alternating) and one-sided irrigation at 50\% ET (50\% one-side). The $50 \%$ alternating irrigation treatment simulated the irrigation practice of partial root zone drying where irrigation was alternated about weekly from one side of the tree to the other. Root pigmentation was remarkably fast among these trees, with median days to browning ranging from 4 to 10 days among treatments. For $50 \%$ one-side trees, root pigmentation on the dry side of the tree was much faster than roots on the wet side ( 4 and 7 days, respectively; $P<0.007$ ). Otherwise, no additional significant effects of irrigation on pigmentation were detected.

\section{(322) The Effect of Plant Growth Regulators and Time of Plantings on Stem Cuttings of Peach cv. Shan-i-Punjab}

\section{Sushobitbir Singh Thind*1, Harmander Pal Singh ${ }^{2}$, Sukhdev Singh ${ }^{1}$}

${ }^{1}$ Khalsa College, Faculty of Agriculture, Amritsar, Punjab, 143001, India; ${ }^{2}$ University of Guelph, Department of Plant Agriculture, Guelph, Ontario, N1G 2W1, Canada

Peach [Prunus persica Batsch. (L.)] is a major fruit of northern India, which is commercially propagated through stem cuttings. There is a scarcity of information available on the effect of plant growth regulators (PGRs) and time of plantings on rooting of peach stem cuttings. Studies were conducted to learn the effects of various PGRs and planting times on stem cuttings of peach cv. Shan-i-Punjab at the fruit nursery of the Horticulture Department, Khalsa College, Amritsar, India, in 2001 and 2002. The study on stem cuttings, taken from the middle portion of the shoot, compared three PGRs: indolebutyric acid (IBA), indoleacetic acid (IAA), and naphthaleneacetic acid (NAA), each at concentrations of 50, 100 , and $200 \mathrm{mg} \cdot \mathrm{L}^{-1}$ and two planting dates (20 Dec. and $20 \mathrm{Jan}$.). Cuttings were treated for 24 hours before keeping under moist sand for 1 month for callusing. Callused cuttings were planted in the field. Measurements on sprouting percentage, survival percentage, plant height, shoot diameter, number of leaves per plant, leaf size, average root length, and root weight per cutting were recorded. The study showed that, overall, auxins had significant effect on the success and rooting character of peach plants over the control. The greatest sprouting and survival percentage, plant height, leaf area, and shoot diameter was exhibited by IBA followed by IAA and NAA. IBA at $100 \mathrm{ppm}$ proved to be the most suitable PGR for improving success along with other rooting and vegetative characters of the plant. The cuttings planted on 20 Dec. gave a higher percentage of success (55.32\%) over those planted on 20 Jan. (33.04 \%), during both years of study. The other plant characteristics, such as average root length, plant height, leaf area, and plant height, of cuttings planted on 20 Dec. also showed greater success during both years.

\section{(323) Alternate Approaches for Evaluating Horticultural Efficiency}

Timothy L. Righetti ${ }^{1}$, Carmo Vasconcelos ${ }^{1}$ David R. Sandrock*2, Samuel Ortega ${ }^{3}$, Yerko Moreno ${ }^{3}$

${ }^{1}$ Oregon State University, Horticulture, Department of Horticulture, Corvallis, OR, 97331; ${ }^{2}$ University of Florida, Environmental Horticulture, Gainesville, FL, 32611; ${ }^{3}$ University of Talca, Facultad de Ciencias Agrarias, Talca, 747-721, Chile

Four ratio-based efficiency expressions (yield/trunk cross-sectional area, yield/canopy area, yield/pruning weight, $\mathrm{CO}_{2}$ assimilation/leafarea) were evaluated. These expressions depend on the size of the denominator if the function describing the relationship between the denominator and the numerator has a non-zero intercept. When this occurs, it is difficult to determine if statistically different efficiency expressions reflect physiological differences or are caused by comparing expressions with different sized denominators. When denominators and numerators of efficiency expressions are plotted, the edge of the data cloud can often be statistically identified. The function describing the edge of the data cloud defines the maximum possible value (MPV) obtainable for a given value of the denominator. The percentage of MPV (\%MPV) is an alternate efficiency expression that is not influenced by differing trunk cross-sectional area, canopy area, pruning weight, or leaf area. The difference between MPV and observed performance can be used to define improvement potential (IP). These alternate assessments can supplement traditional efficiency expressions. It is also possible to determine if statistical differences in traditional efficiency expressions are caused by differences in potential, differences in a plant or leaf's ability to achieve its potential, or differences in the size of the efficiency expression denominators.

\section{(324) Irrigation Effects on Fine Root Dynamics in Peach (Prunus persica)}

Christina Wells*, Desmond Layne

Clemson University, Horticulture, Clemson, SC, 29634

We are using a minirhizotron camera system to observe fine root dynamics beneath irrigated and nonirrigated peach trees. Our long term goals are: 1) to relate the timing of fine root production to tree phenology, soil water content, and soil temperature; and 2) to determine how fine root architecture and demography differ between trees with and without supplemental irrigation. In early 2002, minirhizotrons were constructed and installed beneath each of 72 open-center, 4-year-old 'Redglobe' peach trees at the Musser Fruit Research Farm near Clemson University. Beginning in May 2002, videotaped images from each minirhizotron were collected at 2-week intervals; notes on tree phenology were also recorded biweekly. Videotapes were digitized in the lab, and information on root length, diameter, appearance and longevity was extracted from the images. Soil temperature and volumetric water content were measured in the orchard throughout the growing season. In the 2 years following minirhizotron installation, irrigated trees allocated a significantly greater percentage of their fine root length to the upper soil layers and exhibited less root branching than nonirrigated trees. Fine roots produced by irrigated trees lived significantly longer: irrigated trees had a median root life span of 165 days, while nonirrigated trees had a median root life span of only 115 days $(P<0.001$; proportional hazards regression). Fine roots from irrigated trees remained in the physiologically active "white" state for an average of 10 days longer than roots from nonirrigated trees $(P<0.001)$. Data from $2002-03$ indicate that the trees produce new root flushes at least three times during the year, with a significant flush occurring immediately after harvest.

\section{(325) Soil Solarization and Methyl Bromide Fumigation Alter Fine Root Dynamics at a Peach Replant Site}

Shann Tanner, Christina Wells*, Gregory Reighard

Clemson University, Horticulture, Clemson, SC, 29634

The effectiveness of soil solarization as an alternative to methyl bromide 
$(\mathrm{MBr})$ fumigation in replanted peach orchards was investigated at the Musser Fruit Research Farm near Clemson, S.C. A split plot experimental design was used, with soil treatment as the whole-plot factor and rootstock as the sub-plot factor. In Spring 2002, preexisting trees were removed from the study site, and six orchard rows were cultivated and subsoiled. In June, two rows were covered with clear polyethylene sheeting and solarized for the remainder of the summer. In November, two additional rows were treated with $\operatorname{MBr}\left(474.3 \mathrm{~kg} \cdot \mathrm{ha}^{-1}\right)$, while the two remaining control rows received no soil sterilization treatment. In Jan. 2003, 36 'Redglobe' peach trees budded on Guardian ${ }^{\mathrm{TM}}$ or Lovell rootstock were transplanted to the site, and one minirhizotron was installed beneath each tree. Minirhizotron observations were made every 14-21 days from Feb. through Oct. 2003, and stem caliper measurements were taken on four dates during this interval. Trees grew significantly larger in the $\mathrm{MBr}$ and solarized rows than in the control rows $(P<0.1$; Tukey's HSD), but there were no differences in stem caliper growth between $\mathrm{MBr}$ and solarization-treated trees. Reduced aboveground growth in control trees may have been related to greater carbon expenditure belowground: in the absence of soil sterilization, fine root median life spans were reduced by $27-28$ days $(P<0.0001$; proportional hazards regression) and rates of root production and mortality were significantly higher $(P<0.1$; repeated measures ANOVA). Solarization and $\mathrm{MBr}$ fumigation appeared to provide similar benefits in reducing root turnover and improving aboveground growth at this site.

\section{Poster Session 27-Genetics and Germplasm 2}

\section{July 2005, 1:15-2:00 PM Poster Hall-Ballroom E/F}

\section{(7) Molecular Phylogenetic Analysis of Genes of the Carotenoid Pathway in Cucurbita}

Marilyn Rivera-Hernández ${ }^{1}$, Linda Wessel-Beaver*1, José X. Chaparro ${ }^{2}$

${ }^{1}$ University of Puerto Rico, Mayaguez Campus, Agronomy and Soils, Mayaguez, PR, 00681-9030; ${ }^{2}$ USDA-ARS-HRL, Ft. Pierce, FL, 34942 (currently at the Univ. of Florida, Dept. of Horticulture, Gainesville, FL 32611)

Squash and pumpkins (Cucurbita sp.) are important contributors of beta-carotene to the diet. Consumers of tropical pumpkin and butternut squash (both C. moschata Duchesne) prefer a deep orange mesocarp color. Color intensity is related to carotene content. Among the five domesticated Cucurbita species, C. moschata and C. argyrosperma Huber have a close relationship. In crosses between these two species, fertile $\mathrm{F}_{1}$ plants can be easily obtained when using C. argyrosperma as the female parent. This research studied the relationship between and within $C$. moschata and $C$. argyrosperma by sequencing three genes in the carotenoid biosynthesis pathway and generating gene trees. Genotypes used in the study differed in flesh color from very pale yellow to dark orange. In some cases, haplotypes were associated with a particular mesocarp color. Further study of these types of associations may improve our understanding of color development in Cucurbita. The frequency of single nucleotide polymorphisms (SNPs) in the sequenced fragments was low. There were more SNPs and more heterozygotes among $C$. moschata accessions than among C. argyrosperma accessions. Haplotypes of the outgroups (C. ficifolia C.D. Bouché and C. maxima Duchesne) were always distinct from $C$. moschata and $C$. argyrosperma. These later species had both distinct haplotypes and shared haplotypes. Haplotypes shared among species tended to be maintained in the same branch of the phylogenetic tree, suggesting either gene flow between the species or a common ancestral gene. Both explanations suggest a close genetic and evolutionary relationship between $C$. moschata and $C$. argyrosperma.

\section{(8) Summary of Fertility Characteristics of the USDA Garlic Collection When Grown in Pullman, Washington}

Barbara C. Hellier*, Marie Pavelka

USDA-ARS, Western Regional Plant Introduction Station, Pullman, WA, 99164-6402

The USDA garlic (Allium sativum and Allium longicuspis) collection is maintained at the ARS, Western Regional Plant Introduction Station
(WRPIS) in Pullman, Wash. This collection comprises 269 accessions, of which 153 are hardneck (flower producing) types. The fertility characteristics of these accessions was evaluated in the field at Pullman, Wash. After the spathes opened, bulbils were removed from all the evaluated accessions to facilitate flower development. The umbel and flower characteristics taken were anther color, flower color, flower shape, stigma position, flowers per umbel, umbel diameter, umbel shape, umbel defects, bulbil size, bulbil color, ease of bulbil removal, spathe opening, pollen production, and pollen viability. Of the 153 accessions, 10 produced only partial scapes with bulbils midstalk and no seed production capability. Viable pollen was shed in 85 accessions with viability ranging from $8 \%$ to $85 \%$. Open-pollinated seed was generated by 19 of the Pullman, Wash., grown accessions. Seed production was low with yields from 6 to 91 seeds per accession.

\section{(9) Compositional Characterization of a Garlic Germplasm Collection}

Marita Cantwell*, Gyunghoon Hong, Ron Voss

University of California, Dept. Plant Sciences, Davis, CA, 95616

A USDA germplasm collection of garlic (Allium sativum) and related species (A. ophioscorodon, A. longicuspis) has been evaluated for horticultural characteristics and composition under California production conditions for several years. In 2004, 198 of the 217 accessions in the collection were evaluated. Bulbs were manually harvested late June to early July, cured about 3 weeks shaded at ambient temperatures, and the outer whorl of cloves manually peeled. Bulb and clove weights and percentage of dry matter were determined. Freeze-dried garlic powder was analyzed for alliin (precursor of flavor and health compounds) concentrations by HPLC. Thiosulfinates (mostly allicin, responsible for flavor and pungency) were determined by a spectrophotometric assay. Among the accessions evaluated in 2004, the percentage of dry matter ranged from $32.8 \%$ to $44.9 \%$. Alliin content varied from 8.9 to $29.7 \mathrm{mg} \cdot \mathrm{g}^{-1}$, and thiosulfinate concentrations ranged from 32.7 to 114.0 $\mu \mathrm{mol} \cdot \mathrm{g}^{-1}$. For comparison, the widely grown varieties California Early and California Late averaged $39.5 \%$ and $40.8 \%$ dry matter, 18.6 and $20.6 \mathrm{mg} \cdot \mathrm{g}^{-1}$ alliin, and 68.1 and $78.8 \mu \mathrm{m} \cdot \mathrm{g}^{-1}$ thiosulfinates.

\section{(10) Four Genes Controlling Watermelon Fruit and Seed Traits}

Gabriele Gusmini, Todd C. Wehner*

North Carolina State University, Horticultural Science, Raleigh, NC, 27695-7609

Watermelon [Citrullus lanatus (Thunb.) Matsum. \& Nakai] is a diverse crop, with much variability for fruit and seed traits. This study measured the inheritance of scarlet red flesh color, egusi seed type, yellow belly (ground spot) rind pattern, and intermittent stripes on the rind. Scarlet red is a dark red flesh color found in 'Dixielee' and 'Red-N-Sweet'. Egusi seed is an unusual mutant having a fleshy pericarp adherent to the seed coat found in PI 490383 and PI 560006. Yellow belly is found in 'Black Diamond, Yellow Belly'. Intermittent stripes are found in 'Navajo Sweet', which has narrow dark stripes that are irregular or nearly absent across the fruit. In order to study the inheritance of these traits, six generations, including parents, crosses, and backcrosses $(\mathrm{P}$, $\left.\mathrm{P}_{b}, \mathrm{~F}_{1}, \mathrm{~F}_{2}, \mathrm{BC}_{1} \mathrm{P}_{\mathrm{a}}, \mathrm{BC}_{1} \mathrm{P}_{\mathrm{b}}\right)$, were produced in each of seven crosses. Phenotypic data were recorded in the field, and analyzed with the Chi-square method for the segregation of Mendelian genes. Scarlet red color in 'Dixielee' was allelic to scarlet red color in 'Red-N-Sweet'. Four new genes were identified and named, in conformance with gene nomenclature rules for Cucurbitaceae: Scr for scarlet red, eg for egusi seed, $Y b$ for yellow belly, and ins for intermittent stripes. Thus, we have added four new genes to the 52 morphological and disease resistance genes already published.

\section{(11) Inheritance of Resistance to Zucchini Yellow Mosaic Virus-Florida Strain in Watermelon}

Nihat Guner ${ }^{1}$, Todd C. Wehner*2

${ }^{1}$ Sakata Seed, Plant Breeding, Fort Myers, FL, 33970-1118; ${ }^{2}$ North Carolina State University, Horticultural Science, Raleigh, NC, 27695-7609

Inheritance of resistance to zucchini yellow mosaic virus-Florida 
strain (ZYMV-FL) was studied in the resistant watermelon accession of PI 595203 (Citrullus lanatus var. lanatus), an egusi type originally collected in Nigeria. The $\mathrm{F}_{1}, \mathrm{~F}_{2}$, and $\mathrm{BC}_{1}$ generations derived from the cross 'Calhoun Gray' $\times$ PI 595203 and 'New Hampshire Midget' $\times$ PI 595203 were used to study the inheritance of resistance to ZYMV-FL. Seedlings were inoculated with a severe isolate of ZYMV-FL at the first true leaf stage and rated on a 0 to 9 scale, based on the severity of virus symptoms. A single recessive gene was found to control resistance, for which we propose the symbol zym-FL2. The gene probably was not allelic to the previously published gene, $z y m-F L$, for resistance to the Florida strain of ZYMV in the accession PI 482261, since PI 482261 was not resistant to the ZYMV-FL isolate used in our tests.

\section{(12) Detection of QTL for Three Individual Sugar Compositions in Muskmelon}

\section{S. Park*1, J. Sinclair ${ }^{1}$, K. Crosby ${ }^{1}$, K. Yoo*2, L. Pike ${ }^{2}$}

${ }^{1}$ Texas A\&M University, Texas Agricultural Research and Extension Center, Weslaco, TX, 78596; ${ }^{2}$ Texas A\&M University, Vegetable \& Fruit Improvement Center, College Station, TX, 77843

The ratio of individual sugar compositions is an important fruit quality trait in muskmelon. Our objective was to identify RAPD markers associated with QTL for percentage of each individual sugar (sucrose, glucose, and fructose) using bulked segregant analysis in an $\mathrm{F}_{2}$ population derived from the melon cross of 'TAM Dulce' (high sucrose percentage of total sugars) x TGR1551 (low sucrose percentage of total sugars). Continuous distributions for sucrose, glucose, and fructose percentages of total sugars were observed in the genetic population indicating quantitative inheritance for the traits. A significant positive correlation was observed between sucrose percentage and sucrose $(r=0.89)$ or soluble solids $(r=0.33)$, whereas a significant negative correlation was noted between sucrose percentage and glucose percentage $(r=-0.85)$ or fructose percentage $(r=-0.58)$. A total of 500 primers was used to screen between low and high DNA bulks for three individual sugar percentages. Ten RAPD markers, four amplified from 'TAM Dulce' and six amplified from TGR1551, were significantly associated with QTL for at least one individual sugar percentage. Of the 10 markers identified, six were consistently associated with two to three traits. The OAU13.1350 obtained from 'TAM Dulce' accounted for 13\% and $19 \%$ of the phenotypic variation for sucrose and glucose percentages, while OAW06.600 obtained from TGR1551 explained 17\% and 18\% of the variation for the two traits. The OAA09.350 and OAU05.600 markers accounted for $4 \%$ to $13 \%$ of the variation for three sugar percentages. These markers associated with QTL for three individual sugar compositions could be useful in melon breeding for improving the mature fruit quality.

\section{(13) Comparative Mapping of Early Blight Resistance QTLs and Candidate Resistance Genes in $\mathrm{F}_{2}, \mathrm{~F}_{3}, \mathrm{~F}_{4}$ and a RIL Population of Tomato}

Hamid Ashrafi*, Arun Sharma, David Niño-Liu, Liping Zhang, Majid Foolad

The Pennsylvania State University, Dept. of Horticulture, University Park, PA, 16802

Most cultivars of tomato (Lycopersicon esculentum) are susceptible to early blight (EB), a devastating fungal (Alternaria solani) disease of tomato in the northeast and eastern part of the U.S. The most economic and durable measure of disease control is by using genetic resistance. There is limited EB resistance within the cultivated tomato. However, genetic sources of resistance exist within the tomato-related wild species L. hirsutum and L. pimpinellifolium. Early blight resistance does not follow the gene-for-gene model of host-pathogen interaction. Mapping QTLs conferring horizontal resistance is an effective approach for studying complex resistance traits such as EB. We have developed $\mathrm{F}_{2}, \mathrm{~F}_{3}, \mathrm{~F}_{4}$, and an $\mathrm{F}_{2 \cdot 7}$ derived RIL population of a L. esculentum $\times L$. pimpinellifolium cross and evaluated them for $\mathrm{EB}$ resistance under field conditions. Genetic maps were constructed based on the $\mathrm{F}_{2}$ (including 256 RFLP, EST and RGA markers) as well as the RIL population (including over 220 RFLP and EST markers). In each of the $\mathrm{F}_{2}, \mathrm{~F}_{3}$, and $\mathrm{F}_{4}$ population, an average of seven QTLs were identified for resistance, which were highly consistent across populations. Mapping of EB resistance
QTLs in the RILs is underway. Co-localizations of QTLs with several ESTs and RGAs were observed, suggesting potential involvement of the latter markers with EB resistance. Furthermore, co-localizations were observed among QTLs, ESTs, and RGAs and several known tomato vertical disease resistance genes. Possible occurrence of such co-localization in the RIL population will be reported. It is speculated that candidate-gene approach is an effective way of identifying and mapping new $\mathrm{R}$ genes in tomato. This study may lead to the identification of genes underlying EB resistance in tomato.

\section{Poster Session 28-Ornamental/Landscape and Turf 1 \\ 19 July 2005, 1:15-2:00 p.m. Poster Hall-Ballroom E/F}

\section{(79) All-America Daylilies: Landscape Performance and Rust Observations}

Allen Owings*1, Gordon Holcomb ${ }^{2}$, Anthony Witcher ${ }^{1}$, Allen Broyles ${ }^{3}$, Edward Bush ${ }^{1}$

${ }^{1}$ LSU AgCenter, Horticulture, Baton Rouge, LA, 70803; ${ }^{2}$ LSU AgCenter, Plant Pathology and Crop Physiology, Baton Rouge, LA, 70803; ${ }^{3}$ LSU AgCenter, Burden Center, Baton Rouge, LA, 70809;

All-American daylily cultivars named from 1994-2004 were evaluated for landscape performance and daylily rust (Puccinia hemerocallidis) susceptibility during 2003 and 2004. Cultivars included 'Black-Eyed Stella', 'Bitsy, 'Leebea Orange Crush', 'Plum Perfect', 'Judith', 'Starstruck', 'Frankly Scarlet', 'Lullaby Baby', 'Lady Lucille', and 'Chorus Line'. Bareroot plants were planted in raised beds composed of an Olivier silt loam soil in full sun and received irrigation as needed to prevent stress. Visual quality ratings were made weekly from 19Apr.-25 Oct. 2003 and 15 Mar.-20 Sept. 2004. Visual quality ratings included growth habit, based on compactness, foliage color, uniformity, and overall aesthetics, and flowering, based on longevity and visual appeal. Other flower observations were made in regard to time in bud and peak blooming periods over the same time frames. Flowering observations indicated that 'Black Eyed Stella' and 'Bitsy' were the only cultivars showing reliable repeat bloom potential. Among the other cultivars, 'Judith' was the earliest to bud and bloom, but also had a blooming period of only 2-3 weeks compared to 4-5 weeks of bloom for other cultivars. Daylily rust ratings were taken in Sept. and Nov. 2003 and in Aug. and Nov. 2004. Rust was most severe on 'Judith', 'Leebea Orange Crush', 'Starstruck', and 'Lady Lucille'. 'Judith' and 'Leebea Orange Crush' showed rust symptoms earlier than other cultivars. 'Plum Perfect', 'Frankly Scarlet', 'Bitsy', 'Black Eyed Stella', and 'Lullaby Baby' were least susceptible to daylily rust.

\section{(80) Calculating Base Temperature and Leaf Appearance Rate for Sweet Viburnum}

Gisele Schoene ${ }^{1}$, Thomas Yeager*1, Joe Ritchie

${ }^{1}$ University of Florida, Environmental Horticulture, Gainesville, FL 32611; ${ }^{2}$ University of Florida, Dept. of Agricultural and Biological Engineering, Gainesville, FL 32611

In crop models, it is important to determine the leaf area, because the amount of light interception by leaves influences two very important processes in the plant: photosynthesis and evaporation. Leaf area is dependent on leaf appearance and expansion rates. Leaf appearance rate is driven mainly by temperature. Although the influence of temperature on leaf area development is well known for several agronomic crops, there is no information for woody ornamentals. An experiment was conducted to study the relationship between temperature and leaf appearance of container-grown sweet viburnum. Plants were grown in field conditions in Gainesville, Fla., during two growing periods (Apr. to Aug. 2004 and Aug. 2004 to Jan. 2005). Daily maximum and minimum temperature and leaf appearance were recorded. Linear regression equations were fitted to data and maximum and minimum temperature and leaf appearance were recorded. Linear regression equations were fitted to data and base temperature was assumed to be $8^{\circ} \mathrm{C}$. Thermal time $\left({ }^{\circ} \mathrm{C} \mathrm{d}\right)$ was calculated as daily average maximum and minimum air temperature minus the base temperature and was regressed against leaf number. The sum of accumulated thermal time was found to be linearly 
correlated with leaf number. Phyllochron, which is the thermal time between the appearances of successive leaves, was estimated $51^{\circ} \mathrm{C}$ per day. The information presented in this study will be useful in modeling water use of sweet viburnum in response to environmental conditions.

\section{(81) Fine Fescues and Shade Tolerance}

\section{Tara E. Paranick*, N. Suzanne Lang}

${ }^{1}$ Michigan State University, Horticulture, East Lansing, MI, 48824

Shaded environments present major obstacles for establishing high quality, persistent, and resistant turfs. Exogenous fructose applications are being examined as a potential method to counteract the effects of shade on turf. This work examines the effectiveness of fructose applications under different light levels on two fine leaf fescue cultivars: chewings fescue (Festuca rubra var. commutata) 'SR5100' and creeping red fescue (Festuca rubra var. rubra) 'Dawson'. The experiment was conducted at Michigan State University, East Lansing, inside a simulated dome environment. The experiment was a randomized complete-block design that began 21 Oct. 2004 with two main factors: light and fructose. There were three light treatments: ambient light (shaded); supplemental high light; and supplemental low light. Fructose $(0 \%$ or $1.25 \%$ weight/volume), dissolved in water with an organosilicone adjuvant, was applied once per week. Quality and color ratings, clippings, core samples, density, and leaf reflectance were recorded. In addition, light response curves (LRC) were taken inside an Econoair ${ }^{\mathbb{B}}$ growth chamber using a LI-COR-6400 ${ }^{\mathbb{R}}$ on the fine fescues, kentucky bluegrass (Poa pratensis) 'Cynthia', and bermudagrass (Cyondon dactylon) 'Princess'. Preliminary results show that fructose had no significant effect in each light treatment for turf quality and color. However, fructose had a significant impact on clipping weights and density. The LRC specified the required and potential carbon needs as well as indicated the threshold levels, respectively, by species. The impact of fructose alone and in combination with supplemental light on photosynthesis efficiency will be presented.

\section{(82) Turf Species Affect Establishment and Growth of Cercis canadensis and Carya illinoiensis}

\section{Jason J. Griffin*1, William R. Reid ${ }^{2}$, Dale Bremer ${ }^{3}$}

${ }^{1}$ Kansas State University, Dept. Horticulture, Forestry and Recreation Resources, John C. Pair Horticultural Center, Haysville, KS, 67060; ${ }^{2}$ Kansas State University, Dept. Horticulture, Forestry and Recreation Resources, Pecan Experiment Field, Chetopa, KS, $67336 ;{ }^{3}$ Kansas State University, Dept. of Horticulture, Forestry and Recreation Resources, Manhattan, KS, 66506

Successful establishment and growth of newly planted trees in the landscape is dependent on many factors. Weed pressure and water conservation are typically achieved with either organic mulches or chemical herbicides applied over the root ball of the newly planted tree. In the landscape, eliminating turfgrass from the root zone of trees may be more complicated than resource competition. Studies have shown that tall fescue (Festuca arundinaceae Schreb.) has allelopathic properties on pecan trees [Carya illinoiensis (Wangenh.) K. Koch]. Well-manicured tall fescue turf in the landscape may have negative effects on the establishment and growth of landscape trees as well. A study was designed to examine the effects of popular turfgrasses on the growth of newly planted pecan and redbud (Cercis canadensis L.). Results demonstrate that the presence of turfgrass over the root zone of trees negatively impacts tree growth. Through two growing seasons, every growth parameter measured on redbuds (caliper, height, shoot growth, shoot dry weight, root dry weight, leaf area, and leaf weight) was significantly reduced by the presence of turf. However, the warm season bermudagrass [Cynodon dactylon (L.) Pers.] was less inhibitied than the cool season grasses. The affects of turfgrass on pecan growth was less significant; however, caliper, leaf area, and root dry weight were significantly reduced when grown with turf.

\section{(83) New Weed Problems in Midwest Turfgrass and Horticultural Crops}

Pamela B. Trewatha*

Southwest Missouri State University, Agriculture, Springfield, MO, 65804

Through contacts, observations, and travel throughout the midwestern
United States during Spring and Summer 2004, a number of weed species were noted to be relatively new problems, or growing problems in turfgrass and/or horticultural cropping situations. These include hophornbeam copperleaf(Acalypha ostryifolia), garlic mustard (Alliaria petiolata), blackgrass (Alopecurus myosuroides), Palmer amaranth (Amaranthus palmeri), waterhemp species (Amaranthus spp.), biennial wormwood (Artemisia biennis), lambsquarters complex species (Chenopodium spp.), windmillgrass (Chloris verticillata), showy chloris (Chloris virgata), Asiatic dayflower(Commelina communis), horseweed (Conyza canadensis), redstem filaree (Erodium cicutarium), toothed spurge (Euphorbia dentata), dovefoot geranium (Geranium molle), pitted morningglory (Ipomoea lacunosa), purple deadnettle (Lamium purpureum), birdsfoot trefoil (Lotus corniculatus), roundleaf mallow (Malva rotundifolia), star-of-bethlehem (Ornithogalum umbellatum), cressleaf groundsel (Packera glabella), striate knotweed (Polygonum erecta), creeping yellow fieldcress (Rorippa sylvestris), lanceleaf sage (Salvia reflexa), sibara (Sibara virginica), white campion (Silene latifolia ssp. alba), hairy nightshade (Solanum physalifoium), spiny sowthistle (Sonchus asper), and others. Possibilities for this increase or spread include natural invasiveness of the weeds, control of previous weed competitors, resistance to widely used herbicides, changes in cropping practices, and other weed adaptations to current weed management methods.

\section{(84) Application of AFLP Markers on Taxon Discrimination of Cultivated Stewartia}

\section{Ajay Nair*1, Donglin Zhang ${ }^{1}$, Dogyan $\mathrm{Hu}^{2}$}

${ }^{1}$ University of Maine, Plant Soil and Environmental Sciences, Orono, ME, 04469; ${ }^{2}$ Beijing Botanical Garden, Beijing, 100093, China

The natural distribution and cultivated areas of Stewartia taxa are USDA cold hardiness zones 6 or warmer. One cold-tolerant clone, named Stewartia 'UMaine' (UMaine Silk Camellia), has been growing well at the University of Maine Littlefield Ornamentals Trial Garden (USDA Zone 4). The plant also has brilliant red fall color and biennial flowering. Since cold hardiness field evaluation could not provide genetic information and no other taxa could grow in Zone 4, AFLP markers were employed to figure out its genetic relativeness with other 16 named Stewartia taxa. The three primer-pairs generated 360 useful markers with an average of 120 markers for each taxon. The genetic distance between $S$. sinensis and $S$. rostrata is only 0.031 , which indicates that these two species are very similar and should not be treated as two species or cultivars, at least the plants in cultivation. The largest distance (0.533) occurs between S. pesudocamellia and S. malacodendron, two distinguished species accepted by all taxonomists. UMaine Silk Camellia is a distinguished taxon from all other 16 taxa and $S$. malacodendron 'Delmarva' has the largest genetic distance of 0.453 to it. Although S. ×henryae 'Skyrocket' has the smallest genetic distance of 0.183 to Stewartia 'UMaine', UPGMA phenograms showed that they are not in a clad at all. AFLP data support that Stewartia 'UMaine' is a new cultivar, which originated from a gene pool of $S$. pseudocamellia, $S$. sinensis, and $S$. koreana. These molecular results will also be used as guidance for future Stewartia breeding.

\section{(85) Establishment of Seeded Bermudagrass following Preplant Application of Transition Herbicides}

Shawn Brewer, Michael Maurer*

Texas Tech University, Plant and Soil Science Department, Lubbock, TX, 79409

Transition of perennial ryegrass from bermudagrass athletic fields in the spring delays the establishment of bermudagrass when the establishment period is limited. The objective of this field study was to determine the effects of transition herbicides on the establishment of seeded bermudagrass. Treatments consisted of an untreated control, foramsulfuron, rimsulfuron, trifloxysulfuron sodium, metsulfuron methyl methyl, isoxaban, and oxadiazon at low- and high-labeled rates for transitioning perennial ryegrass. 'Riviera' bermudagrass [Cynodon dactylon(L.) Pers.] seed was seeded immediately after treatment and 2 weeks after treatment. Turfgrass coverage was evaluated visually and by digital analysis. Although differences between methods of turfgrass coverage evaluation varied, the differences between treat- 
ments were similar. There was no significant differences in turfgrass establishment between foramsulfuron, rimsulfuron, trifloxysulfuron sodium, metsulfuron methyl methyl, and the control for either seeding date or rate. Turfgrass coverage was significantly less for isoxaban and no turfgrass was established in the oxadiazon treatments. Initial results of this research indicate that bermudagrass seed can be seeded immediately following the application of foramsulfuron, rimsulfuron, trifloxysulfuron sodium, and metsulfuron methyl methyl.

\section{(86) Seed Germination and Seedling Survival of Alnus maritima (Seaside Alder) in Three Soils in Northern Utah}

\section{Heidi ${ }^{1}$ A. Kratsch*}

Utah State University, Plants, Soils, and Biometeorology, Logan, UT, 84322-4820

Alnus maritima may have potential for use in home and commercial landscapes in northern Utah. This fast-growing, fall-blooming shrub is cold-hardy to USDA hardiness zone $3 \mathrm{~b}$ and tolerant of nutrient-poor soils and full sun. Because this taxon is native to low-elevation wetlands, I seek to determine its response to the high desert soils and climate of northern Utah. My specific objective was to test germination and survival of plants from seed sowed in three diverse soil types typical of the Wasatch front in north-central Utah. Seeds were rinsed with distilled water and cold-stratified in darkness for 16 weeks between wet filter paper in sealed petri dishes. Stratified seeds were sowed in flats filled with soil from each of three sites at the Utah Botanical Center in Kaysville and held in a greenhouse. Seeds planted in flats filled with soilless germination mix served as controls. Flats with 60 seeds were experimental units, and each medium was replicated three times. Soils ranged from silty loam to loam, nitrate- $\mathrm{N}$ was 3.2 to $5.4 \mathrm{mg} \cdot \mathrm{kg}^{-1}$, and there was $1.4 \%$ to $2.9 \%$ organic matter. Germination rates were highest in the soilless mix (50\%). Of the three soil types, the highest germination rates $(24 \%)$ occurred in a loamy soil high in organic matter $(2.9 \%)$. Rates were similar (12.5\% and 13\%) in the other two soils. Seeds of $A$. maritima can germinate in soils typical of urban landscapes in northern Utah, so both the potential for invasiveness and the performance of plants in the landscape of northern Utah are being evaluated.

\section{(87) Short-term Freeze Stress Attenuation in St. Augustine Turfgrass with Selected Biostimulants}

\section{J. Pablo Morales-Payan*, William M. Stall}

University of Florida, Horticultural Sciences Department, Gainesville, FL, 32611-0690

Experiments were conducted to determine the effects of selected biostimulants on St. Augustine turfgrass exposed to short-term periods of freezing temperatures, which are common in north-central Florida during March and April. Aqueous solutions of a triterpenic acid-rich extract from Siberian fir (Abies sibirica) [(TTA), 0 and $300 \mathrm{mg} \cdot \mathrm{L}^{-1}$ a.i.], a seaweed (Ascophyllum nodosum) extract [(CSE), $30 \mathrm{mg} \cdot \mathrm{L}^{-1}$ a.i.], acetylthioproline [(AP), $250 \mathrm{mg} \cdot \mathrm{L}^{-1}$ a.i.], and amino levulinic acid [(5-ALA), $15 \mathrm{mg} \cdot \mathrm{L}^{-1}$ a.i.] were sprayed on residential St. Augustine turfgrass about 50 hours prior to the forecasted freezing event. After freezing, the aesthetic quality of AP-treated St. Augustine turfgrass was the same as in untreated turfgrass plots, but it was drastically reduced in turfgrass treated with 5-ALA. In contrast, St. Augustine tufgrass aesthetic quality was higher in CSE- and TTA-treated plots than in untreated plots. These results indicate that CSE and TTA may help alleviate the negative effects of short-term exposure to freezing temperatures in St. Augustine turfgrass.

\section{(88) The Expressway Partnership: Greening Chicago's Highways}

\section{A.M. Shirazi*1, C.P. Dunn²}

${ }^{1}$ The Morton Arboretum, Urban Horticulture Research Lab., Lisle, IL, 60532; ${ }^{2}$ Chicago Botanic Garden, Research, Glencoe, IL, 60022

The Expressway Partnership (a project of the Chicagoland Chamber of Commerce's Gateway Green Committee) is an urban landscape project that promises to change the face of the city's expressways. The Morton Arboretum's Urban Horticulture Research Lab., with the support of ComEd (Excelon Corp.), since 2001 has been selecting, planting, and evaluating various cultivars of trees, shrubs, and ground covers in a search for the most suitable and sustainable plantings for the expressway environment. About 470 trees and shrubs were planted plus more than 10,000 groundcovers. In May 2002 these plants were visually evaluated and ranked from 1-5 with one being in excellent condition and 5 being dead. The control plants planted at Urban Horticulture Research Nursery at the Morton Arboretum had 100\% survival. The survival rates for groundcovers were: Euonymus fortunei (Virginia Creeper) and Hemerocallis $\times$ daylily (day lily) had $80 \%$ to $90 \%$ survival rates, respectively. Pachysandra terminalis (Japanese spurge) plants died due to either de-icing salt sensitivity, or poor weed control. Syringa pekinensis (Peking lilac), as well as four Syringa cultivars, 'President Grevy', 'Summer Charm', 'Charles Joly', and 'James Mcfarlane', had a $100 \%$ survival rate. Survival rates for other plants were: Malus sargentii (Sargent crabapple) 93\%; Robina pseudoacacia (black locust) $\sim 93 \%$; Malus cultivars $\sim 75 \%$; and Pinus banksiana (jack pine) $75 \%$. Cornus sericea (red-osier dogwood) covered with 3 inches of mulch had a significantly better survival rate $(90 \%$ to $100 \%)$ than the mulch treatment $(60 \%$ to $80 \%)$. The growth and performance of other trees and shrubs will be also reported. This research will ensure sustainable and esthetic urban expressway plantings, while enhancing Chicago's stature as a significant urban landmark.

\section{(89) A New Granular Herbicide for Container, Landscape, and Field-grown Ornamentals}

Randy Smith*, Darin Lickfeldt, Dan Loughner, Mike Melichar, James Breuninger

Dow AgroSciences, Specialty Products, Clovis, CA, 93619

In 2003 and 2004, a new herbicide containing three active ingredients was evaluated for efficacy on important weed species and the tolerance of popular ornamental plant species. Currently available ornamental herbicides differ greatly in the weeds they control and tolerance of ornamental plants grown in production nurseries. This new granular product, trade name Showcase, also known by its experimental number, GF- 1162 , contains $2 \%$ trifluralin, $0.25 \%$ isoxaben, and $0.25 \%$ oxyfluorfen. With preemergent applications applied to pots artificially infested with weed seed, GF-1162 demonstrated exceptional control of many difficult to control species, such as spurge, groundsel, bittercress, oxalis, and crabgrass. When applied preemergence at $150 \mathrm{lb} / \mathrm{acre}, \mathrm{GF}-1162$ was as efficacious as current standards. At $200 \mathrm{lb}$ /acre, weed control was exceptional, exceeding all products included in the trials. Ornamental tolerance to GF-1162 was comparable to that of Snapshot TG, with the exception of whorled plants. On whorled plants, such as daylily and hosta, where granular products can be retained on leaf surfaces, products containing oxyfluorfen must be applied with special precautions to immediately shake or wash granules from leaf surfaces. Even when whorled plants were injured by GF-1162, they did eventually recover. GF-1162 received a federal registration in 2004 and state registrations may be complete as early as Spring 2005, at which time this new herbicide would be made available to ornamental nurseries and lawn care companies as an alternative to current herbicide options.

\section{(90) Coleus: Landscape Performance Results from 2003 and 2004}

Allen Owings*1, Anthony Witcher ${ }^{1}$, Allen Broyles ${ }^{2}$

${ }^{1}$ LSU AgCenter, Horticulture, Baton Rouge, LA, 70803; ${ }^{2}$ LSU AgCenter, Burden Center, Baton Rouge, LA, 70809

Coleus were trialed for landscape performance during 2003 and 2004 at Burden Center in Baton Rouge, La. This included a mid-spring through fall evaluation in 2003 and a spring through summer and summer through fall evaluation in 2004. Over 45 cultivars, including the Solar, Hurricane, Stained Glassworks, and Aurora series, were evaluated. Visual quality ratings were taken twice monthly and included compactness, foliage color, uniformity, and overall aesthetics. Flower observations were noted. Beds were located in full sun and consisted of a raised row of an Olivier silt loam soil. Plants were drip irrigated as needed to prevent stress. A separate study compared sun and shade $(60 \%)$ performance of Kong coleus cultivars in the late summer through fall 2004. The Solar series performed well in 2003 and 2004, and generally had visual quality ratings significantly greater 
than cultivars in the Hurricane, Stained Glassworks and Aurora series. Height was also greater in the Solar series. The Hurricane series had significant flowering early in the evaluation periods, although 'Louise' was slower to flower than 'Benji' or 'Jenni'. Kong coleus cultivars in $60 \%$ shade were about $50 \%$ shorter than those in full sun. 'Aurora Black Cherry' was superior to the other cultivars in the series in terms of visual quality and slowness to flower. 'Mississippi Summer Sun' (a/k/a Razzle Dazzle) and 'Red Ruffle' were top performers among the nonseries cultivars evaluated.

\section{(91) Gardening in a Bag: A Viable Alternative for Growing Bedding Plants in the Landscape}

Clydette M. Alsup*, Pamela A. Trewatha

Southwest Missouri State University, Agriculture, Karls Hall, Springfield, MO, 65804

The rocky Ozarks soils make it difficult for some homeowners to establish ornamental gardens. An alternative to digging in rocky soils is planting into bags of potting soil. This study evaluated "Gardening in a Bag" for herbaceous bedding plants. The growth and appearance of Alternanthera, Capisum annuum, Dianthus, Gazania, Tagetes 'Wave', and upright petunias, Salvia splendens, Spilanthes, Verbena, and Catharanthus roseus were evaluated in 2002 under two planting methods: in the ground vs. in bags of potting soil. Wave petunias, Dianthus, $C$. roseus, and Portulaca grandiflora were evaluated in 2003. All plants were mulched with 3 inches of coarse sawdust. In 2002, planting method had no effect on average height for 16 of the 25 cultivars tested. Seven cultivars were taller when grown in the ground while two cultivars were shorter in that treatment. Planting method had no effect on average plant width of 13 of the cultivars. Plant width was greater for nine cultivars grown in bags, while three cultivars were wider when grown in the ground. Visual ratings were similar for 14 of the cultivars, regardless of planting method. In 2003, performance of five species was evaluated on 3 and 29 July and 5 Sept. Plant height and width were greater on plants grown in the ground than plants grown in bags on 3 July and 5 Sept. Only plant width was significantly greater in the soil-grown plants on 29 July, although the greater height trend was still evident. Plants in the ground had more flowers than plants in bags on 3 July, but there were no differences in flower number the other two dates. Visual quality ratings were taken on the second and third dates, with no differences between treatments. Root soil temperature was higher in bags than in the ground on all three dates in 2003.

\section{Poster Session 29-Teaching Horticulture to Diverse Constituencies}

\section{July 2005, 12:00-12:45 p.m. Poster Hall-Ballroom E/F}

\section{(139) Enhancing Professional Development of Graduate Students through a Scientific Writing Course}

Kent D. Kobayashi*

University of Hawaii at Manoa, Tropical Plant \& Soil Sciences, Honolulu, HI, 96822

How do we enhance the learning experience of graduate students in scientific writing, an essential skill in their professional development? Agraduate course TPSS 711 "Scientific Writing for Graduate Students" was developed to address this need. Its objectives were to help students write, analyze, and revise parts of a scientific paper; critically evaluate their own writing and the writings of others; and become familiar with types of publications. The diverse topics included purpose of scientific writing; organizing your writing; parts of a scientific paper; data analysis and growth analysis; writing the content of a poster or oral presentation; newspaper articles and popular works; extension publications; technical writing for the general public; thesis/dissertation writing; a journal editor's perspective; and reviewing a manuscript. TPSS 711 had an enrollment of 11 TPSS master's students. Students were in their second through fifth semesters of their graduate program. A student survey showed no student had submitted a manuscript to a peer-reviewed journal, had a peer-reviewed article published, or had a newspaper, trade magazine, or popular work published. Only $9 \%$ of the students had a paper published in a conference proceedings or presented a scientific paper outside Hawaii, with only $18 \%$ having presented a paper in Hawaii. Writing assignments, in-class activities, and evaluations of the writings of others helped students gain intensive hands-on experience in scientific writing. As a course requirement, students submitted an abstract and presented a paper at our college's annual scientific symposium. Course evaluations indicated this course was important and valuable in helping enhance the students' learning experience.

\section{(140) Survey of Student Perceptions for Course Delivery Methods}

Kimberly K. Moore*, George E. Fitzpatrick, Jane E. Slane

University of Florida, Environmental Horticulture, Davie, FL, 33314

The University of Florida College of Agriculture and Life Sciences offers the Bachelor of Science degree program in Environmental Horticulture at the Fort Lauderdale Research and Education Center (FLREC). Instructors at the FLREC deliver course work and course work is also presented using a variety of distance education (DE) technologies. These DE technologies include interactive video conferencing, videotape, and web-based courses. The question often arises as to how many courses should be delivered using DE versus live onsite instruction. This survey was conducted to ascertain how students perceive the quality of education they are receiving using a mixture of delivery methods.

\section{(141) Blending Interactive Video Conferencing Classes with WebCT}

Cynthia B. McKenney*1, Ellen B. Peffley ${ }^{2}$

${ }^{1}$ Texas A\&M University, Horticulture Sciences, Research and Extension Center, Dallas, TX, 76424; ${ }^{2}$ Texas Tech University, Plant and Soil Science, Lubbock, TX, 79409-2122

Teaching at a distance has many rewards and challenges inherent in its delivery. Interactive video conferencing has the advantages of having audio and visual contact with students during a set class period while having the disadvantages of scheduling multiple locations and keeping the equipment functioning at peak performance. Likewise, using a web platform such as WebCT provides a framework with excellent options to develop a course that is both audio and visually rich. This solution also presents its own difficulties as required textbooks change and the platform version may be upgraded. In this presentation, the advantages and disadvantages of both formats will be reviewed. In addition, helpful hints for blending these two teaching methods together to create a custom course will be discussed.

\section{(142) Evaluating Student Attitudes toward an Interdisciplinary Professional Master Degree Specializing in Landscape Water Conservation as Compared to a Conventional MS Degree}

Cathy Myers-Roche*, Roger Kjelgren

Utah State University, Plants, Soils, and Biometeorology, Logan, UT, 84322

Interdisciplinary graduate degrees are becoming increasingly popular, filling both employer needs as well as student goals. The Plants and Soils Department at Utah State University offers an interdisciplinary master of professional studies in horticulture (MPSH) degree program specializing in urban landscape water conservation. The MPSH is a one calendar year degree consisting of a small group cohort with a strong emphasis on communication and policy development geared toward creating and managing water conservation programs. Core to this model is what personality type is drawn to an MPSH degree compared to the traditional, research-based master of science degree. We are comparing the personality types of 16 students in the MPSH to 15 students in, or having completed, the traditional MS degree program by using the Myers-Briggs test (MBTI), Strong Interest Inventory (SII) test, and key informant surveys. Basic MBTI personality categories in extroversion/introversion, sensing/intuition, thinking/feeling and judging/perceiving are being evaluated by comparison in contrast as well as consistency across the two degree types. Key informant surveys quizzed individual preference regarding the two degrees. Preliminary 
inspection of survey, MBTI and SII results indicate a definite link between type of graduate program and basic personality trait. Students in or having completed the traditional MS degree program that indicated a preference for the MPSH degree shared the same personality types as those in the MSPH program. These preliminary results suggest that an interdisciplinary professional degree in horticulture focused on a particular topic can appeal to horticultural undergraduates that might not otherwise consider a graduate degree.

\section{(143) Development of an Online Certificate Program in Landscape Horticulture}

\section{Karen Stoelzle Midden*, Paul Henry, Amy Boren}

Southern Illinois University-Carbondale, Plant, Soil, and Agricultural Systems, Carbondale, IL, 62901

Online courses are easily accessible and have the potential to attract and recruit a diversity of students. The instructors [also the principal investigators (PIs)] of an online certificate program in landscape horticulture have completed the first of a 3-year project in an effort to provide landscape horticulture courses, including an option for a certificate, to traditional and nontraditional students. The certification, consisting of 20 credit hours, will be the first of its type in Illinois offered by an institution of higher education. The program is aimed toward traditional college students who may need additional college credit, and nontraditional students who are pursuing certification out of interest in career goals or needing continuing education. The Chicago Botanic Garden, a cooperator in this project, has been a driving force for creation of this program and feels that there is a substantial demand among its clientele. It is being funded by the SIUC Office of the Provost and Vice Chancellor Distance Learning Grant. Year one of this project focused on review and revision of curriculum material of six existing courses taught by the PIs. The PIs are working closely with the university's instructional support for the courses to be delivered by WebCT. To date, the "Appreciation of Landscape Design" course has received the most emphasis in the conversion. This poster session will summarize the project to date and projected benefits of this online program.

\section{(144) ePortfolios: A Philosophy for Improving Education in Horticulture}

\section{Michael E. Reinert*, Dan T. Stearns}

Pennsylvania State University, Horticulture, University Park, PA, 16802

ePortfolios are gaining popularity in academic communities worldwide. Purposes of ePortfolios include: converting student work from paper to digital format, thereby allowing it to be centrally organized, searchable, and transportable throughout their academic lives and careers; promoting student centered learning and reflection; improving advising; and career planning and resume building. Pennsylvania State University is investing in the use of ePortfolios in course work throughout the university system. To facilitate these efforts, the university provides all students and faculty with $500 \mathrm{MB}$ of hosted web space to create and share their portfolios. One of the courses using ePortfolios is Horticulture 120, Computer Applications for Landscape Contracting, in the Landscape Contracting program. Outcomes of implementing ePortfolios include increased availability of student work to potential employers, enhanced recruiting through displays of student work, and enabled reflection on completed work. Students showed improved quality in project work because their projects would be publicly available through the Internet to potential employers, faculty, family, and other students.

\section{(145) Integrating Video, Interactive Animations, Images, and Assessment toward an Expandable Instructor Resource for Greenhouse Education}

Milton E. Tignor*1, Sandra B. Wilson², Lisa S. Hightower ${ }^{3}$, Efren Fitz-Rodriguez ${ }^{4}$, Gene A. Giacomelli ${ }^{4}$, Chieri Kubota ${ }^{5}$, Emily Rhoades ${ }^{6}$, Tracy A. Irani ${ }^{6}$, Margaret J. McMahon ${ }^{7}$, Andrew N. Laing ${ }^{8}$, David A. Heleba ${ }^{9}$, Sarah M. Greenleaf ${ }^{9}$

${ }^{1}$ University of Vermont, Plant and Soil Science, Burlington, VT, 05405-0082; ${ }^{2}$ University of Florida, Environmental Horticulture, Indian River Research and Education Center For Pierce, FL, 34945-3138; ${ }^{3}$ University of Florida, IFAS Communication Services, Gainesville,
FL, 32611-0145; ${ }^{4}$ Univeristy of Arizona, Agricultural and Biosystems Engineering, Tucson, AZ, 85719; ${ }^{5}$ University of Arizona, Plant Sciences, Tucson, AZ, 85721-0036; ${ }^{6}$ University of Florida, Agricultural Education \& Communication, Gainesville, FL, 32611-0540; ${ }^{7}$ The Ohio State University, Horticulture and Crop Science, Columbus, OH, $43210 ;{ }^{8}$ University of Vermont, Electrical and Computer Engineering, Burlington, VT, 05405; ${ }^{9}$ University of Vermont, Plant and Soil Science, Burlington, VT, 05405-0082

Using a multidisciplinary approach, we are creating an instrument for utilization in a variety of greenhouse related courses. We now have over 3 hours of edited and titled video segments that were obtained at different locations by the same videographer. The greenhouse businesses in Arizona, Vermont, Ohio, and Florida were chosen due to their unique business strategies, level of computerization, type of greenhouse construction, management philosophies, and climate challenges. Individual video segments are based on nine topics that were covered at each location including computers, structure, plant life cycle, and labor. The videos have been placed on a streaming media server and will be burned to a DVD. An interactive Flash-based greenhouse environment simulator is nearly complete. This instrument allows students to model greenhouse environments based on climate data from each of the four video locations. Additionally, a searchable digital repository has been established that will allow other participants to submit materials for educational use. This open source software (DSpace) has an integrated distribution license which streamlines compliance with the Digital Millennium Copyright Act. Several hundred high quality images have already been uploaded, described and tagged. Learning assessment tools based on numerical self-evaluation and verification narratives are also being developed in conjunction with the multimedia tools. We have created a database of all the greenhouse courses at 1862,1890, and 1994 institutions and hope to build a community of teachers that will utilize and contribute to the multimedia greenhouse collection. This community has already grown to include two international greenhouse experts who contributed interactive software for educational use.

\section{(146) Plantation, Beverage, and Tropical Nut Crops: Enhancing the Instructional Portfolio of the Horticulture Curriculum}

\section{D.H. Picha*}

${ }^{1}$ Louisiana State University, Horticulture, Baton Rouge, LA, 70803

A course entitled "Plantation, Beverage, and Tropical Nut Crops" was developed in order to expand the content and diversity of the horticulture curriculum at Louisiana State University. The course was designed for both upper division undergraduates and graduate students in the plant sciences. The course was intended to broaden the exposure of both domestic and international students to the world's most important plantation, beverage, and tropical nut crops. These crops are generally not commercially grown in the United States, but include some of the world's most economically significant commodities. The selected crops are typically not covered in existing horticulture or agronomy classes. Details of the individual crop cultural practices, harvesting methods, postharvest care, agro-processing, and international marketing are provided. The instructional materials were formatted for delivery via compressed video and transmitted to off-campus sites to afford the opportunity of long-distance learning to nontraditional students. The course was successful in attracting nonhorticulture students and facilitated interdisciplinary interaction among students from diverse curricula.

\section{(147) In the English Landscape}

\section{Michael N. Dana*, Paul C. Siciliano, John L. Larson}

Purdue University, Horticulture \& Landscape Architecture, West Lafayette, IN, 47907

International travel and study courses for undergraduate students can be significant academic learning experiences if there is a well-defined curriculum and high expectations for student performance on homework exercises, class discussions and evaluation instruments. An interdisciplinary perspective serves to broaden students' understanding. "In the English Landscape" is a three-credit, 4-week undergraduate course in-residence, primarily in Corsham, Wiltshire, U.K. Students explore the history of English landscapes and gardens in the context of post-medieval British history. The course is team-taught every other year by Purdue faculty from the Horticulture, History and Landscape 
Architecture programs. Excursions to landscape, garden and cultural sites provide the primary basis for student discovery. Pretravel readings and lectures prepare students for in-country, site-specific worksheets and class discussions. Course philosophy, content, structure, logistics, and instructional materials, which may be useful as a basis for course development by educators at other institutions, are presented.

\section{(148) A Lab Exercise to Enhance a Student's Understanding of Botany in Everyday Life using Fresh Produce \\ Melinda McVey McCluskey*}

University of Minnesota, Natural Resources Department, Crookston, MN, 56716

Students are often unable to relate the vegetables and fruits consumed as a snack or part of a meal to the plant parts discussed in botany class. Therefore, an exercise was developed for an introductory horticulture course to increase a student's awareness of botany in everyday life. Fresh produce was brought in from local gardens, grocery stores, or farmers markets. Vegetables and fruits were selected that are consumed for their roots, stems, leaves, flower, fruit, and seeds. As each vegetable or fruit was introduced, students named the plant and plant part. As each part was identified it was "dissected" to show the taxonomic features. The different fruit types, i.e., berry, hesperidium, pepo, drupe, and pome were explained. Students were encouraged to taste all vegetables and fruits as they were prepared. Most students sampled the produce as it was passed around the group. Students easily recognized much of the produce, i.e., carrots, asparagus, tomatoes, peas, oranges, and broccoli. The second part of the exercise exposed students to vegetables and fruits that were unfamiliar. Most of the students had little exposure to the more exotic fruits and vegetables that are now available. New vegetables and fruits that students said they would add to their diet include jicama, pomegranate, and star fruit.

\section{(149) Arizona Farm Safety Day}

\section{Glenn C. Wright*1, Stephen E. Poe ${ }^{2}$}

${ }^{1}$ University of Arizona, Plant Sciences, Yuma Mesa Agriculture Center, Somerton, AZ, 85350; ${ }^{2}$ University of Arizona, Agricultural and Biosystems Engineering, Yuma, AZ, 85366-6236

Arizona Farm Safety Day has been held annually since 2000 as an attempt to educate students and farm workers (pesticide applicators, tractor and equipment operators, irrigators, and field workers) in farm safety. Our programs have emphasized tractor safety, pesticide safety, ATV safety, electrical safety, and firearms safety. The all-day events have been held in Yuma and in Safford, Ariz., and most of the attendees are high school students. Agriculture students from six to eight high schools typically participate. The agenda is determined by consulting with local agriculture leaders. Attendees have the opportunity to attend a 4-hour training session in the morning. Subjects taught at these sessions might include reading a pesticide label, sprayer calibration, wearing proper protection, avoiding spray drift, tractor safety, and farm safety. At least one of these sessions is an outdoors "hands-on" session. Individual participants receive up-to-date information and literature, a certificate of completion, CEUs, CCA credits, a hat, and a lunch. Spanish translation is available at each session. In the afternoon, a tractor driver safety course and equipment demonstration is typically held. In the course, selected representatives from local farms or local youth get a chance to demonstrate their tractor and ATV driving and safety skills for recognition and awards. Plaques and trophies are awarded to the winners. Additionally, there is an equipment demonstration. Attendees are tested before and after the event.

\section{(150) Outcome Assessment of Resident Instruction: The Colorado State University Experience}

Harrison Hughes*, Elizabeth Mogen, Steven Newman, James Klett, Anthony Koski

Colorado State University, Dept. of Horticulture \& Landscape Architecture, Fort Collins, CO 80524-1173

An assessment plan for the Horticulture and Landscape Horticulture majors has been developed as part of a university-wide effort to assess resident instruction. The program mission has been described as the preparation of graduates with a passion for Horticulture/Landscape Horticulture who can contribute to Colorado's agricultural and green industry economy through high levels of: 1) technical competency and skills, including disciplinary competence, and a working knowledge in the appropriate field; 2) management and leadership skills; and 3) problem-solving skills. Assessment methods involved the development of evaluation forms for internships, practicum, independent study, group study, and the capstone courses. Student, faculty, clients, and industry personnel used standardized forms, which varied somewhat for the two majors and seven concentrations, to critically assess and score student and faculty efforts. Internships, practicum, and capstone courses were evaluated for program purpose. The management and leadership skills of the students were evaluated based on their performance during internships by cooperators and also by their activities, as demonstrated through their involvement in university, college, departmental, and community activities. Problem-solving skills were evaluated primarily through student performance in capstone courses, with specific criteria in the internship and in leadership activities of clubs. The expectation is that $70 \%$ to $75 \%$ of the students will score 3 or $3+$ on all criteria established for a rating system of $1-5$. Students have generally met this standard and plans are under way to continually upgrade courses and related activities to improve the teaching program

\section{Poster Session 30-Floriculture: Mineral Nutrition/Pest Management/Growth Regulators}

\section{July 2005, 12:00-12:45 p.m. Poster Hall-Ballroom E/F}

\section{(92) Effect of GA on Growth and Soft Rot Occurrence in Zantedeschia ('Black Magic')}

Chun-Woo Nam*1, Dong-Lim Yoo ${ }^{1}$, Su-Jeong Kim ${ }^{1}$, Jong-Taek Suh ${ }^{1}$, Myoung-Rae Cho ${ }^{1}$, Kee-Yoeup Paek ${ }^{2}$

${ }^{1}$ National Institute of Highland Agriculture, RDA, Horticultural Division, HoengGe-Ri 20 Doam-Myon, PyongChang, GangWon-Province, 232-955, South Korea; ${ }^{2}$ Research Center for the Development of Advanced Horticultural Technology, Chungbuk National University, Horticulture, GaeShin-Dong 12, CheongJu, ChungBuk-Province, 361-763, South Korea

This experiment was carried out to determine correct applications of $\mathrm{GA}_{3}$ for the production of cut flowers of Zantedeschia albomaculata cv. Black Magic in highlands. Tubers were treated with GA in concentrations of 0,100 , and $200 \mathrm{mg} \cdot \mathrm{L}^{-1}$. ABA contents in the tubers and roots were twice as high $(20 \sim 25 \mathrm{pmol} / \mathrm{mL})$ in the control as in $\mathrm{GA}_{3}$-treated tubers and roots. ABA content in roots increased with increasing $\mathrm{GA}_{3}$ concentration. Growth of the calla was investigated according to the tuber hardness $\left(3.3,6.0 \mathrm{~kg} \cdot \mathrm{cm}^{-2}\right), \mathrm{GA}_{3}$ concentrations $(0,100,200$ $\left.\mathrm{mg} \cdot \mathrm{L}^{-1}\right)$, and $\mathrm{GA}_{3}$ treatment duration $(24 \mathrm{~h}, 12 \mathrm{~h}$, and $30 \mathrm{~min}$ before planting). Tubers with higher tuber hardness were strong against soft rot, regardless of the $\mathrm{GA}_{3}$ concentrations and treatment durations. Tubers with lower tuber hardness showed over $90 \%$ soft rot occurrence when treated with $200 \mathrm{mg} \cdot \mathrm{L}^{-1} \mathrm{GA}_{3}$ for $24 \mathrm{~h}$ before planting. However, soft rot did not occur when treatment with $200 \mathrm{mg} \cdot \mathrm{L}^{-1} \mathrm{GA}_{3}$ was used for $12 \mathrm{~h}$ before planting.

\section{(93) Evaluating the Effectiveness of Prohexadione-Ca as a Plant Growth Retardant on Buddleia, Dianthus, Eupatorium, and Lilium}

\section{Roberto G. Lopez*, Erik S. Runkle}

${ }^{1}$ Michigan State University, Horticulture, E. Lansing, MI, 48824

Prohexadione-Ca (ProCa) is a relatively new plant growth regulator (PGR) that inhibits internode length in rice, small grains, and fruit trees. However, little is known about its efficacy and potential phytotoxicity on floriculture crops and how it compares to other commercially available PGR chemicals. The effects of two foliar spray applications ( 2 weeks apart) of ProCa (500, 1000, or $2000 \mathrm{ppm})$, paclobutrazol (30 ppm), or a tank mix of daminozide plus chlormequat $(2500$ and $1000 \mathrm{ppm}$, respectively) were quantified on Dianthus barbatus L. 'Interspecific Dynasty Red', Ageratina altissima R. King \& H. Robinson (Eupatorium rugosum) 'Chocolate', Lilium longiflorum Thunb. 'Fangio', and Buddleia davidii Franch. 'Mixed.' All plants were forced in a glass- 
glazed greenhouse with a constant temperature setpoint of $20^{\circ} \mathrm{C}$ under a 16-h photoperiod. Two weeks after the second spray application of ProCa at 500, 1000, or 2000 ppm, plant height of Dianthus and Lilium was shorter than control plants by $56 \%, 60 \%$, and $65 \%$ and by $6 \%$, $26 \%$, and $28 \%$, respectively. However, ProCa bleached and reduced the size of Dianthus flowers. ProCa at $2000 \mathrm{ppm}$ and daminozide plus chlormequat were effective at controlling the height of Eupatorium (64\% and 53\% reduction, respectively); however, leaves of Eupatorium were discolored and showed symptoms of phytotoxicity 1 week after the first ProCa application. Only daminozide plus chlormequat were effective on Buddleia. ProCa is an effective PGR for most of the crops we tested; however, its discoloration of red flowers and foliage may limit its application for commercial use.

\section{(94) Efficacy of Application Methods and Concentration of Plant Growth Retardants on Growth of Chrysanthemum (Dendranthema $\times$ grandiflorum 'Cheasepeake')}

\section{Chun Ho Pak ${ }^{1}$, Seung Won Kang ${ }^{1}$, Chiwon W. Lee*2}

${ }^{1}$ Korea University, Dept of Horticultural Science, A-nam Dong, Sung buk Gu, Seoul, 136701, South Korea; ${ }^{2}$ North Dakota State University, Department of Plant Sciences, Fargo, ND, 58105-5051

Efficacy of application methods and concentration of plant growth retardants on growth of chrysanthemum (Dendranthema $\times$ grandiflorum cv. Cheasepeake) was tested. B-9 or cycocel (CCC) as a growth retardant was applied as drench or subapplication with nutrient solution. In the case of B-9 drench treatments, as B-9 concentrations increased, numbers of flowers and flower buds increased except in the 1500-ppm treatment. Increasing concentration of CCC also resulted in reduction of flower numbers, total plant height, total leaf area, branch number, and fresh weight. Reduction ratio of total plant height in $2000 \mathrm{ppm}$ showed about $56.9 \%$ being compared to that of the 100 -ppm drench treatment. B- 9 or $\mathrm{CCC}$, combined with nutrient solution, was also supplied from the Cchannel subirrigation system. The B-9 subapplication treatment showed no significance among these concentrations, but flower numbers, total plant height, average plant height, and leaf numbers decreased as concentrations of CCC increased. B-9 or CCC with the same concentration was drenched after 2 weeks of the first experiment to compare planting time efficacy. Measured data increased until B-9 increased up to 2500 ppm and severe growth retardation resulted from the 5000-ppm treatment. Through this growth retardant application study, the combination of drenching concentration and period of plant growth regulators (PGRs) may result in effective growth retardation and reduction of application concentrations for pot plant production.

\section{(95) Black-eyed Susan (Rudbeckia hirta L.) as a Potted Plant Crop in Response to Pinching and Paclobutrazol}

Clydette M. Alsup, Pamela B. Trewatha*

Southwest Missouri State University, Agriculture, Springfield, MO, 65804

In two experiments, seedlings of black-eyed susan were transplanted into $15-\mathrm{cm}$ pots and after 1 week received one of the following treatments: media drench application of $0.1,1,10$, or $100 \mathrm{mg} \cdot \mathrm{L}^{-1}$ of paclobutrazol or pinching back of terminal growth once, twice, or three times. After plants reached salable size, plant height, lateral branch length and number, and flower counts were taken, and plants were harvested for dry weights. In the first experiment, all pinching treatments and $10 \mathrm{mg} \cdot \mathrm{L}^{-1}$ paclobutrazol reduced plant height and increased lateral branching. Flower count at harvest was enhanced by paclobutrazol and reduced by pinching, due to delayed development of inflorescences. Lateral branching and flower bud count were greatest in the second study on plants receiving three pinches. The $100 \mathrm{mg} \cdot \mathrm{L}^{-1}$ paclobutrazol-drenched plants had lowest height, dry weight, and bud count and were severely stunted. The most attractive plants appeared to be those that received the $10 \mathrm{mg} \cdot \mathrm{L}^{-1}$ paclobutrazol drench treatments.

\section{(96) Color Generation in Hydrangea Sepals as Controlled} by Metal Ion Complexes

Henry D. Schreiber*, Timothy Berry, Nam Trant

Virginia Military Institute, Department of Chemistry, Lexington, VA, 24450

The sepals of many hydrangea cultivars change color from red in basic/neutral soil to blue in acidic soil. This change is generally attributed to $\mathrm{Al}$ (III) becoming mobile in acidic soils, allowing it to be absorbed through the roots as a citric acid complex; the ion of $\mathrm{Al}$ (III) then forms a blue complex in the sepals with an anthocyanin that is red in the absence of Al(III). This study investigated selected metal ions that might also result in similar color changes in hydrangea sepals. Model anthocyanins such as cyanidin and delphinidin glucoside readily formed blue complexes with metal ions with a high charge/size ratio [that is: $\mathrm{Mo}(\mathrm{VI}), \mathrm{U}(\mathrm{VI})$, and $\mathrm{Zr}(\mathrm{IV})$, in addition to $\mathrm{Al}(\mathrm{III})$ ]. The anthocyanins only formed weak complexes with Fe(III) and $\mathrm{Ga}(\mathrm{III})$, and no complexes with $\mathrm{Mg}(\mathrm{II})$ and $\mathrm{Mn}(\mathrm{II})$. In order for the color change to occur in the sepals, though, the hydrangea must first be able to selectively concentrate the metal ion in the plant from the soil as a complex with citric or oxalic acid. The complexation of Al(III) with the organic acid is shown by the measurement of the heat of solution of citric and oxalic acid in Al(III) solutions as half that of the acids in just water. The presence of Al(III) also enhanced the solubility of oxalic acid in water. Mo(VI) likewise enhanced the organic acid's solubility, while Fe(III), Fe(II), and U(VI) did not appreciably affect the solubility. $\mathrm{Mo}(\mathrm{VI})$ and similar ions may be candidates to artificially induce bluing of hydrangea sepals, instead of the current use of Al(III).

\section{(97) Screening Pythium sp. Associated with Greenhouse Crops in Colorado for Mefanoxam Resistance}

Miriam Fishell*, Laura Pottorff

Colorado State University, Cooperative Extension, Brighton, CO, 80601

Research was conducted on the fungus-like organism Pythium to observe its sensitivity to the fungicide Subdue MAXX, active ingredient mefanoxam. Pythium is a plant pathogen that causes root and crown rot in plants that are exposed to extensive soil moisture and poor drainage. This study, conducted on Pythium isolated from Colorado greenhouse crops, began in Apr. 2004. Symptomatic tissues from bedding plants and perennials were placed on selective media $\left(\mathrm{P}_{10} \mathrm{VP}\right)$. Resulting isolations of Pythium were transferred to cornmeal agar amended with the recommended low and high label rates of mefanoxam. Mycelia growth was monitored for 72 hours. Pythium sp. showing $20 \%$ growth on amended mefanoxam agars, compared to the control growth, were considered resistant to mefanoxam. Results from this study showed that about $64 \%$ of the Pythium sp. isolated from greenhouse crops in Colorado are resistant to mefanoxam. Data compiled from greenhouse integrated pest management surveys in Colorado show a high dependence on the use of mefanoxam. Research and screening for mefanoxam-resistant Pythium sp. will continue to provide Colorado growers with effective control solutions for this pathogen.

\section{(98) Impact of Selected Insecticides on Gas Exchange, Vegetative and Floral Development, and Overall Quality of Gerbera (Gerbera jamesonii var. 'Festival Salmon')}

James D. Spiers*1, Fred T. Davies ${ }^{1}$, Chuanjiu $\mathrm{He}^{1}$, Carlos Bogran ${ }^{2}$, Amanda Chau ${ }^{2}$, Kevin M. Heinz ${ }^{2}$, Terri W. Starman ${ }^{1}$

${ }^{1}$ Texas A\&M University, Horticulture, College Station, TX, 77840-2133; ${ }^{2}$ Texas A\&M University, Entomology

This research focused on the influence of insecticides on gas exchange, chlorophyll content, vegetative and floral development, and overall plant quality of gerbera (Gerbera jamesonii var. 'Festival Salmon'). Insecticides from five chemical classes were applied weekly at $1 \times$ and $4 \times$ the recommended concentrations. Insecticides used were: abamectin $\left(\right.$ Avid $^{\circledR} 0.15$ EC), acephate (Orthene ${ }^{\circledR}$ Turf, Tree \& Ornamental Spray 97), bifenthrin (Talstar ${ }^{\circledR}$ Nursery Flowable), clarified hydrophobic extract of neem oil (Triact ${ }^{\circledR} 70$ ), and spinosad (Conserve ${ }^{\circledR}$ SC). Phytotoxicity occurred in the form of leaf chlorosis on all acephate treatments, with the greatest damage occurring at the $4 \times$ concentration. Photosynthesis and stomatal conductance were significantly reduced in plants treated with neem oil extract. Plants treated with the neem oil extract $(1 \times$ and $4 \times)$ flowered later and had reduced growth [lower shoot dry mass (DM) and total DM]. Plants that received $4 \times$ the recommended concentration of neem oil extract had reduced leaf area, thicker leaves (lower specific leaf area), higher leaf chlorophyll content, and reduced flower production, as determined by flower number 
and flower DM. Plants treated with acephate $4 \times$ concentration were the lowest quality plants due to extensive phytotoxicity (leaf burn), which also reduced photosynthesis. The highest quality plants were treated with spinosad and abamectin due to zero phytotoxicity and/or no thrips damage (thrips naturally migrated into the greenhouse). The control plants and plants treated with bifenthrin $1 \times$ were not marketable due to thrips damage; however, plant growth characteristics and gas exchange were not statistically different.

\section{Poster Session 31-Citrus}

20 July 2005, 12:00-12:45 p.m. Poster Hall-Ballroom E/F

\section{(459) Preliminary Evaluation of 17 Satsuma Mandarin (Citrus unshiu Marco.) Cultivars in the Coastal Region of California}

ChihCheng T. Chao*

University of California-Riverside, Botany and Plant Sciences, Riverside, CA, 92521-0124

The citrus industry in California is changing, and growers are planting more easy-peeling, seedless, and nice-tasting mandarins. Our industry tries to develop new early- and late-season mandarin cultivars to be competitive in the global mandarin market. Seventeen satsuma mandarin (Citrus unshiu Marco.) cultivars were top-worked onto 4-6 Valencia orange [C. sinensis (L.) Osbeck] as interstocks and Carrizo citrange [C. sinensis (L.) Osbeck $\times$ Poncirus trifoliata (L.) Raf.] as rootstocks in 30 May 2001 near Santa Paula, Calif. All trees set the first crop in Fall 2003. Fruit maturity of all cultivars was measured based on ${ }^{\circ}$ Brix level, percent acid, and S:A ratio on a weekly basis since the first week of Sept. 2004. Five cultivars, 'Armstrong', 'KunoWase', 'Miyagawa', 'S9' and 'Xie-Shan' ('Wakiyama'), are very early- or early-season cultivars. A small-scale degreening experiment with $72 \mathrm{~h}$ treatment of $0.5 \mathrm{mg} \cdot \mathrm{L}^{-1}$ ethylene with fruit harvested on 6 Oct. 2004 also showed the rind color of all five cultivars could be enhanced nicely. 'Miyagawa' had very intense internal orange flesh color visible in the second week of Sept. 2004, comparing with other cultivars. All these five cultivars could potentially become early-season, completely seedless, and easy-peeling satsuma cultivars in California. 'Miyagawa' and 'Xis-Shan' could potentially be harvested as early as from late September to early October in the central coastal region and from late August to mid-September in the San Joaquin Valley. Both cultivars should command a high price when there is no seedless mandarin in the market.

\section{(460) De-greening of Early Season Satsumas in Louisiana} David Picha*1, Wayne Bourgeois ${ }^{2}$

${ }^{1}$ Louisiana State University, Horticulture, Baton Rouge, LA, 70803; ${ }^{2}$ Citrus Research Station, Horticulture, Port Sulphur, LA, 70083

Significant opportunities exist for expanding the marketing season of Louisiana-grown satsumas. De-greening of the early season fruit coupled with optimal storage conditions for the late season fruit may allow for 6 months of market availability. Consumer demand in the U.S. for specialty citrus, particularly easy peel seedless mandarins, has increased in recent years. South Louisiana is one of the principal satsuma production areas in the United States, with harvest beginning in late September. Although the sugar : acid ratio of early season satsumas may meet the state-mandated 10:1, peel color typically ranges from green to greenish-yellow. Most consumers prefer a darkeryellow-orange peel color. Postharvest de-greening tests were conducted to determine the appropriate method(s) and protocol for enhancing peel coloration of early season harvested satsumas. Green peel satsuma fruit were exposed to $0,3,5,10$, and 50 ppm ethylene for $12,24,36$, and 48 hours at 21 or $29^{\circ} \mathrm{C}$. An atmospheric ethylene concentration of $\geq 5$ ppm for $\geq 24$ hours at $29^{\circ} \mathrm{C}$ provided optimal de-greening. However, peel darkening in the form of irregular dark brown areas was observed after several days in fruit exposed to ethylene concentrations of $50 \mathrm{ppm}$. Ethephon was also an effective de-greening agent. Submersion of the fruit in 500 ppm ethephon for 30 seconds provided optimal de-greening. Buffering of the submersion solution $\mathrm{pH}$ had no effect on de-greening effectiveness.

\section{(461) Endocytic Uptake of Quantum Dots and Endocytic Markers into 'Sweet Lime' Juice Cells}

\section{Ed Etxeberria*1, Pedro Gonzalez ${ }^{1}$, Javier Pozueta ${ }^{2}$}

${ }^{1}$ University of Florida, Citrus Research Center, Lake Alfred, FL, 33850; ${ }^{2}$ Nafarroako Unibertsitate Publikoa eta CSIC, Agrobioteknologia eta Natura Baliabideetako Instituta, Mutiloako etorbidea zenbaki gabe, Mutiloabeti, Nafarroa, 31192, Spain

To determine whether the mechanisms of sucrose accumulation into the low acid 'Sweet Lime' (Citrus limmetioides Blanco) juice cells are consistent with those previously reported for the more acidic cultivars, we followed similar developmental changes in determinants of sink strength. In addition, we followed the incorporation and distribution of quantum dots and fluorescent endocytic probes into the cell with time of incubation. As in other citrus fruits, sucrose levels, sucrose synthase, sucrose phosphate synthase, and sucrose phosphate phosphatase increased throughout fruit development. The $\mathrm{pH}$ however, was much higher than in the more acidic cultivars. Sucrose uptake into energized plasmalemma vesicles was inhibited by gramicidin, in accordance with the presence of an active symport mechanism of sucrose from the apoplast into the cytosol. On the contrary, tonoplast vesicles were shown to lack active transport mechanism of sucrose into the vacuole. In conformity with recent findings showing the occurrence of an endocytic mechanism in 'Murcott' mandarin, 'Sweet Lime' juice cells were shown to incorporate membrane-impermeable dyes into their vacuoles in the presence of sucrose. High-definition confocal microscopy revealed the co-localization of membraneimpermeable markers in cytoplasmic vesicles, in membrane-bound intermediate structures such as the endosome and multi-vesicular body, and the eventual distribution of such fluorescent particles. The data provide strong evidence for an endocytic system of transport that allows direct incorporation of sucrose from the apoplast to the vacuole and for the visualization of intermediate distribution and cargo centers in the cell.

\section{(462) Citrus and Its Putative Bioactive Limonoids: Beneficial Effects on Bone Strength}

Kranthi Kiran Mandadi*1, G.K. Jayaprakasha1, Farzad Deyhim², Bhimanagouda S. Patil

${ }^{1}$ Texas A\&M University-Kingsville, Citrus Center, Agronomy and Resource Sciences, Weslaco, TX, 78596; ${ }^{2}$ Texas A\&M University-Kingsville, Citrus Center, Human Sciences, Welasco, TX; ${ }^{3}$ Texas A\&M University, Vegetable and Fruit Improvement Center Department of Horticultural Sciences, College Station, TX, 77845

Citrus proved beneficial to human health in preventing cardiovascular disorders, hypertension, anemia, and several cancers, including colon, lung, skin, stomach, and breast, in animal and cell culture studies. For the first time, current study was focused to determine whether orange juice and grapefruit juice increase bone mass in an orchidectomized (ORX) rat model of osteoporosis. Thirty-six male Sprague-Dawley rats were randomly divided into four groups of 1) sham;2) ORX;3) ORX + orange juice (OJ); and 4) ORX + grapefruit juice (GJ). All rats were fed to the mean intake of the sham group and were provided with freshly squeezed grapefruit or orange juice for 60 days. There was a numerical improvement in femoral density with OJ and GJ compared to the ORX group. Ultimate bone strength and femoral cortical area diameter $(\mathrm{mm})$ increased $(P<0.05)$ with OJ and GJ compared to the ORX group. Furthermore, bone fracture withstand threshold time(s) increased $(P<0.05)$ with OJ and GJ compared to the ORX group. Beneficial effects of citrus juices on bone strength could be related to its bioactive triterpene compounds and nutrient composition. Isolation of triterpenes using specific combinations of food-grade adsorbent and ion exchange resins yielded pure limonin$17-\beta$-D-glucoside and limonin along with obacunone, nomilin, and deacetylnomilin. Identification and characterization of the isolated limonoids were performed by specific analytical techniques, such as HPLC, LC-MS, and NMR. Further studies are needed to determine the protective effects of limonoids on bone homeostasis. Funded by USDA 2001-52102-11257 and 2004-34402-14768. 
(463) Grapefruit Crop Load Affects Net Gas Exchange of Leaves, Tree Growth, and Fruit Quality

Kuo-Tan Li*, Jim Syvertsen, Jill Dunlop

University of Florida, IFAS, Citrus Research and Education Center, Lake Alfred, FL, 33850

Effects of crop load on leaf characteristics, shoot growth, fruit shape, fruit quality, and return bloom were investigated in 13-year-old 'Ruby Red' grapefruit (Citrus paradisi Macf.) on 'Swingle' citrumleo rootstock. Trees were hand thinned in June 2003 and 2004 at the end of physiological fruit drop to establish three to four levels of crop load ranging from normal (high crop load without thinning) to extremely low (near $90 \%$ fruit removal). Leaves on high crop load trees had higher net assimilation of $\mathrm{CO}_{2}\left(\mathrm{~A}_{\mathrm{CO} 2}\right)$ than those on low crop load trees. Crop load enhancement of $\mathrm{A}_{\mathrm{CO} 2}$ continued until harvest. In 2004, however, the effects were diminished in October just prior to the beginning of the harvest season, after leaf and fruit loss from three consecutive hurricanes. There was no difference in leaf dry weight per leaf area and leaf nitrogen among treatments. Nonfruiting branches of high crop load trees produced fewer, but longer, summer flushes than those of low crop load trees. Fruiting branches generally produced few summer flushes with similar shoot lengths among treatments. High crop load trees developed a greater percentage of vegetative shoots, whereas low crop load trees developed more inflorescences. Crop load adjustments did not affect fruit size and total soluble solid content, but low crop load trees produced a higher percentage of irregular shape (sheepnosed) fruit with high acidity.

\section{(464) Temperature Relationships in a Mature Orange Orchard between Areas with or without a Partial Permanent Cover Crop}

Neil V. O'Connel1*1, Craig E. Kallsen², Richard L. Snyder ${ }^{3}$, Blake L. Sanden 2 , Paul W. Giboney ${ }^{4}$, Mark W. Freeman ${ }^{5}$

${ }^{1}$ University of California, Cooperative Extension Tulare Co., Tulare, CA, 93274-9539; ${ }^{2}$ University of California, Cooperative Extension Kern Co., Bakersfield, CA, 93307; ${ }^{3}$ University of California, Davis, LAWR, Hoagland Hall, Davis, CA, 95616; $;{ }^{4}$ Columbine Vineyards, Delano, CA, 93215-9597; ${ }^{5}$ University of California, Cooperative Extension, Fresno, CA, 93702

Many citrus growers are hesitant to plant cover crops, particularly perennial types, because of possible increased frost hazard. To quantify the increased risk, temperature relations over a 3-year period were compared between areas in a 'Valencia' orange orchard with and without a partial perennial cover crop. The partial perennial cover crop consisted of a mowed perennial planting along the double drip line hoses, and an annually fall-replanted unirrigated strip of groundcover in the middle between the tree rows. This partial perennial cover crop increased the frost hazard compared to uncultivated bare ground even when wind machines were operating.

\section{Poster Session 32-Nursery Crops 2}

20 July 2005, 12:00-12:45 p.m. Poster Hall-Ballroom E/F

(99) Development of an Ohio Tree Liner Production System in Retractable Roof Houses; Field Comparisons with West Coast-grown Liners

Hannah M. Mathers, Elizabeth Grosskurth*, Michele Bigger, Luke Case, Jenny Pope

The Ohio State University, Horticulture \& Crop Science, Columbus, OH, 43210

Currently, the majority of tree liners used in the Ohio nursery industry are imported, mainly from the West Coast. The Ohio growing season is 156 days, whereas the Oregon season is 225 days. We are developing an Ohio liner production system, utilizing a retractable roof greenhouse (RRG) that extends the growing season. Liners grown in a RRG have shown greater caliper, height, and root and shoot dry weight than those grown outside of a RRG (Stoven, 2004). The objective of this research was to compare the growth of RRG-grown liners, outdoor-grown liners, and West Coast-grown liners when planted in the field. Four tree species [Quercus rubra, Malus 'Prairifire', Acer $\times$ freemannii 'Jeffersred' (Autumn Blaze ${ }^{\circledR}$ ), and Cercis canadensis] were started from either seed or rooted cuttings in early 2003. They were grown in a glass greenhouse and then moved to their respective environments in March (RRG) and May (outside). In Oct. 2003, the Ohio-grown liners were planted in the field at the Waterman Farm of The Ohio State University, Columbus. In Spring 2004, liners from the West Coast were purchased and planted in the same field setting. Caliper and height were measured in June and Sept. 2004. After one season in the field, trees grown from the RRG and outdoor environments resulted in greater height and caliper than the West Coast liners in Malus, Acer, and Cercis. Acer liners from Oregon had a greater increase in height from June to September than those grown outdoors or in the RRG. Quercus liners from the RRG and outdoor environments displayed greater caliper growth and growth in height than those from the West Coast. Across all species, liners grown from the RRG had the greatest increase in caliper growth.

\section{(100) Use of Raw and Composted Paper Mill Sludges, Municipal Waste Composts, and Other Waste Ingredients in Container Nursery Substrates}

Calvin Chong*, Peter Purvis

University of Guelph, Plant Agriculture, W, Guelph, Ontario, N1G 2W1, Canada

Plug-rooted liners of deutzia (Deutzia gracilis), dogwood (Cornus alba 'Argenteo-marginata'), forsythia (Forsythia xintermedia 'Lynwood Gold'), and ninebark (Physocarpus opulifolius) were grown in 6-L containers. There were 36 different treatment substrates formulated in factorial combinations: two types of paper mill sludge (raw or composted) each at three rates $(25 \%, 33 \%$, or $50 \%$, by volume) mixed with one of three sources of municipal waste compost (cities of Guelph, Toronto, or Waterloo; $25 \%, 33 \%$, or $50 \%$ ), and the remainder consisting of one of two base supplements (pine bark or 1-year-old wood chips; $50 \%, 33 \%$, or $0 \%$ ). The containers were trickle-irrigated and fertilized with a controlled-release fertilizer. Dogwood (no treatment interaction and responding only to the main effect of compost sources) grew equally well with Toronto and Waterloo composts, but less well with the Guelph compost. Ninebark tended to grow better with Toronto compost, intermediate or similar with Waterloo compost, and least with Guelph compost. Forsythia grew equally well in all bark-based substrates, regardless of sludge type and rate or compost source. With wood-chip-based substrates, however, forsythia grew better with Waterloo than with Guelph compost, and better with raw than with composted sludge when mixed with Toronto compost. Deutzia responded similarly to most substrates, but grew marginally better with raw than with composted paper sludge when Waterloo or Toronto compost was present. Despite these differences in species responses, all plants were of marketable size at the end of the season. There was no sign of nutrient toxicity or deficiency due to any of the substrates.

\section{(101) Fertilizer Source Affects Nitrogen and Phosphorus Levels in Leachate from Container-grown Quercus phellos $\mathrm{L}$. and Magnolia virginiana $\mathrm{L}$.}

\section{Donna C. Fare*}

USDA-ARS, Floral Nursery Plant Research Unit, McMinnville, TN, 37110

Environmental concerns with nitrogen and phosphorus use at container nurseries and the subsequent effects of nutrient-laden irrigation effluent prompted this study. Bare root liners of willow oak (Quercus phellos L.) and sweetbay magnolia (Magnolia virginiana L.) were grown in \#5 containers during year one and repotted into \#15 containers during year two using $100 \%$ pine bark or pine bark : peat substrate (4:1 by volume). Two fertilizer sources, Osmocote $19 \mathrm{~N}-2.2 \mathrm{P}-7.5 \mathrm{~K}$ (19-5-9) or Harrell's $17 \mathrm{~N}-2.2 \mathrm{P}-10.0 \mathrm{~K}$ (17-5-12), were included in the container substrate in a fluoropolymer bag with $17 \mathrm{~g} \mathrm{~N}$ in each \#5 container and $63 \mathrm{~g} \mathrm{~N}$ in each \#15 container. Using a split plot design with fertilizer and media as subplots, a cyclic irrigation regime consisting of three irrigation applications spaced one hour apart was compared to a traditional irrigation regime with one irrigation application 
that equaled the total volume applied in the cyclic regime. Fertilizer source influenced cumulative amounts (mg/year) of ammonium-N, nitrate- $\mathrm{N}$ and orthophosphate in the container leachate. Nitrate-N and ammonium-N from Harrell's $17 \mathrm{~N}-2.2 \mathrm{P}-10.0 \mathrm{~K}$ fertilizer were each $\approx 20 \%$ higher in the container leachate from sweetbay magnolia than Osmocote $19 \mathrm{~N}-2.2 \mathrm{P}-7.5 \mathrm{~K}$ fertilizer. In the case of the willow oak, the differences were $32 \%$ and $19 \%$, respectively. Orthophosphate averaged about $65 \%$ greater in leachate from both sweetbay magnolia and willow oak containers when grown with Osmocote compared to Harrell's fertilizer. At the end of year two, height and caliper growth were similar among treatments with both species.

\section{(102) Monitoring Nutrient Mitigation at a Container Nursery Wetland: A 3-Year Study}

Milton D. Taylor ${ }^{1}$, Sarah A. White ${ }^{1}$, Stephen J. Klaine ${ }^{1}$, Ted Whitwell*2

${ }^{1}$ Clemson University, Clemson Institute of Environmental Toxicology, Pendleton, SC, $29670 ;{ }^{2}$ Clemson University, Department of Horticulture, Clemson, SC, 29634-0375

Container-grown plants require large amounts of water and nutrients during their production cycle. This results in substantial runoff that is contaminated with nitrogen and phosphorus. At our study site, nutrients were delivered through incorporation in the potting media as timed-release prills and through liquid feeding by injection into irrigation water. Mitigation of nutrients in runoff water was dealt with proactively by the container nursery with construction of 3.77 ha of planted wetlands to receive runoff from a 48.6-ha drainage basin and excess water diverted from adjacent watersheds. Water flowed though drains between wetland cells and eventually into stilling ponds before it was allowed to exit the property. Water flow through the wetlands ranged from 1.1 to 3.1 million liters per day over the period. Three years of monitoring data indicate some seasonal differences in nitrogen removal efficiencies. Nitrogen removal between March and November averaged $\geq 95 \%$ while removal during winter (December through February) averaged $\geq 72 \%$. Nitrogen (as nitrate) varied from $4.28 \mathrm{ppm}$ to $\leq 0.01 \mathrm{ppm}$ in wetland discharge, well below drinking water quality standards, but occasionally above levels that may cause downstream eutrophication. Orthophosphate phosphorus removal was highly variable with greatest removal occurring during late spring, late fall, and winter. There was a significant net export of phosphorus during some summer months for years 2 and 3. Phosphorus levels in wetland discharge ranged between 0.84 and $2.75 \mathrm{ppm}$. While there is currently no legal water quality standard for phosphorus, these levels were above the generally accepted level for preventing downstream eutrophication.

\section{(103) Screening Landscape Plants for Their Ability to Accumulate Nitrogen and Phosphorus}

Robert F. Polomski ${ }^{1}$, Milton D. Taylor ${ }^{2}$, Sarah A. White ${ }^{2}$, Ted Whitwell*1, Stephen J. Klaine ${ }^{2}$, William C. Bridges, Jr. ${ }^{3}$

${ }^{1}$ Clemson University, Horticulture, Clemson, SC, 29634-0319; ${ }^{2}$ Clemson University, Clemson Institute of Environmental Toxicology and Biological Sciences, Pendleton, SC, 29670-0709; ${ }^{3}$ Clemson University, Applied Economics and Statistics,Clemson, SC, 29634-0367

Commercial nurseries use large amounts of water and nutrients during production cycles. Runoff contaminated with $\mathrm{N}$ and $\mathrm{P}$ can adversely impact surface and groundwater quality. A 3-year monitoring study of nutrient mitigation by a constructed wetland at a container nursery found nitrogen removal was highly efficient. However, orthophosphate$P$ removal was highly variable. Partial removal occurred during some months, but net export also occurred. P levels in wetland discharge- - between 0.84 and $2.75 \mathrm{ppm}$-were well above the generally accepted level for preventing downstream eutrophication. Therefore, identifying landscape plants that remediate nutrients, especially $\mathrm{P}$, could be useful in improving constructed wetlands. A 2003 greenhouse study screened commercially available landscape plants for their phytoremediation potential. Among the 17 taxa and 19 cultivars examined were woody shrubs, e.g., Cornus amomum, Myrica cerifera 'Emperor', and Salix integra 'Hakura Nishiki'; herbaceous semiaquatics, e.g., Canna (two cultivars), Colocasia esculenta 'Illustris', Rhyncospora colorata, Iris 'Full Eclipse', Pontederia cordata 'Singapore Pink', and Thalia geniculata 'Red Stem'; and floating aquatics, e.g., Myriophyllum aquaticum, Eichhornia crassipes, and Pistia stratiotes. Plants were grown in pea gravel media and kept saturated with one of five concentrations of Hoagland's. Herbaceous and woody plants were harvested after 8 and 13 weeks, respectively. Experiments were replicated twice for each cultivar. The nutrient uptake efficiency was determined for each taxon from the total amount of $\mathrm{N}$ and $\mathrm{P}$ applied and the biomass dry weight and $\mathrm{N}$ and $\mathrm{P}$ content.

\section{(104) Green Ash (Fraxinus pennsylvanica) Response to Nitrogen Rate and Timing in a Field Nursery}

\section{Catherine Neal*}

University of New Hampshire, Plant Biology, Durham, NH, 03824

Bare-root, 4-ft whips of green ash (Fraxinus pennsylvanica 'Marshall's Seedless') were planted in June 2001 in a randomized complete-block design with three trees per plot. An incomplete factorial design was used to test whether annual fertilizer rate and/or application dates affected growth. Treatments were fertilized from 0 to 4 times per year in mid-April, mid-June, mid-August, and/or mid-October. A rate of $1 \mathrm{lb}$ of nitrogen $(\mathrm{N}) / 1000 \mathrm{sq} \mathrm{ft}$ was used whenever fertilizer was applied to a plot. Each treatment received 0, 2, 3, or $4 \mathrm{lbs} \mathrm{N} / 1000 \mathrm{sq} \mathrm{ft} /$ year depending on the number of applications. Caliper, height, and terminal growth were measured annually for three growing seasons. At the end of seasons 2 and 3, one plant per plot was destructively harvested and processed to obtain dry weights of shoots and roots, and the shoot to root ratio was calculated. Data were analyzed by analysis of variance with least square means contrasts. Treatment effects on top weights, root weights, and shoot to root ratios were nonsignificant. There were significant treatment differences for caliper and terminal growth in years 1 and 2, but not 3 . A set of orthogonal contrasts was used to determine that the effect was due primarily to growth differences in plants receiving 2 vs. 3 or $4 \mathrm{lbs} \mathrm{N} / 1000 \mathrm{sq} \mathrm{ft} /$ year, but that 3 vs. $4 \mathrm{lbs}$ made no difference. Another set of planned, but nonorthogonal contrasts was used to compare application date effects. Plants fertilized in June were greater in caliper and terminal growth in the first 2 years than plants not fertilized in June. There were nonsignificant effects of fertilizing vs. not fertilizing in late fall or early spring.

\section{(105) Holding Bareroot Colorado Spruce Trees in a Gravel Bed}

Robert R. Tripepi*, Mary W. George, John E. Lloyd

University of Idaho, Horticultural Sciences Division, PSES, Moscow, ID, 83844-2339

Field-grown conifers are usually discarded if their root balls break during digging, but using an alternative holding system until the root systems recover could reduce production losses. The objective of this study was to determine if a gravel bed could be used as a holding treatment for 1.5- to 1.8-m-tall Colorado spruce (Picea pungens) trees that had soil removed from their root systems in the spring. Root systems from 12 trees were washed free from pine bark mulch and soil before the trees were randomly assigned to a gravel bed. One bed held a mixture of $88 \%$ pea gravel (1-cm minus), $2 \%$ Turface $^{\circledR}$, and $10 \%$ silica sand (by volume). The other bed contained a mixture of $90 \%$ basalt gravel $(1.2-\mathrm{cm})$ and $10 \%$ sand. Trees were grown in the gravel beds for 5 or 6 months before height increases were determined. If the terminal leader died on the tree, the next highest lateral branch was measured for its increase in length. All trees survived and actually grew a little during the summer after removing all the soil from their root systems. Several trees suffered slight needle burning at the ends of random branches, but the damage appeared minimal. Tips of several small branches randomly located around the canopies on several trees died back, and up to $10 \mathrm{~cm}$ of the terminal leaders on about half the trees died back. Height increases were similar among the different trees grown in the two types of gravel, with the mean increase in height being $8.9 \mathrm{~cm}$. The trees regenerated many roots in both types of gravel. In fact, new roots formed all over the root systems and encased large amounts of gravel, making its removal difficult. This study demonstrated that gravel beds can be used to help $1.8-\mathrm{m}$ tall Colorado spruce trees recover from severe root losses. 


\section{(106) Improved Root Growth of Corkbark Fir and Pinyon Pine Seedlings Grown in a Gravel Bed}

Robert R. Tripepi*, Mary W. George

University of Idaho, Horticultural Sciences Division, Moscow, ID 83844-2339

Seedlings of several conifer species can be difficult to transplant, with the problem often related to poor root regeneration. The objective of this study was to determine if corkbark fir (Abies lasiocarpa arizonica) seedlings or pinyon pine (Pinus edulis) seedlings would produce more root growth when grown in a Missouri gravel bed growing system compared to field soil. The 3-0 fir seedlings and 4-0 pine seedlings were planted in a gravel bed in mid-April. The gravel bed was $3 \mathrm{~m} \times$ $3.7 \mathrm{~m}$ and was filled with a mixture of $60 \%$ pea gravel ( $1 \mathrm{~cm}$ minus), $30 \%$ Turface $^{\circledR}$, and $10 \%$ silica sand (by volume). A field bed $3 \mathrm{~m} \times 3.7$ $\mathrm{m}$ in size was also prepared. Fir seedlings were harvested in September and October, but pinyon pine seedlings were harvested only in October due to their poor transplant survival. Plant heights, stem diameters, and root volumes, as well as root and shoot dry weights, were determined at harvest. Of all the measured growth parameters for both species, only root dry weights and root volumes were significantly different. In particular, fir seedlings grown in the gravel bed produced at least $30 \%$ more root dry weight and $74 \%$ more root volume than those planted in field soil whether plants were harvested in September or October. Likewise, pine seedlings grown in gravel produced at least 37\% more root dry weight and $86 \%$ more root volume than those grown in soil. In addition, only $10.6 \%$ of the pine seedlings planted in soil survived transplanting, but $23.3 \%$ of those grown in the gravel bed survived. This study demonstrated that corkbark fir and pinyon pine seedlings grown in a gravel bed produced larger root systems than those planted into field soil, and the gravel bed also improved pinyon pine seedling survival after transplanting.

\section{(107) Effects of Defoliants (CuEDTA and $\mathrm{ZnSO}_{4}$ ) and Foliar Urea on Defoliation and Nitrogen Reserves of Almond Nursery Plants}

\section{Guihong Bi*1, Carolyn Scagel ${ }^{2}$, Leslie Fuchigami ${ }^{1}$}

${ }^{1}$ Oregon State University, Horticulture, Corvallis, OR, 97331; ${ }^{2}$ USDA-ARS, Horticultural Crops Research Unit, Corvallis, OR, 97330

One-year-old field-grown 'Nonpareil'/'Nemaguard' and 'Nonpareil'/ 'Lovell' almond nursery trees were used to study the effects of chemical defoliants (CuEDTA and $\mathrm{ZnSO}_{4}$ ) and foliar applications of urea on defoliation and nitrogen $(\mathrm{N})$ reserves. Although both chemical defoliants significantly promoted earlier defoliation, CuEDTA was more effective than $\mathrm{ZnSO}_{4}$ in promoting early defoliation. Two applications of defoliant had a similar effect as one application on promoting leaf abscission. Foliar applications of urea in addition to defoliant applications (urea + defoliant treatments) generally increased the efficiency of $\mathrm{ZnSO}_{4}$ $(1.25 \%$ to $2 \%)$ and CuEDTA $(0.5 \%)$ in promoting early defoliation. Although treatments with only defoliants did not consistently lower $\mathrm{N}$ reserve levels, trees treated with foliar urea or urea + defoliants had significantly higher nitrogen reserves compared to trees receiving only defoliant treatments. $\mathrm{N}$ reserves were comparable in urea + defolianttreated trees to the levels found in naturally defoliated (control) trees. We conclude that both $\mathrm{CuEDTA}$ and $\mathrm{ZnSO}_{4}$ are effective in promoting early defoliation of almond nursery trees. Combining urea with defoliants can effectively promote early defoliation and is important for achieving $\mathrm{N}$ reserves similar to naturally defoliated trees.

\section{Poster Session 33-Plant Biotechnolgy 3}

\section{July 2005, 12:00-12:45 p.m. Poster Hall-Ballroom E/F}

(278) Virus Resistance in Orchid Plants Transformed with a Mutated Movement Gene of Cymbidium mosaic virus

Kullanart Obsuwan*1, Wayne B. Borth ${ }^{2}$, John $\mathrm{Hu}^{2}$, Adelheid R. Kuehnle ${ }^{1}$

${ }^{1}$ University of Hawaii, Tropical Plant and Soil Sciences, Honolulu, HI, $96822{ }^{2}$ University of Hawaii, Plant and Environmental Protection Sciences, Honolulu, HI, 96822

A Cymbidium mosaic virus movement protein gene with a site-specific mutation (mut11) under control of a ubiquitin promoter was inserted using biolistics into two Dendrobium varieties with the intention of creating CymMV-resistant orchids. Presence of the transgene in regenerated plants of $D . \times$ Jaquelyn Thomas 'Uniwai Mist' and $D . \times$ Jaq - Hawaii 'Uniwai Pearl' was confirmed by PCR using genomic DNA, and mut11-positive plants were potted ex vitro. Forty-two transgenic plants and four non-transgenic control plants at the 4- to 6-leaf stage were inoculated with a 1:1000 dilution of CymMV obtained from infected orchids. Plants were analyzed for systemic infection using tissue blot immunoassay (TBIA). Seventeen plants from at least six independent transformations remained virus-free, whereas all control plants were infected with CymMV within 1 month. Further analysis by RT-PCR showed that the mut-11 mRNA was detectable in only two of these 17 plants. All plants were challenged again with a second CymMV inoculation as above, followed by TBIA analysis after 1 month. Thirteen of 17 plants remained free from virus. A third challenge of these plants with CymMV as above was followed by TBIA analysis at 1 week, 2 weeks, 1 month, 3 months, 6 months, and 12 months after challenge. Results at 2 weeks post-inoculation showed that all six controls and four individual transgenic plants, including the RT-PCRpositive plants, became systemically infected. Nine transgenic plants from both varieties remained free from CymMV 12 months after the third challenge. Lack of detectable mut 11 mRNA in these resistant lines suggests that a post-transcriptional gene silencing (PTGS) mechanism may be conferring resistance to CymMV.

\section{(279) Morinda citrifolia In Vitro Seminal Germination, Callus and Organogenesis Induction}

\section{Michael J. Tanabe*, Nicole Wakida}

University of Hawaii at Hilo, College of Agriculture, Forestry and Natural Resource Management, Hilo, HI, 96720-4091

Noni, Morinda citrifolia, is receiving a lot of attention for its potential medicinal effects. Hawaii is an ideal growing environment for this plant, where it has been used for many purposes, including medicinal ones, by ancient Polynesians. Currently, there is a rapidly developing noni industry in the state of Hawaii. Propagation of this plant is almost exclusively by seeds, and germination generally requires a couple of months without preconditioning or about a month if mechanically scarified. We developed an in vitro protocol that significantly improves percent germination rate by altering incubation temperature and the in vitro culture basal medium. Germination time was decreased to 4 days when the embryo was extracted and exposed to $31^{\circ} \mathrm{C}$. A basal medium containing 1/2 Murashige and Skoog (M\&S) salts was the most effective in reducing germination time and increasing percent germination. Stem pieces obtained from in vitro-propagated seedlings produced callus when explanted in $1 / 2 \mathrm{M} \& \mathrm{~S}$ containing various levels of naphthalene acetic acid (NAA). The most effective treatment was $0.5 \mu \mathrm{M}$ NAA and the least effective treatment was $2 \mu \mathrm{M}$ NAA. Treatments without NAA did not produce callus. Calli treated with $4.40 \mu \mathrm{M}$ 6-benzylaminopurine (BA) or $8.80 \mu \mathrm{M}$ BA were the most effective in promoting caulogenesis. We also demonstrated that the number of first generation seedlings produced from each embryo could be increased by treatment with $8.80 \mu \mathrm{M}$ BA.

\section{(280) Plant Regeneration of Periwinkle (Catharanthus roseus) from In Vitro Leaf Tissues}

Wenhao Dai*, Victoria Jacques

North Dakota State University, Plant Sciences, Fargo, ND, 58105

Periwinkle, a perennial commonly used as a summer bedding plant, is known as the source of vinca alkaloids used to treat lymphocytic leukemia and Hodgkin's disease. It is also one of the natural hosts of many phytoplasma diseases, such as X-disease of major Prunus species, aster yellows, and ash yellows diseases. Therefore, periwinkle is an ideal plant species for phytoplasma disease research, such as disease transmission, species resistance, and resistant gene screening. Periwinkle tissue culture was established by incubating sterile seeds in hormone-free Murashige and Skoog(MS) medium. Plants were successfully regenerated from in vitro leaf tissues of periwinkle. Adventitious shoots were induced when leaf tissues were cultured on Murashige and 
Skoog (MS) medium or woody plant medium (WPM) supplemented with benzyladenine (BA) and naphthaleneacetic acid (NAA). Nearly $75 \%$ of leaf explants produced shoots in both media with $10-20 \mu \mathrm{M}$ BA and $1 \mu \mathrm{M}$ NAA. A mean of 4.3 shoots was produced from each explant cultured on WPM, whereas only 2 shoots were produced on MS medium under 16-h photoperiod. Leaf explants under dark treatment for 2 weeks produced big callus only, indicating that light is necessary for shoot formation. Most adventitious shoots were induced from the joint of leaf blade and petiole. In vitro shoots $(>1.5 \mathrm{~cm})$ were easily rooted in half-strength MS medium. Addition of NAA dramatically increased root number, with more than 20 roots being induced in 5 $\mu \mathrm{M}$ NAA medium. Rooted plants were transferred to potting medium and grown in a greenhouse.

\section{(281) Effects of Colchicine and Oryzalin on Callus and Adventitious Shoot Formation of Euphorbia pulcherrima 'Winter Rose ${ }^{\text {'m }}$}

\author{
Kimberly A. Pickens ${ }^{1}$, (Max) Zong-Ming Cheng*2, \\ Stephen A. Kania ${ }^{3}$ \\ ${ }^{1}$ Macon Sate College, Natural Sciences \& Math, Macon, GA, $31206 ;{ }^{2}$ University of Ten- \\ nessee, Department of Plant Sciences, Knoxville, TN, 37996; ${ }^{3}$ University of Tennessee,
} Department of Comparative Medicine, Knoxville, TN, 37996

Poinsettia, Euphorbia pulcherrima, is an important holiday symbol and is the number one flowering potted plant in the United States. The technique of chromosome doubling has been utilized to increase size of flowers, stems, and leaves of many species, and has been used in poinsettia breeding to obtain new cultivars. Application of colchicine or oryzalin to in vitro tissues may be used to enlarge the inflorescences and brackets and reduce the height of 'Winter Rose ${ }^{\text {'TM }}$ poinsettias, reduce the likelihood of chimeric tetraploids, and provide a rapid means for producing many tetraploid plants. The purpose of this research was to evaluate the effect of colchicine and oryzalin on callus and adventitious shoot formation of 'Winter Rose' ${ }^{\text {, }}$ poinsettia with in vitro grown leaf tissues and its potential for tetraploid induction. In vitro grown leaf midvein sections were placed on various media supplemented with either colchicine or oryzalin at various concentrations for 1-4 days. Colchicine was least damaging to leaf tissues at concentrations of 0.25 or $250.4 \mu \mathrm{M}$. A large amount of callus, as well as adventitious shoots, were produced. Regenerated shoots were found to be diploid, determined by flow cytometry. On media with oryzalin $(28.9-144 \mu \mathrm{M})$, leaf tissues produced callus, but not adventitious shoots. Calluses produced on oryzalin-containing media were tested using the flow cytometer and were found to be diploid.

\section{(282) In Vitro Indirect Organogenesis of Leucocoryne purpurea, an Ornamental Geophyte Species Endemic to Chile}

Luis Humberto Escobar Torres*, Eduardo Alejandro Olate Muñoz, Miguel Jordan, Marlene Gebauer

Pontificia Universidad Católica de Chile, Horticulture, Vicuña Mackenna \#4860, Santiago, Región Metropolitana, Chile

Callus induction (CI) and later shoot induction (SI) were studied in Leucocoryne purpurea, a native and endemic Chilean geophyte species. Basal leaf portions (BL), bulb basal plate (BP), and root tips (RT) from in vitro plants were used as explants. Treatments for CI included all three explants and media containing different sources and concentrations of auxins and cytokinins as plant growth regulators (PGRs). Plant material was initiated on MS basal medium (Murashige and Skoog, 1962), supplemented with vitamins, $30 \mathrm{~g} \cdot \mathrm{L}^{-1}$ sucrose, $6.0 \mathrm{~g} \cdot \mathrm{L}^{-1}$ agar and $\mathrm{pH}$ adjusted to 5.7 before autoclaving. The experiments were carried on a growth chamber at $24 \pm 1.5^{\circ} \mathrm{C}$. CI cultures were maintained in darkness for 16 weeks, and SI for 12 weeks in a 16-hour photoperiod. $\mathrm{BL}$ and RT explants did not respond to any of the CI treatments. BP explants cultured on MS basal medium without PGRs also did not produce any callus. The average frequency of callus induction for BP was $78 \%$ and the average fresh weight of callus was $10.06 \mathrm{~g} /$ explant after 16 weeks of culture. Best treatment for CI was BP cultured on $4.52 \mu \mathrm{M}$ 2,4-dichlorophenoxyacetic acid (2,4-D) in combination with $0.45 \mu \mathrm{M}$ 6-benzyladenine (BA), when they were compared to 2,4-D alone or picloram as auxin source. After 16 weeks of culture, calli were transferred to SI medium, supplemented with three different concentrations of thidiazuron (TDZ), either intact or subdivided ( $150 \mathrm{mg} /$ explant). SI treatments had a greater and significant response when the callus came from a CI medium containing auxin and cytokinin combined, in comparison to those coming from a CI medium containing auxins only.

\section{(283) Petal Color Changes in Carnation Plants Transformed with an Antisense DFR and a CHI Gene}

Kyung Hee Hwang ${ }^{1}$, Byung Hwan Min², Haki Shin², Byung Joon Ahn*1

${ }^{1}$ Dankook University, Ornamental Horticulture; ${ }^{2}$ Nong Woo Bio Co., Ltd, Bio Res Institute, Yeoju, Kyunggido, 469-880, Korea; ${ }^{3}$ National Horticultural Research Institute, RDA, Floriculture, Suwon, 440-760, Korea

To produce transgenic carnation plants expressing modified flower colors, cultivars of red-flowering carnation ('Desio' and 'Garnet') were transformed with a antisense DFR gene encoding dihydroflavonol-4reductase, and yellow-flowering carnations ('Pallas' and 'Keumbyul') were introduced with a $\mathrm{CHI}$ gene encoding chalcone synthease isomerase. Explants of leaves, stems, and shoot tips were inoculated with Agrobacterium and grown overnight in induction broth supplemented with $0.2 \mathrm{~mm}$ acetosyringone. The cocultures of carnation explants were maintained in the light at $24^{\circ} \mathrm{C}$ on one-half strength MS medium solidified with $0.3 \%$ Gelite and supplemented with $1.0 \mathrm{mg} \cdot \mathrm{L}^{-1} \mathrm{BA}$ for 10 days, and then were transferred to a selection medium containing $250 \mathrm{mg} \cdot \mathrm{L}^{-1}$ cefotaxime/carbenicillin, $500 \mathrm{mg} \cdot \mathrm{L}^{-1}$ kanamycin. They were subcultured every 2 weeks for over six times and regenerated. In 'Garnet' and 'Desio' carnation cultivars, a total of 146 plants was transformed with anti-sense DFR gene in pGA748/LBA4404. In yellow flowering cultivars 'Pallas' and 'Keumbyul', transformed with CHI gene in pGA748/LBA4404, 20 putative transformants obtained. The introduction of the transgenes were confirmed through PCR and flower color changes. Rates of phenotypic expression of the transgene, antisense DFR gene, vary among the transformants such as lighter pigmentation or chimeric discoloration, more prominently in outer petals of the flowers. Transgenic plants of chi gene bloomed flowers of lighter yellow petals in general. The most prominent phenotypic changes were discoloration of red strips on petals, which are typical characteristics of the cultivars.

\section{(284) Characterization of the Genus Corylopsis}

Mark S. Roh*1, Eunju Cheong ${ }^{1}$, Ik-Young Choi ${ }^{2}$, Eun-Ha Yoo ${ }^{3}$, Jae-Young $\mathrm{Kim}^{3}$, Nam Sook Lee ${ }^{4}$

${ }^{1}$ Floral and Nursery Plants Research Unit, USDA, ARS, National Arboretum, Beltsville, MD, 20705; ${ }^{2}$ Soybean Genomics and Improvement Laboratory, USDA, ARS, Plant Sciences Institute; ${ }^{3}$ Floriculture Division, RDA, NHRI, Suweon, Korea; ${ }^{4}$ Department of Life Sciences, Ewha Womans University, College of Natural Science, Seoul, Korea

We investigated the interspecific relationships and intraspecific variations in the genus Corylopsis using RAPD and single nucleotide polymorphism (SNP) in the internal transcribed spacer1(ITS1), 5.8S ribosomal RNA gene specific in C. glabrescens Franch. \& Sav. Differences in species identification between morphological characteristics and RAPD result were noticed in some accessions. All C. glabrescens, C. coreana Uyeki, and C. glabrescens f. gotoana (Makino) T. Yamanaka accessions clustered in one major group. However, they could be divided into five subgroups that are not related to the geographical origins. For example, $C$. coreana accessions from Korea were clustered with $C$. glabrescens from Japan. Although grouping based on SNP data does not agree with that by RAPD markers, it revealed the limitation in identification and classification of the genus due to high intraspecific variations in SNP. At SNP positions 464, 465, 466, 467, and 496, most accessions of C. glabrescens and C. coreana have C, G, A, A, and T, respectively. In both analyses, $C$. glabrescens, $C$. coreana, and $C$. glabrescens f. gotoana Japan are closely related and this suggests that nomenclature for these three species should be discussed. Although ITS1 5.8S ribosomal RNA gene can not be used for identification at a subspecies level of $C$. glabrescens, it proved to be useful to differentiate $C$. sinensis from $C$. sinensis var. calvescens. It is suggested to use C. glabrescens f. gotoana or C. glabrescens f. coreana rather than using C. coreana. 


\section{Poster Session 34-Propagation 2}

20 July 2005, 12:00-12:45 p.m. Poster Hall-Ballroom E/F

\section{(173) Monolithic Slag as a Substrate for Rooting and Production of Bare-root Cuttings}

Eugene K. Blythe*, Jeff L. Sibley, Ken M. Tilt

Auburn University, Dept. of Horticulture, AL, 36849

Stem cuttings of Hydrangea paniculata Sieb., Rosa L. 'Red Cascade', Salvia leucantha Cav., and Solenostemon scutellarioides (L.) Codd 'Roseo' were inserted into six rooting substrates: monolithic slag $\left[(\mathrm{MgFe})_{2} \mathrm{Al}_{4} \mathrm{Si}_{5} \mathrm{O}_{18}\right]$, sand, perlite, vermiculite, Fafard 3B, or fine pine bark. Rooting, initial shoot growth, and ease of dislodging substrate particles from root systems upon bare-rooting by shaking and washing cuttings rooted in monolithic slag were compared to cuttings rooted in the five other substrates. Rooting percentage, number of primary roots per rooted cutting, and total root length per rooted cutting for cuttings rooted in monolithic slag were generally similar to the five other substrates. Particles of monolithic slag were dislodged more readily from root systems by shaking than were the other substrates. Gentle washing removed almost all particles of monolithic slag and sand from the root systems of all taxa and removed almost all particles of pine bark from all taxa except $S$. scutellarioides 'Roseo'. Monolithic slag had a bulk density similar to sand, retained less water than the other substrates, and was similar to perlite, vermiculite, and pine bark in particle size distribution. Our studies indicate that monolithic slag, where regionally available, could provide a viable material for producing bare-root cuttings.

\section{(174) In Vitro Regeneration of Cornus kousa}

Denita Hadziabdic ${ }^{1}$, Robert N. Trigiano*1, Stephen Garton ${ }^{2}$, Mark T. Windham ${ }^{1}$

${ }^{1}$ University of Tennessee, Entomology and Plant Pathology, Knoxville, TN, 37996-4560; ${ }^{2}$ University of Tennessee, Dept. of Plant Sciences

Axillary and apical buds from five Cornus kousa cultivars ('Little Beauty', 'Samaritan', 'Heart Throb', 'Rosabella', and 'Christian Prince') were initially established on two basal media, woody plant medium (WPM) and woody plant medium/broad leaved tree medium (BW), amended with the following concentrations of 6-benzylaminopurine (BA): $0,2,4$, and $8 \mu \mathrm{M}$. After explants were transferred at 4-week intervals for 28 weeks beginning in April, only microshoots of 'Samaritan', 'HeartThrob' and 'Rosabella', were harvested from proliferating cultures and placed on rooting media. 'Little Beauty' and 'Christian Prince' did not perform well in multiplication phase of tissue culture and were excluded from further studies. Rooting media contained WPM or BW supplemented with either 1-naphthaleneacetic acid (NAA), indole-3-butyric acid (IBA) or indole-3-acetic acid (IAA) at the following concentrations: $0,0.5,1.5,4.5$, and $13.5 \mu \mathrm{M}$. Six weeks following rooting experiment, preliminary data were collected and results showed that total of nine plants rooted on both WPM and BW media supplemented with IBA, 17 plants rooted on media supplemented with NAA, and 14 plants rooted on media supplemented with IAA. These results indicated that NAA and IAA appeared to be better for root production on C. kousa cultivar microshoots than IBA. Additionally, WPM supported more root production, when compared to BW, even though both media resulted in rooted microshoots. Proliferating masses were placed on fresh medium with $2 \mu \mathrm{M}$ BA and were used again for the rooting projects.

\section{(175) In Vitro Regeneration of Cladrastis kentukea}

Denita Hadziabdic ${ }^{1}$, Robert N. Trigiano*1, Stephen Garton ${ }^{2}$, Mark T. Windham ${ }^{1}$, William E. Klingeman ${ }^{2}$

${ }^{1}$ University of Tennessee, Entomology and Plant Pathology, Knoxville, TN, 37996-4560; ${ }^{2}$ University of Tennessee, Dept. of Plant Sciences, Knoxville, TN, 37996-4561

Axillary buds from a single Cladrastis kentukea tree were initially cultured on two media, woody plant medium (WPM) and Murashige and Skoog (MS) containing 0, 1, 2, or $4 \mu \mathrm{M} 6$-benzylaminopurine(BA).
Cultures were transferred to fresh media every 4 weeks. Elongated shoots were harvested after 39 weeks and transferred to half-strength MS medium supplemented with the following concentrations of IBA: $0,3,30,100$, and $300 \mu \mathrm{M}$ for $3 \mathrm{~d}$, then returned to half-strength MS without growth regulators. Explants exposed to $300 \mu \mathrm{M}$ of IBA produced significantly more roots $(75 \%)$ compared to explants exposed to other treatments. Fifty-four and $45 \%$ of the microshoots rooted when exposed to 100 and $30 \mu \mathrm{M}$ IBA, respectively. Only $4 \%$ of the microshoots rooted when exposed to $3 \mu \mathrm{M}$ IBA and none of the control microshoots rooted. Although the $300 \mu \mathrm{M}$ treatment yielded the most rooted plantlets, there was significantly higher terminal meristem abortion compared to other treatments. There were no statistical differences between the numbers of roots and total root length among all treatments. Additionally, all microshoots that rooted had lenticels, suggesting that presence of lenticel cambial activity can possibly improve rooting abilities of selected microshoots. Rooted microshoots were gradually acclimatized to nonsterile environment.

\section{(176) In Vitro Germination of Galax under Different Culture Medium pH Conditions}

Guochen Yang*, Carl Niedziela, Zhongge (Cindy) Lu

North Carolina A\&T State University, Natural Resources and Environmental Design, Greensboro, NC, 27411

The goal of this study was to expedite galax seed germination in vitro. Galax seeds were collected from Yancey County, N.C., at an elevation of about $1100 \mathrm{~m}$. Aseptic cultures were established using the tiny rustcolored seeds. In vitro seed germination was achieved under different $\mathrm{pH}$ conditions (4.2, 5.0, and 5.8). Seeds cultured in the medium with $\mathrm{pH} 4.2$ tended to germinate early with a better rate than those cultured with a higher $\mathrm{pH}$ of 5.0 or 5.8 at the very beginning. Gradually, seeds from media with pH 5.0 and 5.8 caught up in germination. Eventually, seeds from all $\mathrm{pH}$ treatments produced a very similar germination rate. Attempts to use the matted and scaly rhizomes and very tender new growth as explant materials to establish aseptic cultures were not successful, due to severe contamination. However, our observations suggested that the very tender new growth could be a good source of explants once the optimum sterilization time is established.

\section{(177) Evaluation of Different Factors on Regeneration of Plantlets from Embryos of Cycas revoluta Thunb.}

\section{Laura M.R. Rinaldi*}

CNR, IVALSA, Via Madonna Del Piano, Sesto Fiorentino, Firenze, 50019, Italy

The micropropagation of Cycas revoluta Thunb. via somatic embryogenesis was tested on immature and mature embryos using 2,4dichlorophenoxyacetic acid (2,4-D) in combination with benzyladenine (BA) or kinetin. In addition, the effect of media manipulation on the induction of adventitious buds was studied to optimize culture parameters for the regeneration of plantlets via organogenesis from mature embryos. Schenk and Hildebrandt basal medium containing six different $\mathrm{NO}_{3}{ }^{-}: \mathrm{NH}_{4}^{+}$ratios (from $90: 10$ to $65: 35$ ) and BA at $9 \mu \mathrm{M}$ was used. The development of induced buds occurred on the medium containing the identical $\mathrm{NO}_{3}^{-}: \mathrm{NH}_{4}^{+}$composition without growth regulators. The effects of two IBA concentrations on the rooting of elongated shoots were evaluated. The treatment of immature embryos with $2.26 \mu \mathrm{M} 2,4-\mathrm{D}$ and $0.44 \mu \mathrm{M}$ BA and that of mature embryos with $0.9 \mu \mathrm{M} 2,4-\mathrm{D}$ and $4.40 \mu \mathrm{M}$ BA promoted growth of embryogenic tissue followed by embryo formation that failed to develop further. Bud induction was obtained through the whole range of $\mathrm{NO}_{3}^{-}: \mathrm{NH}_{4}^{+}$ ratios tested. Small decrease in these ratios affected subsequent differentiation and growth. Adventitious shoots obtained on $70 \% \mathrm{NO}_{3}^{-}$ showed two-fold increase in height and diameter compared with those regenerated on $75 \% \mathrm{NO}_{3}^{-}$. Furthermore, $7 \%$ of the former produced at the shoot base adventitious shoots that have similar morphology to offset growing at the base of mature plant. The rooting percentage of shoots was low. Considering the difficulty in achieving somatic embryogenesis, these results suggested that among micropropagation techniques organogenesis can be applicable for production of Cycas, although rooting is still the limiting factor. 


\section{(178) Layering Propagation of Bigtooth Maple, Acer grandidentatum}

\section{Larry A. Rupp*1, William A. Varga², Roger Kjelgren ${ }^{3}$}

${ }^{1}$ Utah State University, Plants, Soils, and Biometeorology, Logan, UT, 84322-4820; ${ }^{2}$ Utah State University, Utah Botanical Center; ${ }^{3}$ Utah State University, Plants, Soils, and Biometeorology

Bigtooth maple (Acer grandidentatum Nutt.) is of interest for its fall color and potential use in water-conserving landscapes. Clonal propagation of desirable selections would be beneficial. Since bigtooth maple commonly self-propagates by layering, we explored mound layering as a means of vegetative propagation. A stool bed was established in 1999 with seedlings grown from northern Utah seed. Beginning in 2001, seedlings were dormant pruned to their base and shoots allowed to grow until early July, when treatments were applied. At the time of treatment application for the reported experiments, shoot bases were girdled with 24-gauge copper wire, covered with conifer wood shavings, and kept moist during the growing season. The effects of rooting hormones and enclosure of the rooting environment on rooting were examined. On 7 July 2002, 32 trees were randomly selected and the four tallest shoots within each tree were treated with either $0,1: 5,1: 10$, or $1: 20(\mathrm{v} / \mathrm{v})$ solutions of Dip-N-Gro ${ }^{\circ}$ rooting hormone $(1 \% \mathrm{IBA}, 0.5 \%$ NAA, boron). There was no significant difference in rooted shoots between treatments and $81 \%$ of the trees had at least one rooted shoot. On 9 July 2004, 39 trees were selected and two shoots per tree were girdled. One-half of the stool bed area was treated by underlaying the shavings with BioBarrier ${ }^{\mathcal{O}}$ (17.5\% trifluralin a.i.). Measurements on 12 Nov. 2004 showed no apparent treatment effect on rooting and $90 \%$ of the trees had at least one rooted shoot. This research demonstrates that mound layering is an effective means of rooting shoots of juvenile bigtooth maples. Further research will examine the effectiveness of the technique in propagating mature clones.

\section{Poster Session 35-Vegetable Crops Management- Cropping Systems 2}

20 July 2005, 12:00-12:45 p.m. Poster Hall-Ballroom E/F

\section{(195) Evaluation of Solid Artificial Media on Lettuce Seedling Growth and Anchorage}

Jill A. Montgomery*, H. Chris Wien

Cornell University, Horticulture, Ithaca, NY, 14850

A study was conducted to compare three sterile, commonly used soilless media (Agrifoam ${ }^{\mathrm{TM}}$ and Oasis ${ }^{\mathrm{TM}}$, growth foams, and Grodan ${ }^{\mathrm{TM}}$, an expanded rockwool substrate) to determine which media characteristics favor seedling development and establishment in hydroponic systems. These media were studied during days $7-10$ of the seed germination stage, when one often observes with the use of foam media the occurrence of "pop-outs," a disorder in which actively growing roots do not penetrate and spiral on the media surface causing the root tip to die. High percentages of pop-outs cause poor seedling stand, and discourage the use of soilless media for seedling germination. Pop-outs were more frequently observed in Agrifoam (50\%) compared to the other media, with Oasis intermediate (15\%), and Grodan least affected $(>5 \%)$. Both physical and chemical characteristics were analyzed to isolate the causes of pop-outs. Oasis and Agrifoam both have higher water retention, and pop-outs increased as the water content of the foam increased. High soluble salts, particularly high magnesium in the root zone, produced roots that were "burned" and did not grow. When magnesium salts in concentrations equivalent to that found in Agrifoam were added to Grodan (control substrate), the number of pop-outs increased. The roots were stunted with little or no root hairs, resembling roots when grown in Agrifoam. We conclude that the high incident of pop-outs in Agrifoam, and to a lesser extent, in Oasis, is caused by high-medium water content and toxic levels of magnesium ions in solution.

\section{(196) Inducing Lettuce Tipburn with Relative Humidity Modification}

H. Chris Wien*1, David S. de Villiers ${ }^{2}$

${ }^{1}$ Cornell University, Horticulture, 156 Plant Science Hall, Ithaca, NY, 14853; ${ }^{2}$ Cornell University, Biological and Environmental Engineering, Ken Post Laboratory

Tipburn is a necrosis of the rapidly expanding young leaves of lettuce, caused by a localized $\mathrm{Ca}$ deficiency that is a major constraint to raising productivity of hydroponically-grown leaf lettuce. Root pressure is thought to be important in distributing calcium to young tissue that is not transpiring rapidly in crops such as cabbage, tomato and strawberry. Since root pressure is enhanced by high relative humidity $(\mathrm{RH})$, experiments were conducted with two cultivars of leaf lettuce to determine if regulating relative humidity during the day or night would influence tipburn incidence. Lettuce was grown hydroponically in a glass-covered greenhouse. Plants were transferred to ponds of $1 \times 2 \mathrm{~m}$ size, starting at about day 25 from sowing. Four ponds containing 42 plants each were subjected to ambient or elevated $\mathrm{RH}$, either during the day, or at night, or at both times. Each pond was covered by a clear polyethylene ventilated canopy, to ensure maintenance of the desired $\mathrm{RH}$ condition. The experiment was conducted five times. In three experiments, tipburn developed in 3 or 7 days, depending on the cultivar. The disorder was most severe in ponds whose atmosphere was constantly humid, followed by the treatment that provided humid days and dry nights. Treatments which provided dry conditions, either during the day, or continuously, were least affected. In two experiments, ambient $\mathrm{RH}$ rose above $70 \%$, and the differential effect of humidity on tipburn incidence was no longer evident. Both cultivars reacted similarly to the treatments, even though 'Winter Density' developed the disorder 4 days before 'Batavian'. The results imply that root pressure is less important than transpiration in distributing $\mathrm{Ca}$ to the edges of young leaves of leaf lettuce.

\section{(197) Effect of the Number of Fruit per Plant on Production of Dried Seed and Fruit Yield in Pumpkin}

Sang Gyu Lee*1, Dong Kum Park ${ }^{1}$, Kyung Sup Park ${ }^{1}$, Yun Chan $\mathrm{Heo}^{1}$, Yoon Ah Jang ${ }^{1}$, Kwan Dal Ko ${ }^{1}$, Chiwon W. Lee ${ }^{2}$

${ }^{1}$ National Horticultural Research Institute, Vegetable Research Division, 475 Imok-dong, Jangan-gu, Suwon, Kyunggi-do, 440-706, South Korea; ${ }^{2}$ NDSU, Plant Sciences, $266 \mathrm{~F}$ Loftgard Hall, Fargo, ND, 58105-5051

The fruits of pumpkin are good material for soup and a very popular side dish in Korea. The purpose of this study was to investigate how number of fruit set per plant (2, 3, or 4 fruit) affected production of dried seed and fruit yield. 'Golden Delicious' (GD) and hull-less (HL) pumpkins were planted $60 \mathrm{~cm}$ apart in $200-\mathrm{cm}$ rows. Production of dried seed per hectare (11,000 plants) were 1985, 2193, and $2074 \mathrm{~kg}$, respectively, at 2-, 3-, and 4-fruit set per plant for GD. The fruit yield per hectare $(11,000$ plants) was $58,360 \mathrm{~kg}$ for 2-fruit set treatment, $74,680 \mathrm{~kg}$ for 3-fruit set, and 73,240 kg for 4-fruit set per plant for GD. The production of dried seed per hectare ( 11,000 plants) was 535,603 , and $545 \mathrm{~kg}$, respectively, for 2-, 3-, and 4-fruit set per plant for HL. The fruit yield per hectare (11,000 plants) was $28,200 \mathrm{~kg}$ for 2-fruit set treatment, $44,660 \mathrm{~kg}$ for 3-fruit set, and $39,200 \mathrm{~kg}$ for 4 -fruit set per plant for HL. The highest production of dried seed and fruit yield were for 3-fruit set per plant for GD and HL. Differences in production for dried seed and fruit yield, as influenced by number of fruit set per plant, were also characterized.

\section{(198) Growth and Development of Watermelon Plants Grafted onto Citrullus Rootstocks Selected for Disease Resistance at Two Temperature Regimes}

Yun-Chan Huh ${ }^{1}$, Du-Hyun Kim², Sang-Gyu Lee ${ }^{1}$, Kyoung-Sub Park ${ }^{1}$, Dong-Kum Park ${ }^{1}$, Young-Hoe Woo ${ }^{3}$, Jung-Myung Lee*4

${ }^{1}$ National Horticultural Research Institute, Vegetable Science Division, 475, Imok-dong, Jangan-Gu, 441-440, Korea, Suwon, Gyeonggi-do, 440-706, Korea; ${ }^{2}$ National Plant Quarantine Service, Pest Survey \& Control Division, 433-1 Anyang 6-dong, Manan-ku, Anyang, Gyeonggi-do, 430-016, Korea ${ }^{3}$ Korea National Agricultural College, Dept. of Vegetable, 11-1 Donghwa-Ri Bongdam-eup, Hwaseong, Gyeonggi-do, 445-893, Korea; ${ }^{4}$ Kyunghee University, Dept. of Horticulture, 1 Sochen-ri, Giheung-eup, Yongin, Gyeonggi-do, 449-701, Korea

Growth response of ‘Sambok Honey’watermelon grafted onto different 
rootstocks, including four Citrullus rootstocks and three other cucurbitaceous rootstocks, was evaluated at low and normal temperature regimes. Marked reduction in plant growth rate was observed in plants grown at low temperatures as compared to those grown at normal or optimal temperatures. Relative growth reduction rates were $40 \%$ to $48 \%$ for vine length, $39 \%$ to $51 \%$ for total leaf area, $37 \%$ to $60 \%$ for shoot fresh weight, and $50 \%$ to $79 \%$ for shoot dry weight, respectively. Watermelon rootstock PI 482322 showed comparable plant growth as the most popular rootstock (Shintozwa pumpkin) even at low temperatures. 'Sambok Honey' watermelon grafted onto watermelon hybrids 'PI $271969 \times$ PI 296341' and 'PI $271769 \times$ Calhoun Gray', showed comparable plant growth as FR Dantos bottle gourd rootstock. Index of growth ability at low temperature (IGALT), which was calculated on the basis of reduced rate of vine length, dry weight, and leaf area, was comparatively high in C. martinezii, Shintozwa, PI 482322, and 'PI $271769 \times$ PI 296341 ' rootstocks $(50 \%$ or higher) and lowest in own-rooted 'Sambok Honey' or in watermelon plants on 'Knight' rootstock. Watermelon hybrids 'PI $271969 \times$ PI 296341' and 'PI $271769 \times$ Calhoun Gray' exhibited better or at least comparable growth at low temperatures as compared to 'FR Dantos', thus confirming the feasibility of using watermelon rootstocks even in winter greenhouse conditions.

\section{(199) Effect of Soil Amendments and Mulching on the Incidence of Fusarium Wilt and Cantaloupe Yield in the Pacific Central Region of Mexico}

Mario Orozco-Santos ${ }^{1}$, Javier Farías-Larios*2, Jaime MolinaOchoa $^{2}$, José Gerardo López-Aguirre

${ }^{1}$ INIFAP, Campo Experimental Tecomán, Colima, 28100, México; ${ }^{2}$ Universidad de Colima, Facultad de Ciencias Biológicas y Agropecuarias, Tecomán, Colima, 28100, México

Melon wilt (MW) is one of the main diseases affecting the cucurbitaceous crops in the Pacific Central region of Mexico. The use of resistant varieties is the most effective strategy to reduce the damage caused by MW; however, variety performance depends on the fungal race occurring in the field. The use of fungicides, such as benzimidazols and methyl bromide, is a common practice, but there are contamination concerns, and a search is on for alternatives to diminish the negative effects on the agro-ecosystem. The aim was to determine the effect of the application of soil amendments and mulching on the incidence of MW, and on melon yield. Soil amendments incorporated were: rice straw $\left(3 t \cdot h a^{-1}\right)$; compost 1 , prepared with chicken and bovine manure, and banana and orange wastes $\left(5.7 \mathrm{t} \cdot \mathrm{ha}^{-1}\right)$; compost 2 , prepared with bovine and horse manure, coconut wastes and grasses $(8$ $\left.\mathrm{t} \cdot \mathrm{ha}^{-1}\right)$, vermicompost $\left(3 \mathrm{t} \cdot \mathrm{ha}^{-1}\right)$, and a control. All treatments were established using transparent mulching during 21 days. The number of MW propagules in amended soils were similar at 5, 10, and 20 $\mathrm{cm}$ deep, but the percentage of diseased plants was higher $(4.5 \%)$ in the control, which could be caused by the incidence of other fungi propagules, perhaps antagonistic, that contributed in diminishing the MW when compared with the control. The fruit weights and fruit sizes were not different between treatments on small (21-30 sizes), medium (15-18 sizes), and large (9-12 sizes), but total fruit numbers were 1.15-, 1.07-, 0.99-, and 1.09-fold higher when compared with the control. The application of soil amendments affected the antagonistic fungal populations even when it did not affect the cantaloupe yield. We suggest that soil amendments will improve soil fertility and increase melon yields, and studies are currently running.

\section{(200) Influence of Planting Density on Yield and Quality of Confectionery Seed Pumpkins}

Sung Eun Lee*, Chun Ho Pak, Yong Beom Lee, Harlene Hatterman-Valenti, Chiwon W. Lee

North Dakota State University, Plant Sciences, Loftsgard Hall, Fargo, ND, 58105

A field study evaluated the influence of planting density on the yield and quality of confectionery seed pumpkins grown near Hatton, N.D. An open-pollinated selection of Chinese snow-white seeds (CS) and a hull-less (HL) seed cultivar ('Takai', Johnny's Selected Seeds) were grown at three different planting densities (1-, 2-, or 3-ft plant spacing on rows $5 \mathrm{ft}$ apart) from 5 May to 7 Oct. The total number of plants at high, medium, and low densities was 8712, 4356, and 2904 per acre $(21,529,10,764$, and 7176 plants per ha, respectively). The average number of fruits harvested at high, medium, and low densities, respectively, was $0.93,1.2$, and 1.4 per plant for CS and 1.2, 1.7, and 2.5 per plant for HL. Total seed yields were estimated at 1011, 599, and $466 \mathrm{~kg} /$ acre $\left(2498,1480\right.$, and $\left.1151 \mathrm{~kg} \cdot \mathrm{ha}^{-1}\right)$ for CS and 661, 500, and $498 \mathrm{~kg} /$ acre $\left(1633,1235\right.$, and $\left.1231 \mathrm{~kg} \cdot \mathrm{ha}^{-1}\right)$ for HL, respectively, at high, medium, and low planting densities. While the average weight of fruits decreased as planting density increased, the total number and weight of seeds produced per fruit were unaffected by changing plant density in either cultivar.

\section{(201) Strategies to Encourage Grower/Industry Participation in the Development of BMPs for Vegetables in Southern Florida}

Mary Lamberts*1, Teresa Olczyk ${ }^{2}$, Phyllis Gilreath ${ }^{3}$, Gene McAvoy $^{4}$, Alicia Whidden 5 , Darrin Parmenter ${ }^{6}$, Ed Skvarch ${ }^{7}$, Yuncong $\mathrm{Li}^{8}$, Christine Coffin ${ }^{9}$, Donald Pybas ${ }^{1}$

${ }^{1}$ University of Florida, Miami-Dade County Extension, Homestead, FL, 33030-2309; ${ }^{2}$ University of Florida, Miami-Dade County Extension, Homestead, FL, 33030-2309; ${ }^{3}$ University of Florida, Manatee County Extension, 1 Palmetto, FL, 34221; ${ }^{4}$ University of Florida, Hendry County Extension, LaBelle, FL, 33975; ${ }^{5}$ University of Florida, Hillsborough County Extension, Seffner, FL, 33584; ${ }^{6}$ University of Florida, Palm Beach County Extension, West Palm Beach, FL, 33415; ${ }^{7}$ University of Florida, St. Lucie County Extension, Ft. Pierce, FL, 34945; ${ }^{8}$ University of Florida, Tropical Research \& Education Center, Homestead, FL, 33031; ${ }^{9}$ USDA, Natural Resource Conservation Service, Florida City, FL, 33034

Florida, like other states, is developing BMPs for specific commodities. Vegetables are in a statewide document that includes field crops. Vegetable advisory committee members from the counties in southern Florida were concerned that the existing document was too broad in its scope and that many practices did not apply to production on sandy or calcareous soils. Based on grower comments, extension agents organized grower meetings to address these issues. The first meeting was a presentation by the Florida Department of Agriculture and Consumer Services (FDACS) Office of Agricultural Water Policy. The second meeting in Miami-Dade was a hands-on session, where growers and industry were divided into three areas - nutrition, pesticides, and water quality. Each group was facilitated by a faculty member or the NRCS conservationist. Other counties used newsletters and other methods to receive grower feedback. Participant comments were compiled and forwarded to FDACS, where they are being incorporated into a greatly revised document. Concerns will be presented.

\section{(202) Microclimate and Reference Crop Evapotranspiration in High Tunnels and Open Field during Summer Lettuce Production}

Xin Zhao*1, Edward E. Carey ${ }^{2}$

${ }^{1}$ Kansas State University, Horticulture, Forestry and Recreation Resources, Manhattan, KS, 66506; ${ }^{2}$ Kansas State University, Horticulture, Forestry and Recreation Resources, Olathe, KS, 66061

High tunnels, unheated greenhouses, have been shown to be a profitable season-extending production tool for many horticultural crops. Production of cool-season vegetables during hot summer months can be achieved using shaded high tunnels. Microclimate in high tunnels and open field was monitored during summer trials of leaf lettuce, in which unshaded tunnels and shaded tunnels (39\% PAK white shadecloth) were used, respectively, in 2002 and 2003. Wind speed was consistently lower in high tunnels. Compared to open field, daily air temperature was about $0.7^{\circ} \mathrm{C}$ higher in unshaded high tunnels, and $0.5^{\circ} \mathrm{C}$ lower in shaded high tunnels. Relative humidity was slightly lower in unshaded tunnels, but tended to increase in shaded tunnels, in comparison to the open field. When using shadecloth, soil temperature was lowered by $1 \sim 3{ }^{\circ} \mathrm{C}$ and the leaf surface temperature was significantly reduced by $1.5 \sim 2.5^{\circ} \mathrm{C}$. In shaded high tunnels, PAR light dropped by at least $50 \%$ relative to the outside, where the maximum PAR light intensity reached $1800 \mu \mathrm{mol} \cdot \mathrm{m}^{-2} \cdot \mathrm{s}^{-1}$. Overall, shaded high tunnels resulted in higher quality lettuce, with less bolting and bitterness. Reference crop evapotranspiration $\left(\mathrm{ET}_{0}\right)$ was estimated from meteorological data on a daily basis using the FAO-56 method. ET was lowest in shaded high tunnels, and highest in the open field. Relatively lower $\mathrm{ET}_{0}$ in 
high tunnels indicated a likely lower water requirement and therefore improved water use efficiency compared with the open field.

\section{(203) Evaluation of Phostrol for Downy Mildew Control on Pumpkin (C. pepo)}

Winfred Cowgill ${ }^{1}$, Kristian Holmstrom ${ }^{2}$, Andrew J. Wyendandt ${ }^{3}$, Jon Clements ${ }^{4}$, Martha Maletta*1

${ }^{1}$ Rutgers and the N.J. Ag. Experiment Station, Rutgers Cooperative Research of Hunterdon County Extension, Flemington, NJ, 08822; ${ }^{2}$ Rutgers and the N.J. Ag. Experiment Station, Rutgers Cooperative Research and Extension, 9Cook College, New Brunswick, NJ, 08901-8524; ${ }^{3}$ Rutgers and the N.J. Ag. Experiment Station, Rutgers Cooperative Research and Extension, Bridgeton, NJ, 08302-5919; ${ }^{4}$ University of Massachusetts, U Mass Extension, Horticultural Research Center, Belchertown, MA, 01007

Downy mildew (DM) is a serious foliar fungal disease of cucurbits. DM can cause yield losses for New Jersey growers if not properly controlled. In 2004, five chemical control programs were evaluated in a research trial at the Rutgers Snyder Research and Extension Farm (Hunterdon Co.). Materials evaluated were: 1) Phostrol, 5 pt/A; 2) Phostrol, 5 pt/A plus Bravo WS, 3 pt/A; 3) Flint WDG, 2 oz/A alternated with Bravo WS, 3 pt/A plus Nova 40W, 5 oz/A; 4) Maneb 75DF, 2 lb/A plus Champ Formula 2 Flowable, 1 1/3 pt/A; and 5) untreated control. All fungicide programs were applied weekly. Phostrol (Nufarm Americas, Inc.) is a new product with systemic mode of action that is newly labeled for cucurbits for control of DM, but not powdery mildew (PM). The active ingredients are mono- and dibasic-sodium, potassium, and ammonium phosphates. Phostrol and Phostrol plus Bravo were evaluated against industry standard fungicide programs which include alternating chlorothalonil + myclobutanil with strobiluron chemistries on a weekly basis. Fungicide applications were made weekly beginning at first observance of DM in the field on 23 July. Plots were rated for DM and PM incidence and extent of defoliation on 6 Aug. and 24 Sept. Phostrol plus Bravo applied on a weekly basis (7 to 10 days) provided the best control of DM, which appeared much earlier in the season than usual in northern New Jersey. Treatments Phostrol, Flint alternated with Bravo + Nova, Maneb + Champ reduced DM compared to the UTC. Maneb plus Champ provided the best control for PM. At harvest, fruit was graded and weighed. Marketable yield from Phostrol, Phostrol plus Bravo and Maneb plus Champ treatments was significantly higher than the UTC and Flint/Bravo plus Nova treatment. Handle quality was not affected by treatment.

\section{(204) The Effect of High Tunnels and Row Covers on Air Temperatures and Spring-planted Tomato Yield in Louisiana}

\section{Koji Takeuchi*, Carl E. Motsenbocker}

Louisiana State Univ., Agriculture Center, Dept. of Horticulture, Baton Rouge, LA, 70808

Tomato is an important vegetable crop in Louisiana for small- to largescale growers. Growers often use protected cultivation with structures, such as greenhouses, in order to take advantage of higher prices early in the season and increase profits through increased tomato yield and quality. A negative aspect of greenhouse use is the high investment and production costs associated with these structures. High tunnels, or simple greenhouse-like structures, have been used to protect crops from cold temperature in northern states, as they often provide benefits similar to greenhouses with considerably lower cost. Very little research has been conducted on the use of high tunnels for crops in the southern states. High tunnels in combination with row covers were evaluated for field cultivation of spring season fresh market tomato in Louisiana. The studies were set up in a randomized complete-block design with three replications. Tomatoes were transplanted into single rows on four-row raised beds covered with black plastic mulch on $1.2-\mathrm{m}$ centers on 13 Mar. 2004. Row covers were installed immediately after transplanting and removed on 3 May. Plants were harvested for 6 weeks starting 12 May 2004. Both high tunnels and row covers significantly increased minimum and maximum air temperatures at a $15-\mathrm{cm}$ height compared to the black plastic mulch control. Early yield was highest with the tunnel treatment without row cover compared to tunnel with row cover and similar to row cover alone or the control. There were no differences in total marketable yield between treatments. Research results from 2 years will be presented.

\section{(205) Root Restriction Improves Nutritional Values of Hydroponically Cultured Leafy Vegetables}

Tae-Cheol Seo*1, Changhoo Chun ${ }^{2}$, Hyung-Kweon Yun ${ }^{1}$, Han-Cheol Rhee

${ }^{1}$ National Horticultural Research Institute, Vegetable, I-mok Dong 475, Jang-an Gu, Suwon, Gyeonggi, 440-706, South Korea; ${ }^{2}$ Seoul National University, Plant Science, San 56-1, Sillim-dong, Gwanak-gu, Seoul, 151-742, South Korea

Edible chrysanthemum, pak-choi, endive, chicory, and lettuce were hydroponically cultured under root-restricted conditions in DFT systems and their growth and nutritional values were investigated. Cylindrical plastic tubes $100 \mathrm{~mm}$ tall and 20,25, and $30 \mathrm{~mm}$ in diameter were used for root restriction. Growth of all the species was retarded, as the roots were restricted. Pak-choi and edible chrysanthemum showed the greater reduction in growth compared with chicory and endive. Percentage of dry matter, $\mathrm{C}: \mathrm{N}$ ratio, and ascorbic acid and anthocyanin contents increased in the root-restricted treatments. Changes in mineral contents as affected by root restriction were not consistent among tested species. Optimized root volumes to improve the nutritional values and to reduce the retarding of growth varied according to species of leafy vegetables. Tubes of $\Phi 25 \mathrm{~mm} \times 10 \mathrm{~cm}$ and $\Phi 30 \mathrm{~mm} \times 10 \mathrm{~cm}$ gave the best results in chicory, endive, and lettuce, and edible chrysanthemum and pak-choi, respectively. Results indicate that nutritional values of hydroponically cultured leafy vegetables can be improved by root restriction using plastic tubes.

\section{(206) Control Methods for Mexican Bean Beetle (Epilachna varivestis Mulsant) Infestations on Snap Bean (Phaseolus vulgaris $\mathbf{L}$.) Crops}

Tiffany Fess*, Sven Verlinden

West Virginia University, Division of Plant and Soil Sciences, Morgantown, WV, 26506

Three different control methods, row cover, staggered plantings, and the release of a parasitic wasp, Pediobius foveolatus, were used to test effectiveness at controlling Mexican bean beetle (MBB) infestations on snap beans. The study consisted of six plots, on five different farms in the Morgantown, W.Va. area, three with and three without the application of the control methods. Releases of 15 adults and 100 larvae during flowering of the bean crop occurred at each plot. Weekly counts of the three MBB life stages, parasitized MBB larvae, and bean yields were taken. The results showed that the release of the parasitic wasp maintained the MBB populations below economic thresholds throughout the growing season. The average yield from plots that received wasp treatments was $34.2 \mathrm{~kg}$, compared to $15.2 \mathrm{~kg}$ harvested from untreated plots. Plots that received row cover treatments were shown to be slightly more effective than staggered plantings at controlling MBB populations. Row cover plots yielded an average of $15.3 \mathrm{~kg}$, in comparison to the $11.8 \mathrm{~kg}$ yield from untreated plots, while staggered plantings in treated plots yielded $9.5 \mathrm{~kg}$, compared to $6.0 \mathrm{~kg}$ from untreated plots. End of season MBB populations in treated plots consisted of 75 adults, 57 pupae, 275 larvae, and 94 parasitized larvae compared to untreated populations, 98 adults, 214 pupae, 420 larvae on average. In conclusion, increased yields can likely be correlated to decreased MBB populations, indicating the release of $P$. foveolatus as a viable option for control of MBB, especially in organic systems.

\section{(207) Productivity and Fruit Quality in European Cucumber under Greenhouse Conditions in Northwest Mexico}

Raul Leonel Grijalva-Contreras*1 ${ }^{* 1}$ Rubén Macias-Duarte ${ }^{1}$, Fabián Robles-Contreras ${ }^{1}$, Manuel de Jesus Valenzuela-Ruiz ${ }^{1}$

${ }^{1}$ INIFAP-Caborca, Protected Horticulture, Caborca, Sonora, 83600, México; ${ }^{2}$ INIFAPCaborca, Soli \& Horticultural; ${ }^{3}$ INIFAP-Caborca, Agroclimatology; ${ }^{4}$ INIFAP-Caborca, Viticulture

Mexican production of vegetables under greenhouse conditions has been increased notably during the last year to about $1500 \mathrm{ha}$. The main crop in greenhouse production is tomato, but european cucumber is a potential crop due to high yield and quality, with a good price in the 
marketplace and a short growing season. The objective of this trial was to evaluate eight european cucumber varieties and to choose those with high yield and fruit quality, and disease resistance. The experiment was carried out at the experimental station (INIFAP-CIRNO). Greenhouse conditions were: polyethylene $(8.0 \mathrm{~mL})$, without temperature control; natural ventilation; and soil with electrical conductivity of $1.22 \mathrm{dS} \cdot \mathrm{m}^{-1}$ and $\mathrm{pH}$ 7.96. Sowing date for seed was 15 Oct. 2004. Plant density was 3.78 plants per $\mathrm{m}^{2}$. The harvest period was $26 \mathrm{Dec}$. 2004 to 11 Mar. 2005, with an average of 10 cuttings. Varieties with highest yield were 'Imanaol', 'Bermejo', 'Dominica', and 'Kalunga', with 18.9, $15.2,14.8$, and $14.3 \mathrm{~kg} \cdot \mathrm{m}^{2}$, respectively. Fruit quality was excellent in all varieties; however, 'Imanaol' had the highest percentage of size and fruit number. The main insect pest during the year was white fly (Bemissia sp.) and the most important disease was powdery mildew (Erishipe cichoracearum).

\section{Poster Session 36-Vegetable Crop Physiology \\ 20 July 2005, 1:15-2:00 p.m., Poster Hall-Ballroom E/F}

\section{(208) Production of Double-stemmed Grafted Tomato Plug Seedlings}

Ki-yun Jung*, Yu-Jin Park, Jung-Myung Lee

Kyung-hee Univ., Horticulture, Sdochon-Ri 1, Kiheung-up, Yongin-si, Gyunggi, 449701 , Korea

Cultivation of grafted tomatoes has been sharply increased in recent years. Millions of grafted seedlings were grown in California as well as other parts of the world, and the need for high quality grafted tomato seedlings is also rapidly growing. Since the price of grafted plug seedlings are 3-4 times higher than the nongrafted ones, production and commercial distribution of double-stemmed plugs, even though slightly more expensive than the single-stemmed plugs, will greatly cut down the expenses needed to purchase grafted seedlings. Several methods of producing double-stemmed grafted plug seedlings are presented and the advantages as well as the disadvantages of these methods will be fully discussed. Brushing or painting lanolin paste containing thidiazuron at $100-500 \mathrm{ppm}$ to the lower node of the decapitated scion is effective in fast-growing cherry, whereas inducing double stems from the cotyledonary node of grafted scions appeared to be more practical for ordinary tomatoes for table use. Methods of grafting, especially in relation with machine grafting, will be discussed.

\section{(209) Rooting Response of Grafted Seedlings of Hot Peppers (Capsicum annuum)}

Hee-Ju Lee*1, Sang-Gyu Lee ${ }^{2}$, Jung-Myung Lee ${ }^{3}$

${ }^{1}$ Rural Development Administration, Farm Management and Information Bureau, 250 Seodun-Dong, Suwon, Gyeonggi-Do, 441707, Korea; ${ }^{2}$ NHRI, Vegetable Division; ${ }^{3}$ Kyung-Hee Univ., Horticulture

Increasing numbers of vegetables are being grafted in recent years and many different grafting methods, as well as grafting aids, have been developed and practiced among farmers as well as commercial plug seedling producers. For solanaceous crops, such as tomatoes, peppers, and eggplants, splice grafting at very young stages of development is recommended. Several types of grafting machines and/or robots are now available for commercial use. The presence of roots often slows down and reduces the efficiency of robot or machine grafting. Therefore, grafting with root-removed rootstocks is frequently used for grafting, mostly because of the grafting efficiency, especially in cucurbitaceous crops. The feasibility of producing grafted pepper plug seedlings using root-removed rootstock was investigated. After grafting, the seedlings were placed in pot soil in cell trays, usually 128-cell trays, and then placed in a conditioning room for subsequent rooting and graft union formation. Young pepper cuttings readily rooted in pot soils and the use of rooting substances greatly accelerated the speed of rooting. Even though rooting was delayed a few days in grafted seedlings, normal rooting took place in all graft combinations.

\section{(210) Effect of Shading on the Germination and Vegetative Development of 'Jalapeño' Hot Pepper (Capsicum annuum $\mathrm{L}$.)}

Marcelino Bazan Tene*, Juan Manuel González Gonzalez, Francisco Radillo Juarez, Jorge Pahul Covarrubias Corner, Salvador Guzman Gonzalez

Universidad de Colima, Facultad de Ciencias Biológicas y Agropecuarias, Tecomán, Colima, 28100, México

The hot pepper (Capsicum annuum L.) is a plant domesticated in Mesoamerica. Hot pepper is currently widespread worldwide, and its uses are varied, such as for flavoring, pigment base, and as a nutritional food resource. Mexico produces about 623,238 tons/year of fresh fruits in 136,398 ha; the State of Colima produced 17,181 tons in $676 \mathrm{ha}$, with a mean of $27 \mathrm{t} \cdot \mathrm{ha}^{-1}$. The culture of hot pepper in Colima faces certain limitations to its productive potential, such as lack of fertile and well-drained soils, constant soil moisture, and being free of weeds during the first weeks after transplanting; and maintaining plant uniformity in transplantation. This last practice is carried out in the side bed, but there is a lack of scientific evidence about the requirements of luminosity in the seed nursery in order to accelerate improvement of plant quality for transplanting, and the impact on fruit yield. The aim of this study was to evaluate the effect of different levels of shading on germination and vegetative development of 'Jalapeño' hot pepper under greenhouse conditions. Four levels of luminosity were evaluated using mesh fabrics in order to produce $90 \%$, $75 \%$, and $50 \%$ shade, and control $(0 \%)$ without shading on the seed beds. A completely randomized design with four treatments and four replications was used. The shading treatments reduced the germination period in about 2 days; increased the percentage of germination with a range between $1.6 \%$ and $3.7 \%$; increased the plant height $2.3,4.8$, 7.72 , and $10.1 \mathrm{~cm}$ at $3,7,13$, and 18 days postemergence; increased the root biomass about $7.1 \mathrm{~g} / \mathrm{plant}$, and $5.4 \mathrm{~g}$ of fresh foliage with the $90 \%$ shade treatment in comparison with control. Overall, a better agronomic performance of the 'Jalapeño' hot pepper was obtained with $90 \%$ shading.

\section{(211) Effect of Supplementary Light on Growth and Physiological Characteristics of Cucumber (Cucumis Sativus L.) Seedlings in the Greenhouse}

Yuhe Li, Feishi Luan*, Hongyan Ma

Northeast Agricultural University, Horticultural College, Xiangfang District, Harbin, Heilongjiang, 150030, China

This experiment researched the effects of supplementary light on cucumber [Cucumis sativus (L.)] seedling growth and some physiological characteristics under the same temperature. The purpose was to afford basic light condition control of cucumber cultivation in a greenhouse during winter to spring. Two cucumber cultivars, No. 3 'Jinchun' (greenhouse cultivar) and No. 7 'Longzahuang' (open field cultivar), were transplanted with supplementary light at different intensities. The experimental results indicate that plant height, leaf area, and stem diameter of cucumber seedlings were significantly increased with increasing intensity of supplementary light. Supplementary light at the cucumber seedling stage led to the increase of chlorophyll content, soluble sugar content, protein content, and CAT activity. At the same time, reduction in POD activity and MDA content with increasing levels of supplementary light was found. In addition, cells of supplementary light treatments have more chloroplasts, grana, and starch grains. Chloroplast growth of supplementary light treatments was better than CK. The grana lamella was arranged in order and its structure was clear. These results show that supplementary light could improve the growth of seedling plants, alleviate the damage of membrane lipid peroxidation, and facilitate chloroplast growth. The effects of supplementary light on the two cultivars were the same, but their extent was different. Effects on No. 7 Longzahuang were more significant than those on No. 3 Jinchun. 


\section{(212) Gas Exchange and Antioxidant Properties of Two Spinach (Spinacia oleracea L.) Cultivars of Contrasting Morphology}

Alexis M. Barbarin ${ }^{1}$, Frank J. Williams*1, Greg T. Bettmann², Donald P. Hauber ${ }^{3}$, Harish H. Ratnayaka

${ }^{1}$ Xavier University of Louisiana, Department of Biology, New Orleans, LA, 70125; ${ }^{2} \mathrm{New}$ Mexico State University, Department of Entomology, Plant Pathology and Weed Science; ${ }^{3}$ Loyola University of New Orleans, Department of Biology

Knowledge of constitutive levels of gas exchange and antioxidant properties under unstressed conditions is critical for elucidating their potential roles in stress tolerance, planning cultural practices, and evaluating nutritional quality of vegetable crops. This greenhouse study reports gas exchange, photosystem II efficiency, and pigment and antioxidant profiles of two spinach cultivars [Spinacia oleracea L., cvs. Bloomsdale Long Standing (Bloomsdale) and Hybrid Tyee (Tyee)] with contrasting morphology. 'Bloomsdale', the cultivar with more compact stature and larger leaves, had $47 \%$ greater photosynthesis $\left(P_{\text {net }}\right)$ than 'Tyee'. Stomatal conductance $\left(g_{\mathrm{s}}\right)$ and transpiration $(E)$ were $94 \%$ and $46 \%$ greater in 'Bloomsdale' than 'Tyee', respectively. However, photosystem II efficiency $\left(F_{\mathrm{v}}\right.$ ' $/ F_{\mathrm{m}}$ ') was only $8 \%$ greater in 'Bloomsdale' than 'Tyee'. Instantaneous water use efficiency was similar in both cultivars. 'Bloomsdale' had nonsignificantly greater concentrations of chlorophylls $a$ and $b$, lutein, $\beta$-carotene and violaxanthin than 'Tyee'. Both cultivars had similar, marginal $\alpha$-tocopherol concentrations $\left(<0.1 \mathrm{ng} \cdot \mathrm{g}^{-1} \mathrm{FW}\right)$. However, 'Tyee' had a greater chlorophyll a:b ratio which, combined with lower $g_{\mathrm{s}}$ and $E$, suggests a possible advantage for 'Tyee' over 'Bloomsdale' under relatively dry and high light conditions. Further studies must be conducted to compare nutritional quality of the two cultivars, based on constitutive levels of pigments and antioxidants. Greater gas exchange activity in 'Bloomsdale' than 'Tyee' appears to be due more to $\mathrm{CO}_{2}$ acquisition/metabolism than photosystem II efficiency or concentrations of pigments and antioxidants.

\section{(213) Effect of Shading on Yield and Composition of Fruit} and Leaves of Greenhouse Tomato

\section{Martin P.N. Gent*}

Connecticut Agricultural Experiment Station, Forestry and Horticulture, New Haven, CT, 06511

Tomatoes were grown in spring and summer in Connecticut in greenhouses covered with a double layer of 4-mL clear polyethylene film. Some sections were covered with reflective aluminized shadecloth that provided $85 \%, 70 \%$, or $50 \%$ transmittance of direct radiation, respectively. This shading was applied in mid-June, after fruit began to ripen, and remained for the rest of the summer. Fruit was picked through August. A similar experimental protocol was used in 2003 and 2004. The maximum shading only decreased daily integrated solar radiation to $69 \%$ of that without shade, as measured by PAR sensors set at a $2-\mathrm{m}$ height in each greenhouse. Shading reduced yield of ripe fruit from 16.6 and $13.1 \mathrm{~kg} \cdot \mathrm{m}^{-2}$, proportional to the measured decrease in radiation. Neither fruit size nor weight fraction of marketable fruit was affected by shading in 2004. Nutrient content was analyzed in tissues of ripe fruits, and uppermost expanded leaves harvested in early August. As shading decreased transmittance, it increased the concentration of most elements in leaves. Total N, P, and K concentrations followed this trend; however, Ca was not affected by shading. Fruit dry matter content declined slightly, from $5.9 \%$ to $5.7 \%$ of fresh weight, for plants grown with no shade or shade with $50 \%$ transmittance, respectively. However, there was no significant effect of shading on $\mathrm{K}, \mathrm{Ca}, \mathrm{Mg}$, or on minor elements in fruit tissue, whether expressed on a fresh weight or dry weight basis. Thus, shading a greenhouse to improve fruit quality had no effect on the value of ripe tomatoes as a dietary source of mineral nutrients.

\section{(214) Brassinosteroid-induced Femaleness in Cucumber and Relationship to Ethylene Production}

Ekaterina Papadopoulou, Rebecca Grumet*

Michigan State University, Horticulture, Plant and Soil Sciences Bldg., East Lansing, MI, 48824

The cucurbit family is noted for diversity in sex expression phenotypes.
Typically, a phase of male flowers precedes the appearance of female or hermaphrodite flowers. Sex determination of individual flowers is regulated by genetic, environmental, and hormonal factors. Ethylene, auxins, and gibberellins all influence flower sex, with ethylene, which promotes femaleness, playing a predominant role. In this study, we tested whether brassinosteroids, a more recently identified class of plant hormones, also influence cucurbit sex expression. Applied epi-brassinolide (epi-BL) caused a significant decrease in time of appearance of the first female flower on monoecious cucumber plants, and increased total female flowers on the main stem. Increasing concentrations had a stronger effect. Of the three species tested, cucumber, melon, and zucchini, cucumber was the most responsive. Application of epi-BL also caused an increase in ethylene production by cucumber and zucchini seedlings, suggesting that the BR effect may be mediated by ethylene. To investigate the possible relationship between BR and ethylene on sex expression, we identified the concentration of ethephon (5 ppm) that caused an increase in ethylene production comparable to that induced by $10 \mu \mathrm{M}$ epi-BL (about two-fold). Treatment with $5 \mathrm{ppm}$ ethephon was sufficient to increase femaleness of cucumber plants, but not zucchini plants, suggesting that the difference in response to epi-BL may reflect differences in sensitivity to ethylene. Collectively, our results indicate that application of brassinosteroids to cucumber cause earlier and increased female flower production, and that the effects may be mediated, at least in part, by brassinosteroid-induced increased production of ethylene.

\section{Poster Session 37-Small Fruit}

20 July 2005, 1:15-2:00 p.m. Poster Hall-Ballroom E/F

(366) Bloom Delay and Fruit Thinning of Blueberry with Soybean Oil

Dennis Deyton*1, Carl E. Sams ${ }^{1}$, Jim R. Ballington ${ }^{2}$, John Cummins ${ }^{1}$

${ }^{1}$ University of Tennessee, Department of Plant Sciences, Knoxville, TN, 37796-4561; ${ }^{2}$ N.C. State University, Horticulture Department, Raleigh, NC, 7695-7609

Trials were conducted in 2004 to compare the effects of soybean oil formulations and concentrations on flowering and fruit thinning of rabbiteye and southern highbush blueberries. Mature 'Climax' bushes near Spring City, Tenn., were sprayed to runoff on $10 \mathrm{Feb}$. with water, or $9 \%$ soybean oil in the formulations TNsoy11, TNsoy 12, TNsoy13, TNsoy 14, or Golden Natur'l(GN). In a second trial, 3-year-old 'Legacy' southern highbush plants at Spring Hill, Tenn., were sprayed on 11 Feb. with $0 \%, 6 \%, 9 \%, 12 \%$, and $15 \%$ GN. A similar trial was sprayed on 5 Mar. at Fletcher, N.C., using young plants of various Southern highbush cultivars. Each formulation of soybean oil (9\%) delayed bud development and flower anthesis of 'Climax' bushes. Bloom opening on 'Legacy' bushes was delayed by 2 to 6 days with sprays of $\geq 9 \%$ GN, with higher concentrations causing more delay. However, flower bud mortality of 'Legacy' plants was greater when sprayed with the higher oil concentrations. 'Legacy' plants sprayed with $0 \%, 6 \%$, and $\geq 9 \%$ oil had $0 \%, 30 \%$ and $\geq 70 \%$ bud mortality, respectively, at 36 days after treatment. 'Legacy' plants sprayed with $12 \%$ and $15 \%$ oil sprays had an estimated $24 \%$ and $13 \%$, respectively, of a crop load compared to the estimated $100 \%$ crop load on control plants. Flower bud development, flower bud mortality, crop load and berry size (across cultivars) of Southern highbush cultivars at Fletcher were not affected by oil treatments. Results were variable among trials, perhaps due to factors such as cultivars, timing of application (date), maturity of plants, environmental conditions, etc. There is potential for soybean oil formulations to be used as a chemical thinner as well as to delay blooming.

(367) Symptom Expression of Mixed Virus Infections in 'Chickasaw' Blackberry

Mark M. Bray*, John R. Clark, Rose C. Gergerich

University of Arkansas, Horticulture, Fayetteville, AR, 72701

Latent infection of Blackberry yellow-vein associated virus (BYVaV) in 'Chickasaw' blackberry has been reported. However, plants with 
characteristic leaf symptoms, such as vein yellowing, chlorotic mottling, and oak-leaf patterns, have tested positive for BYVaV using reverse-transcription polymerase chain reaction. Experiments were initiated to determine if the symptoms expressed in BYVaV infected 'Chickasaw' were caused by mixed virus infections. BYVaV, a recently identified crinivirus, was evaluated for synergistic interactions with Tobacco ringspot virus (TRSV), Tomato ringspot virus (ToRSV), and Raspberry bushy dwarf virus (RBDV). 'Chickasaw' blackberry plants infected with BYVaV (single infection) were used as receptor plants to establish mixed virus infections with TRSV and ToRSV transmitted by nematodes and RBDV transmitted by bottle grafts. Characteristic symptoms of multi-virus infection will be presented and discussed.

\section{(368) Effect of Four Weed Management Systems on Soil Quality in June-bearing Strawberry Production}

Craig Dilley*, Gail Nonnecke

Iowa State University, Horticulture, Ames, IA, 50011

Sustainable strawberry production depends on effective weed and soil management. Alternative weed management strategies are needed because few herbicides are registered for use in matted-row strawberry culture. Soil analyses are often measured in terms of chemical and physical properties alone. Measuring biological indicators of soil quality that are sensitive to changes in the environment can enhance these analyses. The experiment compared the effects of four weed management systems on weed growth, soil quality properties, and strawberry yield, growth, and development. Treatments were killed-cover crop mixture of hairy vetch (Vicia villosa) and cereal rye (Secale cereale); compost + corn gluten meal + straw mulch; conventional herbicide; and methyl bromide soil fumigation. Results indicated that there were no differences in percentage of weed cover or number of strawberry runners between the four weed management treatments in the planting year (July or Aug. 2004). The soil quality parameters, infiltration rate, soil bulk density, earthworm number, and total porosity were similar for all treatments. Plots that received the straw mulch treatment had a soil volumetric water content $20 \%$ higher and air-filled porosity that was $26 \%$ higher than the average of other treatments. Although treatment plots received similar $\mathrm{N}$, leaf nutrient analysis showed that plants receiving the straw mulch + corn gluten meal treatment had a similar amount of total $\mathrm{N}$ when compared to the conventional and methyl bromide treatments, but was $21 \%$ higher than the killed-cover crop treatment.

\section{(369) Field and Greenhouse Evaluation of Strawberry Genotypes for Tolerance to Black Root Rot Pathogens}

Chrislyn A. Drake*, James F. Hancock

Michigan State University, Horticulture, East Lansing, MI, 48824

Black root rot is a widespread disease of strawberry (Fragaria $\times$ ananassa Duchnesne) that causes the death of feeder roots and the degradation of structural roots. The major causal organisms of black root rot include Rhizoctonia fragariae Husain and W.E. McKeen, Pythium spp. and Pratylenchus penetrans (Cobb) Filipjev and Schuurmans Stekhoven. The current method of control for black root rot is methyl-bromide fumigation; however, methyl bromide is scheduled to be phased out in 2005, and its effects are short-lived in matted-row systems. The objectives of the study were to measure levels of tolerance to black root rot in 20 strawberry genotypes and to determine which pathogens were present in the soil. The genotypes were planted in four blocks each of methyl-bromide fumigated and nonfumigated soil, and were evaluated for crown number, number of flowers per crown, yield, and average berry weight over two years. The results showed that all three pathogens were present in the field, and that there was a significant genotype $\times$ fumigation interaction for yield and crown number in both years. The cultivars Bounty, Cabot, and Cavendish, all released from the breeding program in Nova Scotia, displayed tolerance to the pathogens that cause BRR. Greenhouse studies were conducted using a subset of the genotypes to determine if any one pathogen causes more damage than others, and to determine if susceptibility to a particular pathogen varies between genotypes.
(370) In-row Plant Spacing Affects Early Season Fruit

\section{Yield of Strawberry Grown in a Winter, Annual Hill} Production System

Craig K. Chandler*1, Daniel E. Legard ${ }^{2}$, Chang-Lin Xiao³, James C. Mertely ${ }^{1}$

${ }^{1}$ University of Florida, Gulf Coast Research and Education Center, Wimauma, FL, 33598; ${ }^{2}$ California Strawberry Commission, Research and Education, Watsonville, CA, 95077-0269; ${ }^{3}$ Washington State University, Tree Fruit Research and Extension Center, Wenatchee, WA, 98801-1230

On standard two-row black polyethylene covered beds, 'Camarosa', 'Rosa Linda', and 'Sweet Charlie' strawberry plants were grown at 23, 31,38 , or $46 \mathrm{~cm}$ within-row spacing during the 1997-98 and 1998-99 seasons at Dover, Fla. Ripe fruit were harvested twice weekly from December through March. The first 8 weeks of harvest was considered the early period; the late period consisted of all harvests after the first 8 weeks. The effect of spacing on early marketable yield was consistent across seasons and cultivars. The $23-\mathrm{cm}$ spacing resulted in the highest marketable yield per unit area, followed by the $31-, 38-$, and $46-\mathrm{cm}$ spacing. The percentage of fruit that were small (unmarketable) was higher at the $23-\mathrm{cm}$ spacing than at the wider spacings ( $40 \%$ vs. $35 \%$ or $36 \%$ ), but spacing did not affect the percentage of fruit that were misshapen. For the late harvest period, a spacing effect on marketable yield occurred in 1998-99, but not in 1997-98. The 23-, 31-, and 38-cm spacings in 1998-99 resulted in similar late period yields, which were $15 \%$ to $21 \%$ higher than the yield resulting from the $46-\mathrm{cm}$ spacing. These results indicate that marketable yields per plant during the late period were higher at the wider spacings.

\section{(371) Hydroponic Inoculation of Cranberry with Ericoid Mycorrhizal Fungus}

Piero A. Spada, Beth Ann A. Workmaster, Kevin R. Kosola*

University of Wisconsin, Madison, Horticulture, Madison, WI, 53706

Cranberry (Vaccinium macrocarpon) plants colonized with ericoid mycorrhizal fungi are capable of utilizing organic nitrogen sources that are unavailable to non-mycorrhizal plants. Despite the importance of mycorrhizal colonization in the nitrogen nutrition of wild cranberry, almost all measurements of cranberry nitrogen uptake and assimilation have been carried out with non-mycorrhizal plants. We have found that cranberry can be inoculated directly in solution culture. We cultured the ericoid mycorrhizal fungus Hymenoscyphus ericae in liquid culture, harvested and rinsed hyphae, and added $\approx 200 \mathrm{mg}$ fresh weight hyphae per rooted cranberry cutting (cv. Stevens) growing in a modified Johnson's solution. After 6 weeks, newly developed roots were most heavily colonized. We examined the effects of $\mathrm{NH}_{4}^{+}$concentration $(5$, $10,20,50,100$, and $\left.500 \mu \mathrm{M} \mathrm{NH}{ }_{4}^{+}\right)$in solution on colonization rates. Colonization (\% root length) increased with increasing ammonium concentration in solution, with maximum colonization at 50 and 100 $\mu \mathrm{M} \mathrm{NH}{ }_{4}^{+}$; colonization was much lower at $500 \mu \mathrm{M} \mathrm{NH} \mathrm{NH}_{4}^{+}$. Cranberry inoculated with $\mathrm{H}$. ericae in solution culture will be used for analysis of the effects of mycorrhizal colonization on uptake kinetics of $\mathrm{NH}_{4}^{+}$, $\mathrm{NO}_{3}^{-}$, and amino acids.

\section{(372) Water Requirements of Highbush Blueberry Cultivars Planted at Normal and High Density Spacings}

\section{David Bryla*1, Bernadine Strik ${ }^{2}$}

${ }^{1}$ USDA ARS, Horticultural Crops Research Unit, Corvallis, OR, 97330; ${ }^{2}$ Oregon State University, Horticulture,Corvallis, OR, 97331

Many growers in the Pacific Northwest are planting blueberry fields at higher densities to improve yields and increase the number of berries harvested per acre in the first few years after planting. The objective of this study was to determine the effect of high-density planting on blueberry water requirements. Although close spacing reduces individual plant size, we expected that plants spaced closer together would require more irrigation per unit land area than those spaced further apart due to increased canopy coverage within rows. The study utilized a 5-year-old planting of highbush blueberry, consisting of three cultivars, 'Duke', 'Bluecrop', and 'Elliott', planted at 0.5- and 1.2-m in-row spacings. Plant water use was calculated from changes in soil water content 
measured using TDR probes for shallow depths and a neutron probe and access tubes for deeper depths. Stem water potentials were also measured periodically using a pressure chamber to determine how well irrigation was meeting crop water demands throughout the season. Surprisingly, plants spaced $0.5 \mathrm{~m}$ apart required only slightly more water than those spaced $1.2 \mathrm{~m}$ apart. They did, however, require more frequent irrigations due to their smaller root systems, especially during fruit filling. Water use by each cultivar increased during fruit filling and then rapidly decreased after harvest. 'Duke' required the most water among cultivars, using 5-10 mm/day from mid-May to mid-August, while 'Elliott' required the least, using $3-5 \mathrm{~mm} /$ day.

\section{(373) Use of Calcium Foliar Feed Fertilization to Reduce Rain-related Splitting in Rabbiteye and Southern Highbush Blueberry}

Donna A. Marshall*1, James M. Spiers ${ }^{1}$, Kenneth J. Curry ${ }^{2}$

${ }^{1}$ USDA-ARS, Small Fruit Research Service, Poplarville, MS; ${ }^{2}$ University of Southern Mississippi, Biological Sciences, Hattiesburg, MS, 39426

Calcium is commonly known to affect the developmental processes of many plants, and its role as a major nutrient has been interpreted in terms of its interaction with components of the cell wall and membrane. A2-year study was conducted to assess the affects of calcium foliar feed fertilization applied at bloom and throughout floral development on the reduction of rain-related splitting in blueberries. Foliar-applied calcium at $0.2 \%$ or $0.9 \%$ concentration did not successfully decrease splitting in blueberries to a statistical and, more importantly, an economically significant level. Calcium sprays also had no adverse affects on the fruit firmness, quality, or calcium concentrations within the fruit.

\section{(374) Fertilization of Southern Highbush Blueberries on Pine Bark Beds}

Jeffrey G. Williamson*, E. Paul Miller

University of Florida, Horticultural Sciences Department, Gainesville, FL, 32611

Bearing 'Misty' and 'Star' southern highbush blueberries were grown on pine bark beds and fertilized at three rates using granular and liquid fertilizers with a $3-1-2(1 \mathrm{~N}-0.83 \mathrm{~K}-0.88 \mathrm{P})$ ratio. Granular fertilizer was applied 8 times per year at 4-week intervals beginning in April and continuing through October. Liquid fertilizer was applied with low volume irrigation 16 times per year at 2-week intervals during the same period. During the growing season, irrigation was applied at 2- to 3 -day intervals in the absence of rain. A 2 cultivar $\times 2$ fertilizer type $\times 3$ fertilizer rate factorial arrangement of treatments was replicated 8 times in a randomized complete-block design. All fruits were harvested from single-plant plots at 3- to 4-day intervals. Canopy volume was not affected by fertilizer type, but fruit yield was slightly greater for granular than for liquid fertilizer treatments. In 2003, fruit yield of 2.5-year-old 'Misty' and 'Star' plants increased with increasing fertilizer rates up to the highest rate tested ( $50 \mathrm{~g} \mathrm{~N} /$ plant/year). Similarly, in 2004, fruit yields increased with increasing fertilizer rates up to the highest rate ( $81 \mathrm{~g} \mathrm{~N} /$ plant/year). Root distribution was limited to the 12 -cm-deep layer of pine bark with very few roots penetrating into the underlying soil. The positive growth responses of blueberry plants to high fertilizer rates in pine bark beds suggests that soluble fertilizer was leached through the pine bark layer into the soil below the root zone. More frequent, lighter applications of soluble fertilizers, use of slow-release or controlled-release fertilizers, and careful irrigation management may improve fertilizer use efficiency of blueberry plantings on pine bark beds.

\section{(375) Highbush Blueberry Cultivar Evaluation in South Central Missouri Mineral Soil}

Martin L. Kaps*, Patrick L. Byers

Southwest Missouri State University, Fruit Science, Mountain Grove, MO, 65711

Fourteen highbush blueberry cultivars are being evaluated in south central Missouri mineral soil. This soil is often not ideal for culture of highbush blueberry. The planting site was initially $\mathrm{pH} 6.3$ with a $92 \%$ base saturation on the cation exchange capacity. Sulfur additions, and summer and fall cover cropping were done for 2 years prior to planting to lower soil $\mathrm{pH}(5.3)$ and increase organic matter content. Four replications of three plants were set in a randomized complete block in early Apr. 1998. Plant spacing is $1.2 \times 3.0 \mathrm{~m}$ on bermed rows that are mulched with chipped hardwood. Acidified irrigation water is supplied through drip lines. Fertilizer is applied annually both as dry ammonium sulfate and soluble nitrogen through drip lines at $84 \mathrm{~kg} \cdot \mathrm{ha}^{-1} \mathrm{~N}$. Cumulative yield per bush after the first five harvest seasons showed 'Bluecrop', 'Brigitta Blue', 'Chandler', 'Darrow', 'Legacy', 'Nelson', and 'Reka' at 17 to $21 \mathrm{~kg}$; 'Duke', 'Nui', 'Ozarkblue', and 'Sierra' at 14 to $15 \mathrm{~kg}$; and 'Collins', 'Summit', and 'Toro' at 9 to $10 \mathrm{~kg}$. Berry weight averaged $2 \mathrm{~g}$ with a low of $1.4 \mathrm{~g}$ ('Reka') to a high of $3.3 \mathrm{~g}$ ('Chandler'). Plant height averaged $155 \mathrm{~cm}$ with a low of $117 \mathrm{~cm}$ ('Nui') to a high of $188 \mathrm{~cm}$ ('Legacy', 'Nelson'). Cultivars in the two higher yield groups were recommended to Missouri growers for planting.

\section{(376) Carbon Mobilization and Yield Components in Raspberry}

Horacio E. Alvarado*, Rebecca L. Darnell, Jeffrey G. Williamson University of Florida, Horticultural Sciences, Gainesville, FL, 32611

Raspberry root growth during fruiting appears to be a strong sink for assimilates, and may decrease carbon availability for fruits and, consequently, cane yield. Both floricanes and primocanes may contribute to root carbon supply in raspberry during fruiting. To test this, 'Tulameen' raspberry canes were grown outdoors in containers filled with perlite and peat $(1: 1)$. One-half of the plants were girdled and the rest were nongirdled. Within each girdling treatment, either 0 or 3 primocanes were allowed to grow. Treatments were applied at early bloom (10 May), and 50\% fruit harvest occurred the first week in June. Fruit number and yield per plant decreased in girdled plants and plants without primocanes compared with nongirdled plants and plants with primocanes. Individual fruit fresh weight was not affected by treatments, but individual fruit dry weight and the dry weight to fresh weight ratio was higher in girdled plants without primocanes than in the other treatments. Neither girdling nor the presence of primocanes affected dry weight allocation to primocanes or floricanes. Root dry weight was higher in girdled plants with primocanes than in nongirdled plants without primocanes. It appears that primocanes supply carbon to roots during fruiting, and subsequently, roots mobilize carbon to floricanes. Thus, roots appear to serve primarily as a translocation pathway for carbon from primocanes to floricanes. However, when primocane growth is suppressed, root carbon is mobilized to support floricane development. If carbon flow from roots to floricanes is restricted, fruit number and yield is significantly decreased.

\section{Poster Session 38-Ornamentals/Landscape and Turf- Mineral Nutrition/Pest Management/Stress Physiology}

\section{July 2005, 1:15-2:00 p.m. Poster Hall-Ballroom E/F}

\section{(344) Effects of Ozone-treated Irrigation Water on Vegetative Growth of Chrysanthemum}

Garry V. McDonald*1, Michael A. Arnold ${ }^{1}$, Bruce J. Lesikar², Larry W. Barnes ${ }^{3}$, Don C. Wilkerson ${ }^{1}$

${ }^{1}$ Texas A\&M University, Horticultural Sciences, College Station, TX, 77843-2133; ${ }^{2}$ Texas A\&M University, Biological and Agricultural Engineering; ${ }^{3}$ Texas A\&M University, Plant Pathology and Microbiology

An experiment was initiated in June and Aug. 2004 to determine affects of ozonated fertilizer-injected water on plant growth of chrysanthemum (Chrysanthemum $\times$ morifolium T. de Romatuelle 'Covington'). Aliquots $(20 \mathrm{~L})$ of reverse osmosis water were amended with 0,50 , and $300 \mathrm{mg} \cdot \mathrm{L}^{-1} \mathrm{~N}(21 \mathrm{~N}-3.1 \mathrm{P}-5.8 \mathrm{~K})$ water-soluble fertilizer and exposed to ozone $\left(\mathrm{O}_{3}\right)$ gas for $0,30,60$, or $120 \mathrm{~s}$ at a flow rate of $300 \mathrm{~mL} / \mathrm{min}$. Containers were sealed and allowed to set for $15 \mathrm{~min}$ for $\mathrm{O}_{3}$ diffusion. Treated water was used to irrigate plants. Plants were in $10.2-\mathrm{cm}$ pots and grown until floral initiation. Plants were harvested on 12 Aug. 2004 or 24 Nov. 2004. Growth index (height $x$ canopy width $\times$ canopy width in a perpendicular direction/3), and shoot and root dry masses were determined. Interactions between fertility concentration and 
ozone exposure rates were nonsignificant $(P \leq 0.05)$. Significant main effect differences occurred in growth index and shoot/root dry masses in response to fertilizer concentrations, but growth measures were not affected by ozone exposure. Peak ozone concentrations in fertilizerinjected irrigation water averaged $0.21 \mathrm{mg} \cdot \mathrm{L}^{-1} \mathrm{O}_{3}(120 \mathrm{~s}$ exposure at $300 \mathrm{~mL} \cdot \mathrm{L}^{-1}$ ) after $15 \mathrm{~min}$ diffusion time. At $20 \mathrm{~min}$ diffusion times, ozone levels dropped to $0 \mathrm{mg} \cdot \mathrm{L}^{-1}$. No gross morphological differences or obvious necrosis typical of ozone damage on chrysanthemum occurred at any $\mathrm{O}_{3}$ exposure level. No observable nutritional deficiencies were noted. Vegetative growth of chrysanthemum was not directly injured by irrigation water that was exposed to ozone gas for 0 to $120 \mathrm{~s}$ at a $300 \mathrm{~mL} / \mathrm{min}$ flow rate.

\section{(345) Mushroom Farm and Anaerobic Digestion Wastewaters as Supplemental Fertilizer Sources for Growing Container Nursery Stock}

C. Chong*1 ${ }^{*}$ P. Purvis ${ }^{1}$, G. Lumis ${ }^{1}$, B.E. Holbein ${ }^{2}$, R.P. Voroney ${ }^{1}$, H. Zhou ${ }^{3}$, H.-W. Liu ${ }^{2}$

${ }^{1}$ University of Guelph, Dept. of Plant Agriculture, Bovey Building, Guelph, Ont., Canada ${ }^{2}$ Super Blue Box Recycling Corporation, Etobicoke, Ont., Canada; ${ }^{3}$ University of Guelph, School of Engineering, Guelph, Ont., Canada

Wastewaters from farm and composting operations are often rich in certain nutrients that can be reutilized in crop production. Liners of silverleaf dogwood (Cornus alba L. 'Argenteo-marginata'), common ninebark [Physocarpus opulifolius (L.) Maxim.], and 'Anthony Waterer' spirea (Spiraea $\times$ bumalda Burvenich) were grown in 6-L containers filled with a medium consisting of $73 \%$ bark, $22 \%$ peat, and $5 \%$ pea gravel, by volume. Plants were fertigated daily via a computer-controlled multi-fertilizer injector with three recirculated fertilizer treatments: 1) a stock solution with macro- and micronutrients, electrical conductivity (EC) $2.2 \mathrm{dS} \cdot \mathrm{m}^{-1} ; 2$ ) wastewater from a mushroom farm; and 3 ) process wastewater from anaerobic digestion of municipal solid waste. The wastewaters used in both treatments 2 and 3 were diluted with tap water, and the computer was programmed to amend, dispense, and recirculate nutrients, based on the same target EC as in treatment 1. For comparison, there was a traditional controlled-release fertilizer treatment [Nutryon 17-5-12(17N-2P-10K) plus micronutrients incorporated into the medium at a rate of $6.5 \mathrm{~kg} \cdot \mathrm{m}^{-1}$, nutrients not recirculated]. All three species responded similarly to the three recirculated fertilizer treatments. Growth in the recirculated treatments was similar and significantly higher than that obtained with controlled-release fertilizer. A similar trend in EC was observed in the media near harvest. Throughout the study, there was no sign of nutrient toxicity or deficiency with any of the species or treatment.

\section{(346) Effect of Rhizosphere pH on Root Growth of Two Landscape Species}

Amy N. Wright*1, Robert D. Wright ${ }^{2}$, Brian E. Jackson ${ }^{1}$, Jake A. Browder ${ }^{2}$

${ }^{1}$ Auburn University, Horticulture, 101 Funchess Hall, Auburn, AL, $36849 ;{ }^{2}$ Virginia Tech, Horticulture, Saunders Hall, Blacksburg, VA, 24061

Rhizosphere $\mathrm{pH}$ preferences vary for species and can dramatically influence root growth rates. Research was conducted to determine the effect of root zone $\mathrm{pH}$ on the root growth of Buxus microphylla Sieb. \& Zucc. 'Green Beauty' (boxwood) and Kalmia latifolia L. 'Olympic Wedding' (mountain laurel). Boxwood plants removed from 3.8-L containers and mountain laurel plants removed from 19-L containers were situated in the center of separate Horhizotrons ${ }^{\mathrm{TM}}$. The key design feature of the Horhizotron is four wedge-shaped quadrants (filled with substrate) that extend away from the root ball. Each quadrant is constructed from glass panes that allow the measurement of roots along the glass as they grow out from the root ball into the substrate. For this experiment, each quadrant surrounding a plant was filled with a pine bark substrate amended per $\mathrm{m}^{3}\left(\mathrm{yd}^{3}\right)$ with $0.9 \mathrm{~kg}$ Micromax (Scotts-Sierra, Marysville, Ohio) and $0,1.2,2.4$, or $3.6 \mathrm{~kg}$ dolomitic limestone. All plants received $50 \mathrm{~g}$ of $15 \mathrm{~N}-3.9 \mathrm{P}-9.8 \mathrm{~K}$ Osmocote Plus (Scotts-Sierra), distributed evenly over the surface of the root ball and all quadrants. Plants were grown from May to Aug. 2003 in a greenhouse. Root lengths were measured about once per week throughout the experiment. Root length increased linearly over time for all species in all substrates. Rate of root growth of boxwood was highest in pine bark amended with $3.6 \mathrm{~kg} \cdot \mathrm{m}^{3}$ lime and lowest in unamended pine bark. Rate of root growth of mountain laurel was lowest in pine bark amended with $3.6 \mathrm{~kg} \cdot \mathrm{m}^{3}$ lime. Results support the preference of mountain laurel and boxwood for acidic and alkaline soil $\mathrm{pH}$ environments, respectively.

\section{(347) Identifying Common Reflectance Properties in Diverse Ornamental Species to Nondestructively Determine Nitrogen Status}

\section{Jonathan M. Frantz*1, Dharmalingam S. Pitchay ${ }^{2}$, Glen Ritchie ${ }^{3}$,} Heping $\mathrm{Zhu}^{4}$

${ }^{1}$ ARS, USDA, Toledo, OH, 43606; ${ }^{2}$ University of Toledo, Department of Biological Sciences, Toledo, OH, 43606; ${ }^{3}$ University of Georgia, Coastal Plain Experiment Station, Tifton, GA, 31794; ${ }^{4}$ ARS, USDA, Wooster, OH, 44691

Nitrogen $(\mathrm{N})$ is often supplied to plants in excess to minimize the possibility of encountering $\mathrm{N}$ deficiency that would reduce the plant quality due to leaf chlorosis and necrosis. This is not only costly, but it can reduce the quality of plants, predispose the plants to biotic stress such as Botrytis gray mold, and extend the production cycle. Several tools can be used to identify $\mathrm{N}$ deficiency in plants, and most are based on chlorophyll reflectance or transmittance. While sensitive when plants are experiencing $\mathrm{N}$ deficiency, spectral signals can saturate in an ample $\mathrm{N}$ supply and make it difficult to discern sufficient and supra-optimal $\mathrm{N}$ nondestructively. Three diverse ornamental species (begonia, Begoniaceae $\times$ tuberhybrida; butterflybush, Buddleja davidii; and geranium, Pelargonium $\times$ hortorum) were grown with a broad range of N supplied (1.8 to $58 \mathrm{~mm}$ ) in three separate studies that resulted in a range of $1.8 \%$ to $6 \%$ tissue $\mathrm{N}$ concentration. Using a spectroradiometer, we measured reflectance from the whole plants twice over a period of 3 weeks. A first-derivative analysis of the data identified six wavebands that were strongly correlated to both begonia and butterflybush tissue $\mathrm{N}$ concentration $\left(r^{2} \sim 0.9\right)$, and two of these also correlated well to geranium $\mathrm{N}$ concentration. These wavebands did not correlate to chlorophyll peak absorbance, but rather blue, green, red, and far-red "edges" of known plant pigments. These wavebands hold promise for use as a nondestructive indicator of $\mathrm{N}$ status over a much broader range of tissue $\mathrm{N}$ concentration than current sensors can reliably predict.

\section{(348) Geranium Nutrient Deficiency Symptoms, Partitioning, and Bioenergetic Costs of Construction}

Dharmalingam S. Pitchay*1, Jonathan M. Frantz ${ }^{2}$, James C. Locke ${ }^{2}$

${ }^{1}$ University of Toledo, Department of Biological Sciences, Toledo, OH, 43606; ${ }^{2}$ ARS, USDA, Toledo, $\mathrm{OH}, 43606$

Geranium (Pelargonium $\times$ hortorum) is considered to be one of the topselling floriculture plants, and is highly responsive to increased macroand micronutrient bioavailability. In spite of its economic importance, there are few nutrient disorder symptoms reported for this species. The lack of nutritional information contributes to suboptimal geranium production quality. Understanding the bioenergetic construction costs during nutrient deficiency can provide insight into the significance of that element predisposing plants to other stress. Therefore, this study was conducted to investigate the impact of nutrient deficiency on plant growth. Pelargonium plants were grown hydroponically in a glass greenhouse. The treatment consisted of a complete modified Hoagland's millimolar concentrations of macronutrients $\left(15 \mathrm{NO}_{3}-\mathrm{N}, 1.0 \mathrm{PO}_{4}-\mathrm{P}, 6.0\right.$ $\mathrm{K}, 5.0 \mathrm{Ca}, 2.0 \mathrm{Mg}$, and 2.0 $\mathrm{SO}_{4}-\mathrm{S}$ ) and micromolar concentrations of micronutrients (72 Fe, 9.0 Mn, 1.5 Cu, 1.5 Zn, 45.0 B, and $0.1 \mathrm{Mo}$ ) and 10 additional solutions each devoid of one essential nutrient (N, P, $\mathrm{Ca}, \mathrm{Mg}, \mathrm{S}, \mathrm{Fe}, \mathrm{Mn}, \mathrm{Cu}, \mathrm{Zn}$, or B). The plants were photographed and divided into young, maturing, and old leaves, the respective petioles, young and old stems, flowers, buds, and roots at "hidden hunger," incipient, mid- and advanced-stages of nutrient stress. Unique visual deficiency symptoms of interveinal red pigmentation were noted on the matured leaves of $\mathrm{P}$ - and $\mathrm{Mg}$-deficient plants, while $\mathrm{N}$-deficient plants developed chlorotic leaf margins. Tissue $\mathrm{N}$ concentration greatly influenced bioenergetic construction costs, probably due to differences in protein content. This information will provide an additional tool in producing premium geraniums for the greenhouse industry. 


\section{(349) Fertilizer-N Effects on Cycas-Nostoc Symbiosis}

Laura M.R. Rinaldi*1, Maria C. Margheri ${ }^{2}$, Alba Ena ${ }^{2}$

${ }^{1}$ CNR, IVALSA, Via Madonna del Piano, Sesto Fiorentino, Firenze, 50019, Italy; ${ }^{2} \mathrm{CNR}$, ISE, Firenze, Italy

Cycas revoluta Thunb., cultivated as an ornamental plant for indoor and outdoor use, is characterized by an extremely slow rate of growth. In spite of the occurrence in its coralloid roots of the nitrogen-fixing cyanobiont Nostoc, $\mathrm{N}$ fertilization is commonly used to accelerate Cycas growth. A greenhouse experiment was conducted to examine the effects of two forms of combined $\mathrm{N}$ on growth of Cycas plants and cyanobacterial nitrogenase activity, measured on intact plants. Cycas plants grown in pots were fertilized from June to September with nutrient solution containing macronutrients as $\mathrm{P}, \mathrm{K}, \mathrm{Mg}$, and Hoagland's micronutrients. N (700 mg/plant ) was supplied as $\mathrm{KNO}_{3}$, or applied as $\mathrm{NH}_{4} \mathrm{NO}_{3}$; control plants received nutrient solution without nitrogen. Treatments were applied monthly and repeated for three times. Each treatment consisted of 15 plants. The length of the new leaves was recorded during the growth cycle of the plants. The nitrogenase activity, based on acetylene reducing activity (ARA), was measured on the plants in situ in July and in October. $\mathrm{N}$ fertilization stimulated both the nitrogenase activity and the growth of the plants. In comparison with the control, average increases in ARA of more than $20 \%$ were observed in the treated plants. Nitrogenase activity was slightly better in the presence of $\mathrm{NH}_{4} \mathrm{NO}_{3}$ in July, whereas the values measured in October were about the same for two treatments. The two forms of nitrogen were the same also regarding the stimulus on growth: in N-treated plants the total length of the new leaves was more than double with respect to the control at the end of the growing season. Control plants grown without fertilizer $\mathrm{N}$ had a slow start to their growth cycles and were unable to recover and compensate later for the lack of transient $\mathrm{N}$.

\section{(350) A Water-wise Plant Recognition Program for Utah}

Rick Heflebower*1, Teresa Cerny-Koenig ${ }^{2}$, Molly Waters ${ }^{3}$, Ruby Ward ${ }^{4}$

${ }^{1}$ Utah State University, Extension, St. George, UT, 84770; ${ }^{2}$ Washington State University, Horticulture and Landscape Architecture; ${ }^{3}$ State of Utah, Utah Division of Water Resources; ${ }^{4}$ Utah State University, Economics Department

A cooperative program to recognize water-wise plants for Utah landscapes was developed by 10 horticulture and water organizations throughout the state. Representatives from each of the organizations met to develop a plant list containing woody and ornamental species that were attractive in the landscape, water conserving, adapted to the climate, and available in the industry. A yellow tag with the words "water- wise plant" outlined by the state of Utah was designed by the committee and used to identify the plants. Tags were provided at no cost to garden centers due to the funding of the organizations. A survey conducted at the end of the first season gave very favorable results. Sixty-seven percent of the participating nurseries indicated they would "definitely" participate in the program again, and 27\% indicated they "probably" would participate. The Water-Wise Plant Tagging Program serves as a model of how universities, governmental agencies, and private businesses can work together to accomplish a common goal.

\section{(351) Production of Rhododendron delavayi Franch.}

\section{Gu Zhanying*1, Chen Xun ${ }^{1}$, Wu Huamei ${ }^{2}$}

${ }^{1}$ Central South Forestry University, Resource and Environment College, Changsha, Hunan, 410004, China; ${ }^{2}$ Institute of Biology, Plant Biology Experiment Base

Rhododendron delavayi Franch. is an evergreen tree up to $5 \mathrm{~m}$ tall. Since few tree rhododendron are available in the market, the demand for this plant is high. Unfortunately, the supply is limited due to production difficulty. Under natural conditions (control), seed germination rates were $3 \%$ to $5 \%$. When a special propagation bed was set up with mixed media of humus, loess, and sand, the germination rate reached $75 \%$ if the temperature was set from $20-25^{\circ} \mathrm{C}$, humidity was $80 \%$ to $90 \%$, and irrigation water $\mathrm{pH}$ was 6--6.5. In growing Rhododendron delavayi, medium $\mathrm{pH}$, water-holding capacity, aeration, and organic matter were considered. The medium, mixed with cinder, loess, humus, and perlite, yielded a $95 \%$ survival rate and the tallest plants. To produce aestheti- cally pleasing plants with flowers, apical dominance was removed and the growth of lateral buds was promoted by pinching the terminal buds of the seedlings in their second year. Also, $3 \mathrm{~N}-1 \mathrm{P}-1 \mathrm{~K}$ fertilizer should be used to increase seedling growth. With proper pruning, the seedlings were flowering and ready for market in 3-4 years (instead of 8 years under natural conditions). The acceptable germination rate, better growing conditions, and feasible cultural practices should enable growers to produce quality plants, which ultimately enhance the popularity of Rhododendron delavayi.

\section{Poster Session 39-Herbs, Spices, and Medicinals 2 \\ 20 July 2005, 1:15-2:00 p.m. Poster Hall-Ballroom E/F}

\section{(398) Basil Competition Above and Below Ground with Livid and Smooth Amaranths}

\section{J. Pablo Morales-Payan*, William M. Stall}

University of Florida, Horticultural Sciences Department, Gainesville, FL, 32611-0690

Competition partitioning experiments were conducted to determine the extent of shoot and root interference between sweet basil (Ocimum basilicum) and the weeds smooth amaranth (Amaranthus hybridus) and livid amaranth (A. lividus). Sweet basil and amaranths were grown for 45 days in plastic 19-L containers filled with fertilized sandy soil. The plants were grown: 1) individually (one plant per container $=$ no interference); 2) one basil plant and one amaranth plant together in the same container (= full interference); 3 ) one basil plant and one amaranth plant together in the same container, training the shoots apart to avoid canopy contact (= below ground interference); or 4) basil and amaranth grown in different containers set side by side (= above ground interference). Each basil/amaranth treatment was replicated five times and the experiment was conducted twice. The effects of smooth and livid amaranths on basil yield were the same for a given type of interference (full, above ground, below ground). Full interference from amaranth reduced basil shoot yield by about $35 \%$, as compared to the yield of basil with no interference from amaranth. The effects of above-ground and below-ground interference on basil yield were additive, but interference above ground had a greater impact (about $21 \%$ basil yield loss) than below ground interference (about $14 \%$ basil yield loss). These results show that smooth and livid amaranths may drastically reduce sweet basil shoot yield, and that amaranth interference with sweet basil occurred to a greater extent above ground than below ground.

\section{(399) Amino Levulinic Acid Effects on Basil Competition with Slender Amaranth}

\section{J. Pablo Morales-Payan*, William M. Stall}

University of Florida, Horticultural Sciences Department, Gainesville, FL, 32611-0690

Experiments were conducted to determine the effect of the biostimulant amino levulinic acid (5-ALA) on canopy and root competition of transplanted sweet and purple basils with the weed slender amaranth (Amaranthus viridus). Before transplanting, basil plants were sprayed with an aqueous solution of 5-ALA (0 and $15 \mathrm{mg} \cdot \mathrm{L}^{-1}$ a.i. $)$. Basil and amaranth were grown in plastic 19-L containers either: 1) individually (one plant per container $=$ no interference); 2 ) one basil plant and one amaranth plant together in the same container (= full interference); 3) one basil plant and one amaranth plant together in the same container, training the shoots apart to avoid canopy interference (= below ground interference); or 4) basil and amaranth grown in different containers set side by side (= above ground interference). When 5-ALA was not applied, full-interference from slender amaranth reduced sweet basil shoot yield by $33 \%$, and purple basil shoot yield by $48 \%$. Above ground interference from slender amaranth was about $65 \%$ of the total interference effect. Basil plants treated with 5-ALA were less affected by amaranth interference than untreated basil plants, but the magnitude of the 5-ALA effect was greater in sweet basil than in purple basil. 5-ALA increased the yields of weed-free sweet basil and purple basil by about $15 \%$ and $10 \%$, respectively. 


\section{(400) Basil Yields Were Affected by Production Systems and Environmental Control Strategies in a Retractable Roof Greenhouse}

Jennifer Nelkin, Ursula Schuch*

University of Arizona, Plant Sciences, Forbes Bldg. Tucson, AZ, 85721

Fresh weight production of basil (Ocimum basilicum 'Genovese') growing in a retractable roof greenhouse (RRGH) or outdoors was evaluated under different shade environments, cultural production systems, and roof control strategies in a semi-arid climate. Cultural production systems included raised beds and towers consisting of six pots arranged vertically and stacked on edge. The growing substrate in both systems was perlite. The three shade environments included a RRGH with either a clear woven roof ( $35 \%$ shade) or a white woven roof $(50 \%$ shade $)$, or outdoors in full sun $(0 \%$ shade $)$. Within the RRGH, three strategies of roof control were tested based on air temperature thresholds, quantum thresholds, and globe thermometer temperature thresholds. After establishment, plants were grown for 4 weeks, each under the three roof control strategies in each environment and in both cultural systems. New shoots were harvested weekly and fresh weights were determined. Overall, fresh weight per plant was significantly affected by cultural production system, and basil grown in raised beds produced twice the biomass compared to plants grown in vertical towers. Productivity of basil grown in raised beds was not affected by the three shade environments, but plants in vertical towers produced about $20 \%$ more when grown in full sun or under $35 \%$ shade compared to under $50 \%$ shade. Within the RRGH, roof control strategy significantly affected basil fresh weight per plant. Roof control, based on either a quantum sensor or globe thermometer, increased production by $31 \%$ compared to air temperature control. Greater productivity was related to higher cumulative light exposure of plants. Quality of basil grown in the RRGH was superior to that grown in full sun.

\section{(401) Broadleaf Cilantro (Eryngium foetidum) Growth as Affected by Selected Organic Biostimulants}

\section{J. Pablo Morales-Payan*, William M. Stall}

University of Florida, Horticultural Sciences Department, Gainesville, FL, 32611-0690

Experiments were conducted to determine the effects of a Siberian fir (Abies sibirica) extract rich in triterpenic acid (TTA), a seaweed (Ascophyllum nodosum) extract with cytokinin-like activity (CSE), and a mixture of amino acids and short-chain peptides from fermented animal tissue (APC) on broadleaf cilantro (Eryngium foetidum) shoot weight and leaf area. Aqueous solutions of CSE, TTA, and APC at various rates were applied individually on the broadleaf cilantro leaves 15 and 30 days after transplanting. Broadleaf cilantro leaf area and shoot fresh and dry weights were determined after harvest (60 days after transplanting). APC, TTA, and CSE significantly increased broadleaf cilantro shoot weights and leaf area as compared to control plants. Aqueous solutions of APC at the rate of $900 \mathrm{~g} \cdot \mathrm{L}^{-1}, \mathrm{CSE}$ at the rate of $50 \mathrm{mg} \cdot \mathrm{L}^{-1}$, and TTA at the rate of $300 \mathrm{mg} \cdot \mathrm{L}^{-1}$ resulted in the highest broadleaf cilantro shoot weights.

\section{(402) Effect of Light Quality on Growth and Essential Oil Composition in Rosemary}

Giuliana Mulas, Lyle E. Craker*

University of Massachusetts, Medicinal Plant Program, Amherst, MA, 01003

Variation in light quality is known to modify plant morphology, growth, and chemical constituency in plants. In the present study, the effect of light quality on growth and essential oil composition in rosemary (Rosmarinus officinalis L.) was investigated by comparing plants receiving supplemental red $(660 \mathrm{~nm})$ and far-red $(730 \mathrm{~nm})$ with each other and with control plants not receiving supplemental light. Except for the supplemental light treatments, all plants were grown under natural light conditions in a greenhouse and received full daylight, averaging 9.23 $\mathrm{h}$ /day during the study. The red and far-red light treatments, given as day extensions, started daily $15 \mathrm{~min}$ before sunset and continued for 4 $\mathrm{h}$ each evening for 4 weeks. No significant differences were observed in biomass yield from the different light treatments, but far-red light caused elongation of internodes and a reduction in the number of leaves in comparison with control and red-light treated plants. Essential oil production was highest in plants grown under far-red light treatments.

\section{(403) Rosmarinic Acid (RA) Content in Leaves and Callus of Five Different Rosemary Genotypes}

\author{
Hany M. El Naggar*1, Paul E. Read ${ }^{1}$, Susan L. Cuppett ${ }^{2}$
}

${ }^{1}$ University of Nebraska-Lincoln, Agronomy and Horticulture Dept., Lincoln, NE, 68503; ${ }^{2}$ University of Nebraska-Lincoln, Food Science and Technology, Lincoln, NE, 68583

Rosemary (Rosmarinus officinalis) belongs to the Lamiaceae family, and is native to the Mediterranean and one of the most important medicinal herbs containing antioxidants in its leaves. One of the most important antioxidants is rosmarinic acid (RA). The aim of this study was to test the concentration of (RA) and chlorophyll content in leaves and callus of five successive subcultures of five different genotypes of rosemary. They were: 1) 'Majorca'; 2) Rosmarinus officinalis; 3) 'Pine Scented'; 4) 'Madeline Hill', and 5) APR. It was found that the highest concentration of RA in leaves was in 'Pine Scented', while the lowest concentration was for APR and 'Madeline Hill'. However, in the callus the highest RA concentration was for Rosmarinus officinalis in the second subculture and 'Madeline Hill' in the third subculture, while the lowest RA concentration was for 'Majorca', 'Pine Scented', and APR. The RA concentration in callus declined after the second and the third subculture for Rosmarinus officinalis and 'Madeline Hill', respectively. We concluded that it is preferred to use 'Pine Scented' for RA extraction from the leaves while for RA extraction from callus it is better to use Rosmarinus officinalis in the second subculture or 'Madeline Hill' in the third subculture.

\section{(404) Effect of Seed Source, Light during Germination, and Cold-moist Stratification on Seed Germination in Three Species of Echinacea}

Fredy R. Romero*, Kathleen Delate, David J. Hannapel

Iowa State University, Horticulture, Ames,IA 50011

With the increase in popularity of echinacea as a botanical supplement, organic production of this herb continues to grow. Echinacea seeds typically show a high percentage of dormancy that can be broken by ethephon or gibberellic acid, but these methods are not accepted in organic production. We examined in three experiments the effects of varying seed source and germination conditions on echinacea growth. To determine the efficacy of nonchemical treatments, we evaluated the effect of light with and without cold-moist stratification on seed germination of the three most important medicinal species of echinacea, E. angustifolia, $E$. purpurea, and E. pallida. We used cold-moist stratification under $24 \mathrm{~h}$ light, $24 \mathrm{~h}$ dark, and 16/8 h (light/dark) to break seed dormancy. We found that germination was enhanced in seeds from a commercial organic seed source, compared to a public germoplasm source. When seeds were not cold-moist stratified, light increased germination in $E$. angustifolia only, suggesting differential dormancy among the three species. We found that when seeds were cold-moist stratified under 16-24 h of light for 4 weeks, the percentage and rate of germination increased $10 \%$ over the control, suggesting this method as an alternative to chemical seed treatments.

\section{(405) Regeneration of Venus Fly Trap (Dionaea muscipula Ellis) from Leaf Culture}

Khalid M. Ahmad*, Syed M.A. Zobayed, Praveen K. Saxena, David M. Hunter

Univ. of Guelph, Plant Agriculture, Ontario Agriculture College, Guelph, Ontario, Canada

Dionaea muscipula Ellis commonly known as Venus fly trap is an important carnivorous plant with medicinal importance. It contains certain secondary metabolites like naphthoquinones and is used in anti-aid and anti-cancer drugs and other medicines like Cornivora. Increasing interest and use as an ornamental and medicinal plant, and dietary supplement have put it in an endangered state. Development of in vitro techniques for the preservation of germplasm that is on the brink of extinction is highly demanded. A regeneration protocol for the multiplication and micropropagation of Dionaea muscipla Ellis was established. In vitro 
regeneration potential of leaf explants in different concentrations and combinations of plant growth substances was investigated in this study. Seeds were grown and leaf disc explants were excised and cultured under aseptic conditions on nutritional medium containing half strength Murashige and Skoog (MS) mix with combinations of 1.0-20.0 $\mu \mathrm{M} \mathrm{BA}$, 2.5.0 $\mu \mathrm{M} \mathrm{IBA}, 1.0-10.0 \mu \mathrm{M} 2 \mathrm{iP}$ and $0.1-0.5 \mu \mathrm{M}$ TDZ. The cultures were kept in growth cabinet with cool white light $\left(40-60 \mu \mathrm{mol} \cdot \mathrm{m}^{-2} \cdot \mathrm{s}^{-1}\right)$ under 16-h photoperiod. Regeneration was recorded after 60 days with the intervals of 15 days based on the degree of shoot organogenesis and somatic embryogenesis. $1 / 2 \mathrm{MS}+0.1 \mathrm{TDZ}$ appeared to be efficient for somatic embryogenesis and simple MS for direct shoot organogenesis. $1 / 2$ MS combined with 2iP appeared to be efficient for regeneration either by direct shoot organogenesis or by somatic embryogenesis. Plants were rooted well in Cape Cundew medium. These investigations will aid in the development of a model system for clonal mass propagation and in vitro regeneration of Dionaea muscipla Ellis.

(406) A Comprehensive Echinacea Germplasm Collection Located at the North Central Regional Plant Introduction Station, Ames, Iowa

Joe-Ann McCoy*, Mark Widrlechner, Jeff Carstens

USDA/ARS \& ISU, Agronomy, USDA/ARS North Central Regional Plant Introduction Station, Iowa State University, Ames, IA, 50011-1170

Echinacea is becoming a well-established, high-value crop, both as an ornamental and a dietary supplement. A comprehensive collection of Echinacea germplasm is conserved by the USDA-ARS North Central Regional Plant Introduction Station (NCRPIS) in Ames, Iowa, and is available via seed distribution for research and educational purposes (ars-grin.gov/npgs). Representing all nine species collected throughout their respective North American geographic ranges, the Echinacea collection includes 179 accessions. Extensive morphological characterization data associated with this collection have been compiled and are available to researchers on the Germplasm Resources Information Network (GRIN) database to aid in selection criteria. The collection has been used extensively for various research projects, ranging from ornamental breeding studies to HPLC analyses of metabolites of interest to the phytopharmaceutical industry. This poster will summarize the Echinacea collection conserved at the NCRPIS, including a list of available accessions by species, illustrations of seed, and control-pollinated cage propagation methods; and facilities utilized for seed cleaning, testing, and storage. In addition, instructions on how to use the GRIN database to view evaluation data and acquire germplasm will be provided.

\section{(407) Tropical Spiderwort (Commelina benghalensis)} Density and Time of Emergence Effects on Cilantro Yield

J. Pablo Morales-Payan*, William M. Stall

University of Florida, Horticultural Sciences, Gainesville, FL, 32611-0690

The effect of density and time of emergence of the weed tropical spiderwort (Commelina benghalensis) (TS) on cilantro (Coriandrum sativum) yield were determined in a field experiment in Citra, Fla. TS $(0,1,2$, and 4 plants per $\mathrm{m}^{2}$ ) emerged at $0,1,2,3$, or 4 weeks after cilantro emergence (WACE) and allowed to grow with the crop for the remainder of the season. No significant yield loss was detected when TS emerged 4 WACE. Season-long competition with 1,2 , and 4 TS plants per $\mathrm{m}^{2}$ resulted in yield loss of $27 \%, 44 \%$, and $65 \%$, respectively. Cilantro yield was reduced by $<10 \%$ when TS emerged 3 WACE or later, regardless of TS density.

\section{Poster Session 40-Marketing/Consumer Horticulture/ Human Issues}

\section{July 2005, 1:15-2:00 p.m. Poster Hall-Ballroom E/F}

\section{(151) Extension Outreach for Hispanic Workers: Ohio} and Beyond

Alejandra Acuna*, Hannah Mathers, Pope Jennifer

The Ohio State University, Horticulture \& Crop Science, Columbus, OH, 43210

In 1998 , the wholesale nursery industry represented the largest sector in horticultural sales in the United States and $11 \%$ of the total value of U.S. agricultural production. The majority of jobs available in the nursery industry are labor intensive. In Ohio, $60 \%$ of the nursery workforce is composed of Hispanic laborers. A survey conducted in 2000 targeting Hispanic nursery workers in Oregon and Ohio revealed a great need for basic technical information in their native language. In order to address this issue in Ohio, a Spanish language nursery tour was developed in 2002 and offered annually thereafter. Conducted entirely in Spanish, the tour focuses on basic technical information in the area of field and container production. Tours take place at commercial nursery sites in the Lake County region of Ohio. Demonstrations at the nurseries have highlighted such practices as planting, pruning, and irrigation. Interest in disseminating more technical information in Spanish to the Hispanic workforce has developed as a result of these tours. In Jan. 2005, supervisors of Hispanic nursery workers were surveyed at the Central Environmental Nursery Trade Show ("CENTS") in Columbus, Ohio, to determine the level of interest in technical education programs for Hispanic employees $(65 \%)$ and what programs were needed (Safety 16\%, Pruning 14\%, and English 13\%). A multi-state survey in English and Spanish will be conducted over the next two years (2005 and 2006). The goal of this project is to better understand the backgrounds and technical needs of the workers in seven states filling predominantly manual labor positions, in order to help stabilize and engage the workforce through education.

\section{(152) The Effect of Live Plants and Window Views on Employee Job Satisfaction}

Andrea K. Dravigne*1, Tina M. Waliczek ${ }^{1}$, Jayne M. Zajicek ${ }^{2}$, R. Daniel Lineberger ${ }^{2}$

${ }^{1}$ Texas State University, Department of Agriculture, San Marcos, TX, 78666; ${ }^{2}$ Texas A\&M University, Department of Horticultural Science, College Station, TX, 77843-2133

The purpose of this study was to determine the effect of the presence of live interior plants or window views of exterior green spaces on employee job satisfaction. A survey was administered through an online database. The survey included questions regarding physical work environment, the presence or absence of live interior plants, windows, exterior green spaces, environmental preferences, job satisfaction, and demographical information. About 600 office workers from Texas and the Midwest responded to the on-line workplace environment survey. Data were analyzed to compare levels of job satisfaction of employees that worked in office spaces that included live interior plants or window views of exterior green spaces and employees that worked in office environments without live plants or window views. Demographic information collected allowed controlling for salary, occupational level, educational level, age group, gender, and ethnicity. This research data can be particularly useful in urban planning, commercial property design and to encourage the incorporation of plants and green spaces in interior and exterior development projects.

\section{(153) Delighted Consumers Buy Again}

Jessica M. Hicks ${ }^{1}$, Bridget K. Behe ${ }^{1}$, Thomas J. Page ${ }^{2}$, Jennifer H. Dennis*3, R. Thomas Fernandez ${ }^{1}$

${ }^{1}$ Michigan State University, Horticulture, East Lansing, MI, 48824; ${ }^{2}$ Michigan State University, Marketing and Supply Chain Mgt., East Lansing, MI, 48824; ${ }^{3}$ Purdue University, Horticulture and Ag Economics, West Lafayette, IN, 47907

Customers take some risk when they buy plants, and the emotions they experience from that purchase are important indications of whether they will return to buy again. Previous research by Dennis et al. showed that regret, a negative emotion, caused consumer switching behavior by their intentions to either buy an alternative product, purchase products from an alternative retailer, or switch out of gardening entirely. What happens when things go right? Customer satisfaction has been the metric businesses use to quantify success in customer retention. If customers who regret the purchase switch, do happy customers return to buy again? This research investigated the role of customer satisfaction, delight (a positive emotion), and prior plant knowledge on repurchase intentions. An Internet survey with 659 flowering plant purchasers throughout the U.S. was conducted in Sept. 2004 to examine the initial purchase and the actual performance of the plant following purchase. 
Data were analyzed using structural equation modeling with LISREL software. Results showed that customer satisfaction level and delight were not affected by prior plant knowledge. Satisfaction level did not affect repurchase intentions, but customer delight did. Results were consistent with existing literature, indicating that greater emphasis should be placed on delighting consumers, rather than merely satisfying them.

\section{(154) Investigating Consumer Demand for Fresh Market Edamame in Metro-Philadelphia Supermarkets}

\section{Dru N. Montri*, Kathleen M. Kelley, Elsa S. Sánchez}

The Pennsylvania State University, Dept. of Horticulture, University Park, PA, 16802

An in-store marketing study was conducted in Fall 2004 to determine consumer demand for fresh, inshell edamame [Glycine max (L.) Merrill]. Each Wednesday from 1 Sept. to 6 Oct. 2004, thirty 12-ounce plastic clamshells were placed in the produce department of four supermarkets in metro-Philadelphia, Pa. Packaged edamame remained in the supermarkets for 1 week and was replaced with fresh product when the next weekly delivery was made. A sample recipe, a follow-up survey and an addressed, postage-paid reply envelope were attached to the bottom of each clamshell. The survey was used to determine consumer perceptions, interest in Pennsylvania-grown edamame and the criteria they consider when choosing new produce items sold at supermarkets for themselves and their families. Of the 480 clamshells that were delivered, 312 were purchased. The total number of clamshells purchased weekly ranged from 64 to 87 , while the number of clamshells purchased weekly at individual stores ranged from 6 to 30. Thirty-three surveys were returned with all participants responding that they had heard of or were familiar with edamame prior to purchasing the container. Of those who responded, $78.8 \%$ had purchased edamame before. Based on the total number of packages sold, a potential demand for fresh, inshell edamame exists among consumers in metro-Philadelphia. Results from this study will be used to assist small-acreage growers interested in marketing specialty vegetable crops, such as edamame, to chain supermarkets. By understanding consumer interests, we are able to more effectively determine which type of packaging and promotional materials best attract the attention of potential buyers.

\section{(155) New Opportunities for Asian Vegetables in Local Markets}

Kurt T. Range*1, S. Alan Walters ${ }^{1}$, Bradley H. Taylor ${ }^{1}$, Wanki Moon ${ }^{2}$

${ }^{1}$ Southern Illinois University, Plant, Soil, and Agricultural Systems, Carbondale, IL, 62901$4415 ;{ }^{2}$ Southern Illinois University, Agribusiness Economics

Consumers at two local direct produce markets in greater St. Louis, Illinois, were surveyed to measure interest and buying habits for Asian vegetables in 2003. A written survey instrument containing 20 questions about use, attitudes, and purchasing behavior of Asian vegetables was completed by 40 randomly selected shoppers at each market: a farmers market and a roadside market. Although most respondents were not familiar with Asian vegetables and $79 \%$ consumed less than $5 \mathrm{lbs}$ of the product annually, they expressed a strong interest to learn more about these vegetables. Respondents reported typically purchasing Asian vegetables at supermarkets (31\%), restaurants (30\%), and direct markets $(9 \%)$, while $30 \%$ did not normally purchase the product. Only $20 \%$ of the participants consumed Asian vegetables more than once per month, while an additional $25 \%$ avoided these vegetables entirely. When asked, "What would persuade you to purchase fresh Asian vegetables?", surprisingly $40 \%$ of respondents answered "access to recipes." Our results suggest local marketers can dramatically increase sales of Asian vegetables with simple education/promotion efforts.

\section{(156) New Entrepreneurial Approach: A Model for Asian Herbal Products with Small Business Management Strategies}

\section{Usha Palaniswamy*1, Zafar Bokhari²}

${ }^{1}$ University of Connecticut, Asian American Studies, Storrs, CT, 06268; ${ }^{2}$ Chicago State University, Marketing

The important effect of dietary factors on health status has been recognized since antiquity. Since the discovery of the beneficial effects of dietary phytochemicals and bioactives, a new dimension of foods have emerged in the market. These "functional foods" are being developed by all major food companies and new ones are regularly brought into the market. While developing new functional foods and nutraceuticals, the association and identification of such foods and beverages with traditional foods and medicinal preparations, and/or popular forms of existing products are bound to bring long-standing consumer acceptance, which is an important desirable factor in sales and marketing. Following this concept, Zafi Beverages, Inc., Chicago, is developing a new line of functional products (new herbal teas and energy drinks). Zafi is also introducing a unique marketing and distribution system to create a new team of entrepreneurs, providing an excellent opportunity for growth in sales and marketing to new entrepreneurs. It targets ethnic entrepreneurs by offering an opportunity to use their networking abilities and be part of an exciting new partnership in the new host country, as well as a strategic business plan. The ethnic entrepreneurs are also constantly in contact with their consumers by virtue of the existing ethnic allegiance and cohesion and are able to identify the consumer needs and concerns directly. These small ethnic entrepreneurial networks can be identified as distinct "micro-marketing systems" within the national economy. The advertised market potential for Zafi is summarized to include an offer of immediate cash flow, more revenue and profits, marketing and financial education support, as well as a promising new line of products.

\section{(157) Analysis of Ornamental Horticulture Products and Services in Iowa}

Cynthia Haynes*, Ann Marie VanDerZanden, Jeffery Iles

Iowa State University, Department of Horticulture, Ames, IA, 50011

In 2004, the greenhouse and nursery industry was ranked as the fourth largest crop group in the United States based on farm cash receipts (USDA, 2004). The ornamental crop sector was expected to post total sales in excess of 15.3 billion dollars in 2004 (USDA, 2004). Landscape services within the green industry have risen from 28.9 billion in 2002 to 41.6 billion in 2004 (ALCA, 2004). In Iowa, recent surveys of turfgrass and edible food crop production and services have shown a combined net worth of more than 1 billion dollars. However, these surveys failed to include nursery and garden centers, greenhouse growers, landscape designers/contractors, arborists, and florists. Therefore, the objective of this project was to better understand the scope and scale of the ornamental horticulture industry in Iowa. A questionnaire was developed and mailed to 1293 horticulture businesses in Iowa. The survey instrument was developed with input from members of the Iowa Nursery and Landscape Association Research Corporation. Before mailing, it was reviewed by survey professionals and piloted to a select group of green industry representatives and edited per their suggestions. Three weeks after mailing, a reminder postcard was sent. Respondents were sorted as to type and size of business, number of employees, and annual sales. The percentage of gross receipts was categorized by types of plants sold and services provided. Respondents also were asked about the factors that limit their success, their strengths compared to competitors, and their expectations for future growth.

\section{(158) Evaluating Grower, Retailer, and Consumer Interest in Annual Planters}

Jonathan D. Phillips, Kathleen M. Kelley*, E. Jay Holcomb

The Pennsylvania State University, Dept.of Horticulture, University Park, PA, 16802

Three intercept surveys were conducted at the Penn State Southeast Research and Extension Center in Landisville, Pa., at three separate field days during the period of 28 July 2004 to 4 Aug. 2004 to determine grower $(n=78)$, retailer $(n=52)$, and consumer $(n=55)$ preference for annual planters. Survey participants were self-selected and asked to answer questions evaluating both their preference for and past experience with purchasing annual planters, as well as sociographic and demographic questions. Growers who were 45 years of age or younger were more likely to take price into consideration when creating an annual planter $(68.8 \%)$ than those who were 46 years of age or older (43.3\%), but less likely to use point-of-purchase material to educate consumers on proper container care $(45.2 \%$ and $75.0 \%$, respectively). Additionally, retailers 
whose business was $89 \%$ retail or less were less likely to consider price when creating annual planters $(53.3 \%)$ than those participants whose business was $90 \%$ retail or greater $(84.2 \%)$, and were also found to be less likely to use point-of-purchase material to educate consumers on proper container care $(46.7 \%$ and $72.2 \%$, respectively). Consumers were more likely to consider price when purchasing an annual planter if they were female $(92.7 \%)$ than if they were male $(66.7 \%)$. Consumer participants who resided in single-family homes were more likely to take the color combination into consideration when purchasing annual planters $(100.0 \%)$ than those who live in another form of housing (e.g., apartment or mobile home; $66.7 \%$ ). Additionally, consumers who live in single-adult households were less likely to consider color combination when purchasing an annual planter $(88.9 \%)$ than those who live in households with two or more adults $(100.0 \%)$.

\section{(159) The Impact of Interior Houseplants in University Classrooms on Course Performance, Course Satisfaction, and Student Perceptions of the Course and Instructor}

Jennifer Doxey*, Tina M. Waliczek

Texas State University, Department of Agriculture, San Marcos, TX, 78666

Many individuals and businesses enhance the central design of their homes or offices with living interior plants. While the aesthetic values of interior greenery are obvious, some research has suggested that interior living plants may offer some psychological and restorative values, such as reduced tension, better coping mechanisms, and increased concentration and attention. The main objective of this research was to investigate the impact of plants within a university classroom setting on course performance, course satisfaction, and student perceptions of the instructor. The study was designed to include a minimum of two classes of the same coursework, taught by the same professor in the same room. Three sets of two classes each, and $\approx 500$ students were included within the study. Throughout the semester, the experimental class of students was treated by including an assortment of tropical plants within the classroom. Plants were not present in the control classroom of the study. A survey administered to each classroom of students at the end of the semester asked students to provide demographic data including class rank, gender, and grade point average. The professor for each course provided information on each student's grade for the course, as well as overall quantitative information on how well students were satisfied with the experience they had within the course. The results demonstrate value added to the classroom experience and help to justify consideration of the added expense of interior plants in meeting the goals of instructor and curriculum.

\section{Poster Session 41-Fruit and Nut Crops Nutrition}

\section{July 2005, 1:15-2:00 p.m. Poster Hall-Ballroom E/F}

\section{(326) Foliar Applications of 6-BA, Potassium Phosphate, and Calcium Chloride Affect Pear Fruit Quality}

\author{
Xiaogang $\mathrm{Li}^{1}$, Ling Jin ${ }^{2}$, Jing Ling ${ }^{1}$, Zhongchun Jiang*3 \\ ${ }^{1}$ Jiangsu Academy of Agriculture Science, Institute of Horticulture, Nanjing, Jiangsu, \\ 210014, China; ${ }^{2}$ Dr. Sun Yatsen's Mausoleum, The Administration Bureau, Nanjing, \\ Jiangsu, 210014, China; ${ }^{3}$ State Univ. of New York College of Ag and Tech, Department \\ of Plant Science, Cobleskill, NY, 12043
}

Foliar application of hormones and nutrients can improve fruit quality, but specific conditions for applying hormones and nutrients may vary among fruit species. The objective of this study was to determine the effects of 6-BA, potassium phosphate (monobasic), and calcium chloride on fruit weight, palatability, and storage quality of 8-year-old pear trees, cv. Hosui. Foliar applications of $1 \mathrm{mg} \cdot \mathrm{L}^{-1} 6-\mathrm{BA}, 0.3 \%$ potassium phosphate, $0.3 \%$ calcium chloride, or $0.3 \%$ potassium phosphate + $0.3 \%$ calcium chloride were made at 20-day intervals from June until maturity. All foliar applications increased average fruit weight over the control (distilled water). 6-BA or the combination of potassium phosphate and calcium chloride increased fruit weight more than did potassium phosphate or calcium chloride alone. Fruit palatability, measured as the ratio of sugar content to acid content, was significantly lower in 6-BA, potassium phosphate, and calcium chloride treatments than in the control. All treatments increased vitamin $\mathrm{C}$ content over the control. Fruit storage quality in calcium chloride or calcium chloride + potassium phosphate treatments was superior to that in the control. Potassium phosphate alone and 6-BA treatments had no effects on fruit storage quality. We conclude that foliar applications of $0.3 \%$ potassium phosphate $+0.3 \%$ calcium chloride or $1 \mathrm{mg} \cdot \mathrm{L}^{-1} 6-\mathrm{BA}$ can increase average fruit weight and improve fruit palatability.

\section{(327) Correcting Ni Deficiency in Pecan and Other Crops}

Bruce W. Wood*, Charles C. Reilly, Andrew P. Nyczepir

USDA-ARS, SE Fruit and Tree Nut Research Laboratory, Byron, GA, 31008

The discovery of nickel (Ni) deficiency in field plantings of pecan [Carya illinoinensis (Wangenh.) K. Koch] (Wood et al., 2004) has led to efforts to identify appropriate management approaches to correct tree deficiency and to identify the causes for Ni deficiency. Evaluation of several inorganic and organic forms of $\mathrm{Ni}$ have indicated that solutions from all sources function well to correct deficiencies when timely applied as a foliar spray to affected trees at $\mathrm{Ni}$ concentrations $>10 \mathrm{mg} \cdot \mathrm{L}^{-1}$. Addition of urea, ammonium nitrate, or nicotinic acid to Ni spray solutions increased apparent foliar uptake from Ni sprays. The lower critical level of $\mathrm{Ni}$, based on foliar analysis, appears to be in the 3-5 $\mathrm{mg} \cdot \mathrm{L}^{-1} \mathrm{dw}$ range, with the upper critical level appearing to be $>50$ $\mathrm{mg} \cdot \mathrm{L}^{-1} \mathrm{dw}$. The cause of Ni deficiency in soils possessing plenty of $\mathrm{Ni}$ is associated with excessive amounts of one or more metals (e.g., Ca, $\mathrm{Mg}, \mathrm{Fr}, \mathrm{Mn}, \mathrm{Cu}$, and $\mathrm{Zn}$ ) that inhibit Ni uptake and/or utilization. Root damage by nematode feeding and cool/dry soils during early spring also contributes to Ni deficiency. Foliar application of Ni to foliage in the autumn and subsequent appearance of Ni in dormant season shoot tissues indicates that $\mathrm{Ni}$ can be mobilized from senescing foliage to dormant season shoots and is therefore available for early spring growth. Evidence indicates that pecan has a higher Ni requirement than most other crop species because it transports nitrogenous substances as ureides. Thus, there is evidence that Ni-metalloenzymes are playing either a direct or indirect role in ureide and nitrogen metabolism. It is postulated that crop species that are most likely to exhibit field level Ni deficiencies are those that transport $\mathrm{N}$ as ureides. Candidate crops will be discussed.

\section{(328) Effect of Supplemental Nitrogen Application at Selected Times on Pecan}

Michael Smith*

Oklahoma State University, Department of Horticulture and Landscape Architecture, Stillwater, OK, 74078

Supplemental nitrogen applications were tested to reduce irregular bearing and improve yield on drip-irrigated pecan (Carya illinoinensis Wangenh. C. Koch. cv. Mohawk) trees planted in 1989. Treatments were: 1) no $\mathrm{N}$ fertilization; 2) $75 \mathrm{~kg} \cdot \mathrm{ha}^{-1} \mathrm{~N}$ in March; 3) $75 \mathrm{~kg} \cdot \mathrm{ha}^{-1} \mathrm{~N}$ in March plus $50 \mathrm{~kg} \cdot \mathrm{ha}^{-1} \mathrm{~N}$ in August; and 4) $75 \mathrm{~kg} \cdot \mathrm{ha}^{-1} \mathrm{~N}$ in March plus $50 \mathrm{~kg} \cdot \mathrm{ha}^{-1} \mathrm{~N}$ in October. Withholding $\mathrm{N}$ did not reduce July leaf $\mathrm{N}$ concentration compared to the other treatments until the sixth year of the study. Trees receiving $\mathrm{N}$ had similar July leaf $\mathrm{N}$ concentrations regardless of treatment throughout the study. October leaf $\mathrm{N}$ concentrations were unaffected by treatment, except in 2002, when withholding $\mathrm{N}$ suppressed leaf $\mathrm{N}$ compared to other treatments. The percentage of fruiting shoots was lower when supplemental $\mathrm{N}$ was applied in October compared to August during 2 of 6 years. Otherwise, the percentage of fruiting shoots was unaffected by treatment. Weight per nut and kernel percentage were not affected by treatment, except kernel percentage was lower during 1 year when supplemental $\mathrm{N}$ was applied in August compared to October. Kernel grade was usually not affected by treatment.

\section{(329) Postharvest Urea Foliar Sprays Affect Almond and Prune Leaf Nitrogen and Sulfur Dynamics}

Franz J.A. Niederholzer*1, R. Scott Johnson ${ }^{2}$

${ }^{1}$ University of California, Cooperative Extension, Yuba City, CA, $95991 ;{ }^{2}$ University of California, Cooperative Extension, Kearney Ag Center, Parlier, CA, 93648

Urea foliar sprays may be a more efficient and environmentally sound 
alternative to soil applied fertilizer $\mathrm{N}$ in the postharvest period in tree crop production in California. While tree crop sulfur (S) status can interact with tree $\mathrm{N}$ status to affect growth, we know of no study assessing tree crop leaf $\mathrm{N}$ and $\mathrm{S}$ dynamics following fall (postharvest) foliar urea applications. We conducted a field study to measure temporal dynamics of leaf $\mathrm{N}$ and leaf $\mathrm{S}$ (\% dry weight basis) following postharvest urea sprays on prune (Prunus domestica) and almond (Prunus dulcis). June-budded nursery stock prune ('French' on Myro 29C) and almond ('Price' on Lovell) trees were sprayed to dripping with $6.5 \%$ $(\mathrm{w} / \mathrm{w})$ and $10 \%(\mathrm{w} / \mathrm{w})$ standard urea solutions, respectively. Prunes were sprayed on 1 Oct. 2003 and almonds on 18 Nov. 2003. Leaf samples were taken over a 3-week (almond) or 8-week (prune) period, beginning just before treatment. Foliar urea sprays significantly increased prune $(23 \%)$ and almond $(14 \%)$ leaf $\mathrm{N}$ compared to untreated control within 8 days of application. This affect was transient, as there were no differences in leaf $\mathrm{N}$ concentrations between treated and untreated trees at final leaf sampling. Urea sprays did not affect almond leaf S concentration relative to untreated trees. Prune leaf $\mathrm{S}$ was significantly reduced compared to untreated trees 8 days after treatment, but only on that sampling date. Remobilization of S from the leaves of control trees of either species was not apparent.

\section{(330) Growth and Nutritional Response of Six Citrus Rootstocks to Increasing Levels of Copper}

\section{Joseph Albano*, Kim Bowman}

USDA-ARS, U.S. Horticultural Research Laboratory, Horticulture \& Breeding Research Unit, Fort Pierce, FL, 34945

Nutrient disorders related to excessive levels of copper in soils are common in Florida citrus groves that have been under production for many years, mainly due to the continual use of copper-containing pesticides. The objectives of the study were to investigate the growth and nutritional response of six citrus rootstocks (nonbudded) grown in 4-L containers in sand to increasing concentrations of copper. The rootstocks included: Swingle citrumelo (Citrus paradisi Macf. $\times$ Poncirus trifoliata [L.] Raf.), Volkamer lemon (C. volkameriana Ten. and Pasq.), Cleopatra mandarin (Citrus reticulata Blanco), Flying Dragon (P. trifoliata); and two new USDA series rootstocks, US-812 (Sunki mandarin $\times$ P. trifoliata released in 2001), and US-897 (a hybrid of Cleopatra $\times$ Flying Dragon not yet released). Copper was supplied at $0.05,0.25,1.00$, and $2.00 \mathrm{mg} \cdot \mathrm{L}^{-1} \mathrm{CuEDTA}$ incorporated into a modified Hoagland's nutrient solution. As a mean of all $\mathrm{Cu}$ treatments, whole plant $\mathrm{Cu}$ levels $\left(\mu \mathrm{g} \cdot \mathrm{g}^{-1}\right)$ were: Flying Dragon, 17.33; US-897, 21.68; Cleopatra, 27.33; US-812, 28.84; Swingle, 29.74; and Volkamer, 34.05. As a mean of all $\mathrm{Cu}$ treatments, foliar $\mathrm{Cu}$ levels $\left(\mu \mathrm{g} \cdot \mathrm{g}^{-1}\right)$ were greatest and least in US-812 (7.74) and Cleopatra (4.05), respectively; and root $\mathrm{Cu}$ levels $\left(\mu \mathrm{g} \cdot \mathrm{g}^{-1}\right)$ were greatest and least in Volkamer (61.08) and Flying Dragon (30.08), respectively.

\section{(331) In Brazil, Preharvest Calcium Sprays Were Not Always Needed to Improve Fruit Quality of 'Gala' Apples} Paulo Roberto Ernani*1, Jaques Dias², Cassandro Vidal Amarante ${ }^{1}$, Diorvania Ribieiro ${ }^{3}$

${ }^{1}$ Santa Catarina State University, Soil Science, Av. Luis de Camões, 2090, Lages, SC, 88520 000, Brazil; ${ }^{2}$ Grupo Schio, Agropecuaria Schio, BR $285 \mathrm{~km} 3$ Bairro Gloria, Vacaria, RS, 95200-000, Brazil; ${ }^{3}$ Santa Catarina State University, Soil Science, Lages, SC, Brazil

Calcium sprays have improved quality and storage life of apples throughout the world as a result of Ca prevention of many fruit physiological disorders. The efficacy of Ca sprays, however, varies according to soil, cultivar/rootstock, orchard cultural practices, and weather conditions. This study was carried out from 1998 to 2004 in southern Brazil in order to assess the effect of Ca sprays on quality of 'Gala' fruits in an orchard planted in 1988 on a density of 1234 trees/ha. Treatments consisted of $0,4,8$, and 12 sprays of $0.5 \% \mathrm{CaCl}_{2}$. Fruits of same size and maturity level were annually analyzed at harvest and after 5 months of cold storage. In five out of six seasons, fruits from all treatments were free of any physiological disorder, and Ca sprays had no effect on leaf composition and on fruit quality attributes (soluble solids, acidity, starch pattern index, flesh firmness, and concentrations of $\mathrm{N}, \mathrm{K}, \mathrm{Ca}$, and $\mathrm{Mg}$ ). In the 2000-01 season, however, when yield was $18 \mathrm{t} \cdot \mathrm{ha}^{-1}$ and fruits had an average weight of $175 \mathrm{~g}$, the incidence of bitter pit plus lenticel blotch pit on stored fruits decreased from $24 \%$ in the treatment with no calcium to $2 \%$ in that with 12 calcium sprays. Two seasons later, yield was also light $\left(25 \mathrm{t} \cdot \mathrm{ha}^{-1}\right)$ and fruits were big in size $(168 \mathrm{~g})$, but they did not show any disorders regardless of Ca sprays. It seems that the incidence of Ca related disorders in 'Gala' apples grown on limed soils in Brazil only occurs in seasons with a light crop load as a result of large fruits and a high leaf/fruit ratio, associated with some unknown climatic factor.

\section{(332) Fabric Cover Effects on Soil Fertility and Plant Nutrition of Sweet Cherry}

Xinhua Yin*, Janet Turner, Clark Seavert, Roberto Nunez-Elisea, Helen Cahn

Oregon State University, Mid-Columbia Agricultural Research and Extension Center, Hood River, OR, 97031-9512

The influences of a synthetic fabric cover in the row area of sweet cherry trees on soil fertility and plant nutrition are largely unknown. A field trial has been conducted on young 'Regina' sweet cherry on a sandy loam soil at the Mid-Columbia Agricultural Research and Extension Center, Hood River, Ore., since 2001. The difference in soil $\mathrm{NO}_{3}{ }_{3}^{-}, \mathrm{P}$, $\mathrm{K}, \mathrm{Ca}, \mathrm{Mg}, \mathrm{S}, \mathrm{B}, \mathrm{Zn}, \mathrm{Mn}, \mathrm{Cu}, \mathrm{pH}$, or organic matter was nonsignificant between the covered and non-covered treatments in any year. Leaf $\mathrm{N}$ content was $11 \%$ to $16 \%$ greater with the covered treatment compared with the non-covered treatment in 2002 and 2003, but leaf $\mathrm{N}$ was similar for the two treatments in 2001. Leaf P content was similar for the two treatments in 2001 , but was about $36 \%$ less with the covered treatment than the non-covered treatment in 2002 and 2003. Leaf Ca content was decreased by $11 \%$ to $17 \%$ due to a synthetic fabric cover in 2002 and 2003. Leaf $\mathrm{Mg}$ content was $13 \%$ to $24 \%$ less with the covered treatment than the non-covered treatment in 2002 and 2003. However, the decreased leaf $\mathrm{P}, \mathrm{Ca}$, and $\mathrm{Mg}$ contents with the covered trees were due to the dilute effects of increased tree growth. The effects of a fabric cover on leaf $\mathrm{K}, \mathrm{S}, \mathrm{B}, \mathrm{Zn}, \mathrm{Mn}$, and $\mathrm{Cu}$ contents were primarily nonsignificant. Our results suggest that although nutrient availability in the soil is not reduced by a wide synthetic fabric cover, higher rates of fertilizers may be needed for the covered sweet cherry trees due to the elevated tree growth and fruit production from a longterm perspective.

\section{Poster Session 42-Genetics and Germplasm 3}

\section{July 2005, 1:15-2:00 p.m. Poster Hall-Ballroom E/F}

\section{(14) Hybrid Azalea (4X) $\times$ Rhododendron (2X) 'Azaleodendron' Progeny Have an Azalea Phenotype}

Stephen L. Krebs*

The Holden Arboretum, Research, Kirtland, OH, 44094

Genus Rhododendron contains more than 800 species worldwide, currently grouped into eight subgenera. Four of these subgenera-comprising the evergreen azaleas, deciduous azaleas, small scaly-leaved rhododendrons, and large non-scaly leaved rhododendrons - have been the focus of ornamental breeding for over 150 years. As a rule of thumb, species within a subgenus are cross-fertile, and most hybrids are derived from intra-subgeneric crosses. Success with wider (inter-subgeneric) crosses, especially deciduous azaleas $\times$ large-leaved rhododendrons, has been occasionally reported in the past, based on the intermediate morphology of the hybrids. I crossed a tetraploid 'Ilam group' azalea with $R$. 'Catlalgla' (a selection of the native diploid rhododendron species $R$. catawbiense) and produced a small population of seedlings that proved to be true 'azaleodendron' hybrids, based on shared parental alleles at 2 isozyme loci, $I d h-1$ and $M d h-3$. However, none of the progeny are hybrid in appearance; they share the leaf morphology and deciduous trait of the maternal azalea parent. I attribute this result to a dosage effect in these (probable) triploid hybrids, where the azalea genetic contribution is twice that of the rhododendron parent. Higher copy number can be inferred from stronger band intensities for the azalea gene at diallelic loci $(I d h-1)$, or from triallelic loci $(M d h-3)$ where the genetic contribution to the hybrid progeny appears to be $2: 1$, 
azalea : rhododendron. Previously, azalea-like progeny from azalea $\times$ rhododendron crosses were thought to result from parthenogenesis or accidental self-pollination.

\section{(15) Evaluation of Genetic Variation in Pawpaw Cultivars using Simple Sequence Repeat Markers}

Jeremiah D. Lowe*, Kirk W. Pomper

Kentucky State University, Horticulture, 146Atwood Research Center, Frankfort, KY, 40601

Pawpaw [Asimina triloba (L.) Dunal] is a tree fruit native to areas in the Midwest and Southeast United States. Since 1994, Kentucky State University (KSU) has served as the USDANational Clonal Germplasm Repository, or gene bank, for pawpaw; therefore, the assessment of genetic diversity in pawpaw is an important research priority for the KSU program. There are over 1800 pawpaw accessions (trees) from 16 different states and over 40 cultivars that are planted on 8 acres at the KSU farm. The objectives of this study were to develop microsatellite markers for pawpaw, and to then use those markers to evaluate 19 cultivars in the repository collection. Leaves of the pawpaw cultivar Sunflower were sent to Genetic Information Systems (Chatsworth, Calif.) for simple sequence repeat (SSR) primer and marker development. A total of 34 microsatellite primers were developed for pawpaw. These primers were then used in a preliminary screening with five pawpaw cultivars ('Sunflower', 'Mitchell', 'Sweet Alice', 'Overleese', and 'Prolific'). Results from this preliminary screening indicate that four of the primers failed to amplify any product, 12 primers were monomorphic, and 18 primers were polymorphic. Eleven additional cultivars were then screened, which produced numerous polymorphic products. For example, Primers B3 and B118 produced products ranging in size from 490 to $350 \mathrm{bp}$. Polymorphic products will be used to examine genetic variation among the pawpaw cultivars screened.

\section{(16) Fruit Quality of the USDA Opuntia sp. Germplasm Collection}

Maria M. Jenderek, Barbara Hellier*

USDA, ARS, National Arid Land Plant Genetic Resource Unit, Parlier, CA, 93648

The fruit of several Opuntia species (prickly pear) are a good source of calcium, potassium, and ascorbic acid and are consumed fresh or processed as juices or preserves. Plants of Opuntia may be grown in arid and semiarid environments on marginal soils. Various cultivars, particularly in the species Opuntiaficus-indica, are grown commercially in the United States, Israel, Italy, Mexico, and South Africa. There is a need for new sources of genetic diversity and subsequent germplasm evaluation, and until recently, no publicly maintained germplasm collection of Opuntia existed in the United States. The purpose of this study was to evaluate fruit quality of 25 Opuntia accessions, originating from six countries, and maintained at the USDA collection at the National Arid Land Plant Genetic Resource Unit, Parlier, Calif. The largest fruits were harvested from plants of accessions PARL 201,202, and 228 (227.6, 247.3, and $231.3 \mathrm{~g}$ /fruit, respectively). The hardest peel was on fruits of PARL 225 and 234 (both $3.7 \mathrm{~kg}$ ), and fruit pulp of the same two accessions had the highest firmness $(2.3$ and $2.4 \mathrm{~kg}$, respectively). Soluble solids in mature fruit varied from $6.1 \%$ (PARL 231 ) to $15.0 \%$ (PARL 254). The fruit color ranged from light yellow through orange, pink to dark purple. These characteristics and other traits such as fruit acidity, presence of spines, and seed mass/fruit indicated that the material represents a diverse germplasm collection, usable for future cultivar development.

\section{(17) TRAP Markers Help Categorize a Pelargonium Collection}

Rose Palumbo*1, Wai-Foong Hong ${ }^{1}$, Jinguo $\mathrm{Hu}^{2}$, Charles Krause ${ }^{3}$, David Tay ${ }^{4}$, Guo-Liang Wang ${ }^{1}$

${ }^{1}$ The Ohio State University, Plant Pathology; ${ }^{2}$ USDA-ARS Northern Crop Science Laboratory, Sunflower Research Unit; ${ }^{3}$ USDA-ARS, Application Technology Research Unit; ${ }^{4}$ The Ohio State University, Ornamental Plant Germplasm Center

The Ornamental Plant Germplasm Center (OPGC) maintains a collection of herbaceous ornamental plants in order to protect future breeders from a loss of genetic diversity. The current Pelargonium collection includes $\approx 870$ accessions. Our preliminary studies showed that TRAP (Target Region Amplified Polymorphism) has promise for analyzing the variation in our collection, and so we have expanded the study to analyze the entire Pelargonium collection. We have used the same primers for this screening of the Pelargonium collection as were used on sunflowers, and TRAP results run on a sequencing gel showed 90-150 bands that segregate the population into groups of similar accessions. In order to facilitate analysis of OPGC's large population, we have converted the method to a high throughput technique that efficiently analyzed the entire population. We used a 96-well DNA extraction kit from Qiagen that produced high quality DNA in spite of the high phenol levels in some Pelargonium species. Also, the use of labeled primers allowed analysis of the gels to be aided by a computer. These results produce a categorization of the collection that, combined with morphology and taxonomy, will form the basis for future studies that will use target genes specific to Pelargonium.

\section{(18) Biodiversity of the Flavonoid Phlorizin in a Subset of the USDA Apple Germplasm Core Collection}

Todd C. Einhorn*1, Cecil Stushnoff ${ }^{1}$, Ann E. McSay ${ }^{1}$, Phil L. Forsline ${ }^{2}$, Sam Cox ${ }^{3}$, Joel R.L. Ehrenkranz ${ }^{4}$, Loretta Sandoval ${ }^{5}$

${ }^{1}$ Colorado State University, Department of Horticulture and Landscape Architecture, Fort Collins, CO, 80523; ${ }^{2}$ Cornell University, Department of Horticultural Sciences, Ithaca, NY; ${ }^{3}$ USDA-ARS, High Plains Grasslands Research Station; ${ }^{4}$ Little Nell Laboratories, Scientific Director; ${ }^{5}$ Colorado State University, Department of Food Science and Human Nutrition

Phlorizin is known for its role in reducing glucotoxicity and has a long history of use in diabetes research. In addition, its contribution to the pool of total phenolics adds to the overall health benefits attributed to fruit. Phlorizin is limited to Rosaceae family plants, of which apple comprises its current commercial source; however, limited information exists regarding its biodiversity among apple taxa. A subset of 22 taxa from a core collection of apple accessions representative of the global genetic diversity of apple was used to investigate the biodiversity of phlorizin present in apple shoots and in fruit relative to total phenolic content and free radical scavenging capacity. Fruit and shoots were harvested from the USDA Plant Genetic Resources Unit in Geneva, N.Y. Validation and quantification of phlorizin was conducted using a rigorous high-pressure liquid chromatography (HPLC) procedure. Total phenolics in fruit, assayed using a Folin-Ciocalteu method and expressed as gallic acid equivalents, ranged from 227 to $7181 \mathrm{mg} \cdot \mathrm{L}^{-1}$ and were strongly related to 2,2' azinobis (3-ethylbenzothiazoline6-sulfonic acid) (ABTS) antioxidant capacity for the core collection $(r=0.778)$. On a molar basis, phlorizin had lower antioxidant capacity than other major phenolic compounds present in apple fruit, but was more effective than ascorbic acid. Phlorizin yield in dormant apple shoots, expressed as percent weight, ranged from $0.9 \%$ to $5.5 \%$. A rapid, 96 well micro-plate spectrophotometric assay was also developed to aid in the screening of multiple samples for selection of high phlorizin yielding apple taxa. Spectrophotometry overestimated phlorizin content as expected, but the calibration curve between HPLC and spectrophotometry was acceptable, $r^{2}=0.88$.

\section{(19) Cryopreservation of Arabidopsis thaliana Shoot Tips}

\section{Leigh E. Towill*, Gayle M. Volk}

National Center for Genetic Resources Preservation, USDA-ARS, Fort Collins, CO, 80521

Arabidopsis thaliana shoot tips provide a model to study processes important for cryopreservation. Cryopreservation was accomplished using both vitrification and two-step cooling methods. With vitrification methods, shoot formation after liquid nitrogen (LN) exposure was as high as $100 \%$ and $95 \%$ for shoot tips exposed to PVS2 at $0{ }^{\circ} \mathrm{C}$ and to PVS3 at $23{ }^{\circ} \mathrm{C}$, respectively. A two-step cooling method also gave greater than $90 \%$ survival if shoot tips were cooled at $0.3{ }^{\circ} \mathrm{C}$ per minute to below $-30{ }^{\circ} \mathrm{C}$ before immersing the samples into $\mathrm{LN}$. The high levels of shoot formation after LN exposure in Arabidopsis thaliana shoot tips will allow the use of mutants to examine how alterations in biochemical, metabolic, and developmental processes affect survival and growth. 


\section{Poster Session 43-Viticulture}

\section{July 2005, 12:00-12:45 p.m. Poster Hall-Ballroom E/F}

(377) Consumer Acceptance of Mayhaw (Crataegus opca Hook. and Arn.) Fruit Juice Blended with Muscadine (Vitis rotundifolia Michx.) Grape Juice

Alfred F. Trappey*1, Charles E. Johnson²

${ }^{1}$ Louisiana State University, Food Science, Baton Rouge, LA, 70803; ${ }^{2}$ Louisiana State University, Horticulture,

Growth in juice-based products is supported by an increasing consumer base, which perceives fruit and fruit-based beverages as an integral component of nutritious food types that can benefit health. New flavor combinations, as well as added ingredients (i.e., vitamins) continue to help boost juice appeal as a nutraceutical. New juice-based food products such as blends, jellies, marinades, and pastry fillings could benefit from the unique flavor attributes specific to mayhaw fruit juice. Juice from one cultivar of muscadine grape (Vitis rotundifolia Michx.) 'Carlos' (bronze skinned) was mixed with varying levels of juice from one cultivar of mayhaw (Crataegus opaca) 'Texas Star'(reddish-orange skinned) fruit. Five different blend combinations were tested for both individual juice quality and for juice-blend compatibility. A consumer preference test was conducted $(n=75)$ on a 9-point hedonic scale for color, taste, and overall liking. Next to the taste/flavor preference scores for control (6.8), mayhaw juice used as the primary flavor ingredient in blends was the second most preferred of all juices by the panelists. A $50 / 50$ juice blend and 70/30 mayhaw/muscadine blend were the least desirable of the five combinations tested. Juices from 60/40, 30/70, and 40/60 mayhaw/muscadine were considered by the panelists as best in flavor and overall acceptability. "Taste" had the strongest effect on overall acceptability of juice from varying levels of mayhaw juice in combination with muscadine grape juice. Panelists' mean score averages collectively were favorable of 60:40 and 50:50 juice blends and were significant $(P<0.05)$ toward acceptance of a "mayhaw-muscadine" fruit juice blended drink.

\section{(378) Weed Management in Organic Grapes}

\section{Kathleen Delate*1, Andrea McKern ${ }^{1}$, Michelle Kirkland ${ }^{2}$}

${ }^{1}$ Iowa State University, Horticulture \& Agronomy, Ames, IA, 50011; ${ }^{2}$ Kirkland Vineyards, Norwalk, IA

Iowa was the sixth largest producer of grapes in the United States in the early 1900 s, with 24,000 ha under production. The rapid expansion of petrochemicals post-World War II and grape's sensitivity to 2,4-D herbicides reduced vineyard size in Iowa to 28 ha in 2001. Recent state governmental support for organic fruit research and viticulture in general has led to the expansion of the grape and wine industry in Iowa. As of 2001, 5883 ha of organic grapes were produced in the United States. Challenges to organic grape production in the Midwest include diseases and weeds. The cultivation of American grape cultivars is essential in organic viticulture in the Midwest, including cultivars that are relatively cold hardy and disease tolerant. From 2003 to 2004, we experimented on-farm at Kirkland Vineyards, Norwalk, Iowa, with methods of organically approved weed management. Three replications of plots consisting of five vines each of 'Marechal Foch' were laid out in 2003 in a completely randomized design in a 1-year-old vineyard. Treatments consisted of wood chips, wood chips plus vinegar herbicide (All-Down ${ }^{\mathrm{TM}}$, SummerSet Co., Chaska, Minn.), and mowing when weeds and groundcover reached $15 \mathrm{~cm}$. Wood chips decreased weed load significantly over mowing alone, but wood chips plus vinegar herbicide provided the most control over 2 years of the experiment. There was a trend toward greater plant height in the wood chip treatment, but no significant differences in plant height were observed among treatments.

(379) Ploidy Determination in Vitis rotundifolia using Flow Cytometry

Xia Xu, Jiang Lu*, Zhongbo Ren

Florida A\&M University, Center for Viticulture, Tallahassee, FL, 323177

Ploidy level in grapevines varies, especially since in vitro techniques are employed in the breeding process and after plants are treated with either chemicals or radiation. Detection of ploidy level in grapevines by microscopic chromosome counting is complicated by their high number and the small size of chromosomes. Flow cytometry provides an accurate and rapid method in determining the ploidy level in plant tissue by measuring the nuclear DNA content in living cells and thus is a very useful tool in plant breeding or genetic studies. The objective of this research was to analyze the ploidy level of a selected group of muscadine vines that were different from normal diploid vines in morphology. These grapes were derived from either chemical treatment of known varieties or from controlled/open pollinations. Among the 26 grapevines investigated, 8 were found to be diploids, 11 were tetraploids, and 7 were chimeric aneuploids. Results of this study indicate that flow cytometry is a quick, reliable tool for determining ploidy levels of grapevines.

\section{(380) The Effect of Kaolin Clay-based Particle Film Applications and Canopy Manipulations on Fruit Composition and Incidence of Cluster Damage due to Sunburn in 'Cabernet Sauvignon' Grapevines}

Rhonda J. Smith*

University of California, Cooperative Extension, Santa Rosa, CA, 95403

The effect of sunlight exposure on yield, fruit composition, amount of damaged clusters, and berry temperature was evaluated in a terraced, hillside 'Cabernet Sauvignon' vineyard on the north coast of California. Each terrace contained two vine rows identified as "inside" and "outside" relative to the terrace surface. The standard canopy management practice of removing lateral shoots from below the clusters was imposed with three modifications ("umbrella", "fogger", and "umbrella+fogger") and an unmodified control. Applications of a kaolin-based particle film were made to unmodified canopies and a final treatment consisted of leaving lateral shoots. Canopies with umbrella modifications were not fully vertically shoot positioned. Fogger emitters directed water into the cluster area when ambient temperature reached $33.9^{\circ} \mathrm{C}$ beginning in mid-July for a total of 16 fogger-events through 8 Sept. 2004. Treatments were harvested 17 Sept. Yield was affected by row type but not treatment, and inside and outside rows produced an average of 2.1 and $3.4 \mathrm{~kg} /$ vine, respectively. Particle film applications significantly reduced berry surface temperatures in the afternoon of two measurement dates by 0.7 and $1.5^{\circ} \mathrm{C}$, respectively. Applications did not significantly affect fruit maturity indices when compared to fruit in the control; however, at the $7 \%$ probability level, berry samples from vines that had been treated with kaolin-clay had lower ${ }^{\circ}$ Brix than samples from control vines. The mean range of sunburn fruit across all treatments was 0.2 to 1.4 clusters per vine. Umbrella and umbrella+fogger treatments significantly reduced the number of damaged clusters $(P<0.05)$.

\section{(381) Nutraceutical Profile of Selected Muscadine (Vitis rotundifolia Michx.) Cultivars and Breeding Lines}

Stephen J. Stringer ${ }^{1}$, Penelope Perkins-Veazie ${ }^{2}$,

Donna A. Marshall*1

${ }^{1}$ USDA ARS, Small Fruit Research Station, Poplarville, MS, 39470; ${ }^{2}$ USDAARS, South Central Agricultural Research Laboratory, Lane, OK, 74555

The consumption of fresh fruit and vegetables has always been known to provide essential nutrition to mankind and, both anecdotally and clinically, has been linked to the prevention or alleviation of chronic diseases. The muscadine grape, a fruit native to the southeastern U.S., contains numerous phenolic compounds that act as antioxidants and also other compounds, such as resveratrol, that acts as a chemopreventative. The concentrations of these compounds present in the muscadine grape equal or exceed that known for any other small fruit. Fruit of selected muscadine grape genotypes, including breeding lines and cultivars, were evaluated over a 2-year period to assess the existing genetic base for these nutraceutical compounds. Results demonstrated that concentrations of total phenolics, ellagic acid, and resveratrol differ significantly among cultivars and breeding lines. These results suggest that it should be possible to breed for increased concentrations of the health-promoting compounds in muscadine grapes. 


\section{(382) Application of a Molecular Marker for Berry Seed Size to Two Populations of Grapevines (Vitis sp.) Developed in a Breeding Program}

Frederick J. Ryan*, David W. Ramming

USDA ARS, Crop Diseases, Pest, and Genetics Research Unit, Parlier, CA, 936488

The development of grapevines with berries with small seed traces, so-called seedless grapes, is a costly process. Marker assisted selection would save time and money. Adam-Blondin et al. (Vitis 40:147. 2001) demonstrated that a sequence characterized amplified region, SCC8, could identify seedless grapevine cultivars in European accessions of Vitis vinifera L. We have applied this marker to two populations of grapevines in a breeding program in California. One population consisted of 100 individuals while the second had 109. The two crosses had a common female parent, derived from 'Flame Seedless'. Fruit were evaluated over several seasons for parameters including total weight of seeds or traces. DNA was isolated from leaves during the spring. Amplification was carried out with SCC8 primers, followed by digestion with $\mathrm{Bgl} \mathrm{II}$, and agarose gel electrophoresis. Individuals were scored as homozygous SCC8+ (small seeded), heterozygous SCC8+/scc8- (intermediate sized seeds), or homozygous scc8- (large seeded) and mean total seed weight per berry was calculated for each genetic class. In the first population, the number of individuals in the inferred genotypes fit an expected 1:2:1 distribution $\left(\chi^{2}=0.480\right.$, $P>0.787)$ and seed weights for each genetic class were reasonable. For the second population, it was necessary to postulate a null allele in one parent, with a 1:1:1:1 expected distribution for genotypes SCC8+/SCC8+, SCC8+/null, SCC 8+/scc8-, and scc8-/null. The actual distribution was in agreement with this model $\left(\chi^{2}=4.379, P>0.223\right)$. The genotype SCC $8+$ /null had the SCC $8+$ marker and total seed weight $>10 \mathrm{mg}$ per berry. Large seeded individuals and heterozygotes could be reliably identified with this marker.

\section{(383) Effect of Harmony and Freedom Rootstocks on Yield and Quality of 'Red Globe' Table Grapes}

Manuel de Jesus Valenzuela-Ruiz', Fabián Robles-Contreras², Raul Leonel Grijalva-Contreras*3 ${ }^{*}$, Rubén Macias-Duarte ${ }^{4}$

${ }^{1}$ INIFAP-Caborca, Viticulture, Caborca, Sonora, 83600, México; ${ }^{2}$ INIFAP-Caborca, Agroclimatology, ${ }^{3}$ INIFAP-Caborca, Protected Horticulture, ${ }^{4}$ INIFAP-Caborca, Soli \& Horticultural

The region of Caborca, Sonora, Mexico, is one of the main area producers of table grapes, in particular the cultivar Red Globe. However, the main problems in the region include shortage and high cost of water, nematode infestation, and salinity. The objective of the present research was to determine the behavior of 'Red Globe' cultivated on the rootstocks Harmony and Freedom. This study was carried out in the INIFAP Caborca research station in the year 2002, and consisted of 10 plants for treatment (on each rootstock). When water was low, a drip irrigation system was used. There was a completely randomized statistical design. We observed no differences among the two rootstocks in the different phonological stages (budbreak, flowering, and harvest time). The results indicated statistical differences between the rootstocks. Yield was higher on Freedom rootstock, with 2120 boxes/ha (boxes of $10 \mathrm{~kg}$ ), an average of 470 boxes/ha more than on Harmony rootstock. Freedom rootstock also improved the quality of the grape (better color, bigger size of berry, and clusters, and the foliage was also more developed with this rootstock). In both rootstocks, nematode control was $100 \%$, $30 \%$ in water consumption, and no fertilizer was used.

\section{(384) Raisin Production of 'Fiesta Seedless' on Freedom Rootstock under Different Plantation Densities}

Manuel de Jesus Valenzuela-Ruiz ${ }^{1}$,

Raul Leonel Grijalva-Contreras*2, Fabián Robles-Contreras ${ }^{3}$,

Rubén Macias-Duarte ${ }^{4}$

${ }^{1}$ INIFAP-Caborca, Viticulture, Caborca, Sonora, 83600, México; ${ }^{2}$ INIFAP-Caborca, Protected Horticulture; ${ }^{3}$ INIFAP-Caborca, Agroclimatology; ${ }^{4}$ INIFAP-Caborca, Soli \& Horticultural

Grape is one of the more important crops in northwestern Mexico (Sonora), especially for table grape. Although raisin production is a good option, it must be efficient and productive due to the problems of shortage and high cost of water, salinity, and nematodes. The objective of this research was the evaluation of 'Fiesta Seedless' on Freedom rootstock for raisin production with different plantation densities. This study was carried out in the INIFAP Caborca research station in 2002. Four plant separations $(1.0,1.5,1.7$, and $2.0 \mathrm{~m})$ were evaluated on furrows $4 \mathrm{~m}$ apart. Plants were grafted on Freedom rootstock in 1999. We also considered a control treatment $(4 \times 2 \mathrm{~m}$ on its own feet $)$ and fertilized it with $80 \mathrm{~N}-60 \mathrm{P}-80 \mathrm{~K}$. All experiments were carried out under the espalier training system with double crossbeam; watering was under a drip-irrigation system; and the statistical design was completely randomized. Statistical differences between the evaluated spacings were not observed, but all densities surpassed the control. Greatest yields were obtained with $1.5-$ and $1.7-\mathrm{m}$ spacings, at 6.1 and $6.0 \mathrm{t} \cdot \mathrm{ha}^{-1}$ of raisin, respectively, which were $2.2 \mathrm{t} \cdot \mathrm{ha}^{-1}$ more than the control $\left(3.8 \mathrm{t} \cdot \mathrm{ha}^{-1}\right)$. There were no differences in sugar content and harvest time, since all treatmens, including the control, were harvested at $24{ }^{\circ}$ Brix. Freedom rootstock had $100 \%$ nematode control, $30 \%$ less water consumption, and was not fertilized.

\section{(385) Phenolic Analysis of Selected Grape Cultivars}

Keri L. Andersen*1, Susan L. Cuppett ${ }^{2}$, Ellen T. Paparozzi ${ }^{1}$, Paul E. Read

${ }^{1}$ University of Nebraska-Lincoln, Agronomy and Horticulture, Lincoln, NE, 685830724; ${ }^{2}$ University of Nebraska-Lincoln, Food Science and Technology, Lincoln, NE, 68583-0919;

Phenolic levels have been analyzed in several grape cultivars that are suited for growing in southeastern Nebraska. The phenolic levels of these cultivars are not known to have been previously published. The polyphenol content of fruits and fruit products such as wine have been shown to be directly correlated to the antioxidant potential of the product. Antioxidants help to prevent the effects of aging and age-associated diseases. The grape cultivars in the study are grown primarily for wine production, but also as fresh table grapes and for making juice and jellies. The total phenolic content is being analyzed by the Folin-Ciocalteu method. Of the red grapes, 'St. Croix' and 'Frontenac' have the highest levels of polyphenols, followed by 'Chambourcin' and 'deChaunac', with levels varying from $1.4-4.9 \mathrm{mg} \cdot \mathrm{g}^{-1}$ (polyphenols/grape), measured as gallic acid equivalents (GAE). The white grapes 'Vignoles' and 'LaCrosse' have total phenolic levels of 1.4 to $2.2 \mathrm{mg} \cdot \mathrm{g}^{-1}$ (polyphenols/ grape), also measured as gallic acid equivalents (GAE).

\section{(386) The Commercial Potential and Antioxidant Characteristics of Unique Varietal Grape Juices}

Joseph C. Scheerens ${ }^{1}$, Todd E. Steiner ${ }^{1}$, Artemio Z. Tulio, Jr. ${ }^{1}$, Mustafa Ozgen*2, Diane D. Miller ${ }^{1}$, R. Neil Reese ${ }^{3}$, A. Raymond Miller ${ }^{1}$, David C. Ferree ${ }^{1}$

${ }^{1}$ Ohio State Univ., OARDC, Horticulture and Crop Science, Wooster, OH, 44691; ${ }^{2}$ GOP Univ., Horticulture, Tasliciftlik, Tokat, 60240 , Turkey; ${ }^{3}$ South Dakota State Univ., Department of Biology \& Microbiology, Brookings, SD, 57007

Eight unique varietal grape juices were examined for their antioxidant characteristics and commercial potential compared to that of commercial 'Niagara' and 'Concord'. Grape juices were cold-pressed from mature grapes, clarified, preserved, analyzed for $\mathrm{pH}$, soluble solid and titratable acidity levels, pasteurized at $73{ }^{\circ} \mathrm{C}$ for 12 seconds, and sampled for microbial testing. A preliminary panel of 41 routine evaluators assessed all juices for 18 quality characteristics against known and blind controls. Based on these results, 'Reliance', 'Traminette', and New York 73 juices were presented to a 107-member panel of untrained judges. Panelists rated experimental juices against commercial controls for color, appearance, aroma and flavor intensity, sweetness, tartness, overall quality, and preference. Among juices tested, 'Reliance' and NY 73 offer the greatest potential as specialty grape juices. 'Traminette', 'Chardonel', 'Chambourcin', and NY 62 may also have potential as grape juice cultivars, if processed to improve their color and clarity. Small juice lots were hand-pressed from mature grapes and examined for total anthocyanin and phenolic content, antioxidant characteristics (DPPH and FRAP) and levels of individual phenolic compounds via GC-MS. Total anthocyanin and phenolic contents of experimental juices varied from $0-1460 \mu \mathrm{g} \cdot \mathrm{gfw}^{-1}$ and $1001-2850 \mu \mathrm{g} \cdot \mathrm{gfw}^{-1}$, respectively, and were highest in NY 73. Estimates of antioxidant activity differed 
slightly among tests, but activity appeared highest in 'Chambourcin' and NY 73 and lowest in 'Reliance'. Levels of individual compounds varied substantially among juices.

\section{(387) Evaluating the Resistance against Anthracnose by Bioassay using Culture Filtrates from Elsinoe ampelina}

Hae Keun Yun*, Kyo Sun Park, Jeong Ho Rho, Hyeon Mo Jo

National Horticultural Research Institute, RDA, Fruit Research Department, 475 Imockdong, Suwon, Kyunggi, 440-706, Republic of Korea

Breeding of cultivars resistant to anthracnose is one of the most important grape-breeding goals in Korea. Culture filtrates produced by $E$. ampelina were used to determine varietal susceptibility to anthracnose in grape cultivars as a substitute for pathogen inoculation or field screening in this study. Resistance evaluated by bioassay of grape leaves with culture filtrates and their ethyl acetate extracts was compared with ones from pathogen inoculation and field screening. To evaluate the resistance to anthracnose disease in grape germplasm, European grapes, American grapes, and Vitis hybrids were tested. Bioassay with culture filtrates produced by the pathogen showed that 'Black Eye', 'Mario', 'Niunai', 'Rizamat', and 'Rosario Bianco' were sensitive; and 'Campbell Early', 'Niagara', and 'Honey Red' were tolerant to anthracnose. In the result of anthracnose resistance evaluation by pathogen inoculation, some cultivars, such as 'Black Swan', 'Rizamat', 'Rosario Bianco', and 'Kaiji', were susceptible; and others, such as 'Campbell Early', 'Niagara', 'Sheridan', and 'Izumo Queen', were found to be resistant to anthracnose. Evaluation in the vineyard showed that 'Black Eye', 'Mario', 'Niunai', 'Rizamat', and 'Rosario Bianco' were susceptible; 'Campbell Early', 'Niagara', and 'Honey Red' were resistant. The results of bioassay with culture filtrates of the pathogen were consistent with ones from the results by pathogen inoculation and screening in the vineyard.

\section{Poster Session 44-Organic Production}

\section{July 2005, 12:00-12:45 p.m. Poster Hall-Ballroom E/F}

\section{(408) Effects of Essential Oils on $\mathrm{CO}_{2}$ Assimilation, Stomatal Conductance, and Evapotranspiration of Apple}

Jason McAfee*, Curt Rom

University of Arkansas, Horticulture, Fayetteville, AK 72701

Pesticides and alternative fruit thinners are needed for certified organic fruit growers. Transient reductions in photosynthesis $(\mathrm{Pn})$ have proven an effective technique for fruit thinning. Pesticides can be detrimental to plant growth by Pn reduction. This study was developed to measure plant response to foliar applications of essential oils at $2 \%$ concentrations. Treatments were applied to vegetative apple trees grown under controlled environment conditions to study photosynthetic effects. There was no significant effect on Pn for treatments; however, clove oil was very phytotoxic and defoliated all trees in this study. Cinnamon oil and cedarwood oil significantly decreased evapotranspiration and stomotal conductance 1 day after treatment. Differences in plant growth were not significantly different for all treatments excluding clove oil. Studies on concentration effects may determine horticultural usefulness of these compounds.

\section{(409) The Impact of Tarnished Plant Bug Damage on Antioxidant Characteristics of Organically and Conventionally Grown Strawberries}

Mustafa Ozgen*1, Joseph Kovach ${ }^{2}$, Lauren D. Harper², Simeon Wright ${ }^{3}$, Joseph C. Scheerens ${ }^{1}$

${ }^{1}$ Ohio State Univ., OARDC, Horticulture and Crop Science, Wooster, OH, 44691; ${ }^{2}$ Ohio State Univ., OARDC, Integrated Pest Management Prog.; ${ }^{3}$ Univ. of Missouri, Plant Diagnostic Lab, Columbia, MO, 65211

Six strawberry cultivars ('Earliglow', 'Honeoye', 'Idea', 'Jewel', 'Northeaster', and 'Seneca') were grown organically on three different composts (yard waste, dairy barn waste, and vermicompost). Organic treatments were contrasted against a synthetic fertilizer standard, a conventional pesticide standard and an untreated control. Plots were rated for tarnished plant bug (Lygus lineolaris) damage during the growing season. At harvest, berries were examined for their ascorbic acid levels and total anthocyanin and phenolic contents. Ascorbic acid content of berries in different cultivars and treatments were similar. As expected, fruit anthocyanin and phenolic contents were significantly different among the cultivars, and ranged between 160-230 $\mu \mathrm{g} \cdot \mathrm{gfw}^{-1}$ and $1039-1333 \mu \mathrm{g} \cdot \mathrm{gfw}^{-1}$, respectively. Among treatments, anthocyanin contents of strawberries were not significantly different, but berries grown on the conventional pesticide standard had $8 \%$ to $12 \%$ lower total phenolic content than the other treatments. In organic treatments, production of phenolic compounds may have been induced in response to increased tarnished plant bug feeding. This putative biotic stress defense mechanism was seen most dramatically on tarnished plant bugsusceptible cultivars. However, as differences in phenolic levels were greater among cultivars than among treatments, cultivar choice may be a more important consideration than growing system for optimizing antioxidant levels in commercially available fruit.

(410) Soil and Tissue Nitrogen and Fall Cabbage Yield Associated with Varying Rates of Nitrogen Applied as Different Organic Sources

\section{Mark Gaskell*, Rachel Grande}

University of California, Cooperative Extension, Santa Maria, CA, 93455

Fertilization is the most expensive cultural practice for increasing numbers of organic vegetable growers in California. Nitrogen $(\mathrm{N})$ is the most important and costly nutrient to manage and cost-effective $\mathrm{N}$ management practices are needed for efficient organic vegetable production. Compost and green manure cover crops are widely used, economical sources of $\mathrm{N}$ for organic vegetable production, but the pattern of release from these pre-plant incorporated $\mathrm{N}$ sources may not adequately match crop need for $\mathrm{N}$. Additional application of an organic $\mathrm{N}$ fertilizer material is needed to provide adequate $\mathrm{N}$ to long-season vegetable crops. Seven types of organic fertilizers-feather meal $(13 \% \mathrm{~N})$, blood meal $(14 \%$ $\mathrm{N})$, liquid fish waste $(6 \% \mathrm{~N})$, a micronized liquid feather meal $(4 \%$ $\mathrm{N})$, a micronized feather/blood meal $(13 \% \mathrm{~N})$ for injection as a liquid suspension, and the two micronized materials with an added microbial inoculant-were each applied to fall cabbage at $\mathrm{N}$ rates of $0,90,180$ $\mathrm{lb} /$ acre. Weekly residual soil nitrate $\mathrm{N}(\mathrm{SNN})$ was proportional to applied $\mathrm{N}$ rate much of the season and varied from 5 to over $70 \mathrm{ppm}$. Marketable yield ranged from 8000 to 33,300 lb/acre. The SNN was highest in plots receiving the liquid fish waste most weeks, and marketable cabbage yield was also highest following application of $\mathrm{N}$ as liquid fish waste at $180 \mathrm{lb} /$ acre. A positive marketable yield response to increasing rates of applied $\mathrm{N}$ was also observed for the other organic $\mathrm{N}$ materials.

\section{(411) Companion Choice, Crop Density, and Mixture Ratio Affect Polyculture Yield Advantage}

Michael K. Bomford*

Kentucky State University, Community Research Service, Atwood Research Facility, Frankfort, KY, 40601

Polycultures are thought to offer yield advantages over monocultures when net competition between plants of different species is less than that between plants of the same species. Planting density and crop ratios may both alter these competitive effects. To observe such effects, dicultures of basil (Ocimum basilicum L.), brussels sprout (Brassica oleracea L.), and tomato (Lycopersicum esculentum Mill.) were grown organically at a range of ratios and densities (1-47 plants $\left./ \mathrm{m}^{2}\right)$ over two field seasons. Relative land output (RLO) values were calculated from field data and from modeled yield-density-ratio surfaces. Both methods showed yield advantages from polyculture at high planting densities $(\mathrm{RLO}=2.20 @$ top density), but not at low densities. Dicultures offered a $19 \%$ yield advantage, on average. Competition for resources was compared by measuring canopy light interception and soil moisture content, showing tomato to be the most competitive crop, followed by brussels sprout, then basil. Diculture yield advantages were most pronounced when individuals of a less competitive species outnumbered those of a more competitive species. Yield advantages were $36 \%$ and $20 \%$ for dicultures dominated by basil and brussels sprout, respectively. 
Dicultures dominated by tomato offered no yield advantage. The results are discussed in terms of the current ecological understanding of plant interactions, and possible advantages to be derived from small-scale intercropping, popularly termed companion planting.

\section{(412) Tomato Diseases}

Donald Krizek*1, Patricia Millner ${ }^{1}$, Mary Camp², David Clark ${ }^{1}$, Mark Davis ${ }^{1}$, Bryan Butler ${ }^{3}$, John Teasdale ${ }^{1}$, Deborah Fravel ${ }^{4}$, Sara Reynolds ${ }^{1}$, Ruth Mangum ${ }^{1}$, Ted Currier ${ }^{5}$

${ }^{1}$ USDA-ARS, SASL, BARC-W, Beltsville, MD, 20705; ${ }^{2}$ USDA-ARS, Biometrical Consulting Service, BARC-W, Beltsville, MD, 20705; ${ }^{3}$ University of Maryland, MD Cooperative Extension Service, Carroll Co., Westminster, MD, 21157; ${ }^{4}$ USDA-ARS, Vegetable Lab, BARC-W, Beltsville, MD, 20705; ${ }^{5}$ USDA-ARS, FMOD, BARC-W, Beltsville, MD, 20705

Afield study of organic production of tomato (Lycopersicon esculentum Mill.) in high-tunnels was conducted in 2004. 'Mountain Fresh' was transplanted 31 Mar.; 'Ultra Sweet' and 'Sun Leaper'were transplanted on 21 July. The primary objective was to determine the feasibility of obtaining two crops of fresh-market tomatoes by starting plants $4-8$ weeks earlier than the average last spring-killing frost, and extending the growing season 4-6 weeks past the average first fall-killing frost. Plants were started at weekly intervals for 4 weeks in both seasons. Data and observations were recorded on the yield of marketable fruits, plant growth and development, and plant health. Other objectives were to evaluate: 1) the benefits of using a selective UV-blocking film on plant growth and development, disease events; and 2) compost amendments on soil improvement and disease control. Major cultural challenges included water management, soil texture/drainage, prevention of chilling injury, plant support, and adequate ventilation. Major disease/pest challenges involved stalk rot caused by Sclerotinia sclerotiorum in the spring, powdery mildew in spring and late summer, Alternaria and Septoria leaf blight in late summer, and aphids, tomato hornworm, corn earworm, and beet army worm also in late summer. In addition, macrofaunal intrusions by fox, mice, and birds occurred sporadically. Poor drainage and stalk rot in the spring necessitated relocating the tunnels to an uninfested site with better drainage. The fall crop yielded high numbers of marketable quality fruits, well beyond the 15 Oct. average killing frost date. The results suggest that with improved management, there is a considerable potential for profitable extended-season production of organic tomatoes in this region.

\section{(413) Evaluating Tomato Production during the First Year of Organic Transitioning in High Tunnels}

Adam Montri*, William J. Lamont, Jr., Michael D. Orzolek

The Pennsylvania State University, Department of Horticulture, University Park, PA, 16802

High tunnels offer growers in temperate regions the ability to extend the production season. Past research has shown that these low-input structures also reduce disease and pest pressure. These characteristics make high tunnels extremely attractive to organic growers. Tomatoes (Lycopersicon esculentum Mill.) are the crop most often produced in high tunnels in Pennsylvania and many producers are interested in combining both high tunnel and organic production methods. Growers may be hesitant to transition to organic production due to conceptions concerning reduced yields specifically during the 3 -year transition period to USDA certified organic status. A field trial investigating tomato production in high tunnels during the first year of organic transitioning was conducted in 2004 at The Penn State Center for Plasticulture, Russell E. Larson Agricultural Research Center, Rock Springs, Pa. The objective of this research was to evaluate yield of the four cultivars Big Beef, Mountain Fresh, Plum Crimson, and Pink Beauty in an organic system relative to a scheduled fertilization/irrigation regime and a fertilization/irrigation regime employed using T-Systems International's Integrated Agronomic Technology. Data collected included total weight, total fruit number, weight by grade, fruit number by grade, total marketable yield, and fertilizer and water usage. Yield across cultivars ranged from 4.96 $\mathrm{kg} /$ plant to $6.83 \mathrm{~kg} / \mathrm{plant}$. 'Pink Beauty' exhibited the lowest yields in both treatments, while 'Plum Crimson' and 'Mountain Fresh' exhibited the highest yields in the IAT and scheduled treatments, respectively. This experiment will be repeated in 2005 to further evaluate the performance of these cultivars.

\section{(414) Evaluation of Potato Leafhopper Control and Plastic Mulch Culture for Organic Potato Production}

Martha Maletta*1, Melvin Henninger ${ }^{2}$, Kristian Holmstrom ${ }^{3}$

${ }^{1}$ Rutgers Cooperative Research and Extension and the New Jersey Agricultural Experiment Station, Hunterdon County, Flemington, NJ, 08822; ${ }^{2}$ Rutgers Cooperative Research and Extension and the New Jersey Agricultural Experiment Station, Plant Biology and Pathology, New Brunswick, NJ, 08901-8520; ${ }^{3}$ Rutgers Cooperative Research and Extension and the New Jersey Agricultural Experiment Station, Pest Management, Vegetable IPM, New Brunswick, NJ, 08901-8524

Potato leafhopper (PLH) control and plastic mulch culture for certified organic potato production were evaluated in 2003 and 2004. The trials were conducted on the Rutgers Snyder Research and Extension Farm's certified organic fields. Production practices conformed to the National Organic Program. The potato cultivar grown was 'Superior'. In 2003, PLH controls were: untreated control (UTC); Surround WP, 25 lb/acre; PyGanic EC 1.4, 1 pt/acre; Surround plus PyGanic; and silver plastic mulch. PyGanic and Surround/PyGanic treatment reduced PLH nymph counts and damage (hopperburn-HB), when compared to the UTC. Counts were higher and HB more severe in silver mulch plots than in the UTC, but marketable yield was more than double the UTC. PyGanic and Surround/PyGanic treatment yields were 50\% higher than the UTC. In 2004, PLH controls were: PyGanic EC 1.4, 1-2 pt/acre; Diatect V, 2-4 lb/acre; and Surround WP, $25 \mathrm{lb} / \mathrm{acre}$. The crop was grown on bare ground or silver plastic mulch. Nymph counts and HB were lowest on PyGanic- and Diatect-treated plots. Nymph counts and HB for UTC and Surround treatment were higher on plastic mulch than bare ground plots. Marketable yield was highest from PyGanic-treated plots. PyGanic or Diatect treatment yields were higher from plastic mulched than from bare ground plots. The PLH control and plastic mulch culture significantly increased organic potato yields. Marketable yield from the UTC was lower than the New Jersey average for conventional potato ( 275 hundred wt/acre) by $71 \%$ on bare ground and by $39 \%$ with plastic mulch in $2003 ; 59 \%$ on bare ground; and $52 \%$ with plastic mulch in 2004. PLH control with PyGanic combined with plastic mulch culture resulted in yields just $7 \%$ less than the state average; yield on bare ground was $26 \%$ less.

\section{(415) Evaluation of Weed Control Practices in an Organic Bell Pepper Production System}

Derek M. Law*, Brent Rowell

University of Kentucky, Horticulture, Lexington, KY, 40546

A 2-year field study in Lexington, Ky., evaluated the use of mulches in two organic production systems for bell peppers. Two planting strategies, flat ground and plastic-covered raised beds, and five weed control practices, straw mulch, compost mulch, wood chip mulch, corn gluten, and "living mulch" clover were tested. In 2003, the mulches were applied at planting, while in 2004, shallow soil cultivation was used for 6 weeks prior to mulch application. In 2003, the experimental field had been under a winter wheat cover crop; in 2004, the field had been cover cropped for more than a year prior to planting with sudex/cowpea (Summer 2003) and rye/hairy vetch (Winter/Spring 2004). Bell pepper yields in both bed treatments were very low in 2003 due to extensive weed competition. In 2004, plastic-covered raised beds coupled with mulching in-between beds resulted in significantly higher yields than the peppers grown on flat ground. These yields were as high as yields from a conventional pepper trial conducted on the same farm. Compost mulch, continuous cultivation, and wood chip mulch provided excellent weed control in 2004. Straw mulch was variable in its weed control efficacy; corn gluten and "living mulch" clover were ineffective.

\section{(416) Weed Management in Organic Sweet Corn}

Anthony Silvernail*

Kentucky State University, Community Research Service, Frankfort, KY, 40601

Organic weed control in direct seeded vegetables depends on management strategies that control weed germination or growth which depletes the weed seedbank. In 2004, a randomized complete-block experiment conducted on land transitioning to organic production examined the effects of tillage and control treatments on weed pressure in sweet corn [Zea mays (L.) cv. SilverQueen]. The two tillage treatments consisted of 
conventional (moldboard and rototill) and spader tillage. Weed control treatments included a weed free control, a spring-tine weeder, rolling cultivator, row flamer, stale seedbed, and corn gluten meal. In August, the weed infestation was primarily goose grass [Eleusine indica (L.) Gaertn.], crab grass [Digitaria sanguinalis (L.) Scop.], giant foxtail (Setaria faberi Herrm.), and smooth pigweed [Amaranthus hybridus (L.)] species. Dried weed weights indicated that smooth pigweed constituted about $80 \%$ of the total weed biomass in all but the control and flamer treatments. Plots managed with the spring-tine weeder or corn gluten had twice the weed biomass of those managed with the rolling cultivator and flamer. The rolling cultivator and control treatments produced equivalent husked corn yields $\left(6.9 \mathrm{t} \cdot \mathrm{ha} \mathrm{a}^{-1}\right)$; yields were reduced by the other weed control methods. At $5.4 \mathrm{t} \cdot \mathrm{ha}^{-1}$, yields in the flamer treatment were the lowest among all weed control methods. The flamer suppressed both weeds and the crop, which may preclude its utility for sweet corn production. Results demonstrated that the rolling cultivator provided the best weed control without negatively affecting potential yields.

\section{(417) The Chilean Organic Wine Industry}

Jorge O'Ryan ${ }^{1}$, Monica Ozores-Hampton*2

${ }^{1}$ Universidad de las Americas, Horticulture, Santiago, Chile; ${ }^{2}$ University of Florida/SWFREC, Horticulture, Immokalee, FL, 34143-9515

The Chilean organic wine industry has comparative advantages with Europe and the United States because of its ideal environmental conditions, resulting in low presence of pests and diseases and lower production cost. Additionally, the wine production process is one of the strictest in the world, so the transformation from conventional to organic wine production can be achieved economically. A survey was conducted of 32 Chilean organic vineyards during 2004. The survey included 18 questions about total surface area, certification, varieties, final market, etc. The survey covered $95 \%$ of the land under organic wine production, with a total of $1892 \mathrm{ha}$, of which 1088 ha have organic certification and 804 ha are in transition to organic production. The major vineyards and valleys with organic wine production are Maipo (33.7\%), Colchagua (17.2\%), El Maule (14.0\%), Curicó (9.9\%), and Cachapoal $(8.8 \%)$. The most important organic red varieties currently under production are 'Cabernet Sauvignon' $(40.9 \%)$, 'Merlot' $(15.1 \%)$, 'Syrah' (9.1\%), 'Carmenere'(7.3\%), 'Malbec'(3.3\%), and 'Pinot Noir' $(2.5 \%)$. The white varieties are 'Sauvignon Blanc' (6.4\%), 'Chardonnay' $(5.1 \%)$, and 'Semillón' $(1.0 \%)$. The potential for the organic wine industry in Chile is tremendous since organic vineyards represent only $2 \%$ of the total vineyard industry.

\section{(418) The Development of a Southern Region Organic Fruit Initiative}

Heather Friedrich*1, Curt Rom, ${ }^{1}$ Jennie Popp ${ }^{2}$, Barbara Bellows ${ }^{3}$, Donn Johnson ${ }^{4}$, Dan Horton ${ }^{5}$, Kirk Pomper ${ }^{6}$, David Lockwood ${ }^{7}$,

Steve McArtney ${ }^{8}$, Geoffrey Zehnder ${ }^{9}$

${ }^{1}$ University of Arkansas, Horticulture, Fayetteville, AR, $72701 ;{ }^{2}$ University of Arkansas, Ag riculture Economics, Fayetteville,AR, $72701 ;{ }^{3}$ National Center for Appropriate Technology, Horticulture, Fayetteville, AR, 72702; ${ }^{4}$ University of Arkansas, Entomology, Fayetteville, AR, 72701; ${ }^{5}$ University of Georgia, Entomology, Athens, GA, 30602; ${ }^{6}$ Kentucky State University, Horticulture, Frankfurt, KY, 40601; ${ }^{7}$ University of Tennessee, Plant Sciences Knoxville, TN, 37996; ${ }^{8}$ North Carolina State University, Mountain Horticultural Crops Research and Extension Center, Fletcher, NC, 28732; ${ }^{9}$ Clemson University, Entomology, Clemson, SC, 29634

Southern organic fruit production is limited by a lack of regionally appropriate, scale-neutral, and market-focused research and technology. There has been limited research, outreach, and cooperation among universities on organic fruit crops in the southern region. Organic research and outreach activities, based on producer input, must be focused on the most limiting areas of the organic system in order to allow southern producers to receive the economic and environmental benefits that organic agriculture can provide. With funding from USDASARE and USDA-SRIPMC, researchers at the University of Arkansas have collaborated with scientists, extension specialists, growers, and representatives of the organic industry in Arkansas, Georgia, Kentucky, North Carolina, South Carolina, and Tennessee to create a Southern Region Organic Fruit Working Group (SROFWG). The SROFWG conducted in-state focus group meetings through which barriers to production and marketing, and opportunities for organic fruit in the region were identified. Prioritized research and outreach needs that were identified in the focus groups included use and understanding of organic fertilizers and nutrient management; methods, knowledge and awareness of pest disease and weed control including orchard floor management; information on transition to organic; consumer awareness and market development and the economics of organics. The planning activities of the SROFWG support the development and submission of grants for cooperative and collaborative research and outreach programs to sustain and expand organic fruit production in the southern region.

\section{(419) The Relation of Cooperative Extension Programs, Materials, and Publications for Organic Farming Systems as Relates to Production}

Kristen Harper*, Curt R. Rom

University of Arkansas, Horticulture, Fayetteville, AR, 72701

Since the passage of the Organic Foods Production Act in 1990, certified organic produce has begun to make a large impact on national markets. However, USDA statistics indicate that many states in the southern region have considerably reduced certified organic acreage when compared to other regions in the United States. The absence of organic acreage may perhaps originate with a lack of training and educational materials provided to producers due to unanticipated growth of organic markets. A thorough review of all Arkansas Cooperative Extension Service (ACES) materials, such as bulletins, publications, and workshops over the past 10 years, would reveal what information has been provided to producers on certified organic production. This review of ACES materials defines the existing groundwork on which ACES could construct future organic publications and outreach programs in order to sustain and stimulate organic farming within the state.

\section{Poster Session 45-Vegetable Nutrition}

\section{July 2005, 12:00-12:45 p.m. Poster Hall-Ballroom E/F}

\section{(215) From Recommendation to Implementation: Involving Vegetable Growers in Best Management Practices}

Eric Simonne, David Studstill, Robert Hochmuth, Justin Jones, Cynthia Stewart*

University of Florida, Horticultural Sciences, Gainesville, FL, 32611

The Federal Clear Water Act and Florida legislation have mandated the clean-up of impaired water bodies. The BMP manual for vegetable crops lists the cultural practices that could maintain productivity while minimizing environmental impact. BMPs focus on increased fertilizer and irrigation efficiency, but growers must be involved in the demonstration and adoption process if this voluntary program is to be successful. Three commercial vegetable fields from farms recognized as leaders in fertilizer and irrigation management were selected to demonstrate how irrigation and fertilizer management are linked together and how management may prevent water movement below the root zone of melons grown with plasticulture. In Spring 2004, dye (Brilliant blue FCF) was injected into the irrigation water three times during the growing season and soil profiles were dug to determine the depth of dye movement. Similar results were found at all three locations as the dye moved below at an average rate of 1.9 to $3.6 \mathrm{~cm}$ per day. Water movement was greater early in the season as irrigation was applied for transplant establishment. These results suggest that some leaching is likely to occur on light-textured soils, even when sophisticated irrigation and fertilization practices are followed. Based on these observations, cooperators spontaneously proposed to use two drip tapes, reduce preplant fertilizer, use a $100 \%$ injected $\mathrm{N} / \mathrm{K}$ program, and/or add organic matter to the soil as attempts to slow water movement below the root zone of their crops. This project shows that growers are more likely to try and adopt sustainable practices when 
they actively participate in the educational process than when production changes are mandated through legislation.

\section{(216) Effect of Supplemental Potassium on Yield and Quality of Processing Tomato}

\section{Christopher C. Gunter*1, David Francis ${ }^{2}$}

${ }^{1}$ Purdue University, Horticulture and Landscape Architecture, Southwest Purdue Ag. Program, Vincennes, IN , 47591; ${ }^{2}$ The Ohio State University, Horticulture and Crop Science, Ohio Ag. Research and Development Center, Wooster, OH, 44691

Physiological disorders affect both the appearance and nutritional quality of processing tomatoes intended for whole-peel and diced products. The cause of color disorders, such as yellow shoulder disorder (YSD), involves an interaction between plant genotype and the environment. Soil factors that correlate with the incidence of YSD are soil $\mathrm{K}, \mathrm{K}: \mathrm{Mg}$ ratios, organic matter, and phosphorus. Fields with an organic matter above $3.5 \%$ have a lower incidence of YSD. Progress in developing an integrated crop management system that growers and processors can use to profitably improve quality and nutritional value while reducing color disorders of tomato has been made. Decision tools for managing color disorders have been developed. Varieties of tomato differ in their susceptibility to color disorders; thus, variety use may offer growers a strategy to manage fields with low potassium, phosphorus, or low organic matter. Soil K application through drip irrigation was effective when applied at full bloom when the plants were most actively growing. Trials conducted in Indiana and Ohio during the 2003 and 2004 growing seasons demonstrated that weekly K application as a batch injection or solid application improved fruit color and reduced internal whitening. The effect of $\mathrm{K}$ addition is toward improved hue and $\mathrm{L}$ (lower values), but that trend is not always statistically significant and variety-specific responses are observed. Environmental factors for this response are explored. Managing this complex color disorder will entail minimizing risk of incidence, rather than preventative or curative applications.

\section{(217) An Evaluation of Sulfur Status and the Effects of $S$ on Uptake, Distribution, and Yield of Processing Carrots (Daucus carota L.)}

F. Christine Pettipas ${ }^{1}$, Rajasekaran R. Lada*1, Claude D. Caldwell ${ }^{1}$, Steve Kyei-Boahen ${ }^{2}$

${ }^{1}$ Nova Scotia Agricultural College, Plant and Animal Sciences, Cox Institute, Truro, Nova Scotia, Canada; ${ }^{2}$ Mississippi State University, Delta Research and Extension Center

A reduction in the atmospheric deposition of sulfur (S) and S-containing fertilizers has greatly reduced $S$ inputs to the soil in recent years. At the same time, $\mathrm{S}$ removal from the soil has increased as a result of increased crop production and higher yields. Sulfur deficiency has been found to reduce yields in several crops. A study was conducted to gain an understanding of the S status of Nova Scotia soils that support carrot production, as well as to examine the effects of rate of S application, method of S application, and type of S fertilizer on carrot uptake, distribution, yield, and recovery. Initial S concentrations in carrot-producing fields ranged from $52-440 \mathrm{~kg} \cdot \mathrm{ha}^{-1}$ of S. In general, King's County soils were lower in S than Colchester County soils. In the $\mathrm{S}$ trial, banding and broadcasting $\mathrm{S}$ on the side of carrot rows improved yield, and recovery compared to placing the $\mathrm{S}$ in the seed row. Banding $\mathrm{S}$ also significantly increased undersize carrots, leaf fresh weight, leaf dry weight, and root fresh weight. Rate of S application did not affect yield, recovery, or growth of carrots. At this time, $\mathrm{S}$ supplies from the atmosphere and soil are sufficient to meet the demands of carrots produced for processing in Nova Scotia. Growers do not need to apply $\mathrm{S}$ as fertilizer at this time to improve carrot yields. Monitoring of the S status of soils should be periodically conducted to assess $\mathrm{S}$ concentration as $\mathrm{SO}_{2}$ emissions and crop production continue to change.

(218) Optimum Soil K Application and Sufficient Leaf K concentration for Fresh Market Tomatoes Grown on a Midwest Fine Textured Soil

Henry G. Taber*

Iowa State University, Horticulture, Ames, IA, 50011

Tomato transplants were set mid-May 1998, 1999, and 2001, with black plastic mulch and a single line source drip irrigation system. The soil type was a well-drained, central Iowa loam (prairie developed on glacial till) with $2.4 \%$ organic matter, $13.1 \mathrm{CEC}$, and a $\mathrm{pH}$ of 6.8 . The soil test level of $89 \mathrm{~kg} \cdot \mathrm{ha}^{-1}$ of $\mathrm{K}$ was considered low for field corn and would require $121 \mathrm{~kg} \cdot \mathrm{ha}^{-1}$ of $\mathrm{K}$ for optimum yield. The experimental design was a factorial, split-plot, randomized complete block with four replications. The whole unit was K rates ( 0 to $372 \mathrm{~kg} \cdot \mathrm{ha}^{-1}$ of $\mathrm{K}$ as $\mathrm{KCl}$ ). The subunit was cultivar, either 'Mtn. Spring' (a determinate) or 'Jet Star' (an indeterminate). Fruit harvest began the first week of August and continued weekly for 5 to 8 weeks. As expected, 'Jet Star' produced from $12 \%$ to $35 \%$ more total fruit than 'Mtn. Spring'. The K response was best described by a quadratic function. Total maximum yield occurred from 325 to $372 \mathrm{~kg} \cdot \mathrm{ha}^{-1}$ of $\mathrm{K}$, depending on the production year. Cullage was high, mostly as a result of ripening disorders, and 'Jet Star' consistently produced more culls than 'Mtn. Spring', $10 \%$ to $11 \%$. Increasing soil $\mathrm{K}$ rate did not reduce the percentage of culls. For 2001, increasing K rate to $300 \mathrm{~kg} \cdot \mathrm{ha}^{-1}$ of K enhanced 'Mtn. Spring' marketable fruit size $18 \%$, from $258 \mathrm{~g}$ to $305 \mathrm{~g}$ each, but not 'Jet Star', which remained at $258 \mathrm{~g}$. There was a difference $(P<0.01)$ between the varieties for leaf K; 'Mtn. Spring' consistently had higher $\mathrm{K}$ concentrations, from $0.2 \%$ to $0.4 \%$. The leaf $\mathrm{K}$ sufficiency range at the rapid flowering and vegetative growth stage was determined to be $3.10 \%$ to $3.25 \%$ with the corresponding petiole leaf sap K (using a dilution of $1 \mathrm{sap}: 1$ water) of $5000 \mathrm{mg} \cdot \mathrm{kg}^{-1}$, for the same time period. The correlation between the Cardy meter petiole sap $\mathrm{K}$ values and whole leaf $\mathrm{K}$ was $r=0.83$.

\section{(219) Nitrogen Relationships to Yield and Quality of Carrots Grown on Mineral and Organic Soil in Ontario}

Sean Westerveld ${ }^{1}$, Alan McKeown*2, Mary Ruth McDonald ${ }^{1}$

${ }^{1}$ University of Guelph, Plant Agriculture, Guelph, Ontario, Canada; ${ }^{2}$ University of Guelph, Plant Agriculture, Simcoe, Ontario, Canada

In previous work with carrots (Daucus carota L.), little effect of nitrogen could be found on yield, but low nitrogen increased foliar disease. To determine if residual soil nitrate supplies sufficient nitrogen for carrots, plots were located on the same site for 3 years. Two sites were selected, one sand $(\mathrm{pH} 8.1,2.6 \% \mathrm{OM})$, one organic $(\mathrm{pH}$ $6.0,75 \% \mathrm{OM}$ ). Treatments consisted of $0 \%, 50 \%, 100 \%, 150 \%$, and $200 \%$ of recommended levels $\left(\mathrm{kg} \cdot \mathrm{ha}^{-1}\right)$ for organic (60) and mineral soils (110), plots were spilt in half with one fertilized every year, one in 2002 and were arranged in a split plot design with four replications. Foliar and soil samples were taken for nitrate analysis plus levels of Alternaria dauci and Cercospora carotae foliar blight were recorded each year. Applied nitrogen had no effect on yield on muck soils. Over 3 years on mineral soils, total yield ranged from 36 to $48 \mathrm{t} \cdot \mathrm{ha}^{-1}$ with no applied N. On mineral soils, yield was maximized at $\left(\mathrm{kg}^{\circ} \mathrm{ha}^{-}\right.$ l) 110 , over 165 , and 55-165 in 2002, 2003, and 2004, respectively. Stands on mineral soils were reduced at or above recommended rates in 2004. It is possible that carrots obtained considerable nitrogen perhaps deep in the soil profile. As in previous studies, applied nitrogen reduced foliar blights. Thus, nitrogen application is required for pest management purposes even if there is almost sufficient residual nitrogen for yield.

\section{(220) Determination of Water and Nitrogen Requirements of Cabbage using Fertigation}

\section{Alan McKeown*, Cathy Bakker}

University of Guelph, Plant Agriculture, Simcoe, Ontario, Canada

Fertigation is a promising strategy to improve nitrogen use efficiency, yield, and quality of cabbage (Brassica oleracea var. capitata), but there is a lack of data relevant to growers in Ontario. Field trials were conducted in 2003 and 2004 to determine the optimum rate of water and nitrogen application in terms of yield and quality of 'Huron' cabbage. Treatments consisted of combinations of target soil moisture levels (25\% to $100 \%$ field capacity) and nitrogen fertilizer $\left(0-400 \mathrm{~kg} \cdot \mathrm{ha}^{-1} \mathrm{~N}\right)$ as dictated by a central rotatable composite design. Nitrogen applications were split with $50 \%$ broadcast and incorporated before planting and the remaining split into weekly applications via a trickle irrigation system. Water was applied two to three times per 
week to bring soil moisture up to the target levels. Maximum marketable yield was reached at a combination of $400 \mathrm{~kg} \cdot \mathrm{ha}^{-1} \mathrm{~N}$ and a soil moisture target of $100 \%$ field capacity. Many heads were undersized or undeveloped at low rates of nitrogen. Applications of nitrogen required for high yield and quality can pose a risk of leaching; however, use of fertigation minimizes potential in-season leaching. Estimated total residual nitrogen at harvest ranged from $83-211 \mathrm{~kg} \cdot \mathrm{ha}^{-1} \mathrm{~N}$, which could have a negative impact on the environment. Thus, there is a considerable challenge to reduce environmental impact without economic losses. Improved knowledge of in-season nitrogen requirements might further reduce the levels of nitrogen applied without reducing yield and quality.

\section{(221) Controlled-release Nitrogen Fertilizer Release under Field Temperature and Precipitation Conditions for Potato Production in Northeast Florida}

Jeffery Pack*, Chad Hutchinson

University of Florida, Horticultural Sciences, Gainesville, FL, 32608

Potato production in the Tri-County Agricultural Area of northeast Florida accounts for nearly half of the state's \$120 M, 18-K hectare annual crop. Concern over nitrate movement into watersheds from potato production have stimulated research into alternative fertilizer sources and practices. This study evaluated the potential of several controlled-release fertilizer (CRF) products to release nutrients over a 100-day growing season under field temperature and precipitation conditions. In 2003 and 2004, 6 and 3 CRF products were evaluated, respectively. Meshbags containing $3 \mathrm{~g}$ of product mixed with $200 \mathrm{~g}$ of soil were buried $15 \mathrm{~cm}$ below the top of the potato row. Meshbags were removed at 2-week intervals. Samples were dried and sieved to remove soil. Fertilizer prills were ground and mixed with DI water to dissolve residual fertilizer. Samples were analyzed for total $\mathrm{N}$ by the Dumas (combustion) method (2003) or for TKN (2004). In 2003, initial release (after 20 days) ranged from $23 \%$ to $85 \%$ for the six products. In 2004, initial release (after 9 days) ranged from $34 \%$ to $65 \%$ for the three products. In 2003, total N release from CRF prills after 104 days ranged from $72 \%$ to $99 \%$. In 2004 , total $\mathrm{N}$ release from samples ranged from $79 \%$ to $92 \%$ release after 91 days. The shape of the release curve described some release patterns comparable to water-soluble fertilizers while others exhibited sustained-release properties. If release characteristics are designed to match potato plant uptake requirements in time and quantity, CRF products may be used to reduce off-site $\mathrm{N}$ movement while maintaining potato production.

\section{(222) The Residual Effect of Organic Amendment Applications on the Yield of Sweet Corn, Zucchini, and Mustard Cabbage}

Hector Valenzuela*, Roger Corrales, Ted Goo

University of Hawaii at Manoa, CTAHR, Honolulu, HI, 968222

Amajor issue in the preparation of nutrient budgets for organic farmers is the residual nutrient effect from organic amendments available for follow-up crops in year-round rotation systems. A series of separate experiments were conducted to evaluate: 1) the residual nutrient effects on double-cropped sweet corn from initial applications of several organic amendments locally available in Oahu, Hawaii;2) the residual effect of double cropped zucchini; and 3) mustard cabbage from the application of similar organic amendments. The sweet corn experiment consisted of six treatments, with organic amendments applied only prior to the first planting. The second follow-up sweet corn planting was grown without additional amendment applications. Treatments included: 1) a fruit fly based compost; 2) aged chicken manure; 3) bone meal; 4) synthetic fertilizer (farmer's practice); 5) a combination of compost and fertilizer; and 6) a combination of compost and chicken manure. The experiment was arranged with a randomized completeblock design. Each treatment plot consisted of two 20-m long rows of corn with five replications per plot for a total of 30 treatment plots. On a separate location similar trials were conducted on long-term organic farming plots, with double cropped zucchini and with double cropped mustard cabbage. The results from this research shows that crop yields were similar or greater under the organic amendment plots compared to the synthetic fertilizer plots. In crops with a high $\mathrm{N}$ uptake demand, yields from the organic amendment plots declined by about $10 \%$ in follow-up plantings. This data will allow organic farmers to prepare nutrient budgets to better match their organic fertilizer applications with crop nutrient demands.

\section{(223) The Effect of Commercial Home Garden Fertilizers on the Growth and Yield of Two Chinese Cabbage Varieties}

Hector Valenzuela*, Ted Goo, Ray Uchida, Susan Migita

University of Hawaii at Manoa, CTAHR, Honolulu, HI, 96822

Home gardening is a popular year-round recreational activity in Hawaii that helps to increase community food security in suburban and rural communities where high levels of poverty and unemployment exist. Updated fertilizer recommendations and accurate information about the latest products allows home gardeners to improve crop growth, and to minimize nutrient imbalances in the soil, pest problems, and environmental risks from nutrient runoff or leaching. Two field experiments were conducted in Oahu, Hawaii, to evaluate several new products in the market for the production of two home-garden Chinese cabbage varieties. The treatments included Miracle Grow, a new Miracle Grow Plus formulation, Plant Power 2003 nutrient solution, a Maui Liquid Compost product, and a standard fertilizer control $\left(150 \mathrm{~kg} \cdot \mathrm{ha}^{-1} \mathrm{~N}\right.$ rate). Each treatment consisted of a 6-m long row with $30-\mathrm{cm}$ plant spacing in the row. Each treatment was replicated four times in a completely randomized block design, for a total of 40 plots (two varieties $\times$ five treatments $\times$ four replications). Data collected included soil fertility before initiation and after experiment completion, tissue nutrient analysis, plant height collected twice during the growing cycle, and head weight and length measured at harvest time. The variety Pagoda was more responsive to fertilizer applications, showing an average of $30 \%$ yield increases between the best and poorest treatment, compared to $20 \%$ for 'China Express'. Overall, the Miracle Grow formulations outperformed the other products. The tissue nutrient data showed tissue nutrient levels above those recommended by the Extension Service. The treatments with highest yield response also showed greater symptoms of "black heart" from possible boron deficiency.

\section{(224) In Situ N Monitoring for Safe Leafy Vegetables using Quick and Advanced Tools}

Chin H. Ma, Manuel C. Palada*

AVRDC-The World Vegetable Center, Crop \& Ecosystem Management, Shanhua, Tainan, 74151, Taiwan

High levels of $\mathrm{N}$ fertilizers are generally applied in intensive leafy vegetable production in the peri-urban agriculture of Southeast Asia. This study was conducted to develop a simple and rapid method of determining nitrate- $\mathrm{N}$ accumulation in selected leafy vegetables. Five leafy vegetables, including amaranth (Amaranthus tricolor), kangkong (Ipomoea aquatica), Ethiopian kale (Brassica carinata), choysum (Brassica campestris sp. parachinensis), and leafy lettuce (Lactuca sativa) were grown on raised beds in 32-mesh nethouse in randomized complete-block design with four replications. The crops were fertilized with eight $\mathrm{N}$ levels: 0, 50, 100, 150, 200, 250, 300, and $350 \mathrm{~kg} \cdot \mathrm{ha}^{-1}$ in three splits. At harvest, nitrate contents were determined in tissue sap of fully expanded leaf blades, petioles and whole plant using a Cardy nitrate meter. Chlorophyll content readings were also measured on the same leaf using a chlorophyll meter. Nitrate accumulations varied with vegetable species. Significant correlations $(P<0.001)$ existed between $\mathrm{N}$ fertilizer rate and nitrate content as well as leaf chlorophyll and yield. Using $\mathrm{N}$ application rate of 200 $\mathrm{kg} \cdot \mathrm{ha}^{-1}$, nitrate accumulation in Ethiopian kale was highest (7000 ppm), followed by kangkong (4000 ppm), amaranth (3500 ppm), and leafy lettuce $(1200 \mathrm{ppm})$. The correlation between leaf chlorophyll meter reading (LCMR) and nitrate content was also significant $(P<$ 0.001 ), suggesting the feasibility of using Cardy nitrate meter test and LCMR for monitoring production of low-nitrate and safe vegetables. The Cardy meter was also sensitive in detecting soil nitrate- $\mathrm{N}$ below $20 \mathrm{ppm}$ and is a rapid and reliable alternative to conventional distillation method. 


\section{(225) Challenges and Opportunities with Vegetable BMPs in Southwest Florida}

Monica Ozores-Hampton*1, Eric Simonne ${ }^{2}$, Eugene McAvoy ${ }^{3}$, Phil Stansly ${ }^{4}$, Sanjay Shukla ${ }^{5}$, Pam Roberts ${ }^{6}$, Fritz Roka ${ }^{7}$,

Tom Obreza ${ }^{8}$

${ }^{1}$ University of Florida/SWFREC, Horticulture, Immokalee, FL, 34142; ${ }^{2}$ University of Florida, Horticulture, Gainesville, FL, 32611; ${ }^{3}$ University of Florida/IFAS, Hendry Co. Coop. Ext. Office, Labelle, FL, 33975; ${ }^{4}$ University of Florida/SWFREC, Entomology, Immokalee; ${ }^{5}$ University of Florida/SWFREC, Agricultural and Biological Engineering, Immokalee; ${ }^{6}$ University of Florida/SWFREC, Plant Pathology, Immokalee; ${ }^{7}$ University of Florida/SWFREC, Food and Resource Economics, Immokalee; ${ }^{8}$ University of Florida/ IFAS, Soil and Water Sciences, Gainesville

About 10,000 ha of staked tomato are grown each year in the winter-spring season in southwest Florida. Tomatoes are produced with transplants, raised beds, polyethylene mulch, drip or seepage irrigation, and intensive fertilization. With the development of nutrient best management practices (BMPs) for vegetable crops and increased competition among water users, $\mathrm{N}$ recommendations must ensure economical yields, but still minimize the environmental impact of tomato production. The current University of Florida-IFAS (UF-IFAS) N fertilization rate of $224 \mathrm{~kg} \cdot \mathrm{ha}^{-1}$ (with supplemental fertilizer applications under specified conditions) may require adjustment based on soil type and irrigation system. Because growers should be involved in the development and implementation of BMPs, this project established partnerships with southwest Florida tomato growers. Studies evaluated the effects of $\mathrm{N}$ application rates on yield, plant growth, petiole $\mathrm{N}$ sap, pests, and diseases. Nine on-farm trials were conducted during the dry winter 2004-05 season. Treatments consisted of $\mathrm{N}$ fertilizer rates ranging from 224 to $448 \mathrm{~kg} \cdot \mathrm{ha}^{-1}$, with each trial including at least the UF-IFAS rate and the traditional rate. Although total yields were comparable among $\mathrm{N}$ rates, there were differences in size category. Nitrogen rates had little effect on tomato biomass 30 and 60 days after transplanting. Changes in petiole sap $\mathrm{NO}_{3}-\mathrm{N}$ and $\mathrm{K}$ concentrations were different between seepage and drip irrigation, but usually above the sufficiency threshold. It is important to consider the type of irrigation when managing tomato and determining optimum $\mathrm{N}$ fertilizer rates.

\section{(226) Tomato Cultivar Differences in Ion Uptake and Growth in Closed Hydroponic Culture}

\section{Hyung Jun Kim¹, Chris Harlow², Mary Peet*2}

${ }^{1}$ National Horticultural Research Institute, Div. Protected Cultivation, Imok-Dong 475, Gangan-Gu, Suwon, 440-706, Korea; ${ }^{2}$ North Carolina State University, Horticultural Science, Raleigh, NC, 27695-7609

The objective of this study was to compare nutrient ion uptake and growth of Lycopersicum esculentum Mill. cvs. Trust, widely grown in North America, and Momotaro, widely grown in Korea and Japan. Tomatoes were planted July 2004, two per pot, in 36 perlite-filled pots fertigated with modified Steiner solution in a closed system. Inorganic ions $\left(\mathrm{K}, \mathrm{NO}_{3}-\mathrm{N}, \mathrm{Mg}, \mathrm{P}, \mathrm{S}\right)$ in the nutrient solution were measured weekly. Weekly solution uptake rate for both cultivars increased from $70 \mathrm{mg} \cdot \mathrm{MJ}^{-1}$ irradiance at 36 days to $200 \mathrm{mg} \cdot \mathrm{MJ}^{-1}$ at 133 days (end of experiment). The uptake rate of 'Trust' was lower than 'Momotaro' until 92 days after planting, then higher for the remainder of the experiment. This corresponded to lower leaf area in 'Trust' prior to 92 days, then greater leaf area than 'Momotaro'. Similarly, the nutrient uptake rate ( $\mathrm{ppm}$ ) of $\mathrm{K}, \mathrm{Ca}, \mathrm{Mg}$, and $\mathrm{S}$ ions in 'Trust' were lower than 'Momotaro' until 92 days and higher after 92 days. The $\mathrm{P}$ uptake showed the opposite pattern with a higher uptake rate in 'Trust' than 'Momotaro' until 92 days and lower uptake thereafter. The $\mathrm{N}$ uptake rate did not differ between the cultivars. Thus, except for $\mathrm{P}$ and $\mathrm{N}$, uptake of individual ions was proportional to total nutrient solution uptake. Plant height, number of clusters and total leaf area at 133 days was higher in 'Momotaro' but fruit number and total aboveground dry weight (leaf, stem, and fruit) was higher in 'Trust'. Percentage of total dry weight, represented by leaf and fruit in 'Momotaro', were $40 \%$ and $41 \%$, respectively, and $30 \%$ and $57 \%$, respectively in 'Trust'.

\section{(227) Does Salinity Reduce Boron's Toxic Effect in} Broccoli?

Stephen R. Grattan*1, Catherine M. Grieve ${ }^{2}$, James A. Poss ${ }^{2}$, Timothy E. Smith ${ }^{3}$, Donald L. Suarez

${ }^{1}$ University of California, Land, Air and Water Resources, Dept of LAWR, Davis, CA, 95616; ${ }^{2}$ USDA-ARS Salinity Laboratory, Plant Science, Riverside, CA, $92507 ;{ }^{3}$ Reedley College, Plant Science, Fresno, CA, 93704;

High salinity and boron often occur together in irrigation water in arid climates, but very little research has been done to study the interaction of the two. A greenhouse experiment was conducted at the US Salinity Laboratory in sand tanks to evaluate the interactions between $\mathrm{B}$ and saline drainage water on the performance of broccoli. Particular interest in this study was directed towards the composition of the salinizing solution to determine what role various salts have on the salinity-boron interaction. Results from this study indicate that both Cl-based salts and those characteristic of saline drainage water (i.e., a mixture of salts dominated by sodium sulfate) showed a significant salinity-boron interaction. At high salinity, increased B concentration was less detrimental, both visually and quantitatively (i.e., biomass), than it was at low salinity. That is, plants could tolerate a higher solution B-concentration at higher salinity. However, there was no significant difference between salt types. The effects on head weights were more exaggerated than those on shoot biomass. Shoot B concentration was influenced by salinity, but interestingly the direction of influence was dependent upon the B concentration in the solution. Regardless of the composition of the salinizing solution, increased salinity increased shoot B concentration when B concentrations in the solution were relatively low (i.e., $0.5 \mathrm{mg} \cdot \mathrm{L}^{-1}$ ). At the highest solution B concentration $\left(28 \mathrm{mg} \cdot \mathrm{L}^{-1}\right)$, increased salinity reduced shoot B concentration. Solution B in itself had very little influence on shoot ion accumulation, but both salinity (i.e., EC) and salinity composition had very strong influences on shoot tissue ion composition. Therefore, these data indicate that salinity and B are antagonistic.

\section{Poster Session 46-Temperature Stress Physiology}

21 July 2005, 12:00-12:45 p.m. Poster Hall-Ballroom E/F

\section{(430) Leaf Gas Exchange of Carrots in Response to Increasing Leaf Temperatures}

F. Christine Pettipas ${ }^{1}$, Rajasekaran R. Lada*1, Robert Gordon², Tess Astatkie ${ }^{2}$

${ }^{1}$ Nova Scotia Agricultural College, Plant and Animal Sciences, Truro, Nova Scotia, Canada; ${ }^{2}$ Nova Scotia Agricultural College, Engineering, Truro, Nova Scotia, Canada

Increasing temperature as a result of global climate change is expected to exert a great influence on agricultural crops, possibly through effects on photosynthesis. Response to temperature of leaf gas exchange parameters of carrot (Daucus carota L. var. sativus) cultivars Cascade, Carson, Oranza, and Red Core Chantenay (RCC) were examined in a controlled growth room experiment. Leaf net photosynthetic rate $\left(\mathrm{P}_{\mathrm{N}}\right)$, stomatal conductance $\left(\mathrm{g}_{\mathrm{s}}\right)$, and transpiration rate $(\mathrm{E})$ were measured at temperatures ranging from 15 to $35^{\circ} \mathrm{C}$ at $370 \mu \mathrm{mol} \cdot \mathrm{mol}^{-1}\left(\mathrm{CO}_{2}\right)$ and $450 \pm 20 \mu \mathrm{mol} \cdot \mathrm{m}^{-2} \cdot \mathrm{s}^{-1} \mathrm{PAR}$. The cultivars responded similarly to increasing temperature and did not differ in most photosynthetic parameters except $g_{s}$. The $P_{N}$ increased between 20 and $30^{\circ} \mathrm{C}$, thereafter increasing only slightly to $35^{\circ} \mathrm{C}$. On average, increasing temperature from 20 to $30{ }^{\circ} \mathrm{C}$ increased $\mathrm{P}_{\mathrm{N}}$ by $69 \%$. Carboxylation efficiencies $\left(\mathrm{Ca} / \mathrm{Ci}\right.$ ratio) ranged from $1.12-2.33 \mathrm{mmol} \cdot \mathrm{mol}^{-1}$ while maximum $\mathrm{P}_{\mathrm{N}}$ were $3.25,3.90,5.49,4.19 \mu \mathrm{mol} \cdot \mathrm{m}^{-2} \cdot \mathrm{s}^{-1}$ for Carson, $\mathrm{RCC}$, Cascade, and Oranza, respectively. The $\mathrm{E}$ did not reach maximum at $35^{\circ} \mathrm{C}$ while $\mathrm{g}_{\mathrm{s}}$ peaked at $30{ }^{\circ} \mathrm{C}$ and then decreased by $93 \%$ at $35^{\circ} \mathrm{C}$. The water use efficiency (WUE) decreased with an increase in temperature due to increases in both $\mathrm{P}_{\mathrm{N}}$ and $\mathrm{E}$. The results indicate that increasing temperatures above the seasonal average $\left(<20{ }^{\circ} \mathrm{C}\right)$ increases both $\mathrm{P}_{\mathrm{N}}$ and E up to $30-35^{\circ} \mathrm{C}$. An increase in photosynthesis due to an increase in temperature is expected to hasten growth. Carrots may be able to withstand a moderate increase in temperature. 


\section{(431) Evaluation of Anti-transpiration Organic Materials on Strawberry Performance}

\section{Sorkel Kadir*1, Said Ennahli², Ben Glass ${ }^{3}$}

${ }^{1}$ Kansas State University, Horticulture, Forestry, \& Recreation Resources, Manhattan, KS 66506; ${ }^{2}$ Kansas State University, Horticulture; ${ }^{3}$ Kansas State University, Agronomy

Interactive effects of different temperature regimes and anti-transpiration organic materials, Surround WP (kaolinite clay) and Raynox (sun-protectant), on two strawberry (Fragaria xananassa) cvs. Chandler and Sweet Charlie were investigated under controlled environmental conditions. Newly planted strawberries treated with Surround and Raynox were subjected to $20 / 15,30 / 25$, and $40 / 35^{\circ} \mathrm{C}$ (day/night) temperature regimes and 16 day/8 night photoperiod in growth chambers for $42 \mathrm{~d}$. Photosynthesis (A) and photochemical efficiency $(\mathrm{Fv} / \mathrm{Fm})$ were measured at 7 -d intervals during the experiment. Plants treated with Raynox displayed greater resistance to high temperature $\left(40 / 35^{\circ} \mathrm{C}\right)$ compared to those treated with Surround. Net photosynthesis of both cultivars decreased significantly with time at $40 / 35^{\circ} \mathrm{C}$. There was no significant difference in photosynthetic rate between the two cultivars. Nevertheless, there was difference in plant biomass between the cultivars. Raynox provided more protection against high temperature, specifically in reducing stomatal conductance and limiting transpiration, than Surround.

\section{(432) Heat-tolerant Traits of Salvia (Salvia splendens)}

\section{Seenivasan Natarajan*, Jeff Kuehny}

Louisiana State University, Horticulture, Baton Rouge, LA, 70808

One of the greatest impediments to the production of marketable ornamental herbaceous plants in the southern U.S. is high temperature stress. Exposure of plants to sublethal temperature (heat preconditioning) prior to sustained heat stress helps some plants to tolerate subsequent heat stress, a phenomenon often referred as acquired thermotolerance. The objective of this experiment was to examine various morphological, physiological, and anatomical responses of two red varieties of each of the 'Vista' (heat tolerant) and 'Sizzler' (heat sensitive) series of Salvia splendens to heat preconditioning (HC) and subsequent heat stress treatments [challenging temperatures (CT)]. Cultivars of salvia were subjected to short duration ( 3 hours) $\mathrm{HC}$ of $35^{\circ} \mathrm{C}$ every third day until 5 weeks after germination and subsequent exposure to two CT treatments: $30 / 23{ }^{\circ} \mathrm{C}$ and $35 / 28{ }^{\circ} \mathrm{C}$ (day/night) cycles in growth chambers until flowering. Plant growth, marketable quality, stomatal conductance and net photosynthesis declined for 'Sizzler' without $\mathrm{HC}$ treatment. Compared with nonpreconditioned plants, heat-preconditioned 'Sizzler' had 38.28\% higher root dry weight, $95 \%$ greater leaf thickness, and 50\% higher marketable quality at $35 / 28$ ${ }^{\circ} \mathrm{C}$ heat stress condition. Heat preconditioning helped both 'Vista' and 'Sizzler' to survive in both the heat stress treatments. 'Vista' had greater heat-tolerant traits than 'Sizzler'; these traits were enhanced with heat preconditioning treatment. The results demonstrated that heat preconditioning enhanced heat tolerance in varieties of salvia, which could be related to heat-tolerant traits, such as dense plant growth with shorter internodes, thicker stems, greater stomatal conductance, and extensive root growth that compensated for the transpiration water loss and cooling effect.

\section{(433) Gas Exchange and Chlorophyll Fluorescence Responses of Closely Related Pepper Genotypes to High Temperature Stress}

\section{John Jifon*, Kevin Crosby, Daniel Leskovar}

Texas A\&M University, Horticulture,Weslaco, TX, 78596

High temperature stress is a major limitation to commercial production of habanero pepper (Capsicum chinense Jacq.) in tropical and subtropical regions. The ability to sustain physiological activity under stress is an important trait for newer varieties. We evaluated leaf thermotolerance [based on the cell membrane stability (CMS) test] of three habanero pepper varieties to: 1) determine genetic variability in CMS among the genotypes studied; and 2) to assess correlations between CMS, photosynthesis and chlorophyll fluorescence [(CF), an indicator of membrane-dependent photosystem II quantum efficiency, $\left.\Phi_{\mathrm{PSII}}\right]$. The genotypes evaluated were TAM Mild Habanero (TMH, a recently developed mild habanero pepper) and its closely related parents (Yucatan and PI 543184). Net $\mathrm{CO}_{2}$ assimilation rate $\left(\mathrm{A}_{\mathrm{n}}\right)$ of intact leaves was measured in the field and leaf samples collected and exposed to heat stress $\left(55^{\circ} \mathrm{C}\right.$ for $\left.20 \mathrm{~min}\right)$ in temperature-controlled water baths under dim light conditions. The CF was assessed before and after the heat treatment. The CMS was highest in PI 543184, lowest in TMH and intermediate in Yucatan. All genotypes maintained high $\mathrm{A}_{\mathrm{n}}$ rates in the field $\left(25 \pm 6 \mu \mathrm{mol} \cdot \mathrm{m}^{-2} \cdot \mathrm{s}^{-1}\right)$; however, correlations between $\mathrm{A}_{\mathrm{n}}$ and CMS were weak. The $\Phi$ values were similar among the genotypes $(\sim 0.8)$ under nonstress conditions, but differed significantly following stress exposure. PI 543184 had the highest post-stress $\Phi_{\text {PSII }}$ values $(0.506$ $\pm 0.023)$, followed by Yucatan $(0.442 \pm 0.023)$ and TMH $(0.190 \pm$ $0.025)$. Observed differences in CMS and $\Phi_{\text {PSII }}$ indicate plasticity in the response to heat stress among these genotypes.

\section{(434) Changes in Gene Expression Are Regulated by Temperature Stress in Pachysandra terminalis}

Suping Zhou*, Roger Sauve, Tingting Chen, Sara Bhatti, Debrah Long

Tennessee State University, Institute of Agricultural and Environmental Research Nashville, TN, 37209

Identification of low temperature-regulated gene expression in Pachysandra terminalis: Pachysandra terminalis is a cold-hardy, evergreen plant species. In order to identify molecular mechanism of cold tolerance of this plant species, seedlings with four fully expanded leaves were subjected to 4,0 , and $-1{ }^{\circ} \mathrm{C}$ low temperature treatments. Low temperature-induced genes were identified from treated plants using cDNA differential display. The cDNA fragments were cloned onto PCR-trap vectors. Low temperature regulation of these genes was confirmed by reverse-northern blot. Sequence analysis has identified that these genes can be classified into three groups, stress-related, photosystem-related. Most of the genes cannot find matching sequences in the database. To further study the regulation of these genes by temperature fluctuation, the plants were treated at 4,0 , and $40{ }^{\circ} \mathrm{C}$. Northern blot analysis showed that several clones showed increased expression after cold and heat shock. Previous cold treatment at 4 ${ }^{\circ} \mathrm{C}$ can negate the effect of heat shock on expression of these genes. Complete sequence of these genes is cloned from the cDNA library and their temporal regulation by environmental stresses is analyzed using real-time PCR.

\section{(435) Physiological Study of Deacclimation and Reacclimation in Deciduous Azalea (Rhododendron subgenus Pentanthera) Species}

Scott Kalberer ${ }^{1}$, Norma Leyva-Estrada ${ }^{2}$, Stephen $\mathrm{Krebs}^{3}$, Rajeev Arora*1

${ }^{1}$ Iowa State University, Horticulture, Horticulture Hall, Ames, IA, 50011; ${ }^{2}$ Iowa State University, Dept. of Statistics, Ames, IA; ${ }^{3}$ Holden Arboretum, Horticulture Sciences, Kirtland, OH, 44077

Winter survival of temperate-zone woody perennials requires them to resist loss of frost hardiness (deacclimation) during winter and early spring thaws. However, little is known about deacclimation response in woody landscape plants. Moreover, what impact, if any, the degree of deacclimation has on reacclimation capacity has not been systematically studied. We used nine genotypes of deciduous azaleas (Rhododendron subgenus Pentanthera) to investigate effects of deacclimating conditions on bud cold hardiness and reacclimation ability. Dormant floral buds, with 3-5 cm stem attached, were collected in late December from field-grown plants, and placed in constant warm $\left[22{ }^{\circ} \mathrm{C} 15{ }^{\circ} \mathrm{C}(\mathrm{D} / \mathrm{N})\right]$ and humid conditions for increasing durations (0-day to 14-day) to stimulate deacclimation. Bud cold hardiness $\left(\mathrm{LT}_{50}\right.$ ) was determined (using logistic regressions) by evaluating immature flower survival at subfreezing treatment temperatures. Results indicated that azalea genotypes from colder provenances showed greater initial frost hardiness. Typically northern genotypes had slow to intermediate deacclimation rates, while rates of southern genotypes were intermediate to rapid. High initial frost hardiness was frequently associated with slow deacclimation. Buds retained the capacity to 
reacclimate upon cold exposure $\left[2{ }^{\circ} \mathrm{C} /-2{ }^{\circ} \mathrm{C} ;(12 \mathrm{~h} / 12 \mathrm{~h})\right]$ even after 8 days of deacclimation. Distinct differences were observed between the two latitudinal ecotypes of $R$. viscosum with respect to their initial bud hardiness, deacclimation rates, and reacclimation capacities. We suggest that the three attributes, i.e., high initial hardiness, slow deacclimation, and high reacclimation capacity, together may be important for winter-survival of azalea buds.

\section{(436) Comparative Cold Hardiness and Freezing Behavior of Leaves, Buds, and Flowers in Selected Woody Plants in Northern Latitudes}

\author{
A.M. Shirazi*, M.V. Thierry \\ The Morton Arboretum, Urban Horticulture Lab., Lisle, IL, 60532
}

It is not well known how cold-hardy new buds and emerging leaves or flowers are during spring. Extreme temperature fluctuations that sometimes bring early frost in spring (April-May) are very common in northern latitudes and cause severe damage to emerging leaves and flowers. Even though most woody plants can tolerate frost in spring, others show early tissue damage and can fully recover. There are some trees, e.g., Japanese maples (Acer palmatum) that when leaves are damaged due to spring frost, the results include severe dieback and eventual death. We tested new flowers and leaves of four crabapples: Malus $\times$ micromalus, M. sargentii, 'Mary Potter', and M. hupehensis, after budbreak for 3 years using electrical conductivity (EC) and differential thermal analysis (DTA) in spring: May 1997, Apr. 1998, and Apr. 2000, at The Morton Arboretum. Both flowers and leaves can tolerate from -6 to $-12{ }^{\circ} \mathrm{C}$ and we observed higher ion leakage in leaves than flowers. The high temperature exotherm (HTE) of flowers were -8 to $-10^{\circ} \mathrm{C}$ in April. In a companion study, testing other species that had premature budbreak due to "near lethal" (sublethal) freezing stress in Jan. 2001, the following HTE were observed: Cornelian cherry (Cornus mas) flower (about $-7.5^{\circ} \mathrm{C}$ ), Spindle trees leaves (about -6 $\left.{ }^{\circ} \mathrm{C}\right)$, Judd's viburnum (Viburnum $\times$ juddii) (about $-8^{\circ} \mathrm{C}$ ), Brevipetala witch-hazel (Hamamelis mollis 'Brevipetala') flower (about $-5^{\circ} \mathrm{C}$ ), redbud (Cercis candensis) flower (about $-9{ }^{\circ} \mathrm{C}$ ), flowering quince (Chaenomeles $\times$ superba) flower $\left(-8^{\circ} \mathrm{C}\right)$. Multiple LTE at $-13,-18$, -22 , and $-27^{\circ} \mathrm{C}$ were observed for Judd's viburnum. This information could be useful for selection and breeding of woody plants.

\section{(437) Application of Differential Thermal Analysis to Study Freezing Behavior and Supercooling in Plants}

A.M. Shirazi*, M.V. Thierry

The Morton Arboretum, Urban Horticulture Research Lab., Lisle, IL, 60532

Survival of temperate plants is often dependent upon their resistance or ability to tolerate low temperatures. Differential thermal analysis (DTA) has been employed to explore the freezing characteristics of plants and other organisms. However, there appears to be a need for further studies to better understand the physiology of freezing and its significance as related to supercooling. Methods employing thermocouples, differential wiring, and digital data acquisition boards allow detection of very small exothermic responses (about $0.025^{\circ} \mathrm{C}$ ). This study reports on techniques and apparatus for using DTA as well as results obtained on various plant tissues. When Fagus grandifolia (American beech) was compared to Fagus sylvatica (European beech), it exhibited both a lower high temperature (HT) and low temperature (LT) exotherm that correlated with lower stem tissue water content during September to May. The DTA on Acer pseudosieboldianum (Korean maple) from a higher elevation showed lower LT exotherm in stem tissues when compared to lower elevation samples. Incubation of Cornus amomum, Cornus obliqua, and Larix gmelinii var. olgensis stem tissue with d-H20 for 20 hours resulted in an induction of LT exotherm at a significantly higher temperature than a normal LT exotherm. This phenomenon was attributed to the bark tissue in Larix gmelinii var. olgensis. Sucrose and glycerol exotherm profiles exhibited lower exotherm temperatures. In a companion study, we used thermal analysis (non-differential) to study supercooling in [Homadaula anisocentra (Mimosa webworm)] and a single exotherm event was detected. New technology provides a great deal of flexibility in the method of evaluation of exothermic responses in plants and other organisms.
(438) Searching for Cold Hardy Lace-bark EIm (Ulmus parvifolia Jacq.) for Northern Latitudes

\section{A.M. Shirazi*, G.H. Ware}

The Morton Arboretum, Urban Horticulture Research Lab., Lisle, IL, 60532

The genus Ulmus contains numerous stress-tolerant species, especially those from areas of China with climates similar to various regions of the United States. Lace-bark elm, Ulmus parvifolia, the true Chinese elm, has an extensive temperature distribution range in China and offers great promise as a street tree. The high resistance of this elm to Dutch elm disease and other elm problems makes it an excellent tree for urban landscapes. Two new U. parvifolia cultivars, Athena ${ }^{\circledR}$ and Allee ${ }^{\circledR}$, are not cold hardy for northern climates and there is a need for new cold hardy lace-bark elms. Screening thousands of seedlings for cold hardiness, upright form, beautiful bark characteristics, and larger leaves will bring the most desirable $U$. parvifolia cultivars into the green industry. We determined that seed dormancy and the percentage of seed germination of four selected lacebark elms after 2 and 4 weeks were $>30 \%$ and $>50 \%$, respectively. There were significant differences in stem cold hardiness among new lace-bark elms from China (about -32 to $-40^{\circ} \mathrm{C}$ ). Laboratory determination of cold hardiness can provide great advantages over years of field testing. Response to the outdoor temperature in December, January, and February on a seed cold hardiness freezing test showed significant reduction in seed germination, especially at $-30{ }^{\circ} \mathrm{C}$. Freezing test of seeds to $-40{ }^{\circ} \mathrm{C}$, resulted in $\mathrm{LT}_{50}$ of -3 to $-5^{\circ} \mathrm{C}$ in December, so, it is less likely that these $U$. parvifoilia will become invasive in northern latitudes. Invasiveness of these $U$. parvifolia for higher zones, e.g., 6-8 could be greater and selection of these elms is suitable for zones 5 and lower. Planting these elms in zones 4, 3, and 2 will give us useful information regarding their winter performance.

\section{(439) Influences of Low Temperature and Xylem Bubble Treatments on Deformed Leaves in 'Hayward' Kiwi Trees}

\section{Wol-Soo Kim*, Xiu-Yu Wu, Soon-Ju Chung}

Chonnam National University, Department of Horticulture, 300 Yongbong-dong, Gwangju, 500-757, Korea

During the early spring, embolism symptoms may be observed on the leaves of kiwi trees after a severe, cold winter. The morphological character of embolism in young leaves in early spring is typically parachute shaped, at the basal part of kiwi shoots. Deformed leaves were observed at the beginning stage of development. To test the factors, we used water stress, low temperature, and xylem bubble treatments on kiwi vines during the winter season. Low temperature treatments on trees were carried out in $\mathrm{a}-15^{\circ} \mathrm{C}$ chamber for $0,12,24$, and 48 hours. For the xylem bubble treatment, the trees were injected with 3.5 $\mathrm{MPa}$ compressed air at $-15^{\circ} \mathrm{C}$ for 24 hours. For water stress treatments, the trees were not irrigated until dry soil conditions reached as little as $50 \%$ soil moisture. Treated kiwi trees planted in plastic pots $(20 \mathrm{~cm} \times 25 \mathrm{~cm})$ were moved into the growth chamber at $25^{\circ} \mathrm{C}$ with 12 hours of light, and the rate of deformed leaf symptoms was observed. In all treatments, deformed leaves were observed and bud burst rates were lower than for the control. Therefore, we confirmed that the main factors for deformed leaves were low temperature, xylem bubbles, and water stress.

\section{(440) Flowering and Fruiting in Olives in the Absence of Chilling Temperatures}

Nasir Malik*, Joe M. Bradford, Jim E. Brockington

USDA-ARS, IFNRRU, Weslaco, TX, 78596

Cultivation of olives was not developed in southern and coastal Texas because it was assumed that the winters in this area do not provide enough chilling for flowering. Our initial experiments have demonstrated that olive trees of 'Arbequina' could flower and fruit under mild winter conditions; i.e., without the typical chilling conditions (below $7.2{ }^{\circ} \mathrm{C}$ are chilling temperatures, but $2-4^{\circ} \mathrm{C}$ during the night was considered optimal chilling) that have previously been considered necessary for flowering and fruiting in olives. We propose that lack of flowering in southern Texas is due more to high temperatures during the day (many 
days reaching $26^{\circ} \mathrm{C}$ ) than lack of chilling temperatures in the night. Thus, 'Arbequina', and perhaps other cultivars of olives, should be able to grow and flower and fruit normally in coastal Texas, where daytime temperature do not rise as high as in southern Texas. A survey of coastal Texas revealed that this is indeed a possibility, because a few trees planted in areas of coastal Texas do flower and fruit. Experiments have now been started at different sites to evaluate the performance of olives in coastal Texas.

\section{Poster Session 47-Ornamental/Landscape and Turf 2}

\section{July 2005, 12:00-12:45 p.m. Poster Hall-Ballroom E/F}

\section{(108) Assessing the Preparedness of College/University- trained Graduates Entering the Landscape Contracting Industry}

Kory Beidler*, Jeffery Iles

Iowa State University, Horticulture, Ames, IA, 50011

Using a mail questionnaire, we invited landscape contracting decision-makers to comment on the effectiveness of landscape contracting programs at colleges and universities in preparing students for professional careers. After organizing the Associated Landscape Contractors of America 2003 online member list (2049 companies) into four strata, based on company size, we chose a stratified random sample of 400 companies for our study. Completed questionnaires were received from 137 companies (35\% response rate). A much larger percentage of respondents were either satisfied or extremely satisfied (52\%) with college graduates recently hired than those who were dissatisfied or extremely dissatisfied (8.1\%). But, when asked to consider four knowledge categories, a majority $(53 \%)$ said recent graduates are deficient in business knowledge, whereas smaller percentages of respondents noted deficiencies in construction $(25.1 \%)$, horticulture $(9.6 \%)$, and design skills $(5.1 \%)$. When asked to rate the importance of topics that could be taught in undergraduate landscape contracting programs, respondents identified business topics (personnel management, estimating and bidding, and clientele management) as their top three choices. Respondents also named three business-related skills (client relationships, time management, and managing employees) among the top five most important skills for landscape contracting professionals. Despite the stated importance of business training and business skills, more than two-thirds $(68.3 \%)$ of respondents said when hiring for an entry-level landscape contracting position, they would prefer candidates with strong horticulture skills over those with strong business skills.

\section{(109) Evaluation of Weather-sensing Landscape Irrigation Controllers}

Dennis R. Pittenger*1, David A. Shaw ${ }^{2}$, William E. Richie

${ }^{1}$ University of California, Riverside, Cooperative Extension/Botany \& Plant Sciences, Riverside, CA, $92521 ;{ }^{2}$ University of California, Cooperative Extension San Diego County, San Diego, CA, 92123

We conducted an evaluation of three commercial weather-sensing irrigation controllers to determine the climatic data they use, how easy they are to set up and operate, and how closely their irrigation regimes match landscape irrigation needs established by previous field research. The devices virtually controlled an existing reference irrigation system and used its system performance data as required in their initial setup. Reference standard treatments for cool-season turfgrass, trees/shrubs and annual flowers were calculated using onsite, real-time reference evapotranspiration (ETo) data and plant factors developed primarily from previous research. The reference irrigation system applied the correct amount of water to an actual tall fescue turfgrass planting whose water needs served as the reference standard treatment comparison for the cool-season turfgrass treatment. Virtual applied water was recorded for other plant materials and it was compared to the corresponding calculated reference standard amount. Results show each controller adjusted its irrigation schedules through the year roughly in concert with weather and ETo changes, but the magnitudes of adjustments were not consistently in proportion to changes in ETo. No product produced highly accurate irrigation schedules consistently for every landscape setting when compared to research-based reference comparison treatments. Greater complexity and technicality of required setup information did not always result in more accurate, water-conserving irrigation schedules. Use of a weather-sensing controller does not assure landscape water conservation or acceptable landscape plant performance, and it does not eliminate human interaction in landscape irrigation management.

\section{(110) Composition and Place of Origin of Trees in Residential Neighborhoods and Embedded Parks in Phoenix, Arizona}

Chris A. Martin*

Arizona State University East, Department of Applied Biological Sciences, Mesa, AZ, 85212

This study evaluated the influence of social economic rank (SER) and neighborhood and park age on the composition and place of origin of trees in residential neighborhoods and embedded small urban parks in Phoenix, Ariz. During 2000 and 2001, trees were surveyed within an array of 16 residential neighborhoods and embedded small urban parks that spanned a range of socioeconomic rank (SER) and age. Parks were embedded within residential neighborhoods of similar density across three SER classifications, high, moderate, or low. Neighborhoods and parks ranged in age from about 1947 to 1997. Counts of all trees in each park were made and neighborhood tree composition was approximated by tree counts along four transects, distributed away from each park along streets in a northerly, easterly, southerly, or westerly direction, respectively. Transect widths extended about the depth of a front yard residence on both sides of the street. Park and surrounding neighborhood tree composition was calculated as total frequency (abundance) and taxa frequency (diversity) per hectare of landscape surface area. Tree abundance in parks was highest when surrounded by neighborhoods of high SER. Neighborhoods of high SER had greater tree diversity than neighborhoods of low SER. Distinct patterns of tree origin, dictated by both classifications of SER and age, were found. Overall, trees in residential neighborhoods and embedded parks tended to be indigenous to arid regions of North America, South America, Australia, south Asia, and China.

\section{(111) Establishment of Root-bound Plumbago auriculata Lam. in a Landscape}

\section{Sudeep Vyapari*1, Edmund L. Thralls2, Michele S. Scheiber ${ }^{2}$}

${ }^{1}$ University of Florida, Environmental Horticulture, UF/IFAS-Plant City Campus, Plant City, FL, 33563; ${ }^{2}$ University of Florida, Environmental Horticulture, Mid-Florida Research \& Education Center, Apopka, FL, 32703

A study was conducted to evaluate establishment of root-bound vs. nonroot-bound container-grown Plumbago auriculata Lam. in a landscape. A total of 144 plants were transplanted from \#1 containers in a rain-out shelter at Mid-Florida Research and Education Center, Apopka, Fla., in June 2004. The field soil type was amended with composted yard waste. The three treatment types used for the study were: 1) root-bound plants; 2) root-bound plants with a vertical slice made through the root ball at a $90^{\circ}$ angle; and 3) nonroot-bound plants. To evaluate the effect of these three treatments during the course of establishment period, harvesting was done once every 2 weeks. Data on growth indices (height $\times$ width $\times$ width), shoot dry weight, root dry weight, and length of the longest root were recorded. The experimental design was a completely randomized design consisting of three treatments, 12 harvest dates (days after planting), and four replicates per harvest date. Plants were maintained according to the best management practices recommended by the UF/IFAS, and were irrigated once a day using microirrigation. Experimental data were analyzed for significance of correlation among variables using SAS version 9.1. Results of the correlation and regression analysis indicated that the increase in the shoot dry weights $(\mathrm{g})$, root dry weights $(\mathrm{g})$, growth indices $\left(\mathrm{m}^{3}\right)$, and root : shoot ratio had significant relationship with the harvest dates. Correlation among harvest dates and shoot dry weight, root dry weight, or growth indices was found to be positive. However, results of the study indicated that as the number of days after planting increased, the root to shoot ratio decreased. 


\section{(112) Heat and Drought Affect Photosynthesis of Sugar Maple (Acer saccharum) Ecotypes}

\section{Jason J. Griffin*}

Kansas State University, Dept. of Horticulture, Forestry and Recreation Resources, John C. Pair Horticultural Center, Haysville, KS, 67060

Common sugar maple (Acer saccharum Marshall) selections suffer from prolonged drought and constant wind on the southern Great Plains. Nonirrigated plants often have scorched and torn leaves as a result of these environmental stresses. In field studies, a sugar maple ecotype native to western Oklahoma (known as 'Caddo' maple) has shown improved tolerance to drought and leaf tatter. A study to examine drought tolerance of seedling 'Caddo' maple compared to typical seedling sugar maple was established at the John C. Pair Horticultural Center. One seedling of each type was planted in a single 38 -L container. Containers were placed on a greenhouse bench, and once acclimated, irrigation was withheld until predawn leaf water potential indicated a substrate water potential of $-1.5 \mathrm{MPa}$. Containers were weighed, and seedlings were maintained in a prolonged drought condition for 3 weeks by adding water each morning to return the container to the original weight. After 3 weeks, photosynthetic temperature response curves were generated for the drought-stressed and the irrigated control plants. Osmotic potential of expressed sap was also measured on rehydrated leaves. The main effects of species, irrigation, and temperature were all significant. 'Caddo' maples were able to maintain a higher rate of net photosynthesis than the typical seedlings when drought stressed and as temperature increased. The optimum temperature for photosynthesis did not significantly differ among treatments $\left(36^{\circ} \mathrm{C}\right)$, whereas the maximum rate of photosynthesis was significantly greater for the 'Caddo' maples $\left(41 \mu \mathrm{mol} \cdot \mathrm{m}^{-2} \cdot \mathrm{s}^{-1}\right)$ than the typical sugar maples $\left(16 \mu \mathrm{mol} \cdot \mathrm{m}^{-2} \cdot \mathrm{s}^{-1}\right)$.

\section{(113) Quantifying Landscape Microclimates and Related Cold Injury}

Shadd Taylor*, Derald A. Harp, Kristen McDowell, Roque Lemus

Texas A\&M University-Commerce, Agricultural Sciences, Commerce, TX, 75482

It is generally accepted that plants closer to structures benefit from the warmth emitted via imperfect insulation and solar energy reemitted as long-wave, thermal radiation. However, while claims of protection are given, little quantifiable information exists on the extent or pattern of this protection. We studied existing plantings of Trachelospermum asiaticum, an evergreen groundcover that is frequently damaged in northeast Texas. The plantings studied were part of a landscape with at least five different identifiable microclimates: 1) near building (NB); 2) mid-bed (MB); 3) bed edge (BE); 4) beneath Quercus virginiana (LO); and 5) beneath Pyrus calleryana 'Bradford' (BP). We placed HOBO temperature data loggers recording one temperature per minute in each location. Following our first damaging freeze, we waited 7 days before collecting leaf samples. Leaf samples were collected by using a $25-\mathrm{cm}$ square, $2 \mathrm{~cm}$ deep on two sides. The square was placed on the groundcover so that the top of the groundcover was level with the top of the square. All leaves and stems that extruded through the top $2 \mathrm{~cm}$ of the square were excised. Four samples were taken from each location, and the number of damaged and nondamaged leaves were counted for each sample. Leaves that were at least $50 \%$ discolored were considered damaged. Leaf damage data were analyzed using SAS Proc ANOVA. Leaves in the BE and BP locations showed significantly fewer live leaves than any other locations. NB leaves were virtually undamaged. Average temperatures in the BE and BP locations were 4.5 to $5^{\circ} \mathrm{F}$ colder than the "near building" locations, comparable to an $\mathrm{a}$ or $\mathrm{b}$ zone in the current USDA Plant Hardiness Zone map.

\section{(114) Effects of Planting Depth on Landscape Tree Survival and Girdling Root Formation}

Christina Wells*1, Karen Townsend ${ }^{2}$, Judy Caldwell ${ }^{1}$, Donald Ham ${ }^{2}$, E. Thomas Smiley ${ }^{3}$, Michael Sherwood ${ }^{3}$

${ }^{1}$ Clemson University, Horticulture, Clemson, SC, $29634 ;{ }^{2}$ Clemson University, Forestry and Natural Resources, Clemson, SC, 29634; ${ }^{3}$ Bartlett Tree Research Lab, Charlotte, NC

Landscape trees are frequently planted with their root collars below grade, and it has been suggested that such deep planting predisposes trees to transplant failure and girdling root formation. The objective of the present research was to examine the effect of planting depth on the health, survival, and root development of two popular landscape trees, red maple (Acer rubrum) and 'Yoshino' cherry (Prunus xyedoensis). Trees were transplanted with their root flares at grade, $15 \mathrm{~cm}$ below grade or $31 \mathrm{~cm}$ below grade. Deep planting had a strong negative effect on the short-term survival of 'Yoshino' cherries. Two years posttransplant, $50 \%$ of the $15-\mathrm{cm}$ - and $31-\mathrm{cm}$-deep planted cherries had died, whereas all the control cherries had survived $\left(P<0.001 ;{ }^{2}\right)$. Short-term survival of maples was not affected by planting depth. Deep-planted trees of both species exhibited little fine root regrowth into the upper soil layers during the first year after transplant. Four years posttransplant, control maples had $14 \% \pm 19 \%$ of their trunk circumference encircled by girdling or potentially-girdling roots; this number rose to $48 \% \pm 29 \%$ and $71 \% \pm 21 \%$ for $15-\mathrm{cm}$ - and $31-\mathrm{cm}$-deep planted maples, respectively $(P<0.01$; ANOVA main effect). There were no treatment-related differences in girdling root development in the cherries.

\section{(115) Soil Inoculum Potential and Mycorrhizal Colonization of Acer rubrum in Forested and Developed Landscapes}

\section{P. Eric Wiseman ${ }^{1}$, Christina Wells*2}

${ }^{1}$ Clemson University, Forestry and Natural Resources, Clemson, SC, 29634; ${ }^{2}$ Clemson University, Horticulture

Arbuscular mycorrhizal fungi (AMF) form a symbiotic relationship with numerous landscape tree species and can improve tree growth and environmental stress tolerance. Construction-related soil disturbance is thought to diminish AMF colonization of transplanted trees in newly developed landscapes. We gathered root, soil, and foliar data from red maples (Acer rubrum) growing in newly developed landscape sites and adjacent native forest sites to test the hypotheses that: 1) landscape trees show lower levels of AMF colonization than forest trees; and 2) the AMF inoculum potential of landscape soils is lower than that of forest soils. Fine roots sampled from landscape maples had significantly lower AMF colonization than maples from adjacent forest sites ( $3 \%$ vs. $22 \% ; P=0.0002$ ). However, soil-sand mixtures made from landscape soils possessed greater AMF inoculum potential than those made from forest soils $(10 \%$ vs. $4 \% ; P=0.0081)$. Forest soils were more acidic and possessed less extractable $P$ than landscape soils, and differences in AMF colonization between forest and landscape maples appeared to reflect differences in soil chemical properties rather than in soil inoculum potential.

\section{(116) Short-term Responses of Live Oak to Planting Depth and Soil Amendments}

Donita L. Bryan*1, W. Todd Watson ${ }^{2}$, Leonardo Lombardini ${ }^{1}$, John J. Sloan ${ }^{3}$, Andrew D. Cartmill ${ }^{1}$, Geoffrey C. Denny ${ }^{1}$, Michael A. Arnold ${ }^{1}$

${ }^{1}$ Texas A\&M University, Horticultural Sciences, College Station, TX, 77843-2133; ${ }^{2}$ Texas A\&MUniversity, Forest Science, College Station, TX, 77843-2135; ${ }^{3}$ Texas A\&MUniversity, Environmental Soil Science, Dallas, TX, 75252

Tree transplanting practices influence plant survival, establishment, and subsequent landscape value. However, transplanting practices vary substantially within the horticultural industry. Of particular importance is the location of the root collar relative to soil grade at transplant. The objective of this study was to determine the effects of factorial combinations of planting depths, root collar at grade or $7.6 \mathrm{~cm}$ either above or below grade, and soil amendments on container-grown (11 L) Quercus virginiana Mill. Soil treatments included a tilled native soil (heavy clay loam, Zack Series, Zack-urban land complex, fine, montmorillonitic, thermic, udic paleustalfs), native soils amended with $7.6 \mathrm{~cm}$ of coarse blasting sand or peat that were then tilled to a depth of $23 \mathrm{~cm}$, or raised beds containing $20 \mathrm{~cm}$ of sandy loam soil (Silawa fine sandy loam, siliceous, thermic, ultic haplustalfs). A significant $(P \leq 0.05)$ block by soil amendment interaction occurred for photosynthetic activity. Incorporation of peat significantly decreased the bulk density of the native soil. Planting depth had no significant effect on photosynthetic activity or stem xylem water potential at 3 months after transplant. Soil water potentials did not statistically differ among treatments. 


\section{(117) A Profile of Landscape Service Providers in West Central Florida}

Sudeep Vyapari*1, Robert J. Graves ${ }^{1}$, Edmund L. Thralls ${ }^{2}$

${ }^{1}$ University of Florida, Environmental Horticulture, UF/IFAS, Plant City, FL, 33563; ${ }^{2}$ University of Florida, Environmental Horticulture, Mid Florida Research and Education Center, Apopka, FL, 32703

A survey of landscape service providers was conducted in conjunction with the 2004 Tree and Landscape Short Course in Tampa, Fla. A greater proportion of participants $(56 \%)$ provided landscape maintenance services, and $60 \%$ of the businesses were independently owned. About $67 \%$ of the respondents indicated that their businesses were in operation for over 10 years with $33 \%$ of the participants making one million dollars or more in gross sales per year. Although $43 \%$ of the respondents indicated that they served only one type of account, at least $29 \%$ of the providers served two types of accounts, and $24 \%$ served three types. In response to various questions on a Likert scale of 1-5, about $39 \%$ of the respondents completely agreed that word-of-mouth is the best marketing method and $41 \%$ agreed that an attractive logo on company trucks works as a great marketing tool. Many participants either agreed (27\%) or were neutral (27\%) when asked if they thought that the customers have no understanding of the costs involved in providing services to them. The survey results show that $73 \%$ of the respondents believe the most important factor that impacts and helps retain a customer base at a steady level is quality of work performed followed by professional employees, appearance, and knowledgeable employees. Cheap prices or discounts offered were rated as being low factors in retention of customers. Most service providers (31\%) do not communicate with their customers using brochures, newsletters, flyers, emails, or websites. About $61 \%$ of service providers promote low water use plants followed by use of Florida native plants.

\section{Poster Session 48-Plant Biotechnology 4}

21 July 2005, 12:00-12:45 p.m. Poster Hall-Ballroom E/F

\section{(285) DNA Fingerprinting of Flowering Dogwood Cultivars}

Naomi R. Smith, Robert N. Trigiano*

University of Tennessee, Entomology and Plant Pathology, Knoxville, TN, 37996-4560

Flowering dogwood (Cornus florida L.) is an important tree of forests and urban landscapes in the eastern United States. Currently, there are over 100 cultivars of flowering dogwood commercially available. An identification process based on genotype would be of use to researchers, breeders, and nurserymen, as many cultivars are similar phenotypically. Molecular markers offer a promising way of definitively identifying flowering dogwood cultivars. Amplified fragment length polymorphism (AFLP) is a technique that can be used to generate DNA fingerprints. DNA was isolated from leaves of 17 common cultivars of dogwood and AFLP fingerprints were generated by a Beckman Coulter CEQ ${ }^{\mathrm{TM}}$ 8000 . Fingerprints were converted to binary data and verified manually. Two drafts of a cultivar identification key were generated based on the corrected, verified binary data and cultivar-specific peaks. Six primer combinations were used to construct all keys and were tested with seven unknown dogwood cultivar samples. Six unknown samples were correctly identified using the keys. Only one unknown, 'Cherokee Brave', was unidentifiable with any key. In all cases, some intracultivar variation was observed. A similarity index was calculated and visualized with a tree of genetic relatedness using NTSYSpc. Intracultivar variation was observed in the similarity index as well. This database for cultivar-specific molecular markers will serve as a starting point to which other cultivars can be added and also can be used in breeding applications, patent application and other projects, such as mapping the $C$. florida genome.

\section{(286) Hairy Root Culture as a Source of Unique Secondary Metabolites from Echinacea Species}

Fredy R. Romero*, David J. Hannapel, Kathleen Delate Iowa State University, Horticulture, Ames, IA, 50011

Echinacea is one of the best-selling medicinal plants in the United
States. It was historically harvested from wild populations, but its demand has increased so significantly that commercial production has become a necessity to supply the increasing demand and to protect wild populations. The medicinal properties of echinacea are associated with secondary metabolites that are produced mainly in the roots. Hairy roots, induced by the Ri plasmid of Agrobacterium rhizogenes, have been produced in other crops as alternative sources of secondary metabolites that commonly are produced and synthesized in the roots of mature plants. This method of production offers some advantages over traditional agricultural systems, such as the possibility of producing novel compounds year-round. The overall goal of this project is to explore the utility of hairy root cultures (mediated by $A$. rhizogenes) as an efficient, alternative, and enriched source of secondary compounds with medicinal properties, such as alkamides, flavonoids, and caffeic acid derivatives. We have been successful in transforming roots from E. angustifolia, E. pallida, and E. purpurea plants, and confirming the presence of rol $A B C$ genes in hairy roots using molecular techniques. Roots from control plants show no active growth under dark conditions, whereas transformed roots from E. pallida and E. purpurea show a low degree of branching with a slow growth rate on solid media under darkness. However, transformed E. angustifolia show a faster growth rate and higher degree of branching under the same conditions. Currently, we are working on the optimization of the growing conditions of the transformed roots and will proceed to the biochemical analysis phase of the project.

\section{(287) Chloroplast Small Subunit Rubisco Protein Is Ingested by Migratory Endoparasitic Nematodes}

\section{Tridate Khaithong*1, Brent S. Sipes ${ }^{1}$, Adelheid R. Kuehnle ${ }^{2}$}

${ }^{1}$ University of Hawaii, Department of Plant and Environmental Protection Sciences, Honolulu, HI, 96822; ${ }^{23}$ University of Hawaii, Department of Tropical Plant and Soil Sciences, Honolulu, HI, 96822

Lack of a conclusive evidence of ingestion of plastid components by plant-parasitic nematodes cautions the use of plastid transformation technology for nematode resistance. Nematode-resistant effector proteins generally require ingestion by the nematode to be effective. Transgene-encoded proteins produced in plastids are not known to be exported into the cytoplasm. Disintegration of plant cell organelles after nematode feeding suggests that nematodes possibly ingest plastid components. Proof of ingestion will validate the development of plastid transformation for nematode resistance. Small subunit ribulose-1,5bisphosphate carboxylase/oxygenase (SSRubisco) protein is prevalent in chloroplasts and thus chosen as a study molecule. The migratory endoparasitic nematodes Pratylenchus penetrans and Radopholus similis were cultured on green carrot callus containing chloroplasts. Total nematode proteins were extracted and subjected to western blot analysis using cross-reactive polyclonal antibody raised against spinach SSRubisco. Positive detection of SSRubisco occurred in protein extracts from nematodes fed on green carrot callus, but not in extracts from nematodes cultured on non-green alfalfa root callus as negative control. These results confirm the ingestion of plastid components of MW 14 kDA by migratory endoparasitic nematodes.

\section{(288) An Arabidopsis thaliana Phytochelatin Synthase (AtPCS1) Gene Expressed in Transgenic Indian Mustard Contributes Partial Tolerance to $\mathbf{C d}$ and $\mathrm{Zn}$}

Ksenija Gasic, Schuyler S. Korban*

University of Illinois, Department of Natural Resources \& Environmental Sciences, 310 ERML, Urbana, IL, 61801

Phytochelatins (PCs) are heavy metal binding peptides that play important roles in sequestration and detoxification of heavy metals in plants. To develop transgenic plants with increased tolerance and/or accumulation of heavy metals from soil, an Arabidopsis thaliana FLAG-tagged AtPCS1 cDNA encoding phytochelatin synthase (PCS) under the control of a $35 \mathrm{~S}$ promoter was expressed in Indian mustard (Brassica juncea). Four transgenic Indian mustard lines, designated pc lines, with different levels of AtPCS1 mRNA accumulation and correspondent AtPCS1 protein levels were selected and analyzed for tolerance to cadmium (Cd) and zinc ( $\mathrm{Zn})$. Heavy metal tolerance was 
assessed by measuring root length of 10-day-old seedlings grown on agar medium supplemented with different concentrations of $\mathrm{Cd}(0,100$, 150 , and $200 \mu \mathrm{M} \mathrm{CdCl})$ and $\mathrm{Zn}(200,400,600$, and $800 \mu \mathrm{M} \mathrm{ZnCl})$. All transgenic lines showed significantly longer roots when grown on a medium supplemented with $100 \mu \mathrm{M} \mathrm{CdCl}_{2}$. No significant differences were observed between transgenic lines and wild type when plants were grown on higher levels of Cd. This indicated that only partial tolerance to $\mathrm{Cd}$ was observed in these transgenic lines. Similarly, partial tolerance for $\mathrm{Zn}$ was also observed in these transgenic lines, but up to levels of $400 \mu \mathrm{M} \mathrm{ZnCl}_{2}$. Expression levels of AtPCS1 protein were not related to tolerance responses for either $\mathrm{Cd}$ or $\mathrm{Zn}$ stresses in transgenic lines.

\section{(289) GUS Expression in $L E A C O 1_{0.92 \mathrm{~kb}}-G U S$ Tobacco Plants Suggests That Auxin and Ethylene Are Involved in LEACO1 0.92kb $_{\text {Promoter Induction }}$}

Richard McAvoy*, Mariya Khodakovskaya, William Smith, Degang Zhao, Hong Liu, Hui Duan, Yi Li

University of Connecticut, Department of Plant Science, Storrs, CT, 06269-4163

A $920 \mathrm{bp}$ fragment of the ACC oxidase gene promoter from tomato ( $L E A C O 1$ ) was used to drive GUS gene expression. The $L E A C O 1$ fragment contained two stress-responsive short motifs; a $10 \mathrm{bp} \mathrm{TCA}$ motif(5'-TCATCTTCTT-3') twice (allowing two substitutions) and an 8 bp element (5'-AA/TTTCAAA-3') once. The TCA motif is found in over 30 stress- and pathogen-inducible genes while the 8 bp element is necessary for ethylene-response in the carnation GST1 and the tomato E4 gene promoters. Previously in chrysanthemum, cytokinin regulation with $L E A C O 1_{0.92 \mathrm{~kb}}$ produced dramatic increases in lateral branching and bud initiation. Tobacco plants carrying $L E A C O 1_{0.92 \mathrm{~kb}}-G U S$ were used to examine the response of the $\angle E A C O 1_{0.92 \mathrm{~kb}}$ promoter to various hormones and hormone inhibitors. GUS activity in $L E A C O 1_{0.92 \mathrm{~kb}}-G U S$ plants was detected in leaves and stems, but not roots. High expression was detected in shoots with the apical bud intact, but GUS activity decreased with the apical bud removed. Applying IAA to the shoot apex after removing the apical bud, restored GUS activity. However, the IAA transport inhibitor TIBA reduced GUS activity in shoots with intact apical buds, and in IAA-treated shoots with excised buds. In shoots with excised apical buds, GUS activity increased when the ethylene precursor ACC was applied, but decreased in intact shoots when the ethylene biosynthesis inhibitor AOA was applied. These data suggest that auxins produced in the apical meristem are capable of regulating $L E A C O 1_{0.92 \mathrm{~kb}}$ activity, probably through auxin-induced ethylene biosynthetic pathway activity.

\section{(290) Increased Tolerance to Dark, Cold Storage in Double Transgenic Plants Expressing FAD7 and IPT Genes under the Control of a Cold-inducible Promoter}

Mariya Khodakovskaya ${ }^{1}$, Richard McAvoy*1, Hao Wu ${ }^{1}$, Jeanne Peters ${ }^{2}$, Yi $\mathrm{Li}^{1}$

${ }^{1}$ University of Connecticut, Department of Plant Science, Storrs, CT, 06269-4163; ${ }^{2}$ Rutgers University, Department of Plant Biology \& Pathology

Chill injury and leaf senescence occur in plants held in prolonged cold, dark storage. To increase tolerance to these conditions, Nicotiana alata and N. tabacum were transformed with either the FAD7 or IPT genes under the control of a cold-inducible promoter $(\operatorname{cor} 15 a)$. FAD7 encodes for omega-3-fatty acid desaturase and was used to resist cold-stress. $I P T$ encodes the cytokinin-pathway enzyme isopentenyl transferase and was used to delay senescence. Independent FAD7 and IPT lines were crossed to produce double transgenic seed. Seedlings from single transgenic (cor15a-IPT or cor 15a-FAD7) lines, double transgenic lines, and the wild-type were exposed to prolonged cold, dark conditions. After 3 months in the dark at $2{ }^{\circ} \mathrm{C}$, survival of independent double transgenic $N$. tabacum lines ranged up to $80 \%$ to $90 \%$. However only $40 \%$ of FAD 7 seedlings survived, $10 \%$ of $I P T$ seedlings survived, and no wild-type plants survived. Double transgenic $N$. alata seedlings average $90 \%$ survival under similar conditions and RT-PCR revealed expression of both the IPT and FAD7 genes. Omega-3-FAD enzyme activity increases desaturation in chloroplast membrane fatty acids. When exposed to prolonged cold, the molecular fraction of polyunsaturated fatty acids (18:3 and 16:3) in leaves of wild-type $N$. alata decreased while monounsaturated (16:1 and 18:1) and saturated fatty acid species (16:0 and 18:0) increased dramatically. In double transgenic $N$. alata lines exposed to prolonged cold, the molecular fraction of 18:3 and 16:3 increased, while the 16:0 and 18:0 species decreased dramatically compared to nonchilled double transgenic plants.

\section{(291) Adventitious Shoot Production and Transformation of Euonymus alata}

Alan G. Smith*, Elizabeth S. Zimmermann

University of Minnesota, Horticultural Science, Saint Paul, MN, 55108

Euonymus alata is an attractive landscape plant that has been reported to be an invasive species. Genetic modification through transformation is a method of reducing its invasiveness by producing sterile cultivars having limited or no seed production. A critical step in Agrobacteriummediated gene transfer is the production of adventitious shoots. E. alata internodes and leaves from in vitro cultures were tested for adventitious shoot production on 16 plant growth regulator combinations: four levels of 6-benzylamino purine (BA) and three auxin treatments $[0.5$ or $0.25 \mathrm{mg} \cdot \mathrm{L}^{-1}$ indole-3-butyric acid and $0.1 \mathrm{mg} \cdot \mathrm{L}^{-1}$ naphthaleneacetic acid (NAA)], as well as no auxin. The optimal BA levels were found to be 0.5 or $1.0 \mathrm{mg} \cdot \mathrm{L}^{-1}$ for maximizing the number of explants forming shoots and for producing the greatest number of shoots per explant. Culturing on NAA gave the greatest number of shoots per explant with both 0.5 and $1.0 \mathrm{mg} \cdot \mathrm{L}^{-1} \mathrm{BA}$. Shoot production from internode segments was markedly superior to leaves. An initial dark treatment of 10 days did not influence shoot production. Using $1.0 \mathrm{mg}$ BA with 0.1 $\mathrm{mg} \cdot \mathrm{L}^{-1} \mathrm{NAA}, E$. alata internodes were transformed with $A$. tumefaciens EHA105 carrying Kanamycin resistance and $\beta$-glucuronidase genes. Transformed shoots were selected on $30 \mathrm{mg} \cdot \mathrm{L}^{-1}$ Kanamycin. Of the 36 shoots produced, 16 were confirmed to be transformed by $\beta$-glucuronidase histochemistry. Treatment with rooting powder containing indole-3-butyric acid did not aid rooting of shoots, but after 3 months in soil in high humidity, 21 of 24 E. alata shoots from tissue culture were rooted and acclimated.

\section{(292) In Vitro Rooting of Bigtooth Maple Microshoots}

Clare Bowen-O'Connor ${ }^{1}$, John Hubstenberger ${ }^{1}$, Dawn VanLeeuwen ${ }^{2}$, Rolston St. Hilaire*1

${ }^{1}$ New Mexico State University, Agronomy and Horticulture $;{ }^{2}$ New Mexico State University, Agricultural Biometric Service

Double-node microshoots of bigtooth maple (Acer grandidentatum Nutt.) were rooted in vitro on Driver-Kuniyuki Walnut (DKW) tissue culture media containing indole acetic acid (IAA). Microshoots represented six sources from three locations within Texas and New Mexico. Microshoots were placed in Phytatrays $\mathrm{II}^{\mathrm{TM}}$ containing DKW media with no plant growth regulator (DKW0) to reduce the high cytokinin levels used for shoot proliferation. Microshoots were induced to form roots for 15 days by placing them on DKW media containing IAA at 0.01 , $1,2.5,5,10,15$ or $20 \mu \mathrm{mol}$. Rooting frequency, the number of leaves and callus area were recorded every 30 days for 60 days. Rooting frequency increased up to $29 \%$ as IAA concentration increased $(P=0.004)$. However, as much as $71 \%$ of shoots for one of the three Guadalupe Mountain, Texas, sources rooted without auxin treatment after 30 days. The IAA concentration also affected the number of leaves per shoot $(P=0.0228)$ which averaged seven and callus area $(P=<0.0001)$ which averaged $52 \mathrm{~mm}^{2}$. Average leaf size was $307 \mathrm{~mm}^{2}$. We conclude that IAA induces rooting in microshoots of bigtooth maple after 15 days of root induction. However, one source rooted without auxin treatment. The presence of callus does not interfere with root formation.

\section{(293) Single Nucleotide Polymorphism in matK and Ribosomal ITS of Astilbe}

Brian W. Trader*, Richard E. Veilleux, Holly L. Scoggins Virginia Tech, Horticulture, Blacksburg, VA, 24061

The genus Astilbe (Saxifragaceae) comprises about 13 species and is ranked consistently among the top 10 landscape perennials. Through extensive hybridization, selection and marketing, the lineage of many Astilbe has been lost. Subdioecious Astilbe biternata is the only species 
in the genus native to North America while other members of the genus are endemic to Asia and monoecious. Due to the unusual geographic distribution of the species and the variation in floral development among them, development of genetic markers using single nucleotide polymorphisms (SNPs) would confirm phylogenetic relationships and establish lineage within the genus. Astilbe species, hybrids, and cultivars were obtained from plant nurseries and botanical gardens across the country. To elucidate relationships among the genus, we conducted phylogenetic analysis of DNA sequences of the chloroplast gene $m a t K$ and the internal transcriber spacer (ITS) of ribosomal rDNA genes. DNA was extracted, and gene primers trnK3914 and trnK2R were used to amplify matK, and primers $1406 \mathrm{~F}$ and ITS2 were used to amplify the ITS1 region between $18 \mathrm{~S}$ and 5.8S ribosomal DNA units. Both $m a t K$ and ITS were sequenced for each plant specimen and sequences were aligned to identify nucleotide diversity and detect SNPs. Variation in nucleotide sequence for either gene yielded similar dendrograms. Nucleotide variation among the Astilbe utilized in this study has allowed the development of SNP markers that may be useful for fingerprinting unknown hybrids or cultivars in the industry, and may be used for species alignment within the genus.

\section{Poster Session 49-Tropical Horticulture/Working Group of Asian Horticulture}

21 July 2005, 1:15-2:00 p.m. Poster Hall-Ballroom E/F

\section{(441) Evaluation of Three Grafting Methods for Propagating Soursop (Annona muricata L.) in the Dry Tropic Region of Mexico}

Juan Manuel González Gonzalez*, Francisco Radillo Juarez, Marcelino Bazan Tene, Juan Carlos González Ramos

Universidad De Colima, Facultad de Ciencias Biológicas y Agropecuarias, Tecomán, Colima, 28100, México

Soursop (Annona muricata L.) is reproduced by seeds from 'Criollo' cultivars in Mexico. The replication of desirable agronomic traits is difficult when selected plants are from sexual reproduction. The heterogeneity of plants is observed as taller trees, irregular fresh fruit yield, variable fruit quality, different insect pests, disease susceptibilities, and lower number of plants per hectare. There is an extended time period for recovering investments and commericialization problems due to fruit quality and price. Vegetative propagation is an alternative for reducing the heterogeneity of soursop trees. Three grafting methods were evaluated for propagating soursop in the dry tropic region of Colima, Mexico: 1) splice side graft; 2) wedge graft; and 3) bud graft. The experiment was carried out on the Tecoman Campus of the Universidad de Colima. Rootstocks were from 8-month-old healthy plants, 1-m tall and 1-cm diameter, obtained from 'Criollo' seedlings, and the scions were obtained from a healthy 10-year-old 'Sin Fibra' donor tree. This donor tree was selected for its excellent agronomic traits and fruit yield. Vigorous and terminal scions were used, disinfected with fungicide, and used the same day of excision. The experiment was distributed under a completely randomized design. Splice side grafting had $67 \%$ success after 60 days, while wedge grafting and bud grafting had $0 \%$ success.

(442) Catechins and Compatibility in Calocarpum sapota (Jacq.) Merr. Homografts and Calocarpum sapota on Achras sapota (L.) Heterografts during Two Phenological Stages

Juan Manuel González Gonzalez*, Oscar Rebolledo Dominguez, Lourdes Diaz Jimenes

Universidad de Colima, Facultad de Ciencias Biológicas y Agropecuarias, Tecomán, Colima, 28100, México

The responsible substances involved in the phenomenon of compability/incompatibility in Sapotaceae species during two phenological stages were elucidated. An experiment was carried out to determine the compatibility/incompatibility relationship between homografts and heterografts of Sapotaceae species during two phenological stages, and to identify the responsible substances involved in the phenomenon. In order to determine the compatibility/incompatibility between Sapotaceae species, heterograftings were made using the mamey [Calocarpum sapota (Jacq.) Merr.] as scion, and chicozapote [(Achras sapota (L.)] was used as rootstock. Grafting was conducted during the phenological stage of defoliation of the scion donor plant, as well as during budding. Homografts were also made using $C$. sapota on C. sapota in both phenological stages. Plant tissue samples were obtained from scions and rootstocks in both phenological stages, and they were used for HPLC analysis. Heterografts (C. sapota on A. sapota) showed $100 \%$ incompatibility in both stages, and lack of success during grafting was obtained; similar results were registered with the homografts (C. sapota on C. sapota) during the budding stage; however, during the defoliation stage, $80 \%$ successful grafting was obtained. The responsible substances involved in the phenomenon of compatibility/incompatibility using samples taken during the grafting day and 60 days after (C. sapota grafted on A. sapota during defoliation stage), were identified as catechin and epicatechin. Catechins are the responsible substances of incompatibility in the heterografts of $C$. sapotalA. sapota in both phenological stages, as well as during the budding stage in the homografts on $C$. sapota.

\section{(443) International Conference on Vegetables: ICV-2002}

\section{Prem Nath*1, Sundari Velu ${ }^{2}$}

${ }^{1}$ Dr. P.N. Agricultural Science Foundation (PNASF), Chairman, \#9, Bangalore, Karnataka, 560 094, India; ${ }^{2}$ Dr. P.N. Agricultural Science Foundation (PNASF), Technical Advisor, Irvine, CA, 92620-2717

In a world that produces enough food for everyone, about 800 million people in the developing world do not have enough to eat. The important challenge facing agriculture in the new millennium is to eliminate chronic hunger. Safe and better quality food is equally important to ensure that people not only have sufficient energy but also the nutrients necessary for adequate productive lives. In order to release the pressure on cereals as well as to improve human nutrition through consumption of the other nutritious crops, diversification in cropping patterns provides better options, and horticultural crops, including vegetables with their wide adoption and providers of important nutrients, offer promise for the future. In this spirit and in the wake of the present global call for eliminating food and nutritional insecurity, the technologists, entrepreneurs, policy-makers and those interested in agriculture were invited to participate and contribute to fruitful discussion at the International Conference on Vegetables (ICV-2002), which was held 11-14 Nov. 2002 in Bangalore, India. About 700 participants from 37 countries across the globe participated in the conference, and a total of 621 papers were presented. The ICV-2002 addressed 13 theme areas, which included vegetable improvement in production, protection, underutilized vegetables, postharvest management, developmental policies and programs, marketing and trade including WTO policies and programs, and, finally, technical cooperation among developing countries. The salient recommendations of the ICV-2002 will be presented.

\section{(444) Management Practices to Improve Yield of Camellia oleifera Abel}

\section{Jiangfan Yu*}

Central South Forestry University, School of Resource and Environment, Changsha, Hunan, 410004, China

Oil-tea plant (Camellia oleifera Abel), one of the four woody plants that produce edible oil for human consumption, is widely cultivated in Jiangxi Province (China) with production areas of 834,000 ha. Under conventional cultivation techniques, the oil yield of oil-tea plant was only 30 to $45 \mathrm{~kg} \cdot \mathrm{ha}^{-1}$, which significantly limited its economic impact and development. In the past 10 years, management practical techniques, such as preparing soil with organic fertilizer, weed control, thinning, pruning, alternated harvest time, improved harvest techniques, etc., had been implemented to replace traditional practices. Also, some new and promised clones were used to reforest and regenerate some areas with aged and degraded Camellia oleifera plantations. The results indicated that the new plantations and regenerated forests produced fruits for refining oil in their third year. The yield was significantly higher than that of the original stands in their fourth year and reached $712.5 \mathrm{~kg} \cdot \mathrm{ha}^{-1}$ 
in their sixth year. The highest yield, $750 \mathrm{~kg} \cdot \mathrm{ha}^{-1}$, was harvested at their eighth year after the new management practices. Oil-tea plant is not a low-yield and low-valued crop and the average yield could improve 6-7 times per hectare with selected clones and proper management. Both management practices and clone selection are key issues to the yield of oil-tea plant plantations. Best management techniques and better clones have been applied by the farmers today and the goal is to reforest or regenerate $80 \%$ of the production areas in Jiangxi Province. Future studies will focus on breeding better cultivars under these new management practices.

\section{Poster Session 50-Pomology-Physiology/Plant Growth Regulators}

\section{July 2005, 1:15-2:00 p.m. Poster Hall-Ballroom E/F}

\section{(333) Floral Commitment and Morphogenesis in Ten Apple Cultivars}

Jianying Peng ${ }^{1}$, Peter Hirst*2

${ }^{1}$ Agricultural University of Hebei, College of Horticulture, Baoding, Hebei, 071001, China; ${ }^{2}$ Purdue University, Department of Horticulture and Landscape Architecture, West Lafayette, IN, 47907-2010

Buds were sampled from nonflowering spurs on 1-year-old wood of 10 apple cultivars during the 2004 growing season and dissected to determine floral commitment and morphogenesis. Dissected buds were classified into five stages based on floral bud morphogenesis. The 10 cultivars differed in their patterns of floral commitment and morphogenesis. At the end of the growing season, the proportion of floral buds was $30 \%$ to $100 \%$ depending on cultivar. The probability of observing doming, indicating floral commitment, was from $5 \%$ to $50 \%$ depending on cultivar, with 'NJ90' (50\%), 'Zestar' (30\%), and 'CQR10T17' (30\%) rated among the highest. The lowest probability (5\%) was with 'Ambrosia', 'Pinova', and 'Silken'. The time of a peak of floral commitment was earliest in 'Delblush' and 'CQR10T17' and latest in 'Sundance'тм and 'Pinova'. Most cultivars exhibited a single peak of floral commitment, except for 'Pink Lady' in which two peaks were present. The duration of the process of flower initiation was from 20 to 43 days depending on cultivar. The timing of floral commitment and morphogenesis was not related either to blooming date, or to fruit harvest time of the cultivar.

\section{(334) Fruit Set and Yield in Relation to Reserve Nitrogen and Reserve Carbohydrates in 'Gala' Apple Trees}

Guohai Xia, Lailiang Cheng*

Cornell University, Horticulture, Ithaca, NY, 14853

Four-year-old 'Gala'/M.26 trees were grown under low (2.5 mm), medium $(12.5 \mathrm{~mm})$, or high $(25 \mathrm{~mm}) \mathrm{N}$ supply with balanced nutrients in sand culture and the cropload was adjusted to $5 \mathrm{fruit} / \mathrm{cm}^{2}$ trunk cross-sectional area at $10 \mathrm{~mm}$ king fruit. After harvesting, half of the trees in each $\mathrm{N}$ treatment were sprayed twice with 3\% urea a week apart in late September. Before budbreak the following spring, four trees from each treatment combination were destructively sampled for reserve nitrogen and carbohydrate analysis. Foliar urea application significantly increased tree $\mathrm{N}$ concentration and concentrations of both free amino acids and proteins, but decreased the concentration of total nonstructural carbohydrates (TNC) at each soil N supply level. When the carbon in free amino acids and proteins are taken into account, trees sprayed with foliar urea had similar levels of total sum of carbon in TNC, free amino acids and proteins. On a whole tree basis, trees sprayed with foliar urea had more N and less TNC. During the second year of the experiment, all the trees received normal $\mathrm{N}$ supply. Trees sprayed with foliar urea the previous fall had a significantly larger total leaf area and higher fruit set, fruit number, and total yield than those unsprayed. We conclude that fruit set and early fruit development as well as vegetative growth in spring is mainly determined by reserve nitrogen, not by reserve carbohydrates. Conversion of a portion of TNC to amino acids and proteins leads to better growth and fruiting of apple trees.

\section{(335) Purification and Characterization of ADP-glucose Pyrophosphorylase from Apple Leaves}

\section{Rui Zhou, Lailiang Cheng*}

Cornell University, Horticulture, Ithaca, NY, 14853

Apple leaf ADP-glucose pyrophosphorylase was purified over 1400fold to apparent homogeneity with a specific activity of 58.9 units per mg of protein. The enzyme was activated by 3-phosphoglycerate (PGA) and inhibited by inorganic phosphate (Pi) in the ADPG synthesis direction. In the pyrophosphorolysis direction, however, high concentrations of PGA $(>2.5 \mathrm{~mm})$ inhibited the enzyme activity. The enzyme was resistant to thermal inactivation with a $\mathrm{T}_{0.5}$ (temperature at which $50 \%$ of the enzyme activity is lost after $5 \mathrm{~min}$ of incubation) of $52{ }^{\circ} \mathrm{C}$. Incubation with $2 \mathrm{~mm}$ PGA or $2 \mathrm{~mm}$ Pi increased $\mathrm{T}_{0.5}$ to 68 ${ }^{\circ} \mathrm{C}$. Incubation with $2 \mathrm{~mm}$ dithiothreitol (DTT) decreased $\mathrm{T}_{0.5}$ to 42 ${ }^{\circ} \mathrm{C}$, whereas inclusion of $2 \mathrm{~mm}$ PGA in the DTT incubation maintained $\mathrm{T}_{0.5}$ at $52{ }^{\circ} \mathrm{C}$. DTT-induced decrease in thermal stability was accompanied by monomerization of the small subunits. Presence of PGA in the DTT incubation did not alter the monomerization of the small subunits of the enzyme induced by DTT. These findings indicate that the binding of PGA may have dual functions in regulating apple leaf AGPase activity - activating the enzyme and rendering the enzyme with a conformation more stable to thermal inactivation.

\section{(336) Temperature Effect on Seasonal Growth of Pear Fruit}

Patricia Garriz*, Hugo Alvarez, Graciela Colavita

Comahue National University, Applied Biology, c.c. 85, Cinco Saltos, Rio Negro, 8303, Argentina

Temperature has long been recognized as a major environmental factor affecting the net carbon exchange in the pear tree, as well as the growth of fruit. The objective of this work was to predict pear fruit growth as a function of accumulated growing-degree-days (DD) using a mathematical model. A crop of 'Abbé Fetel' trees was studied at the Experimental Farm of the Comahue National University, Argentina (lat. 38 $56^{\prime}$ 'S ; long. 67 $59^{\prime} \mathrm{W}$ ). Maximum fruit diameter(FD) measurements were carried out every 2 weeks during three growing seasons (2000-01, 2001--02, and 2002-03). The range of sampling dates was 26 and 143 days after full bloom (DFB). An automated meteorological station, situated close to the orchard, collected temperature data, which were expressed on the basis of DD from time of full bloom to harvest, with critical temperatures at 4 and $35{ }^{\circ} \mathrm{C}$. Equations were developed with SYSTAT procedure and model suitability was evaluated using goodness-to-fit measures. It was found that the following logistic regression provided the most satisfactory fit for the pooled data: $\mathrm{FD}(\mathrm{mm})=71.62 /[(1+\mathrm{e} \wedge(1.7450-0.0027 \mathrm{DD})]$, coefficient of determination $=0.96$. The testing on an independent crop showed that predictions were accurate. Analyses of fruit growth, based on DD, did not improve data interpretation over that on a DFB basis. The average monthly temperature varied little between seasons. A remarkably consistent heat-unit accumulation function was obtained from year to year, with a $5 \%$ maximum variation in number of DFB to maturity, compared to a $6 \%$ variation in DD, occurring between the 2002 and 2003 commercial harvests. These results have important implications for cultural practices, such as fruit thinning and final size forecast.

\section{(337) Effect of Selenium Supply by Trunk Injection on Fruit Quality of 'Niitaka' Asian Pear}

\section{Wol-Soo Kim*, Jung-An Jo, Soon-Ju Chung}

Chonnam National University, Department of Horticulture, 300 Yongbong-dong, Gwangju, 500-757, Korea

Many trials to supply selenium to fruit have been carried out since tests have confirmed selenium's role as a medical substance. Supplying selenium in orchards by soil and foliar application was not effective because of loss from rainfall. In order to increase selenium absorption by fruit, this study carried out tree trunk injections during the growing season. Selenium solutions in concentrations of $5,10,25$, and 50 $\mathrm{mg} \cdot \mathrm{L}^{-1}$ were supplied to 'Niitaka' pear (Pyrus pyrifolia) trees by trunk injection (1.5 L/tree) four times at 15-day intervals from June 2004. 
The treatment with $50 \mathrm{mg} \cdot \mathrm{L}^{-1}$ selenium showed necrosis symptoms at leaf-margins after secondary treatment and toxicity as abnormally red fruit skin color. Fruit weight and leaf area were decreased by selenium treatments, while severe symptoms appeared with higher selenium concentrations. Hunter values ' $a$ ' and ' $b$ ' in fruit skin color were increased by selenium treatment in comparison to the control. The selenium treatment showed lower soluble solids by as much as $1.2 \%$, and higher fruit firmness. Selenium concentration in pear fruit was increased by trunk injection with a $5 \mathrm{mg} \cdot \mathrm{L}^{-1}$ solution. The bound selenium in pear fruit after 3 months of storage in cold room conditions was very high, but free selenium was low.

\section{(338) Effect of Germanium Supply by Trunk Injection on Tree Growth and Fruit Quality of 'Niitaka' Asian Pear (Pyrus pyrifolia)}

\section{Wol-Soo Kim*, Jung-An Jo}

Chonnam National University, Department of Horticulture, 300 Yongbong-dong, Gwangju, 500-757, Korea

Many trials to supply germanium to fruit have been carried out since tests have confirmed germanium's role as a medical substance. Supplying germanium in orchards by soil and foliar application was not effective because of loss from rainfall. In order to increase germanium absorption by fruit, this study carried out tree trunk injections during the growing season. Two types of germanium, $\mathrm{GeO}$ (inorganic type) and Ge-132 (organic type), in concentrations of 5, 10, 25, and 50 $\mathrm{mg} \cdot \mathrm{L}^{-1}$ were supplied to 'Niitaka' pear trees by trunk injection $(1.5$ $\mathrm{L} /$ tree), four times at 15 -day intervals from June 2004. The treatment with $50 \mathrm{mg} \cdot \mathrm{L}^{-1} \mathrm{GeO}$ showed decreased fruit weight, but $50 \mathrm{mg} \cdot \mathrm{L}^{-1}$ Ge-132 showed no difference to the control and other treatments. Fruit lenticels were increased in size by all of the Ge treatments in comparison to control fruit. Soluble solids as well as Hunter value ' $a$ ' of the fruits of all $\mathrm{Ge}$ treatments were higher than that of the control. Flesh browning after peeling the fruit was delayed by the germanium treatment, and polyphenoloxidase (PPO) activities were lowered. Postharvest potentials were maintained at high levels for fruit firmness, physiological disorders, and decayed fruit during cold storage at 0 to $1^{\circ} \mathrm{C}$ for 2 months.

\section{Poster Session 51-Floriculture Nutrition and Substrates}

\section{July 2005, 1:15-2:00 p.m. Poster Hall-Ballroom E/F}

\section{(119) Celosia argentea Can Be Produced Using Saline Wastewaters}

Christy T. Carter, Catherine M. Grieve, James A. Poss*

USDA-ARS, George E. Brown, Jr. Salinity Laboratory, Plant Sciences, Riverside, CA, 92507

Salinity tolerance of two cultivars of Celosia argentea ('Chief Rose' and 'Chief Gold') was investigated using a completely randomized design with three replications. Seedlings grown in greenhouse sand tanks were exposed to six salinity levels $\left(2.5,4,6,8,10\right.$, and $\left.12 \mathrm{dS} \cdot \mathrm{m}^{-1}\right)$ and two water ionic compositions mimicking sea water and drainage waters from the Imperial and Coachella valleys. Phenotypic measurements were made when plants were harvested during flowering, and concentrations of $\mathrm{Ca}^{2+}, \mathrm{Mg}^{2+}, \mathrm{Na}^{+}, \mathrm{K}^{+}, \mathrm{Cl}$, total-S, and total-P were also determined from leaf tissues. Overall, phenotypic measurements (including stem length, stem weight, stem diameter, inflorescence length, inflorescence weight, and number of leaves) tended to decrease as salinity increased, yet stem lengths were still above the minimum stem length recommended for marketability $(41 \mathrm{~cm})$. Significant interactions were found for salinity and water ionic composition for all mineral analyses for both cultivars. As salinity increased, $\mathrm{Ca}^{2+}, \mathrm{K}^{+}$, and total-P decreased as $\mathrm{Mg}^{2+}, \mathrm{Na}^{+}$, and $\mathrm{Cl}^{-}$increased for both cultivars. 'Chief Gold' can be produced commercially in either water composition up to $12 \mathrm{dS} \cdot \mathrm{m}^{-1}$. 'Chief Rose' can be produced up to $8 \mathrm{dS} \cdot \mathrm{m}^{-1}$ in sea water and $10 \mathrm{dS} \cdot \mathrm{m}^{-1}$ in water ionic compositions similar to those of the Imperial and Coachella valleys. Saline waters dominated by chloride and sulphate salts can be used to produce Celosia argentea commercially.

\section{(120) Response of Ornamental Sunflower to Irrigation with Saline Wastewaters}

Catherine M. Grieve*, James A. Poss, John H. Draper

USDA-ARS George E. Brown Jr. Salinity Laboratory, Plant Sciences, Riverside, CA, 92507

To explore the possibility that saline wastewaters may be used to grow high value floriculture crops, the effects of salinity were tested on $\mathrm{He}$ lianthus annuus (L.). Sunflower cultivars Sunbeam and Moonbright were grown in 30 greenhouse sand tanks and irrigated initially with nutrient solution. One week after planting, saline treatments were imposed with solutions differing in ion composition. Fifteen tanks were irrigated with waters typical of agricultural wastewaters present in the San Joaquin Valley (SJV) and 15 tanks were irrigated with water compositions similar to saline tailwaters found in the Imperial and Coachella valleys (ICV). Five treatments of each salinity type were used with electrical conductivities (EC) of 2.5, 5, 10, 15, and 20 $\mathrm{dS} \cdot \mathrm{m}^{-1}$. Length of the flowering stems was significantly reduced as salinity rose to $20 \mathrm{dS} \cdot \mathrm{m}^{-1}$. Reduction was more pronounced when the plants were irrigated with the sodium-sulfate dominated waters of SJV composition. Flower diameter was reduced when the EC of SJV waters exceeded $15 \mathrm{dS} \cdot \mathrm{m}^{-1}$, but was not affected by any treatment when ICV waters were used. Salt tolerance in sunflower appears to be associated with mechanism(s) that regulate transport of potentially injurious ions. Both $\mathrm{Na}^{+}$and $\mathrm{Cl}^{-}$were partitioned to the lowest portion of the stem, and effectively excluded from the remainder of the shoot. This study illustrates that saline waters with $\mathrm{EC}=15$ or $20 \mathrm{dS} \cdot \mathrm{m}^{-1}$ may be used to produce ornamental sunflowers without significant loss of quality. Salt stress also provides an environmentally friendly alternative to the use of growth regulators for the control of plant height.

\section{(121) Matthiola incana as a Model Crop for Recycling Greenhouse Effluents}

James A. Poss*, Christy T. Carter, Catherine M. Grieve,

Peter J. Shouse

USDA-ARS, George E. Brown, Jr. Salinity Laboratory, Plant Sciences, Riverside, CA, 92507

Common stock flower production can be achieved under moderate levels of salinity and relatively low levels of nitrogen with no significant decrease in quality in a closed-recirculating irrigation system. A $4 \times 4$ factorial design with partial replication was used to assess the effects of salinity and nitrogen on the production of Matthiola incana (L.). Seeds were sown in outdoor volumetric lysimeters at the George E. Brown, Jr., Salinity Laboratory in Riverside, Calif., with target electrical conductivity (EC) levels of $2,5,8$, and $11 \mathrm{dS} \cdot \mathrm{m}^{-1}$ combined with four nitrogen treatments of $35,50,75$, and $100 \mathrm{ppm} \mathrm{N}$. An empirical model was implemented to evaluate the growth response of each combination of salinity and nitrogen treatments over the course of plant development. The three-phase model is represented by an initial size parameter (alpha), an estimation of the intrinsic growth rate of the exponential phase (beta), a transitional phase between the first two phases (tl), the length of the linear phase (epsilon), and the final intrinsic saturation rate (gamma), The model successfully fitted the plant height data over time for all 16 nitrogen and salinity treatment combinations. Effects of salinity on epsilon and $\mathrm{t} 2($ epsilon $+\mathrm{t} 1)$ were nonsignificant. Nitrogen treatments had no significant effect on any of the model parameters and the effect of salinity was greatest when irrigation water EC was 11 $\mathrm{dS} \cdot \mathrm{m}^{-1}$. The length of the flower-bearing stems exceeded the standards recommended for commercial acceptability in all treatments $(>41 \mathrm{~cm})$. If $60 \mathrm{~cm}$ is the minimum length acceptable, then $50 \mathrm{ppm} \mathrm{N}$ or more where the EC was $8 \mathrm{dS} \cdot \mathrm{m}^{-1}$ or less is required. Nitrogen uptake per unit evapotranspiration increased with salinity and nitrogen.

\section{(122) Simulation of Poor Quality Irrigation Waters in Subirrigation and Top-watering using Mixture Experiments}

Matthew W. Kent, David W. Reed*

Texas A\&M University, Dept of Horticultural Sciences, College Station, TX, 77843-2133

The effects of cations vs. anions in salinity studies cannot be separated by traditional means. Analysis of mixture experiments allows ionic ef- 
fects to be analyzed individually by varying proportions of ions without changing their total concentrations. A series of mixture experiments were performed in the greenhouse to determine the effects of the anions bicarbonate, chloride, and sulfate, given a constant and equal concentration of the cation sodium, on vinca 'Pacifica Red' grown with different irrigation systems and leaching fractions. In subirrigation, increasing total ion concentrations from 30 to $60 \mathrm{meq} / \mathrm{L}$ total ion concentrations (TIC) caused a general decrease in shoot fresh and dry weights, with bicarbonate contributing to the greatest degree of reduction, and sulfate the least. Root dry weight was similarly decreased with increasing TIC, but the differences between individual ion effects were more subtle. SPAD data, an indication of chlorophyll concentration, showed a sharp decrease with increase in bicarbonate, but not with sulfate or chloride. Medium $\mathrm{pH}$ increased as TIC increased, being influenced primarily by bicarbonate. Conversely, growing medium EC was influenced most by sulfate and chloride, and least by bicarbonate with increasing TIC. At 30 meq/L TIC, top-watered treatments with a leaching fraction (LF) of $5 \%$ generally had reduced shoot and root dry weight without regard to ion species, while a leaching fraction of $35 \%$ produced results more similar to those of subirrigation. While medium EC and $\mathrm{pH}$ varied with layer and irrigation method, bicarbonate generally affected $\mathrm{EC}$ least and $\mathrm{pH}$ most.

\section{(123) Correlation between Tissue and Substrate Silicon Content of Greenhouse-produced Helianthus annuus 'Ring of Fire'}

\section{Sophia Kamenidou*, Todd Cavins}

${ }^{1}$ Oklahoma State University, Horticulture and Landscape Architecture Dept., Stillwater, OK, 74078

Silicon ( $\mathrm{Si}$ ) is a beneficial element to many agricultural crops. We found improved horticultural traits in our preliminary Si supplementation research on floricultural greenhouse crops produced in soilless substrates. The objective of this study was to establish optimum Si rates based on previous results and investigate the relationship of Si tissue and substrate content. Potassium silicate $\left(\mathrm{KSiO}_{3}\right)$ weekly drenches $(0$, $\left.50,100,150 \mathrm{mg} \cdot \mathrm{L}^{-1} \mathrm{SiO}\right)$, media-incorporated $\mathrm{KSiO}_{3}$ flakes $(0,280$, $\left.400,520 \mathrm{~g} \cdot \mathrm{m}^{-3} \mathrm{SiO}_{2}\right)$, and ashed rice hulls $\left(0,200,270,360 \mathrm{~g} \cdot \mathrm{m}^{-3} \mathrm{SiO}_{2}\right)$ were provided to Helianthus annuus 'Ring of Fire'. Leaf, stem, and flower tissues as well as soilless substrate samples were collected for $\mathrm{Si}$ analysis. Several Si treatments resulted in plants with increased flower and stem diameter compared to untreated controls $(P \leq 0.05)$. Weekly drenches with $\mathrm{KSiO}_{3}\left(150 \mathrm{mg} \cdot \mathrm{L}^{-1} \mathrm{SiO}_{2}\right), \mathrm{KSiO}_{3}$ flakes $\left(280 \mathrm{~g} \cdot \mathrm{m}^{-3} \mathrm{SiO}_{2}\right)$, and ashed rice hulls $\left(360 \mathrm{~g} \cdot \mathrm{m}^{-3} \mathrm{SiO}_{2}\right)$ were the most efficient treatments based on the increased quality characteristics. Leaftissue had the highest Si content, followed by flower, then stem tissue. Correlation analysis indicated that leaf and flower Si content was positively correlated with saturated media extract substrate samples (correlation coefficients $r=0.75$ and 0.63 , respectively).

\section{(124) Tuber Production of Sandersonia aurantica Grown in a Soilless Medium Affected by the Medium Composition and Harvesting Time}

Su-Jeong Kim, Chun-Woo Nam, Dong-Lim Yoo, Jong-Taek Suh, Myoung-Rae Cho, Ki-Sun Kim*

National Institute of Highland Agriculture, Horticulture, 3-ri, Hyonggye, Doam-yeon, Pyeongchang-gun, Gangwon-do, 232-955, S. Korea

This study was conducted to overcome the problems occurring in soil cultured Sandersonia, such as secondary tuber formation, tuber russeting, browning and surface cracking. For the tuber production, soilless culture medium compositions (peatmoss, perlite, cocopeat) and harvesting times $[4,6,8,10$, and 12 weeks after flowering time (WAF) $]$ were compared. The mother tubers were planted and grown in a plastic box $(40 \times 60 \times$ $23 \mathrm{~cm}$ ) under a PE film house with shading in summer season. The tuber number and weight were higher in peatmoss-based media of peatmoss, 1 peatmoss : 1 perlite, and 2 peatmoss : 1 perlite (by volume) than in the other media. Particularly, the plant height and the numbers of leaf and flower were also higher. The contents of total nitrogen and phosphorus in leaves were lower when the tubers were grown in perlite. Leaf area index per plant reached the maximum at $8 \mathrm{WAF}$ and decreased thereafter. The optimal harvesting time for tuber production was 8-10 WAF.

\section{(125) Response of Six Begonia Species to Different} Substrate pH

\author{
Ka Yeon Jeong*1, Claudio Pasian ${ }^{1}$, David Tay ${ }^{2}$
}

${ }^{1}$ The Ohio State University, Horticulture and Crop Science, Columbus, OH, 43210; ${ }^{2}$ The Ohio State University, Ornamental Plant Germplasm Center, Columbus, OH, 43210

Substrate $\mathrm{pH}$ of soilless media directly affects nutrient availability. Limited information about the effect of substrate $\mathrm{pH}$ on growth of begonia species (not cultivated hybrids) was found in the literature. The objective of this study was to evaluate the effect of substrate $\mathrm{pH}$ on the growth and quality of six begonia species grown from June to Aug. 2004. The targeted $\mathrm{pH}$ ranges $(<4.5,4.5 \sim 5.0,5.0 \sim 5.5,5.5 \sim 6.0,6.0 \sim 6.5,6.5 \sim 7.0$, and over 7.0 ) of the peat-based substrates were obtained by adding seven different amounts of dolomitic hydrated lime: $0,1.0,1.3,1.6,2.0,2.4$, and 2.6 $\mathrm{kg} \cdot \mathrm{m}^{3}$. Begonia albopicta, B. cucullata var. cucullata, B. echinosepala var. elongatifolia, B. holtonis, B. fuchsioides (red), and B. fuchsioides (pink), were propagated by stem cuttings, and then transplanted into plastic containers. This experiment was a factorial experiment arranged in a randomized complete-block design. The $\mathrm{pH}$ was monitored weekly using the pour-through method and adjusted accordingly by adding flowable lime or a mild sulfuric acid solution. The $\mathrm{pH}$ values were averaged for each treatment of each species. There were significant differences between species in the inflorescence number and SPAD readings, but no interaction between species and substrate $\mathrm{pH}$ was found. Stem length, leaf area, and dry weight of each plant were significantly affected by species and substrate $\mathrm{pH}$. B. albopicta performed best at substrate $\mathrm{pH}$ of 5.6 and 6.0, showing no symptoms of phytotoxicity. B. cucullata, above substrate $\mathrm{pH}$ 6.0, and B. holtonis at $\mathrm{pH} 5.0$ and 5.6 had the highest vegetative growth and plant quality. Plant mortality was observed for $B$. cucullata and B. fuchsioides (red) at pH below 4.4 and 5.3, respectively.

\section{(126) Response of Six Begonia Species to Different Substrate EC}

Ka Yeon Jeong*1, Claudio Pasian ${ }^{1}$, David Tay ${ }^{2}$

${ }^{1}$ The Ohio State University, Horticulture and Crop Science, Columbus, OH, 43210; ${ }^{2}$ The Ohio State University, Ornamental Plant Germplasm Center, Columbus, OH, 43210

There is limited information on optimal substrate EC level for begonia species (noncultivated hybrids). The objective of this study was to evaluate the response of six species to different substrate EC in a greenhouse. Begonia albopicta, B. cucullata var. cucullata, B. echinosepala var. elongatifolia, B. holtonis, B. fuchsioides (red) and B. fuchsioides (pink) plants were propagated by stem cuttings, and transplanted into plastic pots using a soilless mix. Five concentrations $(20,80,200,400$, and $\left.600 \mathrm{mg} \cdot \mathrm{L}^{-1} \mathrm{~N}\right)$ of $17-5-17$ fertilizer were applied as irrigation water to derive the five substrate EC levels. This experiment was a factorial randomized complete-block design. Substrate EC was measured weekly using the PourThru method and averaged for each treatment of each species. Inflorescence number, the longest stem length, SPAD readings, leaf area, and dry weight of each plant were measured as growth parameters. There were significant responses to substrate EC level and species on begonia growth parameters. The highest growth parameters of B. albopicta and B. cucullata were obtained at EC 5.7 and $6.6 \mathrm{mS} \cdot \mathrm{cm}^{-1}$, respectively. The maximum growth of $B$. echinosepala and $B$. holtonis was observed at 2.6 and $3.0 \mathrm{mS} \cdot \mathrm{cm}^{-1}$, respectively. $B$. fuchsioides, grown at $1.2 \mathrm{mS} \cdot \mathrm{cm}^{-1}$, had the best growth parameter values. As EC level increased, SPAD value for $B$. fuchsioides (pink) and $B$. holtonis also increased. The highest SPAD reading was observed at EC $3.7 \mathrm{mS} \cdot \mathrm{cm}^{-1}$ for B. albopicta, EC $6.6 \mathrm{mS} \cdot \mathrm{cm}^{-1}$ for B. cucullata, EC 2.6 $\mathrm{mS} \cdot \mathrm{cm}^{-1}$ for $B$. echinosepala, and EC $4.1 \mathrm{mS} \cdot \mathrm{cm}^{-1}$ for $B$. fuchsioides (red). Plant mortality of several begonia species was observed when grown at EC value above 6.4 or below $4.4 \mathrm{mS} \cdot \mathrm{cm}^{-1}$.

\section{(127) Effects of Substrate on Nutrient Uptake and Nitrate Leaching in Lilies}

\section{Donald J. Merhaut*1, Julie P. Newman ${ }^{2}$}

${ }^{1}$ University of California, Riverside, Botany and Plant Sciences, Riverside, CA, 92521; ${ }^{2}$ University of California, Cooperative Extension, Ventura, CA, 93003

Lilies are produced throughout the year in coastal areas of California. 
Cultural practices involve daily applications of water and fertilizer, using both controlled release fertilizers (CRF) and liquid fertilizers (LF). However, many production facilities are in proximity to coastal wetlands and are therefore at greater risk of causing nitrogen pollution via runoff and leaching. Due to federal and state regulations, nurseries must present a plan of best management practices (BMPs) to mitigate nutrient runoff and leaching and begin implementing these practices in the next 2 years. In the following studies, we determined the potential for nitrate leaching from four different types of substrates (coir, coir : peat, peat, and native soil). There were four replications of each treatment, with a replication consisting of one crate planted with 25 bulbs. Two cultivars were used in two separate experiments, 'Star Fighter' and 'Casa Blanca'. Nitrate leaching was determined by placing an ion-exchange resin bag under each crate at the beginning of the study. After plant harvest (14-16 weeks), resin bags were collected and analyzed for nitrate content. Plant tissues were dried and ground and analyzed for nitrogen content. Based on the results of these studies, it appears that the use of coir, peat, and soil may not influence plant growth significantly. Substrate type may mitigate the amount of nitrate leaching through the media. However, the cultivar type may also influence the degree of nitrate mitigation, since leaching results varied between the two cultivars.

\section{(128) Determination of Limestone Requirement of Soilless Root Media for a Specific $\mathbf{p H}$}

Pauline H. Andrews, P. Allen Hammer*

Purdue University, Horticulture and Landscape Architecture, West Lafayette, IN, 47907

Limestone requirement tests are routine in agronomic laboratories; however, no tests exist for soilless root medium although there is still a need to predict the limestone additions. This research was to develop a rapid, accurate test to determine the limestone requirement of soilless root media for a specific $\mathrm{pH}$. Thirty-four media formulations were amended with increasing rates of limestone. Media were incubated in the greenhouse. Pots were irrigated to container capacity every 2 days with RO-water; $\mathrm{pH}$ was recorded after 5 weeks; and limestone requirement for $\mathrm{pH} 5.5$ was determined for each media. A modified SMP buffer procedure for mineral soils was used. A $40-\mathrm{mL}$ aliquot of the SMP buffer was added to $6 \mathrm{~g}$ of media, equilibrated for 48 hours and $\mathrm{pH}$ determined. Media-buffer $\mathrm{pH}$ was plotted against the incubation limestone requirement for $\mathrm{pH}$ 5.5. A separate regression was required for media containing coir since the modified SMP buffer test overestimated the limestone requirement of coir media. The correlation for non-coir media was $-0.97(\mathrm{Y}=-1.19 \mathrm{x}+7.52)$ and $-0.94(\mathrm{Y}=-1.12 \mathrm{x}+6.14)$ for coir media. The procedure was verified using 15 media. Media-buffer $\mathrm{pH}$ was determined and the limestone requirement was calculated using the corresponding regression equation. Two sets of media treatments were potted and incubated in the greenhouse. Rooted cuttings of geranium 'Candy Lavender' were transplanted into one set of pots. Pots were irrigated every 2 days with RO-water and geraniums were irrigated with nonacidified fertilizer water. Media $\mathrm{pH}$ was determined at week 5. Media was nonsignificant for pots or geraniums $(P \leq 0.01)$. The mean $\mathrm{pH}$ of non-coir media was $\mathrm{pH} 5.66$ and 5.67 for pots and geraniums and $\mathrm{pH} 5.39$ and 5.39, respectively, for coir media.

\section{(129) Effect of Foliar Application of Calcium, Boron, and Molybdenum in Nutrient Content of Poinsettia Plants}

Juan Ayala, Ana-Maria Castillo*, Maria-Teresa Colinas, Joel Pineda Universidad Autonoma Chapingo, Fitotecnia, Chapingo, Edo. Mexico, 56230, Mexico

The effect of foliar application of calcium, boron, and molybdenum on macronutrient and micronutrient content of poinsettia (Euphorbia pulcherrima) plants cv. Supjibi was evaluated. Plants were grown under greenhouse conditions in 7-inch containers. Fourteen treatments were applied (10 replicates per treatment); these were formed by three calcium levels (calcium nitrate at 300,400 , and $500 \mathrm{mg} \cdot \mathrm{L}^{-1}$ ), boron (borax at $0.2,0.5$, and $0.8 \mathrm{mg} \cdot \mathrm{L}^{-1}$ ), and molybdenum (sodium molybdate at $0.3,0.4$, and $0.5 \mathrm{mg} \cdot \mathrm{L}^{-1}$ ) and their combinations. Plants were spayed three times during the growing period: 51, 72, and 94 days after transplant. Plants were covered with black polyethylene from $5 \mathrm{pm}$ to 7 am every day in order to induce bract development.
$\mathrm{N}, \mathrm{P}, \mathrm{K}, \mathrm{Ca}, \mathrm{Mg}, \mathrm{B}, \mathrm{Mo}, \mathrm{Mn}, \mathrm{Fe}, \mathrm{Zn}$, and $\mathrm{Cu}$ content was evaluated 2 weeks after finishing the induction period. The treatment with a combination of $\mathrm{Ca}+\mathrm{Mo}$ increased by $26 \%$ the $\mathrm{N}$ content compared with the control. Application of $\mathrm{B}+\mathrm{Mo}$, and $\mathrm{Ca}+\mathrm{B}$ decreased the $\mathrm{P}$ content by $32 \%$ and $28 \%$, respectively. Treatment with $\mathrm{Ca}+\mathrm{B}+\mathrm{Mo}$ increased foliar $\mathrm{K}$ by $46 \%$. B+Mo increased $72.5 \% \mathrm{Ca}$ content, $38 \% \mathrm{Mg}$, and there was about 75 times more $\mathrm{Cu}$ than in the control (2.20 vs. 166.7 $\left.\mathrm{mg} \cdot \mathrm{L}^{-1}\right)$. Treatments with $\mathrm{Ca}$ and $\mathrm{B}$ decreased Mn content by $32.7 \%$. $\mathrm{Ca}\left(500 \mathrm{mg} \cdot \mathrm{L}^{-1}\right)$ decreased B content by $76 \%$. Treatments did not have any significance on $\mathrm{Mo}, \mathrm{Fe}$, and $\mathrm{Zn}$ content. As a general conclusion it can be said that foliar applications of $\mathrm{Ca}, \mathrm{B}, \mathrm{Mo}$, alone or in certain combinations, affected significantly the content of foliar nutrients due to specific nutrient interactions in plants.

\section{(130) Dieffenbachia Calcium Oxalate Crystal Formation Affected by Cultivars, Nitrogen Rates, and Light Intensity}

\author{
Hui Cao, Jianjun Chen*, Dennis B. McConnell
}

University of Florida, Environmental Horticultural Department and Mid-Florida Research and Education Center, Apopka, FL, 32703

Tissue-cultured explants of Dieffenbachia maculate 'Exotic Perfection', $D$. 'Snow Flake', and $D . \times$ 'Tropic Breeze' were grown on ebb-and-flow trays subirrigated with nitrogen (N) at 50, 200, or 800 $\mathrm{mg} \cdot \mathrm{L}^{-1}$ using a water-soluble fertilizer $17 \mathrm{~N}-2.1 \mathrm{P}-15.7 \mathrm{~K}$ for 10 weeks in a shaded greenhouse under a maximum photosynthetic photon flux density of $285 \mu \mathrm{mol} \cdot \mathrm{m}^{-2} \cdot \mathrm{s}^{-1}$. Plants were then transferred to interior rooms under a light level of $8 \mu \mathrm{mol} \cdot \mathrm{m}^{-2} \cdot \mathrm{s}^{-1}$. Samples of the midrib were taken from the first mature leaf of plants before being placed indoors and also from the first mature leaf of plants 8 months after growing indoors. Counts of calcium oxalate crystal idioblasts in cross-sections of the basal midrib using polarized light microscopy showed that the number of crystal idioblasts was higher in all three cultivars fertigated with $200 \mathrm{mg} \cdot \mathrm{L}^{-1} \mathrm{~N}$ than those fertigated with either 50 or $800 \mathrm{mg} \cdot \mathrm{L}^{-1}$ $\mathrm{N}$. The number of crystal idioblasts in each cultivar grown under 8 $\mu \mathrm{mol} \cdot \mathrm{m}^{-2} \cdot \mathrm{s}^{-1}$ was about $50 \%$ of the number detected when plants were grown under $285 \mu \mathrm{mol} \cdot \mathrm{m}^{-2} \cdot \mathrm{s}^{-1}$. 'Snow Flake' had the highest number of crystal idioblasts with counts up to 60 per cross-section, whereas 'Exotic Perfection' had the lowest with only 30 per cross-section. This study shows that in addition to cultivar differences, light intensity and $\mathrm{N}$ can significantly affect calcium crystal formation, and the highest number of crystal idioblasts occurred when Dieffenbachia cultivars were grown under optimum conditions.

\section{(131) Nitrogen and Potassium Changes during Growth of Poinsettia (Euphorbia pulcherrima Wild) 'Supjibi Red'}

Jorge-Moises Rosas-Ramos*1, Ana-Maria Castillo-Gonzalez', María Teresa Colinas-Leon ${ }^{1}$, Joel Pineda-Pineda ${ }^{2}$

${ }^{1}$ Universidad Autonoma Chapingo, Fitotecnia, Chapingo, Edo. Mexico, 56230, Mexico $;{ }^{2}$ Universidad Autonoma Chapingo, Instituto de Horticultura, Chapingo, Edo. Mexico, 56230, Mexico

Nitrogen and potassium changes in poinsettia 'Supjibi Red' were evaluated at four stages: vegetative growth, inductive stage, bract development and flowering. Nitrogen doses were 100, 200, 300, 400, and $500 \mathrm{mg} \cdot \mathrm{L}^{-1}$ and those of potassium were: $175,250,325$, and 400 $\mathrm{mg} \cdot \mathrm{L}^{-1}$, which were applied constantly with irrigation. Plants were grown in 7-inch pots with tezontle as the substrate. A completly random experimental design with nine treatments and 10 replicates was used. Short photoperiod was applied from 61 days after transplant, covering plants for 14 hours from $7 \mathrm{pm}$ on. Samples for nitrogen and potassium evaluations were taken from recently grown-up leaves at $25,50,75,100$ and 125 days after transplant. Nitrogen absorption increased up to 75 days after transplant; treatments with 400 and 500 $\mathrm{mg} \cdot \mathrm{L}^{-1}$ of nitrogen induced the highest foliar levels $2.44 \%$ and $2.6 \%$, respectively. In the following sampling dates, nitrogen decreased for all treatments. Potassium content decreased as plants developed; highest levels were obtained 25 days after transplant. The 325 and $400 \mathrm{mg} \cdot \mathrm{L}^{-1}$ $\mathrm{K}$ treatments induced the highest concentrations in leaves $7.04 \%$ and $7.02 \%$, respectively. Thus, it is confirmed that nitrogen is required throughout vegetative growth, and potassium just in the initial stage of vegetative growth. 


\section{(132) Withdrawn}

\section{(133) Influence of Two Types of Fertilizers on the Growth and Development of Tissue-cultured Daylilies Transferred to the Greenhouse}

Johnny Carter*, Diondre Palmer, Lianghong Chen

Fort Valley State University, Agricultural Research, Fort Valley, GA, 31030

During Summer 2004, a study was conducted to determine the effect of two types of fertilizers on the growth and development of tissue-cultured daylilies transferred to the greenhouse. Peters 20-20-20 water-soluble fertilizer and a slow-release fertilizer were the two fertilizers evaluated. Peters 20-20-20 fertilizer was used at 0 (control), 50, 100, and 200 $\mathrm{mg} \cdot \mathrm{L}^{-1}$ rates. The slow release fertilizer was used at $2.5 \mathrm{~g}$ per $10.2 \mathrm{~cm}$ pot. Each treatment was replicated four times in a randomized completeblock design. After 6 weeks of growth, the results showed that, when compared to the control, all treatments except for $200 \mathrm{mg} \cdot \mathrm{L}^{-1}$ caused a significant increase in root growth. Shoot growth was significantly increased by the $100 \mathrm{mg} \cdot \mathrm{L}^{-1}$ treatment, while the $200 \mathrm{mg} \cdot \mathrm{L}^{-1}$ and slowrelease treatments suppressed shoot growth. Similar to root and shoot growth, the $100 \mathrm{mg} \cdot \mathrm{L}^{-1}$ treatment caused a significant increase in fresh weight, while the $200 \mathrm{mg} \cdot \mathrm{L}^{-1}$ and slow-release treatments caused a reduction. These results imply that the $100 \mathrm{mg} \cdot \mathrm{L}^{-1}$ Peters $20-20-20$ fertilizer treatment is the best treatment for maximum growth and development of tissue-cultured daylilies transferred to the greenhouse.

\section{Poster Session 52-Postharvest Storage}

\section{July 2005, 1:15-2:00 p.m. Poster Hall-Ballroom E/F}

\section{(47) Optimal Low Pressure Conditions for Long-term Storage of Fresh Commodities Kill Caribbean Fruit Fly Eggs and Larvae}

Thomas L. Davenport*1, Stanley P. Burg ${ }^{2}$, Thomas L. White ${ }^{1}$

${ }^{1}$ University of Florida, IFAS, Tropical Research and Education Center, Homestead, FL, 33031; ${ }^{2}$ VacuFresh Corporation, CEO, Miami, FL, 33133

U.S. regulations prevent importation of fresh horticultural commodities that have not received an approved quarantine treatment assuring $100 \%$ mortality of potentially invasive insect pests. Because imported mangoes are likely to be infested by the Caribbean fruit fly (Anastrepha suspensa Loew) and other tropical fruit flies such as A. ludens Loew, A. striata, A. distincta, A. fraterculus, A. serpentina, or A. oblique, they must be hot-water treated prior to shipment in order to satisfy quarantine requirement. Hot water treatment often damages the fruit, especially if it is not fully mature. Hypobaric (low pressure = LP) intermodal shipping containers developed by the VacuFresh ${ }^{\mathrm{SM}}$ Corp. preserve fresh commodities, such as horticulturally mature mangoes, far longer than is possible using other technologies. We tested the ability of over 70,000 Caribbean fruit fly eggs and larvae to survive a simulated optimal hypobaric condition for shipment of mangoes (15 $\mathrm{mm} \mathrm{Hg}, 98 \% \mathrm{RH}$, at the lowest, safe non-chilling temperature, $13{ }^{\circ} \mathrm{C}$ ). A. suspensa eggs or larvae were maintained on agar media, flushed with one air change per hour at the storage pressure, and shielded with Mylar to prevent radiant heat uptake and limit evaporative cooling. Nearly $98 \%$ of the eggs and larvae were killed within 1 week at 15 $\mathrm{mm} \mathrm{Hg}$ in eight replicated experiments. All eggs were killed at that pressure by 11 days, whereas a significant number survived at ambient pressure. Shipment of fresh produce using this technology promises to provide quarantine control while preserving the freshness of fully mature tropical fruits and vegetables.

(48) Prestorage Delay Effects on Soft Scald and Soggy Breakdown of 'Honeycrisp' Apples

Renae E. Moran*

University of Maine, Dept. of Plant, Soil, and Environmental Sciences, Monmouth, ME, 04259

In 2004, prestorage delays and CA storage were compared for occurrence of disorders. Fruit were harvested at a starch index of 5.9. Fruit were exposed to either a 2- or 5-day prestorage delay at $17{ }^{\circ} \mathrm{C}$; or placed immediately into cold storage (control) at $0.5^{\circ} \mathrm{C}$. An additional treatment was CA storage at $2.5^{\circ} \mathrm{C}$. In February, occurrence of soft scald, soggy breakdown, and bitter pit were measured on 40 fruit per replication. Fruit were from 'Honeycrisp'/M.26 trees planted in 1994. Treatments were replicated five times with four trees in each replication. Soft scald was very severe in this year, with $84 \%$ of control fruit being affected. Two-day prestorage delay reduced it to $48 \%$ and 5 -day delay to $21 \%$. Soggy breakdown was also severe with $14 \%$ of the fruit being affected. Two- and 5-day delays had no effect on occurrence of soggy breakdown, but CA storage increased it to $65 \%$. Bitter pit was very rare and not affected by any of the treatments. These results demonstrate that in severe cases, shorter prestorage delay is not effective in preventing soft scald or soggy breakdown.

\section{(49) Effect of Low Temperature Storage on Quality and Enzymatic Activity of Zapote Mamey Fruit (Pouteria sapota)}

Iran Alia-Tejacal ${ }^{1}$, Maria-Teresa Colinas-Leon*1, Maria-Teresa Martinez-Damian¹, Marcos Soto-Hernández ${ }^{2}$

${ }^{1}$ Universidad Autonoma del Estado de Morelos, Facultad de Ciencias Agropecuarias, Domicilio conocido, Cuernavaca, Morelos, 62210, Mexico; ${ }^{2}$ Colegio de Postgraduados, Instituto de Recursos Naturales, Domicilio Conocido, Montecillo, edo. Mexico, Texcoco, Edo. de México, 56320, Mexico

Zapote mamey is a climacteric fruit that shows an increase in the content of carotenoids and total soluble sugars and in the activity of different enzymes during maturation. In the present study, zapote mamey fruits were harvested at physiological maturity and stored for 7, 14, and 21 days at 5,10 , and $15{ }^{\circ} \mathrm{C}, 85 \%$ relative humidity (RH). At the same time, immediately after harvest a group of fruits (control) was kept and evaluated at ambient temperature $\left(20{ }^{\circ} \mathrm{C}, 50 \%\right.$ to $\left.60 \% \mathrm{RH}\right)$. The objective was to determine the effects of temperature and storage time on content of carotenoids, and total soluble sugars, as well as to evaluate the enzymatic activity of peroxidase (POD), catalase (CAT), and superoxide dismutase (SOD). Fruits stored at $5{ }^{\circ} \mathrm{C}$ for 14 and 21 days developed chilling injury, as shown by a negative effect on carotenoids and total soluble sugars content. The activities of POD, CAT and SOD were also reduced after storage at $5{ }^{\circ} \mathrm{C}$ for 21 days. Fruits stored at 10 and $15^{\circ} \mathrm{C}$ for 7,14 , and 21 days showed similar characteristics to the control fruits in carotenoids and total soluble sugars. Enzymatic activities were affected only by storage at $10{ }^{\circ} \mathrm{C}$ for 21 days. Storage at $15{ }^{\circ} \mathrm{C}$ for 21 days delayed, but did not stop maturation. Results suggest that zapote mamey fruits can be stored at $10^{\circ} \mathrm{C}$ with no negative effect on quality.

(50) Effect of Delayed MA Packaging and Packaging Film on Quality Maintenance of Fresh-cut Iceberg Lettuce

\section{Ji Gang Kim, Sun Tay Choi*, Chai Il Lim}

National Horticultural Research Institute, Postharvest Technology Division, 475 ImokDong, Jangan-Gu, Suwon, Kyeonggi, 440-706, South Korea

Modified atmosphere (MA) packaging has been used to maintain quality of fresh-cut lettuce, but $\mathrm{O}_{2}$ depletion and excessive $\mathrm{CO}_{2}$ accumulation can be injurious. This study was conducted to evaluate the effect of delayed MA packaging using three different films on quality maintenance of fresh-cut iceberg lettuce. Iceberg lettuce leaves were sliced, washed, dried, and placed for $0,5,10$, and 15 hours under air atmosphere at $5{ }^{\circ} \mathrm{C}$. Samples were packaged with 2.9 and $16.6 \mathrm{pmol} \cdot \mathrm{kg} \cdot \mathrm{Pa} \cdot \mathrm{s}$, oxygen transmission rate (OTR) films and microperforated film (P-plus), and stored for 12 days at $5{ }^{\circ} \mathrm{C}$. Results indicated that delayed packaging affected gas composition $\left(\mathrm{O}_{2}\right.$ and $\left.\mathrm{CO}_{2}\right)$, fermentative volatile production, off-odor, color, and tissue electrolyte leakage. With 2.9 OTR film, longer delayed time maintained quality by inhibiting off-odor development and the accumulation of ethanol. However, delayed packaging was not effective in maintaining quality of samples packaged with 16.6 OTR film and P-plus film. Regardless of delayed time, all 16.6 OTR-packaged samples had severe discoloration after 7 days of storage. All delayed treatments packaged with P-plus film attained the desired $\mathrm{O}_{2}(3-5 \mathrm{kPa})$ and $\mathrm{CO}_{2}$ levels $(10-12 \mathrm{kPa})$ from day 9 to the end of storage. A 15-hour delayed packaging into packages prepared 
from 2.9 OTR film and samples packaged with P-plus film maintained quality by inhibiting off-odor development. The results indicate that delayed packaging could be an alternative method when fresh-cut lettuce is packaged with low OTR films.

\section{(51) Changes in Phenolic Compounds in Sweetpotatoes during Low Temperature Storage}

\section{M.S. Padda*, D.H. Picha}

Louisiana State University, Horticulture, Baton Rouge, LA, 70803

Sweetpotatoes may be potentially high in concentration of certain phytochemical compounds, including phenolics. Low temperature stress-induced phenolic compounds may enhance the nutraceutical value of sweetpotatoes. However, extended exposure to low temperature results in chilling injury. Cured and non-cured roots of 'Beauregard' sweetpotatoes were exposed to low temperature storage $\left(5^{\circ} \mathrm{C}\right)$ for up to 4 weeks. The total phenolics and individual phenolic acid contents were determined at weekly intervals using Folin-Denis reagent and reversed-phase HPLC, respectively. Total phenolics and individual phenolic acids increased with length of low temperature exposure. Non-cured roots had a higher phenolic content than cured roots after 4 weeks. A 3-day exposure period to room temperature $\left(22^{\circ} \mathrm{C}\right)$ following removal from low temperature storage typically resulted in increased phenolics. In a comparison of different tissue locations, the highest phenolic content was found in peel tissue and the lowest in the pith tissue. The major individual phenolic acid in all root tissues was chlorogenic acid.

\section{(52) Postharvest Alleviation of Chilling Injury and Diseases of Cantaloupe Melons}

Christian Krarup*, Oscar Núñez

Universidad Católica de Chile, Ciencias Vegetales, Casilla 306, Santiago 22, Chile

Chilling injury of cantaloupe melons (Cucumis melo, Cantalupensis group), although variable among cultivars, precludes the use of temperatures close to $0{ }^{\circ} \mathrm{C}$ for long term storage or transport. Diseases, either associated with chilling or independent from it, are usually the main factor terminating postharvest life of these melons. 'Colima', a Western Shipper cultivar highly sensitive to chilling, was used to evaluate chilling and disease response to the following treatments: immersion in water at $60{ }^{\circ} \mathrm{C}$ for 1 minute (with or without $150 \mathrm{ppm}$ chlorine), individual packaging ( $\mathrm{PVC}$, whole or perforated), exposure to air at $38{ }^{\circ} \mathrm{C}$ for 12 hours (with or without individual packaging), and control. After storage for 18 days at $0{ }^{\circ} \mathrm{C}$ and a simulated retail period of 3 days at $20^{\circ} \mathrm{C}$, there were significant differences among treatments: chilling was alleviated in heat-treated and especially in plastic-wrapped fruit, and the presence of diseases caused by pathogens such as Alternaria, Cladosporium, Fusarium, and Rhizopus was markedly reduced by heat treatments. Overall, visual quality was high and superior in fruit immersed in water at $60^{\circ} \mathrm{C}$ with $150 \mathrm{ppm}$ chlorine due to almost complete supression of diseases. Project financed by FONDECYT 1020882.

\section{(53) Do Pawpaw Varieties Behave Differently during Ripening and Cold Storage?}

Federica Galli*1, Douglas D. Archbold ${ }^{1}$, Kirk W. Pomper ${ }^{2}$

${ }^{1}$ University of Kentucky, Department of Horticulture, Lexington, KY, 40546-0091; ${ }^{2}$ Kentucky State University, 129 Atwood Research Facility, Frankfort, KY, 40601

Pawpaw [Asimina triloba (L.) Dunal] is a highly perishable climacteric fruit. Generally, fruit may be stored at $4{ }^{\circ} \mathrm{C}$ for 4 weeks with minimal loss in quality or subsequent ripening capacity. However, comparisons among cultivars and advanced selections for ripening behavior and postharvest storage life have not been reported. Ideally, cultivars with superior ripening traits (higher firmness, or a slower rate of firmness loss) and longer storage life may be identified for the commercial market. To determine if differences among genotypes may exist, respiration, $\mathrm{C}_{2} \mathrm{H}_{4}$ production, and fruit firmness of six varieties, 8-20, 9-58, 'Middletown', 'PA Golden', 'Taytwo', and 'Taylor', were measured during ripening after harvest and after 1, 2, 3, 4, 5, and 6 weeks of $4{ }^{\circ} \mathrm{C}$ storage. No differences were observed among the cultivars regarding respiration and $\mathrm{C}_{2} \mathrm{H}_{4}$ production. Respiratory and ethylene peaks were detected within 48 hours after harvest or removal from cold storage. Rapid loss of firmness was measured during ripening at ambient temperature after harvest and after removal from cold storage (days 0-3), with some loss during cold storage itself (weeks 1-6). As expected, firmer fruits at harvest had a lower respiration rate. However, no obvious differences in ripening behavior or cold storage response were observed among the six genotypes. As a general guideline, only firmer fruits should be cold stored, since fruit softening did not stop at $4{ }^{\circ} \mathrm{C}$. A broader analysis of all of the named cultivars and advanced selections of pawpaw will be needed to determine if the present results are generally representative of pawpaw.

\section{Poster Session 53-Vegetable Breeding 2 \\ 21 July 2005, 1:15-2:00 p.m. Poster Hall-Ballroom E/F}

\section{(254) Molecular Characterization of Doubled Haploid and Conventional Onion Lines using AFLPs and SSRs}

Ryan Walker*1, Leonard Pike ${ }^{1}$, Monica Menz ${ }^{2}$, Kil Sun Yoo ${ }^{1}$, Sung Gil Kim ${ }^{1}$

${ }^{1}$ Texas A\&M University, Horticulture Science, College Station, TX, 77845; ${ }^{2}$ Texas A\&M University, Agronomy, College Station, TX, 77843

Onions suffer from severe inbreeding depression, which has prevented the creation of homozygous inbreds in breeding programs. The creation of doubled haploid (DH) lines in onion is an anomaly, and provides a unique opportunity to study both how these lines would perform in a breeding program and why they do not exhibit more inbreeding depression. Seven DH lines were developed at Texas A\&M University from five different short-day $F_{1}$ and $F_{2}$ populations. Five equivalent conventional inbred lines, breeding lines developed from the same parents as the DH lines, have been identified from the onion-breeding program. The DH lines, the conventional inbred lines, and their parents have been analyzed using SSR and AFLP markers. SSR markers yielded a polymorphism rate of $55 \%$ vs. $3 \%$ with the AFLPs. Analysis has shown remnant heterozygosity both in the parental lines and in the conventional inbreds and has confirmed the uniformity of the DH lines. Genetic similarity estimates have been calculated using the molecular data to determine the suitability of comparing the yield heterosis of crosses between the conventional lines and the DH lines in a diallele analysis.

\section{(255) A Comparison of Phenotypic and Marker-assisted Selection in Cucumber}

\section{Matthew D. Robbins*1, Jack E. Staub ${ }^{2}$, Zhicheng Fan ${ }^{1}$}

${ }^{1}$ University of Wisconsin-Madison, Department of Horticulture, Madison, WI, 53706; ${ }^{2}$ University of Wisconsin-Madison, USDA/ARS, Vegetable Crops Unit, Madison, WI, 53706

To increase yield in cucumber (Cucumus sativus L.), we designed a recurrent selection program utilizing phenotypic (PHE) and marker-assisted (MAS) selection for the development of multiple lateral branching (MLB; branches per plant), gynoecious, early genotypes possessing high fruit length to diameter ratio (L:D). These yield components are under genetic control of few quantitative trait loci (QTL; 2-6 per trait), which have been placed on a moderately saturated molecular linkage map. Four inbred lines, complementary for the target traits, were intermated and the resulting population underwent MAS and PHE, as well as random mating (RAN), for three cycles. Selections by PHE were visually made for all four traits at the whole plant level. Selections based on MAS contained the highest number of desired marker genotypes from 20 marker loci (SSR, RAPD, SCAR, SNP). Using the same selection scheme and intensity allowed a direct comparison of MAS to PHE. Selection was equally effective for MLB and L:D by MAS (3.5 and 3.0) and PHE (3.6 and 3.0), which were both superior to RAN (2.8 and 2.8). For earliness (days to anthesis) and gynoecy (percent female), MAS (41.8 and 26.6) was less effective than PHE (40.5 and 81.8) and RAN (41.0 and 80.9), which were equal. For yield (fruit per plant), RAN (1.90) and MAS (1.88) were equal, but less than PHE (2.15). After three cycles of PHE, further selection by 
MAS identified superior genotypes, which were intermated. Superior hybrids were selected by MAS and underwent one backcross generation. In some backcrosses, gains were made in every trait compared to the PHE Cycle 3 mean, while in other backcrosses, gains were made only in some traits. Improvement by MAS was very effective during line extraction for these yield components.

\section{(256) Evaluation of 25 Varieties of Race 3 Bacterial Spot Resistant Bell Peppers}

Russell T. Nagata*1, Kenneth L. Pernezny ${ }^{1}$, Darrin M. Parmenter ${ }^{2}$, Eugene McAvoy ${ }^{3}$, Kent E. Cushman ${ }^{4}$

${ }^{1}$ University of Florida, Everglades Research and Education Center, Belle Glade, FL33430; ${ }^{2}$ University of Florida, Palm Beach County Extension, West Palm Beach, FL33415; ${ }^{3}$ University of Florida, Henery County Extension, Labelle, FL 33975; ${ }^{4}$ University of Florida, Southwest Florida Research and Education Center, Immokalee, FL 34142

Twenty-five varieties of bell peppers (Capsicum annuum) were transplanted in commercial pepper fields in Immokalee and Delray Beach, Fla., to evaluate horticultural characteristics and resistance to race 3 bacterial spot of peppers caused by Xanthomonas campestris pv. vesicatoria. All cultural and management procedures were based on commercial best management practices. Eighty to $90 \%$ of marketable fruits had three or four lobes. Total marketable fruit yield from three harvests ranged from 4596 to $7089 \mathrm{~kg} \cdot \mathrm{ha}^{-1}$ and marketable fruit number ranged from 20,571 to 31,224 fruit/ha. Most fruit were slightly elongated with length to diameter ratios between 1.1 and 1.2. Seminis 7602 had a ratio of one, while lines ACR 252, PRO2R-3, and PR99R-16 had ratios of $1.40,1.36$, and 1.28, respectively. Significant differences were observed for fruit wall thickness, with those grown in Delray Beach having thicker fruit walls that averaged $7.5 \mathrm{~mm}$ vs. 5.3 $\mathrm{mm}$ for the Immokalee site. Bacterial spot infection at both sites did not affect yield, due to late natural infection of the field. Susceptible control 'Jupiter' had a mean foliage disease incident rating of $26 \%$ after the final harvest and was surpassed only by 7682 and 8328 from Enza. The most resistant lines with disease ratings of $<3 \%$ were 5776 , 7141, and 8302 from Seminis, and Telstar from Hazera.

\section{(257) Pepino Mosaic Virus: Variability in U.S. Isolates}

Clarissa J. Maroon-Lango ${ }^{1}$, Mary Ann Guaragna ${ }^{1}$, Ramon Jordan ${ }^{1}$, John Hammond ${ }^{1}$, Murali Bandla ${ }^{2}$, Steve Marquardt ${ }^{2}$, John R. Stom$\mathrm{mel}^{* 3}$

${ }^{1}$ USDA, ARS, Floral and Nursery Plant Research Unit, Beltsville, MD, 20705; ${ }^{2}$ Agdia, Inc., Elkhart, IN; ${ }^{3}$ USDA, ARS, Vegetable Laboratory, Beltsville, MD, 20705

Pepino mosaic virus (PepMV) was first found in pepino (Solanum muricatum) growing in coastal Peru in 1974 and described in 1980; it reappeared in protected tomato (Lycopersicon esculentum) in the Netherlands in 1999. Since then, it has been reported to occur in tomato in several countries including Austria, Belgium, Canada, France, Germany, Italy, Peru, Spain and the Canary Islands, the United Kingdom, and in 11 states within the United States. Three strains of PepMV found in the United States have been cloned and sequenced. Full-length genomic sequences were obtained for two strains, PepMVUS1 and PepMV-US2, from co-infected tomato plant samples from Arizona. The 3'-end sequence of PepMV-US3 came from infected tomato fruits from Maryland. The genome organization, motifs and domains typical of the genus Potexvirus, and of other PepMV isolates, were found in full-length sequences of both US1 and US2 isolates. Direct comparison of US1 and US2 at the nucleotide level revealed an $86.3 \%$ identity; whereas, when individually compared to the French and Spanish isolates, which share $\sim 99 \%$ identity at the nucleotide level, US1 and US2 had 82\% and 79\% identities to each, respectively. Pairwise gene-for-gene comparisons between United States and European isolates revealed a similar trend. While unique, US1 is more closely related to the previously reported European isolates than is US2. The CP of US3 is nearly identical to the European isolates at the amino acid level. None of 18 tomato germplasm accessions or 10 cultivars were resistant to mechanical inoculation with US3; in contrast, no infection was detected in nine pepper cultivars or four germplasm accessions. Plants grown from seeds of infected tomato fruits did not test positive for PepMV.
(258) Differential Response of Colored Carrots to Cavity Spot

Mary Ruth McDonald*1, Kevin Vander Kooi², Philipp Simon ${ }^{3}$

${ }^{1}$ University of Guelph, Plant Agriculture, Crop Science Bldg., Guelph, Ontario, N1G 2W1, Canada $;{ }^{2}$ University of Guelph, Plant Agriculture, Kettleby, Ontario; ${ }^{3}$ USDA, ARS, Vegetable Research Unit, Department of Horticulture, Madison, WI, 53706

Cavity spot of carrot, caused by several species of Pythium, is endemic in many carrot production areas of the world, including the Holland/ Bradford Marsh region of Ontario, Canada. Field trials were conducted from 2002-04 to determine if carrots with different pigments varied in susceptibility to the disease. Carrots from the USDA breeding program at the University of Wisconsin were seeded in muck soil ( $\mathrm{pH} 6.4,60 \%$ organic matter) on 28, 30, and 27 May, harvested 22, 22, and 23 Oct., and assessed for disease on 5, 8, and 10 Dec. 2002, 2003, and 2004, respectively. The carrots were white (W 105-7), yellow (W 102-1), dark orange (W 101-23), red (W 104-3), and purple (W 106-3). Cultivar 'Cellobunch' was included in 2003 and 2004. Twenty-five carrots of each of four replicate plots were assessed in 2002 and 2003, and 50 carrots were assessed in 2004, for disease incidence and severity [disease severity index (DSI), based on the size of the largest lesion per carrot]. Disease incidence was moderate in 2002 and 2003 (34\%, $33 \%$ ), and high in 2004 (60\%). Consistent differences in susceptibility to cavity spot were identified over the three years of trials. The purple carrot had the lowest incidence (12\%) and severity (7 DSI) of cavity spot, followed by the dark orange carrot $(39 \%, 22 \mathrm{DSI})$ as compared to the susceptible yellow carrot $(58 \%, 41 \mathrm{DSI})$. There was no difference in disease reaction between the yellow and white carrots. 'Cellobunch' had the same reaction as the dark orange carrot. Studies are needed to determine whether the pigments themselves cause differences in the disease response.

\section{(259) A Genetic Linkage Map and a cDNA Library for Watermelon}

Amnon Levi ${ }^{1}$, C.E. Thomas ${ }^{1}$, Angela Davis ${ }^{2}$, O.U.K. Reddy ${ }^{3}$, Y. Xu ${ }^{4}$, X. Zhang ${ }^{5}$, A. Hernandez 6 , G. Gusmini ${ }^{7}$, Todd C. Wehner*7, J. King ${ }^{8}$, S.R. King

${ }^{1}$ USDA, ARS, U.S. Vegetable Laboratory, Charleston, SC, 29414; ${ }^{2}$ USDA, ARS, South Central Agricultural Research Laboratory, Lane, OK, $74555 ;{ }^{3}$ West Virginia State University, Department of Biology, Institute, WV, $25112 ;{ }^{4}$ China National Engineering Research (NERCV), Center for Vegetables, Beijing, 100089, China; ${ }^{5}$ Syngenta Seeds, Inc., 21435 Road 98, Woodland, CA 95695; ${ }^{6}$ University of Illinois at Urbana-Champaign, Biotechnology Center-W.M. Keck Center for Comparative and Functional Genomics, Urbana, IL $61801 ;{ }^{7}$ North Carolina State University, Department of Horticultural Science, Raleigh, NC 27695; ${ }^{8}$ Seminis Vegetable Seeds, Inc., Woodland, CA 95695; ${ }^{9}$ Texas A\&M University, Department of Horticultural Sciences, College Station, TX 77843

A genetic linkage map was constructed for watermelon based on a testcross population and an $\mathrm{F}_{2}$ population. The testcross map includes 312 markers (RAPD, ISSR, AFLP, SSR, and ASRP). This map covered a genetic distance of $1385 \mathrm{cM}$, and identified 11 large (50.7-155.2 $\mathrm{cm})$, five intermediate $(37.5-46.2 \mathrm{~cm})$, and 16 small linkage groups (4.2-31.4 cm). Most AFLP markers are clustered in two linkage regions, while all other markers are randomly dispersed throughout the genome. Many of the markers in this study were skewed from the classical (Mendelian) segregation ratio of 1:1 in the testcross or 3:1 in the $\mathrm{F}_{2}$ population. The order of the markers within linkage groups was similar in the testcross and $\mathrm{F}_{2}$ populations. Additionally, a cDNA library was constructed using RNA isolated from watermelon flesh 1 week (rapid cell division stage), 2 weeks (cell growth and storage deposition stage), 4 weeks (maturation stage), and 5 weeks (mature fruit) after pollination. More than $1020 \mathrm{cDNA}$ clones were sequenced, and analyzed using the basic local alignment search Tool (BLAST). The sequenced cDNA clones were designated as expressed sequenced $\operatorname{tag}$ (EST). The ESTs were searched for simple sequence repeats. About $7 \%$ of the ESTs contained SSR motifs. The ESTs containing SSRs are being used to design PCR primers and the putative markers are being tested for polymorphism among the parental lines of the mapping populations. Polymorphic markers will then be mapped using the mapping populations. 
(260) Development of SCAR and CAPS Markers Linked to Tomato Begomovirus Resistance Genes Introgressed from Lycopersicon chilense

Yuanfu Ji, John W. Scott*

University of Florida, Gulf Coast Research \& Education Center, Wimauma, FL, 33598

Resistance to begomoviruses tomato mottle virus (ToMoV) and tomato yellow leaf curl virus (TYLCV) has been introgressed to tomato ( $\mathrm{Lyco}$ persicon esculentum) from $L$. chilense accessions LA 1932, LA 2779, and LA 1938. Resistance genes have been mapped to three regions on chromosome 6 using randomly amplified polymorphic DNA (RAPD) markers. We call these regions 1,2 , and 3 . To facilitate breeding by marker assisted selection, advanced breeding lines with resistance from the above sources were assayed for the presence of RAPD markers to determine which were most tightly linked to begomovirus resistance. The best RAPD markers were then converted to sequence characterized amplified region (SCAR) markers or cleaved amplified polymorphic sequence (CAPS) markers. In addition, selected restriction fragment length polymorphism (RFLP) markers near the three regions were converted into CAPS markers, which were tested for association with the advanced breeding lines. Only LA 2779 derivatives have the $L$. chilense introgression in region 1 , which is near the location of the $T y-1$ gene and spans across CAPS markers 32.5Cla and TG118. Two region 1 RAPD markers UBC197 and UBC621 were converted co-dominant SCAR or CAPS markers, which were present in all 16 resistant breeding lines tested. Derivatives from all three accessions have introgressions in region 2. Further assays with more markers in this region are under way to determine the lengths and locations of the introgressions. No tightly linked RAPD markers have been found for the resistance gene from LA 1932 in region 3. RFLP and CAPS markers are being used to more precisely locate the region 3 gene.

\section{(261) A PCR-based Linkage Map of Broccoli [Brassica oleracea (L.) var. italica] and Comparisons with Existing Brassica Maps}

Allan Brown'1, Khalid Ibrahim*1, Sultana Islam², Elizabeth Jeffery³, John Juvik ${ }^{4}$

${ }^{1}$ University of Illinois, Department of Natural Resources and Environmental Sciences, Urbana, IL, 61801; ${ }^{2}$ Department of Crop Science; ${ }^{3}$ Department of Food Science and Human Nutrition; ${ }^{4}$ Department of Natural Resources and Environmental Sciences

A set of 216 PCR-based molecular markers was screened for polymorphisms using two morphologically dissimilar broccoli lines, 'VI-158' and 'BNC'. Fifty-nine of these markers, representing 69 detected polymorphisms and two morphological markers, were used to construct a genetic linkage map of broccoli [Brassica oleracea (L.) var. italica] from a population of $162 \mathrm{~F}_{2.3}$ families generated from the cross between these two lines. Ten genetic linkage groups were generated that spanned a distance of $468 \mathrm{cM}$ with an average interval width of $9.4 \mathrm{~cm}$. This map represents the first combined SSR and SRAP map of Brassica oleracea. Comparisons are made to existing maps of Brassica napus and to inter-specific maps of Brassica oleracea. To our knowledge this is the first linkage map of broccoli [Brassica oleracea (L.) var. italica] and should provide a useful tool for the genetic analysis of traits specific to the italica subspecies.

\section{Poster Session 54-Produce Quality, Safety, and Health}

\section{July 2005, 1:15-2:00 p.m. Poster Hall-Ballroom E/F}

\section{(464) Antioxidant Activity in Lingonberries (Vaccinium vitis-idaea $\mathrm{L}$.)}

Shiow Wang*1, Ross Penhallegon ${ }^{2}$

${ }^{1}$ U.S. Department of Agriculture, Fruit Laboratory, BARC-W, Beltsville, MD, 20705 ${ }^{2}$ Oregon State University, Lane County Extension

Lingonberries have been shown to contain high antioxidant activity. Fruit from different cultivars of lingonberry (Vaccinium vitis-idaea $\mathrm{L}$ ) were evaluated for fruit quality, antioxidant activity, anthocyanin and phenolic contents. The fruit soluble solids content (SSC), titratable acids (TA), antioxidant capacity, anthocyanin and phenolic contents varied with cultivars. The SSC ranged from $12.9 \%$ to $16.9 \%$, the TA ranged from $0.31 \%$ to $0.41 \%$ and the ratios of SSC/TA ranged from 35.37 to 51.21. Lingonberries contain potent free radical scavenging activities for $\mathrm{DPPH}, \mathrm{ROO}, \mathrm{OH}$ and $\mathrm{O}_{2}{ }^{-}$radicals. The oxygen radical absorbance capacity (ORAC) values from acetone extraction of lingonberries ranged from 58.5-223.6 $\mu \mathrm{mol}$ of Trolox equivalents (TE) $/ \mathrm{g}$ fresh berries. The ED50 values for DPPH-radical scavenging ranged from $5.91-11.77 \mathrm{mg}$ fresh weight. The DPPH-radical scavenging activity correlated with ORAC values with a $R^{2}$ of 0.8009 . ESR spectrum showed that $50 \mathrm{mg} \cdot \mathrm{mL}^{-1}$ of lingonberry extract decreased $\mathrm{OH}$ radicals by $83 \%$ and $\mathrm{O}_{2}-$ radicals by $99 \%$. Cyanidin 3 -galactoside was the most dominant anthocyanin and contributed the most antioxidant activity in lingonberries. The antioxidant properties of lingonberries may play an important role in protecting cells against the oxidative damage caused by free radicals.

\section{(465) Inhibitory Effect of Lingonberry (Vaccinium vitis-idaea L.) Extracts on Activator Protein-1, Nuclear} Factor-KappaB, and Mitogen-activated Protein Kinases

Shiow Wang*1, Ren-tian Feng ${ }^{2}$, Linda Bowman², Ross Penhallegon ${ }^{3}$, Min Ding ${ }^{2}$

${ }^{1}$ U.S. Department of Agriculture, Fruit Laboratory, BARC-W,Beltsville, MD, 20705; ${ }^{2}$ Center for Disease Control and Prevention, Pathology and Physiology Research Branch; ${ }^{3}$ Oregon State University, Lane County Extension

The effects of lingonberry (Vaccinium vitis-idaea L.) extracts on activator protein-1 (AP-1), nuclear factor-kappaB (NF-кB), and mitogen-activated protein kinases (MAPKs) were evaluated. Pretreatment of JB6 $\mathrm{P}^{+}$mouse epidermal cells with lingonberry extracts produced a dose-dependent inhibition of AP-1 and NF- $\kappa \mathrm{B}$ induced by either 12-O-tetradecanoylphorbol-13-acetate (TPA) or ultraviolet-B (UVB) light. Lingonberry extracts blocked UVB-induced phosphorylation of MAPK family members ERK1, ERK2, and p38, but not JNK. Lingonberry extracts also prevented TPA-induced phosphorylation of ERK1 and ERK2. Results of soft agar assays indicated that lingonberry extracts suppressed TPA-induced neoplastic transformation of JB6 $\mathrm{P}^{+}$ cells in a dose-dependent manner. Lingonberry extracts also induced the apoptosis of human leukemia HL-60 cells in a dose-independent manner. These results suggest that ERK1 and ERK2 may be inhibited by lingonberries, which results in suppression of AP-1 and neoplastic transformation in JB6 $\mathrm{P}^{+}$cells and causes cancer cell death by an apoptotic mechanism in human leukemia HL-60 cells.

\section{(466) Comparison of Autumnberry and Cornelian Cherry Antioxidant Potential with that of Well-known Fruit Crops}

Mustafa Ozgen*1, Artemio Z. Tulio, Jr. ${ }^{2}$, Aparna Gazula ${ }^{2}$, Joseph C. Scheerens ${ }^{2}$, R. Neil Reese ${ }^{3}$, A. Raymond Miller' ${ }^{2}$, Shawn R. Wright ${ }^{4}$, Brent L. Black ${ }^{5}$, Ingrid M. Fordham ${ }^{5}$

${ }^{1}$ GOP Univ, Horticulture, Tasliciftlik, Tokat, 60240, Turkey; ${ }^{2}$ The Ohio State Univ., OARDC, Horticulture and Crop Science, Wooster, OH, 44691; ${ }^{3}$ South Dakota State Univ., Biology/Microbiology, Brookings, SD, 57007; ${ }^{4}$ The Ohio State Univ., OARDC South Centers, Piketon, OH, 45661; ${ }^{5}$ USDA-ARS Henry A. Wallace Beltsville Agr. Res. Cnter., Fruit Laboratory, Beltsville, MD, 20705

Autumnberry (Elaeagnus umbellata, "A") and cornelian cherry (Cornus mas, "CC") genotypes were examined for mineral composition, anthocyanin, phenolic and tannin contents, antioxidant characteristics and levels of individual phenolic compounds via GC-MS. Values were compared with those of 58 cultivars of blackberries ("B"), black raspberries ("BR"), cranberries ("C"), elderberries ("E"), grapes ("G"), red raspberries ("RR") and strawberries ("S"). The phenolic content of "CC" $\left(6955 \mu \mathrm{g} \cdot \mathrm{gfw}^{-1}\right)$ was greater than $2 \times$ that of "B", "BR" and "E". Phenolic contents of "A" samples (1058-1776 $\left.\mu \mathrm{g} \cdot \mathrm{gfw}^{-1}\right)$ were similar to those of "RR", red "G" and "S". Anthocyanin levels in "CC" $\left(270 \mu \mathrm{g} \cdot \mathrm{gfw}^{-1}\right)$ resembled those in "C". "A" did not contain anthocyanins. Fruit of "CC" and "A" possessed high tannin levels (9291 $\mu \mathrm{g} \cdot \mathrm{gfw}^{-1}$ and $1410-5403 \mu \mathrm{g} \cdot \mathrm{gfw}^{-1}$, respectively) and exhibited high antioxidant potential ( $\mu \mathrm{mol} \cdot \mathrm{gfw}^{-1}$ trolox equiv.). DPPH and FRAP values of "CC" (72.1 and 94.9, respectively) were greater than $2 \times$ those of "BR". DPPH values of "A" (23.9-56.2) were $\geq$ values for "BR", whereas "A" FRAP values (13.3-34.0) were similar to those 
of "B" and "RR". However, the lipid-soluble antioxidant potential of lycopene-rich "A" was substantial. Levels of individual compounds varied among cultivars. $\mathrm{Ca}$ and $\mathrm{Mg}$ contents of " $\mathrm{A}$ " were less than those found in "CC" and "BR". Other mineral levels were comparable.

\section{(467) Anthocyanins as Primary Antioxidants in Black Raspberries}

Artemio Z. Tulio, Jr.*1, Mustafa Ozgen², R. Neil Reese ${ }^{3}$,

Steven J. Schwartz ${ }^{4}$, Qingguo Tian ${ }^{4}$, Gary D. Stoner ${ }^{5}$,

A. Raymond Miller ${ }^{1}$, Joseph C. Scheerens ${ }^{1}$

${ }^{1}$ The Ohio State Univ., OARDC, Horticulture and Crop Science,Wooster, OH, 44691; ${ }^{2}$ GOP Univ., Horticulture, Tasliciftlik, Tokat, 60240. Turkey; ${ }^{3}$ South Dakota State Univ., Biology and Microbiology, Brookings, SD, 57007; ${ }^{4}$ Ohio State Univ., Food Science and Technology, Columbus, OH, 43210; 5Ohio State Univ., Div. Hematology and Oncology, Col. Medicine, James Cancer Hosp. and Res. Inst., Columbus, OH, 43210

Anthocyanins in black raspberry extracts may play a key role in the regulation of oncogene expression in cancer cell cultures. Variations in anthocyanin levels of 'Jewel', 'Mac Black', and 'Bristol' black raspberries grown at seven commercial farms in Ohio were investigated using HPLC and uv-vis spectrometry. Cyanidin-3-rutinoside (cy-3-rut) and cyanidin-3-(2G-xylorutinoside) (cy-3-2-xyl), the two major compounds present in all cultivars $(\approx 2: 1)$, were highly correlated with total anthocyanin contents. Sample variation in total anthocyanin, cy-3-rut, and cy-3-2-xyl levels was greater among commercial farms than among cultivars grown at the same location. The antioxidant activities of cy-3-rut, cyanidin-3-glucoside, cyanidin3,5-diglucoside (cy-3,5-diglc), and pelargonidin-3-glucoside from purified extracts were determined using the free radical scavenging assays DPPH and ABTS, and the ferric reducing power assay FRAP. All pure anthocyanins showed strong antioxidant potentials except for cy-3,5-diglc. Cy-3-rut was identified and quantified as the dominant anthocyanin in black raspberries and was also the most potent antioxidant. Results suggest that anthocyanins, cy-3-rut in particular, may function as the primary antioxidants in black raspberries. Genetic and environmental variation in the anthocyanin contents necessitate characterization of the antioxidant and anthocyanin levels in fruits from any given source prior to measuring biological and medicinal activities.

\section{(468) Comparison of Methods to Determine Antioxidant Levels in Fruit}

Mustafa Ozgen*1, Artemio Z. Tulio, Jr. ${ }^{2}$, A. Raymond Miller ${ }^{2}$, R. Neil Reese ${ }^{3}$, Joseph C. Scheerens ${ }^{2}$

${ }^{1}$ GOP Univ., Horticulture, Tasliciftlik, Tokat, 60240, Turkey; ${ }^{2}$ The Ohio State Univ., OARDC, Horticulture and Crop Science, Wooster, OH, 44691; ${ }^{3}$ South Dakota State Univ., Biology and Microbiology, Brookings, SD, 57007

In preliminary studies, we found that relative and absolute antioxidant (AO) levels varied within and among small fruit types. AO levels were affected by assay method used, time of reaction, volume of sample, and the ratio of reactants to total AO activity. To identify the physicochemical parameters that affect accuracy and reproducibility, a series of experiments were conducted to test the roles of AO assay, different $\mathrm{AOs}$, and $\mathrm{AO}$ concentration on measured $\mathrm{AO}$ content and reaction kinetics. Three assays (DPPH, FRAP, ABTS) were used to evaluate AO capacity of seven fruit types (black and red raspberry, blackberry, strawberry, grape, elderberry, and cranberry) and nine purified AOs (ascorbic, caffeic, chlorogenic, gallic, and ellagic acids, $\alpha$-tocopherol, trolox, cyanidin-3-glucoside, and quercetin). Ascorbic acid, trolox, caffeic acid, chlorogenic acid, and $\alpha$-tocopherol exhibited simple reaction kinetics and reached endpoints quickly, regardless of assay. Gallic and ellagic acids, quercetin, cyanidin-3glucoside, and all fruit extracts exhibited more complex kinetics and long reaction times $(>70 \mathrm{~min})$ to reach an endpoint. Moreover, the latter four AOs had the highest AO capacity among the compounds tested. We observed differences in reactivity between assays, compounds and fruit extracts, but relative AO activity was comparable, although the absolute values differed. Since AO capacity of fruit extracts is a composite of the individual AOs present, it is important that reactions progress to near steady state, assay reactants are in excess of $(30-50 \times)$ the AO capacity being measured, more than one assay is used to describe the total AO activity of fruit samples. Thus, there may not be a single AO assay method that completely defines the $\mathrm{AO}$ activity of a given fruit.

\section{(469) Replacing Cantaloupe with Orange-fleshed Honeydew Melon: Antioxidant Metabolism}

D. Mark Hodges*1, Gene E. Lester ${ }^{2}$, Robert D. Meyer ${ }^{2}$, Vivian E. Willmets ${ }^{1}$, Michele L. Elliot ${ }^{1}$

${ }^{1}$ Agriculture and Agri-Food Canada, Atlantic Food and Horticulture Research Centre, Kentville, Nova Scotia, B4N 1J5, Canada; ${ }^{2}$ USDA-ARS, Kika de la Garza Subtropical Agricultural Research Center, Weslaco, TX, 78596

Consumption of phytochemicals has been associated with reduced risks of human health dysfunctions such as cancers and heart disease. Such information has led to increased sales of fruits and vegetables. For example, in the United States, an estimated 23\% increase in melon consumption (up to $13.2 \mathrm{lbs} /$ capita/annum) has been recorded over 16 years. However, some health issues have been attributed to cantaloupe due to bacteria such as Salmonella attaching to inaccessible sites, such as the rind netting. Honeydew melons do not have a netted rind. The purpose of this study was to compare concentrations of antioxidants between cantaloupe and both green- and orange-fleshed honeydew melons during 14 days of storage to determine if orangefleshed honeydew melon would represent a feasible alterative to cantaloupe to the increasingly health/food safety-conscious consumer. Cantaloupe ('Cruiser'; C), green-fleshed Honeydew ('HoneyBrew'; $\mathrm{HB}$ ), and orange-fleshed Honeydew ('OrangeDew'; OD) melons were harvested in Texas at the beginning and at the end of the production season. $\beta$-carotene content was highest in OD, followed by $\mathrm{C}$; no $\beta$-carotene was detected in HB. $\beta$-carotene levels did not change during storage. Phenolic levels increased in all three melon species during storage, whereas total ascorbate content declined in OD and in early harvest HB. Ascorbate peroxidase activities were lowest in OD, perhaps due to the lower ascorbate levels; little difference between the melon species in activities of the other ascorbate-associated enzymes were observed. Based on the phytochemicals measured in this study, choosing non-netted OD over netted $\mathrm{C}$ in order to reduce potential exposure to pathogens would not represent a less healthy food choice.

\section{(470) Lycopene Content of Mini Watermelon Varieties Grown at Four Locations}

Penelope Perkins-Veazie*1, Julie Collins ${ }^{1}$, Richard Hassell ${ }^{2}$, Steve Olson ${ }^{3}$, Donald Maynard ${ }^{4}$, Jonathan Schultheis ${ }^{5}$, Missy O'Hern ${ }^{6}$, Toni Magby ${ }^{6}$, Shelli Magby ${ }^{6}$

${ }^{1}$ USDA-ARS, SCARL, Hwy. 3 West, Lane, OK, 74555; ${ }^{2}$ Clemson University, Horticulture, Charleston, SC, $29414 ;{ }^{3}$ University of Florida, Research Center, Quincy, FL, 32351; ${ }^{4}$ University of Florida, Horticulture; ${ }^{5}$ North Carolina State University, Horticulture; ${ }^{6}$ Southeastern Oklahoma State University, Biological Sciences

Mini watermelons are the size of cantaloupes and weigh 1.5 to $3 \mathrm{~kg}$ (4 to $8 \mathrm{lbs}$ ). Melons of 18 selections were grown in replicated trials in North Carolina, South Carolina, and north and south Florida. Melons were harvested when ripe, and samples of heart and locule tissue were frozen and sent to Lane, Okla. A total of 960 samples, representing 612 melons per selection per location, were analyzed for total lycopene content using colorimeter and spectrophotometer methods. Subsamples of 'Mohican', 'Hazera 6007', 'Vanessa', 'Petite Treat', and 'Precious Petite' were analyzed by HPLC for carotenoid profiles. Total lycopene content ranged from 52 to $108 \mu \mathrm{g} \cdot \mathrm{g}^{-1}$, depending on variety. Selections were grouped into two levels of lycopene content. The varieties Precious Petite, Petite Perfection, Betsy, Bonny, Petite Treat, Valdoria, Vanessa, Hazera 5133 and 5138, RWT 8149, 8155, 8162 had 60 to $79 \mu \mathrm{g} \cdot \mathrm{g}^{-1}$ lycopene and the varieties Hazera 6007, 5123, 5109, 5177, Mohican, and Extazy had 80 to $100 \mu \mathrm{g} \cdot \mathrm{g}^{-1}$. Melons harvested from the Florida locations had more total lycopene than those from North and South Carolina. 'Precious Petite' had more $\beta$-carotene as a percentage of total carotenoids than other varieties tested. These results indicate that lycopene content is affected primarily by germplasm and also by environment. 


\section{(471) Application of Mustard and Hop Extract Agents Mixed with Sucrose Fatty Acid Esters as a Food Preservative for Fresh-cut Vegetables}

Daisuke Hamanaka*, Takashi Watakabe, Kazuyuki Kitano, Hidemi Izumi

Kinki University, School of Biology-Oriented Science and Technology, Uchita, Wakayama, 6496493, Japan

Cabbage shreds and cucumber slices were dipped in water or solutions of mustard extract agent (WASAOURO ${ }^{\circledR}$, Mitsubishi-Kagaku Foods Corp.) and hop extract agent (HOPREX ${ }^{\circledR}$, Mitsubishi-Kagaku Foods Corp.) with or without sucrose fatty acid esters (SE; Mitsubishi-Kagaku Foods Corp.) and stored in MA packaging at $10{ }^{\circ} \mathrm{C}$. With cabbage shreds, treatment with mustard extract agent reduced the depletion of $\mathrm{O}_{2}$ and accumulation of $\mathrm{CO}_{2}$ and ethylene in MA packaging and the reduction was greater when mixed with SE. Treatment with the combination of mustard and hop extract agents with SE also had suppressing effects on respiration and ethylene production of cabbage shreds throughout the MA storage period. Counts of mesophilic aerobic bacteria and coliforms were 0.3 to $0.7 \operatorname{logs}$ lower in cabbage shreds treated with mustard extract agent with or without SE than with the water-dipped control for the first 2 days of storage at $10^{\circ} \mathrm{C}$. However, mustard extract agent stimulated the growth of lactic acid bacteria. When hop extract agent was combined with mustard extract agent with $\mathrm{SE}$, counts of mesophilic aerobic bacteria, coliforms, and lactic acid bacteria on treated cabbage shreds were reduced by $0.8,1.6$, and 2.6 $\operatorname{logs}$, respectively, relative to control samples after 5 days of storage. Cucumber slices treated with mustard extract agent with or without SE accelerated respiration and ethylene production and did not retard any bacterial growth during MA storage at $10{ }^{\circ} \mathrm{C}$.

\section{(472) Yeast Expressed Tomato $\beta$-Galactosidases 1, 4, and 5 Have Activity against Synthetic and Plant-derived Cell Wall Substrates}

\section{Megumi Ishimaru*1, David L. Smith ${ }^{2}$, Kenneth C. Gross ${ }^{2}$}

${ }^{1}$ Osaka Prefecture University, Graduate School of Life and Environmental Sciences, Gakuen-cho, 1-1, Sakai, Osaka, 599-8531, Japan; ${ }^{2}$ USDA-ARS, Produce Quality and Safety Lab., Beltsville, MD, 20705

Fruit softening occurs by several mechanisms, including modifications of cell wall structure by wall degrading enzymes. The most prominent change in tomato fruit pericarp wall composition is the loss of galactosyl residues throughout development and especially during ripening. In order to understand the role of galactosyl turnover in fruit softening, we successfully produced three recombinant tomato $\beta$-galactosidase/exo-galactanase (TBG) fusion proteins in yeast. TBG1, 4 and 5 enzyme properties and substrate specificities were assessed. Optimum pH of TBG1, 4 and 5 was 5.0, 4.0, and 4.5 and optimum temperature was $40 \sim 50,40$, and $40{ }^{\circ} \mathrm{C}$, respectively. The $K \mathrm{~ms}$ for TBG1, 4 and 5 were 7.99, 0.09, and $2.42 \mathrm{~mm}$, respectively, using $p$ nitrophenyl- $\beta$-D-galactopyranoside as substrate. Using synthetic and plant-derived substrates, TBG1 and 5 released galactosyl residues from $1 \rightarrow 4$ linkages. TBG4 released galactosyl residues from a wide range of plant-derived oligosaccharides and polysaccharides. Using tomato fruit cell wall material, TBG1, TBG4 and TBG5 released galactosyl residues from a variety of fruit stages and cell wall fractions. TBG4 released the most galactosyl residues from the ASP fraction and especially the ASP fraction from fruit at the turning stage. Interestingly, even though walls from Turning fruit stage contain less total galactosyl residues than at the Mature Green stage, TBG4 released 3-4 fold more galactose from the CSP and ASP fractions from Turning fruit. These results suggest that changes in structure of wall pectic polysaccharides leading up to the Turning stage may cause the wall to become more susceptible to hydrolysis by the TBG4 product.

\section{(473) Influences of Fertilizer Source and Insecticide Application on Phenolic Compounds in Pac Choi (Brassica rapa L.)}

Xin Zhao*1, Edward Carey ${ }^{2}$, James Nechols ${ }^{3}$, Kim Williams ${ }^{1}$, Weiqun $\mathrm{Wang}^{4}$

${ }^{1}$ Kansas State University, Horticulture, Forestry and Recreation Resources, Manhattan, KS, 66506-5506; ${ }^{2}$ Kansas State University, Horticulture, Forestry and Recreation Resources, Olathe, KS, $66061{ }^{3}$ Kansas State University, Entomology, Manhattan, KS, 66506-4027; ${ }^{4}$ Kansas State University, Human Nutrition, Manhatttan, KS, 66506-1407

Implications of dietary phenolic compounds for human health and disease prevention have been indicated by a body of literature. A greenhouse pot study was performed to investigate the impacts of fertilizer source and preventive insecticide application on phenolic compound levels in pac choi [Brassica rapa (L.) cv. Mei Qing]. A two-way randomized complete-block design with five replications was used in this experiment. Fertilizer source consisted of two levels: conventional fertilizer (pre-plant application of Osmocote slow-release fertilizer), and organic fertilizer (pre-plant application of vermicompost and fertigation with compost tea and fish emulsion). Insecticide application consisted of three levels: organic (pyrethrin) vs. conventional (permethrin), and a plain water control. At harvest, total phenolics and individual phenolic compounds in pac choi leaves (blades) were analyzed by Folin assay and HPLC, respectively. Head weight of pac choi was significantly higher under conventional fertilizer treatment, while it was not affected by insecticides. Total phenolic content of pac choi was significantly increased by organic fertilizer treatment. HPLC results indicated that organic fertilizer treatment resulted in significantly higher levels of individual phenolic compounds, including chlorogenic acid and ferulic acid. In contrast, preventive insecticide application showed little effect on the phenolics in pac choi. Correlation analysis excluded the influence of plant size (head weight) on phenolic content in pac choi. Differential N-forms, rates of nutrient release, and/or variable nutrient content in organic and conventional fertilizer treatments may contribute to elevated phenolic content in organically fertilized pac choi.

\section{(474) A Selected Yeast for Control of Aspergillus flavus in Pistachio Orchards}

Dan E. Parfitt*1, Siov B. Ly², Ali A. Almehdi' ${ }^{1}$, Helen Chan, Sui-Sheng T. Hua ${ }^{2}$

${ }^{1}$ University of California, Davis, Dept. of Plant Sciences, Davis, CA, 95616; ${ }^{2}$ USDA-ARS, Western Regional Research Center, Albany, CA, 94710

Aspergillus flavus produces aflatoxin, a cancer-causing contaminant of pistachio in many production areas. A superior yeast strain of Pichia anomala has been demonstrated to inhibit the growth of A. flavus in the laboratory. It was selected for further study and potential release based on tests of durability and ability to inhibit A. flavus growth. This strain has been tested in the field for the past two years to evaluate its ability to survive in a field environment and to inhibit A. flavus production. The yeast was evaluated in the field to determine if: 1) the biocontrol yeast can survive in pistachio orchards; 2) the yeast has no phytotoxic effects on the pistachio trees or nuts; and 3) the yeast can be demonstrated to control A. flavus in the field. Studies during 2003 were conducted using a replicated experiment with three yeast concentrations and a water control. Treatments applied later in the season were found to be most effective. Highest yeast concentrations were observed just prior to harvest. Three spray concentrations and a water control were applied to evaluate possible phytotoxic effects on pistachio during 2004. No differences in leaf or nut appearance, in nut percent splits, or dry weight were observed for any of the treatments when compared to the water control. Artificial wounding experiments were also conducted during 2003 and 2004 to simulate the occurrence of early split nuts, the primary repository for $A$. flavus contamination. A $5 \times$ reduction in $A$. flavus colonization was observed on treated wounded nuts vs. untreated wounded nuts. A $5 \times$ reduction in A. flavus sporulation was also observed on treated wounded nuts vs. untreated wounded nuts. 